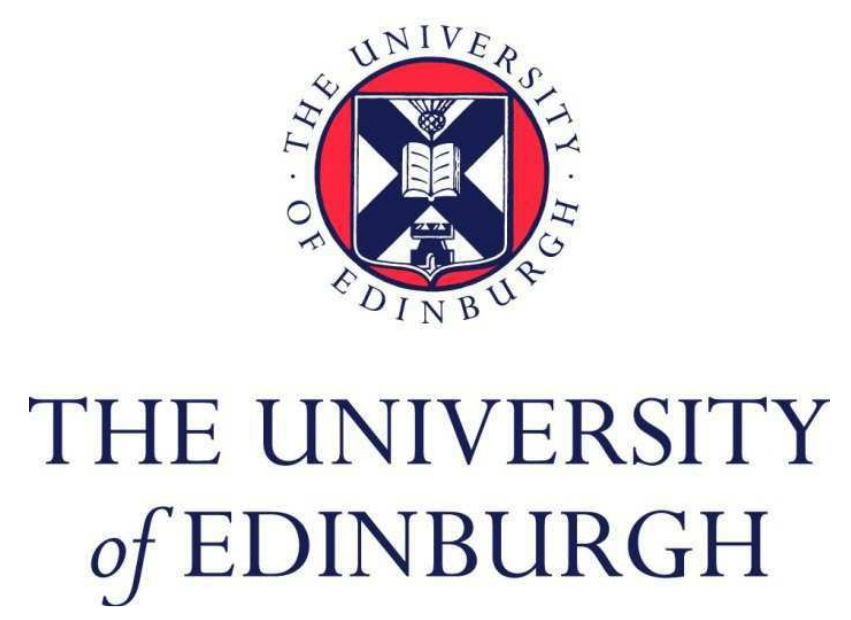

This thesis has been submitted in fulfilment of the requirements for a postgraduate degree (e.g. PhD, MPhil, DClinPsychol) at the University of Edinburgh. Please note the following terms and conditions of use:

This work is protected by copyright and other intellectual property rights, which are retained by the thesis author, unless otherwise stated.

A copy can be downloaded for personal non-commercial research or study, without prior permission or charge.

This thesis cannot be reproduced or quoted extensively from without first obtaining permission in writing from the author.

The content must not be changed in any way or sold commercially in any format or medium without the formal permission of the author.

When referring to this work, full bibliographic details including the author, title, awarding institution and date of the thesis must be given. 


\title{
Ownership Structure and \\ Operating Performance of Acquiring Firms: \\ The Case of English-Origin Countries
}

\author{
Tze-Yu Yen
}

$\mathrm{PhD}$

The University of Edinburgh

2007 


\section{This thesis is dedicated to}

\section{Pi-Chen $\mathcal{L} u$}

-My dear mom who gives me endless love all her life.-

With your sacrifice and support, I have the chance to dream and to pursue what I want without any concern.

\section{Ting-Yen $\mathcal{H}$ wang}

-My thoughtful and inspiring son who brings sunshine to me always.With your companion and comfort, I have the courage to persevere and to continue this Conely sojourn.

\section{Chorng-Sí H Hwang}

-My beloved husband who endured great hardship in our past ten-year marriage life.-

With your patience, trust and love, I know I already own everything no matter what the end will be. 


\section{ACKNOWLEDGEMENTS}

This journey as a doctoral research was filled with times of suffering and also moments of jubilation. As I look back at these past three years, I would like to thank many people who have provided me with great help and inspiration during this endeavor.

First of all, I am deeply indebted to my supervisor, Dr. Paul André. Without you, this dissertation would not have been possible to be completed. Thanks to your suggestions and instructions that benefit me a lot on developing research skills. Thanks to your patience and encouragement that carried me on through these difficult days. Above all, thanks to your professional spirit and attitude that not only inspired me throughout my PhD training process but will also influence me greatly in my rest of academic life.

Secondly, I respectfully acknowledge the significant contributions of my second supervisor, Dr. Chris Pong. Thank that you passed your trust and confidence to me in these three years and provided me invaluable advice and comments at each critical point. Your constant and earnest support definitely facilitated the completion of this thesis.

I also really appreciate my external examiner, Professor Joe Danbolt in University of Glasgow and internal examiner, Professor Jonathan Crook. Thank you both for making constructive comments, criticisms and suggestions to improve this thesis. And also thank you both for providing such friendly atmosphere to help me pass through the viva.

I also thank Christine Proudfoot and Charis Stewart, the outstanding secretary and coordinator in Management School. Thanks for providing reliable and efficient administrative support to me during this research period.

I am also grateful to all my friends in Edinburgh: Annie, Christine, I-Hsin, Robin, Kai-Li, Shu-Lin, Shu-Min, Wen-I, Zeng-Siu, and Yi-Fang. Your precious friendships have made the life in Edinburgh, this beautiful but soulless city much warmer and more endurable. I will never forget those gatherings with laughs and tears in Biblos, in 35 Buccleuch, in Robin's and in Shu-Lin's place. 
Thank you all for sharing each stressful and glorious time with me. I love you all and believe that we will get together soon to celebrate for all of us.

Special appreciation would be expressed to Annie. Thank you for taking care of Timothy no matter what time it was, for standing on my side no matter what the things were, for dealing with those trivial things for me no matter how busy you are, and for showing up at the very moment that I needed a friend's hands most.

Last but not least, to my other lovely family in Taiwan: my dad (Da-Lu Yen), my parents-in-law (Hung-Lung Huang and Yu-Lan Lee), my brother (Tzu-Chao Yen), my sister-in-law (Joyce Lai), my sweet niece (Ivy Yen) and nephews (Leo Huang and Gordon Huang). Thank you all for your encouragement and confidence to support me in this journey of self-actualization.

The same gratitude is also extended to those who I have inadvertently overlooked or forgot to mention in my acknowledgements but who equally deserve. 


\section{DECLARATION}

I hereby declare that this thesis has been carried out by me; the work is original and it has not been submitted for any other degree or professional qualification unless otherwise stated.

Tze-Yu Yen

Date: 


\section{TABLE OF CONTENTS}

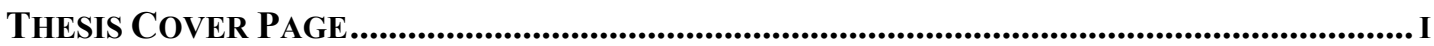

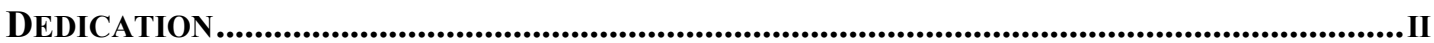

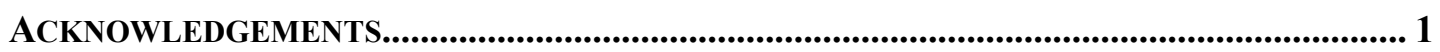

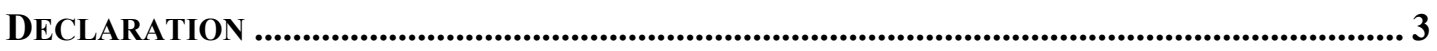

TABLE OF CONTENTS ............................................................................................................................... 4

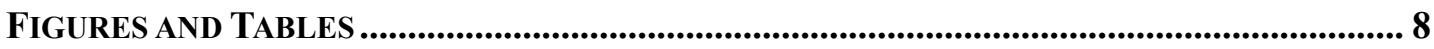

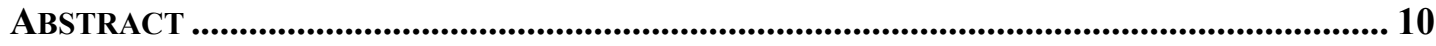

CHAPTER ONE: INTRODUCTION .............................................................................................. 12

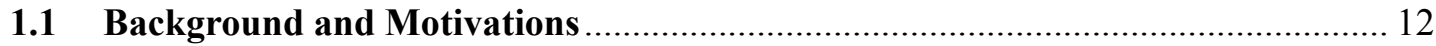

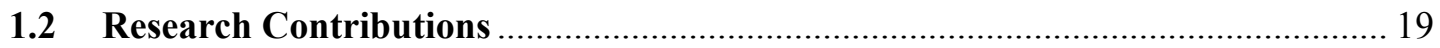

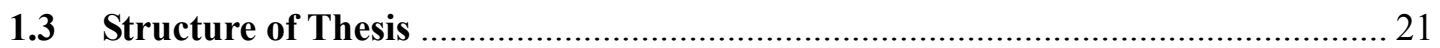

CHAPTER TWO: CONCENTRATED OWNERSHIP, CORPORATE GOVERNANCE, AND FIRM

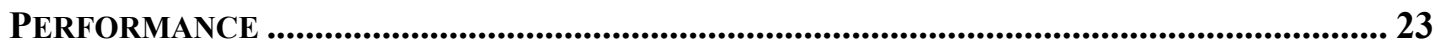

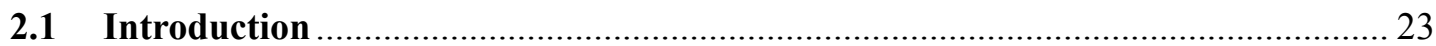

2.2 The Nature of the Problems with Concentrated Ownership ................................ 24

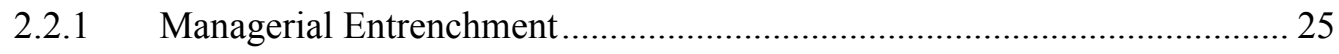

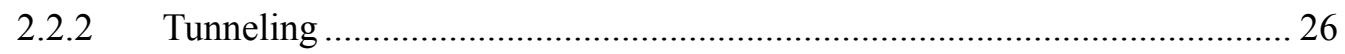

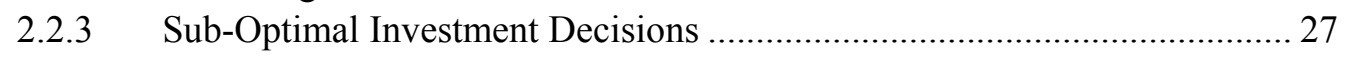

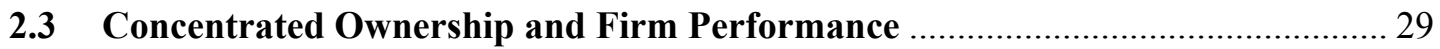

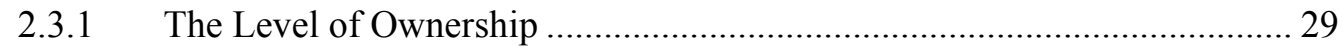

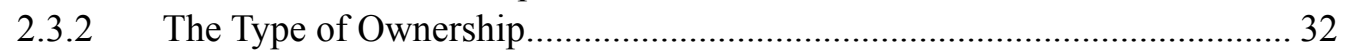

2.4 Accentuating Factor to the Agency Problem with Concentrated Ownership........ 36

2.5 Mitigating Factors to the Agency Problem with Concentrated Ownership ........... 40

2.5.1 Corporate Governance Mechanisms: $1^{\text {st }}$ generation ................................... 40

2.5.1.1 Chief Executive Officer (CEO) Position ....................................... 40

2.5.1.2 Board Characteristics.................................................................. 43

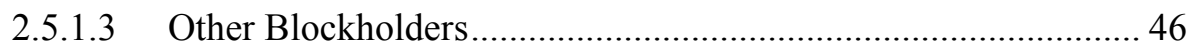

2.5.2 Corporate Governance Mechanism: $2^{\text {nd }}$ generation ..................................... 48

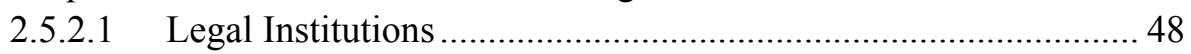

2.5.2.2 Extra-legal Institutions ............................................................. 55

2.5.2.3 Anti- Self-Dealing Index (Private Enforcement) and Public

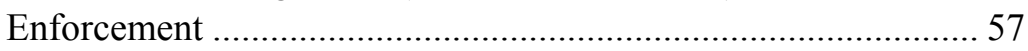

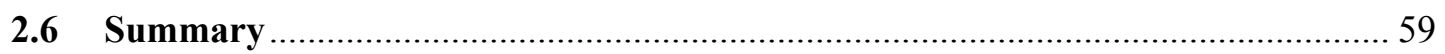


Chapter Three: Merger AND ACQuisition, PerformanCe Measures, AND ACQUISITION PERFORMANCE UNDER CONCENTRATED OWNERSHIP................................ 61

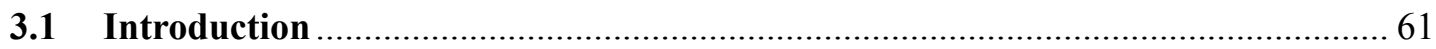

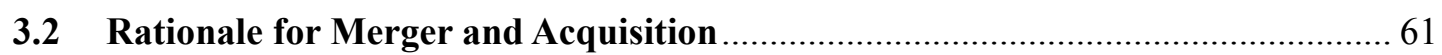

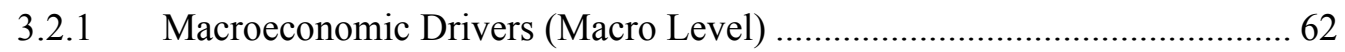

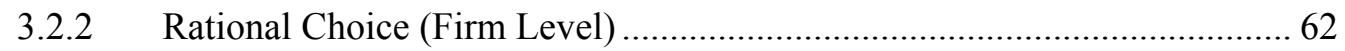

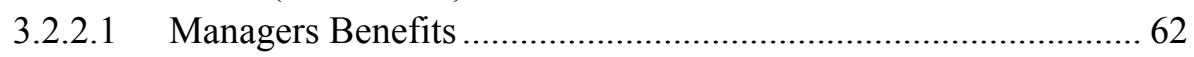

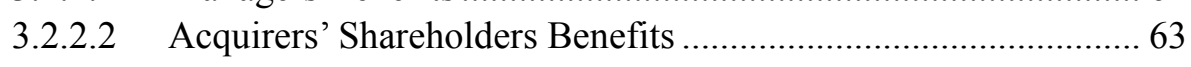

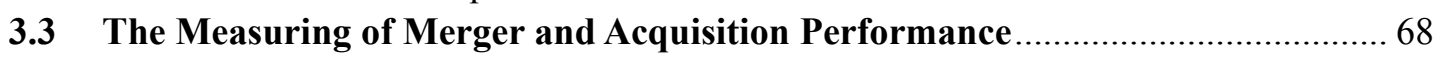

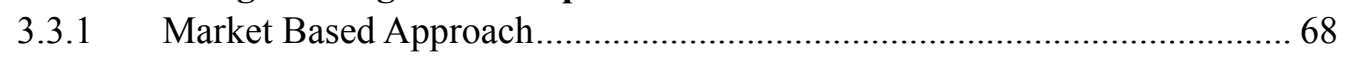

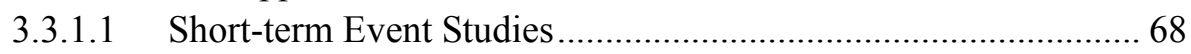

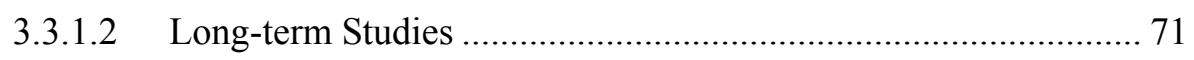

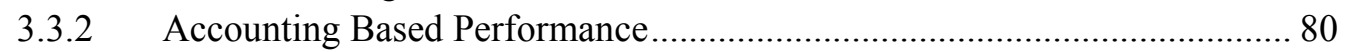

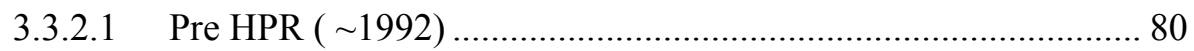

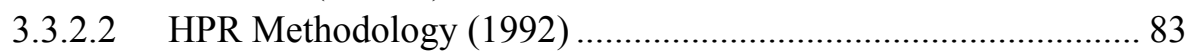

3.3.2.3 Post HPR (1992 ) .............................................................. 86

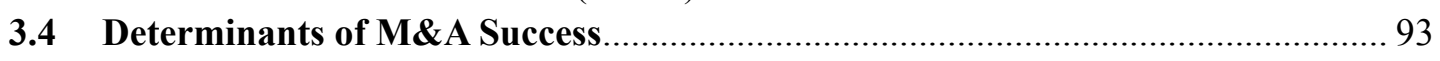

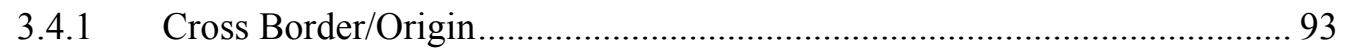

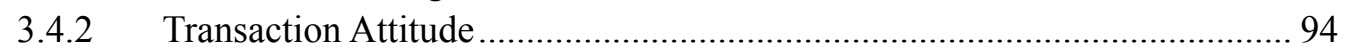

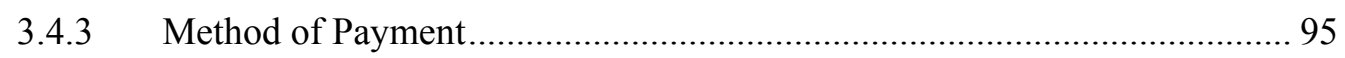

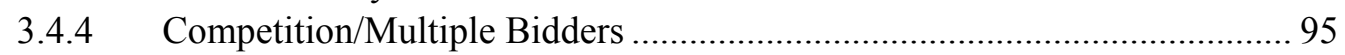

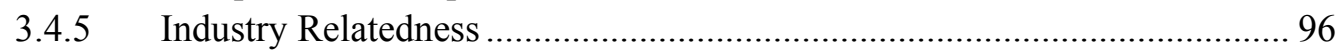

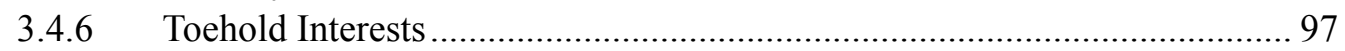

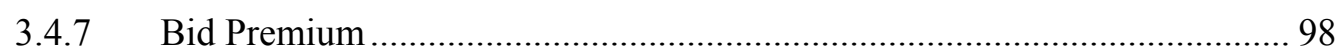

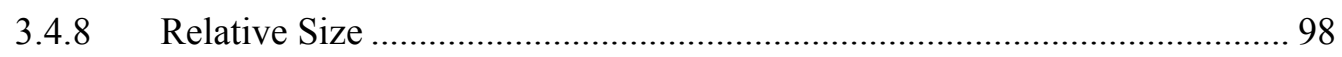

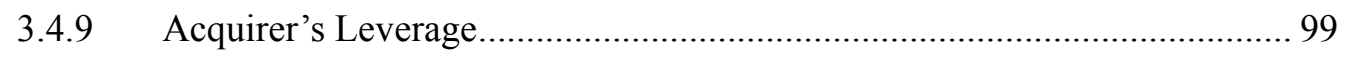

3.5 Concentrated Ownership, Governance Mechanisms, Legal/ Extra-Legal

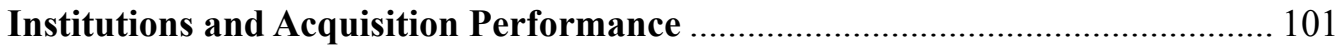

3.5.1 Concentrated Ownership Structure …….................................................. 101

3.5.1.1 The Level of Ownership Concentration .................................... 101

3.5.1.2 The Type of Ownership Concentration...................................... 104

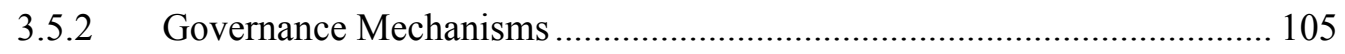

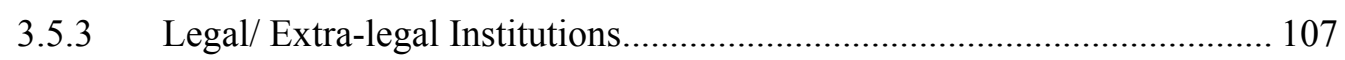

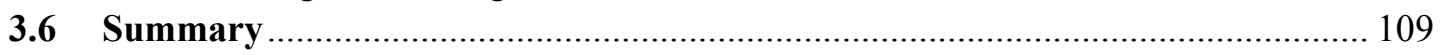

CHAPTER FOUR: RESEARCH FRAMEWORK AND HYPOTHESES.........................................111

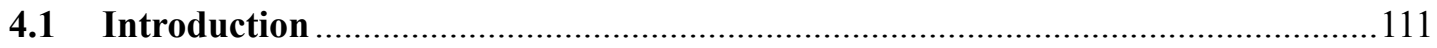

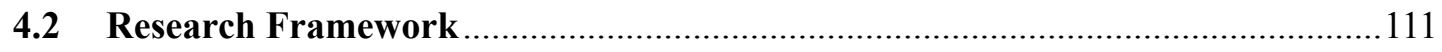

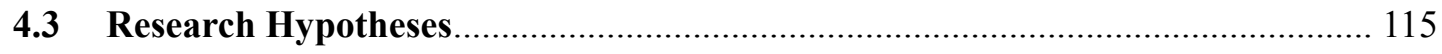

4.3.1 Hypotheses regarding Acquisition Operating Performance...................... 115

4.3.2 Hypotheses regarding Ownership Structure............................................... 115

4.3.3 Hypotheses regarding Governance Mechanisms .................................... 117

4.3.4 Hypotheses regarding Legal and Extra-legal Institutions ......................... 119

4.3.5 Hypotheses regarding Transaction Characteristics .................................. 120

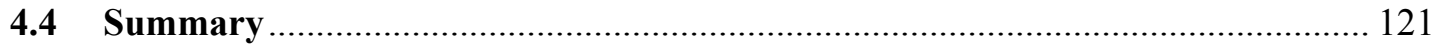




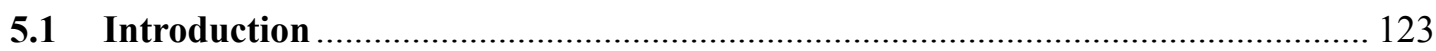

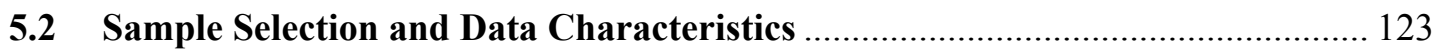

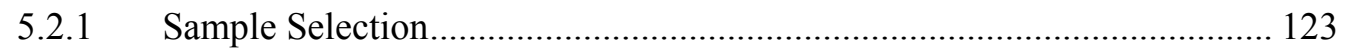

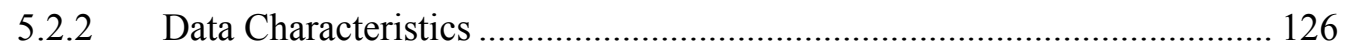

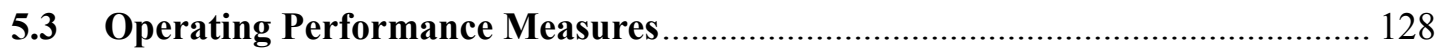

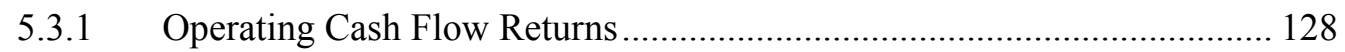

5.3.2 Construction of Performance Benchmark ................................................... 131

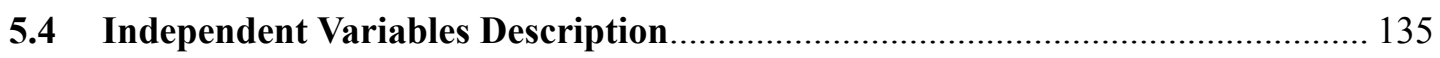

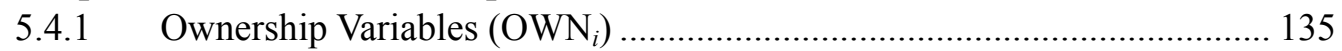

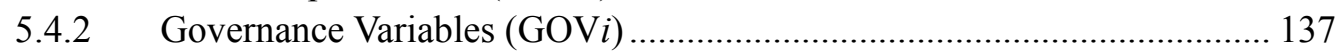

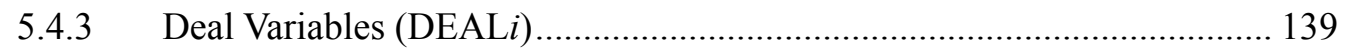

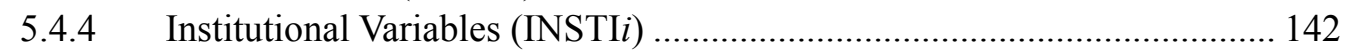

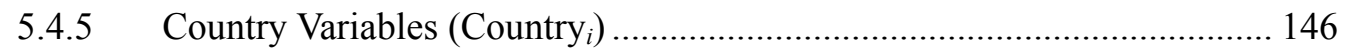

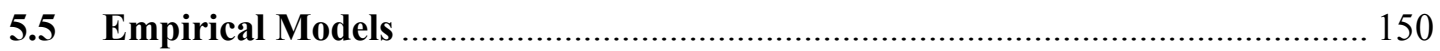

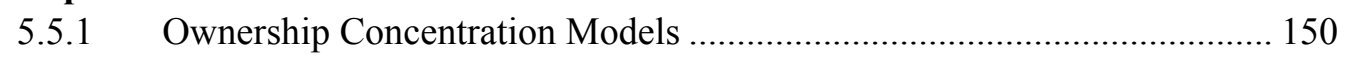

5.5.2 Institution Mechanisms Model ............................................................... 153

CHAPTER SIX: EMPIRICAL ANALYSIS AND DISCUSSION.................................................... 155

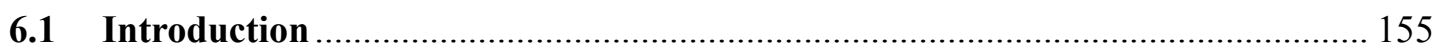

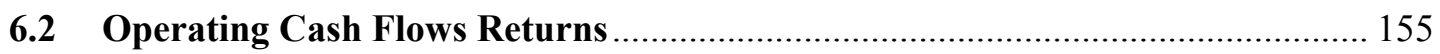

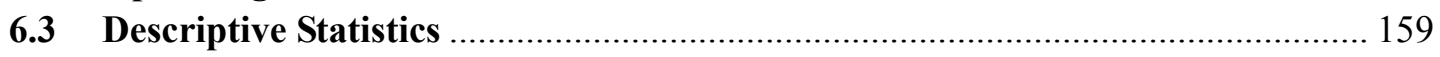

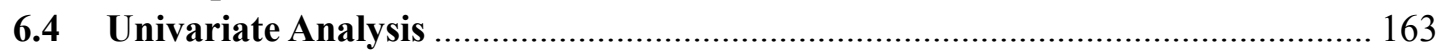

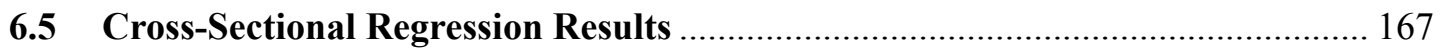

6.5.1 Regression Results at First Stage-For Ownership and $1^{\text {st }}$ Generation

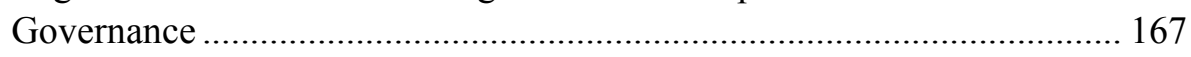

6.5.2 Regression Results at Second Stage-For $2^{\text {nd }}$ Generation Governance: Legal

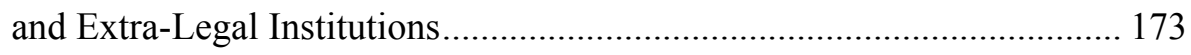

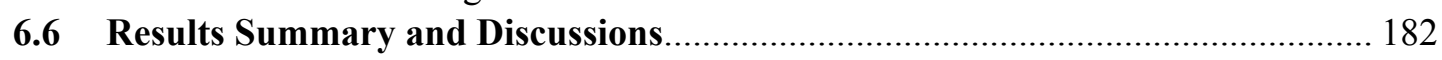

CHAPTER SEVEN: ADDITIONAL ANALYSIS ........................................................................... 185

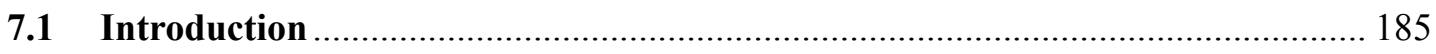

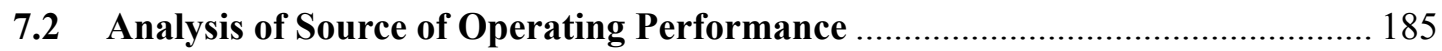

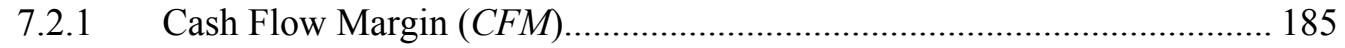

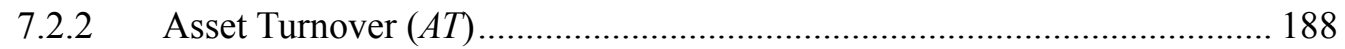

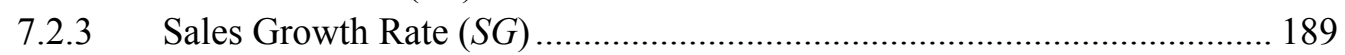

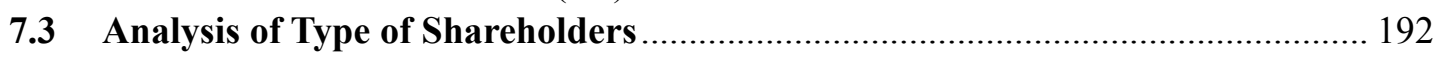

7.3.1 Statistics Description and Univariate Analysis .......................................... 193

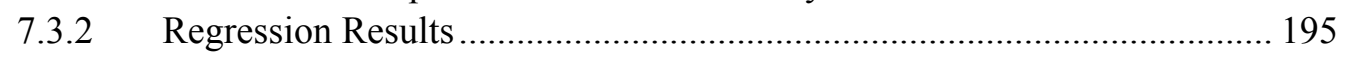

7.4 Analysis of Cross Effects of Type I and Type II Agency Problem........................ 198

7.5 Analysis of Different Definition of Independent Variables.................................. 202

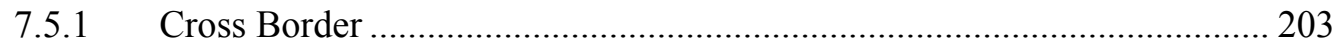

7.5.2 Industry Relatedness: two-digit and three- digit SIC codes..................... 203

7.5.3 Pre- bid Period for Premium Measure: one week and four weeks............. 204

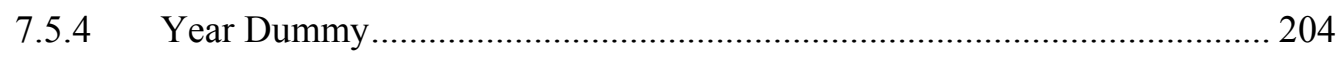




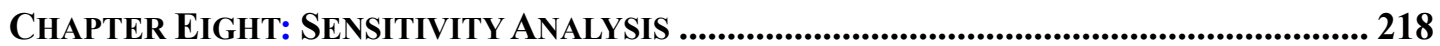

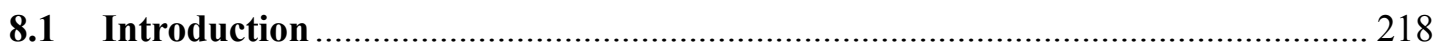

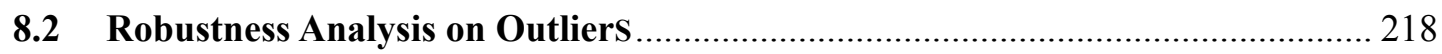

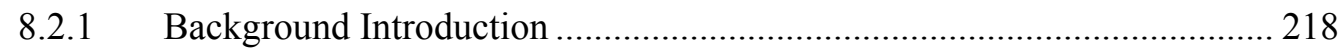

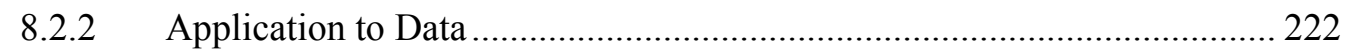

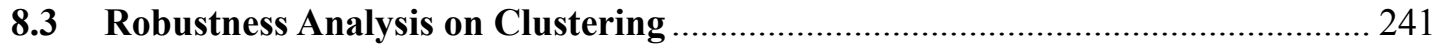

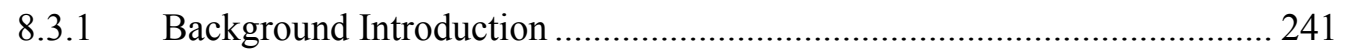

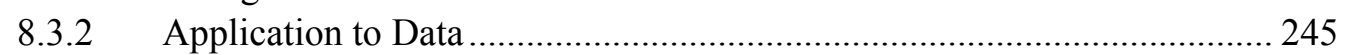

8.4 Robustness Analysis on Windows of Measuring Performance ............................ 260

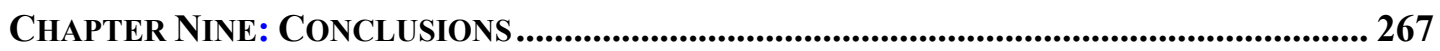

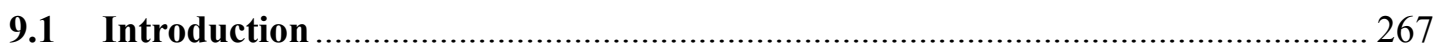

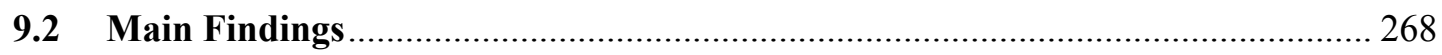

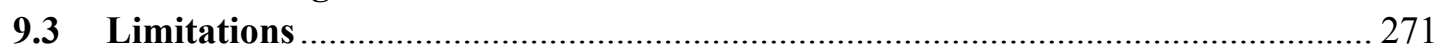

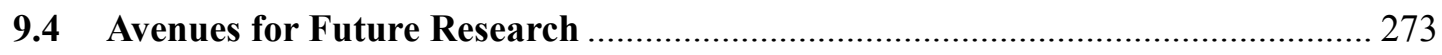

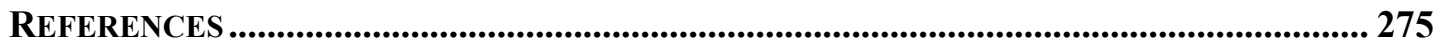

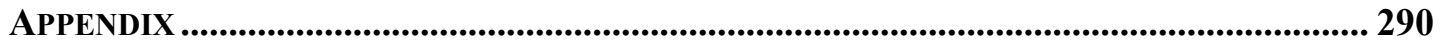

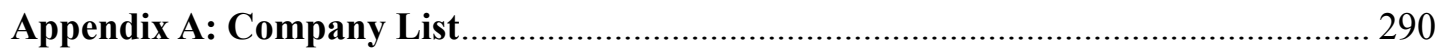

Appendix B: Results by using Enforcement measures with the average of three LLSV

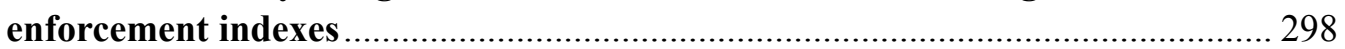

Appendix C: Non-Parametric Mann-Whitney Tests for Dummy Variables................. 299

Appendix D: Regressions Results in Table 6.5 \& 6.6 with Beta Coefficients and R Square

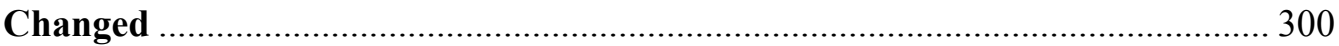

Appendix E: Regressions Results in Table 6.5 \& 6.6 with VIF Value ............................ 301

Appendix F: Regressions Results on Robustness Test of Standard Error using Jackknife

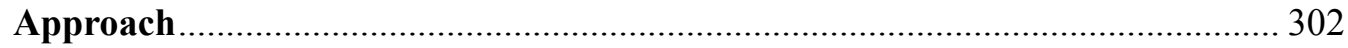

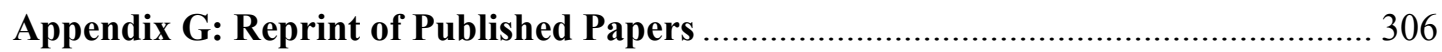




\section{FIGURES AND TABLES}

\section{List of Figures}

Figure 2.1 Control Chain of a Pyramid Structure.............................................................. 37

Figure 2.2 Control Chain of a Cross Holding Structure..................................................... 38

Figure 2.3 Chart and Calculating of Ownership and Voting Shares of Teck Corporation..... 39

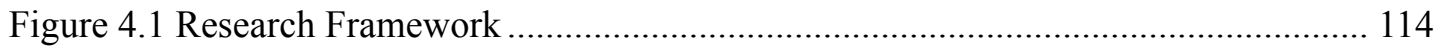

Figure 5.1 Calculation Process of Operating Performance Measures................................. 130

Figure 5.2 Construction Processes of Matched Firms ........................................................ 132

Figure 6.1 Curve of Cube Relationship between Ownership and Acquisition Performance 169

Figure 8.1 Box Plots for the Data Set of Operating Cash Flow of Merging and Matched Firms

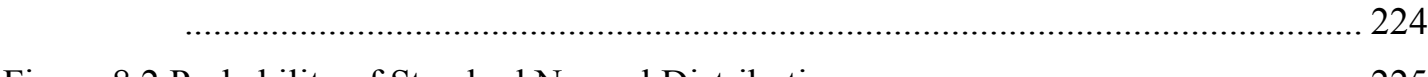

Figure 8.2 Probability of Standard Normal Distribution ................................................ 225

\section{List of Tables}

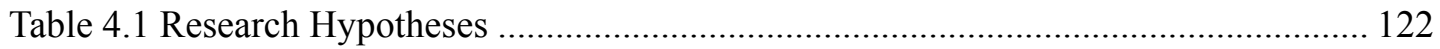

Table 5.1 Sample Selection Criteria and Number of Deals................................................. 125

Table 5.2 Description of Sample Characteristics ............................................................... 127

Table 5.3 Comparison of Merging Firms and Matched Firms .......................................... 134

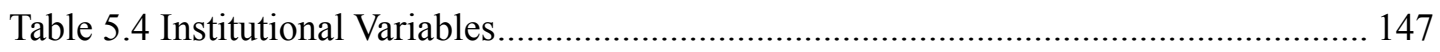

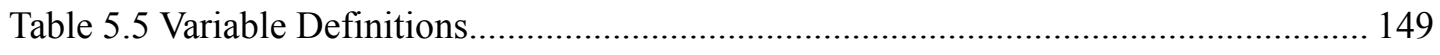

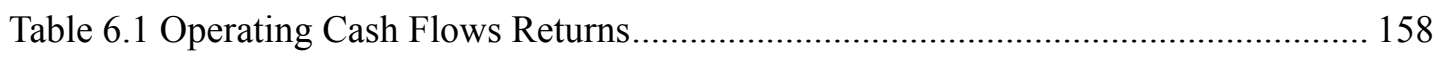

Table 6.2 Descriptive Statistics (By Sample Country)........................................................ 162

Table 6.3 Univariate Statistics of All Independent Variables............................................... 165

Table 6.4 Regression of Acquiring Firm Performance on Ownership Structure, Governance

Mechanisms and Deal Characteristics (Basic Models)...................................... 171

Table 6.5 Regression of Acquiring Firm Performance on Legal \& Extra-Legal Institutions (Full Models)

Table 6.6 Regression of Acquiring Firm Performance on Legal \& Extra Legal Institutions

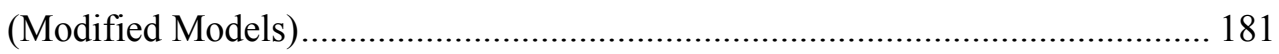

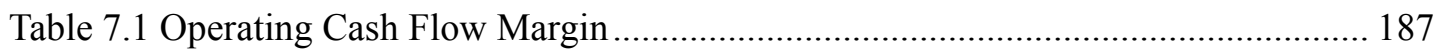

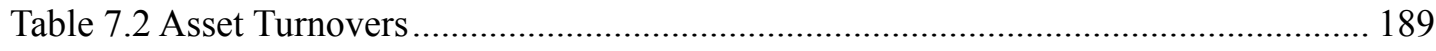

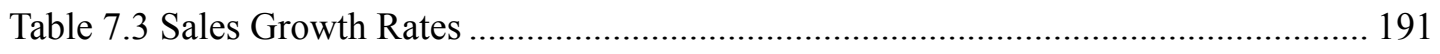


Table 7.4 Statistics Description and Univariate Test of Type of Shareholders 194

Table 7.5 Regression Results of Type of Large shareholders 196

Table 7.6 Cross Effects of Type I and Type II Agency Problems using Independent t Test. 200

Table 7.7 Cross Effects of Type I and Type II Agency Problems using non-parametric Mann-Whitney U Test ...... 201

Table 7.8 Univariate Statistics of Additional Independent Variables .................................. 202

Table 7.9 Regression Results of Cross Border Deals.......................................................... 206

Table 7.10 Regression Results of Industry Relatedness: Two- digit Primary SIC Code ..... 208

Table 7.11 Regression Results of Industry Relatedness: Three- digit Primary SIC Code ... 209

Table 7.12 Regression Results of Pre Bid Period for Premium Measure: One- Week ........ 211

Table 7.13 Regression Results of Pre Bid Period for Premium Measure: Four- Weeks ...... 213

Table 7.14 Regression Results of Acquisition Years............................................................. 215

Table 8.1 Outlier Robustness Test: Original Data ........................................................... 223

Table 8.2 a Outlier Robustness Test: Winsorizing at different estimators ........................... 226

Table 8.2 b Outlier Robustness Test: Trimming at different estimators.............................. 228

Table 8.3 Summary Results of Variables in Regressions with Significance for Outliers

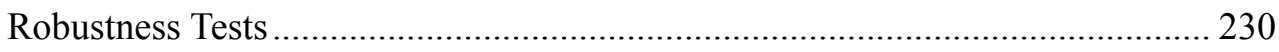

Table 8.4 Ownership Structure, Institutional Mechanisms and Acquiring Firm Performance:

Outlier Robustness Test on $\mu \pm 2 \sigma$ - Winsorized

Table 8.5 Ownership Structure, Institutional Mechanisms, and Acquiring Firm Performance:

Outlier Robustness Test on 20\%- Winsorized Mean

Table 8.6 Ownership Structure, Institutional Mechanisms and Acquiring Firm Performance:

Outlier Robustness Test on $\mu \pm 2 \sigma$ - Trimmed 235

Table 8.7 Ownership Structure, Institutional Mechanisms and Acquiring Firm Performance:

Outlier Robustness Test on M-estimator $\mathrm{K}=1.28$ Trimmed. 236

Table 8.8 Ownership Structure, Institutional Mechanisms and Acquiring Firm Performance:

Outlier Robustness Test on 20\%- Trimmed Mean 239

Table 8.9 Standard Errors Robustness Test on Default OLS estimators 248

Table8.10 Standard Errors Robustness Test on Clustered-Robust Standard Errors Estimators

Table 8.11 Standard Error Robustness Test on Bootstrap Standard Errors Estimators 254

Table 8.12 Operating Cash Flows Returns: Robustness Test on Year Window of Measuring Performance. 262

Table 8.13 Ownership Structure, Institutional Mechanisms and Acquiring Firm Performance:

Robustness Test on Year Window of Measuring Performance. 265 


\begin{abstract}
$\underline{\text { ABSTRACT }}$
This thesis provides empirical evidence on the relation between concentrated ownership and the long term operating performance of acquiring firms. Large shareholders are generally viewed as beneficial monitors of corporate performance but high levels of concentration can lead to potential expropriation from minority shareholders via managerial entrenchment, tunneling, or sub-optimal investment decisions. This problem is potentially greater in firms with separation of voting and ownership rights. This thesis investigates the performance around takeovers in English origin countries other than the US by following the classification of La Porta, Lopez-de-Silanes, Shleifer and Vishny (1998). While generally considered similar to the US, these countries vary with respect to ownership concentration and investor protection.
\end{abstract}

This thesis controls a broad set of corporate governance mechanisms including first generation governance measures like CEO positions, board characteristics, and other blockholders. Furthermore, this thesis also examines whether different degrees of second generation governance mechanisms such as anti-director rights, accounting standards, legal enforcement, and extra-legal institutions lead to different levels of M\&A performance. In addition, this thesis includes the new legal indexes recently developed by Djankov, La Porta, Lopez-de-Silanes and Shleifer (2006); these measures have yet to be examined through empirical research.

By using an accounting based methodology, this thesis presents Healy, Palepu and Ruback (1992) abnormal post cash flow return regression-based results and results of a change model (Ghosh 2001). Moreover, this thesis refers to the sample matching techniques in Barber and Lyon (1996) and develops the industry, size, and pre performance benchmark.

The principal finding of this thesis is that M\&A transactions should improve the long-term financial and operating performance of merging firms to reflect that accounting performance can capture real economic creations. After controlling for well documented governance mechanisms and deal characteristics, the relationship between concentrated ownership and the level and change in operating cash flow returns after takeovers is non-linear. Value creating deals are associated with higher levels of concentration consistent with decreasing 
agency costs as the large shareholder's wealth invested in the acquiring firm increases. Further, separation of ownership and voting rights leads to greater value destruction; acquiring firms with controlling CEO make significant improvements in post acquisition performance after controlling pre-performance; and the presence of CEO-Chairman duality and board size are both significantly negatively associated with acquisition operating performance.

This thesis also finds, although all acquiring firms are from English origin countries, that the greater investor protection, as measured by the initial anti-director right index in La Porta et al. (1998) and revised anti-director rights index in Djankov et al. (2006) has a positive impact on operating cash flow returns from acquisitions. However, this thesis does not document any differential performance with respect to the extra- legal systems of Dyck and Zingales (2004) and the anti-self-dealing index of Djankov et al. (2006). 


\section{Chapter One}

\section{Introduction}

\subsection{Background and Motivations}

This thesis adds to the ongoing debate about the agency nature of concentrated ownership and provides empirical evidence concerning the relationship between this type of ownership structure and the long-term operating performance of acquiring firms. This thesis also examines the effects of differing levels of country-specific legal protections on value creation following mergers and acquisitions (M\&As) in English origin countries.

Why concentrated ownership structure? Stemming mostly from the agency model of Jensen and Meckling (1976), corporate governance research generally emphasizes the role of control mechanisms in ownership structures. Jensen and Meckling (1976) first used the term "ownership structure" instead of "capital structure" to highlight the fact that the fraction of equity held by the insider and outsider is a key variable in determining corporate value. Following this ownership structure theory, a substantial amount of theoretical and empirical study has continuously been devoted to investigating the relationship between corporate performance and the allocation of equity ownership. However, most research is generally set in the US and explains only the typical dispersed ownership structure initially described by Berle and Means (1932) (Fama and Jensen 1983a.,b, Hunt 1986, Shleifer and Vishny 1986, Morck, Shleifer and Vishny 1988b, Ang and Cole 2000).

More recent work challenges the generalization of dispersed ownership. La Porta, Lopez-de-Silanes and Shleifer (1999) identify the ultimate controlling shareholders of 20 large firms and 10 median firms in each of the 27 wealthy countries, providing important evidence to indicate that the dispersed ownership pattern is only common to large firms in countries with good shareholder protection. According to their study, many public corporations are controlled by one or two shareholders who own a large percentage of the firm's shares. Concentrated ownership structures are predominant around the world. 
Several subsequent studies following La Porta et al. (1999) focus on specific regions. Claessens, Djankov and Lang (2000), for example, examine 2,980 corporations in nine East Asian countries. Their results prove quite conclusively that individual shareholders control over two-thirds of firms and that corporate wealth is largely concentrated in the hands of a small number of families. Similarly, Faccio and Lang (2002) analyze the ultimate ownership and control of 5,232 corporations in 13 western European countries. They find that 36.93 percent of firms are widely held, while 44.29 percent of firms are family controlled; widely held firms are more common in the UK and Ireland, while family control is the norm in continental Europe. Barontini and Caprio (2005) investigate the ownership structure using data from 675 publicly listed firms in eleven Continental European countries. Their findings reveal that half of the sample companies have a majority of shareholders who hold more than 37 percent of the ultimate voting rights. Concentrated ownership structures are important but have clearly been overlooked.

Since concentrated ownership has its own specific costs and benefits, a growing body of empirical work has begun to investigate the unique characteristics of concentrated ownership firms. Some earlier studies suggest that larger shareholders, i.e. blockholders, provide a good internal mechanism for reducing agency costs: these shareholders have greater incentive to efficiently monitor decisions and to ensure that such decisions maximize firm value (Jensen and Meckling 1976, Fama and Jensen 1983a.,b, Shleifer and Vishny 1986, Morck et al. 1988b). However, recent researchers such as La Porta et al. (1999) and Claessens et al. (2000) report that there exists an agency problem between controlling shareholders and minority shareholders in concentrated ownership structures. Furthermore, they suggest that controlling shareholders often have greater control rights than cash flow rights. This is due in large part to pyramidal structures, cross-holdings, dual class shares and various other control devices (La Porta et al. 1999, Claessens et al. 2000). Such a separation of rights provides an opportunity for controlling shareholders to expropriate minority shareholders.

Tunneling is one commonly cited problem (Johnson, Lopez-de-Silanes, La Porta and Shleifer 2000b). Dominant shareholders who don't bear the full cost of their decisions often have incentive to act according to their own interests rather than in the interests of firm performance. There are many ways to achieve tunneling such as by special dividends, excessive perks, excess compensation, advantageous transfer prices, inter-company loans at non-market rates, guaranties of other entities borrowing, or enhancing the value of other 
firms in the group by sub-optimal investment decisions such as merger transactions. Sub-optimal decision is the other potential agency problem. Zhang (1998) provides empirical evidence that controlling shareholders may make sub-optimal decisions because they are more risk averse than other shareholders whose portfolios are better diversified. Managerial entrenchment is another cost associated with concentrated ownership. Schulze, Lubatkin, Dino and Buchholtz (2001) argue that concentrated ownership structures, especially family structures, may reserve top management positions for affiliated members instead of hiring more qualified (external) professional managers. Furthermore, high ownership stakes by those that are also top managers, as in family firms, can limit the effectiveness of outside monitoring because the probability of managerial turnover or successful takeover bids when the firm is performing poorly is reduced (Stulz 1988, Morck et al. 1988b, Davies, Hillier and McColgan 2005).

The impact of concentrated ownership on corporate performance is a question still open for discussion. Some studies show that firm value increases with the cash flow ownership of the largest shareholders (McConaughy, Walker, Henderson and Mishra 1998, Claessens, Djankov, Fan and Lang 2002, La Porta, Lopez-de-Silanes, Shleifer and Vishny 2002, Anderson and Reeb 2003). In contrast, other studies suggest that without effective monitoring, controlling shareholders are likely to exploit minority shareholders and make sub-optimal decisions, especially when control rights exceed cash flow rights (Faccio, Lang and Young 2001, Cronqvist and Nilsson 2003). Also, many studies suggest that the relationship may not be linear (Anderson and Reeb 2003, Morck et al. 1988b, McConnell and Servaes 1990). A major study concerning this issue appears in work by Morck et al. (1988b). The investigation documents an important non-linear relationship between ownership concentration and firm performance. It seems clear that incentive effects impact the entire range of ownership while entrenchment effects more significantly influence the middle levels ( 5 to 25 percent).

The following question arises from such situations: how to mitigate these agency costs? In general, the solution for these agency concerns is to enhance the monitoring mechanisms in corporate systems. In recent years, numerous studies have provided some understanding regarding the scope of these mechanisms (Shleifer and Vishny 1997, Hermalin and Weisbach 2003, Murphy 1999, Core, Guay and Verrecchia 2003, Holderness 2003, Holmstrom and Kaplan 2001, Karpoff, Malatesta and Walkling 1996). Agrawal and Knoeber (1996), among others, suggest seven alternative mechanisms that are commonly used to 
control the agency problem: insider ownership, institution shareholding, large shareholders, independent directors, debt monitoring, managerial labor market, and the takeover market. Denis and McConnell (2003) termed this stream of study as first generation international corporate governance research, pointing out that this group of research generally focuses on internal and external corporate governance mechanisms and that it pays little attention to the importance of the legal system. Some literature investigates the legal system as an essential outside governance mechanism but provides little evidence detailing the concentrated ownership structures in single country (Yurtoglu 2003 for Turkey, Bae, Kang and Kim 2002 for Korea, Holmen and Knopf 2004 for Sweden, Bigelli and Mengoli 2004 for Italy, Lee and Yeh 2004 for Taiwan).

Why English origin? Following the investor protection classification scheme of La Porta, Lopez-de-Silanes, Shleifer and Vishny (1998), second generation research as defined by Denis and McConnell (2003) focuses on comparing corporate performance among countries with different legal characteristics (La Porta, Lopez-de-Silanes, Shleifer and Vishny 2000 and 2002, Fauver, Houston and Naranjo 2003, Gugler, Mueller and Yurtoglu 2004). These subsequent cross-country studies mostly document that common law countries have the strongest legal protection; the corporate performance of concentrated ownership is positively related to the legal protection of minority shareholders. Companies that operate in counties with English origin legal systems exhibit higher levels of corporate performance.

In addition to comparing the divergence among different legal origin families, second generation research also examines individual measures of legal protection including anti-director rights, accounting standards, and legal enforcement (La Porta et al. 1998, Johnson, Boone, Breach and Friedman 2000a, Nenova 2003, Esty and Megginson 2003). Some articles also consider extra-legal institutions such as market competition, labor pressure, moral norms (Zingales 2000, Coffee 2001, Stulz and Williamson 2003), public opinion and corporate tax enforcement (Dyck and Zingales 2004). Djankov, La Porta, Lopez-de-Silanes and Shleifer (2006) also introduce two important legal measures: anti-self dealing index (i e. private enforcement) and public enforcement. Furthermore they detail a revised anti-director right index.

From these measures this thesis observes that while English origin countries are often lumped together and viewed as examples of dispersed ownership and heightened investor 
protection, concentrated ownership is still prevalent in many of these countries; levels of investor protection vary within the group, as measured by legal protection (La Porta et al. 1998), by extra-legal systems (Dyck and Zingales 2004), or by the risks of self-dealing (Djankov et al. 2006). Thus, this thesis intends to compare the impact of different levels of legal/extra-legal protections on corporate performances in countries that share the same legal origins. At present, little research has been conducted in this framework; the new legal measures identified by Djankov et al (2006) have yet to be tested in empirical published papers.

Why M\&As? One of the most important drivers of corporate performance over the last decade is mergers and acquisitions (M\&As). The most recent fifth merger wave emerged in the mid 1990s and reached its peak around the year 2000 (Gugler, Mueller, Yurtoglu and Zulehner 2003, Sudarsanam 2003). One significant feature of the recent M\&A wave is that corporate takeovers are larger than ever. The value of M\&A deals in the US at the height of the year 2000 merger boom was nearly $\$ 1.8$ trillion; this was 5.5 times the value of the previous peak in 1989 (Sudarsanam 2003). This steep increase was not confined to US and UK markets, but also occurred throughout major industrial countries worldwide (Gugler et al. 2003). Although companies clearly invest billions of dollars in making acquisitions, most empirical studies demonstrate that shareholders associated with acquiring firms experience wealth destruction on average or at best break even (Jensen and Ruback 1983, Agrawal, Jaffe and Mandelker 1992, Franks and Harris 1989, Goergen and Renneboog 2004).

Due to the high costs and risks associated with M\&A investment, merger activity has produced great interest among academics. What leads to the value reduction? What determines M\&A success? Healy, Palepu and Ruback (1992) point out the importance of transaction characteristics such as target attitudes (either hostile or friendly), particular defense strategies (white knight, golden parachutes, etc), relative firm size, payment methods (cash, stock or combined), type of deal (merger, tender offer, or proxy contest), industry relatedness (horizontal/ vertical/ conglomerate), bid premiums, multi-bidders, toehold interests, and cross-border topics (Sudarsanam, Holl and Salami 1996, Loughran and Vijh 1997, André, Kooli and L'Her 2004). Carline, Linn and Yadav (2002) add in the agency characteristics such as insider ownership, outside large shareholders, CEO turnover/ compensation, board composition, CEO compensation, and capital structures etc. (Kaplan and Weisbach 1992, Cyert, Sok-Hyon and Kumar 2002, Gugler et al. 2003). 
Most studies in this field emphasize United States markets with widespread dispersed ownership structures (Jensen and Ruback 1983, Franks, Harris and Mayer 1988, Agrawal et al. 1992, Loughran and Vijh 1997). Recent developments in the field of concentrated ownership structures, however, introduce a new dimension to M\&A considerations. A number of governance researchers now explore the relationship between concentrated shareholdings, corporate governance and the value creation/reduction of this specific corporate decision (Bae et al. 2002, Bigelli and Mengoli 2004, Holmen and Knopf 2004, Ben-Amar and André 2006, Faccio and Stolin 2006). One line of study argues that in countries with low investor protection, minority shareholders of acquiring firms experience overall wealth reduction because M\&As are tools used by controlling shareholders to facilitate the potential entrenchment that benefits themselves at the expense of minority shareholders (Bae et al. 2002, Bigelli and Mengoli 2004). Another line of study declares that in countries with better corporate governance controlling shareholders may not be in a position to benefit themselves from acquisition transactions but they may choose instead to reduce personal risks by making sub-optimal investment decisions (Holmen and Knopf 2004, Ben-Amar and André 2006, Faccio and Stolin 2006). This thesis basically extends the research of Ben-Amar and André (2006) by doing a cross-country analysis over English origin countries.

Why operating performance? To date, most research adopts traditional market based event study methodology to examine the relationship between acquisition performance and ownership structures. Such an investigation is based on the assumption that stock prices will immediately reflect any benefits resulting from the deals (Agrawal et al. 1992, Andrade, Mitchell and Stafford 2001, Franks and Harris 1989, Limmack 1991, Sudarsanam et al. 1996, Goergen and Renneboog 2004). However, Healy et al. (1992) argue that the nature of short term market performance methodology may not fully capture anticipated benefits from an acquisition. They suggest that long-term operating cash flow returns could prove better measures for understanding M\&A value creation and its drivers. Following the work of Healy et al. (1992), financial researchers take a longer term perspective and examine acquisition improvements by operating performance (Hitt, Harrison, Ireland and Best 1998, Ghosh 2001, Powell and Stark 2005).

Motivated by Healy et al. (1992), Ghosh (2001), Sharma and Ho (2002), and Powell and Stark (2005), this thesis intends to expand the discussion concerning long-term operating performance for the post acquisition period. It examines levels of post-operating 
performance (ACFRpost) (Healy et al. 1992, Loughran and Ritter 1997, Linn and Switzer 2001, Rahman and Limmack 2004, Powell and Stark 2005) and changes in operating cash flow return ( $\triangle A C F R$ ) (Ghosh 2001, Carline et al. 2002, Rahman and Limmack 2004). Performance measurements (ACFRpost and $\triangle A C F R$ ) are adjusted by the matched companies based upon size, industry, and pre-performance. To compare with earlier works, this thesis basically constructs matching procedure using various approaches introduced by Barber and Lyon (1996); Loughran and Ritter (1997); and Ghosh (1997).

In summary, this thesis intends the following: to investigate the impact of ownership structures on acquiring firm performance; to explore the effective monitoring mechanisms including corporate governance system and legal/extra-legal protection for alleviating the possible expropriating problems; to complete the debate about deal characters; and to examine the improvement of acquisition performance by the measurement of long term accounting based performance. A sample of 282 deals is obtained from the Thomson Financial Securities Data's SDC Platinum ${ }^{\mathrm{TM}}$ Worldwide Mergers \& Acquisitions Database over 1997 to 2001. Following the classification of La Porta et al. (1998), this thesis covers eleven English origin countries other than the US: Australia, Canada, India, Republic of Ireland, Israel, Malaysia, New Zealand, Singapore, South Africa, Thailand, and the United Kingdom. The financial and accounting data for the seven-year window (transaction year plus three years before and after transactions) was collected from Thomson Financial or DataStream database. Ownership data was gathered by recording information taken from proxies or annual reports of each company, as well as from the Mergent database, the SEDAR filing system, SEC fillings, and company websites. 


\subsection{Research Contributions}

This thesis makes a number of contributions to the current academic literature. First of all, this thesis examines the potential consequences of concentrated ownership. Ownership concentrated in the hands of small groups is the norm around the world. This concept is the cornerstone of corporate governance research. A growing body of research devoted to firms with concentration ownership generally focuses on emerging economies outside the Anglo-American world. This thesis joins the cross-country research by investigating eleven English origin nations those comprise both developed and developing economies.

By examining this interesting sample of English origin countries (often assumed to be homogeneous in law and finance literature) this thesis highlights important differences in the impact of firm-level ownership concentrations and governance mechanisms across countries, as well as in country-level legal protections surrounding firm values. In addition, this thesis provides evidence for various level of ownership concentration. It examines low- level controlled (10\%-20\%), middle-level controlled (20\%-50\%), and high-level controlled (over $50 \%$ ) firms. It also attempts to identify the non-linear relationship between ownership and firm performance. Along with levels of ownership, types of owners are also investigated. This thesis traces the ultimate owners of controlling shareholders and classifies these owners into four groups: family firms, financial institutions, widely held corporations, and states. Looking at particular types of ultimate owners might provide better understanding for the identity of concentrated firms.

Second, corporate governance research generally examines the effects of ownership structures on overall corporate performance. There are relatively few articles that consider the impact of ownership structures on M\&A activities and these activities are usually regarded as the most important and substantial investment decisions. This thesis focuses on acquisition performance rather than on overall firm performance. It therefore provides remarkable evidence in those areas where controlling shareholders either create real synergies by M\&A transactions or indeed expropriate minority shareholders through M\&A activities. In addition, most previous M\&A research observes M\&A activities in the early part of the 1990s. This thesis goes beyond earlier work to consider the period between 1997 and 2001. The empirical evidence contained herein contributes to the most recent merger wave. 
Third, this thesis controls for a broad set of corporate governance mechanisms since corporate governance can be viewed as an optimal set of choices. First generation governance measures like CEO positions, board characteristics, and other blockholders are examined mostly with regard to general corporate performance but without much regard to specific M\&A performance as it appears in the existing governance research. Furthermore, in addition to investigating the impact of individual governance mechanisms, this thesis also examines relevant cross effects between type I agency problems (separation between ownership and control rights) and type II agency problems (separation between ownership and management).

Second generation governance mechanisms such as anti-director rights, accounting standards, legal enforcement, and extra-legal institutions are essential to corporate performance but have been overlooked until recently. There is little evidence regarding these institutional measures and general firm values, and even less concerning the M\&A value creations in existing published articles. This thesis provides empirical evidence for determining whether different degrees of legal/extra-legal protection lead to different levels of M\&A performance. In addition, this thesis includes the new legal indexes recently developed by Djankov et al. (2006); these measures have yet to be examined through empirical research.

Fourth, considering that short-term market performance can only reflect investor expectations and may not capture the real long-term economics, this thesis examines the operating abnormal returns created by M\&A transactions using an accounting based methodology rather than a standard event study approach. Thus, it adds to methodological debates about certain performance measures and various estimates for improvement. Furthermore, this thesis refers to the sample matching techniques in Barber and Lyon (1996) and develops the industry, size, and pre performance benchmark. This approach provides an important contribution in controlling the under or over pre-performance problems that are inherent in some of the earlier studies of operating performance concerning M\&As. Moreover, this thesis analyzes the drivers of operating cash flow returns by decomposing cash flow returns into cash flow margins and asset turnovers. Sales growth rates are also tested as another major component for operating cash flow. 


\subsection{Structure of Thesis}

The rest of this thesis is organized as follows. Chapter two summarizes the literature that concerns the nature of concentrated ownership such as tunneling, sub-optimal decisions, and managerial entrenchment problems. It also considers the impact of concentrated ownership on general firm performance, including the positive incentive effects, negative agency costs, and non-linear relationship; any accentuating factors such as separation problems in ownership concentration; and mitigating factors like CEO positioning, board characteristics, and the existence of other large shareholders. The end of chapter two offers a discussion into various institution mechanisms and focuses on anti-director rights, accounting standards, legal enforcement (La Porta et al. 1998), extra-legal systems (Dyck and Zingales 2004), anti-self dealing, pubic enforcement, and revised anti-director rights (Djankov et al. 2006).

Chapter three studies the rationale for merger and acquisition and introduces the background for measuring merger and acquisition performance as related to the empirical evidence, discussions and limitations of both short-term/long-term market performance and accounting based performance. This chapter also summarizes several transaction characteristics that are well documented as determinants of M\&A success. These include target origin, transaction attitude, payment type, multiple bidders' competition, industry relatedness, toehold interests, deal premiums, size deviation between bidders and targets, and levels of acquirer leverage. The final section of chapter three is devoted to describing the impact of concentrated ownership and generation governance mechanisms on acquisition performance.

Chapter four begins by laying out the research framework for this thesis and then postulates major and secondary research hypotheses. Chapter five then illustrates the process of sample selection, the description of sample characteristics, the configuration of independent variables, the definition and calculation of operating performance measures, and the development of benchmark construction. The conclusion of chapter five includes a presentation of the empirical models of this thesis. Chapter six then reports various empirical results including statistics descriptions, univariate analyses, and multiple regression results for seven basic models, two full models, and two modified models. Specific discussions 
concerning the research hypotheses presented in chapter four are included in the last section of chapter six.

Chapter seven provides additional analysis by investigating the elements of the improved operating performance, the impact of the type of ultimate owners, and the cross effects of the type I agency problem (separation between control and cash flow rights) and the type II agency problem (separation between ownership and management). The final part of this chapter further presents the results associated with using different definitions for independent variables such as cross border rather than cross origin, industry relatedness ( 2 or 3- digit SIC codes), and a pre-bidding period for premium measures (1 week or 4 weeks). Results with year dummy variables as control variables are also included.

Sensitivity analysis is conducted and reported in chapter eight. This includes the following: robustness testing on the methods of detecting outliers (Wilcox 2003), the estimation of clustered standard errors including both robust (Woolridge 2003) and bootstrap approaches (Efron and Tibshirani 1986), and the argument for setting the year prior to the event as the base year for change performance (Denis and Denis 1995). Chapter nine provides a summary of all the results included in this thesis, pointing out research limitations and suggesting areas for further research. 


\section{Chapter Two}

\section{Concentrated Ownership, Corporate Governance, and Firm Performance}

\subsection{Introduction}

In 1976, Jensen and Meckling formally developed an agency theory based on Berle and Means's (1932) concept of widely held corporations. This type of agency problem emphasizes the conflict of interest between managers and shareholders; it portrays the manager as having only an attenuated interest in profits generated by the firm. One of the most significant considerations for reducing this type of agency cost is to increase the proportion of shares held by managers in the firm. However, more recent scholars suggest that an owner-manager has more tendency and power to enact undesirable agency behavior if private benefits exceed private costs (La Porta, Lopez-de-Silanes and Shleifer 1999, Claessens, Djankov and Lang 2000). Increasing ownership concentration may, encourage yet another type of agency problem between large and small shareholders. As the first type of agency problem between owners and managers has been well studied in past years, this thesis will focus more on the second type of agency problem between controlling shareholders and minority shareholders.

The purpose of this chapter is to review current research defining the nature of the problem as it relates to concentrated ownership. It also intends to consider how such problems impact corporate performance, what major factor accentuates agency problems of ownership concentration, and what governance mechanisms might mitigate agency costs. Section 2.2 acknowledges the incentive effects of ownership concentration but focuses more on problems with concentrated ownership, specifically with managerial entrenchment, tunneling, and sub-optimal decisions. Section 2.3 summarizes the impact of concentrated ownership structures on general corporate performance. Section 2.4 then discusses the separation problem of control and cash flow rights as the major accentuating factor impacting agency costs in a concentrated ownership structure. Section 2.5 finally reviews governance mechanisms for concentrated ownership structures. These include first generation governance characteristics such as CEO position, board composition, and other 
large shareholders. This section also introduces second generation governance mechanisms which are so-called legal and extra-legal institutions. The most up to date concept of legal protection, termed the anti-self-dealing index by Djankov, La Porta, Lopez-de-Silanes, Shleifer (DLLS, 2006), will also be included in this section.

\subsection{The Nature of the Problems with Concentrated Ownership}

A relatively large number of empirical studies have focused on the agency problems experienced by owners and managers in widely held companies (Jensen and Meckling 1976, Fama and Jensen 1983a,b, Shleifer and Vishny 1986, Morck, Shleifer and Vishny 1988b). They propose that ownership concentration is one of the sound internal mechanisms for reducing agency costs because the owner-managers have stronger incentive to perform efficient monitoring, to solve free-rider problems, and to make beneficial investment decisions to maximize the firm's value. While concentrated firms have their own potential agency problems between the controlling shareholders and minority shareholders, one line of concentrated ownership studies emphasizes positive incentive effects. This line still believes that in order to gain pecuniary benefits the controlling shareholders will devote themselves to increasing the share price in order to benefit themselves and, therefore, the minority shareholders. From this point of view, the incentive effects of concentration ownership parallel those suggested by dispersed ownership research (Jensen and Meckling 1976, Shleifer and Vishny 1986).

However, the other line of concentrated ownership studies argues that controlling shareholders employ corporate resources to benefit themselves not only in pecuniary but also in non-pecuniary ways (Morck 2000). To attain non-economic benefits, controlling shareholders might act in their own interest at the expense of the minority shareholders' wealth. This line of study emphasizes how expropriation effects have a stronger influence on firm value, especially when the company has a policy of controlling shareholders in order to separate their control rights from their cash flow rights.

Expropriation is a broad term used in governance literature. In La Porta, Lopez-de-Silanes, Shleifer and Vishny (2000), expropriation means that "the insiders use the profits of the firm to benefit themselves rather than return the money to the outside 
investors" (La Porta et al. 2000: p4). Expropriation can take a variety of forms such as managerial entrenchment (Fama and Jensen 1983b, Stulz 1988, Claessens et al. 2000, Schulze, Lubatkin, Dino and Buchholtz 2001), tunneling (Johnson, Lopez-de-Silanes, La Porta and Shleifer 2000b, Bertrand, Mehta and Mullainathan 2002, Friedman, Johnson and Mitton 2003), and sub-optimal investment decision (Shleifer and Vishny 1997, Sudarsanam and Huang 2006, Faccio and Stolin 2006). Such actions may not technically be illegal, but they lower the competitiveness and performance of firms. The following sub-sections will focus specifically on the costs of agency problems in concentrated ownership structures.

\subsubsection{Managerial Entrenchment}

This thesis confines managerial entrenchment to issues concerning the resistance to outside monitoring, incompetent managers, and the misplacement of top managers. Topics regarding resource transfer or sub-optimal decision-making will be discussed as the other major agency problems. Both Fama and Jensen (1983a) and Demsetz and Lehn (1985) point out that managers holding a substantial proportion of a firm's equity may have too strong a voting power to ensure their position inside company. This decreases the probability of a successful bid by other agents and results in the failure of outside effective monitoring. The managerial entrenchment becomes the offsetting cost for heightened managerial incentives. Stulz (1988) proposes a model which shows that the more a company's stakes are held by top managers, the lower the probability of turnover among those top managers; this model agrees with the entrenchment hypothesis.

Beyond insulating from external discipline, concentrated firms may also suffer a drawback arising from the selection of company executives within a restricted labor pool, i.e. from among the members of controlling or family shareholders. Schulze et al. (2001) argue that the concentrated ownership structure, especially the family structure, may limit the top management positions to affiliated members instead of hiring more qualified outside professional managers. Empirical research provides evidence that the market performance of family firms is strongly and positively related to the announcement of the departure of a family CEO. Investors expect that a non-family member appointed to succeed the departing top executive can effectively reduce managerial entrenchment costs (Hillier and McColgan 2005, Villalonga and Amit 2006). 


\subsubsection{Tunneling}

Along with entrenchment effects, tunneling is the other type of expropriation usually present in concentrated ownership with pyramid structure. In Johnson et al.'s study (2000b: p22) tunneling is narrowly termed as "the transfer of resources out of a company to its controlling shareholder" and "does not cover other agency problems, such as incompetent management, placement of relatives in executive positions, excessive or insufficient investment or resistant to value increasing takeovers". This definition of tunneling is used throughout this thesis.

Clearly, the most visible way of controlling shareholders to allocate corporate resources to their own parties is through outright theft. But, corporate governance research focuses more on the unfair transfer: "corporate resource is not shared among all the shareholders in proportion of the shares, but it is enjoyed exclusively by the party in control" (Dyck and Zingales 2004: p541). The common form that controlling shareholders use for tunneling comes through self-dealing transactions which include special dividend payouts, luxury expenses, excess compensation, asset transfers at above or below market price, lending at non-market rates, guarantees of other entities borrowing using firm's assets as collateral, or enhancing the value of other group companies through the use of merger transactions. Several attempts have been made to prove that in countries with a poor legal system, controlling shareholders, especially in firms with a pyramid ownership structure, have a tendency to move the company's profit from firms where they have low cash flow rights to firms where they have high ones (Johnson et al. 2000b, Bertrand et al. 2002, Friedman et al. 2003, Riyanto and Toolsema 2004).

Johnson et al. (2000b) point out several well-known tunneling cases in Western European countries and propose that tunneling between firms in the same groups is sometimes allowed not only in emerging countries but also in developed countries. Following the discussion on the legal tunneling, Friedman et al. (2003) and Riyanto and Toolsema (2004) further analyze the reasons why minority shareholders (assuming that they are rational investors) are willing to be expropriated under the controlling minority shareholder (CMS) structure with a separation problem. According to their conclusion, under some circumstances controlling shareholders may use private funds to save the new firms and in order to preserve the opportunity to expropriate or obtain legitimate profit in the future. That is called propping effects or negative tunneling. If propping is possible, minority shareholders are willing to endure the tunneling to some extent in the hopes of future 
positive returns. To date, however, propping remains an initiative that requires further examination.

\subsubsection{Sub-Optimal Investment Decisions}

Under the perception of dispersed ownership, top managerial compensation is closely linked to firm size, growth opportunity, and the probability of survival. These concerns motivate managers to invest their internal funds in negative NPV projects rather than in the paying out of dividends, especially when they are in firms with a substantial free cash flow (Jensen 1986). This kind of investment decision is one type of sub-optimal decision called overinvestment. Many studies typically assume that overinvestment decisions are made by independent and professional managers who hold either very few or no stakes at all in the firms. To reduce the cost of overinvestment decisions, one strand of articles provides theoretical and empirical evidence to show that managers with a large percent of company shareholdings might mitigate this type of agency cost (Jensen and Meckling 1976, Shleifer and Vishny 1986, Huddart 1993, Admati and Pfleiderer 1994).

According to Jensen and Meckling (1976), if a manager owns 100 percent of the residual claims of a firm, he or she will make optimal investment decisions to maximize the firm's value. This argument brings the discussion into the structure of concentrated ownership where the agency cost is not between managers and public shareholders, but between controlling shareholders and minority shareholders. There are two considerations associated with whether or not the owner-managers can reduce the overinvestment. One is that if the owner-managers control the company under the CMS structure, then the overinvestment problems may be similar to those in dispersed ownership structure. Several attempts have been made to prove that managers have a tendency to over-expand the firm size, promote their status, and/or raise their compensation through a value-reducing investment (Jensen and Ruback 1983, Roll 1986, Shleifer and Vishny 1997, Faccio and Stolin 2006).

The other is that even without separation, when the private capital of the owner-managers is more concentrated in the firm, they clearly bear a more unsystematic risk than minority shareholders whose portfolios are fully diversified. Consequently, the risk preference of owner-managers will become more risk-averse. A risk-averse owner-manager without effective monitoring mechanisms may give up a high-risk but value-enhancing investment, or he may undertake a so-so project in order to stabilize the firm's risks - this 
may either limit or fail to benefit the minority shareholders (Amihud and Lev 1981, Lewellen, Loderer and Rosenfeld 1985, Hubbard and Palia 1995, Sudarsanam and Huang 2006). This type of sub-optimal decision is called underinvestment.

If increasing ownership concentration cannot reduce the cost of sub-optimal decisions, what might be other mitigating factors? One view emphasizes the debt monitoring mechanism (Jensen and Meckling 1976, Stulz 1990, Harris and Raviv 1991). This perspective relies on an optimal capital structure in which top managers may be forced to pay out cash because of a debit commitment and then reduce the waste of cash flow. A more detailed review about the debt monitoring mechanism is discussed in chapter three, section 3.4.9. In addition, governance mechanisms such as an independent CEO, an effective board, or an external large shareholder are also expected to encourage or monitor decision makers that might help to mitigate this type of agency cost under the concentrated ownership structure. These corporate governance mechanisms are discussed in the following section 2.4 . 


\subsection{Concentrated Ownership and Firm Performance}

\subsubsection{The Level of Ownership}

\section{Incentive Effect}

The effects of ownership concentration on firm performance remain mixed. Some research shows that if large shareholders who hold a sizeable fraction of company's shares are also top managers then they should have the motivation to act in their own interests and to benefit the investors as well. Moreover, if large shareholders are not in the position of decision makers, then they should have the power to reduce asymmetrical information, solve free-rider problems, diminish moral hazards, and perform efficiency monitoring. Zeckhauser and Pound (1990) outline a model that illustrates the increasing curve between the large shareholder's average per share and the company's current market price (measured by E/P ratio). They test this relationship empirically by sampling 286 US firms across 22 industries. They show that "the market recognized the expected effects of large shareholders on fundamental corporate performance, and incorporates that effect into security prices" (Zeckhauser and Pound 1990: p171). The evidence basically supports the positive incentive effect and suggests that corporate performance increases with the ownership of the large shareholders (Jensen and Meckling 1976, Claessens, Djankov, Fan and Lang 2002).

\section{- Expropriation Problems}

On the contrary, another group of academics that defends expropriation problems declares that without effective monitoring, controlling shareholders are likely to exploit minority shareholders by managerial entrenchment, by tunneling, or by making sub-optimal decisions. Such expropriation problems are even worse when control rights might exceed cash flow rights (Faccio, Lang and Young 2001, Claessens et al. 2002, Cronqvist and Nilsson 2003).

From a dividends perspective, Faccio et al. (2001) investigate expropriation in 5,897 financial and non-financial corporations in nine East Asian and five Western European countries. They find that corporations with large shareholders who control 10 to 20 percent of the control rights fail to pay higher dividends; the greater the deviation between ownership and control, the lower the dividend rates. They provide empirical evidence on tunneling suggesting that large inside shareholders may construct a low or negative deal so as to consume corporate resources and thereby to expropriate minority shareholders through 
these transactions. Furthermore, they specifically identify the Asian financial crisis as caused by "crony capitalism" where powerful political families developing related-party contracts within business groups.

Cronqvist and Nilsson (2003) use a dataset of 309 Swedish firms from 1991-1997 in order to analyze the agency cost of CMS structure. They find a significant negative relationship between the voting rights of CMS and firm value (measured by Tobin's Q). They explain that the source of this discount is from lower return on assets (ROA) and that lower operating performance is more likely to stem from suboptimal decisions than from tunneling behavior in the developed Swedish market. Moreover, they show that about 50 percent of family firms are less likely to face the threat of takeover. The cost of managerial entrenchment exists in the CMS firms, particularly in family firms.

By comparison, Claessens et al. (2002) examine 1,301 listed companies in 8 East Asian countries and conclude that ownership concentration is positively associated with the increase in firm value (measured by the market to book ratio) but that increases in terms of control rights over cash flow rights dramatically decrease the firm value. They confirm that both the incentive and entrenchment hypotheses of large shareholdings have impacts on corporate performance.

\section{- Nonlinear Relationship}

Morck et al. (1988b) are the first to highlight a nonlinear relationship between managerial ownership and corporate performance. They examine 371 Fortune 500 firms for the year 1980 and find a positive relationship between ownership and Tobin Q in the 0 to 5 percent of ownership ranges, a negative relation in the 5 to 25 percent ranges, and perhaps a further positive relation beyond 25 percent. They believe that the convergence of interests between managers and shareholders may be one explanation for this but that it may not be the only one. Another good reason for interpreting the increase from 0 to 5 percent is likely to be the remuneration of the top management, which is generally rewarded in firms with already good performance (high Tobin's Q ratio). Compared to the incentive effects that function over the whole range of ownership, expropriation costs are far more likely to be significant beyond 5 percent without being greater than 25 percent.

Subsequently, Hermalin and Weisbach (1991) have studied 142 NYSE firms and report a consistent result that at low levels of ownership (less than one percent), corporate 
performance (measured by Tobin's Q) improves with increases in ownership. At moderate levels of ownership (between one percent and 20 percent), the Q ratio seems first to be negative and then positive but with no significance. At high levels of ownership greater than 20 percent, the Q ratio decreases significantly with ownership. They explain this result by concluding that the cost of increasing insulation from disciplinary devices offsets the benefit of increasing an alignment of interests. Another US study by McConnell and Servaes (1990) investigates two separate US samples: 113 firms for 1976 and 281 firms for 1986. The study finds that for both 1976 and 1986 Tobin's Q increases with concentration until ownership exceeds 40 to 50 percent.

Two important UK empirical studies (conducted by Lasfer and Faccio (1999) and Davies, Hillier and McColgan (2005) respectively) also report a nonlinear specification between the corporate value and managerial holdings. Lasfer and Faccio (1999) report two turning points at 19.68 percent and at 54.12percent. Davies et al. (2005) study a much higher level of managerial ownership. Their investigation shows that Tobin's Q increases in firms for managerial ownership levels at $7 \%$ and then declines to ownership levels of $26 \%$. This is almost identical to the earlier articles stating turning points of around 5 to 25 percents. Importantly, they further prove that market discipline has an influence up to the 51 percent where the board takes complete control. Tobin's Q then decreases again until ownership levels reach 76 percent after high level Q increases.

Anderson and Reeb (2003) specifically focus on family firms and confirm that firm performance (measured by Tobin's Q and ROA; ROA measured by EBITA/Book value of asset and Net Income/Book value of asset) increases when family ownership rises from 0 to 30 percent, tapers off between 30 and 60 percent, and declines after 60 percent. In sum, this stream of literature generally agrees that at the lower levels of ownership, internal incentives have an impact on managerial behavior; at the median levels of ownership, agency costs are not high enough to behave the large shareholder. As controlling shareholdings rise to high levels of concentration, severe financial penalties will lead them to act towards value-maximization. However, when concentration reaches top levels, expropriation problems then arise, including averse-selection, managerial entrenchment, or the failure of external discipline - each of which may act as a determent to decrease corporate value. 


\section{- Weak or Insignificant Relationship}

Other studies indicate that the relationship between ownership concentration and corporate performance is either weak or insignificant. By sampling 511 US corporations, Demsetz and Lehn (1985) assess the impact of ownership structures on several accounting ratios, including the ratio of capital expenditure, the ratio of advertising expenditures, the ratio of research and development expenditure, and the value of total assets. They fail, however, to discover any significant relationship between ownership concentration and the accounting ratios. Based on the arguments of Demsetz and Lehn (1985), Himmelberg, Hubbard and Palia (1999) add that ownership structure is endogenously determined by the contracting environment. Their findings support the view that since other firm characteristics are significantly correlated to ownership structure and firm performance, it is not meaningful to identify the relationship between ownership concentration and firm performance (measured by Tobin's Q or accounting ratios). Holderness and Sheehan (1988) compare 114 majority shareholder firms with 101 matched dispersed firms. They find that the difference between concentrated and dispersed ownership is small and slightly significant in both the accounting rates of returns and in Tobin's $Q$.

\subsubsection{The Type of Ownership}

The type of the controlling shareholder is also likely to affect a firm's governance and performance. Previous research generally identifies the ultimate owners and classifies those owners into the following four ${ }^{1}$ types: family, widely held financial institution, widely held institution, and state (La Porta et al. 1999, Claessens et al. 2000, Faccio and Lang 2002). In other words, each country mostly has five types of firms: dispersed firms, family controlled firms, firms controlled by widely held financial institutions, firms controlled by widely held corporations, and state-controlled firms. The most critical point regarding the classification is that when the ultimate owner of a corporation is an unlisted private firm and fails to trace its owners using all available data sources, most research regards it as a family firm (La Porta et al. 1999, Claessens et al. 2000, Faccio and Lang 2002). However, in the Maury and Pajuste (2005) study, ultimate owners are specially classified into family, corporation, financial institution, state, and others. The ones who fail to trace are reported as corporations.

1 In La Porta et al (1999) and Faccio and Lang (2002), there is another type defined as 'miscellaneous' which includes voting trusts, a cooperatives, or a group with no single controlling investors, charities, employees, or minority foreign investors. 


\section{- Family Controlled Firms}

A great deal of literature on concentration ownership has addressed the benefits and cost of family firms. One stream of previous research supporting the benefits of family firms advocates that, first of all, family firms have relatively lower agency costs since there is a modest separation problem between management and ownership in family firms. Family members have more incentive to maximize the firm value because their welfare is closely linked to the firm performance (Demsetz and Lehn 1985, Anderson and Reeb 2003). Second, because of the long-term presence family tenure can extend the firm's learning curve to cover longer investment horizons (Stein 1989). Third, family firms have a greater tendency to invest in positive projects to pass on to their descendants (James 1999). Fourth, the long-term nature may encourage external bodies or third parties to deal with the family firms, thereby creating longer-lasting economic benefits or lowering the capital costs of companies (Anderson, Mansi and Reeb 2003). Finally, some literature focuses on the trust that might mitigate the moral hazard problem between parents (principals) and children (agents). Such mitigation will increase the firm performance (DeAngelo and DeAngelo 1985, Lee 2004)

The other stream of existing research suggests the cost of family firms. First, this stream argues that managerial entrenchment problems are even more serious in family structures since the top executives of family firms are usually limited by their kinship. Hiring inferior or inadequate employees from a relatively smaller labor pool with similar characteristics or perhaps lower quality may reduce the competition and company efficiency in such a way as deters the growth of firm (Schulze et al. 2001). Second, when family members cannot separate their own financial preferences from those of minority shareholders, they have more power to act on their own interests at the expense of firm performance (Claessens et al. 2002). Third, family has more influence on reducing the probability of bidding by other agents. The value of the firm will thereby be reduced due to the failure of external monitoring (Barclay and Holderness 1989). Fourth, some research states that in order to avoid the dilution of ownership and to secure their control rights, family firms may be unwilling to raise loans or to issue new stocks so as to make new positive investments. The inadequate investment in R\&D or new technology may impede the development of the firm (Rajan and Zingales 1998). Fifth, family firms may be more averse to risky projects unlike the dispersed shareholders whose portfolios are fully diversified (Zhang 1998). 


\section{Institutions Controlled Firms}

Regarding to the effects of institutional large shareholders on corporate performance, Duggal and Millar (1999) propose two competing hypotheses. The efficiency-augmentation hypothesis supposes that the size of institutional holdings may provide more sufficient incentive for institutional investors to intervene in the governance of firms that might result in corporate efficiency enhancement due to better professional investment decisions and effective monitoring mechanisms. In contrast, the efficiency-abatement hypothesis assumes that institutional investors are unable to effectively perform their monitoring roles because of their passivity, their myopic goals, their conflicts of interests, or their legal constraints. Brickley, Lease and Smith (1988) clearly classify institutional investors in terms of the extent to business relationships with their invested companies. The institutional investors are classified into three categories: pressure-sensitive, pressure-resistant, and pressure-indeterminate. Pressure-sensitive institutions, including banks, insurance companies, and non-bank trusts have business relationships with firms in which they own equities. Pressure-resistant institutions, including public pension funds, mutual funds, and endowments and foundations do not have business relationships with firms in which they hold equities. Pressure-indeterminate institutions include those institutions whose relationships with the firms they invest in cannot be so clearly defined.

David, Kochhar and Levitas (1998) show that pressure-resistant institutions are more effective in influencing managers than pressure-sensitive institutions are. Cornett, Marcus, Saunders and Tehranian (2003) specifically examine the impact of the type of institutional investors on firm performance using cash flow return on assets as measures. They investigate S\&P 100 firms from the 1990s and confirm a significant positive relationship only between pressure-insensitive (resistant) institutional investors in a firm and in its operating cash flow. Cornett et al. (2003) suggest that pressure-sensitive institutional investors might compromise their role as monitors because of a heightened interest in protecting business relationships with the firm.

As major creditors, financial institutions have their own specific characteristics as institutional shareholders in public companies. This type of large shareholder is more common in Europe and Japan (Gugler 2001) than in the US. Gorton and Schmid (2000) study German corporations and discover that firm performance is positively related to bank equity holding. Lichtenberg and Pushner (1994) attempt to identify the importance of types of shareholders in Japan. They find a significantly positive relationship between ownership 
shares of a financial institution and company productivity. Both studies agree with the view that bank involvement in the governance of the firm might expect to provide superior monitoring capabilities, a lower cost of capital, fewer financial constraints, or better support in financial distresses. Weinstein and Yafeh (1998), however, suggest that when banks are the main large shareholders there is actually a negative effect on a firm's profit and growth rate. They investigate the performance of 700 listed manufacturing firms in Japan during the period 1977 to 1986 . They find that firms closely related to banks are less likely to be involved in risky though potentially profitable investments. Besides, banks are likely to use their monopoly power to expropriate minority shareholders through either credit channel or other types of ways when they are a firm's main large shareholder.

\section{- State Controlled Firms}

The State large shareholders have hardly been emphasized. In general, state ownership has been challenged on the idea that the public owns state firms while control rights belong to government departments. This means that these departments can be thought of as having extremely concentrated control rights without any significant cash flow rights; this is because the cash flow ownership is dispersed among the taxpayers of the country. Therefore, the state ownership is broadly considered as an inefficient structure because State firms do not attempt to serve the public interest better than private firms (Shleifer and Vishny 1997). Megginson, Nash and van Randenborgh (1994) compare pre- and postprivatization operating performance of 61 companies from 18 countries during the period 1961 to 1990. They find that profitability, real sales, operating efficiency, and capital investment spending increase significantly after privatization.

After broadly summarizing earlier research, how the level of ownership concentration and the type of owners impacts firm value remains unclear. However, it is relatively clear that the separation of control and cash flow rights is the predominant, accentuating factor for determining the specific agency costs of concentrated ownership structures. However, recent governance research has been devoted to discovering the efficient mitigating factors for reducing the agency costs of this structure. Denis and McConnell (2003) divide the existing governance research into two generations. The first generation research generally focuses on the organizational mechanisms, such as CEO positions, board composition, and outside block shareholders, specifically in individual countries. The second generation research pays more attention to the importance of the legal and extra-legal institutions from country to country. 


\subsection{Accentuating Factor to the Agency Problem with Concentrated Ownership}

\section{- Separation}

Based on the concept that corporate ownership is measured by cash flow rights and that the control right is measured by voting rights, recent researchers, such as La Porta et al. (1999) and Claessens et al. (2000), report that the controlling shareholders often separate their control rights from their cash flow rights using various control devices. Bebchuk, Kraakman and Triantis (2000) term this pattern of ownership a controlling minority shareholder (CMS) structure because it allows the majority of shareholders to control a firm while holding only a small fraction of the firm's cash flow. When the dominant shareholders fail to bear the full costs of their decisions, they may have incentive to expropriate their minority shareholders.

There are three typical control devices used by controlling shareholders in producing the separation of their control from their cash flow rights: dual class share, pyramids, and cross-holdings. The dual-class share structure involves the creation of two or more classes of common stocks with differential voting shares. For example, a company has two types of ordinary shares. 'A' type shares have one vote per share but 'B' type shares are nonvoting shares or have multiple votes (perhaps 5 or 10 votes per share). It is a simple CMS form that the controlling shareholders can separate their control rights from their cash flow rights, without establishing multiple firms. La Porta et al. (1999) investigate the ownership structure of the largest corporation in 27 wealthy countries. They find the average deviation from differential voting rights is very rare. One reasonable explanation for this evidence is that most countries either forbid a dual class shares policy or set a high-low vote shares limitation. Nevertheless, Bebchuk et al. (2000) point out that dual class share structures are particularly common in Sweden and South Africa. Ben-Amar and André (2006) indicate that dual class share structures are widespread in Canada. Furthermore, listed corporations cannot issue ordinary shares with differential voting rights in Australia but they could have voting shares policies (Australian Stock Exchange Listing Rule 6.9) that allow one voting right per share on a poll, as opposed to one voting right per person on a show of hands. This mechanism provides separation, even though it is not necessary to create different classes of ordinary shares (Lange, Ramsay and Woo 2000). 
A pyramid structure can be framed in firms with only a single class of share but with more than one entity. In this structure the controlling shareholders own a substantial amount of the stock of holding corporations which, in turn, hold a majority fraction of the stakes of operating companies (Claessens et al. 2000, Bebchuk et al. 2000). The process can be repeated several times to establish a multiple level pyramid structure. For example, in a three level pyramid, a controlling minority shareholder could hold 60 percent of shares of company A, which, in turn, could hold 20 percent of the stocks of company B. The controlling minority shareholder controls 20 percent of the voting rights of the operating firm (company B) via the holding company (company A), but only has 12 percent $(60 \% * 20 \%)$ of the cash flow rights of the operating firm (company B). Figure 2.1 illustrates this control chain. This structure has been generally regarded as a common device for controlling minority shareholders to make ownership disproportionate in both Asian and European countries.

Family ABC

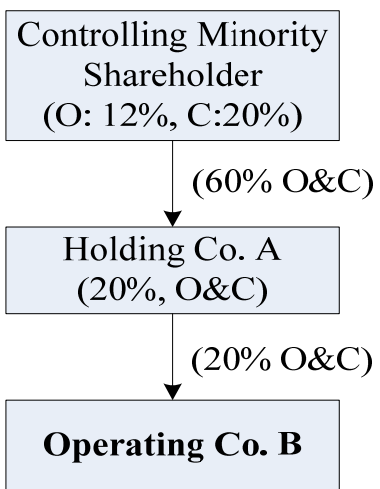

Figure 2.1 Control Chain of a Pyramid Structure. This figure describes a simple case of pyramid structures. Controlling minority shareholders hold 20 percent control rights but only bear 12 percent cash flow risk of company B through their holding company A. Ownership shares (cash flow right) are denoted by "O" and voting shares (control right) are denoted by " $\mathrm{C}$ ".

Cross holding structure happens when the voting shares used to control the operating firm are horizontally distributed over the entire group rather than concentrated in the hands of a single company or an ultimate controlling shareholder (Bebchuk et al. 2000). Affiliates in the conglomerate have cross investment by directly or indirectly owning the shares of one another. For a simple example for this complex structure, assume that a parent company holds 50 percent of the stocks of company A, which in turn holds 20 percent of company B. One of the sister companies owns 20 percent of company $\mathrm{C}$, which in turns has 10 percent of company B. Consequently, the parent company controls 30 percent $(20 \%+10 \%)$ of the voting rights of company B through the sum of the weakest links. However, their group only holds 
12 percent $(20 \% * 50 \%+10 \% * 20 \%)$ of the cash flow risk of company B. Obviously, cross holding patterns are often adopted in combination with pyramid structures. Cross-holding ownership structures are increasing complex; they reduce the efficiency of a defense as well as the transparency of a company. Figure 2.2 illustrates this control chain. Cross holding structures are relatively popular in Asian countries such as Japan, Malaysia, and Singapore, where family conglomerates are more widespread (La Porta et al. 1999, Claessens et al. 2000, Bebchuk et al. 2000).

Family ABC

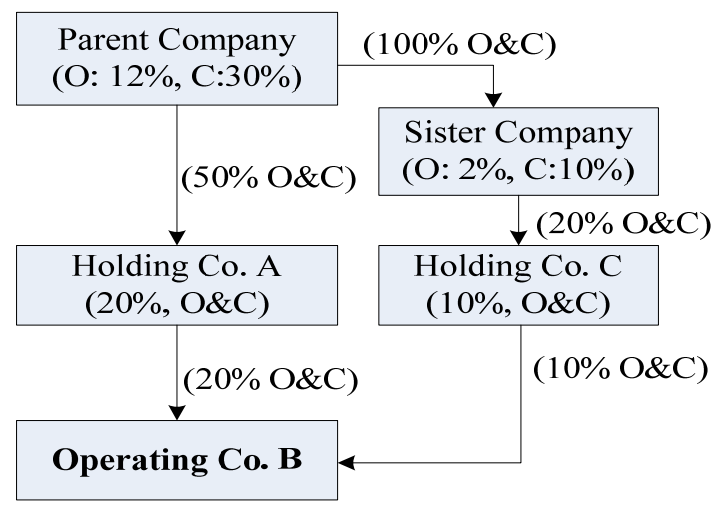

Figure 2.2 Control Chain of a Cross Holding Structure. This figure describes a simple case of cross holding structures. The controlling group including parent and sister companies controls 30 percent of company B through their holding company A and $\mathrm{C}$ but only needs to take 12 percent of cash flow risk. Ownership shares (cash flow right) are denoted by "O" and voting shares (control right) are denoted by "C".

Below is a real sample with more complex ownership structure in this thesis. Teck Corporation, a Canadian acquiring firm on March 2001 (the last report date before M\&A transaction) was authorized to issue an unlimited number of Class A Common shares and Class B Subordinate Voting shares. On March 5, 2001 the corporation had an outstanding 4,682,078 Class A Common shares, each carrying the right to 100 votes per share, and 100,627,557 Class B Subordinate Voting shares, each carrying the right to one vote per share. This company obviously had separation via a dual class structure.

This company also had three large shareholders holding more than 10 percent of the voting shares at that time. Temagami Mining Company Limited was the largest shareholder $(37.8 \%)$ and was a private company based in Canada and controlled by Keevil Holding Corporation (51\%) and SMM Resources Incorporated (49\%). Therefore, this company had another form of separation through a pyramid structure. Tracing its ultimate owner, Keevil 
Holding Corporation was found to be controlled by Norman B. Keevil (Keevil Family) with $98 \%$ of the voting shares. SMM Resources Incorporated was a wholly owned subsidiary of Sumitomo Metal Mining Company Ltd which was a Japanese company widely held by financial institutions and public investors. SMM Resources Incorporated also owned 13.2\% of voting shares of Teck Corporation leading to another type of separation through cross-holding ownership structures. The other large shareholder was Caisse de dépôt et placement du Québec holding 13.2 percent of voting shares and 15.83 percent of common shares. In the case of the Teck Corporation, it is clear that control rested primarily with the Keevil Family (with a $23.42 \%$ ownership and a $37.8 \%$ control rights). The family dominated the Temagami Mining Co. (the largest shareholder of Teck Corp) by 51 percent. Sumitomo Metal Mining Company Ltd was a beneficial blockholders it had almost equal power (49\%) in Temagami Mining Co. as the Keevil Family did. This case is indicative of the complexities of identifying separation structures through various control devices. Figure 2.3 displays the chart and the calculating of Teck's ownership and voting rights structure.

Panel A Structure Chart

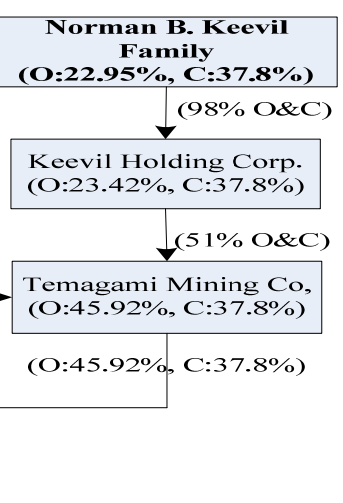

Panel B Calculating of ownership and voting rights of Teck Corp.

\begin{tabular}{|c|c|c|c|c|c|}
\hline Type & $\begin{array}{c}\begin{array}{c}\text { Number of } \\
\text { shares }\end{array} \\
\end{array}$ & Voting rights & $\begin{array}{c}\text { Number of } \\
\text { Voting shares }\end{array}$ & Percent of ownership & $\begin{array}{c}\text { Percent of voting } \\
\text { rights }\end{array}$ \\
\hline$\overline{A-C m m o n ~ s h a r e s ~}$ & $4,682,078$ & 100 & $468,207,800$ & $100 \%$ & $82.31 \%$ \\
\hline B-Voting shares & $100,627,557$ & 1 & $100,627,557$ & $0 \%$ & $17.69 \%$ \\
\hline Al1 & & & $568,835,357$ & $100 \%$ & $100.00 \%$ \\
\hline Beneficial Holders & $\begin{array}{l}\text { A-Cmmon } \\
\text { shares }\end{array}$ & $\begin{array}{l}\text { Separation via } \\
\text { control devies }\end{array}$ & $\begin{array}{l}\text { B-Voting } \\
\text { shares }\end{array}$ & Percent of ownership & $\begin{array}{c}\text { Percent of voting } \\
\text { rights }\end{array}$ \\
\hline Keevil Family & $2,150,000$ & $51 \% * 98 \%$ & - & $\begin{array}{c}22.95 \% \\
(2,150,000 * 0.51 * 0.98 \\
/ 4,682,078) \\
\end{array}$ & $\begin{array}{c}37.80 \% \\
(2,150,000 * 100 \\
1568,835,357) \\
\end{array}$ \\
\hline $\begin{array}{l}\text { Sumitomo Metal } \\
\text { Mining Company } \\
\text { Ltd }\end{array}$ & $\begin{array}{r}2,150,000 \\
734,500\end{array}$ & $49 \%$ & - & $\begin{array}{c}22.50 \% \\
(2,150,000 * 0.49 / 4,682,078) \\
15.69 \% \\
(734,500 / 4,682,078)\end{array}$ & $\begin{array}{c}12.91 \% \\
(734,500 * 100 / 568,835,357)\end{array}$ \\
\hline $\begin{array}{l}\text { Caisse de dépôt et } \\
\text { placement du Qué } \\
\text { bec }\end{array}$ & 741,200 & - & $1,107,684$ & $\begin{array}{c}15.83 \% \\
(741,200 / 4,682,078)\end{array}$ & $\begin{array}{c}13.22 \% \\
((741,200 * 100+1,107,684) \\
/ 568,835,357)\end{array}$ \\
\hline
\end{tabular}

Figure 2.3 Chart and Calculating of Ownership and Voting Shares of Teck Corporation (Mar. 2001). Ownership (cash flow right) are denoted by "O" and voting shares (control right) are denoted by " $\mathrm{C}$ ". 


\subsection{Mitigating Factors to the Agency Problem with Concentrated Ownership}

\subsubsection{Corporate Governance Mechanisms: $1^{\text {st }}$ generation}

The corporate governance mechanisms have been broadly characterized as being either internal or external to the firm (Hirshleifer and Thakor 1994, John and Senbet 1998, O'Sullivan and Wong 1998, Weir, Laing and McKnight 2002, Denis and McConnell 2003). The internal mechanisms usually focus on CEO compensation, board composition, and ownership itself. Denis and McConnell (2003) call these internal mechanisms the first generation of international governance mechanisms. The external mechanisms are generally discussed as takeover markets and as legal/extra-legal systems. When internal mechanisms fail in their function, the market for corporate control is regarded as a potential disciplining mechanism. The consequences of takeovers are debatable and will be thoughtfully reviewed in chapter three. Legal institutions have been hypothesized as a fundamental governance mechanism ever since La Porta, Lopez-de-Silanes, Shleifer and Vishny (LLSV, 1998); they are categorized as the second generation of international governance mechanisms by Denis and McConnell (2003). This subject will be covered in more detail in the following section, 2.5.2. Since first generation governance mechanisms have been widely examined over the last ten years, this thesis reviews only the relevant and frequently cited works.

\subsubsection{Chief Executive Officer (CEO) Position \\ CEO compensation}

Based on the view of dispersed ownership structure, one strand of empirical studies concerning CEO mechanisms emphasizes the setting of an optimal CEO compensation contract to align the interests of managers and shareholders (Ciscel and Carroll 1980, Core, Guay and Verrecchia 2003). Mehran (1995) finds that the form rather than the level of compensation is what motivates the managers to increase the firm value. Firm performance is positively related to the percentage of a manager's compensation that is equity-based. Murphy (1999) provides an in-depth analysis of executive compensation, showing that "pay-performance sensitivities in the US have increased substantially over the past decade, driven primarily by an explosion in stock-option compensation" (Murphy 1999: p53). Executive compensation has tended to become increasingly complex as firms have formed various executive compensation packages. Some firms pay CEOs only salaries and cash bonuses while others also include contingent and deferred compensation. Furthermore, 
compensation data on executive bonuses and stock options are not consistently measured or reported across firms, countries, and periods. While Murphy (1999) sampling from the US large companies described that "detailed biographic and compensation data for individual executives in publicly owned corporations are widely available and easily matched to company performance data" (Murphy 1999: p3), most cross-country research recognizes the difficulty of obtaining compensation data and of identifying a broadly accepted compensation (Joskow, Rose, Shepard, Meyer and Peltzman 1993, Goldberg and Idson 1995, Rose and Shepard 1997, Randøy and Nielsen 2002). Due to data constraints and time limitations, this thesis is unable to examine CEO compensation as in most of the cross-countries studies.

\section{- Degree of Managerial Ownership}

The second strand of studies claims that the rising degree of managerial ownership increases managerial incentive and thus diminishes the conflict of interest between managers and dispersed shareholders (Jensen and Meckling 1976, Stulz 1988). One of the leading discussions in this field is raised by Morck et al. (1988b). As discussed in section 2.3.1, Morck et al (1988b) suggest a nonlinear relationship between managerial ownership and corporate performance. Their conclusion points out that the convergence of interests between managers and shareholders may exist at lower ownership levels (0 to 5 percent), but entrenchment costs have a more important effect on firm performance associated with the increase of managerial ownership, and then incentive effects have functions back at high level of ownership concentration (beyond 25 percent). After Morck et al (1988b), researchers such as McConnell and Servaes (1990), Hermalin and Weisbach (1991) and Davies et al. (2005) basically support the nonlinear relationship between managerial ownership and firm performance; the optimal degree of managerial ownership concentration, however, is still far from resolved.

\section{- Type of CEO}

The third strand of CEO research in the context of concentrated ownership firms is related to the type of CEO. An important debate in this field now considers whether concentrated firms should hire a professional independent CEO or should designate a member of the controlling shareholders to occupy the seat of the CEO. Does a controlling CEO help to diminish the agency costs between ownership and management? Or does such control actually worsen the agency problems between controlling shareholders and minority shareholders due to the cost of managerial entrenchment? 
Smith and Amoako-Adu (1999) use stock market and operating proxies (measured by ROA) to examine the performance of 124 management successions within Canadian family firms. They find that the stock market response is negatively related to the appointment of family members. The operating performance of firms with independent successors is significantly poorer than the industry in the beginning -- though it improves in the long run. By contrast, firms with family successors under-perform after succession. Hillier and McColgan (2005) investigate 683 UK firms over the period 1992 to 1998 and find that a family CEO is less likely to be replaced even if he/she performs very badly; the departure of a family CEO is positively related to corporate performance.

Barth, Gulbrandsen and Schonea (2005) specifically use the Cobb-Douglas production function to analyze the effects of family-managers on the company's productivity. By examining 438 Norwegian firms in 1996, they provide evidence that family controlled firms with family management are significantly less productive than non-family controlled firms. This conclusion is still valid when comparing family managers and professional managers within a sample of family firms only. The authors explain these results as owing to skills difference or the age of the family firm.

By contrast, Anderson and Reeb (2003) focus on individual/family US controlled firms and find that family firms with family members serving as CEOs outperform the firms with external CEOs. Recent research by Villalonga and Amit (2006) investigates two types of agency problems by conducting a panel survey of US family firms. The first type of agency problem is the separation of ownership and management (Jensen and Meckling 1976). The second type of agency problem is the separation of cash flow rights and control rights (La Porta et al. 1999, Claessens et al. 2000). They suggest that, if the large shareholder is an individual or family, he or she will have a higher incentive to reduce the first type of agency problems and, thereby, will cause the second type of agency problem to dominate the corporate performance. On the other hand, if the large shareholder is an institution, such as a financial institution, a widely held firm, or the government, the private benefits of control may need to be divided up. As a result, large shareholders may lose the incentive for expropriation and the interest to perform efficient monitoring. The second type of agency problem could be lessened but may revert to the first type of agency problem.

Their empirical results sustain the idea that "family firms create value only when the founder serves as CEO of the family firm or as Chairman with a hired CEO" (Villalonga and 
Amit 2006: p385). Moreover, they confirm the concept that separation problems between control and cash flow rights reduce the performance (measured by Tobin's Q) of founding family firms. Basically, Villalonga and Amit (2006) recognize the contributions of controlling CEOs in mitigating the first type of agency problem (conflicts between ownership and management) but still recognize the expropriation costs caused by the second type of agency problem (separation between ownership and control rights). Their latter conclusion is generally consistent with the earlier research which state that controlling CEOs could easily entrench themselves and thus deviate from firm value maximization (Smith and Amoako-Adu 1999, Hillier and McColgan 2005, Barth et al. 2005).

\subsubsection{Board Characteristics}

\section{- Independent Directors}

The structure of the board composition is central to the corporate governance system. Directors are assumed to provide professional advice for hiring, compensating, or even replacing the CEO (Jensen1993). The board is usually composed of inside and outside directors, sometimes classified as executive and non-executive directors. Since most inside directors are full-time employees of the company, their interests are tied to the top management. Therefore they are generally unwilling to challenge their boss. Outside directors could be further divided into two groups: related (grey) directors who are not inside employees but have a certain level of business relatedness with current management; and independent directors. Recently, academics, regulators and shareholder activists have placed greater expectations on the role of independent directors. They think that director independence can fulfil their monitoring function because independent directors may possess important individual characteristics such as independence, professional knowledge or experience, and a good reputation (Fama and Jensen 1983b). A great deal of empirical research proves a positive association between board composition and the measurements of corporate financial performance because outside directors could enhance the firm value.

Weisbach (1988) examines the function of independent directors by testing the market performance (stock returns) and accounting performance (measured by earnings before interest and tax) towards any decisions concerning the removal of top management. Based on the sample of 495 US public firms between 1977 and 1980, they find that both performance measures are more closely related to the CEO resignation in firms with outsider dominated boards than to those where insiders predominate, indicating that CEO turnover is likely to signal the effective composition board and, thereby, to boost the firm's value. 
Instead of testing the board efficiency on CEO turnover, Rosenstein and Wyatt (1990), observe the effects of board independence by testing the abnormal stock returns accompanying the appointment of independent directors. The full sample includes 1,251 WSJ announcements for outside directors from 1981 to 1985. Their empirical evidence implies that pubic investors may anticipate company gains from a more effective board following the appointment of an independent director, and may respond to the abnormal market returns.

One line of research directly examines the association between performance and the proportion of independent directors, failing, however, to find a significant positive relationship (Agrawal and Knoeber 1996, Vefeas and Theodorou 1998, Weir et al. 2002). Agrawal and Knoeber (1996) test board independence using the percentages of nonemployment directors on the board of around 400 large US firms. They find a significantly negative relationship between outside directors and firm performance (measured by Tobin's Q). Their results send the important message that independent directors themselves may be insufficient to perform supervision; inside participation is still needed to improve the decision making. Vefeas and Theodorou (1998) employ 250 UK public firms in 1994 to investigate the relationship between board structure and firm performance (measured by market to book ratio). Their results are consistent with the findings in Agrawal and Knoeber (1996) study regarding the US firms.

Weir et al. (2002) extend the board composition to the board quality by including the proportion of independent directors on the audit committee; the measure of director quality, however, is insignificant. They discover a weak but positive association between director independence and corporation performance (measured by Tobin's Q), suggesting that independent directors still have monitoring effects and "may therefore be regarded as a substitute for other governance mechanisms" (Weir et al. 2002: p604).

\section{- Board Size}

Compared to the supervisory function of outside directors, far too little attention has been paid to the effects of board size. Lipton and Lorsch (1992) and Jensen (1993) propose that a small board can improve board performance. They both agree that seven to nine directors on the board is the optimal board size because this will allow directors to function effectively and will also meet the diversity required. However, it is hard, theoretically speaking, to determine an ideal board size. A recent researcher, Raheja (2005) develops a 
model to prove that "the most effective optimal boards are boards in terms with low project verification costs to outsiders and fewer private benefits from inferior projects to insiders" (Raheja 2005: p300). He shows that board size and composition vary with different firm types, life cycles, and the character of directorship.

Empirical work on board size is relatively scarce. Yermack (1996) examines the effect of board size through a sample of 452 large US industrial companies in the period from 1984 to 1991 . They present consistent evidence on the negative relation between board size and firm value (measured by Tobin's Q). Conyon and Peck (1998) point out another perspective of board structure. In practice, there are two types of board structure: unitary structure and two-tier board structure. Five European countries are included in their sample. The UK and Italy have a unitary structure; the Netherlands and Denmark have a two-tier board structure; France is classified as a mixed system, with both a unitary and two-tier board structure. They compare these five economies on the size of company board and on two corporate performance measures (estimated by Return on Equity (ROE), and Tobin's Q). Consistent with the earlier US results of Yermack (1996), their findings also support the negative association existing between measures of corporate performance and board size across these five major European countries.

\section{- CEO-Chairman Duality}

An increasing concern regarding board composition is focused on whether the same individual should act as both CEO and chairman of the board. The dual leadership structure, with a split between the CEO and chairman, is relatively common in the UK but not so popular in the US (Vefeas and Theodorou 1998). From a common view of corporate leadership structure, a separation of the role of CEO from that of chairman should enhance the independence of a non-CEO chairman, allowing the board to exercise its monitoring function efficiently and improving corporate performance. Rechner and Dalton (1991) test the difference between CEO-chairman firms and non-CEO chairman firms in various corporate performance measures: returns on investment (ROI), returns on equity (ROE), and profit margins. They observe 250 US firms from 1978 to 1983 and conclude that firms with a non-CEO chairman have a significantly higher performance than CEO duality firms.

Focusing on the financial industry, Pi and Timme (1993) select 112 banks in the period from 1987 to 1989 and confirm that separating the firm's management should create a better leadership structure, and that banks with a CEO-chairman have lower accounting 
returns on assets than those without. Carline, Linn and Yadav (2002) examine UK merging firms and find a negative but insignificant relationship between CEO duality and the change in industry-adjusted operating performance.

On the contrary, advocates of the CEO-chairman duality, such as Brickley, Coles and Jarrell (1997), argue that a non-CEO chairman generally has enormous power but small capital risk regarding the firm's future performance. The agency costs may outweigh the benefits of independent supervision. Furthermore, a CEO is assumed to be the one with specialized information regarding the strategic challenges and opportunities, firm-specific experience, or any other variable knowledge since "separating the CEO and chairman title necessitates the costly and generally incomplete transfer of critical information between the CEO and the chairman" (Brickley et al. 1997: p194). By analyzing the CEOs of 737 large US firms in 1988, Brickley et al. (1997) point out that combining the CEO and chairman is not definitely associated with inferior market returns and accounting ratio (measured by return on capital).

Vefeas and Theodorou (1998) set a hypothesis to test the positive association between dual leadership structure and firm value. They find that firms with a non-CEO Chairman do not outperform firms with one. The results are contrary to their expectations but remain consistent with the arguments of Brickley et al. (1997). However, their findings may be limited by the Codes of Best Practice which have been issued in a number of European countries, starting with the UK in 1992. These codes specify that different individuals should hold Chair and CEO positions. Despite the codes being voluntary, their effects on empirical evidence should not be ignored.

\subsubsection{Other Blockholders}

Faccio and Lang (2002) analyze 5,232 corporations in 13 Western European countries. They report that 46.01 percent of concentrated firms (at the 20 percent level) have more than one large shareholder who holds at least 10 percent of the voting shares. Maury and Pajuste (2005) sample 136 non-financial Finnish listed firms (612 observations) during 1993-2000 and find that 52 percent of concentrated companies at the 10 percent threshold are dominated by single controlling shareholders, 31.7 percent of cases have the second large shareholders, and 16.3 percent of cases have at least three large shareholders. The existence of blockholders has been viewed as another corporate governance mechanism because the blockholders hold a sizable fraction of voting shares and have more power to influence 
corporate decisions.

As a governance mechanism, blockholders are often questioned as to whether they really do monitor the largest shareholder or whether they form a controlling coalition with other large shareholders and thus expropriate the minority shareholders. Theoretical articles provide some models for the optimal ownership structure (Pagano and Roell 1998, Gomes and Novaes 2001, Bolton and Von Thadden 1998). They suggest several ideas for considering the effect of blockholders.

First of all, blockholders may perform effective monitoring to solve free-rider problems and to prevent overinvestment, but this bargaining power may also block the efficient decisions and lead to underinvestment. Second, large shareholders outside the control group may force the controlling shareholder to maintain enough stakes, otherwise control may be lost. The controlling shareholder with more company shares may have less incentive towards expropriation. Third, when large shareholders hold an equal proportion of equity as the controlling shareholder, they may be more likely to act as decision makers instead of supervisors. Fourth, under a poor legal system the controlling shareholders may tend to bribe the large shareholders. The coalition games will worsen existing agency problems between the controlling and minority shareholders.

Since the effect of blockholders remains an open issue, there are two groups of empirical research bringing blockholder questions into discussion. One group focuses on the existence of blockholders and the other considers the voting shares of blockholders. Faccio et al. (2001) examine effect of blockholders on dividend payout ratio. Their findings show that the presence of other blockholders has a significant positive impact on dividends in European countries due to the monitoring mechanism; whereas in Asian countries, other blockholders are significantly negatively related to the dividends ratio. They think that collusion under the "crony capitalism" ${ }^{2}$ " is the most important reason for this negative effect in Asian countries.

${ }^{2}$ Claessens et al. (2000) consider that "crony capitalism" arising from the concentration of corporate control in the hands of a few families can lead to a vicious circle where family groups lobby government agencies and public officials for preferential treatment, government grants, special tax breaks, favoritism in the distribution of legal permits, and so forth. The ability of lobby in turn leads to increasing family control and an increasing interdependence of politicians and tycoons. The success in related-party transactions depends on an extremely close relationship between the businessman and the state institutions of politics and government, rather than on the free market competition, and economic liberalism. 
Becht and Mayer (2001) find that in most European countries voting shares of the second and third large shareholders decrease rapidly beyond the largest shareholder. They shed light on the importance of control allocation among multiple large shareholders. In the Maury and Pajuste (2005) study, not only the presence but also the voting shares of other blockholders is investigated. They conclude that an equal distribution of voting shares among large shareholders has a positive relationship with firm performance (measured by Tobin's Q). They further suggest that family controlled firms significantly under-perform if they have large shareholders coming from another family while non-family large shareholders, especially financial institutions, offer efficient monitoring for family controlled firms.

\subsubsection{Corporate Governance Mechanism: $2^{\text {nd }}$ generation}

As stated earlier, the second generation governance research is more international and is focused on the importance of legal systems, accounting standards and the extent to which these laws are enforced (LLSV 1998, Denis and McConnell 2003). Zingales (2000) sheds light on the extra-legal systems. He argues that product competitiveness, public opinion, and internal moral norms etc. play no secondary role. This branch of studies basically agrees that more complete legal and extra-legal rights attributed to minority shareholders will curb the effects of private benefits.

\subsubsection{Legal Institutions}

\section{Legal Origin, Anti-Director Right, Revised Anti-Director Right}

La Porta, Lopez-de-Silanes, Shleifer and Vishny (LLSV, 1997/1998) examine 49 countries around the world and assign each company to four legal families ${ }^{3}$ : English common law, French civil law, German civil law, and Scandinavian civil law. Subsequently, they measure the level of the legal environment of each country by considering two rights: shareholder rights and creditor rights. The shareholder rights have two proxies: the one-share-one-vote rule and the anti-director right. The former is set if a country has a company law or commercial code which prohibits any type of dual shares; this country offers better legal protection to investors and gets one score. According to this rule, only 11

${ }^{3}$ English origin countries include Australia, Canada, Hong Kong, India, Ireland, Israel, Kenya, Malaysia, New Zealand, Nigeria, Pakistan, Singapore, South Africa, Sri Lanka, Thailand, United Kingdom, United States and Zimbabwe. French origin countries include Argentina, Belgium, Brazil, Chie, Colombia. Ecuador, Egypt, France, Greece, Indonesia, Italy, Jordan, Mexico, Netherlands, Peru, Philippines, Portugal, Spain, Turkey, Uruguay and Venezuela. German origin countries include Austria, Germany, South Korea, Switzerland and Taiwan. Scandinavian origin countries include Denmark, Finland, Norway, and Sweden. 
countries are qualified ${ }^{4}$ in the LLSV sample.

The anti-director right index ranges from 0 to 6 , formed by six rights: proxy by mail allowed, share not blocked before meeting, cumulative voting/proportional representation, oppressed minority, preemptive right to new issues, and the percentage of shareholding to call an extraordinary meeting (which is under 10\%). If countries provide one of these six rights to their minority shareholders then they achieve one score. According to the LLSV data, the English origin countries have the highest average score of anti-director rights (4.0). Similarly, the creditor rights index measures four rights: the no automatic stay on assets, secured creditors first paid, restrictions for going into reorganization and management does not stay in reorganization. The English origin countries still get the highest average score of creditor rights (3.11). Since different kinds of creditors have different interests, most studies concerning legal protection put more emphasis on the anti-director right index. This thesis consistently uses the anti-director rights index instead of the creditor right index as the chief measure of legal institutions because of its focus on shareholder value.

Stemming from the classification of legal families, an increasing amount of research has attempted to compare the difference between legal families. Mueller and Yurtoglu (2000), for example, investigate the effect of the institutional environment on corporate performance. They sample 38 countries and compare the differences in their legal systems, as LLSV defined. Their results prove that significant differences in investment performance (measured by internal cash flow, new debt issues, and new equity issues) are related to the legal institutions of the countries. The English origin legal system has better investment performance than the civil legal system.

Dittmar, Mahrt-Smith and Servaes (2003) use more than 11,000 companies from 45 countries to prove that firms in countries with stronger legal protection are less likely to hold more free cash flow. Furthermore, Gugler, Mueller and Yurtoglu (2004) analyze the impacts of three different institutions on the company's investment performance (measured by returns on investment to its cost of capital): country legal system, ownership structures and capital market. Their data covers 46 countries for the period 1996-2001, grouped by LLSV. They conclude that agency problems exist in all countries but can be mitigated by all three types of institutions. Among them, legal institutions have the strongest impact on improving

${ }^{4}$ These countries are Malaysia, Pakistan, Singapore, Brazil, Chile, Greece, Jordan, Peru, Uruguay, Japan and South Korea. 
investment performance. In practice, more empirical research provides evidence to prove that companies in countries with English Origin common law legal systems perform significantly better than those in countries with other legal origins (La Porta et al. 2000/ 2002, Fauver, Houston and Naranjo 2003).

Beyond comparing the difference among four legal original countries, one line of legal research now provides a more detailed investigation for particular aspects of corporate governance by measuring the level of anti-director rights in individual countries (Johnson, Boone, Breach and Friedman 2000a, Nenova 2003, Esty and Megginson 2003). Their general conclusion is that companies in countries with a higher score of anti-director right and indicating a stronger protection of investors, can curb private benefits and lead to better performance. However, the anti-director right index has been criticized for its ad-hoc nature, for mistakes in its coding, and for conceptual ambiguity in its definition (Djankov, La Porta, Lopez-de-Silanes and Shleifer, 2006). For example, Berkowitz, Pistor and Richard (2003) analyze the determinants of effective legal institutions using data from 49 countries. They find that "transplant ${ }^{5}$ effect is a more important predictor of legality than the supply of a particular legal family" (Berkowitz et al. 2003: p167). Djankov, La Porta, Lopez-de-Silanes and Shleifer (DLLS, 2006) revised their initial anti-director right index which was reported in LLSV (1997/1998). They present 72 countries in their revised anti-director right, based on laws and regulations that were applicable to public trade firms in May 2003. A similar but more precise definition of the six proxies is applied to form the revised index. This reports that the key difference between the initial and revised index is the treatment of enabling provisions. Most results are consistent with their earlier work. The revised anti-director right index still shows a significantly higher score for English origin countries than for French legal origin ones.

\section{- Legal Enforcement}

Laws protecting investors come from different sources such as company laws, stock

\footnotetext{
${ }^{5}$ Berkowitz et al. (2000: p165-166) describe that "there have been three major transplantations of legal codes during the past two hundred years. First, during the period of imperialism (1890-1914) French law was transplanted throughout Europe and western law (especially French and English law) was exported throughout Latin America, Asia and Africa". "Second, post-World War II, United States law played an increasingly important role and many newly independent states borrowed legal code from those western countries which they had originally received their law". "Third, following the collapse of socialist system in the late 1980s, countries in Central and Eastern Europe and the Former Soviet Union rebuilt their legal systems drawing heavily on the European and the United States models."
} 
exchange regulations and accounting standards. The enforcement of laws is as crucial as the content of laws. LLSV (1998) propose that a strong quality of legal enforcement could be a substitute in countries with weak formal rules. Five measures, including efficiency of the judicial system, rule of law, corruption, risk of expropriation and risk of contract repudiation are employed to judge the enforcement quality.

According to the variable definitions in LLSV (1998: p1140), the first measure represents "the efficiency and integrity of legal environment as it affects business, particularly foreign firms". A country with a higher score has a higher efficiency level. The second measure, rule of law, is the assessment of the law and order tradition. A low score here means less tradition for law and order. The third measure, corruption, implies the degree of corruption in government. A country with a lower score indicates that government officials are more likely there to ask for special bribes. The fourth measure assesses the level of risk of "outright confiscation" or "forced nationalization". Lower scores represent higher risks. The final measure evaluates the level of the "risk of modification in contract taking the form of a repudiation, postponement, or scaling down" due to "budget cutbacks, indigenization pressure, a change in government, or a change in government economic and social priorities." Similarly, lower scores reflect higher risks.

Unfortunately, the results do not support their expectation that the quality of legal enforcement can substitute or compensate for the quality of law. Moreover, they find that enforcement measures are affected by per capita income. By a single measure, richer countries are likely to have higher enforcement scores. The quality of enforcement is higher in richer countries. Once income is controlled, countries with French civil law still score significantly lower, on each measure, than do countries with common law.

Based on the sample of 661 dual-class firms in 18 countries for 1997, Nenova (2003) measured the private benefits of controlling shareholders by examining the value of controlling blocks of votes. She finds that the value of controlling blocks of votes varies from 0 percent in Denmark to 48 percent in South Korea and that the legal environment, including the law enforcement ${ }^{6}$, investor protection, takeover regulations and corporate

\footnotetext{
${ }^{6}$ Nenova (2003) mainly use the measure for rule of law from LLSV (1998) but also test the alternative measures of law enforcement in LLSV (1998) such as efficiency of the judiciary, accounting standards, and corruption. She states that the results are stable.
} 
charter provisions ${ }^{7}$ can explain 68 percent of the cross country differences. Among these legal measures, she shows that the effects of investor protection law and takeover regulations are equally important, but that law enforcement is more powerful.

Johnson et al. (2000a) collected data from 25 emerging markets from the end of 1996 to April 1999 and tried to link the weakness of the legal institutions regarding corporate governance to stock market declines in the Asian crisis. Referring to the data from LLSV (1998), they evaluated four types of legal institution: anti-director rights, creditor rights, accounting standards and the enforceability of contracts. Their results are closely linked to the findings of LLSV (1997/1998) which indicate that weak corporate governance results in more expropriation and hence a larger fall in asset prices. But Johnson et al. (2000a) show that enforcement of shareholder rights plays a more important role than investor rights in their research.

\section{Optimal legal enforcement}

Compared to the considerable amount of literature that has been published to prove the positive effect of legal mechanisms, there is relatively little work that investigates the interrelationships between them. In the final part of the Denis and McConnell (2003: p43) survey a new question is presented: "Would greater protection in the US improve corporate governance, and with it firm value?" They highlight the limits to the value of protection. "For example, a system in which shareholders have the right to approve or disapprove every decision made by managers would be neither practical nor valuable". "What are these limits?" They leave this question open for future researchers. Indeed, one branch of governance research focuses on how to reform optimal law enforcement and on the optimal quality of legal enforcement (Garoupa and Stephen 2004, Polinsky and Shavell 2000, Posner 1998, Burkart, Panunzi and Shleifer 2003). Basically, their major concern is the enforcement cost.

Posner (1998) questions why there has been economic success in East Asian nations such as China and Vietnam in which the rule of law is weak, while in India (having a legal system modelled on that of England) there is significant underperformance - especially

\footnotetext{
${ }^{7}$ Six charter provisions aggregated in Nenova (2003) including golden shares, coattails, poison pills, voting caps, the right of the board of directors to limit transfer of shares, and the right of limited-voting shares to attain full voting power in case of dividend nonpayment, sale of assets, or excessive concentration of voting power to cash-flow rights.
} 
when compared to China? He provided three possible explanations. First of all, the legal reform is too expensive and is usually ignored by wealthy nations because of the relatively low costs. Secondly, the legal system may enforce not only contract and property rights but might also reduce economic efficiency. Thirdly, too high a degree of legal enforcement will lead the decision makers to seek other informal substitutes, such as arbitration, reputation or retaliation, merger, bilateral monopoly, strong-arm tactics, and altruism. Posner (1998: p2) points out that "even in the highly litigious culture of the US, the vast majority of contract and property disputes are resolved informally because of the expense of legal proceedings." When decision makers choose these substitutes, the hidden legal enforcement cost still exists. Poor countries cannot afford the high cost of good legal enforcement and so turn to substitutes; enforcement costs make this even worse.

Burkart et al. (2003) present a theoretical model to test how legal rules affect the trade-off between the benefits and costs of separating ownership and management. They investigate family firms and discover that when the founders give up their private benefits to hire a professional manager, they also transfer the opportunity for managers to divert company revenue rather than to pay out dividends to the shareholders. To limit this extraction, the founders can still control the monitoring but it is usually over-monitoring: "High levels of monitoring and strict legal rules reduce the professional manager's private benefits and may thus discourage him from running the firm." Offering a high wage may make it easy to induce mangers to agree to run the firm. However, "higher ownership concentration and better legal protection make it more difficult to satisfy the professional manager's participation constraint."

When legal protection is strong even in the absence of monitoring, the professional manager is offered a wage at the highest possible level because private benefits are insufficient to induce the professional manager to run the firm (Burkart et al. 2003). On the contrary, when legal protection is poor, the founders have to retain all shares to implement an appropriate monitoring level. This is the trade-off between monitoring cost and managerial rent. In Burkart et al. (2003) model, a legal system with strong protection of outside shareholders is socially desirable: "The best manager is hired to run the firm, and no resources are wasted on monitoring. This conclusion is driven by the assumption that law enforcement is free." This is not actually true. For example, the costs of complying with better accounting and disclosure standards might be very high. If better legal protection imposes higher enforcement costs on the society, Burkart et al. (2003) suggest to compare 
these legal enforcement costs with the social costs of private monitoring.

There is extremely little empirical research focusing on this field. Lerner and Schoar (2005) analyze 210 developing private equity investments and document that investments in countries with a common law or with better legal enforcement are far less likely to employ common stock or straight debt but are more likely to use convertible preferred stock. Transactions in these nations are generally associated with greater contractual protection for the private equity groups and these contracts are generally the second best solution, as suggested by extensive theoretical literature, to contracting in private equity. Their conclusions seem to point out the existence of sub-optimal decision costs a lot in a too strong legal system. However, the casual link has not been further proved.

\section{- Accounting Standards}

The quality of accounting standards is another proxy applied in LLSV (1998) to evaluate the legal environment. The quality of an accounting standard is measured using an index developed by the Centre for International Financial Analysis and Research (CIFAR). The CIFAR index employed in LLSV (1998) was published in 1991 and therefore suffered from the future convergence of accounting standard in European countries. Their results show that countries with Scandinavian origin averagely have the highest quality of accounting standards (74.00); English origin countries score second (69.62) and the French family has the weakest quality of accounting disclosure.

Based on examining and rating the inclusion or omission of ninety accounting items in annual reports of companies, the country-level CIFAR index represents the average scores across a sample of domestic companies. While the CIFAR index has been challenged because it is highly correlated with other country characteristics, this index is commonly used as a measure for examining the relationship between the quality of a country's corporate disclosure regime and economic performance in cross-country analyses (Rajan and Zingales 1998, Levine, Loayza and Beck 2000, Lombardo and Pagano 2000).

Levine et al. (2000) examine whether cross-countries differences in legal and accounting systems explain differences in levels of financial development. They find that to strengthen creditor rights, contract enforcement, and accounting practices (measured by the CIFAR index) can boost financial development and accelerate economic growth. Lombardo and Pagano (2000) document that total stock market returns are negatively related to overall 
measures of the quality of institutions, such as judicial efficiency and rule of law, controlling for risk, and accounting standards. Using a sample from 22 countries, Hope (2003) conducted an interesting international investigation on the relations between the accuracy of analysts' earning forecasts and the level of annual report disclosure (measured by the CIFAR index), and between forecast accuracy and the degree of enforcement of accounting standards. They not only provide evidence consistent with the positive effects of accounting disclosure but also suggest that the enforcement of accounting standards is also and even more important.

\subsubsection{Extra-legal Institutions}

While the existing second generation governance research focuses mostly on the proper functioning of legal institutions, such as legal origin, minority shareholder protection, legal enforcement, accounting standard, etc, a recent study by Dyck and Zingales (2004) draws attention to the features of extra-legal institutions. In their earlier paper (Zingales 2000), they first identify that a broader definition of corporate governance should take market competition and the pressure of public opinion into consideration. By following the arguments in their 2000 study, Dyck and Zingales (2004) study the role of extra-legal institutions, including market competition, public opinion pressures, moral norms, labour as monitors and corporate tax enforcement.

Take a further look at these five extra-legal institutions. First of all, a more competitive structure of input and output market can make the prices more objective, and thereby the controlling shareholders will find it more difficult to extract private benefits through manipulated transfer price. Second, with a strong and reliable formation of public opinion pressures, controlling shareholders may curb their incentive to try tunneling because they fear for losing their reputation. Third, beyond the consideration of legal penalties and reputation costs, controlling shareholders may be unwilling to promote their self-interests simply due to their norm moral. Fourth, labour is regarded as another efficient mechanism because it has a direct interest in the firm's performance and holds private and secret inside information about the company. Fifth, the government can play the role of monitoring through tax enforcement. If tax authorities enforce their rules on transferring prices by, for example, charging two parties for intra-corporate transactions, the private benefit of controlling shareholders may be limited and may thereby reduce their motivation to do so. 
In practice, it is hard to test the effects of the extra-legal institutions. For instance, the existence of a truly independent media is doubtful in most countries. Dyck and Zingales (2004) use an indicator of newspaper diffusion which is measured as the circulation of daily newspapers normalized by population. Nevertheless, the question of independence still remains unsolved. Coffee (2001) uses the violent crime rate as the proxy for moral norms. Stulz and Williamson (2003) take religion to be an indicator of norms. Dyck and Zingales (2004) measure both. Similarly, the causal link between crime rate, religion and the moral norms of top-management is open to discussion. Moreover, the interest related to labour is not the same as for minority shareholders. In some cases, the labour may align itself with the controlling shareholders or fight for their own interests at the expense of the minority shareholders.

Given the difficulties of measuring the effects, this line of research still provides evidence that extra-legal mechanisms can effectively prevent some transactions that might be used to expropriate minority shareholders. Dyck and Zingales (2004) estimates the private benefits of control using the differences between the premiums for voting and non-voting shares for 393 controlling block sales in 39 countries. They examine both the legal and extra-legal institutions and conclude that each single variable is related to the lower level of private benefits. Tax enforcement has the best performance in reducing private benefits and in indirectly enhancing financial development. Public opinion pressures also help to curb private benefits, but not to increase share value. They explain that "strong media also induce corporate managers to bow to environmental pressures, which are not necessarily in the shareholders' interest".

Sampling firm-level control from nine East Asian and 13 Western European countries, Haw and $\mathrm{Hu}$ (2004) investigate the impact of legal and extra-legal institutions on limiting income management. Their legal institutions are proxied by legal origin, anti-director rights, the efficiency of the judicial system, rule of law and accounting standards (all sourced form LLSV 1998). Extra-legal institutions are measured by market competition, public opinion pressure and tax compliance (all sourced from Dyck and Zingales 2004). The univariate test results show that the incentive of income management is significantly associated with the deviation between control and cash flow right, but legal tradition, minority rights protection, the efficiency of the judicial system, disclosure standards competition laws, diffusion of the press, and tax compliance can provide avenues for limiting the use of earnings management. Furthermore, their multiple regression results suggest that common law tradition and an 
efficient judicial system cover the effects of the other legal institutions, and the high rate of tax-compliance is a more dominant factor among the extra-legal mechanisms. Their findings are partially consistent with the results of Dyck and Zingales (2004).

\subsubsection{Anti- Self-Dealing Index (Private Enforcement) and Public Enforcement}

In Djankov, La Porta, Lopez-de-Silanes and Shleifer's (DLLS, 2006) recent work, they not only revise the initial anti-director right index but more importantly present a new measure of legal protection: the anti-self-dealing index. To complete this work, they collected 72 valid samples from questionnaires completed by attorneys working in international law firms with members across 108 countries; these samples were based on the legal rules prevailing in 2003. They designed questions starting with a fixed self-dealing transaction and then measured the hurdles that the controlling shareholders needed to tackle in order to extract private benefit from this transaction: the higher the hurdles, the higher the anti-self-dealing index. Finally, they constructed two up-to-date legal measures: the private enforcement and the public enforcement indexes.

A private enforcement index, that is also called anti-self-dealing index, is the average score of the ex-ante and ex-post control of self-dealing. The ex-ante private control of self-dealing is the average of the approval of disinterested shareholders and ex-ante disclosure (reviewer required). Ex-post private control is the average of disclosure in periodic filings and the ease of proving wrongdoing. All the above indexes range from zero to one after calculation.

In summary, for the anti-self dealing index, they show that common law countries have a higher average ex-ante index (0.58). This means that they typically require extensive disclosure and the approval of the transaction by disinterested shareholders. Scandinavian civil law countries in turn have the lowest average ex-ante index $(0.22)$. For ex-post private control, common law countries still obtain the highest score $(0.76)$, which indicates that countries with common law origins require more severe information disclosure and that plaintiffs will find it easier to prove a wrongdoing in court. The final average anti-self-dealing index in common law countries (0.67) is significantly higher than in civil law ones (0.36).

Specifically, DLLS point out that the US and France have unexpectedly low scores. The US relies more on the ex-post legal protection against self-dealing than on the ex-ante 
approval by disinterested shareholders. France even allows related party transactions to be approved without shareholder approval once they believe that the transaction is on "normal" terms. Besides, DLLS prove no evidence for the relationship between income level and the anti-self-dealing index. And in the end, they do horse races between the anti-self-dealing index and the revised anti-director right index as outlined above. They suggest that self-dealing could provide a better index because it is, to a certain extent, the central problem of corporate governance in most countries.

Turning to the index of public enforcement, this index is a sum-up score that is produced by assigning one quarter point when each of the following sanctions is available: fines for the approving body, jail sentences for the approving body, fines for the controlling shareholder and jail for the controlling shareholder. Evidence here shows a significant but unexpected sign. They suggests that the government's power to impose fines and prison terms for self-dealing transactions that meet disclosure and approval requirements does not benefit stock market development (DLLS 2006: p38). However, they stress that this conclusion may be too narrow because the importance of public enforcement has not been addressed in situations where the criminal sanctions are actually imposed and self-dealing transactions are concealed in most cases. 


\subsection{Summary}

In summary, this chapter reviews the nature of the agency problem in concentrated ownership structures, as well as the effects of ownership concentration on general corporate performance, and the accentuating and mitigating factors of agency costs with concentrated ownership. Section 2.2 contends that increasing ownership may have incentive effects on reducing the agency costs between owners and managers, but that it also causes other conflicts between large shareholders and small shareholders, including managerial entrenchment, tunneling, and sub-optimal decision. Section 2.3 reviews these incentive effects and the agency costs associated with general corporate performance in the existing empirical research. This thesis considers both the level and the type of concentrated ownership structures; conclusions are still mixed. Generally, it seems that incentive effects impact the upper and lower levels of ownership concentration, but that controlling shareholders holding moderate levels of company's shares are likely to act on their own private benefits. The arguments concerning the effect of different types of concentrated firms are even more inconsistent. The nature of each type of concentrated firm is the fundamental consideration. For example, it is important to consider whether the family firm is managed by the founders or by their descendants? Is the institutional large shareholder active or inactive in the governance of the firm? There is still large room for debate on the typology of ownership.

Section 2.4 highlights how expropriation problems may be exacerbated when large shareholders separate the control rights from cash flow rights through various control devices. Section 2.5 of the thesis introduces several well known governance mechanisms and organizes them into two generation international governance studies as discussed by Denis and McConnell (2003). The first generation governance generally focuses on internal mechanisms such as CEO position, board composition, and ownership itself. Since this thesis examines the concentrated ownership structures for ownership itself, the emphasis is on the role of other blockholders. The external mechanism, such as takeover markets as extensively outlined by first generation research, will be discussed in-depth in chapter three.

Referring to LLSV (1998), Dyck and Zinglales (2004), and DLLS (2006), this thesis, in the final part of section 2.5, explains the effects of the second generation governance mechanisms: legal and extra-legal institutions. The legal institutions include the initial 
anti-director right, enforcement and accounting standards in LLSV (1998) and also the revised anti-director right in DLLS (2006). These measures are identified as major factors for investigating the degree of a country's legal protection. A strong legal protection system generally results in better corporate performance. The field of extra-legal systems is relatively under-developed. To date, existing research provides little evidence that extra-legal characters can help to restrain controlling shareholders extracting their own benefits from specific events such as block share sales or income management. Through the compliance of well-functioning legal institutions, the optimal legal system also comes into consideration.

The recent anti-self dealing index and public enforcement proxy formed by the DLLS (2006) paper are brought into this thesis at last. The formation processes of these two indexes are obviously different from those of the previous legal and extra-legal measures. Besides, these new legal indexes (DLLS) have similar characteristics with and are highly correlated to the previous legal (LLSV) and extra-legal (Dyck and Zinglales) measures. Thus, it may not be proper to test these new DLLS indexes in combination with the initial LLSV and the Dyck and Zinglales measures.

After discussing the nature of the agency problem in concentrated ownership structures and the accentuating and mitigating factors of agency costs with concentrated ownership, next chapter would review the fundamental theories of M\&A activities; introduce the measuring of M\&A performance and the outcomes of the major empirical studies; present the deal characteristics of M\&A that have been well documented by most studies as important factors of M\&A success; and consider the possible effects of the concentrated ownership structure on M\&A performance. 


\section{Chapter Three}

\section{Merger and Acquisition, Performance Measures, and Acquisition Performance under Concentrated Ownership}

\subsection{Introduction}

This thesis adds to the discussion about the relationship between merger and acquisition $^{8}$ (M\&A) activities, ownership concentration, and acquiring firm performance. The rest of this chapter is organized as a literature review of previous theoretical and empirical M\&A research. Section 3.2 organizes the fundamental theories of M\&A activities. Section 3.3 gives a brief overview concerning the measuring of M\&A performance and the outcomes of the major empirical studies. There are two parts in this section. The first part (3.3.1) outlines the short-term and long-term market-based approaches. The second part (3.3.2) focuses on the accounting- based methods. Section 3.4 introduces the deal characteristics of M\&A that have been well documented by most studies as important factors of M\&A success. The final section (3.5) discusses the effects of the concentrated ownership structure on M\&A performance.

\subsection{Rationale for Merger and Acquisition}

Although M\&A issues have been extensively explored by both academic and practical studies over the past decade, most discussions are devoted to merger consequences. Strategic research suggests that merger motives ultimately decide whether or not a merger is attempted (Trautwein 1990). The rest of this section will review the rationale for M\&A.

${ }^{8}$ The terms 'merger', 'acquisition' and 'takeover' are used frequently in the group of 'Merger and Acquisition (M\&A)', but the distinctions are not precise. Generally, these terms are used interchangeably and can have different legal meaning under particular business and tax laws (Sudarsanam 2003). 


\subsubsection{Macroeconomic Drivers (Macro Level)}

In Gort's (1969) disturbance theory, mergers are driven by macroeconomic phenomenon. Specifically, the economic disturbance makes information about the past become less effective in predicting the future and thereby discrepancies in valuation arise from differences in expectation. When such discrepancies lead to an estimated higher value on the assets of a firm by non-owners (potential purchasers) than by owners, acquisitions become possible. Merger waves are one indication of the effect of macroeconomic drivers and mergers clustered by industry is another. The most common economic shocks come from rapid changes in technological improvements, financial innovations, supply shocks, foreign competition, or changes in legal regulations. Although this theory tries to explain the general phenomenon of fluctuations in merger frequencies over time and across industries, it is limited because it focuses much too heavily on a macro-level explanation but the fact is that most disturbances are of a more sectional nature on a firm-level (Trautwein 1990).

\subsubsection{Rational Choice (Firm Level)}

\subsubsection{Managers Benefits}

A group of studies focusing on the private interests of managers argues that M\&As are conducted by managers who intend to pursue their own interests instead of their shareholders' welfare. Firth's (1980) UK empirical study shows an abnormal increase in the remuneration level of the directors but negative market performance of the acquiring firms. He interprets this result as self-interest managers use takeovers to benefit themselves at the expense of shareholders.

One of the underlying ideas for this argument is the agency-related problem discussed in chapter two, section 2.2. Rhoades's (1983) empire-building theory contends that acquirers are willing to pay for growth potential rather than for profitability as their private benefits tend to grow with firm size. Conyon and Murphy (2002) document that firm size rather than firm performance is the main source of managerial wealth in the UK. Therefore, managers with size-related interests may be tempted to use free cash flow to expand their firm size, increase their own wealth, or enhance their position through M\&A transactions (Jensen 1986). Moreover, Amihud and Lev (1981) find that without monitoring, managers are likely to reduce their employment risks through unrelated mergers which are generally regarded as having no interest for shareholders. Shleifer and Vishny (1989) describe that when the firm is underperforming or lacking in growth opportunities, managers may make acquisitions in 
order to decrease their chances of replacement. This leads managers to overpay and results in poor acquisition performance.

Another idea is managers make mistakes in evaluating potential targets. In Roll's (1986) hubris hypothesis, he declares that decision makers in the acquiring firms easily overestimate acquisition synergy because of hubris or exaggerated confidence and that they then pay far too much for their targets. This results in wealth transferring from the acquiring shareholders to the acquired stakeholders. Hayward and Hambrick (1997) further support this hypothesis by providing evidence for the relationship between CEO hubris and the size of premiums paid.

\subsubsection{Acquirers' Shareholders Benefits}

In fact, most research shows that mergers are carried out under the rational choice that managers will make a value-enhancing $M \& A$ investment to maximize firm value and to benefit shareholders instead of the managers themselves. These studies can be further distinguished according to the potential sources of merger success. In general, the postulated sources come mainly from net gains through synergies or wealth transfers from other stakeholders (debt holders, government, customers/ suppliers).

\section{- Synergies}

Any merger to be considered a success should generate positive net present value (NPV) from the investment. The net present value, or the so-called synergy, is created when the economic value of targets $\left(\mathrm{V}_{\mathrm{B}}\right)$ plus the net economic value added (NEVA) are higher than the price paid $(\mathrm{P})$. The price paid comprises the premium and the targets' economic value. This thesis will now look more closely at the drivers of synergies. In general, there are three perspectives that identify synergy; these are broadly comprised in the efficiency or synergy theory. First, from the financial perspective, synergies can be created from the lower cost of capital because of a less systematic risk due to portfolio diversification, a stronger bargaining power from size advantage, and a superior internal capital market (Mueller 1969, Chatterjee 1986, Montgomery 1994, Fluck and Lynch 1999). The main argument against the financial synergy hypothesis is that financial synergies are difficult to achieve in an efficient capital market (Montgomery and Singh 1984).

Second, from the operational perspective, synergies can be created from a stronger market power by combining the operations of two separate units (Ghosh 2004); from a larger 
economic scale by expanding activities across a variety of the firm; or from knowledge or skills transfer that is especially meaningful in high technology industry (Porter 1987). The potential concern for operational synergies is the cost of entry and the relocation of resources.

Third, from the managerial perspective, a group of governance research assumes that M\&As can create synergies ascribed to superior management capability and efficient monitoring mechanisms (Manne 1965). Specifically, shareholders, especially target shareholders, can gain from takeovers by expecting a more capable management to ensure a better-quality corporate governance system and the maximization of firm value. Numerous articles complete this argument. For example, Jensen and Ruback (1983) first define corporate control as the right to determine the management of corporate resources and then point out that the takeover market is often described as an efficient method of corporate control in which alternative managerial teams compete for the right to manage corporate resources. Jensen (1988) further indicates that the market for corporate control is benefiting shareholders, society, and corporate forms of organization. Kennedy and Limmack (1996) examine the performance of UK quoted companies involved in takeover bids during the period from 1980 to 1989 . They specifically prove that the potential source of wealth gain from takeover is the replacement of inefficient target management.

\section{- Wealth Transfers}

\section{(i) Through Bondholders}

There is one line of study dealing with shareholder benefits that emphasises wealth transfer from bondholders (Kim and McConnell 1977, Asquith and Kim 1982, Eger 1983, Dennis and McConnell 1986, Maquieira, Megginson and Nail 1998, Billett, King and Mauer 2004). Under the conception of stockholder-bondholder conflicts (Jensen and Meckling 1976), stockholders of leveraged firms may have incentives to earn positive abnormal returns by undertaking an M\&A deal at the expense of bondholders. This is because there is an increase in the variability of firm cash flow. "The bondholders lose because of the increase in the default risk of the existing bonds. The positive abnormal returns present the wealth transfer from bondholders"(Asquith and Kim 1982: p1209-1210).

The evidence is still mixed. Kim and McConnell (1977) and Asquith and Kim (1982) test co-insurance effects by examining US conglomerate mergers. According to the co-insurance hypothesis, combining two leveraged firms will lead to a reduction in the 
default risk of the target firms and will thereby increase the debt-capacity or borrowing-ability of combined firms. They find that bondholders of merging firms do not suffer abnormal negative returns around the time of merger; this confirms those co-insurance effects that signify the lack of any significant wealth transfer. Dennis and McConnell (1986) examine senior securities in merging firms (securities are actively traded around the initial announcement date of the merger) and find results that are compatible with the predictions of the co-insurance hypothesis. They find a small negative announcement effect for acquirer bonds, though this is not significantly different from zero. In a more recent study, Billett et al. (2004), analyzes the correlation between stockholder and bondholder excess returns. Consistent with the findings of earlier studies, their results fail to show any direct evidence to prove the presence of merger-induced wealth transfers among security holder classes. In particular, they tend to find that stockholder and bondholder excess returns tend to be positively correlated.

Focusing on pure stock exchange transactions (where no cash was paid for any securities, and no debt was issued in the transaction), Eger (1983) presents some exclusive evidence to support the wealth redistribution theory which suggests that in a non synergistic merger, bondholders gain and stockholders lose. This redistribution of wealth from stockholders to bondholders results from a decrease in the return variance of the combined firms. Maquieira et al. (1998) also study pure stock-for-stock deals. They find that conglomerate stock-for-stock mergers fail to create synergies and that wealth redistribution has no effect on such non-synergistic mergers because bondholders do not gain statistically. Instead, they document significant net synergistic gains in non-conglomerate mergers and demonstrate that all stakeholders including biding shareholders share these synergies.

In sum, the main challenge is that this line of analyses has to be discussed under the assumption of non-synergistic merger where the value of the combined firm equals the sum of the value of targets and acquirers. In a synergistic merger, the bondholder effects may be masked by the synergy gain that will generally benefit both stockholders and bondholders. Since it is hard to know what factors produce synergy, it is consequently difficult to control for synergy (Dennis and McConnell 1986, Billett et al. 2004).

\section{(ii) Through customers/ suppliers}

The other line of study explains shareholder benefits on the wealth transfers from customers or suppliers. This explanation generally relies on monopoly theory or collusion 
hypothesis (Edwards 1955) and occurs mostly in horizontal acquisitions. A collusion-driven horizontal merger will result in limiting competition, deterring potential entrants, rising up the monopoly rent and ultimately transferring wealth from suppliers and customers to the takeover industry. By contrast, an efficiency-driven horizontal takeover can lead to a more competitive takeover industry, thus benefiting customers and increasing total welfare. In addition, Galbraith's (1954) countervailing power theory proposes that a horizontal takeover between two rivals will massively increase buyer power for the combined firms. Since large buyers usually enjoy lower input prices the result is often a wealth transfer from suppliers.

However, the existing empirical studies investigating the wealth effects of mergers on rivals, customers and suppliers consistently suggest that efficiency gains rather than market power is the main source of shareholder wealth created through horizontal takeovers (Eckbo 1983/ 1985/ 1992, Baker and Bresnahan 1985, Banerjee and Eckard 1998). There is almost no direct practical evidence to support the monopoly or countervailing power theory.

\section{(iii) Through Governments (taxes)}

Another line of study states that a further possible source of wealth transfer is the government. More precisely, it is society that pays the cost. Lewellen (1971) provides a latent-debt-capacity argument which states that one firm may acquire another if the potential target firm is taking only modest interest-tax advantage in its capital structure prior to the merger. Thus any valuation gains can be carved out of a consolidation of a combined firm merely by utilizing these advantages more efficiently. This could be accomplished as part of the merger transaction itself by issuing debt securities for some portion of the purchase price. However, to contradict Lewellen's (1971) perspective, Gilson, Scholes and Wolfson (1988) posit that taxation gains can be obtained with techniques other than mergers. Leland (2007) presents additional theoretical research, advocating that "combining activities into a single firm offers the advantage of risk-reduction from diversification. But keeping activities separate offers the advantage of optimizing the separate capital structures" (Leland 2007: p801).

Empirical articles studying wealth transfer from tax savings are generally confined to a fraction of the premium paid. For example, using a sample of 3,135 takeovers, Fuller, Netter and Stegemoller (2002) find that bidders have significantly negative returns when 
buying public targets and significantly positive returns when buying private or subsidiary targets. Furthermore, in buying private and subsidiary targets deals, acquirer returns are greater for stock bids than for cash bids. Their findings show that the private-firm owners generally prefer stock exchange deals because the tax implications can be deferred. If this tax deferral option is valuable to target owners, they may accept a discounted price and the lower premium will be reflected in the higher bidder returns. Ayers, Lefanowicz and Robinson (2003) present similar evidence to support tax benefits as a source of merger premiums. They test the relationship between premiums and the capital gains of target shareholders. Their results confirm the positive association between shareholder capital gains taxes for individual investors and acquisition premiums for taxable acquisitions.

In conclusion, since targets always gain abnormal returns on average because of high premium, this thesis emphasizes the value creation for acquiring firms. In addition, the value of synergy is difficult to ascertain because of conflicting motives. Therefore, the rest of this chapter reviews the theoretical and empirical literature with respect to measuring success in M\&A, main results and major determinants, as well as the impact of concentrated ownership structures on the acquiring firm performance 


\subsection{The Measuring of Merger and Acquisition Performance}

To date, two major approaches are employed to assess M\&A performance. One is abnormal stock market returns using event study methodology and the other is accounting performance as generally measured by some return metrics. As the focus of this thesis is on the later and as market based event studies is a well-established research methodology, this section will only briefly discuss the methodology and its main findings in the context of M\&A.

\subsubsection{Market Based Approach}

Stock return is a good indicator of M\&A performance because it reflects the expectations of the shareholders regarding M\&A activities and benefits. Short-term event study methodology is a straight-forward and relatively easy approach for measuring abnormal returns. Initial event studies since Ball and Brown (1968), Fama, Fisher, Jensen and Roll (1969), consider abnormal returns surrounding the announcement of major corporate events, including M\&A. From a relatively short window, more recent work has extended the period of interest over several years. The following section will look at the short-term and long-term market-based approach, respectively.

\subsubsection{Short-term Event Studies}

\section{(i) Basic Methodology}

Event study methodology has been widely applied and well-documented in the academic fields of accounting and finance. To briefly and clearly review the structure of this methodology, the procedures for conducting an event study as it appears in Campbell, Lo and MacKinlay's (1997: p150-152) book are presented. They outline the event study according to seven steps:

1. Event definition. This initial task of conducting an event study is to define the event of interest and identify the period over which the security prices of the firms involved in this event will be examined- the event window $[\cdots]$. In practice, the event window is often expanded to two days, the day of the announcement and the day after the announcement. This is done to capture the price effects of announcements which occur after the stock market closes on the announcement day.

2. Selection criteria. After identifying the event of interest, it is necessary to determine the selection criteria for the inclusion of a given firm in the study. The criteria may involve restrictions imposed by data available, such as a listing on the NYSE or AMEX, or may involve restrictions such as membership in a specific industry. At this stage it is useful to summarize some characteristics of the data sample $[\ldots]$ and note any potential biases which may have been introduced through the sample selection. 
3. Normal and abnormal returns. To appraise the event's impact we require a measure of the abnormal return. The abnormal return is the actual ex post return of the security over the event window minus the normal return of the firm over the event window. The normal return is defined as the return that would be expected of the event did not take place. For each firm $i$ and event data $\tau$ we have

$$
\epsilon_{i t}^{*}=R_{i t}-\mathrm{E}\left[R_{i t} \mid X_{t}\right],
$$

where $\epsilon_{i t}^{*}, R_{i t}$ and $\mathrm{E}\left(R_{i t}\right)$ are the abnormal, actual, and normal returns, respectively, for time period $t$. $X_{t}$ is the conditioning information for the normal performance model. There are two common choices for modeling the normal return - the constant-mean-return model where $X_{t}$ is a constant, and the market model where $X_{t}$ is the market return. The constant-mean-return model, as the name implies, assumes that the mean return of a given security is constant through time. The market model assumes a stable linear relation between the market return and the security return.

4. Estimation procedure. Once a normal performance model has been selected, the parameters of the model must be estimated using a subset of the data known as the estimation window. The most common choice, when feasible, is to use the period prior to the event window for the estimation window $[\ldots]$. Generally, the event period itself is not included in the estimation period to prevent the event from influencing the normal performance model parameter estimates.

5. Testing procedure. With the parameter estimates for the normal performance model, the abnormal returns can be calculated. Next, we need to design the testing framework for the abnormal returns of individual firms.

6. Empirical results. The presentation of the empirical results follows the formulation of the econometric design $[\ldots]$. Occasionally, especially in studies with a limited number of event observations, the empirical results can be heavily influenced by one or two firms. Knowledge of this is important $[\cdots]$.

7. Interpretation and conclusions. Ideally the empirical results will lead to insights about the mechanisms by which the effect affects security prices. Additional analysis may be included to distinguish between competing explanations.

\section{(ii) Main Empirical Findings}

Jensen and Ruback (1983) review seven leading US acquisition articles for the sample period from 1962 to 1979, with an event window of around a month and a market model as the benchmark. They show that the abnormal returns for bidding firms in successful mergers range from +0.25 percent to +0.53 percent, and the weighted average abnormal return is +1.37 percent. Instead, abnormal returns for target firms in successful mergers range from +13.3 percent to +21.78 percent, and the weighted average abnormal return is +15.9 percent.

Andrade, Mitchell and Stafford (2001) conduct another US acquisition study that provides evidence for the 1980s and 1990s. They use a three day event window and a longer window beginning twenty days prior to the announcement and ending at the close of the merger. The average three-day abnormal return for acquirers is -0.7 percent and for targets is +16 percent; a longer day abnormal return for acquirers is -3.8 percent and for targets is 23.8 percent. Both abnormal returns for targets are significantly different from zero at the 5 
percent level. Their results are consistent with the summary presented in Jensen and Ruback (1983) and in other US acquisition articles (Schwert 1996, Agrawal, Jaffe and Mandelker 1992).

While the UK has different takeover regulations, most UK empirical studies provide results that are similar to the US research, especially with regard to short-term market performance. Based on the adjusted market model, Franks and Harris (1989) examine over 1,800 UK deals during the period 1955-1985. They show that in month 0 bidders earn a positive but insignificant abnormal return of about 1.0 percent but targets gain statistically positive returns of (on average) about 23.3 percent.

Sudarsanam, Holl and Salami (1996) conduct other UK study by sampling 429 acquisitions during the period 1980-1990. They use the market model with a Dimson thin trading adjustment so as to calculate the cumulative abnormal return (CAR) of an over -40 days to +40 days event window. They find that the period day -20 to day +40 captures all the value changes. Within this period, the CAR for bidders is -4.04 percent; for targets it is +29.18 percent. Both measures are significant from zero at the 1 percent level. These results imply the incidence of wealth transferring from bidder to target and echo the conclusions of most US and UK acquisitions research (Firth 1980, Limmack 1991).

Goergen and Renneboog (2004) particularly provide a cross-country survey of large intra-European (including 18 European countries) M\&A deals for the period 1993-2000. Short-term performance is also calculated by CAR under the CAPM benchmark. The event window starts from 2 months (-60 days to +60 days) prior to the event date. Their figures display similar results: for the 5 day event window, bidders have a significant abnormal return of 3.18 percent and targets have extremely high returns at 26.88 percent.

In sum, the results of these empirical studies mostly show significantly positive wealth effects for the target shareholders but a slight loss or insignificant gain for the bidder shareholders.

\section{(iii) Limitations}

Under the assumption of stock market efficiency, short-term event study usually uses estimators such as the market adjusted model $(\alpha=0, \beta=1)$, the market and risk adjusted (or market) model $\left(\mathrm{AR}_{i t}=\mathrm{R}_{i t}-\alpha_{i}-\beta_{i} \mathrm{R}_{m t}\right)$, and the Capital Asset Pricing Model (CAPM) to assess 
abnormal returns (Jensen and Ruback 1983, Andrade et al. 2001, Franks and Harris 1989, Goergen and Renneboog 2004). However, this method estimates the abnormal returns by controlling for the risk of the stock and the movement of the market during the event period. On some occasions, there are problems with parameter estimation (Blume 1971, Binder 1985/ 1998). For example, the nontrading or nonsynchronous trading effect induces bias for the market model beta (Scholes and Williams 1977). Brown and Warner (1985) examine mean-adjusted returns, market-adjusted returns and market- and risk-adjusted returns. They find that using daily returns on thinly traded securities the different abnormal return measures perform similarly.

In addition, under the unrealistic statistical assumption, abnormal returns are given by the market model with stationary parameters. Therefore, the potential statistical bias may be caused by the fact that the abnormal return estimators are often correlated or have different variances (Mikkleson and Partch 1988, Mais, Moore and Rogers 1989). Jaffe (1974) and Mandelker (1974) suggest that combining securities with the event in the same calendar month into a portfolio can solve the cross sectional dependence problems in the dependent variable. Also, weighting both the portfolio abnormal return estimates and the average portfolio values relating to independent variables can effectively eliminate the heteroskedasticity problem. Moreover, Chandra and Rorhbach (1990) and Karafiath (1994) contend that these biases can be successfully tackled through statistical tests in cross-sectional regressions. Brown and Warner (1980) use one factor model (with the market portfolio return as the factor) as a simple solution to adjust standard errors when the sample firms are from unrelated industries

Overall, since the short-term expected returns are virtually close to zero around event days, selecting an estimator as benchmark is not a fatal problem (Andrade et al. 2001) in short-term event study. While event study methodology may suffer from statistical problems in certain cases, it is still a powerful alternative (with some adjustments) for measuring abnormal return.

\subsubsection{Long-term Studies}

\section{(i) Basic Methodology}

Recent research has heightened the need for analyzing the long-run abnormal stock returns following major corporate events. Nevertheless, unlike short-term performance, long-term performance is assessed under the assumption that markets take time to assess the 
value implications of acquisitions and to await fresh information (Sudarsanam 2003). Therefore, there is considerable variation in the measures and the statistical tests which are normally used to detect long-run abnormal stock returns. Beginning with Ritter (1991), the buy-and-hold return (BHAR) methodology becomes a popular approach for examining long-term stock price performance. However, Fama (1998) argues against the BHAR because of the inadequate abnormal return parameters compounded with long-horizon returns. He strongly advocates a monthly calendar-time portfolio approach for measuring long-term abnormal returns.

To date, there are two major families of long-term market based methodology: event study approach including cumulative abnormal return (CAR) and BHAR, and calendar time approach. Since long-term market performance is not the focus of this thesis, the following section introduces the basic methodology behind these two families by reviewing their implications and discussion through six important articles in the field: Ritter (1991), Ikenberry, Lakonishok and Vermaelen (1995), Barber and Lyon (1997), and Kothari and Warner (1997) for long-term event study methodology; Fama (1998) for time calendar methodology; and Lyon, Barber and Tsai (1999) for comparison. Moreover, as CAR is a more straightforward method and as it is generally employed for comparison with BHAR, this thesis emphasizes the BHAR scheme for long-term event study methodology.

\section{(a) Long-term Event Study Methodology}

In an initial event study approach cumulative abnormal returns (CAR) are calculated as follows:

$$
\mathrm{CAR}_{i t}=\Sigma \mathrm{AR}_{i t}, \quad \mathrm{AR}_{i t}=\mathrm{R}_{i t^{-}} \mathrm{E}\left(\mathrm{R}_{i t}\right)
$$

Buy and hold abnormal returns (BHARs) are defined as

$$
B H A R_{i t}=\prod_{i=1}^{t}\left[1+R_{i t}\right]-\prod_{i=1}^{t}\left[1+\mathrm{E}\left(R_{i t}\right]\right.
$$

Reference portfolios, control firms, market models and Fama-French (1992/1993) three factor models are broadly used as benchmarks to calculate the expected returns $E\left(R_{i t}\right)$. Three to five years event windows are used to measure the long-term horizon. Four influential published academic papers discuss this methodology.

Ritter (1991) evaluates the long-run performance of initial public offerings (IPO) using two measures: (1) CAR calculated with monthly portfolio rebalancing and (2) 
three-year buy and hold return (BHAR). According to Ritter's definition (Ritter 1991: p6-8), "Monthly benchmark-adjusted returns are calculated as the monthly raw return on a stock minus the monthly benchmark return for the corresponding 21-trading-day period". To avoid measurement bias, they used four types of indexes as benchmarks (1) the CRSP value-weighted NASDAQ index, (2) the CRSP value-weighted Amex-NYSE index, (3) listed firms matched by industry and size, and (4) an index of the smallest size.

To reduce the new listing or delisting bias, they calculate an equally-weighted CAR monthly for both the IPO firm portfolio and the benchmark index. This implies a rebalancing process. Three-year BHARs are also used for dealing with this issue. According to their definition, three-year holding period returns are defined as:

$$
R_{i}\left(B H A R_{i}\right)=\prod_{t=1}^{36}\left(1+r_{i t}\right),
$$

where $r_{i t}$ is the raw return on firm $i$ in event month $t$ : "This measures the total return from a buy-and-hold strategy where a stock is purchased at the first closing market price after going public and held until the earlier of (1) its 3-year anniversary, or (2) its delisting." They find evidence of timing ability by using BHAR as measures. IPO managers tend to issue shares that result in long-run underperformance when stock prices are high.

Ikenberry, Lakonishok and Vermaelen (1995) develop a compatible research approach by examining the long-run performance of open market share repurchases. They also present CAR and BHAR approaches. For both of these methods, abnormal returns are calculated relative to four benchmarks: (1) the CRSP equal- weighted NYSE and ASE index, (2) the value-weighted NYSE and ASE index, (3) a ten size-based portfolio benchmark, and (4) a size- and book-to-market-based benchmark. They regard the CAR approach as descriptive in nature and focus more on the correction of BHAR measures which are defined as an equal-weighted return "from buy-and-hold investment in all repurchase firms beginning in the month following the announcement and continuing for 12 months" (Ikenberry et al. 1995: p188). Furthermore, they calculate a rebalancing multi-year total return by compounding average annual returns over a four-year observation period; consequently, they reduce the possibility that a small set of firms will ever dominate the return calculations.

Most importantly, considering that estimating standard errors using an event study approach requires a reasonable number of annual observations but that most firms either do 
not have a long history of returns or have an unstable return distribution over a long period of time, Ikenberry et al. (1995) run statistical inference of annual buy-and-hold and compounded multi-year returns via bootstrapping. This is to correct the skewness problems of individual-firm long horizon abnormal returns and the clustering problems of observations. They describe the bootstrapping sampling process as follows (Ikenberry et al. 1995: p189):

$[\cdots]$ for each repurchase announcement in our sample, we randomly select with replacement a firm listed on the NYSE or ASE that has the same size and book-to-market ranking at that point in time. We treat this randomly chosen company as if it had announced a repurchase on the same day as the corresponding repurchase firm. This matching process continues until each firm in our repurchase sample is represented in this pseudo-portfolio. This portfolio will have one randomly drawn firm for each actual repurchase firm, matched in time with similar size and book-to-market characteristics. After forming a single pseudo-portfolio, we estimate long-run performance in the same manner as we did for the repurchase sample. This yields one observation of the abnormal performance obtained from randomly forming a portfolio with the same characteristics as our repurchase sample. This entire process is repeated until we have 1,000 pseudo-portfolios, and thus 1,000 abnormal return observations. This provides us with an empirical approximation of the distribution of abnormal returns drawn under the null model specific to our sample.

Using a four-year BHAR via bootstrapping, Ikenberry et al. (1995) find a long-term abnormal stock price performance responding to the repurchase announcements. Their findings, consistent with Ritter's (1991), reject the market efficiency hypothesis and take undervaluation as a motivation for managers to conduct share repurchases. In Mitchell and Stafford (2000) academic paper, they suggest that the typical approach in the second wave of long-term event studies is to focus on BHARs with carefully constructed benchmarks and to assess the statistical significance of the mean BHAR via a bootstrapping procedure.

Barber and Lyon (1997), observe biases in test statistics arising from new listings, rebalancing of benchmark portfolio, and skewness of long horizon abnormal returns, thus arguing that long-term abnormal returns should be measured as a simple BHAR on a sample firm less an appropriate expected BHAR on a reference portfolio or control firm. They calculate annual, three-year, and five-year BHARs by developing three approaches for benchmarks: (1) employing the return on a reference portfolio, (2) matching sample firms to control firms on specified firm characteristics, and (3) applying the three-factor model of Fama and French (1993). In the first approach, four sets of reference portfolios are considered: ten size-based, ten book-to-market, 50 size/book-to-market, and the CRSP equally weighted NYSE/AMEX/NASDAQ market index. As an alternative, the second approach is to construct a set of matched firms as control firms on the basis of closest size (measured by market value of equity), similar book-to-market ratio, and similar size and 
book-to-market ratio. The final approach for benchmark is the use of the three-factor model that regresses post-event excess returns on a market factor, a size factor, and the ratio of market to book equity (M/B) (Fama and French 1993).

They finally document that using a reference portfolio (such as a market index) to calculate long-term abnormal returns may in fact cause significant biases as they argued. CARs are generally affected by the new listing bias, but BHARs are usually biased by rebalancing and skewness problems. However, they find that using control firm as a benchmark for calculating abnormal returns has statistical robustness results for virtually all sample situations. Kothari and Warner (1997) also analyze the security-specific long-run abnormal returns by using four different types of benchmark: (1) market-adjusted model, (2) market model, (3) capital asset pricing model (CAPM), and (4) Fama and French three-factor model. The major difference between their work and that of Barber and Lyon (1997) is that they put more concern into the application of the asset pricing model instead of a reference portfolio approach. However, the results in both articles highlight the presence of biases when calculating long-run abnormal returns using either a reference portfolio or an asset pricing model.

Fama (1998) put forward strong arguments against the market inefficiency assumption associated with BHAR methodology. He emphasizes that systematic errors caused by the imperfect estimators of abnormal returns may not be the problem in short-term event study but that they may grow along with the long-term return horizon in event study. And this bad model problem is even worse in the BHAR method because it compounds (multiplies) an imperfect estimator. Besides, Fama (1998) points out that the expected return estimator used in event study is generally firm-specific and doesn't constrain the cross-sectional expected returns. These approaches may explain the reaction of stock prices to firm-specific events such as IPOs and mergers, but they cannot identify anomalies in the cross-section of average returns such as size effect. The failure to adjust for the cross-sectional dependence of event firm abnormal returns may lead to overstatement in statistics results. Instead, Fama (1998) advocates a monthly calendar-time portfolio approach for measuring long-term abnormal market returns. 


\section{(b) Calendar Time Approach}

Based on the Fama-French three-factor model, the calendar time abnormal returns (CTARs) are defined as:

$$
\mathrm{R}_{i}-\mathrm{R}_{f}=\alpha i+b_{i}\left(\mathrm{R}_{M}-\mathrm{R}_{f}\right)+s_{i} \mathrm{SMB}+h_{i} \mathrm{HML}+\varepsilon i
$$

where SMB is the difference between the return on a portfolio of small stocks and the return on a portfolio of large stocks, and HML is the difference between the return on a portfolio of high-book-to-market stocks and the return on a portfolio of low-book-to-market stocks. $b_{i}, s_{i}$, and $h_{i}$ are the slopes in the time series regression (Fama and French 1996). Next, two important articles are studied for calendar time methodology.

In Fama (1998), CTARs are calculated as the following process. "The first step is to calculate abnormal return for each calendar month on each stock (ARit) that had an event in the post-event years. Abnormal returns can be estimated in any reasonable way as previously discussed. The second step is then to average those abnormal returns (ARit) for the calendar month across stocks in order to get the abnormal return (AARt) for the month on the portfolio of stocks with an event in the post-event years. The third step is then to re-form the portfolio every month" (Fama 1998: p295) and to re-do step 1 and 2.

While recognizing that the calendar time approach using average monthly return does not accurately capture the long-term investor experience captured by the BHAR approach, Fama (1998) still contends that average monthly returns have fewer inference problems in tests concerning long-term abnormal returns. The reason for this is that average monthly returns avoid the skewness problems produced by compounding monthly returns to get long-term BHARs. Furthermore, Fama defends market efficiency by regarding anomalies (overreaction or underreaction) as chance results that can be fairly eliminated with reasonable adjustments in the way they are measured. However, Loughran and Ritter (2000) focus on the class of anomalies related to managerial actions involving cash flows (such as equity issues, stock-financed acquisitions, and share repurchases) and provide a contradictory view showing that if there are significant misevaluations in the stock market then there should be some methods which have the power to detect subsequent abnormal returns. They argue that monthly portfolio returns using the Fama and French (1993) three-factor model in time-series regressions have less power for identifying abnormal returns because time is weighted equally. 
Lyon, Barber and Tsai (1999) conduct a comprehensive comparison between these two long-term market based families. A traditional event study approach relies on the BHARs using a carefully constructed reference portfolio such as the population mean abnormal return. Inference is based on either a bootstrapped skewness adjusted t-statistic or the empirically generated distribution of mean long run abnormal stock returns from pseudo portfolios. A calendar-time portfolio approach counts on an equally weighted or value-weighted time series abnormal returns. Lyon et al. (1999) point out that the event study approach yields an appropriate estimator which accurately represents "investor experience"; this method only suffers because there is such sensitivity in the cross-sectional dependence problem. By contrast, a calendar-time portfolio approach controls statistical problems quite well but captures investor experiences quite poorly.

\section{(ii) Main Empirical Findings}

Based on 947 acquisition transactions, Loughran and Vijh (1997) use the abnormal returns of control firms as a benchmark for calculating the five year BHARs over an identical time interval starting on the effective date plus one day. The control firms are matched on a basis of size (measured by market value of equity) and book-to-market effect. They find that the overall sample has an average five-year BHARs of 88.2 percent compared to 94.7 percent for their matching firms. The difference equals -6.5 percent but is not significant. Furthermore, they examine the relationship between the post-acquisition returns and the mode of acquisition and form of payment. They find, on average, that stock deals have significantly negative long-term effects on acquirers' long-term stock price performance, but that cash tender offers earn significantly positive excess returns.

Rau and Vermaelen (1998) use a sample of 3,169 mergers and 348 tender offers to examine three-year cumulative abnormal returns (CARs). They specially construct reference portfolios with dynamic size (ten size deciles at the end of every month) and book-to-market ratios. Portfolio returns are used as expected returns by calculating equal-weighted abnormal returns every month for 36 months after the merger completion date and then summing those averages over time. The significance level is also tested via a bootstrapping approach. They find that acquiring firms have significantly negative bias-adjusted CARs (-4\%) in the three years after the transaction but that long-term underperformance is not homogeneous across firms. The glamour acquirers with low book-to-market account for the poor post performance $(-17 \%)$. 
Mitchell and Stafford (2000) also examine three-year buy-and hold abnormal returns (BHARs) and calendar-time abnormal returns (CTARs). They do this using three large samples of major managerial decisions; these samples include 4,911 SEOs, 2,421 repurchases, and 2,193 mergers completed from 1958 to 1993. Multiple events by the same firm within any 3-year period are excluded. Moreover, similar to most prior research (for example, Loughran and Vijh 1997), they focus more on long-term stock price performance rather than on cross sectional characteristics. For BHARs, they calculate both equal-weight (EW) and value-weight (VW) three-year BHARs using 25 value-weight, nonrebalanced, size/ book-to-market equity (BE/ME) portfolios as expected return benchmark. Statistical inference is based on a bootstrapped skewness adjusted t-statistic. For CTARs, portfolio excess returns are regressed on the Fama and French (FF, 1993) three-factor and the intercepts are decomposed into the expected abnormal returns (based on size-BE/ME portfolio and FF three-factor) and the amount of abnormal returns attributed to other sources.

Focusing on the results of the mergers, the three-year EW BHAR for the full sample is negative with no significance $(-1 \%)$. This result is robust compared to the CTAR methodology on both EW and VW based measures (three year EW CATRs are $-1.44 \%$ $(-0.04 \% * 36)$ percent based on 25 size-BE/ME and $-5.05 \%$ based on $\mathrm{FF}$ three-factor, respectively; three year VW CATRs are -1.08 percent based on 25 size-BE/ME and -2.52 percent based on FF three-factor, respectively). Stock mergers significantly underperform on both three-year EW (-0.084) and VW (-0.053) BHARs. But this result is limited on both three-year EW and VW CATRs either relative to the 25 size-BE/ME portfolio or to FF three-factor benchmarks. Their main findings support a calendar time approach because "event-firm abnormal returns are positively cross-correlated when overlapping in calendar time" (Mitchell and Stafford 2000: p326). They argue that even BHARs with adjustment by bootstrapping procedure, long-term event study approach is not appropriate methodology for measuring long-term abnormal returns because it assumes cross-sectional independence.

By applying the calendar-time portfolio approach, André, Kooli and L'Her (2004) examine the long-term stock price performance for 267 Canadian deals during the period between 1980 to 2000. They employ weighted least squares (equal-weighted and value-weighted) procedures to calculate the three-year mean calendar-time abnormal returns (MCTARs) using reference portfolios as an expected returns benchmark. The portfolios are formed on the basis of size and book to market ratio. The monthly excess returns of portfolio are regressed based on the Fama-French three-factor model. They find a significant negative 
three year abnormal returns on equal-weighted MCTAR (-0.523\% per month). Furthermore, they test cross-sectional dependence problems by examining the sample without overlapping. They discover that acquiring firms suffer over the three post-event years either measuring by the equal- or value-weight method. Their results are consistent with the evidence of most literature that claims bidders significantly underperform in the long run.

\section{(iii) Other Limitations}

According to the discussion above, it is clear that there are several biases in long-term event study methodology. These include the measurement bias, new listing/ survivorship bias, rebalancing bias, skewness bias, cross-sectional dependence, and bad model problem. On the other hand, calendar time methodology suffers from time equally treated and lower power problems.

Beyond the above problems, the selection of a proper benchmark for calculating abnormal returns is also considered a fundamental limitation when assessing the post-event performance. The benchmarks broadly used in measuring short-term performance such as CAPM, even represented by the value-weighted or equal-weighted indexes have been criticized for failing to control the size effect. Dimson and Marsh (1986) suggest a size decile control portfolio where each company is assigned a decile group based on its market capital at the beginning of each year. Also, they use a risk and size control model in which to add a decile beta into each firm. Referring to Dimson and Marsh (1986), Kennedy and Limmack (1996) use size-matched control portfolios as one of their benchmarks. They summarize that the one-year abnormal returns are not significantly different from zero but that the significantly negative excess returns were identified in the second year following the bid. Higson and Elliott (1998) also apply the simple Dimson and Marsh (1986) size-decile control method to examine long-term UK acquisition performance. They conclude that UK acquirers show zero abnormal returns in the three years following transaction completion.

Expanding from the asset pricing model of Sharpe (1964), Lintner (1965), and Black (1972), Fama and French (1992/ 1993) conduct a three-factor asset pricing model. The model implies that the expected return on a portfolio can be explained by three factors: "(1) the excess return on a broad market portfolio $\left(R_{M^{-}} R_{f}\right),(2)$ the difference between the return on a portfolio of small stocks and the return on a portfolio of large stocks (SMB, small minus big), and (3) the difference between the return on a portfolio of high-book-to-market stocks and the return on a portfolio of low-book-to-market stocks (HML, high minus low)" (Fama 
and French 1996: p55). Specifically:

$$
\mathrm{E}\left(\mathrm{R}_{i}\right)-\mathrm{R}_{f}=b_{i}\left[\mathrm{E}\left(\mathrm{R}_{M}\right)-\mathrm{R}_{f}\right]+s_{i} \mathrm{E}(\mathrm{SMB})+h_{i} \mathrm{E}(\mathrm{HML})
$$

As this model has so far been recognized as a proper benchmark for capturing much of the cross-sectional variation in average stock returns, it has been broadly employed to capture the long-term abnormal returns in the existing literature as previously discussed.

In conclusion, the usefulness of event study is that the effect of an event can be directly reflected to a firm's security basically in the short-term event window and can then hopefully cross a long-term period. Therefore, the performance of a corporate event can be measured by stock return. However, Hitt, Harrison, Ireland and Best (1998) shed light on the fact that the nature of market performance methodology may not fully capture the anticipated benefits from an acquisition due to information asymmetries. Healy, Palepu and Ruback (HPR, 1992) further argue that stock returns only reflect investor expectations of takeover benefits but that they do not provide a direct measure of the impact of the acquisition on costs, revenues, profits and cash flow. They think that accounting performance measures can more efficiently seize actual economic benefits.

\subsubsection{Accounting Based Performance}

Rather than focusing on stock price, several empirical studies examine accounting based performance. Based on the efficiency hypothesis that increases in shareholder wealth in takeover are derived from economic synergies, it is reasonable to expect that if the equity price of an acquiring firm increases within the announcement period it is caused by the shareholder's rational expectations and that the subsequent operating performance should increase correspondingly in the following years. A milestone seminar paper looking at accounting based performance in the context of M\&A is presented by HPR (1992). They shed important light on the operating cash flow performance. Hence, the rest of this section will discuss HPR's contribution and will review other related papers before and after HPR (1992).

\subsubsection{Pre HPR ( 1992)}

\section{(i) Empirical Evidences before HPR}

Pre HPR papers use mostly accrual measures to examine the acquisitions performance. For example, Lorie and Halpern (1970) analyze 117 US mergers in the manufacturing and mining industry between the year 1955 and 1967. They compute rate of returns (market 
prices for the stock originally held by the shareholders and for the assets received by the shareholders) to the selling shareholders from the date six months prior to the deal completion to the time of the merger and over two years after. They compare the measures with the general market index and conclude that the investment return performance for initial target stockholders who stay in combined firms for one or two years is largely superior to the market performance of broad market indexes.

Weston and Mansinghka (1971) present a parallel but identical research by focusing on a sample of 63 conglomerate firms covering the year 1958 to 1968 . They examine the post earnings performance by calculating several accounting-based measures such as EBITA/Total asset, EBIT/Total asset, net income/ net worth, net profit/ equity, earnings per share, etc; they compare these measures with two kinds of control firms (industrial companies only and all companies). They provide contradictory results that the earnings performance of the control groups is significantly higher than the earnings rates of the conglomerate acquirers.

A study by Lev and Mandelker (1972) develops another accounting based research with 13 various measures ${ }^{9}$. It uses 69 large acquisitions during the period between 1952 and 1963 to calculate five-year average annual ratios for 13 measures. These measures indicate different synergy sources from M\&A such as profitability, efficiency of operation, capital structure, and tax savings. The performance of control firms is again used as a benchmark. Control firms are matched based on industry (4-digit SIC) and firm size (measured by total asset).

Instead of comparing the performance of two groups, they investigate excess returns for each measure by calculating the difference between the five year average of post-merger and the five year average of pre-merger - as adjusted by returns of matched firms. They document that the profitability of mergers created in favor of the acquiring firms is reflected on both of two market based measures (market annual rate of return and price relative) but only on one accounting based index, i.e. ROA. Moreover, the merger effect seems not to contribute to the acquiring firm's operating efficiency in subsequent years since the relative

9 These measures include (1) market annual rate of return $\left(\left(p_{t}+d_{t}\right) / p_{t-1}\right),(2)$ price relative $\left(p_{t} / p_{t-1}\right),(3)$

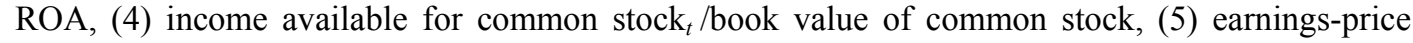
ratio, (6) profitability of sales, (7) earnings per share, (8) annual growth rate in total asset, (9) annual growth rate in sales, (10) annual growth rate in operating income, (11) working capital ratio ${ }_{t}$, (12) Income taxes ${ }_{t} /$ operating income ${ }_{t}$, and (13) stockholders' equity ${ }_{t} /$ total $^{\text {assets }} t$ 
measures are almost negative. While their results support the idea that merging firms perform better than non-merging firms, their evidence is strengthened by testing market based indexes rather than by testing accounting based measures. Indeed, most pre HPR studies tend to stand on the idea that acquisitions fail to improve corporate performance (Mason and Goudzwaard 1976, Melicher and Neilson 1978, Meeks and Meeks 1981, Ravenscraft and Scherer 1987)

\section{(ii) Limitations of pre-HPR studies}

Summarizing these pre HPR studies that generally use accounting based performance measures to evaluate the economic benefits of corporate mergers leads to many questions concerning the long-term mergers effects. If the evidence behind these empirical tests is correct, do mergers really create economic synergies for shareholders of acquiring firms? If mergers do provide benefits, why do most empirical studies fail to detect the benefits? Lubatkin (1983) point out a possible explanation for this is owing to the inappropriate methodology. Pre HPR studies that mostly apply accrual accounting data such as ROA/ ROE in the context of corporate events like M\&As suffer from a number of limitations.

First, financing choice impacts ratios. Several empirical evidences have documented that the choice of different payment methods for acquisitions is relevant for the acquirer's liquidity, for the recent stock price of the acquirer, for the pre-acquisition leverage of acquirer and target, and for the nature of acquirer itself, etc. (Franks, Harris and Mayer 1988, Amihud, Lev and Travlos 1990, Goergen and Renneboog 2004, Faccio and Masulis 2005). When debt financing or surplus cash are used as the primary payment mode, the financial leverage of acquirers increases. Such increases may be part of acquisition strategies to gain interest-tax sheds or other benefits but they cause several side effects in post-merger years. For example, a higher leverage level may result in lower post-acquisition profits because of interest expense increase. Moreover, if stock equity is issued to pay for the transactions, then the shareholder base will be enlarged. This also could be a part of M\&A strategy especially when the stock markets are too high. The dilution of earnings may lead to a lower EPS for several years after the transactions. Unfortunately, most accounting measures used in the studies prior to HPR have difficulty reflecting the viewpoint of the common stock without having those effects embedded (Lubatkin 1983).

Second, tax arbitrage impacts ratios. Tax arbitrage is the transaction that takes advantage of a difference in tax rates or tax systems as the basis for profit. In the M\&A field, 
a target with accumulated income losses (called tax losses) that could be offset against the acquirer's profits would be an attractive target. The acquirer could reduce tax liability for the group after acquisition (Sudarsanam 2003). Obviously, traditional accounting indicators are unable to detect this hidden information. However, this problem may be confined to some degree by enacting an effective tax law or qualified accounting standards.

Third, accounting method for M\&A impacts ratios. There were two accounting methods for M\&A transactions ${ }^{10}$ : Pooling (merging) accounting and Purchase (acquisition) accounting. The major difference between these two accounting methods is the way in which goodwill is accounted for. Pooling does not recognize goodwill but purchase accounting does. Therefore, accounting measures such as ROA or ROE will be higher by using a pooling method than by a purchase method because purchase accounting inflates the asset base with goodwill and reduces the profit through the expenses of amortization. Beyond that, accounting method for M\&A still leaves some avenues for acquirers to do manipulation. For example, since goodwill may not have to be amortized in the following years, the acquirer may have incentive to raise the value of goodwill and to devalue other tangible assets that need to be depreciated in post-merger years.

\subsubsection{HPR Methodology (1992)}

Healy, Palepu and Ruback (HPR, 1992), like the earlier accounting based researchers, argue that market performance may not be able to fully explain the increases in real economics that result from M\&A events because of the market inefficiency. HPR attempts to eliminate such limitations in pre HPR studies. Therefore, they establish an operating cash flow model that employs operating cash flow returns as performance measures, benchmark measures against industry, and also control measures for momentum.

\section{(i) Measure of Performance}

By studying the 50 largest US mergers between 1979 and 1984, HPR (1992) uses pretax operating cash flow returns on assets as measures. They define operating cash flow as sales, minus cost of goods sold and selling and administrative expenses, plus depreciation and goodwill expenses. In other words, it is so called earning before interest, tax, depreciation and goodwill amortization (EBITDA). This measure is deflated by the market

10 The international accounting standards board (IASB) modified rules in 2004 to eliminate the use of pooling and make goodwill and certain intangible assets no longer amortized but needing a periodic impairment test. Similar rules exist since early 2000s in the US, Canada, Australia, and New Zealand (Sudarsanam 2003). 
value of assets so as to offer a compatible return rate across long-term periods and across firm specifics. The market value of the asset is the sum of the market value of equity and the book value of debt. Specifically:

$$
C F R=\frac{E B I T D A}{M V_{A}}
$$

This operating performance measure improves the weakness of the earnings-based performance measures because it is unaffected by depreciation and goodwill and excludes the impact of interests and taxes. Therefore, it is reasonable to expect that the sensitivities of financing choice, tax arbitrage issues, and accounting methods for M\&A are effectively mitigated.

\section{(ii) Benchmark}

HPR (1992) provides a measure of the changes in cash flow returns. This measure is calculated by (1) aggregating the pre-merger weighted-operating cash flow returns of the bidders and targets as a pro forma premerger performance, where the weights are the relative market values of equity of the two firms at one year before the merger announcement, and (2) computing the differences between post-merger performance of combined (sample) firms and this pro forma premerger performance to get the measure of the change in cash flow returns.

However, considering that abnormal returns measured by the change in performance are likely contributed to by industry factors or by continuous outperformance from the acquiring firm itself, HPR (1992) further constructs an industry benchmark on the basis of the Value Line industry definitions at one year before acquisitions. The benchmark performance is measured by the median cash flow returns of industry, excluding target and acquirer's performance. Finally, the industry-adjusted cash flow returns (IACRs) for each combined firm in each year are computed by subtracting the industry-median benchmark returns from the sample firm value. HPR (1992) take IACR as a primary performance measure to examine five years post-acquisition performance.

\section{(iii) The Intercept Model}

Moreover, HPR (1992) extend the IACR measure to test the relationship between pre and post performance. They measure the abnormal industry-adjusted cash flow returns by running a cross-sectional regression model, called the intercept model by Ghosh (2001): 


$$
\mathrm{IACR}_{\text {post }, \mathrm{i}}=\alpha+\beta \mathrm{IACR}_{\text {pre, }}+\varepsilon_{\mathrm{i}}
$$

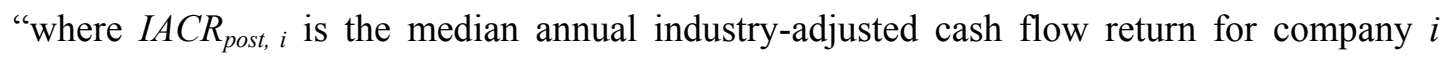
from the postmerger years and $I A C R_{p r e, i}$ is the premerger median for the same company". $\alpha$ is the measure of the abnormal industry-adjusted cash flow returns. $\beta$ estimates the effects of pre performance on post performance. They basically believe that after controlling the pre performance, the intercept $(\alpha)$ is independent from premerger returns and should be appropriate for measuring abnormal returns created by M\&A.

\section{(iv) Main Findings}

Challenging the previous literature that mostly suggests a negative or insignificant post performance based either on stock prices or on accounting data, HPR's (1992) results show that the annual median IACR for the combined firms in five post-merger years is 2.8 percent significantly higher than their industries' annual median returns. The annual median IACR for the combined firms in five pre-merger years is a positive $(0.3 \%)$ but with no significance. Furthermore, the estimators $\alpha$ is 2.8 percent significantly different from zero which indicates that operating performance for acquiring firms increases at 2.8 percent each year after transactions. The other indicator $\beta$ ( 0.37 with significance $)$ also presents a positive and persistent relationship between post and pre performance. In sum, they importantly document how acquiring firms have made significant improvements on operating cash flow returns in the post-merger period.

\section{(v) Further Tests}

To control the momentum, HPR (1992) attempt to identify the sources for improvement in an acquirer's cash flow returns. These variables include cash flow margins, asset turnover, employee growth rate, pension expense/employee, capital expenditure rate, asset sale rate-cash value, asst sale rate-book value, and $R \& D$ rate. Here, this thesis focuses more on two major components: cash flow margins and asset turnovers. Cash flow margin on sales measures the pretax operating cash flows generated per sales dollar. Asset turnover measures the sales dollars generated from each dollar invested in assets. Specifically:

$$
C F R=\frac{E B I T D A}{\text { Sales }} \times \frac{\text { Sales }}{M V_{A}}
$$

Similar testing processes are run in order to examine these two measures. The results show that the combined firms have significantly higher postmerger cash flow margins (1.1\%) owing to their significant higher cash flow margins $(1.4 \%)$ in premerger years. The median 
asset turnover of combined firms in pre-merger years is insignificant negative $(-0.2 \%)$ meaning that combined firms generate 20 cent less in sales than their industrial competitors for each dollar of assets. After acquisition, combined firms significantly improve on the abnormal returns measured by the intercept $\alpha$. Overall, the significant increase in cash flow returns is attributed to the greater asset productivity $(0.2 \%)$ after combination rather than the improvements of operating efficiency because the pre-merger operating cash flow margins of combined firms are already higher than their industry-median performance.

Beyond testing for the momentum, HPR (1992) have another important analysis regarding to the relationship between announcement returns and postmerger cash flow improvements. They prove a strong relationship between stock performance and operating performance, indicating that operating cash flow measures are reasonable for investigating whether the expected gains from mergers at announcement are actually realized in the following years. However, HPR emphasize that this argument should stand under the assumption of market efficiency.

\subsubsection{Post HPR (1992 )}

\section{(i) Evidence on HPR}

Andrade et al. (2001) replicate the HPR model by examining roughly 2,000 US mergers from 1973 to 1998 . They use industry-median adjusted operating cash flow margins (cash flow to sales) as measures for examining the improvements in post operating performance. This measure is calculated by the difference between the combined firm's operating cash flow margin and the corresponding industry median operating margin. Abnormal returns are also measured using the intercept model. They consistently find that the acquiring firms improve post operating performance relative to their industry peers. Also, they compare this result with their market performance analysis and conclude a consistent pattern with the positive announcement-period stock market returns.

\section{(ii) Limitation on HPR}

Nevertheless, HPR model has not escaped criticism from the post studies for the following major limitations:

\section{- Benchmark}

Selecting an appropriate benchmark has always been a critical issue not only for market based performance but also for accounting based performance. Barber and Lyon (1996) present a crucial study regarding operating performance benchmarks. They test four 
major matching approaches that are often used to measure accounting performance: 2-digit SIC code, 4-digit SIC code, 2-digit SIC code and similar size, 2-digit SIC code and similar pre-event performance. The SIC code is based on the Compustat classification, whereby size is measured as the book value of assets within 70-130 percent, and the performance is assessed as the return on assets within 90-110 percent in the prior year of events. The size band (70\%-130\%) and the performance filter (90\%-110\%) are selected because they yield test statistics that are well in-specified in these sampling situations. To avoid dropping firms that have no firms matched, they empirically set several alternative rules for each approach. For example, expanding the two-digit SIC code to one-digit or even no regarding to SIC code; if there is still no firm matched, the final step is to select the firm with the closest performance without industry limit. Their results finally suggest that performance-matched methods are generally well specified in most sampling situations.

Following Barber and Lyon (1996), most research adopts pre performance based matching. Loughran and Ritter (1997) choose their matched firms using the following steps. In the first step, they select firms with the same 2-digit SIC code, with a similar assets size at the end of year 0 within 25-200 percent, and with the closest ratio of operating income before depreciation and amortization to the book value of assets (OIBD/assets). Secondly, if no firms meet the first criteria, the alternative is to pick the firms without regard to industry but with similar assets within 90-110 percent and with closest but higher OIBD/assets.

Under the notion of performance-matched, Ghosh (2001) argues that the empirical results of the HPR model may be biased due to the use of an industry-based benchmark. Since acquiring firms are generally larger than industry-median firms, the results for acquiring firm performance adjusted by an industry-median benchmark are probably too optimistic. A detailed discussion regarding Ghosh's (2001) critics is presented in the latter part about estimate for improvements. To avoid the bias caused by comparing the pre- and post-acquisition performance of merging firms relative to control firms matched on industry-median, Ghosh (2001) sets a benchmark as the size and median performance of the matched firms. Matched firms are collected on the basis of (1) the same 2-digit SIC code, (2) total assets between 25 and 200 percent, and (3) the closest ratio of operating cash flow to market value of assets. Using 315 pairs of acquired and acquiring firms during the period from 1981 to 1995 , he determines whether acquisitions improve operating performance by comparing the difference between pre and post operating cash flow performance of acquiring 
firms relative to that of matched firms. He finds no evidence to conclude that acquiring firms outperform their benchmark firms with industry, size and pre performance adjusted. .

For a comparison of Ghosh (2001) to HPR (1992), Powell and Stark (2005) construct two benchmarks. One is based on the industry-median operating performance in HPR (1992). Following the definition in Datastream's level 4 (Financial Times All Share Index), all firms in the same industry groupings, excluding delisted firms, are used to calculate industry median. The other benchmark, consistent with Ghosh (2001), is based on industry, size and pre performance adjusted operating performance of matched firms. The criteria they used to select the matched firms are: (1) same industry groups as defined in Datastream's level 4 (Financial Times All Share Index), (2) similar firm size based on the size filter between 25 percent and 200 percent at one year before takeover; if there is no firm matched, the size filter will be extended to 0 percent and 300 percent, (3) the closet operating performance at one year before acquisitions; similar processes to examine abnormal operating performance measures are run for 91 UK deals from 1985 to 1993. Surprisingly, their results suggest that takeovers create real improvements in operating performance for acquiring firms but that these are not related to which benchmark is employed. As a general rule, however, the magnitude of the estimates of performance improvements is higher by using adjusted industry, size, and pre performance benchmarks than by using industry adjusted alone.

\section{- Performance Measures}

Along with benchmark problems, the definition of the operating performance used in HPR (1992) raises another major concern. Powell and Stark (2005) argue that operating performance (EBITDA) used in HPR "tends to be an accruals definition of operating cash flow, defined simply as pre depreciation profit" so that it is still likely to be distorted by the accounting policies. Therefore, they use two measures to examine the improvements of operating performance in postmerger years. One is the initial HPR operating cash flow, defined as EBITDA. The other operating performance measure called 'pure' cash flow is defined as "pre depreciation profit adjusted for changes in working capital. That is the changes in inventories, receivables and (non-tax) prepayments less changes in payables and (non-tax, non-interest) accruals". They examine both performance measures and conclude that using 'pure' cash flows leads to an insignificant but stable result in both benchmarks. Using 'accrual' operating performance measure (EBITDA) provides mixed results, depending on the benchmark used. Hence, the increase of operating cash flow returns is supported more by the use of 'accrual' operating cash flow returns than by the use of 'pure' 
cash flow returns.

Sharma and Ho (2002) argue that the operating cash flow measure adopted in HPR (1992) was not properly operationalised. They suggest that working capital from operation could be a better proxy to measure merger benefits. Therefore, unlike HPR (1992), they apply a different formula (Ditna and Largay 1985) to calculate four cash flow performance indicators with different definitions:

(1) cash flow return on assets $\left(\mathrm{CFFO}^{11} /\right.$ Total asset), (2) cash flow return from sales (CFFO/Sales), (3) cash flow return on average ordinary shareholder's equity (CFFO/AOSE), and (4) (cash flow from operations minus preference dividends) on a number of ordinary shares. They also select four accrual performance measures including ROA, ROE, profit margin and EPS for comparison

Using an industry adjusted benchmark for 36 Australian deals occurring between 1986 and 1991, Sharma and Ho (2002) have regression results showing that median performance indicators ROA, PM, EPS and CFFO/SALES are all significantly negative and only CFFO/NOS is weakly positive. The overall results indicate that on the basis of four accrual and four cash flow performance measures, acquiring firms have no improvements in operating performance thought M\&A. Accrual performance indicators are likely to reveal negative returns following an acquisition whereas cash flow measures tend to show positive but statistically insignificant gains.

\section{- Deflators}

Moreover, the deflator used in HPR (1992) to scale the operating performance is another key point. Rahman and Limmack (2004) argue that to capture the real gains from acquisition itself, the use of book value is relatively efficient to exclude any share price changes reflecting the shareholders expectation. Thus, unlike HPR (1992) they use the book value of assets rather than the market value to scale operating cash flow. The book value of asset is calculated as a book value of shareholders funds and total debt less cash and marketable securities at the beginning of the relevant year. Besides, by sampling from Malaysian companies involved in takeovers between 1988 and 1992 and by using industry

${ }^{11} \mathrm{CFFO}=\mathrm{WCFO} \pm \Delta($ Trade receivables + prepayments + inventories + other receivables $) \pm \Delta($ Trade creditors + Interest accrued + Provision for employee entitlements + other creditors); $\mathrm{WCFR}=($ Operating profit before tax + Interest expense $+/-$ extraordinary items + depreciation + Loss on sale of assets and investment + other write off)- (Profit on sale of assets and investment) 
adjusted benchmarks, their outcomes suggest that the operating cash flow performance of acquiring firms has been significantly improved after combination. Their findings are consistent with the results in HPR (1992) which scaled by the market value of assets.

Powell and Stark (2005) have similar concerns as Rahman and Limmack (2004) toward to the deflator problem. They cast doubt on HPR (1992) that operating performance measures scaled on market value of assets may be biased by the market overreaction to the takeover announcement because this would imply that actual operating improvements should be greater than those capitalized by the market around the takeover announcement period. Therefore, they adopt four different alternatives to test the sensitivity of deflators: (1) Total market value of assets (TMV) as defined in HPR (1992) and Ghosh (2001), (2) TMV adjusted for market reaction to the takeover, (3) book value of total assets, and (4) total sales. TMV adjusted for market reaction to the takeover, as compared to TMV, is designed to test the magnitude of any overreaction by the market to takeovers. The regression results are truly sensitive to the deflator used. A clearer sign is that none of the control variables has power enough to explain operating performance scaled by adjusted TMV. But some of the control variables are significantly related to operating performance using either book value of assets or sales as deflator.

\section{- Estimate for Improvements (Abnormal Returns)}

Recall that, HPR (1992) use the cross sectional regression model to estimate the abnormal industry-adjusted cash flow returns (IACR). They take the intercept $(\alpha)$ as a measure to examine the improvement (increase) in the operating cash flow after acquisitions. However, Ghosh (2001) suggests that the change in adjusted cash flow return ( $\Delta$ Cash Flow) should be a better estimate to examine the abnormal cash flow returns. The change in adjusted cash flow return ( $\Delta$ Cash Flow) is defined as the median postmerger adjusted cash flow return minus the median adjusted cash flow return in pre-merger years. Ghosh (2001) named it the change model. Specifically:

$$
\Delta \text { Cash Flow }=\left(\text { Cash Flow }_{\text {post }}^{\text {adi }}-\text { Cash Flow }_{\text {pre }}^{\text {adi }}\right)=\alpha_{\mathrm{i}} \chi_{\mathrm{i}}+\varepsilon_{j}
$$

where $\chi_{\mathrm{i}}$ are denoted to any explanatory variables and $\alpha_{\mathrm{i}}$ measure the improvement in cash flow for $\chi_{\mathrm{i}}$ variables.

The main reason why Ghosh (2001) designed this measure was to tackle benchmark problems with industry-median firms in the HPR (1992) model. He criticizes the fact that 
conclusions about improvements in operating performance based on the intercept model as in HPR (1992) are likely to be biased. Furthermore, he presents three cases to illustrate that the bias may arise from permanent $\mathrm{E}\left(\mathrm{CF}_{\text {pre }}\right)$ and/ or temporary $\mathrm{E}\left(\varepsilon_{\text {pre }}\right)$ difference in operating performance between merging and industry-median firms' in the pre-acquisitions period. Simply to say:

Case 1, when there are no permanent $\left(\mathrm{E}\left(\mathrm{CF}_{\mathrm{pre}}\right)=0\right)$ and temporary difference $\left(\mathrm{E}\left(\varepsilon_{\mathrm{pre}}\right)=0\right)$ in operating performance between merging and industry-median firms' prior to acquisitions, the intercept model and the change model will yield identical unbiased estimates (Ghosh 2001, p157).

Case 2, when there is no temporary difference $\left(\mathrm{E}\left(\varepsilon_{\mathrm{pre}}\right)=0\right)$ but the pre-acquisition performance of merging firms is different from that of industry-median firms because of permanent factors $\left(\mathrm{E}\left(\mathrm{CF}_{\mathrm{pre}}\right)>0\right)$, the estimates from the change model ( $\Delta$ Cash flow) is unbiased but the intercept model will lead to biased conclusion $\left(E(\alpha)=(1-\beta)\left[E\left(\mathrm{CF}_{\mathrm{pre}}\right)\right]\right)$ (Ghosh 2001, p158).

Case 3, when the difference of pre-acquisition performance between merging and industry-median firms results form both permanent and temporary factors, not only the intercept but also the change model yields biased estimators because the temporary differences should not be assumed to persist into post-acquisition years (Ghosh 2001, p159).

In summary, Ghosh (2001)'s argument suggests that if merging firms outperform their peers because of permanent differences in the pre-acquisition period such as sustained competitive advantage or economies of scales, then the superior pre performance will be incorporated into the post performance. This kind of bias, however, (too optimistic a performance) cannot be detected by simply controlling pre performance in the intercept model. The change model may reduce the degree of bias because the measure of change in cash flow return deducts the permanent factors that persist into the future at the beginning. However, if merging firms outperform their peers because of temporary differences in the pre-acquisition period such as windfall profits from a short-term demand surge, a simple comparison of post- and pre-acquisition industry-adjusted cash flows as in the change model are not merely unable to eliminate the bias problems but can even cause the under/ over evaluation of abnormal cash flow returns.

Powell and Stark (2005) evaluate these arguments by addressing the fact that it is unreasonable to assume that after controlling for pre performance, the average of post operating performance left unexplained (i.e. $\alpha$, at $\beta=0$ ) is all attribute to the improvement of 
acquisitions. It is also unreasonable, however, to assume that the superior (or inferior) pre performance will 100 percent (i.e. $\beta=1$ ) continue into the post performance. As it is hard to identify the difference of pre-acquisition performance between merging and industry-median firms due to permanent or temporary factors, one possible solution is to construct control firms matched on pre-acquisition performance and size as discussed above. The other way is to examine both performance metrics as in most recent studies (Linn and Switzer 2001, Ghosh 2001, Carline, Linn and Yadav 2002, Powell and Stark 2005).

\section{- Others}

There are still some other limitations relying on HPR (1992) accounting-based performance approach. For example, separating the impact of acquisitions from that of other corporate events is difficult; measuring the time lag in performance improvement is not clear; and examining accounting numbers is backward-looking on historical performance (Sudarsanam 2003). Despite the above concerns, operating performance is still identified as a useful measure for exploring whether or not the acquisitions increase economic wealth in the long run. 


\subsection{Determinants of M\&A Success}

A number of studies provide background for assessing the determinants of M\&A success. The following sections will briefly review a variety of transaction characteristics that have been well documented as having potential impact on acquisition performance.

\subsubsection{Cross Border/Origin}

\section{- Cross Border}

Cross border acquisitions have become popular corporate activities even though they have presented some controversial issues over the past few decades. Extant studies suggesting that cross border M\&As are usually based on the assumption that this type of mergers provides diversification, reduces risk, and integrates the synergy of internationalization (Markides and Ittner 1994, Morck and Yeung 1991, Seth, Song and Pettit 2002). However, several competing explanations consider the fact that the expected value of the proposed cross border transactions should be low because acquirers may face obstacles of a different nature that offset any possible advantages when entering new markets.

Campa and Hernando (2004) support this point by analyzing 262 European M\&As during the period 1998-2000. They find that the shareholders of the acquiring firms obtain lower abnormal returns in cross-border deals than in domestic deals,. This is probably due to the legal, culture, and transaction barriers. André et al. (2004) examine long-term market performance for Canadian M\&As and also prove that cross border deals perform poorly in the long run. Moeller and Schlingemann (2005) consistently provide empirical evidence that compared to domestic acquirers, US cross-border acquirers suffer in terms of both stock return and operating performance.

Cakici, Hessel and Tandon (1996) conduct an US research to investigate shareholder wealth transfer. They find that foreign (not US) acquirers with US targets have significantly high returns. In turn, US acquirers with foreign targets have no gains from such cross-border mergers. This result has been interpreted by some scholars under the undervaluation hypothesis (Gonzalez and Vasconcellos 1998). The hypothesis indicates that foreign (non US) acquiring firms merging an undervalued US target may minimize the acquisition costs and then efficiently expand their markets to the US marketplace. 


\section{- Cross Origin}

Following the different lines of reasoning, some scholars believe that cross-border mergers may be responsible for any change in corporate governance. For example, Bris and Cabolis (2002) evaluate the industry value (measured by the industry Tobin's Q) of cross border mergers by controlling the variables of legal origin and legal institutions including the anti-director right, creditor right, accounting standard, and corruption indexes. Their central findings are as follows: first, the adoption of targets with better legal institutions (anti-director right and corruption) than those in the domestic market creates merger values. Second, target firms in countries with French, German, and Scandinavian legal origins would benefit from acquisition by acquirers in English origin countries. Moeller and Schlingemann (2005) provide consistent evidence for the positive relationship between bidder returns and the level of investor protection in the target country.

\subsubsection{Transaction Attitude}

There is extensive debate over the association between the acquirer type and the acquisition performance. On the surface, a hostile takeover is not welcome because of potentially high restructuring costs. Hostile acquirers usually have to pay a higher premium to control the target firms. However, when friendly bidders have to pay exceedingly high costs in order to make agreements with inefficient and greedy target managers, friendly takeover is not recommended. In one sense, hostile bids can act as governance mechanisms for corporate control. Morck, Shleifer and Vishny (1988a) defend hostile takeovers by arguing that this type of bid is driven by the urge to replace the inadequate incumbent management of the target firms and thereby to create a merger synergy to benefit the acquirer shareholders. This argument is further been challenged by empirical evidence showing that hostile targets do not necessarily have poor pre-bid performance (Franks and Mayer 1996).

Franks, Harris and Titman (1991) examine 339 American deals during the period from 1975 to 1987 . They use different benchmarks to test post-merger abnormal returns. Their results suggest that adjusted cumulative abnormal returns are overall positive for opposed bids, but that there is no significant difference between the performance of opposed and uncontested bids. In recent research by Sudarsanam and Mahate (2006), 519 UK acquisitions from 1983 to 1995 are used in order to test the three year post-acquisition gains 
of acquirer shareholders. Their conclusions are consistent with the earlier works of Morck et al. (1988a) which suggest that hostility leads to better value creation.

\subsubsection{Method of Payment}

There are two fundamental methods of payment for the acquiring firms: cash and stock shares. Usually, the method of payment signals the acquirer assessment of its own or the target firm's value. The managers of the acquiring firms prefer to pay for their acquisitions by cash when they judge that their stock price is undervalued around the announcement date. If the stock market underreacts in the short-term event window, then the abnormal returns are likely to show up in the post-acquisition performance. These lines of study imply that cash offers might produce better post performance than equity bids (Myers and Majluf 1984, Franks et al. 1991, Loughran and Vijh 1997, André et al. 2004, Faccio and Masulis 2005)

Goergen and Renneboog (2004) examine 228 large (deal value at least USD 100 million) European cross border deals for the period 1993-2000. They find that cash offers triggering larger share price reactions is only for targets and not for bidders. The reason for this is that the market may realize that the choice to make all-cash bids is not possible for such large cross border deals. An all-equity offer does not suggest to the market that the bidder's equity is overvalued.

Except for a few inconsistent evidences against the signal of payment method, most significant current discussions support the positive effect of cash offers. Loughran and Vijh (1997) calculate 5-year BHARs by the form of payment for acquirers and matched firms. They prove that the post-acquisition performance of cash acquirers is better than that of stock acquirers. André et al. (2004) also show that entirely equity-financed M\&As significantly under-perform in the long run.

\subsubsection{Competition/Multiple Bidders}

Numerous studies attempt to use competition in order to explain why targets gain higher wealth but bidders earn smaller returns (Ruback 1983, Franks and Harris 1989). A perfect competition in the acquisition market is assumed to imply that potential bidders will increase their bid premium until the net present value (NPV) for the winner bidder is close to zero. Successful acquirers may create acquisition value but will find it hard to capture the 
abnormal return unless the acquisition market is imperfect. This stream of analysis is strongly supported by the succeeding empirical research (Morck, Shleifer and Vishny 1990, Duggal and Millar 1999). Morck et al. (1990) investigate 326 US deals between 1975 and 1987 and find that multiple bidders reduce the takeover gains for acquirers. Duggal and Millar (1999) observe 108 to 120 US transactions in the 1985-1990 periods and provide consistent evidence that the acquirers suffer when there is competition in the bids.

Capron and Pistre (2002) provide a different view by showing that the value captured by the acquirer depends on which resources create synergies. Their survey combines with event study so as to enable them to conduct an empirical analysis on 101 horizontal acquisitions across a wide range of industries, countries, and firms. Their results support the idea that there is no abnormal return in acquisition with competition if acquirers only receive resources from the targets. However, if the acquirers control unique resources then they can still expect to earn abnormal returns. Their study offers a valuable direction for further research that might explain the positive effects of competition on acquiring performance.

\subsubsection{Industry Relatedness}

There remains some debate regarding the type of transactions. Some previous research accepts that related (non-conglomerate) mergers are more likely to create synergy through the transfer of core skills, economies of scale, and effects of market power (Lubatkin 1983, Porter 1987). Other research claims that unrelated (conglomerate) mergers can raise entry barriers, reduce systematic risk and default probability, improve income stability, and lower capital costs (Lewellen 1971, Scott 1989). Recent empirical studies compare the merging performance among these types of acquisitions. Lahey and Conn (1990) provide the first evidences of related mergers outperforming unrelated mergers in the long run. Datta and Pinches (1992) conduct a meta-analysis and similarly suggest that bidders should prefer related mergers rather than conglomerate acquisitions.

On the contrary, Limmack and McGregor (1995) explore the relationship between industry structure and acquiring performance by testing UK acquisitions during the period 1977 to 1986 . They report that bidders obtain insignificantly negative abnormal returns in unrelated acquisitions but receive statistically negative abnormal returns from related acquisitions. Their striking findings are further supported by André et al. (2004) who show that non-conglomerate mergers significantly underperform in the long run, but that there is 
no significant difference in the returns between conglomerate and non-conglomerate mergers.

Specifically, Gugler, Mueller, Yurtoglu and Zulehner (2003) carry out an international comparison for the effects of merger. They separate deals into three categories: horizontal, vertical and conglomerate. According to their definition, horizontal mergers are mergers between two companies with sales in the same primary four-digit SIC industry; vertical mergers are mergers where at least $10 \%$ of the sales or purchases of the primary four-digit industry to which one of the companies belongs must go to or come from the industry to which the other belongs; and conglomerate mergers consist of all mergers which are neither horizontal nor vertical. Gugler et al (2003) also divide the samples into the manufacturing or service sector. The interesting conclusion here is that mergers in the service sector show better performance than those in the manufacturing sector. Horizontal mergers are more successful in the service sector while vertical mergers generate larger profits in the manufacturing sector.

\subsubsection{Toehold Interests}

Toehold interests are target shares that are held by potential acquirers before the acquirers initiate the bid. Theoretically, when companies (potential acquirers) own enough shares in other companies (targets), they easily obtain special information about target resource allocation that will give the potential acquirers a stronger incentive to launch the bid. From this point of view, toehold interests solve the free-rider problems, increase the probability of successful bids, reduce the average bid premium, and then create more profitable deals for bidders (Grossman and Hart 1981). Unlike the model of Grossman and Hart (1981) under dispersed ownership, Shleifer and Vishny (1986) propose a model under the assumption that a firm is owned by large shareholders (the potential bidders) prior to the offer. Their model confirms that under the asymmetric information, toehold interests are a signal for the target's post-acquisition value. The more toehold interest held by the large shareholders indicates the lower the current target price. Consequently, the target's share price will increase and the actual bid premium paid to the target will be lower.

Both theoretical models support the positive relationship between toehold interest and acquiring firm performance. However, the results of empirical research are ambiguous. The empirical evidence shows that the majority of bidders do not hold the target's shares prior to the offer (Chowdhry and Jegadeesh 1994, Bris 2002). Franks and Harris (1989) set toeholds 
at a $30 \%$ threshold for over 1,800 UK takeovers in the period 1955-1985. They find no strong evidence to prove that pre-merger equity interests affect bidder gains around the merger date. Consistent with Franks and Harris (1989), Sudarsanam et al. (1996) examine 429 UK bids during the years 1980 to 1990 . They report that toehold interests do not help shareholders of acquiring firms to retain the benefits of acquisition.

\subsubsection{Bid Premium}

It is widely agreed that there is a negative effect of bid premiums on the subsequent rate of return among acquiring firms. However, setting too low a price runs the risk of losing a bargaining chance or resulting in a failed profitable offer. Walkling and Edmister (1985) analyze the determinants of bid premiums and set a model for estimating the optimal premium size. Most transaction characteristics are considered by their model such as inside ownership, target attitude, toehold interest, transaction type, payment method and so on. The target's market and financial performance are also included. By focusing on the bid characteristics, their estimations suggest that bid premiums are positively but insignificantly influenced by non-conglomerate and hostile attitudes; bids with multiple bidders have significantly higher premiums while toehold interests are statistically more negative.

After Walkling and Edmister (1985), empirical research has started to focus on an assessment of the relationship between bid premium and other deal characteristics rather than on a direct discussion concerning the impact of bid premium on acquisition. Goergen and Renneboog (2004) investigate 228 European deals in the period 1993-2000. They point out that the higher the target's market to book, the larger the bid premium that then triggers a negative acquiring performance. Healy, Palepu and Ruback (1997) adopt a cash flow measure for examining 382 US samples from 1979 to 1984. They show that strategic acquirers who run friendly transactions with stock payments in related industries pay a lower premium and that leads to a better acquiring performance.

\subsubsection{Relative Size}

Another large body of literature considers size effect to be an influential determinant of post-acquisition performance. Several hypotheses attempt to explain the size effect. First of all, the managers of large firms easily pay more money (hubris hypothesis, Roll 1986). Secondly, large firms are more likely to overestimate their market value and then to offer an equity transaction (over-extrapolation hypothesis by Rau and Vermaelen 1998, signaling 
hypothesis by Myers and Majluf 1984). Thirdly, top managers in large firms with excess free cash flow tend to initiate acquisition instead of increasing payouts to their shareholders (Free cash flow hypothesis by Jensen 1986).

Moeller, Schlingemann and Stulz (2004) conduct an empirical study to test size effect. They examine 12,023 acquisitions from 1980 to 2001 and provide evidence that the hubris hypothesis is related to large firms, while extrapolation, signaling, and cash flow hypotheses have comparatively weak associations. They also suggest that larger firms offer higher premiums that bring about negative returns. This size effect is similar to the conclusion that smaller firms outperform larger firms (Franks et al. 1991).

Another stream of empirical papers extends the discussion of the size of acquirers to the relative size between two parties. Arguments for the merging of two similar sized firms focuse on the economies of scale (Asquith, Bruner and Jr Mullins 1983, Becher and Campbell II 2003b). On the contrary, suggestions for the size deviation emphasize the difficulties of melding culture, bargaining profitable deal, or obtaining entry advantage (Pettway and Yamada 1986, Scanlon, Trifts and Pettway 1989). Loughran and Vijh (1997) use one year buy-and-hold returns as measures and find that merger of equals eventually leads to value destruction. Most other research may find size effect to be either positive or negative but may have difficulty proving any significant relationship between relative size and the acquirer's post performance (Franks and Harris 1989, Franks et al. 1991, Agrawal et al. 1992, Gugler et al. 2003).

\subsubsection{Acquirer's Leverage}

Following Jensen and Meckling (1976), a considerable debate about capital structure now centres on the benefit of debt rather the cost. Jensen (1986) argues that debt can act as a substitute for dividends and can force managers to pay out future cash flows. Companies with a higher leverage ratio will not have the extra cash flow to waste on sub-optimal investment; the threat of bankruptcy caused by large debts will motivate managers to run the corporation more efficiently. Maloney, McCormick and Mitchell (1993) also examine the debt monitoring hypothesis by investigating 428 US mergers from 1958 to 1982 . They empirically suggest a significant and positive relationship between the level of leverage and the abnormal return of acquiring firms. 
Stulz (1990) partially agrees with the debt mechanism but argues that issuing debt may require the management to pay out cash. This would reduce the overinvestment cost but might also prevent the management from undertaking value-enhancing projects. Such a case would exacerbate the underinvestment cost. Harris and Raviv (1991) further support the underinvestment hypothesis. In 1998, however, Zhang established several models to examine the investment decision under the concentration ownership with risk-averse controlling shareholders. These models suggest a view contrary to Stulz (1990). They state that issuing risky debt prior to taking an investment decision could create a risk-shifting effect that might compensate for the risk-averse incentives of large shareholders and mitigate the underinvestment problem.

Myers and Majluf (1984) provide another contradictory view regarding the benefit of debt monitoring. They argue that internal resources are vastly preferred over external financing. Under the asymmetric information assumption, managers learn more about the firm's values than outside investors. Since issuing equity is assumed to transmit bad signals, management may refuse to do so, even when they are forced to miss a positive NPV project. Therefore, Myers and Majluf (1984) suggest that holding a large amount of financial slack e.g. cash or marketable securities, actually benefits firms. Virtually, even under the debt monitoring hypothesis, the optimal debt-equity ratio remains controversial. Linn and Switzer (2001) examine operating cash flow for 413 US transactions. They conclude that the bidder's leverage is positive but not sensitive to the changes in operating performance. 


\subsection{Concentrated Ownership, Governance Mechanisms, Legal/ Extra-Legal Institutions and Acquisition Performance}

\subsubsection{Concentrated Ownership Structure}

\subsubsection{The Level of Ownership Concentration}

\section{- Evidence on Incentive Effects}

One stream of governance research studying the relationship between ownership concentration and acquiring firms performance has proven that increasing insider ownership has a positive impact on acquirers' returns (Lewellen, Loderer and Rosenfeld 1985, Carline et al. 2002). The core concern in this group is the incentive effect as discussed in chapter two, section 2.2. Lewellen et al. (1985) examined 266 US deals from 1963 to 1981. Their results support the idea that the abnormal stock returns of bidders firms are positive when related to the percentage of company shares held by the senior management. Carline et al. (2002) undertook an empirical analysis on the change in industry-adjusted operating performance around transactions for UK firms merging between 1985 and 1994. Their results suggest that the performance of combined firms significantly improves after acquisitions and the increase in operating performance is positively related to the acquirers' managerial ownership.

\section{- Evidence on Managerial Entrenchment}

The other stream of governance research that studies the impact of ownership concentration on acquiring firm performance argues that the ultimate majority shareholders, especially when they can separate their control rights from their cash flow rights, have a stronger ability to expropriate minority shareholders via M\&A events. One of the expropriation costs is caused by managerial entrenchment. A number of studies are devoted to how or why managers entrench themselves by making M\&A transactions. Their studies have already provided rather completed evidence for the impact of managerial entrenchment on acquisition performance (Firth 1980, Rhoades 1983, Jensen 1986, Roll 1986, Shleifer and Vishny 1989, Conyon and Murphy 2002). Most of these issues are covered in the earlier section 3.2.2.1 of this chapter on the subject of managerial benefits as major motivating factors for making transactions. Here, under the heading of ownership concentration, this thesis places some emphasis on the probability of a takeover in concentrated firms and on consequences for firm performance. 
Stulz (1988) argues that an increase in the proportion of voting rights controlled by management decreases the probability of a successful tender offer. Morck et al. (1988a) further prove that a firm controlled by the founder is less likely to be taken over than the average firm. When owner-managers entrench themselves by adopting various types of control devices so as to avoid the pressures from takeover threats, the firm value decrease. Cronqvist and Nilsson (2003) study the controlling minority shareholder (CMS) structure of 309 Swedish firms from 1991 to 1997. They find that the estimated takeover probability for family controlled firms to be taken over is only 4.8 percent -- significantly less than the $8.5 \%$ for other firms. And the estimated takeover probability of ending up in financial distress is as high as 4.1 percent for family controlled firms. This is significantly higher than the $1.6 \%$ for other firms. They conclude that firms with CMS structure will only relinquish control when the controlling shareholders get compensated for their private benefits, resulting in a lower takeover probability -- a lower takeover probability will materialize as a lower q. These arguments are further supported by Holmen and Nivorozhkin (2005).

\section{- Evidence on Tunneling}

The other expropriation cost is caused by tunneling (specifically, in the way of wealth transferring) among the controlling shareholders. Bae, Kang and Kim (2002) investigate 107 mergers by Korean business groups called chaebols. They argue that the owner-managers of chaebols have substantial discretionary powers and that legal protection against the expropriation of minority shareholders is quite weak in Korea. They believe that when chaebol affiliated firms make acquisitions their share price drops so that the minority shareholders of these firms lose out while controlling shareholders gain because of the increase in the value of other firms in the group. Furthermore, they argue that the implicit guarantee of a bailout for chaebols members still makes investments interesting for minority shareholders. This notion of negative tunneling or propping is also discussed in La Porta, Lopez-de-Silanes, Shleifer and Vishny (2000), Friedman, Johnson and Mitton (2003) and Shleifer and Wolfenzon (2002).

Bigelli and Mengoli (2004) examine 280 acquisition announcements made by companies in Italy where the ownership is highly concentrated and the separation of ownership and control is widespread. They find a non-monotonic relationship between the participation of the dominant shareholder and the abnormal returns for bidder shareholders. They also show that separation problems, especially within pyramidal groups, may lead the controlling shareholders to set the price so as to transfer corporate wealth to the ultimate 
level where the controlling shareholders own a greater proportion of the cash flow rights.

Holmen and Knopf (2004) examine Swedish firms which have tunneling problems through pyramid structures and dual-class shares. They show that the existence of shareholders with dual ownership decreases bidder returns, increases target returns, and turns out without any positive synergies. However, they do not find the direct transfer of wealth from minority shareholders to controlling shareholders through takeover.

Ben-Amar and André (2006) study 232 Canadian deals for the period from 1998 to 2002. They suggest a square relationship between ownership level and acquiring firm abnormal market returns, indicating that large shareholders may take less risky projects when their wealth is too much concentrated in the firm. Besides, they find that the separation of ownership and control does not lead to value destruction as expected. These findings confirm "the existence of entrenchment problems but resist the tunneling hypothesis through M\&A." This is attributed to the well investor protection environment in Canada making the expropriation costs too high to achieve private benefits via M\&A investments.

\section{- Evidence on Sub-Optimal Decisions}

However, the other concerns argue that controlling shareholders may not be in a position to do tunneling through acquisitions but may make sub-optimal M\&A decisions so as to reduce their own human capital risk. Amihud and Lev (1981) provide a landmark study for discussing this issue. They propose that managerial income is closely related to the survival and performance of their corporation and that it is less diversified than that of the shareholders. Therefore, risk-averse managers are expected to make sub-optimal decisions that might diversify their employment risks or minimize the company's earnings variance rather than benefiting the shareholders. They examine US deals during the period 1961 to 1970 and document that acquisition, specifically conglomerate mergers, may not be so obvious a profit investment but may generally be used to stabilize the firm income and to reduce managerial employment risks.

Wright, Kroll, Lado and Van Ness (2002) conduct an empirical study which basically confirms the diversification hypothesis of Amihud and Lev (1981). They examine the influence of CEO ownership incentives on the takeover valuation for 163 US firms from 1993 to 1997. They set their hypotheses by assuming that the CEO's personal wealth concentration will induce them to undertake risk-reducing strategies because of the 
preference for portfolio diversification; the value of the acquisition will therefore be decreased. Their results support their hypothesis by stating that the relationship between the value of ownership and abnormal returns is significantly positive at moderate values of CEO equity ownership but significantly negative at substantial values of equity. Consistently, Bigelli and Mengoli (2004), an Italian study, further provide a significant U-shaped relationship to confirm the presence of sub-optimal acquisition decisions under the controlling shareholding structure with separation problems.

Faccio and Masulis (2005) particularly connect corporate governance with the bidders' payment choice. They examine European deals for the period 1997-2000 and focus on the trade-off between bidder corporate control threats and financing constraints. They find that both corporate control concerns and debt conditions have a significant influence on bidder payment decisions. They also find that cash offers are relatively preferred for a bidder's large shareholder holding in the middle level of voting shares in the range of twenty to sixty percents. They define this range as the margin percentage of votes whereby the majority shareholders easily lose control under their equity acquisition. In their sub-sample, the consistent evidence further confirms the cube relationship between voting shares and payment decisions in countries with a common law system. Their implication is insufficient to prove the relationship among voting shares, payment decisions, and acquisition performance under the notion of legal origin, but it could prove an interesting area for further research.

\subsubsection{The Type of Ownership Concentration}

Under the assumption of the agency problem with concentrated ownership, family firms are generally viewed as making M\&A to benefit family interests at the expense of small shareholders. However, James (1999) suggests that family firms may have more incentive to initiate a beneficial M\&A transaction that improves viability of their companies over time and passes the interests to the next generations. In the Ben-Amar and André (2006) study, they provide evidence to support James's (1999) argument. They find that family ownership has a significantly positive relationship with M\&A value creation.

Faccio and Stolin (2006) perform a cross-countriy research through information taken from the dataset in Faccio and Lang (2002) (13 western European countries, from 1997 to 2000 , at 20 percent level of ownership) and obtain 184 family-controlled bidders where the bidder belongs to a specifically identified business group. Expropriation is here defined as 
the disproportional sharing of gains among different investors. They compare the announcement period change in the stock market wealth of the bidder's controlling shareholder with the wealth change implied by their holdings in the bidder. They find a non-proportional sharing of market value changes when they split the sample on the basis of group characteristics like separation or pyramid structures, but there is no significant result when these variables regressed on the measure of expropriation. They conclude, therefore, that the expropriation of minority shareholders does take place in Europe but that acquisitions are unlikely to be the preferred instrument for family acquirers to achieve expropriation purpose.

Institutional large shareholders are expected to have an influence on acquisition bids for enhancing shareholder interests or to force acquirer managers to be more objective in their acquisition strategies. Duggal and Millar (1999) investigate the impact of institutional ownership on corporate performance of 143 US acquiring firms in the 1985 to 1990 period. They do find the positive relationship between institutional ownership and bidder returns, but the ownership concentration is determined by firm-specific factors such as size, insider ownership and the presence in the S\&P 500 index. Moreover, although they identify the firms targeted for monitoring by some active institutions such as CALPERS, the results fail to expose any significant role played by active institutional large shareholders in M\&A market.

In Wright et al. (2002) study, active institutions are defined as institutions (mutual funds, public pension funds, endowment funds, and foundations) have more than one percent ownership in the company. They find a significant positive relationship between active institutional ownership and the value of acquiring firms.

\subsubsection{Governance Mechanisms}

Compared to the wider discussion about corporate governance mechanisms on general firm performance (discussed in 2.5.1), there is relatively scarce theoretical or empirical research to provide evidence concerning the relationship between governance mechanisms and specific acquisition performance. O'Sullivan and Wong (1999) provide an important standpoint for addressing the relationship between internal and external control mechanisms in the context of hostile takeover. However, their study is undertaken from the view of target firms. Here, this thesis summarizes some articles focusing on the mechanisms of corporate 
governance regarding to CEO type, board characteristics and other blockholders-specifically on the acquisition performance of acquiring firms.

\section{CEO positions}

Ben-Amar and André (2006) argue that the decisions made by different types of CEOs can have a varying impact on market expectations. Their results show that family controlled firms with a family member as CEO have a positive impact on abnormal market returns at the announcement date. Basically, their results suggest that family CEOs are more efficient in their investment decisions and that they are trying to maximize firm value in order to transfer this asset to future generations. With well-developed market and effective outside monitoring systems, a family CEO may provide essential firm-specific know-how and hence benefit the firm value.

\section{Board Characteristics}

Researching 225 US banking mergers, Subrahmanyam, Rangan and Rosenstein (1997) find that the effect of the proportion of independent outside directors on the board of acquiring firms is negative when related to the abnormal returns. Similar results are provided by Becher and Campbell II (2003a). Using a sample of US bank mergers from 1990 to 1999, they find that corporate governance mechanisms that are related to the acquirer board (including board size, the ratio of independent directors and the board ownership) have no impact on the target premium so as to the negotiation advantages. However, these studies focus on bank acquisitions; bank boards are, on average, larger than those of nonfinancial firms (Subrahmanyam et al. 1997). Ben-Amar and André (2006) show that the ratio of non-related directors is positive related to the abnormal returns of acquiring firms around the announcement date. This positive effect has been supported by Sudarsanam and Mahate's (2006) recent work which reports acquiring firm performance for more than three years after transactions.

Additionally, Ben-Amar and André (2006) document a negative relationship between board size and the announcement date returns of acquiring firms. However, similar to the study on the effect of the CEO position, it is essential to consider that the negative effect of board size may be endogenously affected by other variables such as company size, ownership structure, past performance or other intangible factors. 
For a sample of 386 UK domestic acquisitions of high-tech targets during the period 1990 to 1999, Sudarsanam and Gao (2003) document that there is no significant difference when it comes to the abnormal returns (three year BHARs) between acquiring firms with dominant, dual-role CEOs and acquiring firms with no duality. Nevertheless, in another study based on a sample of 519 UK acquisitions during the time 1983 to 1995, Sudarsanam and Mahate (2006) find that acquiring firms with $\boldsymbol{C O E - C O B}$ duality problems have weakly negative three-year post-acquisition value creation.

\section{Other Blockholders}

Sudarsanam and Gao's (2003) also examine the effect of the percentage of shares hold by institutional blockholders. They argue that institutional blockholders can provide quality suggestions those should efficiently monitor acquirer managers to avoid the overpayment problems. Their results, however, do not provide any significant evidence to support argument. The expected positive relationship between blockholder ownership and the announcement date abnormal returns of acquiring firms is further proved by Ben-Amar and André's (2006) study.

\subsubsection{Legal/ Extra-legal Institutions}

Even less attention has been paid to the effects of legal and extra-legal mechanisms on the acquisition performance. Some articles touch upon the function of legal origin and shareholder protection rights, but no research has yet been discovered that explain the impact of extra-legal institutions and DLLS's new index on M\&A value creations.

For a large sample of international M\&A across 49 countries between 1990 and 1999, Rossi and Volpin (2004) attempt to examine the determinants of M\&A by focusing on differences in legal institutions. They proxy legal institutions by legal origin, anti-director rights, rule of law and accounting standards. Their main findings are: first, the volume of M\&A activity is significantly larger in countries with stronger investor protection; second, acquirers from countries with better investor protections tend to adopt hostile takeovers; third, takeover premiums in countries with stronger investor protection are higher since the lower cost of capital in markets with better investor protection will increase potential competition and will result in higher premiums; fourth, acquirers in countries with better investor protection do not pay higher premiums than those from countries with weaker investor protection, providing evidence showing that the higher premium in countries with 
better protection is not a proxy of private benefits; and fifth, shareholder protection is negatively related to the all-cash bids which is possibly explained by the higher risk of expropriation to issuing stock mergers. Rossi and Volpin (2004) provide a valuable direction for M\&A activity when it converges with legal protection, but they offer no further direct evidence concerning the M\&A value creation.

Faccio and Masulis (2005) test the effects of legal origin on the choice of payment methods of acquirers. Based upon a large sample of European transactions over the period from 1997 to 2000, they find, in continental Europe (non-common law), that there is a linear relationship between the concentrated control and the likelihood of cash payments. In UK-Irish (common law), a cube relationship exists. That means bidders are reluctant to pay stock over intermediate levels of voting control. This evidence is still too weak, however, to explain the M\&A success. 


\subsection{Summary}

In conclusion, the major purpose of this chapter is to understand a broad scope of research on mergers and acquisitions and to know the impact of ownership structure and governance mechanisms on M\&A performance. In section 3.2, this thesis enhances current knowledge by summarizing the rationale of M\&A. M\&A can be driven by macroeconomic factors that result in merger wave, or by firm-specific rational choices. Focusing on the firm-specific factors, it seems clear that M\&A can be adopted for the private benefits of managers that mostly suffer acquisition value from agency problems like empire-building or hubris, or for acquirers' shareholders benefits. Assuming that managers will make decisions to maximize firm value, this thesis emphasizes how M\&A synergies are created for acquiring shareholders. The sources of M\&A success that may come form M\&A synergies include wealth transfer from bondholders, customers/suppliers, or the society. Certainly, it seems that M\&A might create real synergies from financial benefits, operational advantages, or managerial improvements. Since it is difficult to assess M\&A synergies because of so many different motives, there are many debates surrounding both the measurement and M\&A.

Section 3.3 introduces two primary methodologies for measuring M\&A success. One school of thought is the event study methodology for short and long-term market performance. Under the assumption of market efficiency, short-term event study has relatively few problems such as nontrading or nonsynchronous trading effect, cross sectional dependence or heteroskedasticity problem. However, short-term event study methodology is criticized because it only reflects shareholder expectations around the announcement date without capturing the long-term economic values. Long-term event study methodology is mainly questioned for its measurement bias such as new listing or delisting bias, rebalancing, skewness, and clustering problems, etc. So far this approach remains very controversial.

The other school of thought is accounting-based methodology. This approach is based on an influential seminar paper provided by HPR (1992). Before HPR, most projects used accrual measures such as ROA, ROE that are more direct and simple. These investigations suffer from the impact of financing choices, tax arbitrage, and accounting methods for M\&A. After HPR, most accounting-based studies follow the operating cash flow measures with a different benchmark adjusted. However, this method still has some limitations regarding the benchmark, performance measures, deflators, and estimates for improvement. In order to 
capture the real economic values of M\&A, this thesis adopts the operating cash flow return as one measure and uses size, industry, and pre performance benchmarks to estimate the long-term acquisition performance.

In section 3.4, this thesis reviews several transaction characteristics which have been identified as the possible determinants of M\&A success. These characteristics include cross-border/cross-origin, transaction attitude, payment method, competition, industry relatedness, toehold interest, bid premium, size relatedness and bidder's leverage. Even after summarizing this review, it remains clear that there is still great opportunity for clarifying the effects of these proxy measures. Therefore, these characteristics are considered as control valuables in the following empirical work.

In the final section 3.5 of this chapter, this thesis questions the impact of concentrated ownership structures and corporate governance mechanisms on M\&A performance. Do M\&As create firm value or provide a channel for controlling the shareholders to expropriate minority shareholders? The answers are still far from certain. So far, the most general apprehension is that majority shareholders may have different attitudes under the different circumstances of legal or extra-legal institutions. Considering that there is still an insufficient discussion on the issue of legal institutions, this thesis adds to the examination of the relationship between concentrated ownership and acquiring firm performance under the effects of investor protection. 


\section{Chapter Four \\ Research Framework and Hypotheses}

\subsection{Introduction}

The purpose of this chapter is to present the research framework and testable hypotheses. Beginning with a description of fundamental ideas and core issues, this thesis adopts a two-stage research framework. Within this structure, several testable hypotheses are developed and are divided into major and secondary hypotheses. The rest of this chapter comprises three parts. Section 4.2 describes the research framework; section 4.3 displays the research hypotheses. Section 4.4 summarizes this chapter and provides the table of research hypotheses.

\subsection{Research Framework}

\section{The First Stage}

This thesis develops a two-stage research structure to address two main issues. The first stage attempts to explain the impact of ownership concentration on acquisition operating performance. As discussed in chapter three, this thesis examines the long term acquisition performance using the Healy, Palepu and Ruback (HPR, 1992) model, defined as operating cash flow returns as performance measures and uses size, industry, and pre-performance benchmarks to capture the abnormal returns created by M\&A investments in the long run horizon. Further, following Ghosh's (2001) critic of HPR, two measures are used: the adjusted operating cash flow returns (ACFRpost, similar definition as IACR in HPR (1992) but adjusted by industry, size and pre performance) and the change in adjusted operating cash flow returns ( $\triangle A C F R$, same definition as $\triangle$ Cash Flow in Ghosh (2001)). Full definitions of these variables are presented in chapter five.

This thesis adopts various metrics to ownership. First, the percentage of voting shares held by the largest shareholders at 10 percent threshold is used in order to divide the sample companies into dispersed (voting shares $<10$ percent) and concentrated (voting shares $\geqq 10$ percent) firms. Second, as the 20 percent threshold is also widely used as breakpoint for defining large shareholders (La Porta, Lopez-de-Silanes, Shleifer and Vishny 1999, 
Claessens, Djankov and Lang 2000, Faccio and Lang 2002), it is introduced for comparison. Third, to look more in depth at the level of ownership concentration, this thesis designs three more detailed levels for the concentrated firms: low level controlled firms (10 percent $\leqq$ voting shares $<20$ percent), middle level controlled firms ( 20 percent $\leqq$ voting shares $<$ 50 percent), and high level controlled firms (voting shares $\geqq 50$ percent). Fourth, in reviewing the literature, a quadratic and cubic function relationship between ownership structure and general firm performance is suggested by Morck, Shleifer and Vishny (1988b), McConnell and Servaes (1990), and Anderson and Reeb (2003) to capture non-linearities in the relationship. This thesis also tests for a non-linear relationship between the voting shares of the largest shareholders and acquisition performance. Details on the measurement of these ownership metrics are presented in chapter five, section 5.4.1. Fifth, the type of concentrated ownership is another interesting issue (considered in more detail in chapter seven as an additional analysis). A threshold at 10 percent level is used to identify the ultimate owners of a sample company's largest shareholders. According to the type of ultimate owners, sample firms are classified into five types: (1) dispersed firms, (2) family controlled firms, (3) firms controlled by widely held financial institution, (4) firms controlled by widely held corporation and (5) state-controlled firms.

Moreover, as discussed in section 2.5 of chapter two, a variety of internal and external governance mechanisms are assessed; limited evidence exists relative to the impact of these governance mechanisms on the performance of significant corporate events such as M\&A. The separation of cash flow and control rights must be added in as an accentuating factor, along with several firm-specific mitigating factors including $\mathrm{CEO}$ as the member or representative of large shareholders; CEO and chairman duality; the efficiency of board size; the ratio of independent active directors on the board; and the existence of other blockholders. From this framework is revealed the degree to which concentrated ownership affects the M\&A values after controlling for these governance variables.

In order to clearly identify the effects of ownership structure and corporate governance on M\&A value creation, it is necessary to control the other factors which might be the determinants of the acquisitions performance. As discussed in section 3.4 of chapter three, several determinants of M\&A success are broadly identified in prior literatures. These deal-specific transaction characteristics are also carefully controlled in this thesis. These include cross origin, transaction attitude, payment method, competition, industry related, toehold, premium, size-related, and acquirers' leverage. 


\section{- The Second Stage}

Evidence regarding acquisition operating performance, ownership structure, governance mechanisms, and transaction characteristics is expected to generate a benchmark model. The first stage benchmark model will be used to explore the second main issue: the impact of legal and extra-legal institutions on M\&A value creation. Recent studies investigating the effects of legal system are carried out mostly with regard to legal origins after La Porta, Lopez-de-Silanes, Shleifer and Vishny (LLSV, 1998) and far too little attention is paid to differing levels of investor protection within the same legal origin. This is the other core concern in this thesis.

At the second stage, country-specific legal and extra-legal institutions are investigated by using indexes developed in LLSV (1998), Dyck and Zingales (2004) and Djankov, La Porta, Lopez-de-Silanes and Shleifer (DLLS, 2006). As discussed in section 2.5.2.3, the DLLS (2006) methodology that is used to develop their new indexes (anti-self dealing and public enforcement) is obviously different from the previous research that considered legal and extra-legal measures. The anti-self dealing index has been viewed as a private enforcement index with characteristics close to those in the legal and extra-legal system. Given the correlation between these various metrics, institutional variables are separated into two groups. The first group is comprised of three legal measures (anti-director right, enforcement, and accounting standards) in LLSV (1998) and one extra-legal proxy from Dyck and Zingales (2004). The second group includes all three new indexes in DLLS (2006), i.e. the two legal measures presented by revised anti-director right and public enforcement, and one private enforcement index proxied by anti-self dealing. The research framework is shown in figure 4.1. 


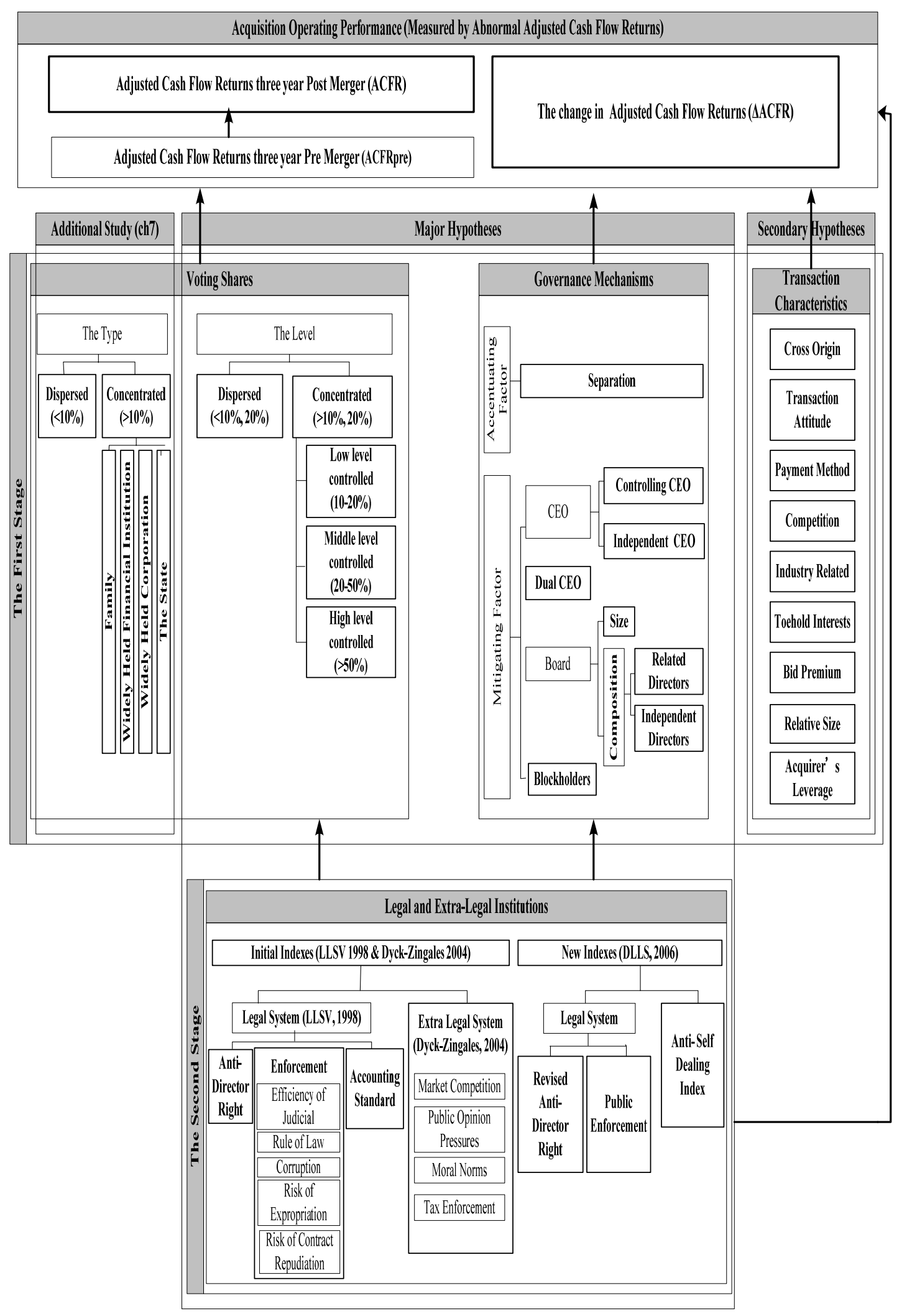

Figure 4.1 Research Framework 


\subsection{Research Hypotheses}

\subsubsection{Hypotheses regarding Acquisition Operating Performance}

According to the extant literature presented in chapter 3, the target company's shareholders seem to be the big winners with significant abnormal returns on share prices around the announcement. The acquiring company's shareholders have mostly negative or 'break even' abnormal returns around the announcement. However, if the acquiring firms will suffer from M\&A transactions in the end, why are M\&A deals still so? One stream of M\&A studies declares that acquisition deals are motivated by expected synergy but that short term stock price performance around the announcement is unable to identify whether takeovers create real economic gains in the long run (HPR 1992, Sharma and Ho 2002, Goergen and Renneboog 2004). This synergy hypothesis indicates that if a market is efficient and if the stock price reflects the anticipation of acquisitions synergy, merger events should lead to the improved financial and operating performance of combined firms. Therefore, the fundamental hypothesis of this thesis is constructed by testing whether the corporate acquisitions generate a significant positive improvement in operating performance (measured by abnormal adjusted cash flow returns and the change in adjusted cash flow returns $(\triangle A C F R)$ in the post-acquisition period). Accordingly, the thesis posits several null hypotheses:

$H$ 1.1: Ceteris paribus, the average abnormal adjusted cash flow returns $(\alpha)$ from cross-sectional regression on the average adjusted operating cash flow returns (ACFRpost) of three post acquisitions years is equal to zero.

H 1.2: Ceteris paribus, the average change in adjusted cash flow returns $(\triangle A C F R)$ is equal to zero.

\subsubsection{Hypotheses regarding Ownership Structure}

Assumptions concerning ownership structure, governance mechanism, and legal institutions are major hypotheses in this thesis. The structure of ownership has been extensively discussed ever since Berle and Means (1932) introduced the separation theory of ownership and control. Jensen and Meckling (1976) further propose the agency theory that defines the relationship between owners and top mangers as a contract; managers may not attempt to maximize firm value, especially in the absence of sufficient monitoring. In this 
context, they suggest a convergence-of-interest hypothesis that increasing managerial ownership will provide a higher incentive for top managers to mitigate the costs associated with the conflict.

While ownership concentration is proposed as a solution for the divergence-of-interest problems, it in turn induces expropriation problems between large and small shareholders as discussed in the literature review of chapter two. A curvilinear relationship between ownership structure and firm performance has been captured in some prior literature (Morck et al. 1988b, McConnell and Servaes 1990). They employ the turning points in order to explain that a convergence-of-interests exists in the whole range of ownership but that expropriation, including tunneling and sub-optima decisions, does dominate when ownership is concentrated over a certain level. This thesis extends the convergence-of-interests and expropriation hypothesis to acquisition performance.

In addition, legal origin is now a core concern in governance research after LLSV (1998). These articles document that agency problems between the controlling shareholders and minority shareholders can be effectively mitigated in English legal origin countries which are regarded as having better corporate governance systems (La Porta, Lopez-de-Silanes, Shleifer and Vishny 2002, Gugler 2003, Mueller and Yurtoglu 2000). They shed light on the importance of legal protection but attenuate the influence of ownership concentration in countries with a good corporate governance system. Does this mean, however, that the convergence-of-interests and the expropriation hypotheses become invalid in English origin countries? Anderson and Reeb (2003) first examine the relationship between the founding family holdings and performance in large US firms. They find that family ownership produces better firm performance than non-family firms. Ben-Amar and André (2006) measure the market reflection of Canadian acquisitions and suggest that the dominant shareholders may not attempt tunneling via acquisitions in countries with better legal systems, but that they might have a tendency to reduce risks by making sub-optimal investment decisions when they have more interest in the firms. Basically, this thesis follows the classification of LLSV (1998) and extends Ben-Amar and André's (2006) research to a cross-country analysis by sampling all countries other than the US in the English origin legal system. The thesis starts by testing the relationship between acquisition operating performance and the level of ownership concentration. 
H 2.1: Ceteris paribus, concentrated ownership has no impact on the average adjusted operating cash flow returns (ACFRpost) and the average change in adjusted cash flow returns $(\triangle A C F R)$.

H 2.2: Ceteris paribus, the level of ownership concentration has no impact on the average adjusted operating cash flow returns (ACFRpost) and the average change in adjusted cash flow returns $(\triangle A C F R)$.

\subsubsection{Hypotheses regarding Governance Mechanisms}

Upon examining the effects of ownership structure on M\&A performance, subsequent consideration is given to influential mitigating or accentuating factors. Firm-specific governance mechanisms are therefore among the first to be contemplated in this thesis. In the literature, the separation problem that exists between control and cash flow rights (called type I agency problem in this thesis) is regarded as the very essence of agency problem and is linked to concentrated ownership structures (Shleifer and Vishny 1997, La Porta et al. 1999). On the one hand, separation may increase the incentive to expropriate small shareholders since the large shareholder does not bear the full costs of his decisions. On the other hand, separating mechanisms like dual class voting shares can ensure control by the dominant shareholder in making good corporate decisions while opening up the capital of the firm to investors.

H 3.1: Ceteris paribus, separation of voting rights and cash flow rights has no impact on the average adjusted operating cash flow returns (ACFRpost) and the average change in adjusted cash flow returns $(\triangle A C F R)$.

Furthermore, this thesis extends the central agency problem between owners and managers in dispersed ownership (here called type II agency problem) to that in concentrated ownership. On the one hand, it is possible that companies with a CEO who is the member or representative of the large shareholders make M\&A decisions in best interest of the large shareholder also benefiting small shareholders. On the other hand, dominant shareholders that also control the CEO position may have even greater power to expropriate small shareholders. 
H 3.2: Ceteris paribus, dominant shareholder involvement in the CEO position has no impact on the average adjusted operating cash flow returns (ACFRpost) and the average change in adjusted cash flow returns $(\triangle A C F R)$.

Some literature provides a monitoring hypothesis as reviewed in chapter two. This thesis basically contends that a separation of the CEO and chairman position leads to better governance; that smaller board size will permit directors to function more effectively; that outside directors should enhance firm value through effective monitoring; and that other blockholders who hold a sizable fraction of voting shares might reduce the cost of obtaining information and solve the free-rider problem for minority shareholders (Rosenstein and Wyatt 1990, Weisbach 1988, Lipton and Lorsch 1992, Conyon and Peck 1998, Demsetz and Lehn 1985, McConnell and Servaes 1990, Agrawal and Knoeber 1996).

While the effects of corporate governance provision on corporate performance are now relatively well documented, the extent to which they impact M\&A decisions under the notion of ownership concentration remains unclear. This thesis intends to contribute to the literature by testing the following hypotheses (in null form):

H 3.3: Ceteris paribus, CEO-Chairman duality has no impact on the average adjusted operating cash flow returns (ACFRpost) and the average change in adjusted cash flow returns $(\triangle A C F R)$

H3.4: Ceteris paribus, the number of board members has no impact on the average adjusted operating cash flow returns (ACFRpost) and the average change in adjusted cash flow returns $(\triangle A C F R)$.

H 3.5: Ceteris paribus, the ratio of independent directors has no impact on the average adjusted operating cash flow returns (ACFRpost) and the average change in adjusted cash flow returns $(\triangle A C F R)$.

H 3.6: Ceteris paribus, the existence of other blockholders has no impact on the average adjusted operating cash flow returns (ACFRpost) and the average change in adjusted cash flow returns $(\triangle A C F R)$. 


\subsubsection{Hypotheses regarding Legal and Extra-legal Institutions}

Following the investor protection classification scheme of LLSV (1998), cross -country research has focused on comparing corporate performance in countries with different legal origins (Fauver, Houston and Naranjo 2003, Friedman, Johnson and Mitton 2003, Gugler, Mueller and Yurtoglu 2004). While English origin countries are often lumped together and viewed as examples of more dispersed ownership and greater investor protection, concentrated ownership is quite prevalent in many of these countries and the level of investor protection does vary from group to group.

This thesis intends to examine the discrepancy in acquisition operating performance among countries with the same legal origin but with different levels of legal and extra-legal systems. Do higher levels of investor protection lead to the better acquisition performance? Seven proxies of legal and extra-legal institutions are employed to test hypothesis: the initial anti-director right; the enforcement index and accounting standard in LLSV (1998); the integrated extra-legal index in Dyck and Zingales (2004); the anti-self dealing indexes; the public enforcement measure; and the revised anti-director right in DLLS (2006). The hypotheses in null form are displayed in the following.

H 4.1: Ceteris paribus, a higher 'original' anti-director rights index has no impact on the average adjusted operating cash flow returns (ACFRpost) and the average change in adjusted cash flow returns $(\triangle A C F R)$.

H 4.2: Ceteris paribus, the degree of enforcement has no impact on the average adjusted operating cash flow returns (ACFRpost) and the average change in adjusted cash flow returns $(\triangle A C F R)$.

H 4.3: Ceteris paribus, the rating of accounting standards has no impact on the average adjusted operating cash flow returns (ACFRpost) and the average change in adjusted cash flow returns $(\triangle A C F R)$.

H 4.4: Ceteris paribus, a higher integrated extra-legal index has no impact on the average adjusted operating cash flow returns (ACFRpost) and the average change in adjusted cash flow returns $(\triangle A C F R)$. 
H 4.5: Ceteris paribus, the degree of anti-self dealing has no impact on the average adjusted operating cash flow returns (ACFRpost) and the average change in adjusted cash flow returns $(\triangle A C F R)$.

H 4.6: Ceteris paribus, a higher public enforcement index has no impact on the average adjusted operating cash flow returns (ACFRpost) and the average change in adjusted cash flow returns $(\triangle A C F R)$.

H 4.7: Ceteris paribus, a higher 'revised' anti-director right index has no impact on the average adjusted operating cash flow returns (ACFRpost) and the average change in adjusted cash flow returns $(\triangle A C F R)$.

\subsubsection{Hypotheses regarding Transaction Characteristics}

This thesis considers transaction characteristic hypotheses as secondary. Several deal features, as reviewed in chapter three, have been well studied in the prior literature; however, there are still open issues. By referring to previous research, this thesis develops the following null hypotheses for the transaction characteristics:

H 5.1: Ceteris paribus, cross origin in takeovers has no impact on the average adjusted operating cash flow returns (ACFRpost) and the average change in adjusted cash flow returns $(\triangle A C F R)$.

H 5.2: Ceteris paribus, hostility in takeovers has no impact on the average adjusted operating cash flow returns (ACFRpost) and the average change in adjusted cash flow returns $(\triangle A C F R)$.

H 5.3: Ceteris paribus, payment method has no impact on the average adjusted operating cash flow returns (ACFRpost) and the average change in adjusted cash flow returns $(\triangle A C F R)$.

H 5.4: Ceteris paribus, the existence of other bidders (competition) has no impact on the average adjusted operating cash flow returns (ACFRpost) and the average change in adjusted cash flow returns $(\triangle A C F R)$. 
H 5.5: Ceteris paribus, industry relatedness in takeovers has no impact on the average adjusted operating cash flow returns (ACFRpost) and the average change in adjusted cash flow returns $(\triangle A C F R)$.

H 5.6: Ceteris paribus, toehold interests has no impact on the average adjusted operating cash flow returns (ACFRpost) and the average change in adjusted cash flow returns $(\triangle A C F R)$.

H 5.7: Ceteris paribus, the level of premium paid has no impact on the average adjusted operating cash flow returns (ACFRpost) and the average change in adjusted cash flow returns $(\triangle A C F R)$.

H 5.8: Ceteris paribus, size differences between the bidders and targets have no impact on the average adjusted operating cash flow returns (ACFRpost) and the average change in adjusted cash flow returns $(\triangle A C F R)$.

H 5.9: Ceteris paribus, the level of acquirer's leverage has no impact on the average adjusted operating cash flow returns (ACFRpost) and the average change in adjusted cash flow returns $(\triangle A C F R)$.

\subsection{Summary}

The core issue of this thesis is how concentrated ownership structures impact the long-term acquisition operating performance of English origin countries, after controlling for internal and external corporate governance mechanisms (first stage) and legal and extra-legal institutions (second stage). All research hypotheses are summarized and shown in table 4.1. 
Table 4.1 Research Hypotheses

Panel A Major Hypotheses at the first stage

\section{H1: Hvpotheses for testing Acquisition Operating Performance}

H 1.1 Ceteris paribus, the average abnormal adjusted cash flow returns $(\alpha)$ from cross-sectional regression on the average adjusted operating cash flow returns (ACFRpost) of three post acquisitions years is equal to zero.

H 1.2 Ceteris paribus, the average change in adjusted cash flow returns ( $\triangle \mathrm{ACFR})$ is equal to zero.

\section{H2: Hypotheses for testing the effects of Ownership Structures}

H 2.1 Ceteris paribus, concentrated ownership has no impact on ACFRpost and $\triangle$ ACFR.

H 2.2 Ceteris paribus, the level of ownership concentration has no impact on ACFRpost and $\triangle$ ACFR.

\section{H3: Hypotheses for testing the effects of Governance Mechanisms}

H 3.1 Ceteris paribus, separation of voting rights and cash flow rights has no impact on ACFRpost and $\triangle \mathrm{ACFR}$.

H 3.2 Ceteris paribus, Ceteris paribus, dominant shareholder involvement in the CEO position has no impact on ACFRpost and $\triangle \mathrm{ACFR}$.

H 3.3 Ceteris paribus, CEO-Chairman duality has no impact on ACFRpost and $\triangle \mathrm{ACFR}$

H 3.4 Ceteris paribus, the number of board member has no impact on ACFRpost and $\triangle \mathrm{ACFR}$.

H 3.5 Ceteris paribus, the ratio of independent directors has no impact on ACFRpost and $\triangle$ ACFR.

H 3.6 Ceteris paribus, the existence of other blockholders has no impact on ACFRpost and $\triangle \mathrm{ACFR}$.

Panel B Major Hypotheses at the second stage

\section{H4: Hypotheses for testing the effects of Legal and Extra-Legal Systems}

H 4.1 Ceteris paribus, a higher 'original' anti-director rights index has no impact on ACFRpost and $\triangle \mathrm{ACFR}$.

H 4.2 Ceteris paribus, the degree of enforcement has no impact on ACFRpost and $\triangle A C F R$.

H 4.3 Ceteris paribus, the rating of accounting standard has no impact on ACFRpost and $\triangle \mathrm{ACFR}$.

H 4.4 Ceteris paribus, a higher integrated extra-legal index has no impact on ACFRpost and $\triangle \mathrm{ACFR}$.

H 4.5 Ceteris paribus, the degree of anti-self dealing has no impact on ACFRpost and $\triangle A C F R$.

H 4.6 Ceteris paribus, a higher public enforcement index has no impact on ACFRpost and $\triangle \mathrm{ACFR}$.

H 4.7 Ceteris paribus, a higher 'revised' anti-director right index has no impact on ACFRpost and $\triangle \mathrm{ACFR}$.

\section{Panel C Secondary Hypotheses}

\section{H5: Hypotheses for testing the effects of Transaction Characteristics}

H 5.1 Ceteris paribus, cross origin in takeovers has no impact on ACFRpost and $\triangle \mathrm{ACFR}$.

H 5.2 Ceteris paribus, hostility in takeovers has no impact on ACFRpost and $\triangle \mathrm{ACFR}$.

H 5.3 Ceteris paribus, payment method has no impact on ACFRpost and $\triangle \mathrm{ACFR}$.

H 5.4 Ceteris paribus, the existence of other bidders (competition) has no impact on ACFRpost and $\triangle \mathrm{ACFR}$.

H 5.5 Ceteris paribus, industry relatedness in takeovers has no impact on ACFRpost and $\triangle$ ACFR.

H 5.6 Ceteris paribus, toehold interests has no impact on ACFRpost and $\triangle \mathrm{ACFR}$.

H 5.7 Ceteris paribus, the level of premium paid has no impact on ACFRpost and $\triangle \mathrm{ACFR}$.

H 5.8 Ceteris paribus, size differences between the bidders and targets have no impact on ACFRpost and $\triangle \mathrm{ACFR}$.

H 5.9 Ceteris paribus, the level of acquirer's leverage has no impact on ACFRpost and $\triangle \mathrm{ACFR}$. 


\section{Chapter Five \\ Methodology and Empirical Models}

\subsection{Introduction}

The objective of this chapter is to provide a detailed description of data and the methodology that is used to test the hypotheses developed in chapter four. The rest of the chapter is organized as follows. Section 5.2 presents the process of sample selection and sample characteristics. Section 5.3 illustrates the measure of operating performance and the criteria of benchmark construction. Section 5.4 defines the independent variables. Section 5.5 displays the empirical models upon which that testing is based. The main empirical results will be reported in chapter six.

\subsection{Sample Selection and Data Characteristics}

\subsubsection{Sample Selection}

In order to cover the recent mergers boom at its peak around 2000 and to have access to necessary information ${ }^{12}$, this thesis selects completed deals from the beginning of 1997 until the end of 2001. To observe firm performance three years before and after acquisition, the accounting data can start as early as 1994 and as late as 2004. To investigate the more influential M\&A transactions, the deal value is set to at least USD10million. To ensure accounting and financial data is available, this thesis, like most of the operational performance literature, focuses on deals between publicly listed firms. Adopting the classification of legal families by La Porta, Lopez-de-Silanes, Shleifer and Vishny (LLSV, 1998), all English origin countries ${ }^{13}$ are set as the sample nations of acquiring firms. Since the United States market has already been extensively studied and since most American

2 Information for earlier periods is often difficult to find.

13 LLSV (1998) include the following countries in the English-origin category: Australia, Canada, Hong Kong, India, Ireland, Israel, Kenya, Malaysia, New Zealand, Nigeria, Pakistan, Singapore, South Africa, Sri Lanka, Thailand, United Kingdom, United States and Zimbabwe. 
firms are widely held, American deals are excluded from this study ${ }^{14}$. Moreover, the acquiring firms must have less than 50 percent of the target's ownership before and more than 50 percent after, i.e. a takeover. Government, financial, and investment companies are excluded because of their specific accounting and regulatory requirements.

In sum, the sample in this thesis meets the following criteria: 1) Observations are for 1997-2001; 2) Only transactions greater than US\$10 million are included; 3) Acquiring and targets firms are listed companies; 4) Adopting the LLSV (1998) classification, acquiring nation is an English origin country except for the US; 5) Deals are completed as mergers, exchange offers, or acquisitions of majority interest; 6) Government, financial, and investment companies are excluded; 7) Companies with several M\&A during the period are included. According to the above restrictions, 715 initial deals in 11 countries were obtained from the Thomson Financial Securities Data's SDC Platinum ${ }^{\mathrm{TM}}$ Worldwide Mergers \& Acquisitions Database. From this initial sample, 52 deals were deleted because no record existed to identify the target firms and 197 deals were dropped because acquirers have either been acquired themselves or gone under and, hence, have no data available whatsoever. At this stage, 466 deals in 11 countries were identified to collect financial and accounting data.

The financial and accounting data for the seven-year window are obtained from the Thomson Financial or DataStream database. In this step, 77 deals were dropped because their financial data is no longer available. Data is needed at least one year before and one year after transactions, therefore another 56 deals were consequently dropped because their missing data is spread over all seven years of observation window (transaction year plus three years before and after transactions) for either acquiring or target firms. At this stage, 333 deals were left to collect ownership data. Ownership data is collected by recording information from the proxies or annual reports of each company, from the Mergent database, from the SEDAR filing system, from SEC fillings, or from the company website. Finally, 43 deals were excluded because profiles are unavailable. After these adjustments, the final

\footnotetext{
${ }^{14}$ Anderson and Reeb (2004) argue that around 35\% of their sample firms are classified as family firms with the average holding 17.9 percent of the firm's equity. Anderson, Durub and Reeb (2006) further report that family ownership in 48 percent of the 2,000 largest industrial firms with the average family holding about 20 percent of the companies' shares. However, According to their classification and following by the criteria used here, this thesis got roughly $3 \%(273 / 7154$, i.e. 273 deals within 7154 US deals are made by the US family firms) of US deals classified as family deals and most of those family deals are made by multiple family acquirers $(81 / 273$, i.e. 81 US family firms launched these 273 US family deals). This thesis understands that the percentage of US concentrated firms (not only US family firms) may be higher, but the costs and benefits are definitely not proportionate.
} 
sample includes 282 deals (222 acquiring firms ${ }^{15}$ and 282 target firms) in 11 countries. The process of sample selection and number of firms is shown in Table 5.1. A complete list of sample firms is supplied in appendix A.

Brown and da Silva Rosa (1998) point out that selecting a sample from a set of criteria may overestimate abnormal performance. They take newly listed firms as an example and explain that newly listed firms generally report systematically negative abnormal returns. If newly listed firms are systematically excluded from any selection, then the abnormal performance will be positively biased. While this sample does suffer from survivorship bias, like most of the finance literature, the matching of acquiring firms with non-acquiring firms also required to have data over the $(-3,+3)$ year-period actually limits the survivorship bias. Using a Heckman (1979) requires a selection equation with available explanatory variables for all selected and non selected firms; these are not available since excluded firms have either been acquired themselves or have gone under (not highly probable in the case of acquiring firms) and have no data available. So far, there are no papers on long-term operational performance that provide a solution to this issue.

Table 5.1 Sample Selection Criteria and Number of Deals

\begin{tabular}{|c|c|c|c|}
\hline Criteria & & Description & No. of deals \\
\hline 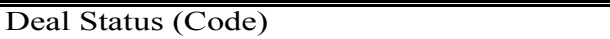 & Include & "01/01/1997 to $12 / 31 / 2001$ & $3 \overline{358,154}$ \\
\hline Date Effective/Unconditional & Between & Completed & 129,194 \\
\hline Acquirer Nation (Code) & Include & English Origin countries & 33,658 \\
\hline Acquirer Public Status (Code) & Include & Public & 16,976 \\
\hline Target Public Status (Code) & Include & Public & 2,678 \\
\hline Percent of Shares Owned after Transaction & Between & 50 to 100 & 1,458 \\
\hline $\begin{array}{l}\text { Percent of Shares Held by Acquirer at } \\
\text { Announcement }\end{array}$ & Between & 0 to 50 & 1,286 \\
\hline Target Macro Industry (Code) & Exclude & $\begin{array}{l}\text { Real Estate, Government and } \\
\text { Agencies Financials }\end{array}$ & 1,043 \\
\hline Acquirer Macro Industry (Code) & Exclude & $\begin{array}{l}\text { Real Estate, Government and } \\
\text { Agencies Financials }\end{array}$ & 962 \\
\hline Deal Value (\$ Mil) & Between & 10 to $\mathrm{HI}$ & 715 \\
\hline Initial Deals & & & 715 \\
\hline No identification number available (e.g. & Exclude & Acquirers: 197 & 518 \\
\hline SEDOL/CUSIP etc.) & Exclude & Targets: 52 & 466 \\
\hline Preliminary Deals & & & 466 \\
\hline $\begin{array}{l}\text { With identification number but no financial } \\
\text { data provided } \\
\text { With financial data but incomplete in all }\end{array}$ & Exclude & 77 & 389 \\
\hline seven years (year $-3,-2,-1,0,1,2,3)$ & Exclude & 56 & 333 \\
\hline Acquirers without Profiles for ownership & Exclude & 51 & 282 \\
\hline
\end{tabular}

${ }^{15}$ Acknowledging that multiple acquirers may cause clustering problem, to control for this, this thesis has rerun regression while estimating the cluster robust (Wooldridge 2003) and the bootstrap (Efron and Tibshirani 1986) standard errors. Regression results are qualitatively similar. A more detailed discussion is added as sensitivity analysis in chapter eight. 


\subsubsection{Data Characteristics}

In panel A of table 5.2, a complete report of the annual numbers, aggregate values, and mean values of acquisitions is presented. The sample comprises 282 acquisitions with a total market value of over US\$553 billion. Consistent with the trend of the fifth merger wave, the transaction amount increased yearly and reached the top in year 2000. In this sample, the deal value of year 2000 occupied 61.2 percent of the total value of the observation years. Acquiring firms paid, on average (median), US\$1,964.5 (238.1) million for the targets. The breakdown of the sample by one digit primary SIC code is presented in panel B of table 5.2. A large percentage $(46.8 \%)$ of deals occurs in the manufacturing sector. The smallest proportion $(8.9 \%)$ of deals is in the consumer and wholesale industry. The rest of the deals are distributed equally among the agriculture $(15.2 \%)$, the transportation (14.5\%) and the services $(14.5 \%)$ industry.

Panel C lists firms and deal values by the acquirer's country. Most deals are initiated in the UK ( 141 deals out of the 282 or 50 percent) followed by Canada (75 deals or $26.6 \%$ ), and Australia (24 deals or $8.5 \%$ ). The other 42 deals (14.9\%) are spread across the following countries: South Africa (14), Ireland (11), India (6), Singapore (5), New Zealand (3), Israel (1), Malaysia (1), and Thailand (1). There are 55 percent (155 out of 282) of deals classified as domestic transactions, that is, 45 percent cross border deals. If this thesis set the breakdown of sample by targets' origin instead of by targets' country, the proportion of target firms coming from the English origin countries dramatically increases to 92.2 percent (260 deals); only 7.8 percent ( 22 deals) belongs to cross origin transactions. 
Table 5.2 Description of Sample Characteristics

Sample of 282 mergers and acquisitions by 222 acquiring firms in 11 English Origin countries (Australia, Canada, India, Ireland, Israel, Malaysia, New Zealand, Singapore, South Africa, Thailand and United Kingdom) between 1997 and 2001 for completed takeovers over US\$ 10 million are obtained from the Thomson Financial Securities Data's SDC PlatinumTM Worldwide

Mergers \& Acquisitions Database.

Panel A Number and Value of Transactions

\begin{tabular}{rcrrrr}
\hline Year & $\begin{array}{c}\text { Number of } \\
\text { Transactions }\end{array}$ & $\begin{array}{r}\text { Average Value } \\
\text { (\$US million) }\end{array}$ & $\begin{array}{r}\text { Median Value } \\
\text { (\$US million) }\end{array}$ & $\begin{array}{c}\text { Total Value } \\
\text { (\$US million) }\end{array}$ & $\begin{array}{c}\text { Total Value } \\
(\%)\end{array}$ \\
\hline 1997 & 10 & 276.1 & 132.1 & $2,761.1$ & $0.50 \%$ \\
1998 & 43 & 703.9 & 173.5 & $30,266.5$ & $5.46 \%$ \\
1999 & 74 & $1,909.2$ & 211.4 & $141,283.1$ & $25.50 \%$ \\
2000 & 88 & $3,852.7$ & 297.5 & $339,039.5$ & $61.20 \%$ \\
2001 & 67 & 606.6 & 205.5 & $40,643.8$ & $7.34 \%$ \\
\hline Total & 282 & $1,964.5$ & 238.1 & $553,994.0$ & $100.00 \%$
\end{tabular}

Panel B Sample by Industry

\begin{tabular}{|c|c|c|c|c|c|c|c|}
\hline By SIC code & 1997 & 1998 & 1999 & 2000 & 2001 & $1997-2001$ & $\%$ \\
\hline $\begin{array}{l}\text { Agriculture and } \\
\text { Natural Resource }\end{array}$ & & & & & & & \\
\hline $\begin{array}{l}\text { 0000-1999 } \\
\text { Manufacturing: }\end{array}$ & 3 & 6 & 8 & 14 & 12 & 43 & $15.2 \%$ \\
\hline $\begin{array}{l}2000-3999 \\
\text { Transportation: }\end{array}$ & 1 & 23 & 35 & 45 & 28 & 132 & $46.8 \%$ \\
\hline $\begin{array}{l}\text { 4000-4999 } \\
\text { Consumer and } \\
\text { Wholesale: }\end{array}$ & 3 & 5 & 10 & 12 & 11 & 41 & $14.5 \%$ \\
\hline $\begin{array}{l}\text { 5000-5999 } \\
\text { Services: }\end{array}$ & 1 & 6 & 7 & 6 & 5 & 25 & $8.9 \%$ \\
\hline 7000-8999 & 2 & 3 & 14 & 11 & 11 & 41 & $14.5 \%$ \\
\hline Total & 10 & 43 & 74 & 88 & 67 & 282 & $100 \%$ \\
\hline
\end{tabular}

\begin{tabular}{lccrrrrc}
\hline \multicolumn{1}{c}{ Country } & $\begin{array}{c}\text { Number of } \\
\text { Transactions }\end{array}$ & $\begin{array}{c}\text { Number of } \\
\text { Firms }\end{array}$ & $\begin{array}{r}\text { Average Value Median Value } \\
\text { (\$US million) }\end{array}$ & $\begin{array}{c}\text { Total Value } \\
\text { (\$U million) }\end{array}$ & $\begin{array}{c}\text { Same Target million) } \\
\text { (\$) }\end{array}$ & $\begin{array}{c}\text { Target Origin: } \\
\text { Counglish }\end{array}$ \\
\hline Australia & 24 & 19 & 899.4 & 160.1 & $21,585.4$ & 17 & 24 \\
Canada & 75 & 55 & 912.7 & 300.1 & $68,449.0$ & 39 & 69 \\
India & 6 & 6 & 155.1 & 155.1 & 930.6 & 5 & 6 \\
Ireland-Rep & 11 & 8 & 420.9 & 207.8 & $4,629.7$ & 1 & 10 \\
Israel & 1 & 1 & 53.4 & 53.4 & 53.4 & 0 & 1 \\
Malaysia & 1 & 1 & 49.5 & 49.5 & 49.5 & 1 & 1 \\
New Zealand & 3 & 3 & 295.4 & 64.0 & 886.2 & 0 & 2 \\
Singapore & 5 & 5 & 223.9 & 193.9 & $1,119.4$ & 5 & 5 \\
South Africa & 14 & 11 & 210.5 & 164.5 & $2,947.4$ & 11 & 14 \\
Thailand & 1 & 1 & 124.1 & 124.1 & 124.1 & 1 & 1 \\
United Kingdom & 141 & 112 & $3,214.3$ & 250.1 & $453,219.1$ & 75 & 127 \\
\hline Total & 282 & 222 & $1,964.5$ & 239.3 & $553,994.0$ & 155 & 260
\end{tabular}




\subsection{Operating Performance Measures}

\subsubsection{Operating Cash Flow Returns}

Based on Healy, Palepu and Ruback (HPR, 1992), this thesis uses pre-tax operating cash flow $(O C F)$ to measure acquisition performance. Operating cash flow is defined as operating income after depreciation plus depreciation and goodwill amortization (in other words, EBITDA). This definition ensures that the performance measure is unaffected by different merger accounting methods, by tax policy, or by the type of financing used to fund the acquisition. Operating cash flow return $(O C F R)^{16}$ is calculated as operating cash flow divided by market value of assets ${ }^{17}$. The market value of assets is computed at the beginning of each year to control for changes in the size of the firm over time (HPR, 1992: 142). Formally,

Operating Cash Flow $(O C F)=$ Operating income after depreciation + Depreciation, Depletion and Amortization Expense

Market Value of Asset $=$ Market Value of Equity at the beginning of each year +Book Value of Net Debt

Book Value of Net Debt $=$ Total Debt - Cash, Marketable securities, and cash equivalents + Preferred Stock

Operating Cash Flow Return $(O C F R)=$ Operating Cash Flow / Market Value of Asset.

Operating cash flow returns $\left(O C F R_{B}, O C F R_{T}\right)$ are computed for each company up to three years before and after the acquisition event. Post acquisition performance is measured by the operating cash flow return of the merging firms after transaction (MEGi, post). Pre acquisition performance is calculated as a weighted-average of the operating cash flow return for the bidder and the target (MEGi, pre). The weights are based on the market values of assets of both companies at the year before acquisition. This measurement is consistent with that of HPR (1992) and Ghosh (2001).

16 To identify the source of the improvement in operating cash flow return, this thesis also decomposed $O C F R$ into operating cash flow margin $(C F M)$ and asset turnover (AT). The operating cash flow margin is measured by EBITDA per dollar of sales. The sales margin ratio is measured by the dollar sales generated for each dollar invested in market value of assets (Ghosh 2001, Rahman and Limmack 2004). Tests and results are reported in chapter seven as further analysis.

17 The limitations of EBITDA performance and the market value of assets deflator have been noted and discussed in chapter three, section 3.3.2. 
The data on the year of the acquisition $(\mathrm{t}=0)$ is excluded from this analysis. One major concern is that the accounting method for acquisition and the transaction costs will be reflected on the operating results of the transaction year. This makes any comparison with other years inappropriate. The other concern is about the potential partial results of mid-year acquisitions for target firms at the year of transaction. For example, if the completion date is in December, one-month partial data will be included to account for the financial performance of acquiring firms at the year of the acquisitions; results may then be misrepresented. This approach that excludes the data on the year of the acquisition is parallel to the method in the other operating performance research such as HPR (1992) and Linn and Swizer (2001).

Following Ghosh's (2001) critique of the industry-median benchmark in HPR (1992), a list of matched firms ${ }^{18}$ is selected based on size, industry and pre-performance. After the list of matched firms is set, the steps for calculating operating cash flows are repeated and then operating cash flow returns $\left(O C F R_{M B} ; O C F R_{M T}\right)$ for the pair of matched firms are determined. Since the pair of matched firms forms the benchmark, both post and pre-acquisition performances are also measured as the weighted-average of the operating cash flow returns (MATi, pre and MATi, post).

The industry, size, and pre-performance adjusted operating cash flow return $(A C F R)$ is the operating cash flow return of the merging firm minus that of the matched firm. After this, a decision is made concerning how best to measure the post operating performance. Similar to HPR (1992) and Linn and Switzer (2001), the median of $A C F R$ three years ${ }^{19}$ before and after acquisition is used as a measure of pre (ACFRpre) and post (ACFRpost) operating performance. The median performance measures are employed in order to avoid the influence of extreme values (HPR 1992, Linn and Switzer 2001, Loughran and Ritter 1997) while Linn and Switzer (2001) execute a sensitivity check and report that the results are robust to the use of mean versus median measures.

18 The list of matched firms is shown in appendix A.

19 This thesis noticed that HPR (1992/1997), Linn and Switzer (2001) and Rahman and Limmack (2004) look at median measures over 5 years pre and post. Ghosh (2001) and Powell and Stark (2005) examine the change between year $\mathrm{t}-1$ and the median post performance over $\mathrm{t}+1$ to $\mathrm{t}+3$. Denis and Denis (1995) examine changes in performance based on the last year (t-1) prior to the event to each of the three years following the event. Therefore, this thesis further carried out the robustness test based on Denis and Denis (1995) approach to examine whether the results are still hold. The robustness results are reported in chapter eight: sensitivity analysis. 
Furthermore, as discussed regarding the estimates for improvements in section 3.3.2.3 of chapter three, HPR (1992) use a cross sectional regression model (called the intercept model by Ghosh (2001)), to estimate the abnormal industry-adjusted cash flow returns. They use the intercept $(\alpha)$ as a measure for examining the improvement (increase) in the operating cash flow after acquisitions. They basically believe that after controlling pre -performance, the intercept $(\alpha)$ is an independent measure that could properly reflect M\&A improvements. Ghosh (2001) argues that if merging firms outperform their peers because of permanent factors, then the superior pre-performance will be incorporated into the post performance; the bias cannot be detected by simply controlling pre-performance in the intercept model. Therefore, Ghosh (2001) suggests that the change in cash flow return ( $\triangle \mathrm{ACFR})$ is a better estimate for examining the abnormal cash flow returns. The change in cash flow return ( $\triangle \mathrm{ACFR})$ is defined as ACFRpost minus ACFRpre.

As it is hard to confirm that the pre-performance relative to the post performance is caused by permanent or temporary difference, most studies investigate both performance measures (Linn and Switzer 2001, Ghosh 2001, Carline, Linn and Yadav 2002, Powell and Stark 2005). While this thesis does attempt to avoid the related problems by developing benchmark firms based on pre-acquisition performance and firm size, these two performance measures (ACFRpost and $\triangle \mathrm{ACFR}$ ) are calculated for comparisons. The calculation process of these two operating performance measures is shown in figure 5.1, and the benchmark construction is discussed in the next section.

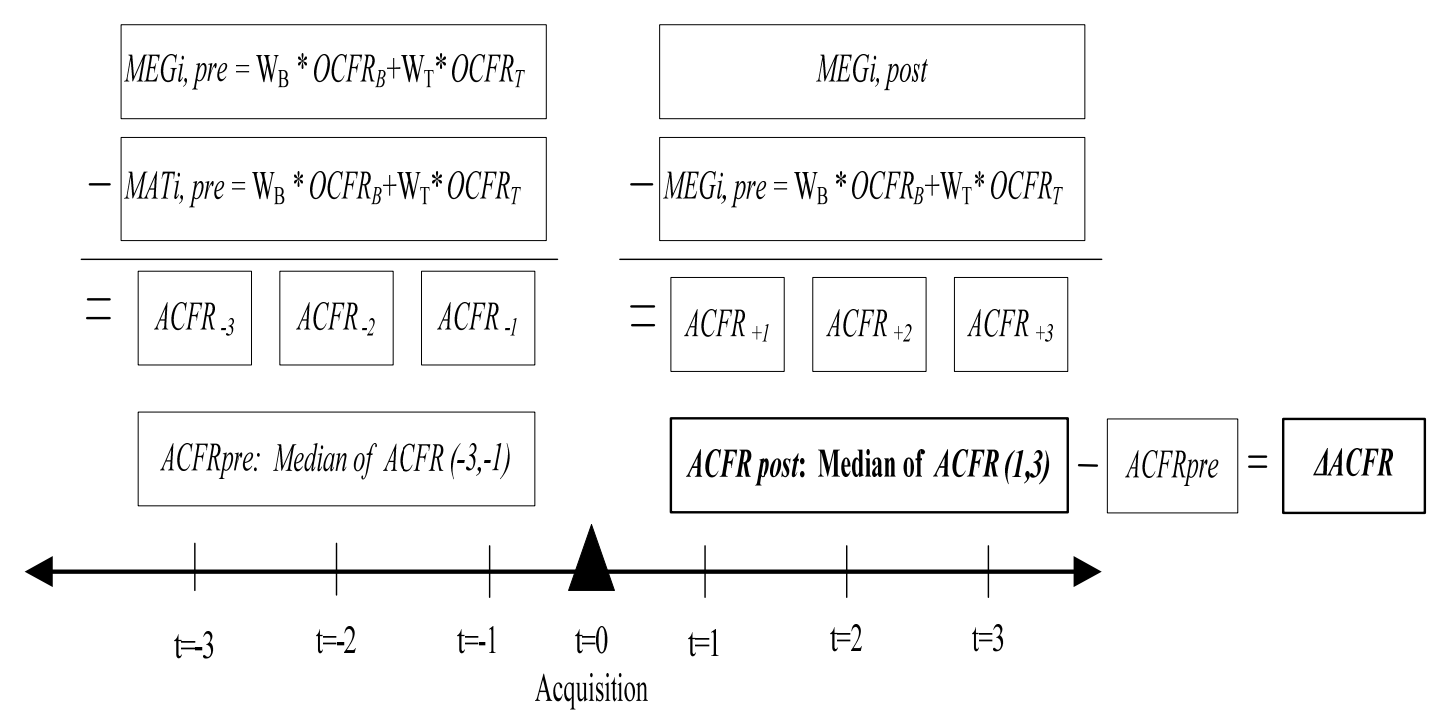

Figure 5.1 Calculation Process of Operating Performance Measures 


\subsubsection{Construction of Performance Benchmark}

As discussed in chapter four, despite that the drawbacks of the accounting data are improved by adopting pre tax operating cash flow, the acquisition performance can still be misled due to the special economy or industry factors of merging firms. HPR (1992) use industry matched as a benchmark to mitigate the impact of firm-specific and industry factors. However, acquiring firms usually possess superior performance before acquisition and are generally larger than their benchmark sample firms (Ghosh 2001). Therefore, the pre-performance matching approach is employed in this thesis. To make these results comparable with previous studies, the matching procedure here remain consistent with the recommendations of Barber and Lyon (1996) and are similar to the techniques applied by Ghosh (2001) and Loughran and Ritter (1997). Benchmarks are constructed using the following initial criteria. Data sources are either from Thomson Financial Securities Data's SDC Platinum ${ }^{\mathrm{TM}}$ Worldwide Mergers \& Acquisitions database or from DataStream database.

1. Same 2-digit primary SIC code.

2. Similar size, measured as book value of assets within 70 and 130 percent one year before takeover.

3. Similar pre-performance, measured as return on asset (ROA) within 90 and 110 percent one year before takeover.

4. Same nation code for the bidder and the target.

From the list of potential matched firms, the firms with the closest ROA are selected. If there is no match, then the pre-performance restriction is extended by choosing a matched firm with ROA between 50 percent and 150 percent. If still no firm meets these restrictions then the limit of the same country is replaced by the requirement of the same legal origin and the pre-performance limit goes back to 90 to 110 percent, at least staying within 50 and 150 percent. If the first run criteria are too strict to give a matched firm, then a second run is attempted with larger bands. That is, same 2-digit primary SIC code, book value of assets within 25 and 200 percent, ROA between 90 and 110 percent, and the same country. After the second run, there still a few cases cannot be matched at this point. This thesis therefore select the firm with the closest ROA within size band ( 25 and 200 percent), industry (2 digit SIC code) and same English origin countries. The construction processes of matched firms are shown in figure 5.2. 


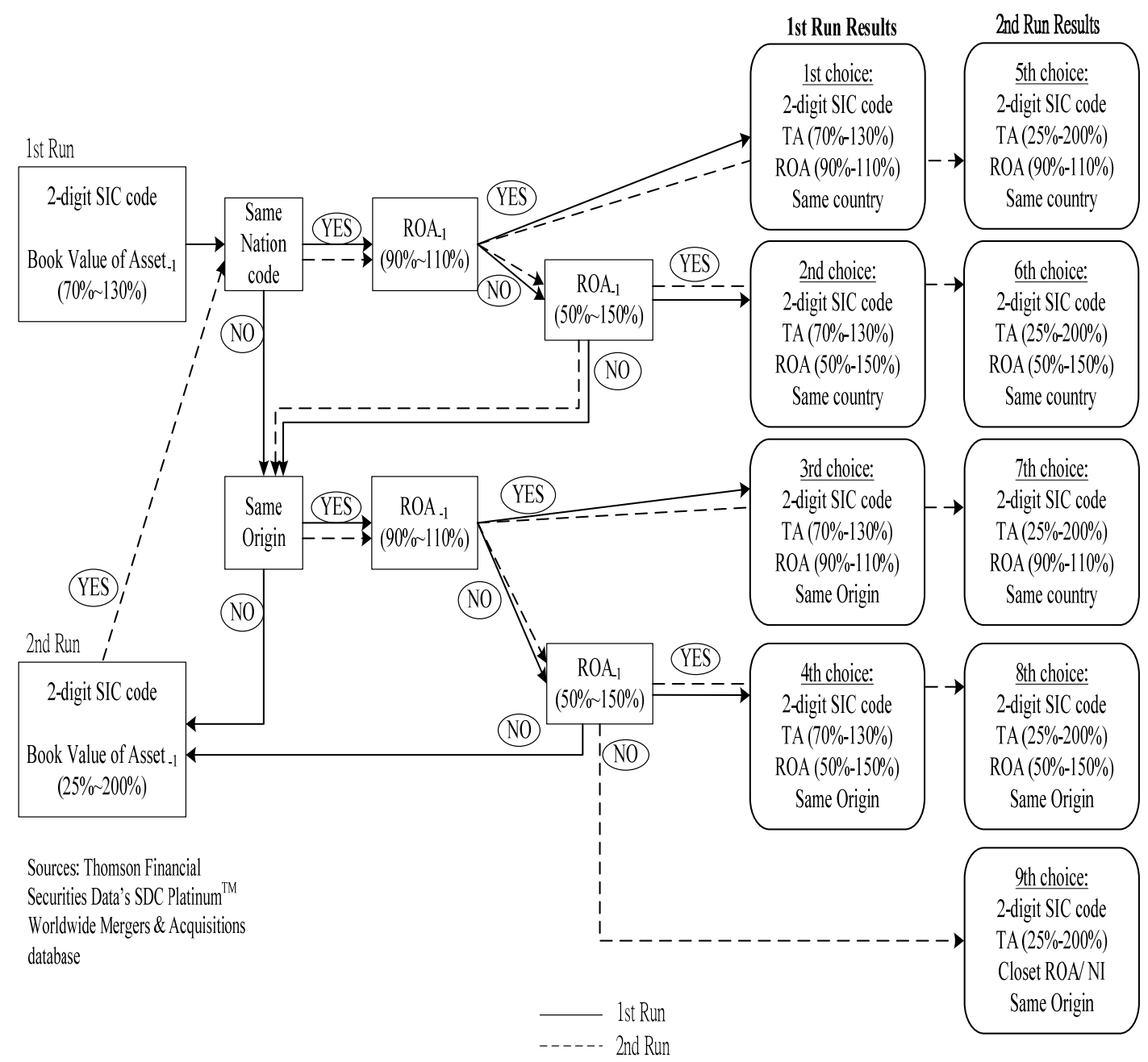

Figure 5.2 Construction Processes of Matched Firms

In the end, 82.27 percent of matched bidders and matched targets are within the size band between 70 percent and 130 percent of book value assets one year before transaction. After extending the size criteria to 25 percent and 200 percent, all the matched firms meet the necessary requirements. Obviously, it is too strict to set the limit of pre-performance between 90 percent and 110 percent of return on assets (ROA) at the year before takeover. Only 36.52 percent of matched bidders and 43.97 percent of matched targets are obtained to meet this performance limit. Fortunately, when performance restrictions are extended to 50 percent and 150 percent, around 87.52 percent matching for acquiring firms and 90.43 percent matching is achieved for target firms. Panel A and B of table 5.3 present the above results. 
A more detailed matrix is reported in panel $\mathrm{C}$ and $\mathrm{D}$; this includes the additional country requirement. From this matrix it is clear that 33.30 percent of matched bidders and 58.16 percent of matched targets have the same country code with their own matching firms, respectively. The other matched firms are selected with the same legal origins according to the classification of LLSV (1998). Finally, results are summarized in panel E based on figure 5.2 as it depicts best to worst choice. It is obvious that while there are only 7.80 percent of marched bidders and 24.11 percent of matched targets classified as first choice matched firms, 74.11 percent matched bidders and 77.66 percent matched targets appear after the first run of the construction process. Moreover, after the second run process there is 87.52 percent matching for acquirers and 90.43 percent matching for targets.

In addition, statistical analysis shows that the original operating cash flow data of both merging and matched firms have heavy tailed distributions. This thesis uses Huber's M-estimator with $\mathrm{k}=1.28$ to estimate the measure of location to detect outliers. In order to maintain sample size, this project applies the winsorizing approach which eliminates outliers by replacing (rather than discarding) them with the observed values. For merging firms, the average level of winsorizing is 15.7 percent for right tail and 9.9 for left tail. For matched firms, 17.9 percent for right tail and 10.1 for left tail were winsorized, on average. A robustness test is employed for the other estimators like $2 \sigma$-winsorized, 20 percentwinsorized, $2 \sigma$-trimmed, $\mathrm{M}$-estimator with $\mathrm{K}=1.28$ - trimmed and 20 percent-trimmed. The process and results are reported as sensitivity analysis in chapter eight. 
Table 5.3 Comparison of Merging Firms and Matched Firms

This table presents summary results of comparison of matched firms to merging firms for bidders and targets, respectively. Size is measured by book value of assets one year before takeover. Pre-performance is measured by return on asset (ROA) one year before takeover. The relatedness is calculated as matched firms (MB, MT) divided by merging firms (B, T). Data sources are from Thomson Financial Securities Data's SDC PlatinumTM Worldwide Mergers \& Acquisitions database or from DataStream database.

Panel A Metrix of Related size and pre-performance for Bidders (B) and Matched Bidders (MB)

\begin{tabular}{|c|c|c|c|c|c|c|c|}
\hline & & \multicolumn{4}{|c|}{ Related Pre-Performance (MB/B) } & \multirow[b]{2}{*}{ Total } & \multirow[b]{2}{*}{$\%$} \\
\hline & & $0.5 \sim 0.9$ & $0.9 \sim 1.1$ & $1.1 \sim 1.5$ & closest & & \\
\hline \multirow{5}{*}{$\begin{array}{c}\text { Related Size } \\
\text { (MB/B) }\end{array}$} & $0.25 \sim 0.7$ & 6 & 11 & 9 & 10 & 36 & $12.77 \%$ \\
\hline & $0.7 \sim 1.3$ & 72 & 89 & 48 & 23 & 232 & $82.27 \%$ \\
\hline & $1.3 \sim 2.0$ & 3 & 3 & 3 & 5 & 14 & $4.96 \%$ \\
\hline & Total & 81 & 103 & 60 & 38 & 282 & $100.00 \%$ \\
\hline & $\%$ & $28.72 \%$ & $36.52 \%$ & $21.28 \%$ & $13.48 \%$ & $100.00 \%$ & \\
\hline
\end{tabular}

Panel B Metrix of Related size and pre-performance for Targets (T) and Matched Targets (MT)

\begin{tabular}{|c|c|c|c|c|c|c|c|}
\hline & & \multicolumn{4}{|c|}{ Related Pre-Performance (MT/T) } & \multirow[b]{2}{*}{ Total } & \multirow[b]{2}{*}{$\%$} \\
\hline & & $0.5 \sim 0.9$ & $0.9 \sim 1.1$ & $1.1 \sim 1.5$ & closest & & \\
\hline \multirow{5}{*}{$\begin{array}{l}\text { Related Size } \\
\qquad(\mathrm{MT} / \mathrm{T})\end{array}$} & $0.25 \sim 0.7$ & 12 & 8 & 8 & 9 & 37 & $13.12 \%$ \\
\hline & $0.7 \sim 1.3$ & 54 & 111 & 54 & 13 & 232 & $82.27 \%$ \\
\hline & $1.3 \sim 2.0$ & 2 & 5 & 1 & 5 & 13 & $4.61 \%$ \\
\hline & Total & 68 & 124 & 63 & 27 & 282 & $100.00 \%$ \\
\hline & $\%$ & $24.11 \%$ & $43.97 \%$ & $22.34 \%$ & $9.57 \%$ & $100.00 \%$ & \\
\hline
\end{tabular}

Panel C Metrix of Related size, pre-performance and country code for Bidders (B) and Matched Bidders(MB)

\begin{tabular}{|c|c|c|c|c|c|c|c|}
\hline \multirow{2}{*}{ country code } & \multirow{2}{*}{\begin{tabular}{|c}
$\begin{array}{c}\text { Related Size } \\
(\mathrm{MB} / \mathrm{B})\end{array}$ \\
\end{tabular}} & \multicolumn{4}{|c|}{ Related Pre-Performance (MB/B) } & \multirow[b]{2}{*}{ Total } & \multirow[b]{2}{*}{$\%$} \\
\hline & & $0.5 \sim 0.9$ & $0.9 \sim 1.1$ & $1.1 \sim 1.5$ & closest & & \\
\hline \multirow{3}{*}{$\begin{array}{c}\text { Yes } \\
\text { (Same Country) }\end{array}$} & $0.25 \sim 0.7$ & 3 & 3 & 2 & 4 & & \\
\hline & $0.7 \sim 1.3$ & 27 & 22 & 27 & 6 & & \\
\hline & $1.3 \sim 2.0$ & 0 & 0 & 0 & 0 & 94 & $33.33 \%$ \\
\hline \multirow{4}{*}{$\begin{array}{c}\text { No } \\
\text { (Same Origin) }\end{array}$} & $0.25 \sim 0.7$ & 3 & 8 & 7 & 6 & & \\
\hline & $0.7 \sim 1.3$ & 45 & 67 & 21 & 17 & & \\
\hline & $1.3 \sim 2.0$ & 3 & 3 & 3 & 5 & 188 & $66.67 \%$ \\
\hline & Total & 81 & 103 & 60 & 38 & 282 & $100.00 \%$ \\
\hline
\end{tabular}

Panel D Metrix of Related size, pre-performance and country code for Targets (T) and Matched Targets (MT)

\begin{tabular}{|c|c|c|c|c|c|c|c|}
\hline \multirow{2}{*}{ country } & \multirow{2}{*}{$\begin{array}{c}\text { Related Size } \\
(\mathrm{MT} / \mathrm{T}) \\
\end{array}$} & \multicolumn{4}{|c|}{ Related Pre-Performance (MT/T) } & \multirow[b]{2}{*}{ Total } & \multirow[b]{2}{*}{$\%$} \\
\hline & & $0.5 \sim 0.9$ & $0.9 \sim 1.1$ & $1.1 \sim 1.5$ & closest & & \\
\hline \multirow{3}{*}{$\begin{array}{c}\text { Yes } \\
\text { (Same Country) }\end{array}$} & $0.25 \sim 0.7$ & 5 & 5 & 5 & 6 & & \\
\hline & $0.7 \sim 1.3$ & 32 & 68 & 31 & 7 & & \\
\hline & $1.3 \sim 2.0$ & 2 & 0 & 1 & 2 & 164 & $58.16 \%$ \\
\hline \multirow{4}{*}{$\begin{array}{c}\text { No } \\
\text { (Same Origin) }\end{array}$} & $0.25 \sim 0.7$ & 7 & 3 & 3 & 3 & & \\
\hline & $0.7 \sim 1.3$ & 22 & 43 & 23 & 6 & & \\
\hline & $1.3 \sim 2.0$ & 0 & 5 & 0 & 3 & 118 & $41.84 \%$ \\
\hline & Total & 68 & 124 & 63 & 27 & 282 & $100.00 \%$ \\
\hline
\end{tabular}

Panel E Count for the rank of the choice (based on figure 5.2)

\begin{tabular}{|c|c|c|c|c|c|c|c|c|c|c|c|c|}
\hline & \multicolumn{12}{|c|}{ Rank of choice } \\
\hline & 1st & 2nd & 3rd & 4th & $\begin{array}{l}\text { sub-total } \\
\text { (1st Run) }\end{array}$ & 5th & 6th & 7 th & 8th & \begin{tabular}{c|} 
sub-total \\
(2ndRun)
\end{tabular} & 9th & Total \\
\hline Matched & 22 & 54 & 67 & 66 & 209 & 3 & 5 & 11 & 16 & 35 & 38 & 282 \\
\hline Bidders (MB) & $7.80 \%$ & $19.15 \%$ & $23.76 \%$ & $23.40 \%$ & $74.11 \%$ & $1.06 \%$ & $1.77 \%$ & $3.90 \%$ & $5.67 \%$ & $12.41 \%$ & $13.48 \%$ & $100.00 \%$ \\
\hline Matched & 68 & 63 & 43 & 45 & 219 & 5 & 13 & 8 & 10 & 36 & 27 & 282 \\
\hline Targets (MT) & $24.11 \%$ & $22.34 \%$ & $15.25 \%$ & $15.96 \%$ & $77.66 \%$ & $1.77 \%$ & $4.61 \%$ & $2.84 \%$ & $3.55 \%$ & $12.77 \%$ & $9.57 \%$ & $100.00 \%$ \\
\hline
\end{tabular}




\subsection{Independent Variables Description}

Independent variables are grouped into five categories: ownership variables as major independent variables; governance variables for individual corporate governance mechanisms; institutional variables for legal and extra-legal systems; typical transaction variables found in event studies; and country control variables.

\subsubsection{Ownership Variables $\left(\mathrm{OWN}_{i}\right)$}

This thesis focuses on the relationship between ownership of the controlling shareholders and acquiring performance. Because controlling shareholders are likely to separate their control rights from ownership by various control devices, La Porta, Lopez-de-Silanes and Shleifer (1999) suggest that a measure of control power should be based on voting rights instead of cash flow rights. Therefore, concentrated ownership is defined relying on the voting shares held by the large shareholders. Ownership variables include five dummy variables reflecting different thresholds of voting shares of the largest shareholder. There is also a continuous variable for the actual percent of voting shares held by the largest shareholder. The information is obtained from the description of substantial/ principal shareholders in each company's proxy circular or annual report at the year prior to the deal.

\section{- Concentrated Ownership at 10 percent threshold (CONCEN10)}

This dummy variable CONCEN10 is for companies having a large shareholder holding more than 10 percent of voting shares. The 10 percent level has been broadly used as a cut point for testing the difference between dispersed and concentrated ownership structure because it provides a significant threshold of votes (La Porta et al. 1998/99, Claessens, Djankov and Lang 2000, Faccio, Lang and Young 2001); most countries mandate disclosure at this level or lower. ${ }^{20}$

\section{- Concentrated Ownership at 20 percent threshold (CONCEN20)}

The 20 percent level is another cutoff generally employed to define ownership concentration in extant research. La Porta et al. (1999) argue that 20 percent is generally

${ }^{20}$ Australia, New Zealand, Singapore, and Thailand require the disclosure of top 20 large and substantial shareholders. Canada requires the disclosure of information with respect to the large shareholders who beneficially own $10 \%$ or more of outstanding common shares whereas the UK and South African thresholds are 3\% and 5\%, respectively. 
sufficient to effect control over a firm (Faccio et al. 2001). Claessens et al. (2000) examine the separation of ownership and control for 2,980 companies in nine East Asian countries. They find large differences across countries in the distribution of ultimate control at the 10 percent level, but the differences across countries are much more widened at 20 percent. Moreover, most Anglo-Saxon GAAP (generally accepted accounting principles) recognize this threshold as reflecting significant influence and requiring the use of the equity method to account for such stakes. Based on the above ideas, this thesis sets the second dummy variable CONCEN20 for companies having a large shareholder with more than 20 percent of voting shares.

\section{- Concentrated Ownership at 50 percent threshold (CONCEN50)}

There is no theoretical research providing strong evidence regarding which cutoff points should be determined to define the ownership concentration. 50 percent cutoff levels are generally regarded as a legal threshold reflecting the stage that the large shareholder not only dominates but effectively controls the company (Davies, Hillier and McColgan 2005). Faccio and Lang (2002) define the controlling owner as the one who controls more than 50 percent of voting shares. To investigate the influence of this specific group of controlling shareholders, this thesis introduces the third dummy variable CONCEN50 for companies having a large shareholder with more than 50 percent of voting shares.

\section{- Voting shares between 10-20 \& 20-50 percent (CONCEN1020 \& CONCEN2050)}

In addition to setting cut points at 10,20, and 50 percent of company shares, some particular ownership studies represent different thresholds for blocks. For example, Zeckhauser and Pound (1990) examine US companies and define a large shareholder as a single entity holding more than 15 percent of the outstanding shares of the corporation. Barth, Gulbrandsen and Schonea (2005) investigate the performance of Norwegian family firms basis on thresholds at 33 percents of the shares owned by one person or by one family. Faccio et al. (2001) find that investors are less likely to be alert to expropriation within corporations that are loosely affiliated to the groups whose control-links are between 10 to 20 percent. In order to explore the effects of different levels of ownership, two dummy variables are used, COCEN1020 and CONCEN2050, in order to allow the creation of three ownership categories: between 10 and 20 percent, between 20 and 50 percent, and more than 50 percent (CONCEN50). 


\section{- Voting shares of the largest shareholder (LSH1P, LSH1PSQ, LSH1PCUBE)}

A continuous variable LSH1P is used for acquiring the actual percent of voting shares held by the largest shareholder (from $10 \%$ or more). This variable is squared and cubed to capture the potential non-linear relationship between controlling ownership and acquiring performance. The introduction of a quadratic and cubic function simply allows the possibility of capturing one or two turning points. Authors attempting to capture such non linearity include Morck, Shleifer and Vishny (1988b), McConnell and Servaes (1990), and Anderson and Reeb (2003).

\subsubsection{Governance Variables (GOVi)}

Information concerning the following variables is obtained by recording the financial statements and notes in each company's proxy or annual report.

\section{- Separation from cash flow right to voting right (SEP)}

The separation problem can be measured in three ways: (1) a dummy variable equals to one when there is separation between ownership and control rights, zero otherwise (Ben-Amar and André 2006, Villalonga and Amit 2006); (2) the ratio of the degree of the deviation between ownership and control rights (O/C) (Faccio et al. 2001, Bigelli and Mengoli 2004, Ben-Amar and André 2006); and (3) the difference between the level of control rights with respect to ownership (C-O) (Claessens, Djankov, Fan and Lang 2002, Ben-Amar and André 2006). In this thesis, Canadian firms usually have multiple voting shares carrying more than one vote per share; Australian and New Zealand companies separate the two rights by setting one vote for one person on a show of hands, one vote for one share upon a poll. In addition, a few companies in Canada, UK and South Africa separate ownership from control by constructing pyramid structures. Notice that different countries use different types of separation. This thesis does not provide evidence concerning the effects of individual control devices but does emphasize whether the existence of such control devices actually causes value reduction. Therefore, a dummy variable, SEP, is used: this is equal to one if an acquiring firm has a capital policy that enables its voting right to deviate from its cash flow right.

\section{- Dominant shareholder involvement in CEO position (CEOLSH)}

Previous research discussing CEO positioning in concentrated firms puts a great deal of emphasis on the family CEO. Many studies define an actively managed family firm as one in which the CEO is a member of family (Smith and Amoako-Adu 1999, Anderson and Reeb 
2003, Villalonga and Amit 2006). This study extends their arguments and sets a dummy variable CEOLSH equal to one when the CEO is the member or representative of any large shareholders, including family and non-family institutions that hold over 10 percent of the voting shares in certain acquiring firms.

\section{- CEO is also the Chairman of the board (CEOdual)}

A third governance variable is set in order to test the effectiveness of separating the role of management and supervision. A dummy variable CEOdual is equal to one when the same individual holds the position of CEO and Chairman simultaneously. This dummy variable is also used, though quite broadly, in earlier research by individuals such as Rechner and Dalton (1991), Brickley, Coles and Jarrell (1997), and Vefeas and Theodorou (1998).

\section{- Numbers of directors on the board (BSIZE)}

The board size is another issue relating to the board composition of a supervision mechanism. Conyon and Peck (1998) use the log of board size as a measure. This thesis, following the measure of Yermack (1996), applies the number of directors on the board as a continuous variable in order to explore the relationship between board size and acquisition performance.

\section{- Ratio of Independent Directors (INDDIR)}

The definition of the independent director is inconsistent in earlier research. Agrawal and Knoeber (1996) simply examine the percentage of non-employee directors on the board. Weisbach (1988) denotes outside directors by excluding the 'grey' directors who are not inside directors but who may still not be independent of the current management. However, there is no clear explanation concerning how to determine a 'grey' director in his study. Lipton and Lorsch (1992) jointly refer to 'grey' directors as non-executive directors having a fiduciary relationship with the firm -- individuals such as management consultants, executives in financial institutions, and firm legal counsel. They view independent directors as those who have no relationship to the company, either as management or as substantial customers or supplier of goods or services. These definitions are followed by Vefeas and Theodorou (1998).

Ben-Amar and André (2006) follow the Toronto Stock exchange (TSE) definition stating that the unrelated board member is a director who is not the manager of the firm or its subsidiaries, and who is not related to the controlling shareholder and does not have business 
dealing with the firm.

Rosenstein and Wyatt (1990) exclusively categorize non-executive directors by the director's primary occupation as (1) financial outsiders who are officers of any potential supplier of capital; (2) corporate outsiders who are officers or employees of other corporations; (3) and neutral outsiders who are outside directors including academics, lawyers in private practice, retired officers of other corporations or financial institutions, consultants, professional directors, retired or active government officials including military officers, employees of trade or non-profit organizations, religious leaders, representatives of ethnic or minority groups, public figures, and others (Rosenstein and Wyatt 1990: p179).

Referring to these prior empirical works, this thesis uses the fractions of independent directors on the board and defines the independent directors as non- executive directors excluding those having associations with the inside or outside large shareholders, company customers or suppliers, partners, and legal or management consultants.

\section{- Other large shareholders (OTHLSH)}

With respect to the information advantage of other large shareholders, this thesis uses a dummy variable OTHLSH that is equal to one if the company has another owner who holds more than 10 percent of voting shares of firm. This variable is the same as those measures regressed in other papers (Faccio et al. 2001, Maury 2005). The large shareholders can be internal investors such as directors, executive and managers, or external stakeholders such as the other families, institutions or the government.

\subsubsection{Deal Variables (DEAL $i)$}

To clearly identify the effects of ownership, governance, and institutional variables on acquisition performance in those multiple regressions of this thesis, it is necessary to control the other variables that have been well defined as deal characteristics having an impact on acquisition performance. Information on the following variables is either defined by or collected from Thomson Financial Securities Data's SDC Platinum ${ }^{\mathrm{TM}}$ Worldwide Mergers \& Acquisitions database.

\section{- Target firms' legal origin (TGORI_English)}

Recent developments in the field of cross border M\&A transactions have led to a renewed interest in the quality of corporate governance in target countries (Bris and Cabolis 
2002, Moeller and Schlingemann 2005). The variable usually used as a proxy is the legal origin classified by LLSV (1998): English, German, Scandinavian, and France. Confined by small observations, this thesis simply extends the concept of cross border ${ }^{21}$ to cross origin and sets a dummy variable TGORI_English which is equal to one if the target firm from English origin countries, otherwise zero (Rossi and Volpin 2004).

\section{- Transaction Attitude (ATTI_Hostile)}

Cernat (2004) points out that there are relatively few deals in Europe belonging either to hostile takeovers or using defensive strategies. The statistics of this thesis confirm this (3.5\% hostile in this thesis) but still retain transaction attitude as an important deal characteristic worthy of control. This control variable is measured with a dummy variable ATTI _Hostile which is equal to one when the management or boards of target firms are initially opposed to amalgamating the acquiring firm and the deals are classified as hostile transactions in Thomson Financial Securities Data's SDC Platinum ${ }^{\mathrm{TM}}$ Worldwide Mergers \& Acquisitions database.

\section{- Types of Payment (PAY_Stock)}

In order to control the signaling effects of payment method, another dummy variable PAY_Stock is used for deal characteristics; this is equal to one if the payment methods is classified as 'stock only' in Thomson Financial Securities Data's SDC Platinum ${ }^{\text {TM }}$ Worldwide Mergers \& Acquisitions database.

\section{- Transaction with Multiple Bidders (COMPETE)}

Whereas Franks and Harris (1989) partition multiple bids into revised or contested bids, most empirical work generally takes the presence of multiple bidders as proxy to measure whether acquirers do worse when they are involved in an open contest (Morck, Shleifer and Vishny 1990, Duggal and Millar 1999). This thesis also sets a dummy variable COMPETE which is equal to one if the bidders are more than one party.

\section{- Relatedness of Business Industry (IND_rel)}

Existing research usually defines the relatedness of business according to the standard industrial classification (SIC) codes (Powell and Stark 2005). However, it is difficult to determine how strictly to define industry relatedness. Some studies define mergers between

\footnotetext{
21 The effects of cross border are further tested in chapter seven as additional analysis.
} 
firms with a common activity at the two- digit or higher as related deals (Limmack and McGregor 1995, Moeller and Schlingemann 2005). Other studies term the acquisition related if the pair of firms share the same top three digits of their SIC code (Morck et al. 1990, Wright, Kroll, Lado and Van Ness 2002). Still others identify horizontal (related) mergers as those taking place between two companies in the same primary four-digit SIC industry (Linn and Switzer 2001, Gugler, Mueller, Yurtoglu and Zulehner 2003). A dummy variable for this characteristic is equal to one if the acquiring firms had an equivalent four-digit primary SIC code at the time of acquisition. ${ }^{22}$

\section{- Shareholdings before Acquisition (TOEHOLD)}

With respect to 30 percent of toehold interests conveyed at purchasing advantage, Franks and Harris (1989) use this cut point to split deals into three categories: without threshold, with toehold below 30 percent, and with toehold above or equal to 30 percent. Sudarsanam, Holl and Salami (1996) use the real percentage of target shares held by the bidder as a testing variable. Considering that there are still many disagreements on the point of threshold to define toeholds, this thesis simply focuses on the presence of toehold and, thereby, sets another dummy variable, TOEHOLD, which is equal to one if an acquiring firm owns any shares of target before the actual bids.

\section{- Bid Premium (PREM_1day)}

Previous research strongly proves that a higher bid premium brings about a negative acquiring performance (Healy, Palepu and Ruback 1997, Goergen and Renneboog 2004). This continuous variable presents the premium offer price to the target trading price one day prior to the original announcement date. ${ }^{23}$

\section{- Relative Size of Deal (SIZE_rel)}

In most existing research, the relative size of target and bidder is measured by the relative market values of target and acquirer respectively (MVt/MVa). Asquith, Bruner and Jr Mullins (1983) calculate the ratio of market value of equity of the two pairs of merging firms. These market values were taken one day after the announcement in their research. Agrawal, Jaffe and Mandelker (1992) also use the market value of equity from both sides of the

${ }^{22}$ This thesis also conducted the analysis using two and three-digit SIC codes to measure industry relatedness. Test and results are reported in chapter seven as additional analysis.

23 This thesis also conducted the analysis using the premium of offer price to target trading price one week and four weeks prior to the original announcement date. Test and results are reported in chapter seven as additional analysis. 
companies but their work is based on the six months before the public announcement day. Scanlon, Trifts and Pettway (1989) measure the same ratio at the year end before announcement day. Except for using the ratio of market value of equity, Becher and Campbell II (2003b) investigate the merger of equals based on the asset ratio where the ratio is defined as a target's assets divided by the sum of the target and bidder firm assets.

This thesis examines the effects of size relatedness by calculating a continuous variable which is the natural logarithm of $\mathrm{MVa} / \mathrm{MVt}$, where $\mathrm{MVa}$ and $\mathrm{MVt}$ are the market value of assets of acquiring and target firms, respectively. The market value of assets is the sum of the market value of equity and book value of net debt at the fiscal year end before the acquisition year. This market value of asset is also used to compute the operating cash flow return as a performance measure in HPR (1992).

\section{Acquirer's Leverage (LEV)}

To test the debt monitoring hypothesis, prior research generally uses the debt equity ratio of acquiring firms as a form of measurement (Myers and Majluf 1984, Stulz, Walkling and Song 1990, Maloney, McCormick and Mitchell 1993). Linn and Switzer (2001) create a dummy variable which equals to one if the leverage of the bidders is greater than the median leverage for firms in the sample at the fiscal year end prior to the bid. They compute the leverage as the company's book value of short and long-term debt divided (BVdebt) by the pseudo-asset value. The value of asset (MVasset) is calculated as a sum of the book value of debt, book value of preferred stock, and the market value of equity. The leverage variable is comparable with that in Linn and Switzer (2001) but is measured as a continuous variable. The bidder's leverage is assessed as the natural logarithm of BVdebt/MVasset in this thesis. BVdebt and MVasset are the acquirer's book value of debt and the market value of assets, respectively. Both of them are defined as in Linn and Switzer (2001).

\subsubsection{Institutional Variables (INSTI $i$ )}

Data used to represent or compute the following variables is basically collected from LLSV (1998), Dyck and Zingales (2004), and Djankov, La Porta, Lopez-de-Silanes and Shleifer (DLLS, 2006). The summary statistics are shown in Table 5.4.

\section{- Anti-director Right (ANTIDIR_high)}

Except for legal origin, the most widely recognized legal measure in recent studies is the score of the anti-director right provided by LLSV (1998) (Johnson, Boone, Breach and 
Friedman 2000a, Nenova 2003, Esty and Megginson 2003). In particular, Moeller and Schlingemann (2005) use a dummy for high versus low shareholder rights, based on whether the anti-director rights variable in LLSV for that country is more than three which is the sample mean score of all sample countries. Similarly, a dummy variable ANTIDIR_high is established in this thesis to examine the difference among countries having the same legal origin. One if the acquiring firms is in countries having more than the median score of anti-director rights, otherwise it is zero. Based on the scores of anti-director right in LLSV (1998), the median score of the 11 countries is 4.0. Countries ranking above the median score are Canada, India, South Africa, and the UK.

\section{- Enforcement (ENFORCE)}

After LLSV (1998), which proposes five individual measures for enforcement variables ${ }^{24}$ several follow up practical studies now research the efficiency of these estimates. As yet, there is little agreement among them. Stulz and Williamson (2003) examine each of these five variables, Johnson et al. (2000a) adopt three of them to measure the enforceability of contracts: judicial efficiency, rule of law, and corruption. Following Johnson et al. (2000a), Shen and Chih (2005) use the mean score of these three legal variables. Nenova (2003) and Dyck and Zingales (2004) simply pick up the rule of law as a single measure for legal enforcement.

Exclusively, Berkowitz, Pistor and Richard (BRP, 2003) aggregate these five individual enforcement proxies into a single legality index, called the BRP index ${ }^{25}$. The validity of this simplification is formally tested in Berkowitz et al.'s (2003) study and the results are robust compared to several alternatives (e.g. Kaufmann, Kraay and Zoido-Lobaton 1999). The BRP composite legality index is adopted for measuring legal enforcement by subsequent authors such as Esty and Megginson (2003). Considering that the high correlation will create a multicollinearity problem if the five LLSV enforcement variables are all regressed on performance, this thesis consistently uses the BRP single legality index as an enforcement continuous variable (ENFORCE) ${ }^{26}$ which ranges from the

${ }^{24}$ Five enforcement measures in LLSV (1998): efficiency of judicial system, rule of law, corruption, risk of expropriation, and risk of contract repudiation. Descriptions are shown in chapter two, section 2.5.2.1.

${ }^{25}$ Legality index $=0.381 *$ efficiency of judicial $+0.578 *$ rule of law $+0.503 *$ corruption $+0.347 *$ risk of expropriation $+0.384 *$ risk of contract repudiation.

26 This thesis also tests the average of three LLSV legal variables as an alternative enforcement measure, like Shen and Chih (2005) did. The correlation between this proxy and BRP index is 0.951 and the regression results are robust. Test and Results are reported in appendix B. 
lowest score of 12.94 for Thailand to the highest score of 21.55 for New Zealand.

\section{- Accounting Standard (ACCTSTD)}

Consistent with the previous research (e.g. Johnson et al. 2000a, Stulz and Williamson 2003, Haw and Hu 2004, and Dyck and Zingales 2004), this thesis uses the rating of accounting standards reported in LLSV (1998) as an estimate of the quality of accounting standards. This continuous variable ACCTSTD ranges from the lowest level of 57 for India to the highest level of 78 for Singapore and the UK. However, the results may be restricted by information that fails to consider the future convergence in the LLSV (1998) study. Besides, the original data from Ireland in LLSV (1998) is not available. Missing values are replaced by the mean of sample countries. The processes of dealing missing data are explained in chapter six, section 6.3 .

\section{- Extra-legal systems (XLEG_high)}

To discover the function of extra-legal systems, some empirical research has attempted to suggest certain estimates (e.g. Coffee 2001 for violent crime rate, Stulz and Williamson 2003 for religion). To date, however, there are no controlled studies that prove a strong measure for extra-legal characteristics. Dyck and Zinglales (2000/2004) explore six $\operatorname{proxies}^{27}$ as extra-legal institutions to restrain the possibility of expropriation. Unfortunately, they only provide data for 39 countries. Moreover, too many figures are missing in these five proxies, especially when it comes to labor protection and the acceptability of cheating on tax. Haw and Hu (2004) apply only three variables in their study: competition law, news circulation pop, and tax compliance.

Following the variables of Dyck and Zinglales (2004) but considering that these variables are highly correlated, this thesis establishes an extra-legal single variable by three steps: (1) ranking each variable (excluding labor protection and the acceptability of cheating on taxes due to the seriously incomplete data); (2) adding the rank score to get an aggregate extra-legal index ${ }^{28}$ for each country; (3) using the median of aggregate extra-legal index to set a high final dummy variable XLEG. The dummy is equal to one when an acquiring firm is in a country with a median ranking above (20) the aggregate extra-legal index derived

${ }^{27}$ Dyck and Zingales (2004) present statistics of six extra-legal proxies including competition law, news circulation pop, serious crime rate, labor protection measures, tax compliance and acceptability of cheating on taxes. Descriptions are shown in chapter two, section 2.5.2.2.

${ }^{28}$ The ranges for the aggregate extra-legal index are from the lowest rank of 6 for South Africa to the highest rank of 30 for Singapore. 
from the sample. Here, countries defined as having high extra-legal institutions are Australia, Malaysia, New Zealand, Singapore and the UK. Similarly, missing value for India and Ireland is replaced by the mean of sample countries to follow the above steps. The processes of dealing missing data are explained in chapter six, section 6.3 .

\section{Anti-self Dealing index (ANTISDI)}

DLLS (2006) create a new investor protection metric in their recent paper: the anti-self dealing measure which focuses on private enforcement mechanisms. So far, there exists no empirical study that uses this new measure to examine the legal protection of minority shareholders against expropriation. This thesis uses the anti-self dealing index in DLLS (2006) as a continuous variable ANTISDI that ranges from the lowest score of 0.55 for India to the highest score of 1.0 for Singapore.

\section{- Public Enforcement (PUBENFORCE_high)}

Another new investor protection metric in DLLS (2006) is the public enforcement mechanisms. They give one quarter point when each sanction ${ }^{29}$ happens and add these four dummy variables to form the index of public enforcement, ranging from 0 to 1 . Once again, a high verses low dummy variable (PUBENFORCE_high) is employed; this equals to one if an acquiring firm is in a country scoring above the median point $(0.5)$ of the public enforcement index. High public enforcement countries include Canada, Israel, Malaysia and Singapore.

\section{- Revised Anti- Director Right (NANTIDIR_high)}

Along with the above two new measures, DLLS (2006) further revises the initial anti-director right index which was reported in LLSV (1998). Adopting these revised statistics, this thesis sets another dummy variable NANTIDIR_high for the new measure. The dummy is denoted to one when an acquiring firm is in a country scoring above the median (4) of a new anti-director right. Countries in the high range include India, Malaysia, Singapore, South Africa, and the UK.

${ }^{29}$ Four sanctions is available as described in chapter two: fines for the approving body, jail sentences for the approving body, fines for the controlling shareholder, and jail for the controlling shareholder. 


\subsubsection{Country Variables (Country)}

Beyond controlling for all this ownership as well as for governance and for deal and legal characteristics, this thesis attempts to extract country-fixed effects from firm-level regressions. The country fixed-effects specification is broadly applied in cross-country analysis such as that in Dyck and Zingales (2004), Mitton (2002), and Maury (2005). Similarly, this thesis includes three country-specific omitted variables for three major countries in order to control for country fixed effects. The first variable is the UK dummy, defined as an acquiring firm from the United Kingdom. The second is the CAN dummy, defined as an acquiring firm from Canada. The last is the AUS dummy, defined as an acquiring firm is an Australian firm. The definition of the variables in this thesis is described in the following section and is summarized in Table 5.5. 
Table 5.4 Institutional Variables

This table presents summary statistics of the institutional variables/ used in Table 5.5. The definitions and sources of variables are shown in Table 5.5.

Panel A Summary Statistics of Institutional Variables

\begin{tabular}{|c|c|c|c|c|c|c|c|c|c|c|c|c|}
\hline \multirow[b]{3}{*}{ Country } & \multicolumn{8}{|c|}{ Legal Institutions } & \multirow{3}{*}{$\begin{array}{l}\text { Extra-Legal } \\
\text { Institution: } \\
\text { Aggregate Rank } \\
\text { Index } \\
\text { (see Panel B) }\end{array}$} & \multirow[b]{3}{*}{$\begin{array}{c}\text { Anti-Self } \\
\text { Dealing } \\
\text { Index }\end{array}$} & \multirow[b]{3}{*}{$\begin{array}{c}\text { Public } \\
\text { Enforcement }\end{array}$} & \multirow{3}{*}{$\begin{array}{c}\text { Revised } \\
\text { Anti- } \\
\text { director } \\
\text { Right }(0-6) \\
\end{array}$} \\
\hline & \multirow[b]{2}{*}{$\begin{array}{c}\text { Initial Ant- } \\
\text { director } \\
\text { Right }(0-6)\end{array}$} & \multicolumn{6}{|c|}{ Enforcement } & \multirow[b]{2}{*}{$\begin{array}{c}\text { Accounting } \\
\text { Disclosure } \\
(0-90)\end{array}$} & & & & \\
\hline & & $\begin{array}{c}\text { Efficiency of } \\
\text { Judicial } \\
\text { System }\end{array}$ & $\begin{array}{c}\text { Rule of Law } \\
(1-10)\end{array}$ & Corruption & $\begin{array}{c}\text { Risk of } \\
\text { Expropriation }\end{array}$ & $\begin{array}{c}\text { Risk of } \\
\text { Contract } \\
\text { Repudiation }\end{array}$ & $\begin{array}{c}\text { BRP } \\
\text { Legality } \\
\text { Index } \\
\end{array}$ & & & & & \\
\hline Australia & 4 & 10 & 10 & 8.52 & 9.27 & 8.71 & 20.44 & 75 & 30 & 0.79 & 0.50 & 4 \\
\hline Canada & 5 & 9.25 & 10 & 10 & 9.67 & 8.96 & 21.13 & 74 & 16 & 0.65 & 1.00 & 4 \\
\hline India & 5 & 8 & 4.17 & 4.58 & 7.75 & 6.11 & 12.80 & 57 & 19 & 0.55 & 0.50 & 5 \\
\hline Ireland-Rep & 4 & 8.75 & 7.8 & 8.52 & 9.67 & 8.96 & 18.92 & $71^{\wedge}$ & 19 & 0.79 & 0.00 & 4 \\
\hline Israel & 3 & 10 & 4.82 & 8.33 & 8.25 & 7.54 & 16.54 & 64 & 20 & 0.71 & 1.00 & 4 \\
\hline Malaysia & 4 & 9 & 6.78 & 7.38 & 7.95 & 7.43 & 16.67 & 76 & 21 & 0.95 & 1.00 & 5 \\
\hline New Zealand & 4 & 10 & 10 & 10 & 9.69 & 9.29 & 21.55 & 70 & 30 & 0.95 & 0.00 & 4 \\
\hline Singapore & 4 & 10 & 8.57 & 8.22 & 9.3 & 8.86 & 19.53 & 78 & 33 & 1.00 & 1.00 & 5 \\
\hline South Africa & 5 & 6 & 4.42 & 8.92 & 6.88 & 7.27 & 14.51 & 70 & 6 & 0.81 & 0.00 & 5 \\
\hline Thailand & 2 & 3.25 & 6.25 & 5.18 & 7.42 & 7.57 & 12.94 & 64 & 10 & 0.85 & 0.00 & 4 \\
\hline United Kingdom & 5 & 10 & 8.57 & 9.1 & 9.71 & 9.63 & 20.41 & 78 & 30 & 0.93 & 0.00 & 5 \\
\hline mean & 4 & 8.57 & 7.40 & 8.07 & 8.69 & 8.21 & 17.77 & 70.60 & 21 & 0.82 & 0.5 & 4 \\
\hline median & 4 & 9.25 & 7.8 & 8.52 & 9.27 & 8.71 & 18.92 & 72.00 & 20 & 0.81 & 0.5 & 4 \\
\hline country missing & None & None & None & None & None & None & None & Ireland & $\begin{array}{l}\text { India } \\
\text { Ireland }\end{array}$ & None & None & None \\
\hline
\end{tabular}

$\wedge^{\wedge}$ missing value is replaced by the mean of sample countries 
Table 5.4 (Continued)

Table 5.4 (Continued)

Panel B Extra Legal Institutions: Aggregate Index

\begin{tabular}{|c|c|c|c|c|c|c|c|c|c|}
\hline \multirow[b]{2}{*}{ Country } & \multicolumn{2}{|c|}{ Competition Law } & \multicolumn{2}{|c|}{ Public Opinion Pressure } & \multicolumn{2}{|c|}{ Serious Crime } & \multicolumn{2}{|c|}{ Tax Compliance } & \multirow{2}{*}{$\begin{array}{c}\text { Aggregate } \\
\text { Rank Index }\end{array}$} \\
\hline & Score & Rank & Score & Rank & Score & Rank & Score & Rank & \\
\hline Australia & 5.52 & 8 & 3.00 & 8 & 57.5 & 7 & 4.58 & 7 & 30 \\
\hline Canada & 5.37 & 6 & 1.60 & 4 & 122.3 & 2 & 3.77 & 4 & 16 \\
\hline India & $5.21^{\wedge}$ & 5 & $2.08^{\wedge}$ & 5 & $85.86^{\wedge}$ & 4 & $4.1^{\wedge}$ & 5 & 19 \\
\hline Ireland-Rep & $5.21^{\wedge}$ & 5 & $2.08^{\wedge}$ & 5 & $85.86^{\wedge}$ & 4 & $4.1^{\wedge}$ & 5 & 19 \\
\hline Israel & 5.11 & 4 & 2.90 & 7 & 68.9 & 6 & 3.69 & 3 & 20 \\
\hline Malaysia & 4.84 & 2 & 1.60 & 3 & 34.5 & 10 & 4.34 & 6 & 21 \\
\hline New Zealand & 5.40 & 7 & 2.20 & 6 & 52.3 & 8 & 5.00 & 9 & 30 \\
\hline Singapore & 5.21 & 5 & 3.20 & 9 & 45.2 & 9 & 5.05 & 10 & 33 \\
\hline South Africa & 4.89 & 3 & 0.34 & 1 & 225.2 & 1 & 2.40 & 1 & 6 \\
\hline Thailand & 4.77 & 1 & 0.60 & 2 & 70.4 & 5 & 3.41 & 2 & 10 \\
\hline United Kingdom & 5.74 & 9 & 3.30 & 10 & 96.4 & 3 & 4.67 & 8 & 30 \\
\hline mean & 5.21 & & 2.08 & & 85.86 & & 4.10 & & \\
\hline median & 5.21 & & 2.20 & & 68.90 & & 4.34 & & \\
\hline
\end{tabular}

$\wedge$ missing value is replaced by the mean of sample countries

Panel C Correlation Matrix

\begin{tabular}{|c|c|c|c|c|c|c|c|}
\hline Institutional Variables & $\begin{array}{l}\text { Initial Anti- } \\
\text { director Right }\end{array}$ & $\begin{array}{c}\text { Enforcement } \\
\text { BRPIndex }\end{array}$ & $\begin{array}{c}\text { Accounting } \\
\text { Disclosure }\end{array}$ & $\begin{array}{c}\text { Extra-Legal } \\
\text { Aggregate } \\
\text { Index }\end{array}$ & $\begin{array}{l}\text { Anti-Self } \\
\text { Dealing } \\
\text { Index }\end{array}$ & $\begin{array}{c}\text { Public } \\
\text { Enforcement }\end{array}$ & $\begin{array}{c}\text { Revised } \\
\text { Anti-director } \\
\text { Right }\end{array}$ \\
\hline ANTIDIR_high & 1.000 & & & & & & \\
\hline ENFORCE & 0.076 & 1.000 & & & & & \\
\hline ACCTSTD & $0.116 *$ & $0.690 * * *$ & 1.000 & & & & \\
\hline XLEG_high & -0.075 & $0.256 * * *$ & $0.662 * * *$ & 1.000 & & & \\
\hline ANTISDI & -0.006 & 0.065 & $0.673 * * *$ & $0.874 * * *$ & 1.000 & & \\
\hline PUBENFORCE_high & $0.135 *$ & $0.310 * * *$ & $-0.241 * * *$ & $-0.727 * * *$ & $-0.748 * * *$ & 1.000 & \\
\hline NANTIDIR_high & $0.415 * * *$ & $-0.289 * * *$ & $0.338 * * *$ & $0.645 * * *$ & $0.794 * * *$ & $-0.676 * * *$ & 1.000 \\
\hline
\end{tabular}

* Correlation is significant at the 0.10 level (2-tailed).

** Correlation is significant at the 0.05 level (2-tailed).

*** Correlation is significant at the 0.01 level (2-tailed). 
Table 5.5 Variable Definitions

\begin{tabular}{|c|c|c|}
\hline \multicolumn{2}{|r|}{ Variables } & Definition \\
\hline \multicolumn{3}{|r|}{ Independent Variables: Ownership Variables (OWN $i)$} \\
\hline \multicolumn{2}{|c|}{ CONCEN10 } & One if a shareholder owns more than $10 \%$ of voting shares of the acquiring firm. \\
\hline \multicolumn{2}{|c|}{ CONCEN20 } & One if a shareholder owns more than $20 \%$ of voting shares of the acquiring firm. \\
\hline \multicolumn{2}{|c|}{ CONCEN50 } & One if a shareholder owns more than $50 \%$ of voting shares of the acquiring firm. \\
\hline \multicolumn{2}{|c|}{ CONCEN1020 } & One if a shareholder owns $10 \%$ and $20 \%$ of voting shares in the acquiring firm. \\
\hline \multicolumn{2}{|c|}{ CONCEN2050 } & One if a shareholder owns $20 \%$ and $50 \%$ of voting shares in the acquiring firm. \\
\hline \multicolumn{2}{|l|}{ LSH1P } & The percentage of voting shares held by the largest shareholder. \\
\hline \multicolumn{2}{|c|}{ LSH1PSQ } & The square of the percentage of voting shares held by the largest shareholder. \\
\hline & The cube of the percentage of voting shares held by the largest shareholder. \\
\hline \multicolumn{2}{|c|}{ LSH1PCUBE } & Other Independent Variables \\
\hline \multirow{6}{*}{ 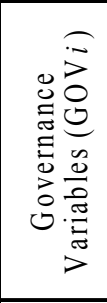 } & SEP & One if there exists separation of ownership and cash flow rights in the acquiring firm. \\
\hline & CEOLSH & One if CEO is related to the largest shareholder. \\
\hline & CEOdual & One if CEO and COB positions are held by the same individual. \\
\hline & BSIZE & Numbers of directors on the board. \\
\hline & INDDIR & The fractions of independent directors on the board. \\
\hline & OTHLSH & $\begin{array}{l}\text { One if there is another shareholder with at least } 10 \% \text { ofthe voting shares of the acquiring } \\
\text { firms. }\end{array}$ \\
\hline \multirow{9}{*}{ 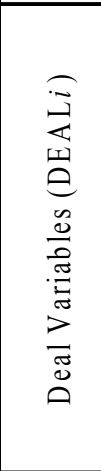 } & TGORI_English & One if the legal origin of target firm is English. \\
\hline & ATTI_Hostile & One if the management or board of target firm were initially opposed to the deal. \\
\hline & PAY_Stock & One if the payment method of transaction was stock only. \\
\hline & COMPETE & One if the acquiring firm had to compete with other possible acquirers. \\
\hline & IND rel & One if the acquiring and target firms had equivalent 4-digit primary SIC code. \\
\hline & TOEHOLD & One if acquiring firm owns any target shares before transaction. \\
\hline & PREM_1day & Premium of offer price to target trading price 1 day prior to the announcement date. \\
\hline & SIZE_rel & $\begin{array}{l}\text { Natural logarithm of the acquiring firm's market value of assets divided by target firm's } \\
\text { market value of asset at the fiscal year end before the acquisition year. }\end{array}$ \\
\hline & LEV & $\begin{array}{l}\text { Natural logarithm of the acquiring firm's leverage (book value of debts divided by market } \\
\text { value of assets) at the fiscal year end before the acquisition year. }\end{array}$ \\
\hline \multirow{7}{*}{ 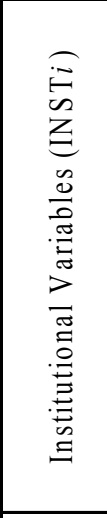 } & ANTIDIR_high & $\begin{array}{l}\text { One if the acquiring firms are in countries with above the median score (4) of anti-director } \\
\text { rights (LLSV 1998). }\end{array}$ \\
\hline & ENFORCE & BRP legality index, a summary statistics from LLSV (1998) analysis on legal enforcements. \\
\hline & ACCTSTD & The rating of accounting standards (LLSV 1998). \\
\hline & XLEG_high & $\begin{array}{l}\text { One if the acquiring firms are in countries with above the median score (19) of aggregate } \\
\text { extra legal index (Dyck and Zingales 2004). }\end{array}$ \\
\hline & ANTISDI & Anti-self-dealing Index (DLLS 2006). \\
\hline & PUBENFORCE_high & $\begin{array}{l}\text { One if the acquiring firms are in countries with above the media points (0.5) of public } \\
\text { enforcement index (DLLS 2006). }\end{array}$ \\
\hline & NANTIDIR_high & $\begin{array}{l}\text { One if the acquiring firm is in a country with above the median score (4) of new anti-director } \\
\text { index (DLLS 2006). }\end{array}$ \\
\hline \multirow{3}{*}{ 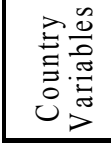 } & UK & One if the nation of an acquiring firm is the United Kingdom. \\
\hline & CAN & One if the nation of an acquiring firm is Canada. \\
\hline & AUS & One if the nation of an acquiring firm is Australia. \\
\hline
\end{tabular}




\subsection{Empirical Models}

\subsubsection{Ownership Concentration Models}

In order to test the major hypotheses at the first stage concerning ownership concentration, two operating performance measures (ACFRpost and $\triangle A C F R$ ) are regressed against different level and types of ownership concentration variables (CONCEN10, CONCEN20, CONCEN1020, CONCEN2050, CONCEN50, LSH1, LSH1SQ, LSH1CUBE, and FAM). To explicitly investigate the effects of ownership structure on acquisition performance, other variables are also controlled: these include governance and transaction variables as introduced in prior chapters. Therefore, at the first stage of the research scheme, the eight principal models to be tested are as follows: Model 1 is for dispersed ownership versus concentrated ownership at $10 \%$ threshold; Model 2 is for dispersed ownership versus concentrated ownership at 20\% threshold; Model 3 and 4 set middle points to investigate the impact of different level of concentrated ownership; Model 5 is for linear relationship; Model 6 is for square relationship; model 7 is for cube relationship. Formally:

Model 1a: ACFRpost $=\beta_{0}+\beta_{1}$ CONCEN10 $+\beta_{2 i} \mathrm{GOV}_{i}+\beta_{3 i} \mathrm{DEAL}_{i}+\beta_{4 i} \mathrm{ACFRpre}+\varepsilon_{j}$ Model 1b: $\Delta \mathrm{ACFR}=\beta_{0}+\beta_{1} \mathrm{CONCEN} 10+\beta_{2 i} \mathrm{GOV}_{i}+\beta_{3 i} \mathrm{DEAL}_{i}+\varepsilon$

Model 2a: ACFRpost $=\beta_{0}+\beta_{1}$ CONCEN20 $+\beta_{2 i} \mathrm{GOV}_{i}+\beta_{3 i} \mathrm{DEAL}_{i}+$ ACFRpre $+\varepsilon_{j}$ Model 2b: $\triangle \mathrm{ACFR}=\beta_{0}+\beta_{1} \mathrm{CONCEN} 20+\beta_{2 i} \mathrm{GOV}_{i}+\beta_{3 i} \mathrm{DEAL}_{i}+\varepsilon$

Model 3a: ACFRpost $=\beta_{0}+\beta_{1}$ CONCEN1020 $+\beta_{2} \mathrm{CONCEN}_{20}+\beta_{3 i} \mathrm{GOV}_{i}+\beta_{4 i} \mathrm{DEAL}_{i}$

$$
+\beta_{5 i} \text { ACFRpre }+\varepsilon_{j}
$$

Model 3b: $\Delta \mathrm{ACFR}=\beta_{0}+\beta_{l} \mathrm{CONCEN1020}+\beta_{2} \mathrm{CONCEN} 20+\beta_{3 i} \mathrm{GOV}_{i}+\beta_{4 i} \mathrm{DEAL}_{i}+\varepsilon_{j}$

Model 4a: ACFRpost $=\beta_{0}+\beta_{1}$ CONCEN1020 $+\beta_{2}$ CONCEN2050 $+\beta_{3}$ CONCEN50

$$
+\beta_{4 i} G O V_{i}+\beta_{5 i} \mathrm{DEAL}_{i}+\beta_{6 i} \mathrm{ACFRpre}+\varepsilon_{j}
$$

Model 4b: $\Delta \mathrm{ACFR}=\beta_{0}+\beta_{1} \mathrm{CONCEN1020}+\beta_{2}$ CONCEN2050 $+\beta_{3}$ CONCEN50

$$
+\beta_{4 i} G O V_{i}+\beta_{5 i} \mathrm{DEAL}_{i}+\varepsilon_{j}
$$


Model 5a: ACFRpost $=\beta_{0}+\beta_{l} \mathrm{LSH1P}+\beta_{2 i} \mathrm{GOV}_{i}+\beta_{3 i} \mathrm{DEAL}_{i}+\beta_{4 i} \mathrm{ACFRpre}+\varepsilon_{j}$

Model 5b: $\Delta \mathrm{ACFR}=\beta_{0}+\beta_{l} \mathrm{LSH} 1 \mathrm{P}+\beta_{2 i} \mathrm{GOV}_{i}+\beta_{3 i} \mathrm{DEAL}_{i}+\varepsilon_{j}$

Model 6a: ACFRpost $=\beta_{0}+\beta_{1} \mathrm{LSH} 1 \mathrm{P}+\beta_{2} \mathrm{LSH} 1 \mathrm{PSQ}+\beta_{3 i} \mathrm{GOV}_{i}+\beta_{4 i} \mathrm{DEAL}_{i}$

$$
+\beta_{5 i} \text { ACFRpre }+\varepsilon_{j}
$$

Model 6b: $\Delta \mathrm{ACFR}=\beta_{0}+\beta_{1} \mathrm{LSH} 1 \mathrm{P}+\beta_{2} \mathrm{LSH} 1 \mathrm{PSQ}+\beta_{3 i} \mathrm{GOV}_{i}+\beta_{4 i} \mathrm{DEAL}_{i}+\varepsilon_{j}$

Model 7a: ACFRpost $=\beta_{0}+\beta_{1} \mathrm{LSH} 1 \mathrm{P}+\beta_{2} \mathrm{LSH} 1 \mathrm{PSQ}+\beta_{3} \mathrm{LSH} 1 \mathrm{PCUBE}+\beta_{4 i} \mathrm{GOV}_{i}$

$$
+\beta_{5 i} \mathrm{DEAL}_{i}+\beta_{6 i} \mathrm{ACFRpre}+\varepsilon_{j}
$$

Model 7b: $\Delta \mathrm{ACFR}=\beta_{0}+\beta_{1} \mathrm{LSH} 1 \mathrm{P}+\beta_{2} \mathrm{LSH} 1 \mathrm{PSQ}+\beta_{3} \mathrm{LSH} 1 \mathrm{PCUBE}+\beta_{4 i} \mathrm{GOV}_{i}$

$$
+\beta_{5 i} \mathrm{DEAL}_{i}+\varepsilon_{j}
$$

where: $\varepsilon_{j}$ is denoted as the error term, the exact definition of all variables are described in section 5.4 and summarized in table 5.5 .

To test the association between operating acquisition performance and the voting shares of the largest shareholders, models 6 and 7 are formed into the square and cube equations. These two models are parallel to the recognition of the non-linear relationship of Morck et al. (1988b), McConnel and Severaes (1990) and Anderson and Reeb (2003), thus allowing the coefficients on the ownership variables to estimate one or two optimal inflection points. Completing the regression with the control variables as modeled above, the expected sign can be obtained as follows. To simplify the notation, let y be the dependent variables (ACFRpost / $\triangle A C F R$ ) and $x$ be the ownership variables (LSH1P). The equation for model 6 is quadratic:

$$
y=\beta_{0}+\beta_{1} x+\beta_{2} x^{2}
$$

The turning point is calculated by differentiating $\mathrm{y}$ with respect to $\mathrm{x}$, letting $\partial y / \partial x=0$, and solving for turning point $\mathrm{x}$

$$
\begin{aligned}
& \partial y / \partial x=\beta_{1}+2 \beta_{2} x=0 \\
& x=-\beta_{1} / 2 \beta_{2}
\end{aligned}
$$


The equation for model 7 is cubic. Similar concepts are used in model 6 to obtain two turning points which then help determine convergence-of-interest and expropriation effects at the level of ownership.

$$
y=\beta_{0}+\beta_{1} x+\beta_{2} x^{2}+\beta_{3} x^{3}
$$

Differentiating $\mathrm{y}$ with respect to $\mathrm{x}$, letting $\partial y / \partial x=0$, and solving for two inflection points $\mathrm{x} 1$ and $\mathrm{x} 2(\mathrm{x} 1, \mathrm{x} 2)$ :

$$
\begin{aligned}
& \partial y / \partial x=\beta_{1}+2 \beta_{2} x+3 \beta_{3} x^{2}=0 \\
& \left(x_{1}, x_{2}\right)=\frac{-2 \beta_{2} \pm \sqrt{4 \beta_{2}^{2}-12 \beta_{1} \beta_{3}}}{6 \beta_{3}}
\end{aligned}
$$

$x_{1}$ is denoted to be the first turning point where performance starts to increase/decrease with the level of concentration and a second turning point at $x_{2}$ where performance reverses.

Additionally, by assuming that the intercept $\left(\beta_{0}\right)$ represents the average performance of widely held firms, the intersection points can be estimated to compare the performance of concentrated firms and dispersed firms. Take the cubic curve as an example, assuming $\mathrm{y}=\beta_{0}$,

$$
\begin{aligned}
& y=\beta_{0}+\beta_{1} x+\beta_{2} x^{2}+\beta_{3} x^{3}=\beta_{0} \\
& \beta_{1} x+\beta_{2} x^{2}+\beta_{3} x^{3}=0 \\
& \beta_{1}+\beta_{2} x+\beta_{3} x^{2}=0
\end{aligned}
$$

Solving for two intersection points $x_{3}$ and $x_{4}\left(x_{3}, x_{4}\right)$ :

$$
\left(x_{3}, x_{4}\right)=\frac{-\beta_{2} \pm \sqrt{\beta_{2}^{2}-4 \beta_{1} \beta_{3}}}{2 \beta_{3}}
$$

This further analysis can show that the acquisition performance of acquiring firms with majority shareholders is below/ above the average performance of the widely-held firms (the intercept, $\beta_{0}$ ) until $x_{3}$ and then remains above/below up to the ownership concentrated at the $x_{4}$ level of ownership. 


\subsubsection{Institution Mechanisms Model}

After building the seven empirical models regarding ownership concentration, another two empirical models are set for testing major hypotheses as the second stage research scheme regarding the effects of legal and extra-legal institutions. One of the seven ownership models with more representativeness is selected to be the benchmark model and the second generation governance mechanisms are further incorporated into the multiple regressions. The second generation governance mechanisms are separated into two groups as described in the research design of chapter four, section 4.2. The first group variables include both legal and extra-legal measures (ANTIDIR_high, ENFORCE, ACCTSTD and XLEG_high) as proposed by LLSV (1998) and Dyck and Zinglales (2004). The second group variables comprise newer legal system measures (ANTISDI, PUBENFORCE_high and NANTIDIR_high) as suggested by DLLS (2006). Moreover, considering the likelihood of the country effect, three dummy variables are set to control three major countries: the UK, CAN and AUS. In the end, two complete models are built in the second research scheme. Formally:

Model 8a: ACFRpost $=\beta_{0}+\beta_{1 i} \mathrm{OWN}_{i}+\beta_{2 i} \mathrm{GOV}_{i}+\beta_{3 i} \mathrm{DEAL}_{i}+\beta_{4} \mathrm{ANTIDIR}_{-}$hgih

$$
\begin{aligned}
& +\beta_{5} \text { ENFORCE }+\beta_{6} \text { ACCTSTD }+\beta_{7} \text { XLEG_high }+\beta_{8 i} \text { Country } i \\
& +\beta_{9 i} \text { ACFRpre }+\varepsilon_{j}
\end{aligned}
$$

Model 8b: $\Delta \mathrm{ACFR}=\beta_{0}+\beta_{1 i} \mathrm{OWN}_{i}+\beta_{2 i} \mathrm{GOV}_{i}+\beta_{3 i} \mathrm{DEAL}_{i}+\beta_{4} \mathrm{ANTIDIR}_{-}$hgih

$$
+\beta_{5} \text { ENFORCE }+\beta_{6} \text { ACCTSTD }+\beta_{7} \text { XLEG_high }+\beta_{8 i} \text { Country }_{i}+\varepsilon_{j}
$$

Model 9a: ACFRpost $=\beta_{0}+\beta_{1 i} \mathrm{OWN}_{i}+\beta_{2 i} \mathrm{GOV}_{1}+\beta_{3 i} \mathrm{DEAL}_{i}+\beta_{4} \mathrm{ANTISDI}$

$$
\begin{aligned}
& +\beta_{5} \text { PUBENFORCE_high }+\beta_{6} \text { NANTIDIR_high }+\beta_{7 i} \text { Country }_{i} \\
& +\beta_{8 i} \text { ACFRpre }+\varepsilon_{j}
\end{aligned}
$$

Model 9b: $\Delta \mathrm{ACFR}=\beta_{0}+\beta_{1 i} \mathrm{OWN}_{i}+\beta_{2 i} \mathrm{GOV}_{1}+\beta_{3 i} \mathrm{DEAL}_{i}+\beta_{4} \mathrm{ANTISDI}$

$$
+\beta_{5} \text { PUBENFORCE_high }+\beta_{6} \text { NANTIDIR_high }+\beta_{7 i} \text { Country }_{i}+\varepsilon_{j}
$$

where: $\varepsilon_{j}$ is denoted as the error term, the definition of all variables are described in section 5.4 and summarized in table 5.5.

It was detected that, in model 9, the explanatory variables ENFORCE, ACCTSTD and XLEG_high are highly correlated with one another (see table 5.4, panel C). To mitigate the multi-collinearity problems and to estimate the stability of regression coefficient, a reduced 
model 8.1 is constructed by excluding ACCOUNT and ENFORCE and by leaving ANTIDIR_high and XLEG_high in the model as measures of legal and extra-legal systems, respectively.

Model 8.1a: ACFRpost $=\beta_{0}+\beta_{1 i} \mathrm{OWN}_{i}+\beta_{2 i} \mathrm{GOV}_{i}+\beta_{3 i} \mathrm{DEAL}_{i}+\beta_{4} \mathrm{ANTIDIR}_{-}$hgih

$$
+\beta_{5} \mathrm{XLEG}_{-} \text {high }+\beta_{6 i} \text { Country }_{i}+\beta_{7 i} \text { ACFRpre }+\varepsilon_{j}
$$

Model 8.1b: $\Delta \mathrm{ACFR}=\beta_{0}+\beta_{1 i} \mathrm{OWN}_{i}+\beta_{2 i} \mathrm{GOV}_{i}+\beta_{3 i} \mathrm{DEAL}_{i}+\beta_{4} \mathrm{ANTIDIR}_{-}$hgih

$$
+\beta_{5} \mathrm{XLEG}_{-} \text {high }+\beta_{6 i} \text { Country }_{i}+\varepsilon_{j}
$$

where: $\varepsilon_{j}$ is denoted as the error term, the definition of all variables are described in section 5.4 and summarized in table 5.5.

Similarly, there are strong correlations in model 9 among the institutional variables ANTISDI, PUBENFORCE_high and NANTIDIR_high (table 5.4 panel C). Also, in the DLLS (2006) conclusion, public enforcement has significant negative effects. They explain that this unexpected sign is caused by concealed transactions in most cases even under countries with criminal sanctions. Considering that this index generates much controversy as discussed in section 2.5.2.3 of chapter two, the PUBENFORCE_high variable is eliminated to form a reduced model 9.1 as follows. Regression results for all above models are reported in the next chapter.

Model 9.1a: ACFRpost $=\beta_{0}+\beta_{1 i} \mathrm{OWN}_{i}+\beta_{2 i} \mathrm{GOV}_{1}+\beta_{3 i} \mathrm{DEAL}_{i}+\beta_{4} \mathrm{ANTISDI}$

$$
+\beta_{5} \text { NANTIDIR_high }+\beta_{6 i} \text { Country }_{i}+\beta_{7 i} \text { ACFRpre }+\varepsilon_{j}
$$

Model 9.1b: $\Delta \mathrm{ACFR}=\beta_{0}+\beta_{1 i} \mathrm{OWN}_{i}+\beta_{2 i} \mathrm{GOV} \beta_{1}+\beta_{3 i} \mathrm{DEAL}_{i}+\beta_{4} \mathrm{ANTISDI}$

$$
+\beta_{5} \text { NANTIDIR_high }+\beta_{6 i} \text { Country }_{i}+\varepsilon_{j}
$$

where: $\varepsilon_{j}$ is denoted as the error term, the definition of all variables are described in section 5.4 and summarized in table 5.5. 


\section{Chapter Six \\ Empirical Analysis and Discussion}

\subsection{Introduction}

This chapter reports the results of the empirical cross-sectional regression models which are presented in chapter five. First of all, section 6.2 describes the two measures of operating cash flow returns. Secondly, section 6.3 provides the descriptive statistics and correlation of the model variables. Third, section 6.4 states the outcomes from univariate analysis. Fourth, section 6.5 presents the results of multiple regressions for testing the hypotheses developed in chapter four. Finally, section 6.6 summarizes results and provides discussions.

\subsection{Operating Cash Flows Returns}

- Pre Performance

Table 6.1 presents the operating cash flow returns (pre, post, and change) for the merging and matched firms and the industry, size, and pre performance adjusted operating cash flow return. The results in panel A report a median (mean) operating cash flow return for merging firms $\left(M E G_{i}\right)$ in the three years before acquisition ranging from 11.22 percent $(11.35 \%)$ for year $t-1$ to 12.57 percent $(13.09 \%)$ for year $t-3$. The median (mean) pre-acquisition operating cash flow return for matched firms $\left(M A T_{i}\right)$ is from 12.85 percent (13.46\%) for year $\mathrm{t}-1$ to 14.21 percent $(14.38 \%)$ for year $\mathrm{t}-3$. And then the median and mean measure of industry, size, and pre performance adjusted return is calculated and tested $\left(A C F R_{i}=M E G_{i}-M A T_{i}\right)$. The mean measures are tested by One-Sample $\mathrm{t}$ test ${ }^{30}$ and the median measures are tested by Wilcoxon Signed Ranks ${ }^{31}$ test of nonparametric method. The median (mean) measure for pre-acquisition year $\mathrm{t}-3, \mathrm{t}-2$, and $\mathrm{t}-1$ is -0.91 percent $(-1.29 \%)$, -0.70 percent $(-1.57 \%)$, and -1.37 percent $(-2.11 \%)$, respectively. All the above measures are

30 The One-Sample $t$ test tests whether the mean of a single variable differs from a specified constant (SPSS). This thesis tests difference from zero.

31 The Wilcoxon Signed Ranks test is designed to test a hypothesis about the median of a population distribution. It often involves the use of matched pairs in which case it tests for a median difference of zero (Easton and McColl 1997). 
statistically different from zero. The median adjusted return over three pre-acquisition years (ACFRpre) is -0.70 percent and statistically different from zero. Similar conclusions are drawn from the measurement of mean operating performance (-1.51\%).

\section{- Post Performance}

Panel A also presents a median (mean) operating cash flow return for merging firms $\left(M E G_{i}\right)$ in the three years after acquisition ranging from 11.06 percent $(11.41 \%)$ for year $\mathrm{t}+1$ to 12.47 percent $(12.87 \%)$ for year $t+3$. The median (mean) post-acquisition operating cash flow return for matched firms $\left(M A T_{i}\right)$ is from 10.52 percent $(10.88 \%)$ for year $\mathrm{t}+1$ to 12.15 percent $(12.71 \%)$ for year $t+3$. The median (mean) measure for post-acquisition year $+1,+2$, and +3 is +0.23 percent $(+0.53 \%),+0.54$ percent $(+0.20 \%)$, and +0.17 percent $(+0.16 \%)$, respectively. As is apparent, the median and mean measures of adjusted returns in each of the three post-acquisition years are insignificant. The median adjusted return over post-acquisition years (ACFRpost) is 0.59 percent and the mean is 0.31 percent. Both are insignificant. Although these results are indistinguishable from zero, all of them are positive. Additionally, the mean measures $(0.53 \%$ to $0.16 \%)$ and the percentage of sample firms with positive adjusted returns ( $54.61 \%$ to $50.18 \%$ ) concurrently decrease from $t+1$ to $t+3$.

Comparing the results in Linn and Switzer (2001) and Powell and Stark (2005), the median adjusted return over post-merger periods is 2.84 percent and 1.55 percent with no significance, respectively. While the sample firms have lower post performance, the sign is consistent. Ghosh (2001) has particular results. He presents significantly positive mean adjusted returns but insignificant median adjusted returns in each and over post-acquisition years $(2.55 \%$ mean and $1.16 \%$ median over three years). Using industry performance as a benchmark, Healy, Palepu and Ruback (HPR, 1992) reports a significantly positive median measure $(2.8 \%)$ over five years industry adjusted cash flow returns after acquisitions.

\section{- Performance Improvement (Abnormal Returns) \\ (i) The change model}

With respect to the Ghosh (2001) suggestion, the change in operating cash flow returns $(\triangle A C F R)$ is computed in order to measure the abnormal adjusted returns of M\&A activities. The median and the mean measure of $\triangle A C F R$ are 1.73 percent and 1.82 percent, respectively. Both are significantly different from zero at the $1 \%$ level. On average, acquiring firms in the sample have acquisition-related improvements in the post-acquisition periods. 
These results are comparable to those in Linn and Switzer (2001) who also find significant results in median (1.81\%) and mean $(2.20 \%)$ abnormally adjusted cash flow returns ( $\triangle A C F R)$.

However, the results differ from Ghosh's (2001) findings. Based on industry, size, and pre performance benchmarks, he determines positive but insignificant median $(0.26 \%)$ and mean (1.25\%) abnormal adjusted returns. This result is further supported by Powell and Stark (2005). They find 0.92 percent abnormal adjusted returns without significance. Note that in these two papers the pre-acquisition performance is used to calculate the $\triangle A C F R$ as it is specifically represented by the one year before the transaction (year -1); this is because the size and performance used to select matched firms is also done as of year t- 1 . As outliers can easily bias the one-year performance, this thesis calculates the $\triangle A C F R$ benchmark by the pre median of adjusted cash flow returns over year t-3 to t- ${ }^{32}$ (HPR 1992/ 1997, Linn and Switzer 2001).

\section{(ii) The Intercept Model}

The other measure used to determine the performance improvement is by HPR (1992) intercept model. Table 6.1 panel B presents the regression results of the three-year post-acquisition median adjusted returns (ACFRpost) on the three-year pre-acquisition median adjusted returns (ACFRpre). The intercept $\alpha(1.1 \%)$ is positive and significant at the 1 percent level, which indicates that average adjusted operating performance has a significant improvement of 1.1 percent in the post-acquisition period after controlling for the effects of pre performance. The slope coefficient $\beta$ (53.7\%) is also positive and statistically different from zero. This captures the correlation in operating cash flow between the pre- and post-acquisition years as a 53.7 percent positive effect per year -- average adjusted cash flow returns tend to persist over time.

Comparing the numbers to those in prior studies, HPR (1992) finds that average post-merger performance reflects significant improvement ( $\alpha=2.8 \%$ ). Ghosh (2001) conducts a test that is similar to the one conducted by HPR and proves that merging firms may

${ }^{32}$ However, this thesis does sensitivity tests for $\triangle A C F R$ by various windows $([-1,+1],[-1,+2]$, $[-1,+3])$ applying similar approach as that used in Denis and Denis (1995). Results are qualitatively similar to the change in pre and post three-year median adjusted performance. This thesis also ran the regressions for benchmark model (model 7) and reduced models (model 8.1 and 9.1) using these alternative measures. Results where again are qualitatively similar. The detailed reports are discussed in section 8.3 of chapter eight as sensitivity analysis. 
outperform industry-median firms over pre- and post-acquisition years. He also proves that there are significant abnormal returns created from $M \& A(\alpha=2.4 \%)$ accounting for increase in industry-adjusted cash flow. Powell and Stark (2005) support Ghosh's (2001) point on the basis of an industry-median benchmark. But if on the basis of an industry, size, and pre performance benchmark, they do find significant improvement for merging firms $(\alpha=1.6 \%)$ as this thesis does.

Summarily, results in table 6.1 demonstrate that merging firms in the sample significantly underperform as compared to the benchmark firms before M\&A; the post adjusted return is not statistically distinguishable from zero but the measures of change in adjusted returns are significant at the 1 percent level when combining the significantly poor pre performance and positive post performance. The intercept model further proves significant improvements surrounding the acquisition. While results in prior literature are still mixed and the findings of this thesis is not completely comparable, an agreement indicating that operating performance of merging firms improves after M\&A events and the improvements are not due to a continuation of superior pre performance.

\section{Table 6.1 Operating Cash Flows Returns}

Sample of 282 mergers and acquisitions by 222 acquiring firms in 11 English Origin countries (Australia, Canada, India, Ireland, Israel, Malaysia, New Zealand, Singapore, South Africa, Thailand and United Kingdom) between 1997 and 2001 for completed takeovers over US\$ 10 million are obtained from the Thomson Financial Securities Data's SDC PlatinumTM Worldwide Mergers \& Acquisitions Database. Operating cash flow return (OCFR) is calculated as operating cash flow divided by market value of asset. Operating cash flow is defined as operating income before depreciation. Post-acquisition performance for each deal is measured by the operating cash flow return of the surviving acquirer after transaction. Pre-acquisition performance is calculated as a weighted-average of the operating cash flow return for the bidder and the target included (MEGi pre and post). The weights are based on the market values of assets of both companies in the year before acquisition. Post- and pre-acquisition performances of the matched firms are measured as weighted-average of the operating cash flow rates (MATi pre and post). Industry, Size, and Pre performance Adjusted Operating Cash Flow Rates (ACFR) is operating cash flow rates of merged firms minus those of matched firms. The change in industry, size, and pre performance adjusted cash flow rate $(\triangle \mathrm{ACFR})$ is defined as 3-year median ACFRpost minus 3 year-median ACFRpre. Outliers have been winsorized using Huber's M estimator approach. *** denotes significance at the $1 \%$ level, $* *$ significance at the $5 \%$ level, $*$ significance at the $10 \%$ level.

Panel A Operating Cash Flows

\begin{tabular}{|c|c|c|c|c|c|c|c|c|c|c|c|c|}
\hline \multirow{2}{*}{$\begin{array}{l}\text { Year Relative to } \\
\text { Acquisition }\end{array}$} & \multicolumn{3}{|c|}{ Mergering Firms (MEG $i$ ) } & \multicolumn{3}{|c|}{ Matched Firms (MAT $i$ ) } & \multicolumn{6}{|c|}{$\begin{array}{l}\text { Industry, Size, and Pre-performance Adjusted } \\
\text { (MEGi-MAT } i)\end{array}$} \\
\hline & $\mathrm{N}$ & Mean\% & Median\% & $\mathrm{N}$ & Mean\% & Median\% & $\mathrm{N}$ & Mean\% & & Median $\%$ & & Positive \\
\hline-3 & 194 & 13.09 & 12.57 & 194 & 14.38 & 14.21 & 194 & -1.29 & $* *$ & -0.91 & $* *$ & $43.81 \%$ \\
\hline-2 & 260 & 12.27 & 11.91 & 260 & 13.84 & 13.32 & 260 & -1.57 & $* * *$ & -0.70 & $* * *$ & $47.31 \%$ \\
\hline-1 & 282 & 11.35 & 11.22 & 282 & 13.46 & 12.85 & 282 & -2.11 & $* * *$ & -1.37 & $* * *$ & $39.01 \%$ \\
\hline 1 & 282 & 11.41 & 11.06 & 282 & 10.88 & 10.52 & 282 & 0.53 & & 0.23 & & $54.61 \%$ \\
\hline 2 & 280 & 11.81 & 11.72 & 280 & 11.61 & 11.12 & 280 & 0.20 & & 0.54 & & $52.14 \%$ \\
\hline 3 & 279 & 12.87 & 12.47 & 279 & 12.71 & 12.15 & 279 & 0.16 & & 0.17 & & $50.18 \%$ \\
\hline \multicolumn{7}{|c|}{ ACFRpre: Median for years ( -3 to -1$)$} & 282 & -1.51 & $* * *$ & -0.70 & $* * *$ & $43.26 \%$ \\
\hline \multicolumn{7}{|c|}{ ACFRpost: Median for years $(+1$ to +3$)$} & 282 & 0.31 & & 0.59 & & $53.19 \%$ \\
\hline \multicolumn{7}{|c|}{$\triangle \mathrm{ACFR}$ : change in operating cash flow rate (ACFRpost -ACFRpre) } & 282 & 1.82 & $* * *$ & 1.73 & $* * *$ & $60.99 \%$ \\
\hline
\end{tabular}

Panel B Regression of ACFRpost on ACFRpre

ACFRpost $=0.011^{* * *+0.537 * * * \text { ACFRpre }}$

$\mathrm{F}=101.832 * * *$

adj. $R^{2}=26.4 \%$ 


\subsection{Descriptive Statistics}

Table 6.2 displays summary statistics for all variables in the full sample along with a breakdown of three major countries (Australia, Canada, and the UK). When comparing adjusted operating cash flows returns across countries, it becomes clear that Canadian firms have the best mean/median pre performance $(-0.24 \%$ / $0.42 \%)$ and post-performance $(0.73 \%$ / 1.18\%) (i.e., performance was not statistically different from matched firms). Sample firms from other English origin countries, however, experience the poorest average mean/median pre-merger adjusted performance $(-2.78 \% /-1.48 \%)$ in the post-merger period $(1.1 \% /$ $0.14 \%$ ), thus leading them to experience greater improvements in the change of adjusted operating cash flow returns $(3.88 \% / 4.43 \%)$. All statistics for ACFRpre and $\triangle A C F R$ for AUS, UK and other countries are significantly different from zero and consistent with the results of the total sample.

For ownership variables, it is evident that concentrated ownership at the $\mathbf{1 0}$ percent threshold is dominant in the total sample (71\% in Australia, 64\% in Canada, 51\% in the UK, $74 \%$ for 'others' and $60 \%$ for total sample). There are only 16 firms out of 141 (11\%) with a 20 percent or more large shareholder in the UK. This is the case in 38 percent of the Australian sample, in 53 percent of cases in Canada, in 52 percent of cases in 'others' and in 31 percent of cases in the total sample. Canada has the largest number of controlling large shareholders (28\% of firms have a shareholder with over $\mathbf{5 0}$ percent of voting shares) followed by the other English origin countries (21\%); there is only one case in the UK and there is zero in Australia. The median voting shares of the largest shareholder is $10 \%$ in the UK (below overall sample median of 11\%), 14\% in Australia, 27\% in Canada, and 24\% in other English origin countries. By comparison, La Porta, Lopez-de-Silanes and Shleifer (1999), use a 10 percent cut off and when looking at medium-sized firms find concentrated ownership in $90 \%$ of cases in Australia, $90 \%$ in the UK, $60 \%$ in Canada, and $82.5 \%$ on average in 'others'. At a $20 \%$ cut off, they find $70 \%$ concentration in Australia, $40 \%$ in the UK and Canada, and $57 \%$ on average for 'others'.

For governance variables, the separation of voting and cash flow rights is present in $17 \%$ of the sample but is most common in Australia (63\%) and Canada (33\%) rather than in the UK (4\%) or in 'others' (5\%). CEOs are linked to controlling shareholders in 14\% of cases but are most prevalent in Australia (17\%) and Canada (29\%). CEO is also Chairman 
in $26 \%$ of cases; Australia ( $8 \%$ ) and the UK (22\%) are below average whereas Canada (36\%) and 'others' (31\%) are above. There exist multiple large shareholders in and around 20 percent of cases across the total sample. This percentage is lower than that in the Maury (2005) study which examines 1672 Western European non-financial firms and reports 36 percent of the sample firms as having multiple block holders. Median board size ranges from seven to ten members across countries and the average is 9.58 which is close to the average UK board size (8.56) reported in Conyon and Peck (1998). The average ratio of independent directors is 54 percent in the overall samples. AUS (63\%) and CAN (67\%) are above the average whereas the UK (46\%) and "others" (50\%) are below.

It is clear from deal characteristics that the quasi-totality of deals are with a target an English origin country (92\%) and that most deals are not hostile (97\%). Cernat (2004) points out that there are relatively few hostile deals in Europe. Between 16 percent and 19 percent of deals are entirely paid with stock as compared to the 11.3 percent of pure stock European deals in Faccio and Masulis (2005). Overall, 36 percent of deals are classified as being in the same industry (both target and acquirer having same 4-digit SIC code). Compared to the 13.29 percent level in Goergen and Renneboog (2004) for European takeovers, there are relatively fewer deals (7\%) involving multiple bidders and only 16 percent of those deals are initiated by acquirers with a toehold. The median 1-day premium is $31.02 \%$ overall, the highest in the UK (37.22\%) and lowest in Canada (19.73\%). The average size of acquirers is about $5.63(\exp (1.73))$ times larger than that of targets and the average level of leverage of acquiring firms is 16 percent (exp (-1.81)) which is relatively low if compared to the 21.5 percent in Maury's (2005) examination of Western European firms.

Looking at the institutional variables, 84 percent of the sample firms in four sample countries (Canada, India, South Africa, and the UK) are classified as having a high level of initial anti-director right index. The mean (median) BRP enforcement index and accounting standard rating of all sample companies is 20.04 (20.41) and 75.36 (78.00), separately. Acquiring firms in Australia and Canada have higher enforcement index (20.44 for AUS, 21.13 for CAN) but lower accounting disclosure ratings (75 for AUS, 74 for CAN). There are 174 deals $(62 \%)$ in the high rank of extra-legal systems including acquirers in Australia, Malaysia, New Zealand, Singapore, and the UK. Turning to the new legal measures of Djankov, La Porta, Lopez-de-Silanes and Shleifer (DLLS, 2006), the average 
score of anti-self dealing index of all sample firms is 0.82 .59 percent of deals in five sample countries including India, Malaysia, Singapore, South Africa, and the UK are cataloged as having the top scores of revised anti-director rights. Canada (0.65) and Australia (0.79) have lower than mean anti-self-dealing indexes and Canada is excluded from the new list of countries with highly revised anti-director right. The UK has both a higher than mean anti-self-dealing index (0.93) and a high anti-director rights index. Surprisingly, a relatively low fraction (29\%) of deals belong to the acquirers in countries with strong public enforcement (all three major countries are not included).

As stated in chapter five, section 5.4.4, the data for accounting standards is missing in Ireland (11 deals) and the extra-legal index is missing in India (6 deals) and Ireland (11 deals). The decision processes to handle these missing data are as follows. First, the missing and non-missing cases are compared based on variables where information is complete. For example, samples with extra-legal index and samples without extra-legal index are compared in terms of acquisition performance measures whose data is complete. The results show that there is no significant difference between these two groups (with and without missing values) on both two-performance measures (ACFRpost and $\triangle A C F R$ ). Second, these two variables with missing values (accounting standard and extra-legal index) are kept in the analysis because this is not a substantial proportion (3.9\% for accounting standard and $6.0 \%$ for extra-legal index) of cases with lacking data. Third, deals in the two countries with missing values (India and Ireland) are retained and those missing values are replaced with some other values. This is because sample firms in this thesis are selected based on the English origin countries. If these two countries were dropped out subjects for these limited data, the remaining cases may not be a truly representative of the population. Finally, the mean of sample countries is adopted as the replacement value. This is a widely used technique for dealing with missing values. The average score applied to replace the missing values for accounting standards is 71 . The mean of sample countries for each single proxy of the extra-legal index is calculated and used to replace the missing value. The detailed figures are shown in table 5.4 . 
Table 6.2 Descriptive Statistics (By Sample Country)

Sample of 282 mergers and acquisitions by 222 acquiring firms in 11 English Origin countries (Australia, Canada, India, Ireland, Israel, Malaysia, New Zealand, Singapore, South Africa, Thailand and United Kingdom) between 1997 and 2001 for completed takeovers over US\$ 10 million are obtained from the Thomson Financial Securities Data's SDC PlatinumTM Worldwide Mergers \& Acquisitions Database. ACFRpre and ACFRpost is the pre and post industry, size, and pre performance adjusted cash flow return. $\triangle A C F R$ is for the change in industry, size, and pre performance adjusted cash flow return. Outliers have been winsorized using Huber's M estimator approach. *,**,*** indicate whether ACFR measures are statistically different from zero at $10 \%, \% 5$ and $1 \%$ significance levels, respectively. See table 5.5 for variable definitions.

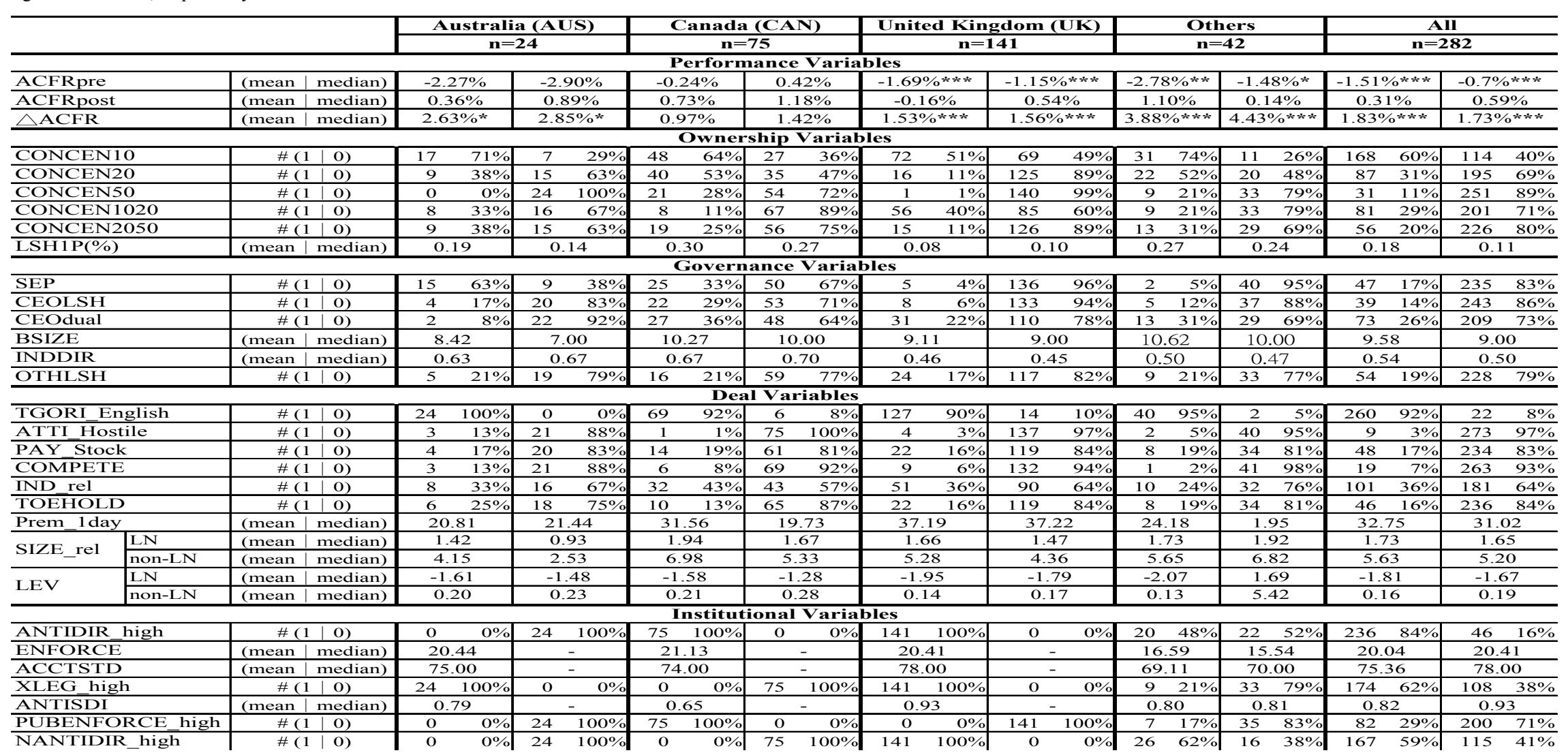




\subsection{Univariate Analysis}

Table 6.3, panel A examines the relationship between performance and the ownership, governance, deals and institutional variables on a univariate basis. ${ }^{33}$ Looking at the ownership variables, the LSH1P voting share (\%) of the largest shareholder is positively but not significantly correlated with performance (0.018 in ACFRpost, 0.029 in $\triangle A C F R$ ). Turning to CONCEN10, the mean (median) post adjusted cash flow return (ACFRpost) for the 168 firms with a large shareholder over $10 \%$ is $0.26 \%(0.59 \%)$ whereas it is $0.38 \%(0.64 \%)$ for the 114 widely-held firms. The mean (median) change in adjusted cash flow returns $(\triangle A C F R)$, is $1.67 \%(1.35 \%)$ for firms with a large shareholder and $2.04 \%(2.44 \%)$ for widely-held firms, both differences being insignificant. The performance for various sub-groups is also analyzed. The CONCEN1020 group has the poorest post performance whereas the CONCEN20 and CONCEN2050 groups perform better than other groups. Panel B further investigates and confirms the above results suggesting a potential non-linear relationship between performance and ownership. These univariate results suggest that firms with lower levels of concentration make poorer M\&A decisions.

Governance variables are weakly related to the change in adjusted cash flow returns $(\triangle A C F R)$. Firms with controlling CEOs outperform their peers on post adjusted performance (ACFRpost) at the 5\% level of significance. This is consistent with Anderson and Reeb (2003) who suggest that family CEOs view themselves as stewards of the firm. Further, board size in this sample has a significantly negative correlation with ACFRpost. This evidence is parallel to that in prior studies. For example, Jensen (1993) argues that keeping boards small should improve firm performance. Yermack (1996) suggests that large boards are associated with problems such as communication and effective decision-making. Conyon and Peck (1998) also find empirical evidence of a negative relationship between board size and firm performance. Besides, companies with chairman in the CEO position have a poor change in operating cash flow returns

33 The Independent-Sample $t$ test procedure is mainly used to compare the means for two groups of each dummy variable. Pearson's correlation coefficient is computed to test the bivariate correlations between two performance measures and a single continuous variable. Besides, this thesis further performs non-parametric Mann-Whitney U test for all dummy variables. Results are consistent with $\mathrm{T}$ tests and shown in appendix $\mathrm{C}$. 
$(\triangle A C F R)$ at the 10 percent of significance. This result weakly supports the arguments of Brickley, Coles and Jarrell (1997) and Vefeas and Theodorou (1998).

Among the deal variables, the COMPETE variable has a significantly negative relationship with $\triangle A C F R$. This evidence is consistent with Duggal and Millar (1999) and shows multiple bidders benefiting targets but not bidders. The correlation between premium and both performance measures (ACFRpost \& $\triangle A C F R$ ) is not significant. The correlation between the relative size and ACFRpost is -0.238 , significant $(-0.040$ for $\triangle A C F R)$. These results contrast with some studies which suggest that deal size is not related to post-merger returns (Frank and Harris 1989, HPR 1992, Agrawal et al. 1992) but support the view that larger deviations in firm size leads to poorer acquisition performance (Loughran and Vijh 1997, Moeller, Schlingemann and Stulz 2004). The findings support the debt-monitoring hypothesis by documenting a significant relation between the leverage ratio, $L E V$, and post adjusted performance (ACFRpost) at the 5\% level. Except for these three deal variables, the univariate results do not reveal any other transaction characteristics that are significant determinants of acquisition performance.

The individual institutional variables have little impact on operating acquisition performance when adopting univariate analysis. The companies with better investor protection in both initial (ANTIDIR_high) and revised anti-director rights indexes (NANTIDIR_high) have positive but not significant mean and median measures of post-acquisition performance (ACFRpost). Results are similar to the change in adjusted operating performance $(\triangle A C F R)$. The correlation between the level of the anti-self-dealing index (ANTISDI) and ACFRpost is negative (-0.068) while that with $\triangle A C F R$ is positive (0.002). None of the relationships are significant. The most striking result emerging from the data is that Enforcement is the only legal variable with significant but negative associations with both post-acquisition (ACFRpost) and the change in adjusted performance $(\triangle A C F R)$. This result is apparently counter-intuitive. One possible explanation is the argument for optimal legal enforcement as discussed by prior research. For example, Burkart, Panunzi and Shleifer (2003) argue that too strong legal enforcement may reduce a professional manager's private benefits and may force company owners to pay higher wages in order to induce managers to run for a company. They point out that legal enforcement is not free. If better legal protection imposes higher enforcement costs on the society, then it is better to compare those legal costs with the 
social costs of private monitoring. Besides, Posner (1998) argues that higher legal enforcement will encourage the decision makers to seek other informal substitutes that will lead to even higher costs. A more detailed literature review is described in chapter two, section 2.5.2.1. Due to the data limitation, this thesis can only illustrate the legal enforcement costs existing in acquiring firms with common law legal origins. There is no further evidence to account for the reason why stronger legal enforcement leads to poorer acquisition performance. All results and tests reported so far are based on univariate analysis. Additional results should be obtained using cross-sectional regression models to test whether those effects continue to hold after controlling for other factors that are expected to affect acquiring performance.

\section{Table 6.3 Univariate Statistics of All Independent Variables}

Sample of 282 mergers and acquisitions by 222 acquiring firms in 11 English Origin countries (Australia, Canada, India, Ireland, Israel, Malaysia, New Zealand, Singapore, South Africa, Thailand and United Kingdom) between 1997 and 2001 for completed takeovers over US\$10 million are obtained from the Thomson Financial Securities Data's SDC PlatinumTM Worldwide Mergers \& Acquisitions Database. ACFRpre and ACFRpost is the pre and post industry, size, and pre performance adjusted cash flow return. $\triangle A C F R$ is for the change in industry, size, and pre performance adjusted cash flow return. Outliers have been winsorized using Huber's $M$ estimator approach. T tests of differences are presented for dummy variables and Pearson correlations for continuous variables *** denotes significant at the $1 \%$ level, ** significant at the $5 \%$ level, * significant at the $10 \%$ level. See table 5.5 for variable definitions.

Panel A All variables

\begin{tabular}{|c|c|c|c|c|c|c|c|c|c|c|c|}
\hline \multirow{2}{*}{\multicolumn{2}{|c|}{ Full Sample $(\mathrm{N}=282)$}} & \multirow{2}{*}{\multicolumn{2}{|c|}{ Count }} & \multicolumn{4}{|c|}{ ACFRpost } & \multicolumn{4}{|c|}{$\triangle \mathrm{ACFR}$} \\
\hline & & & & $\begin{array}{c}\text { Mean } \\
\%\end{array}$ & \begin{tabular}{|c|} 
Median \\
$\%$
\end{tabular} & $\begin{array}{l}\text { SD } \\
\%\end{array}$ & $\begin{array}{c}\text { T test/ } \\
\text { Pearson }\end{array}$ & $\begin{array}{c}\text { Mean } \\
\% \\
\end{array}$ & \multirow[t]{2}{*}{$\begin{array}{c}\text { Median } \\
\% \\
\end{array}$} & \multirow[t]{2}{*}{$\begin{array}{l}\mathrm{SD} \\
\%\end{array}$} & \multirow[t]{2}{*}{$\begin{array}{c}\mathrm{T} \text { test/ } \\
\text { Pearson }\end{array}$} \\
\hline \multicolumn{9}{|c|}{ Ownership Variables } & & & \\
\hline \multirow[t]{2}{*}{ CONCEN10 } & $\mathrm{Y}$ & 168 & $60 \%$ & 0.26 & 0.59 & 7.68 & \multirow{2}{*}{-0.135} & 1.67 & 1.35 & 7.24 & \multirow{2}{*}{-0.435} \\
\hline & $\mathrm{N}$ & 114 & $40 \%$ & 0.38 & 0.64 & 6.68 & & 2.04 & 2.44 & 6.72 & \\
\hline \multirow[t]{2}{*}{ CONCEN1020 } & $\mathrm{Y}$ & 81 & $29 \%$ & 0.24 & 0.53 & 7.23 & \multirow{2}{*}{-0.806} & 0.31 & -0.36 & 7.13 & \multirow{2}{*}{-2.309 ** } \\
\hline & $\mathrm{N}$ & 201 & $71 \%$ & 0.53 & 0.68 & 7.30 & & 2.43 & 2.47 & 6.91 & \\
\hline \multirow[t]{2}{*}{ CONCEN20 } & $\mathrm{Y}$ & 87 & $31 \%$ & 0.73 & 0.68 & 8.08 & \multirow{2}{*}{0.646} & 2.94 & 2.47 & 7.15 & \multirow{2}{*}{1.789 * } \\
\hline & $\mathrm{N}$ & 195 & $69 \%$ & 0.12 & 0.54 & 6.90 & & 1.32 & 1.49 & 6.93 & \\
\hline \multirow[t]{2}{*}{ CONCEN2050 } & $\mathrm{Y}$ & 56 & $20 \%$ & 0.28 & - 1.40 & 7.91 & \multirow{2}{*}{-0.035} & 3.49 & 2.41 & 7.33 & \multirow{2}{*}{1.992 ** } \\
\hline & $\mathrm{N}$ & 226 & $80 \%$ & 0.32 & 1.08 & 7.13 & & 1.41 & 1.66 & 6.90 & \\
\hline \multirow[t]{2}{*}{ CONCEN50 } & $\mathrm{Y}$ & 31 & $11 \%$ & 1.54 & 2.95 & 8.46 & \multirow{2}{*}{0.998} & 1.95 & 2.47 & 6.83 & \multirow{2}{*}{0.104} \\
\hline & $\mathrm{N}$ & 251 & $89 \%$ & 0.16 & 0.34 & 7.12 & & 1.81 & 1.56 & 7.06 & \\
\hline LSH1P (\%) & - & 168 & $60 \%$ & - & & & 0.018 & & & & 0.029 \\
\hline \multicolumn{12}{|c|}{ Governance Variables } \\
\hline \multirow[t]{2}{*}{ SEP } & $\mathrm{Y}$ & 47 & $17 \%$ & -0.91 & -1.83 & 8.54 & \multirow{2}{*}{-1.100} & 0.82 & 0.75 & 6.89 & -1.072 \\
\hline & $\mathrm{N}$ & 235 & $83 \%$ & 0.55 & 0.79 & 6.99 & & 2.02 & 1.76 & 7.05 & \\
\hline CEOLSH & Y & 39 & $14 \%$ & 2.62 & 2.96 & 7.84 & 147 & 1.61 & 2.47 & 6.96 & -0.208 \\
\hline & $\mathrm{N}$ & 243 & $86 \%$ & -0.06 & 0.19 & 7.13 & & 1.86 & 1.63 & 7.05 & -0.200 \\
\hline CEOdual & Y & 73 & $26 \%$ & 0.81 & 1.23 & 7.68 & 0676 & 0.61 & 1.01 & 7.53 & $-1719^{*}$ \\
\hline & $\mathrm{N}$ & 209 & $74 \%$ & 0.14 & 0.54 & 7.14 & & 2.25 & 2.06 & 6.81 & \\
\hline BSIZE (\#) & - & 287 & $100 \%$ & - & & & $-0.168^{* * * *}$ & & & & -0.052 \\
\hline INDDIR (\#) & - & 287 & $100 \%$ & & & & -0.100 & & & & -0.075 \\
\hline OTHLSH & Y & 54 & $19 \%$ & 1.02 & 0.74 & 8.54 & 0700 & 3.22 & 2.35 & 7.97 & 477 \\
\hline & $\mathrm{N}$ & 228 & $81 \%$ & 0.14 & 0.59 & 6.96 & 0.100 & 1.49 & 1.60 & 6.76 & 1.411 \\
\hline
\end{tabular}


Table 6.3 (Continued)

\begin{tabular}{|c|c|c|c|c|c|c|c|c|c|c|c|}
\hline \multicolumn{12}{|c|}{ Deal Variables } \\
\hline \multirow[t]{2}{*}{ TGORI_English } & Y & 260 & $92 \%$ & 0.31 & 0.59 & 7.43 & \multirow{2}{*}{0.056} & 1.83 & 1.73 & 7.08 & \multirow{2}{*}{0.082} \\
\hline & $\mathrm{N}$ & 22 & $8 \%$ & 0.25 & 0.65 & 5.33 & & 1.71 & 1.78 & 6.43 & \\
\hline \multirow[t]{2}{*}{ ATTI_Hostile } & $\mathrm{Y}$ & 9 & $3 \%$ & 0.88 & 1.69 & 6.27 & \multirow{2}{*}{0.237} & 3.17 & 3.86 & 4.66 & \multirow{2}{*}{0.585} \\
\hline & $\mathrm{N}$ & 273 & $97 \%$ & 0.29 & 0.54 & 7.32 & & 1.78 & 1.69 & 7.09 & \\
\hline \multirow[t]{2}{*}{ PAY_Stock } & $\mathrm{Y}$ & 48 & $17 \%$ & -1.05 & -0.08 & 6.79 & \multirow{2}{*}{-1.420} & 1.64 & 1.31 & 7.75 & \multirow{2}{*}{-0.202} \\
\hline & $\mathrm{N}$ & 234 & $83 \%$ & 0.59 & 0.76 & 7.36 & & 1.86 & 1.94 & 6.88 & \\
\hline \multirow[t]{2}{*}{ COMPETE } & $\mathrm{Y}$ & 19 & $7 \%$ & -1.50 & -1.83 & 7.35 & \multirow{2}{*}{-1.123} & -2.58 & -0.85 & 6.85 & \multirow{2}{*}{$-2.866^{* * *}$} \\
\hline & $\mathrm{N}$ & 263 & $93 \%$ & 0.44 & 0.68 & 7.27 & & 2.14 & 2.11 & 6.94 & \\
\hline \multirow[t]{2}{*}{ IND_rel } & $\mathrm{Y}$ & 101 & $36 \%$ & -0.06 & -0.07 & 7.35 & \multirow{2}{*}{-0.637} & 2.11 & 1.42 & 7.22 & \multirow{2}{*}{0.509} \\
\hline & $\mathrm{N}$ & 181 & $64 \%$ & 0.52 & 0.79 & 7.25 & & 1.66 & 2.07 & 6.93 & \\
\hline \multirow[t]{2}{*}{ TOEHOLD } & $\mathrm{Y}$ & 46 & $16 \%$ & 0.37 & 0.27 & 6.32 & \multirow{2}{*}{0.065} & 2.54 & 2.77 & 6.19 & \multirow{2}{*}{0.756} \\
\hline & $\mathrm{N}$ & 236 & $84 \%$ & 0.30 & 0.62 & 7.46 & & 1.68 & 1.57 & 7.18 & \\
\hline PREM_1day (\%) & - & 255 & $90 \%$ & - & - & - & -0.016 & - & -1 & -1 & 0.034 \\
\hline SIZE_rel (\#) & - & 274 & $97 \%$ & - & - & - & $-0.238^{* * *}$ & - & - & - & -0.040 \\
\hline $\operatorname{LEV}(\#)$ & - & 263 & $93 \%$ & - & - & _. & $0.136^{* *}$ & - & -1 & 1 & -0.067 \\
\hline \multicolumn{12}{|c|}{ Institutional Variables } \\
\hline \multirow[t]{2}{*}{ ANTIDIR_high } & Y & 236 & $84 \%$ & 0.50 & 1.00 & 7.21 & \multirow{2}{*}{0.988} & 1.86 & 1.73 & 7.13 & \multirow{2}{*}{0.200} \\
\hline & $\mathrm{N}$ & 46 & $16 \%$ & -0.66 & -0.37 & 7.65 & & 1.63 & 1.83 & 6.50 & \\
\hline ENFORCE (\#) & - & 282 & $100 \%$ & - & - & $-\exists$ & $-0.132^{* *}$ & - & - & - & -0.182 \\
\hline $\operatorname{ACCTSTD~(\# )~}$ & - & 271 & $96 \%$ & - & - & - & -0.078 & 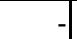 & 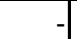 & - & -0.116 \\
\hline \multirow[t]{2}{*}{ XLEG_high } & $\mathrm{Y}$ & 174 & $62 \%$ & -0.27 & 0.54 & 6.69 & \multirow{2}{*}{-1.637} & 1.65 & 1.70 & 6.89 & \multirow{2}{*}{-0.524} \\
\hline & $\mathrm{N}$ & 108 & $38 \%$ & 1.25 & 1.21 & 8.08 & & 2.10 & 2.04 & 7.26 & \\
\hline ANTISDI (\#) & - & 282 & $100 \%$ & - & - & & -0.068 & - & 1 & - & 0.002 \\
\hline \multirow[t]{2}{*}{ PUBENFORCE_high } & $\mathrm{Y}$ & 82 & $29 \%$ & 0.54 & 0.89 & 7.85 & \multirow{2}{*}{0.342} & 0.96 & 1.56 & 7.18 & \multirow{2}{*}{-1.316} \\
\hline & $\mathrm{N}$ & 200 & $71 \%$ & 0.21 & 0.54 & 7.05 & & 2.17 & 1.79 & 6.95 & \\
\hline NANTIDIR_high & $\mathrm{Y}$ & 167 & $59 \%$ & 0.33 & 0.73 & 6.99 & 0.047 & 2.18 & 1.82 & 7.20 & 1042 \\
\hline & $\mathrm{N}$ & 115 & $41 \%$ & 0.28 & 0.53 & 7.71 & & 1.30 & 1.49 & 6.76 & \\
\hline
\end{tabular}

Panel B Further look at ownership

\begin{tabular}{|c|c|c|c|c|c|c|}
\hline Full Sample $(\mathrm{N}=282)$ & \multicolumn{3}{|c|}{$\begin{array}{l}\text { ACFRpost } \\
\text { (\% positive) }\end{array}$} & \multicolumn{3}{|c|}{$\begin{array}{l}\triangle \mathrm{ACFR} \\
\text { (\% positive) }\end{array}$} \\
\hline $\begin{array}{c}\text { Widely held } \\
(\mathrm{N}=114)\end{array}$ & $\begin{array}{c}0.38 \\
(52.6 \%) \\
\end{array}$ & $\begin{array}{c}0.38 \\
(50.0 \%) \\
\end{array}$ & $\begin{array}{c}0.38 \\
(50.0 \%) \\
\end{array}$ & $\begin{array}{c}2.04 \\
(61.2 \%) \\
\end{array}$ & $\begin{array}{c}2.04 \\
(61.2 \%) \\
\end{array}$ & $\begin{array}{c}2.04 \\
(61.2 \%) \\
\end{array}$ \\
\hline $\begin{array}{c}\text { CONCEN1020 } \\
(\mathrm{N}=81)\end{array}$ & \multirow[t]{3}{*}{$\begin{array}{c}0.26 \\
(50.9 \%)\end{array}$} & $\begin{array}{c}-0.24 \\
(50.6 \%) \\
\end{array}$ & $\begin{array}{c}-0.24 \\
(50.6 \%) \\
\end{array}$ & \multirow[t]{3}{*}{$\begin{array}{c}1.67 \\
(54.4 \%)\end{array}$} & $\begin{array}{c}0.31 \\
(48.1 \%) \\
\end{array}$ & $\begin{array}{c}0.31 \\
(48.1 \%) \\
\end{array}$ \\
\hline $\begin{array}{c}\text { CONCEN2050 } \\
(\mathrm{N}=56)\end{array}$ & & \multirow[t]{2}{*}{$\begin{array}{c}0.73 \\
(51.1 \%)\end{array}$} & $\begin{array}{c}0.28 \\
(43.1 \%) \\
\end{array}$ & & \multirow[t]{2}{*}{$\begin{array}{c}2.94 \\
(60.0 \%)\end{array}$} & $\begin{array}{c}3.49 \\
(58.6 \%)\end{array}$ \\
\hline $\begin{array}{c}\text { CONCEN50 } \\
(\mathrm{N}=31)\end{array}$ & & & $\begin{array}{c}1.54 \\
(65.6 \%) \\
\end{array}$ & & & $\begin{array}{c}1.95 \\
(62.5 \%) \\
\end{array}$ \\
\hline Test of difference & -0.135 & 0.380 & 0.452 & -0.435 & $3.070^{* *}$ & $2.371^{*}$ \\
\hline
\end{tabular}




\subsection{Cross-Sectional Regression Results}

\subsubsection{Regression Results at First Stage \\ -For Ownership and $1^{\text {st }}$ Generation Governance}

Table 6.4 reports the first level regression results for the two operating performance measures on ownership structure after controlling for governance mechanisms and transaction characteristics. Panel A provides results for the post performance measure, ACFRpost. It is clear that all models are significant and that those adjusted R squares are between 28.6 and 31.6 percent. Panel B shows results for the change in performance, $\triangle A C F R$. All models are also significant and have adjusted $\mathrm{R}$ squares between 2.4 and 6.2 percent.

\section{- Evidence on Ownership Structure}

Results considering ownership further confirm the non-linear relationship between ownership of the largest shareholder and the two operating performance measures. The presence of a large shareholder (more than $10 \%$ ) does not significantly improve either measures (Models 1 in panel A and B). However, the presence of a large shareholder (more than 20\%) suggests over performance in both measures by 0.024 percent for ACFRpost and 0.026 percent for $\triangle A C F R$ (Models 2 in panel A and B). When firms with large shareholders between 10 percent and 20 percent ownership (CONCEN1020) and more (CONCEN20) are separated, it is evident that the CONCEN1020 group underperforms $(-0.025 \%$ for ACFRpost and $-0.027 \%$ for $\triangle A C F R$, both significant) whereas the CONCEN20 group outperforms the widely-held group (though not significantly).

A continuous variable $L S H 1 P$ (Models 5 to 7 ) is used in order to investigate the actual level of concentration. Given the indications of a non-linear relationship a quadratic and cubic relationship is examined by testing the second order (model 6) and the third order terms (model 7) in the regression models. Model 5, the linear model, suggests that post performance (change in performance) increases by 0.0235 percent $(0.021 \%)$ for a one percent change in concentration, but that linear relationship is not significant. Instead, all ownership variables (LSH1P, LSH1PSQ, LSH1PCUBE) in model 7 are statistically significant at the 5 percent levels. Thus it can be argued that the cubic 
model (Model 7) better fits the data and captures the relationship between ownership and the acquisition improvements. Since this cube relationship to some degree covers the results from prior models (low level controlled underperformance, higher controlled improved), model 7 is proposed as a benchmark regression model at the first stage research scheme and is brought into the second stage research framework in order to test the effects of second generation governance mechanisms: legal and extra-legal systems.

While the correlation matrix is not presented here, there is no serious correlation between variables $(\mathrm{p} \leqq 0.50)$. A variance inflation factors index (VIF) is used to check for evidence of multicollinearity in all eight models; no variable (except the LSH1SQ, LSH1CUBE as expected) has a VIF greater than two in the seven models for both $A C F R$ post and $\triangle A C F R$. Furthermore, the relative stability of results across various model specifications is another sign that multicollinearity is not a serious issue.

\section{Interception and Inflection Points of Model 7}

Another point of investigation considers the inflection points of the entire ownership curve as related to the two performance measures. For the post performance (ACFRpost) in Panel A of Model 7, a first inflection point is discovered around 14.25 percent where performance starts to increase with the level of concentration (ACFRpost at the first inflection point is around 0.041) and a second inflection point is discovered around 61.30 percent where performance starts to taper off (ACFRpost at the second inflection point is around 0.087). Further analysis shows that the curve stays below the level of widely-held firms (the intercept, 0.056) up to the 32.37 percent level of ownership and remains above the level of widely-held firms up to 80.96 percent. Also, performance of ownership dips down below zero around 93 percent of ownership but the maximum level of ownership in this sample is 87 percent. Therefore, the entire ownership curve for post performance is always above zero.

In panel $\mathrm{B}$, similar results appear for the change in performance $(\triangle A C F R)$ with inflexion points around 14.42 percent (change in ACFR at the first inflexion point is around 0.012 ) and 60.92 percent $(\triangle A C F R$ at the second inflexion point is around 0.058 ). The ownership curve is below the level of widely-held firms (the intercept, 0.028) up to the 32.90 percent of ownership and remains above that level until the 80.12 percent of ownership. Performance is below zero around the 86 percent of ownership indicating that 
the two controlling firms in the sample with 87 percent of ownership have a negative estimated $\triangle A C F R$ around -0.002 .

Figure 6.1 demonstrates a clear trend of the above analysis. Hence, parallel to Ben Amar and André (2006) and others, firms with concentrated ownership structures make good M\&A decisions on average. However, at lower levels of concentration there is some evidence that these firms perform more poorly than widely-held firms or more concentrated ones. Anderson and Reeb (2003) show that US family firms outperform non-family firms over the entire spectrum of ownership levels, tapering off from 30 percent and decreasing around 60 percent.
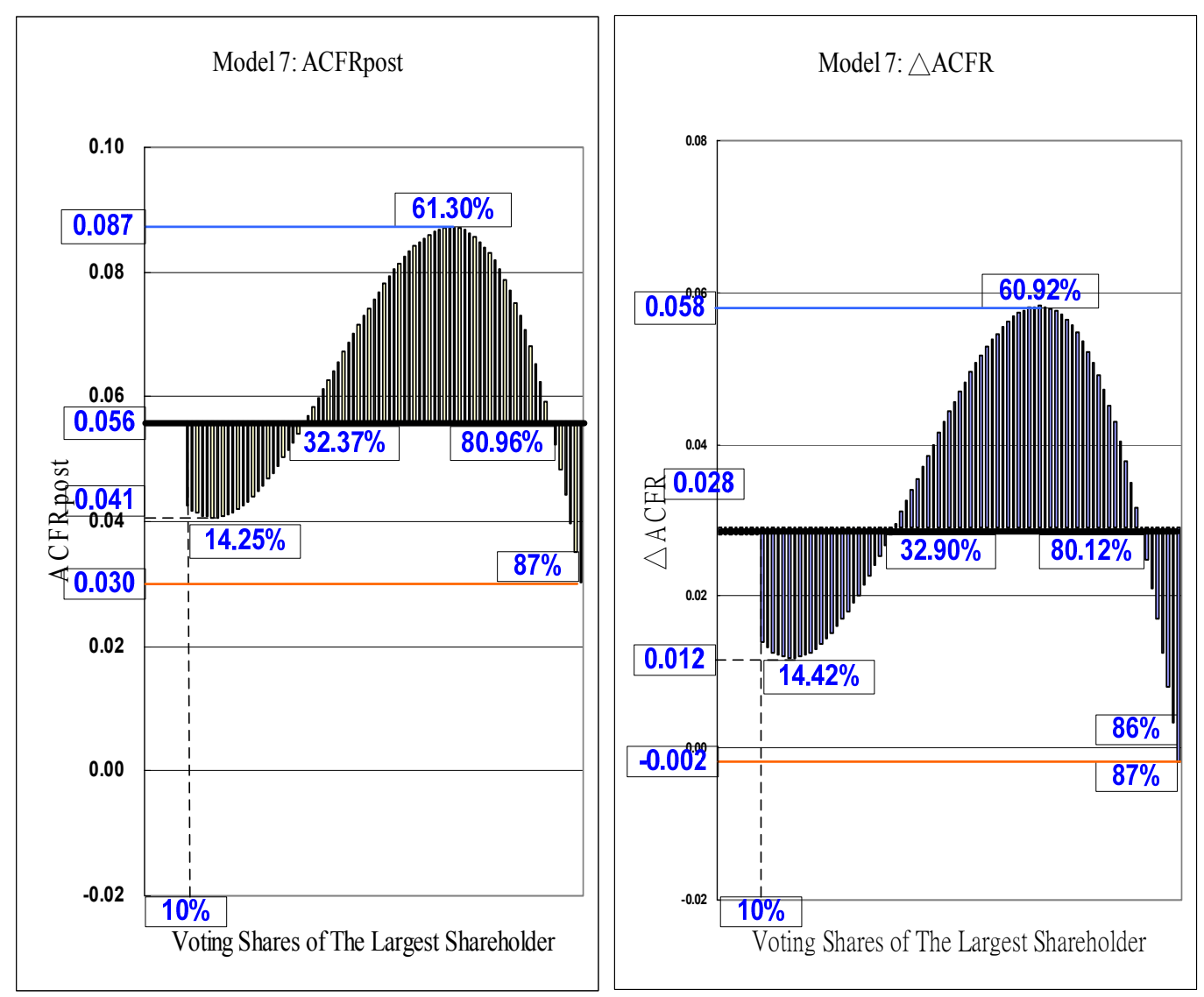

Figure 6.1 Curve of Cube Relationship between Ownership and Acquisition Performance 


\section{- Evidence on $1^{\text {st }}$ Generation Governance Mechanisms}

Turning to look at governance variables, it can be said that the separation of cash flow rights and control rights is negatively related to performance; this conclusion is similarly found in a number of other studies (e.g., Claessens, Djankov and Lang 2000, La Porta, Lopez-de-Silanes, Shleifer and Vishny 2002, Faccio and Lang 2002, Cronqvist and Nilsson 2003, Bennedsen and Nielsen 2005). Perceived good governance or investor protection in English origin countries does not appear sufficient to mitigate the agency costs of separation. This thesis also finds that firms with smaller boards do better than those with larger boards, capturing the potential inefficiency of larger boards as suggested in the prior literature (e.g., Jensen 1993, Yermack 1996, and Conyon and Peck 1998). Companies with a CEO holding large shares have significant improvements on model 1 in post-acquisition performance but not in the change performance (Anderson and Reeb 2003, Ben-Amar and André 2006). Companies with CEO duality significantly underperform in the change in performance but not in the post performance (Rechner and Dalton 1991, Pi and Timme 1993). Other block holders have significant improvements on model 1 in the change performance but not in the post-acquisition performance.

\section{- Evidence on Deal Characteristics}

Among deal characteristics, the regression results are basically consistent with the prior univariate analysis. The presence of multiple bidders has a significant negative impact on post adjusted performance and on the change in adjusted performance (Morck, Shleifer and Vishny 1990, Duggal and Millar 1999). The larger size relative acquirers lead to the poorer post-acquisition performance (Asquith, Bruner and Jr Mullins 1983, Becher and Campbell II 2003b, Moeller et al. 2004), though not significantly to the change in performance (Agrawal, Jaffe and Mandelker 1992, Gugler, Mueller, Yurtoglu and Zulehner 2003).

However, the debt monitoring mechanism loses its effect on post performance (ACFRpost) when combing other factors in regression analyses. Even more, the level of acquirer leverage has negative association with the change in performance $(\triangle A C F R)$ at the 10 percent significance level in model 7. This result is unexpected since the earlier literature (e.g. Stulz 1990, Harris and Raviv 1990 and Maloney, McCormick and Mitchell 1993) generally supports the debt-monitoring mechanism; this effect is proved through the post performance measure (ACFRpost) in the prior univariate test. This evidence 
sustains the view of Myers and Majluf (1984) that internal resources are more preferred than external financing. A company holding a large amount of financial slack may have more opportunity to capture the positive deals and to thus benefit firm performance. Unfortunately, the effect in these regression models is economically trivial and unsteady throughout all examinations.

Table 6.4 Regression of Acquiring Firm Performance on Ownership Structure, Governance Mechanisms and Deal Characteristics (Basic Models)

Sample of 282 mergers and acquisitions by 222 acquiring firms in 11 English Origin countries (Australia, Canada, India, Ireland, Israel, Malaysia, New Zealand, Singapore, South Africa, Thailand and United Kingdom) between 1997 and 2001 for completed takeovers over US\$ 10 million are obtained from the Thomson Financial Securities Data's SDC PlatinumTM Worldwide Mergers \& Acquisitions Database. ACFRpre and ACFRpost is the pre and post industry, size, and pre performance adjusted cash flow return. $\triangle A C F R$ is for the change in industry, size, and pre performance adjusted cash flow return. Outliers have been winsorized using Huber's M estimator approach. Two tail tests *** denotes significant at the $1 \%$ level, ** significant at the $5 \%$ level, * significant at the $10 \%$ level. See table 5.5 for variable definitions.

Panel A Dependent Variable: ACFRpost

\begin{tabular}{|c|c|c|c|c|c|c|c|}
\hline$(\mathrm{N}=\mathbf{2 8 2})$ & Model 1 & Model 2 & Model 3 & Model 4 & Model 5 & Model 6 & $\begin{array}{c}\text { Model } 7 \\
\text { (Benchmark) } \\
\end{array}$ \\
\hline Intercept & $0.048^{* *}$ & $0.050^{* *}$ & $0.070^{* * *}$ & $0.070^{* * *}$ & $0.041^{*}$ & $0.042^{*}$ & $0.056^{* *}$ \\
\hline CONCEN10 & -0.012 & & & & & & \\
\hline CONCEN1020 & & & $-0.025^{* * *}$ & $-0.025^{* * *}$ & & & \\
\hline CONCEN20 & & $0.024^{* *}$ & 0.012 & & & & \\
\hline CONCEN2050 & & & & 0.012 & & & \\
\hline CONCEN50 & & & & 0.012 & & & \\
\hline LSH1P & & & & & 0.0235 & 0.006 & $-0.234^{* *}$ \\
\hline LSH1PSQ & & & & & & 0.025 & $1.012^{* * *}$ \\
\hline LSH1PCUBE & & & & & & & $-0.893^{* * *}$ \\
\hline SEP & -0.019 * & -0.028 & -0.027 & $-0.027^{* *}$ & -0.026 & $-0.026^{* *}$ & -0.030 ** \\
\hline CEOLSH & $0.025^{* *}$ & 0.012 & 0.016 & 0.016 & 0.018 & 0.019 & 0.015 \\
\hline CEOdual & -0.015 & -0.013 & -0.013 & -0.013 & -0.014 & -0.015 & -0.013 \\
\hline BSIZE & -0.001 & $-0.002^{* *}$ & $-0.003^{* *}$ & $-0.003^{* *}$ & -0.002 & -0.002 & $-0.003^{* *}$ \\
\hline INDDIR & -0.023 & -0.013 & -0.022 & -0.022 & -0.013 & -0.013 & -0.013 \\
\hline OTHLSH & 0.012 & 0.001 & 0.005 & 0.005 & 0.006 & 0.007 & 0.009 \\
\hline TGORI_English & 0.004 & -0.002 & -0.002 & -0.002 & 0.001 & 0.001 & 0.001 \\
\hline ATTI_Hostile & 0.009 & 0.007 & 0.005 & 0.006 & 0.009 & 0.009 & 0.007 \\
\hline PAY_stock & -0.010 & -0.013 & -0.013 & -0.013 & -0.011 & -0.011 & -0.011 \\
\hline COMPETE & $-0.035^{* *}$ & $-0.032^{* *}$ & $-0.035^{* *}$ & $-0.035^{* *}$ & $-0.033^{* *}$ & $-0.033^{* *}$ & $-0.035^{* *}$ \\
\hline IND_rel & 0.001 & 0.003 & 0.001 & 0.001 & 0.002 & 0.002 & 0.002 \\
\hline TOEHOLD & 0.006 & 0.006 & 0.006 & 0.006 & 0.006 & 0.006 & 0.006 \\
\hline PREM_1day & 0.000 & 0.000 & 0.000 & 0.000 & 0.000 & 0.000 & 0.000 \\
\hline SIZE_rel & $-0.005^{* *}$ & $-0.005^{* *}$ & $-0.006^{* *}$ & $-0.006^{* *}$ & $-0.005^{* *}$ & $-0.005^{* *}$ & $-0.005^{* *}$ \\
\hline LEV & 0.000 & 0.000 & 0.000 & 0.000 & 0.000 & 0.000 & -0.001 \\
\hline ACFRpre & $0.516^{* \ldots *}$ & 0.518 & 0.521 & 0.521 & 0.514 & 0.514 & $0.516^{* * *}$ \\
\hline Adjust $\mathrm{R}^{2}(\%)$ & 29.0 & 30.0 & 31.6 & 31.3 & 28.9 & 28.6 & 30.6 \\
\hline$F$ & $7.756 * * *$ & $8.083 * * *$ & $8.210 * * *$ & $7.748 * * *$ & $7.706 * * *$ & $7.259 * * *$ & $7.512 * * *$ \\
\hline
\end{tabular}


Table 6.4 (Continued)

Panel B Dependent Variable: $\triangle \mathrm{ACFR}$

\begin{tabular}{|c|c|c|c|c|c|c|c|}
\hline$(\mathrm{N}=\mathbf{2 8 2})$ & Model 1 & Model 2 & Model 3 & Model 4 & Model 5 & Model 6 & $\begin{array}{c}\text { Model } 7 \\
\text { (Benchmark) }\end{array}$ \\
\hline Intercept & 0.021 & 0.023 & $0.045^{*}$ & $0.048^{*}$ & 0.013 & 0.014 & 0.028 \\
\hline CONCEN10 & -0.013 & & & & & & \\
\hline CONCEN1020 & & & $-0.027^{* *}$ & $-0.027^{* *}$ & & & \\
\hline CONCEN20 & & $0.026^{* *}$ & 0.013 & & & & \\
\hline CONCEN2050 & & & & 0.017 & & & \\
\hline CONCEN50 & & & & 0.007 & & & \\
\hline LSH1P & & & & & 0.021 & 0.005 & $-0.243^{* *}$ \\
\hline LSH1PSQ & & & & & & 0.023 & $1.042^{* * *}$ \\
\hline LSH1PCUBE & & & & & & & $-0.922^{* * *}$ \\
\hline SEP & -0.016 & $-0.026^{* * *}$ & $-0.024^{*}$ & $-0.023 *$ & $-0.023^{*}$ & $-0.023 *$ & $-0.026^{* *}$ \\
\hline CEOLSH & 0.012 & -0.001 & 0.003 & 0.002 & 0.005 & 0.006 & 0.002 \\
\hline CEOdual & $-0.024^{* *}$ & $-0.022^{* *}$ & $-0.023^{* *}$ & $-0.022^{* *}$ & $-0.024^{* *}$ & $-0.024^{* *}$ & $-0.022^{* *}$ \\
\hline BSIZE & -0.001 & -0.002 & $-0.002^{*}$ & $-0.002^{*}$ & -0.001 & -0.001 & -0.002 \\
\hline INDDIR & -0.013 & -0.003 & -0.013 & -0.015 & -0.004 & -0.004 & -0.004 \\
\hline OTHLSH & $0.023^{*}$ & 0.011 & 0.016 & 0.014 & 0.017 & 0.018 & 0.020 \\
\hline TGORI_English & 0.011 & 0.004 & 0.004 & 0.004 & 0.008 & 0.008 & 0.008 \\
\hline ATTI_Hostile & 0.017 & 0.014 & 0.013 & 0.011 & 0.017 & 0.017 & 0.015 \\
\hline PAY_stock & -0.007 & -0.010 & -0.010 & -0.010 & -0.008 & -0.007 & -0.008 \\
\hline COMPETE & $-0.050 * * *$ & $-0.046^{* * *}$ & $-0.049^{* * *}$ & $-0.050 * * *$ & $-0.048^{* * *}$ & $-0.048^{* * *}$ & $-0.049^{* * *}$ \\
\hline IND_rel & 0.007 & 0.009 & 0.007 & 0.007 & 0.009 & 0.008 & 0.009 \\
\hline TOEHOLD & 0.015 & 0.015 & 0.015 & 0.015 & 0.015 & 0.015 & 0.015 \\
\hline PREM_1day & 0.000 & 0.000 & 0.000 & 0.000 & 0.000 & 0.000 & 0.000 \\
\hline SIZE_rel & -0.002 & -0.002 & -0.002 & -0.002 & -0.002 & -0.002 & -0.002 \\
\hline LEV & -0.005 & -0.005 & -0.005 & -0.005 & -0.005 & -0.006 & $-0.006^{*}$ \\
\hline Adjust R ${ }^{2}(\%)$ & 3.1 & 4.3 & 6.2 & 6.0 & 2.8 & 2.4 & 4.6 \\
\hline $\mathrm{F}$ & $1.554^{*}$ & $1.789 * *$ & $2.097 * * *$ & $1.997 * *$ & $1.498^{*}$ & $1.409^{*}$ & $1.749^{* *}$ \\
\hline
\end{tabular}




\subsubsection{Regression Results at Second Stage \\ -For $2^{\text {nd }}$ Generation Governance: Legal and Extra-Legal Institutions \\ (i) Full Model}

Table 6.5 reports the second level regression results for the two operating performance measures on ownership structures after controlling for institutional variables. Based on the evidence of regression at the first level, model 7 is selected as a benchmark model for further constructing models 8 and model 9 and for testing the effects of legal and extra-legal variables. Similar to the results of first level regressions, panel A shows that the values of $\mathrm{F}$ of both models for post performance measure (ACFRpost) are significant beyond 0.01 levels and that those adjusted $\mathrm{R}$ square are up to 33.9 (model 8) and 32.8 (model 9) percent. Panel B presents consistent evidence for the change in performance $(\triangle A C F R)$. Both models are significant and have adjusted $\mathrm{R}$ square 6.0 and 8.1 percent respectively. Recall that when model 7 without controlling institutional variables was used to predict acquisition operating performance, adjusted $\mathrm{R}$ square was 30.6 percent for ACFRpost and 4.6 for $\triangle A C F R$. With adjusted $\mathrm{R}$ square increasing, it becomes obvious that adding institutional variables improves the predictive power of the regression equation. ${ }^{34}$

\section{- Evidence on Ownership Structure}

Focusing on the ownership variables, there exists a curvilinear relationship between ownership of the largest shareholder and the two operating performance measures (ACFR and $\triangle A C F R$ ) in these two models; the measures still remain beyond 0.10 percent level of significance but the regression coefficients $(\beta)$ are decreased. ${ }^{35}$ Therefore, while the concentrated ownership structure still has statistical impact on M\&A performance, the explanatory power of ownership variables is diminished after controlling for legal and extra-legal mechanisms.

\footnotetext{
${ }^{34}$ This thesis also runs regressions to test the $\mathrm{R}$ squared and $\mathrm{F}$ change. The value of $\mathrm{R}$ squared change in model 8 for post performance (ACFRpost) is 4.71 with significance $(\mathrm{F}$ change $=2.856$ ) beyond 0.01 levels. More detailed tests and results are provided in appendix D.

${ }^{35}$ It is known that beta coefficients give further than the regression coefficients because each gives a change of one standard deviation on that variable produces the number of changes of standard deviation on dependent variable. Also, beta coefficients are more comparable across independent variables, since they are all in same units (Kinnear and Gray 2004). While this thesis does not present the beta coefficients in the table 6.5, the statistics can be found in appendix $\mathrm{D}$ and those confirm the results of the regression coefficients $(\beta)$.
} 


\section{Interception and Inflection Points of Model 8 and Model 9}

In addition, the last two columns of table 6.5 report the interception and inflection points of the level of ownership on both performance measures of models 8 and 9. The inflection points are again computed to provide further analysis of the relationship between the ownership curve and the operating performance for model 8 (with initial legal and extra-legal indexes) and model 9 (with DLLS new legal indexes). For the post performance measures ACFRpost (Table 6.5, Panel A, Model 8), a first inflexion point appears around 19.12 percent where performance starts to improve with the level of concentration and a second inflexion point around 61.98 percent where performance starts to deteriorate. Moreover, the ownership curve stays below the level of widely-held firms up to the 48.81 percent level of ownership and remains above the level of widely-held firms up to the 72.85 percent. Unlike the form of model 7 , the average performance of widely-held firms (the intercept, -0.158) is negative (but not significant).

Similar results are obtained for the post performance measure of model 9 (panel A). The first inflexion point is at the 18.82 percent level of ownership and the second inflexion point is around 61.91 percent. The ownership curve stays below the level of widely-held firms (the intercept, 0.020) up to the 47.50 percent level of ownership and remains above the level of widely-held firms up to the 73.60 percent. The ownership curve is below zero after an 84 percent level of ownership.

For the change measure $\triangle A C F R$, the results parallel the post-performance measure (ACFRpost). Two inflection points in Model 8 are around 19.52 percent and 64.03 percent, respectively. The inflection points in Model 9 are very close to those in model 8 by 19.16 percent and 63.11 percent separately. Model 8 has an ownership curve below the level of widely-held firms (the intercept, -0.182) up to the 49.37 percent of ownership and remains above the level until the 75.96 percent of ownership. The curve of Model 9 is below the level of widely-held firms (the intercept, 0.011) up to the 48.28 percent and remains above the level until the 75.11 percent. The ownership curve has two intersection points with zero: the first is around 36 percent of ownership and the second is around 82 percent. 
Table 6.5 Regression of Acquiring Firm Performance on Legal \& Extra-Legal Institutions (Full Models)

Sample of 282 mergers and acquisitions by 222 acquiring firms in 11 English Origin countries (Australia, Canada, India, Ireland, Israel, Malaysia, New Zealand, Singapore, South Africa, Thailand and United Kingdom) between 1997 and 2001 for completed takeovers over US\$ 10 million are obtained from the Thomson Financial Securities Data's SDC PlatinumTM Worldwide Mergers \& Acquisitions Database. ACFRpre and ACFRpost is the pre and post industry, size, and pre performance adjusted cash flow return. $\triangle A C F R$ is for the change in industry, size, and pre performance adjusted cash flow return. Outliers have been winsorized using Huber's M estimator approach. Two tail tests *** denotes significant at the $1 \%$ level, ** significant at the $5 \%$ level, * significant at the $10 \%$ level. See table 5.5 for variable definitions.

\begin{tabular}{|c|c|c|c|c|c|c|}
\hline \multirow[b]{2}{*}{$(\mathrm{N}=282)$} & \multicolumn{3}{|c|}{ Panel A: ACFRpost } & \multicolumn{3}{|c|}{ Panel B: $\triangle \mathrm{ACFR}$} \\
\hline & $\begin{array}{c}\text { Model } 7 \\
\text { (Benchmark) } \\
\end{array}$ & Model 8 & Model 9 & $\begin{array}{c}\text { Model } 7 \\
\text { (Benchmark) }\end{array}$ & Model 8 & Model 9 \\
\hline Intercept & $0.056^{* *}$ & -0.158 & 0.020 & 0.028 & -0.182 & 0.011 \\
\hline LSH1P & $-0.234^{* *}$ & $-0.197^{* *}$ & $-0.222 * *$ & $-0.243 * *$ & $-0.228 * *$ & $-0.231 * *$ \\
\hline LSH1PSQ & $1.012^{* * *}$ & 0.674 * & $0.769^{* *}$ & $1.042^{* * *}$ & 0.762 * & 0.786 * \\
\hline LSH1PCUBE & $-0.893^{* * *}$ & $-0.554^{*}$ & $-0.635^{* *}$ & $-0.922^{* * *}$ & $-0.608^{*}$ & $-0.637^{*}$ \\
\hline SEP & $-0.030^{* * *}$ & -0.032 & $-0.033^{* * *}$ & -0.026 & -0.029 & -0.028 \\
\hline CEOLSH & 0.015 & $0.025^{*}$ & 0.022 & 0.002 & 0.018 & 0.012 \\
\hline CEOdual & -0.013 & -0.011 & -0.011 & $-0.022^{* *}$ & $-0.021 *$ & $-0.021 *$ \\
\hline BSIZE & $-0.003^{* *}$ & $-0.003^{* *}$ & $-0.003^{* *}$ & -0.002 & -0.002 & -0.002 \\
\hline INDDIR & -0.013 & -0.027 & -0.031 & -0.004 & -0.011 & -0.010 \\
\hline OTHLSH & 0.009 & 0.005 & 0.008 & 0.020 & 0.016 & 0.019 \\
\hline TGORI_English & 0.001 & -0.005 & -0.004 & 0.008 & 0.004 & 0.002 \\
\hline ATTI_Hostile & 0.007 & 0.016 & 0.005 & 0.015 & 0.008 & 0.012 \\
\hline PAY_stock & -0.011 & -0.011 & -0.012 & -0.008 & -0.006 & -0.009 \\
\hline COMPETE & $-0.035^{* *}$ & $-0.038^{* *}$ & $-0.037^{* *}$ & $-0.049^{* * *}$ & $-0.053^{* * *}$ & $-0.052^{* * *}$ \\
\hline IND_rel & 0.002 & 0.001 & 0.000 & 0.009 & 0.007 & 0.008 \\
\hline TOEHOLD & 0.006 & 0.012 & 0.010 & 0.015 & $0.021 *$ & 0.018 \\
\hline PREM_1day & 0.000 & 0.000 & 0.000 & 0.000 & 0.000 & 0.000 \\
\hline SIZE_rel & $-0.005^{* *}$ & $-0.005^{*}$ & $-0.005^{* *}$ & -0.002 & -0.001 & -0.002 \\
\hline LEV & -0.001 & -0.001 & -0.002 & $-0.006^{*}$ & $-0.006^{*}$ & $-0.007^{*}$ \\
\hline ANTIDIR_high & & $0.083^{* *}$ & & & $0.126^{* * *}$ & \\
\hline ENFORCE & & -0.001 & & & 0.012 & \\
\hline ACCTSTD & & 0.003 & & & 0.000 & \\
\hline XLEG_high & & -0.028 & & & -0.013 & \\
\hline ANTISDI & & & 0.046 & & & 0.018 \\
\hline PUBENFORCE_high & & & $-0.070 *$ & & & -0.056 \\
\hline NANTIDIR high & & & $0.060^{* * *}$ & & & $0.062^{* *}$ \\
\hline$U K$ & & -0.064 & $-0.062^{* *}$ & & $-0.125^{* *}$ & -0.061 \\
\hline$C A N$ & & -0.061 & $0.099^{* *}$ & & $-0.141^{* *}$ & 0.070 \\
\hline$A U S$ & & $0.055^{*}$ & $0.035^{*}$ & & 0.027 & 0.030 \\
\hline ACFRpre & $0.516^{* * *}$ & $0.503^{* * *}$ & $0.512^{* * *}$ & & & \\
\hline Adjust R ${ }^{2}(\%)$ & 30.6 & 33.90 & 32.80 & 4.6 & 7.80 & 6.60 \\
\hline $\mathrm{F}$ & $7.512 * * *$ & $6.531 * *$ & $6.492 * * *$ & $1.749 * *$ & $1.950 * * *$ & $1.826^{* *}$ \\
\hline Inflection points & $(14.25 \%, 61.30 \%)$ & $.12 \%, 61.98 \%$ & $3.88 \%, 61.91 \%)$ & $(14.42 \%, 60.92 \%)$ & $.52 \%, 64.03 \%$ & $.16 \%, 63.11 \%)$ \\
\hline $\begin{array}{c}\text { Intersection points with } \\
\boldsymbol{y}=\text { intercept }\end{array}$ & $(32.9 \%, 80.12 \%)$ & $.81 \%, 72.85 \%$ & $7.50 \%, 73.60 \%)$ & $(32.37 \%, 80.96 \%)$ & $.37 \%, 75.96^{\circ}$ & $3.28 \%, 75.11 \%)$ \\
\hline
\end{tabular}


In summary, it is clear that, first of all, the first inflection point of the ownership curve moves to around 20 percent (14 percent of model 7) which indicates that when the mechanisms of investor protection are controlled, the incentive effects are likely to bring into play with the increasing ownership concentration until the level of ownership concentration goes beyond 20 percent. This number is confirmed by prior univariate analysis and more closely to the arguments of Morck, Shleifer and Vishny (1988b); it reveals agency costs to be significantly higher between 5 and 25 percent levels of ownership concentration.

Second, the range of two intersection points with the average performance of dispersed firms (the axis of the intercept) is narrowed down to roughly between 50 and 80 percent levels (compared to approximate $32 \%-80 \%$ in model 7 ) which illustrates that after controlling institutional variables, concentrated firms worsen M\&A performance on average much more than the dispersed firms do, unless the firms are fully controlled (50 percent levels of ownership) by the largest shareholders. This argument is further confirmed by the third point: the peaking spot over the entire spectrum of ownership levels is around 60 percent and is quite stable across various regression models. After holding more than 60 percent of voting shares, controlling shareholders may choose lower performing acquisition projects in order to diversify the risk of wealth concentration. This may cause the average M\&A performance to decrease although the average performance will still be higher than that of widely held firms. The figures in this analysis are rather close to the decreasing point of Anderson and Reeb (2003) at 60 percent, but they are relatively high when compared to the 40 to 50 percent of McConnell and Servaes (1990). Finally, according to this ownership curve, a few high level concentrated firms (holding more than $80 \%$ ) in this sample may underperform the dispersed firms. In fact, there are five companies (1.8\%) in this sample with the largest shareholders holding more than 80 percent of voting shares (seven companies with the largest shareholders holding more than 75 percent of voting share). Since these are extremely rare cases, it is difficult and also inappropriate to draw any conclusions from this small sample of high-level concentrated firms.

\section{- Evidence on $2^{\text {nd }}$ generation governance: Legal and Extra-legal Institutions}

Upon examining the institutional variables in regression models 8 of Table 6.5, it becomes clear that after controlling for other factors that might be expected to affect acquiring performance, the coefficients of initial anti-director right (ANTIDIR_high) for both performance measures are significant positive (0.083 in panel A for ACFRpost and 
0.126 in panel B for $\triangle A C F R$ ). As expected, acquisitions in countries with better investor legal protections (i.e., countries with a high anti-director right index) have higher M\&A returns. The extra-legal index has a negative coefficient for ACFRpost but a positive one for $\triangle A C F R$. The Accounting standard has a positive relationship with both performances. Unfortunately, as the coefficients for these three legal and extra-legal variables (ENFORCE, ACCTSTD, and XLEG_high) are not significant, the results are not overly conclusive.

A surprising outcome surfaces in the proxy of enforcement. This has a significant negative impact on both performances by the univariate test but shows no sign of coming out on multiple regression results. It is obvious that while enforcement individually has a significant negative relationship with acquiring performance, its significance is replaced by many other variables. This evidence supports the conclusion of La Porta, Lopez-de-Silanes, Shleifer and Vishny (LLSV, 1998) and states that the quality of legal enforcement fails to be a substitute/compensate for the quality of law.

However, there is strong relationship existing among those LLSV institutional variables, especially in relation to the enforcement index (ENFORCE) and accounting standard (ACCTSTD). The pairwise correlation between these two variables is bigger than 0.5 (0.690, which is shown in Tables 5.4 panel C). The presence of a high degree of multicollinearity may result in the unstable regression coefficient estimates. Thus, ENFORCE and ACCTSTD variables were removed in order to eliminate this problem and to create a modified regression model 8.1. The regression results are present in table $\mathbf{6 . 6}$ and will be discussed in the following parts of the modified models.

Model 9 of table 6.5 tests the effects of legal mechanisms as based on the updated measures by DLLS (2006). The revised anti-director rights (NANTIDIR_high) are positively associated with good M\&A decisions for both performance measures. Again, this confirms that investor protection, even in English origin countries, has an impact on acquisition operating performance. The coefficients of public enforcement (PUBENFORCE_high) are negative and weakly significant at the 10 percent level. This unexpected sign is consistent with the evidence of DLLS (2006). Due to data limitations, however, this thesis still has difficulty providing a more detailed explanation as to why the government's power to impose fines and prison terms for self-dealing transactions does not benefit acquiring performance. 
In addition, there does not seem to be a link between long-term acquisition performance and the anti-self dealing index (ANTISDI).

In DLLS (2006) analysis, public enforcement shows significant negative effects. They explain that the way they adopt to construct the public enforcement index may be biased because concealed transactions happened even under countries with criminal sanctions. Besides, considering the existence of multicollinearity problems among the three new legal measures, the PUBENFORCE_high variable is removed and a modified regression model 10.1 is run. The results are also presented in table $\mathbf{6 . 6}$ and discussed in the next part of the modified models. This evidence confirms the results for public enforcement in DLLS (2006). The DLLS argument is depicted in chapter two, section 2.2.1.

\section{- Evidence on $1^{\text {st }}$ Generation Governance Mechanisms and Deal Characteristics}

Turning back to the governance and deal variables in models 8 and 9 for post performance (panel A: ACFRpost), ther results are similar and stable when compared with the coefficients of variables in model 7. Separation (SEP), board size (BSIZE), multiple bidders (COMPETE), and size deviation between bidders and targets (SIZE_rel) continue to have a negative effect on post performance after controlling for institutional variables. The only exception is when the company with a controlling CEO shows its significant positive relationship with post performance (ACFRpost in panel A) after controlling the legal variables. This evidence parallels the sign in the existing univariate test and in the analyses of both Villalonga and Amit (2005) and Ben-Amar and André (2006).

Consistent results also appear when looking at panel B for changes in operating performance ( $\triangle \boldsymbol{A C F R}$ ). Acquiring firms with separation (SEP) capital policy, CEO-chairman (CEOdual), multiple competitors (COMPETE), and size relative (SIZE_rel) again significantly underperform on the change performance measure. A more significant difference is that (even after controlling for the initial legal and extra-legal variables (model 8)) the toehold interests have a slightly positive effect on the change in performance at the 10 percent significance level. This result supports the argument in prior theoretical models stating that the toehold may help potential buyers obtain special information, may solve the free-rider problems, may reduce the average bid premium, and may then create more profitable deals for bidders (Grossman and Hart 1981, Shleifer and Vishny 1986). 


\section{(ii) Modified Models}

All results and tests reported for model 8.1 and 9.1 in table 6.6 are based on the same concepts of model 8 and model 9 . In order to tackle the multicollinearity problems and to still be able to capture the information on the desired variables, model 8.1 is run by selecting the anti-director right index (ANTIDIR) as a symbol variable from the other legal mechanisms of LLSV (1998) and by including the single aggregate extra-legal dummy variable (XLEG_high) of the Dyck and Zingales (2004) study ${ }^{36}$. Except for the multicollinearity problems, the public enforcement measure (PUBENFORCE_high) is excluded in Model 9 also because of the unexplainable sign that is concerned in DLLS (2004) study as well.

Similar patterns are found in model 8.1 and 9.1 when comparing model 8 and model 9 respectively. The cube relationship between ownership and both performance measures still persists; governance and transaction factors in each specification have signs that are stable and consistent with the prior full models in general; legal protection, no matter whether represented by initial anti-director right measures or by a revised anti-director rights index, are positively and significantly associated with good M\&A decisions for both performance measures. Unfortunately, the other institutional variables (XLEG_high and ANTISDI) in their own related specifications are still not strong enough to explain the operating performance measures. The results of Dyck and Zingales (2004) and DLLS (2006) for anti-self dealing cannot be verified in this sample.

After running the regression model 8.1 and 9.1, there appears a high correlation among institutional variables that does not affect the ability to obtain a good fit for the regression $\left(\mathrm{R}^{2}\right.$ are stable). Nor does it affect the quality of predictions from the regression (the coefficient of each control variables is stable across various model specifications). However, there is a major change when the values of the intercept in model 8.1 for two measures turn back to be positive and even have a significant sign at the 10 percent level for ACFRpost. Taking all the results into consideration, model 9.1 seems to be relatively stable and reliable in terms of the updated legal measures by DLLS $(2006)^{37}$. Regression model 9.1 is therefore used as the representative model. Based on the dependent variables in model 9.1,

${ }^{36}$ After correcting the multicollinearity, there is no variable (except the LSH1SQ, LSH1CUBE as expected) with VIF greater than 15 in model 8.1 and 9.1 for both $A C F R p o s t$ and $\triangle A C F R$. Results are not reported in table 6.6 but shown in appendix E.

37 An early version of this regression result has been published in Journal of Economics and Business, article in press (Yen and André 2007). Available online 4 May 2007. 
additional tests are conducted to examine whether the findings of the basic regression models in the first research scheme (model 1 to model 7) are still ongoing. Fortunately, the results are qualitatively similar and stable.

Furthermore, the last two columns of table 6.6 show the interception and inflection points of ownership levels on both performance measures in models 8.1 and 9.1. For the post-performance (ACFRpost) of model 8.1, a first inflexion point is around 17.85 percent and a second inflexion point is around 61.62 percent. The curve stays below the level of widely-held firms (the intercept, 0.108 ) up to the 43.72 percent level and remains above the level up to the 75.49 percent. The entire ownership curve for post performance is always above zero. For the change measure $(\triangle A C F R)$, a first inflexion point is around 19.41 percent and a second inflexion point is around 63.30 percent. The curve is below the level of widely-held firms (the intercept, 0.015) up to the 49.32 percent of ownership and remains above the level until the 74.75 percent of ownership. The curve for the change performance is above zero between 30 and 84 percent level of ownership.

For the post-performance (ACFRpost) of model 9.1, the first inflexion point is around 18.06 percent and the second inflexion point is around 61.33 percent. The curve stays below the level of widely-held firms (the intercept, 0.108) until the 44.62 percent of ownership and then remains above the level up to the 74.46 percent. The entire ownership curve for post performance is always above zero. For the change measure $(\triangle A C F R)$, the first inflexion point is around 18.50 percent and the second inflexion point is around 62.69 percent. The curve is below the level of widely-held firms (the intercept, 0.083 ) till the 45.78 percent of ownership and then remains above the level up to the 76.01 percent of ownership. The curve for the change performance is also above zero for the entire ownership structure in the sample. 
Table 6.6 Regression of Acquiring Firm Performance on Legal \& Extra Legal Institutions (Modified Models)

Sample of 282 mergers and acquisitions by 222 acquiring firms in 11 English Origin countries (Australia, Canada, India, Ireland, Israel, Malaysia, New Zealand, Singapore, South Africa, Thailand and United Kingdom) between 1997 and 2001 for completed takeovers over US\$ 10 million are obtained from the Thomson Financial Securities Data's SDC PlatinumTM Worldwide Mergers \& Acquisitions Database. ACFRpre and ACFRpost is the pre and post industry, size, and pre performance adjusted cash flow return. $\triangle A C F R$ is for the change in industry, size, and pre performance adjusted cash flow return. Outliers have been winsorized using Huber's $M$ estimator approach. Two tail tests *** denotes significant at the $1 \%$ level, ** significant at the $5 \%$ level, * significant at the $10 \%$ level. See table 5.5 for variable definitions.

\begin{tabular}{|c|c|c|c|c|}
\hline \multirow{2}{*}{$(\mathrm{N}=282)$} & \multicolumn{2}{|c|}{ Panel A: ACFRpost } & \multicolumn{2}{|c|}{ Panel B : $\triangle$ ACFR } \\
\hline & Model 8.1 & Model 9.1 & Model 8.1 & Model 9.1 \\
\hline Intercept & $0.055^{*}$ & 0.108 & 0.015 & 0.083 \\
\hline LSH1P & $-0.201 * *$ & $-0.202 *$ & $-0.219 *$ & -0.214 \\
\hline LSH1PSQ & $0.726^{* *}$ & $0.724^{* * *}$ & $0.737^{*}$ & $0.749 *$ \\
\hline LSH1PCUBE & -0.609 * & $-0.608^{*}$ & $-0.594^{*}$ & $-0.615^{*}$ \\
\hline SEP & $-0.033^{* * *}$ & $-0.033^{* *}$ & -0.027 & -0.027 \\
\hline CEOLSH & 0.022 * & 0.021 & 0.014 & 0.012 \\
\hline CEOdual & -0.012 & -0.015 & $-0.021 *$ & $-0.023^{* *}$ \\
\hline BSIZE & $-0.003^{* *}$ & -0.002 * & -0.002 & -0.002 \\
\hline INDDIR & -0.023 & -0.028 & -0.007 & -0.007 \\
\hline OTHLSH & 0.007 & 0.011 & 0.019 & $0.022 *$ \\
\hline TGORI_English & -0.004 & -0.004 & 0.002 & 0.002 \\
\hline ATTI_Hostile & 0.012 & 0.011 & 0.014 & 0.017 \\
\hline PAY_stock & -0.013 & -0.013 & -0.009 & -0.010 \\
\hline COMPETE & $-0.037^{* *}$ & $-0.036^{* *}$ & $-0.052^{* * *}$ & $-0.051^{* * *}$ \\
\hline IND_rel & 0.001 & 0.002 & 0.008 & 0.009 \\
\hline TOEHOLD & 0.012 & 0.009 & $0.019^{*}$ & 0.017 \\
\hline PREM_1day & 0.000 & 0.000 & 0.000 & 0.000 \\
\hline SIZE_rel & $-0.005^{* *}$ & $-0.005^{* *}$ & -0.002 & -0.002 \\
\hline LEV & -0.002 & -0.003 & $-0.007^{* *}$ & $-0.008^{* *}$ \\
\hline ANTIDIR_high & 0.060 & & $0.076^{\ldots * *}$ & \\
\hline XLEG_high & -0.024 & & 0.005 & \\
\hline ANTISDI & & -0.075 & & -0.079 \\
\hline NANTIDIR high & & $0.045^{* *}$ & & $0.049^{* *}$ \\
\hline$U K$ & -0.033 & -0.029 & -0.070 & -0.034 \\
\hline$C A N$ & $-0.041^{* *}$ & 0.013 & $-0.058^{* * *}$ & 0.000 \\
\hline$A U S$ & $0.054^{* *}$ & 0.034 & 0.032 & 0.029 \\
\hline ACFRpre & $0.512^{* * *}$ & 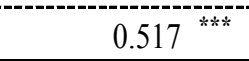 & & \\
\hline Adjust R ${ }^{2}(\%)$ & 33.70 & 31.90 & 7.90 & 6.10 \\
\hline $\mathrm{F}$ & $6.963 * * *$ & $6.495 * * *$ & $2.054 * * *$ & $1.799 * *$ \\
\hline Inflection points & $(17.85 \%, 61.62 \%)$ & $(18.06 \%, 61.33 \%)$ & $(19.41 \%, 63.30 \%)$ & $(18.50 \%, 62.69 \%)$ \\
\hline $\begin{array}{c}\text { Intersection points with } \\
\boldsymbol{y}=\text { =intercept }\end{array}$ & $(43.72 \%, 75.49 \%)$ & $(44.62 \%, 74.46 \%)$ & $(49.32 \%, 74.75 \%)$ & $(45.78 \%, 76.01 \%)$ \\
\hline
\end{tabular}




\subsection{Results Summary and Discussions}

This thesis sets out with the aim of assessing the importance of ownership structures in the long term operating performance of acquiring firms in English origin countries other than the US, following the classification of LLSV (1998). First of all, the results show that the measures of change in adjusted returns are significantly improved when combining the significantly poor pre performance and the positive post-performance. Such evidence rejects hypothesis 1.1. Also, after controlling for the effects of pre-acquisition performance, the operating performance of merging firms improves after M\&A events. This evidence rejects hypothesis 1.2. According to these results, evidence supports the synergy hypothesis as declared by prior literature: M\&A events should lead to improved financial and operating performances among merging firms in order to reflect the market expectation HPR 1992, Sharma and Ho 2002, Goergen and Renneboog 2004).

Second, this study finds that concentrated firms with the largest shareholder holding more than 20 percent of voting shares make better post-acquisition performance than widely-held firms. The group of firms with a large shareholder holding lower levels of voting shares (between 10 and 20 percent) significantly underperforms. Moreover, a cubic relationship between ownership structures and acquisition operating performance is proven to exist in the acquiring firms in countries with English origin. These findings suggest a rejection of hypothesis 2.1 and 2.2 and agree with previous work proposing that increasing ownership might be a solution for the divergence-of-interests problems but expropriation may have effects on performance when the voting shares are concentrated under or over a certain level (Morck et al. 1988b, McConnell and Servaes 1990, Anderson and Reeb 2003). While the sample firms are all from English origin countries, it is clear that the influence of ownership concentration is still valid in acquiring firms with good legal protection. Legal origin itself is not enough to speak for a corporate governance system that might mitigate the expropriation problems.

Third, among the first generation governance mechanisms, hypothesis 3.1 is rejected; separation problems have negative impact on acquisition performance in the post-merger period. While this result remains consistent with the position on the cost of separation in most prior studies (Claessens et al. 2000, La Porta et al. 2002, Faccio and Lang 2002, Cronqvist and Nilsson 2003), it is evident that the so-called good governance mechanism in 
English origin countries is neither sufficient to mitigate the cost of separation. In addition, hypothesis 3.2 is partially rejected for model 1,8 and 8.1 on post-acquisition performance (ACFRpost). Companies with a controlling CEO make significant improvements in post-acquisition performance (ACFRpost) when concentrated ownership at the 10 percent threshold or legal and extra-legal mechanisms are controlled. Besides, results show that the acquisition performance of acquiring firms with a CEO-Chairman is statistically negative. This evidence is closer to the conclusion of Rechner and Dalton (1991) and Pi and Timme (1993). This thesis can only reject hypothesis 3.3 on the change performance $(\triangle A C F R)$ measure and not on the post performance measure (ACFRpost).

Moreover, this thesis concludes that the board size has a significant negative association with acquisition operating performance rejecting hypothesis 3.4 and responds to the findings of previous research (Yermack 1996, Conyon and Peck 1998); however, its significance only exists on the post performance (ACFRpost) and not on the change performance $(\triangle A C F R)$. In contrast to the findings of earlier literature (Agrawal and Knoeber 1996, Vefeas and Theodorou 1998, Weir, Laing and McKnight 2002), no evidence on the ratio of independent directors is detected in this thesis. There is no significant sign concerning the relationship between the fraction of independent directors and the acquisition operating performance; hypothesis 3.5 cannot be rejected. A similar situation exists when testing the efficiency of multiple large shareholders. The presence of multiple large shareholders has no significant effect on the two acquisition performance measures; therefore, this thesis cannot reject hypothesis 3.6.

Fourth, when legal and extra-legal mechanisms are added into the regression equation, these institutional variables significantly improve the predictive power of the regression model. This evidence suggests that there is significant discrepancy in acquisition operating performance among countries with the same legal origin but that there are different levels of legal and extra-legal systems. Therefore, this thesis proposes an argument disputing the manner in which English origin countries are lumped together and collectively viewed as examples of great corporate governance (see Fauver, Houston and Naranjo 2003, Friedman, Johnson and Mitton 2003, Gugler, Mueller and Yurtoglu 2004). Additionally, in the first group of legal and extra-legal variables of LLSV (1998) and Dyck and Zingales (2004), the acquisition operating performance in countries with a higher rank of anti-director right index is significantly better than that in countries with a lower rank of anti-director right index 
(reject hypothesis 4.1). However, no significant differences are found between the acquisition operating performance and the other mechanisms such as degree of enforcement, the rating of accounting standards, and the rank of aggregate extra-legal index (i.e. cannot reject hypothesis 4.2, 4.3 and 4.4).

Correspondingly, in the second group of legal variables of DLLS (2006), the revised anti-director right index is confirmed as having significant and positive effects on the acquisition operating performance (reject hypothesis 4.5). The public enforcement measure has weakly negative significance (reject hypothesis 4.6 ). While this sign is counterintuitive, it is consistent with the evidence in the DLLS (2006) working paper. This measure has not previously been examined or described in the published paper. Restricted by data availability, it is difficult to explain this result except to say that it might be related to legal costs; these might deserve further study. In addition, this thesis cannot provide significant evidence to state the relationship between the anti-self dealing index and the acquisition operating performance (can not reject hypothesis 4.7). Disappointedly, the study fails to support the importance of the anti-self dealing measure which is highly recommended by LLSV (2006).

Finally, it is somewhat surprising that there are few deal characteristics that might be noted as having an effect on acquisition operating performances in this sample. The acquisition operating performance of transactions with more than one bidder is significantly worse than that of transactions with a single bidder. This stable evidence suggests a rejection of hypothesis 5.4 which assumes that competition has no impact on M\&A operating performance. The higher deviation in size ratio of the bidders and targets leads to a poorer acquisition performance (reject hypothesis 5.8), but this evidence is limited on the post operating performance (ACFRpost) and not on the change performance ( $\triangle A C F R$ ). After controlling for the cube relationship of ownership and the change performance ( $\triangle A C F R$ ), it is clear that the degree of acquirer leverage is significant but negatively associated with the change performance ( $\triangle A C F R$ ). Therefore, Hypothesis 5.9 is conditionally rejected. Except for these three deal variables, this thesis is unable to demonstrate the importance of the other transaction characteristics such as target origin, transaction attitude, payment type, industry relatedness, toehold interests, and premium (i.e. cannot reject hypothesis 5.1, 5.2, 5.3, 5.5, 5.6 and 5.7). 


\section{Chapter Seven}

\section{Additional Analysis}

\subsection{Introduction}

This chapter intends to conduct further analysis extending from the main results of chapter six. Section 7.2 attempts to discover the drivers of improved operating cash flow returns. Section 7.3 studies the ultimate owners for the concentrated firms and examines the effects of different types of larger shareholders on M\&A performance. Section 7.4 offers an analysis of the interactive effects between the type I agency problem (separation between control and cash flow rights) and the type II agency problem (separation between ownership and management). Section 7.5 adopts other alternatives for defining independent variables such as cross borders, two or three-digit SIC codes, and one or four week premium measure periods. At the end of this section the year dummy is introduced to test the impact of acquisition year difference.

\subsection{Analysis of Source of Operating Performance}

In order to identify the source of increases in operating cash flow return this section decomposes the operating cash flow return $(C F R)$ into two components: operating cash flow margin (CFM) and asset turnover (AT). In addition, it tests another important component of cash flow rates, the sales growth rate $(S G)$, to see whether acquisitions lead to sales growth.

\subsubsection{Cash Flow Margin (CFM)}

The cash flow margin $(C F M)$ is defined as the operating cash flow per dollar of sales $(O C F / S)$. Operating Cash Flow $(O C F)$ is calculated by operating income after depreciation plus back depreciation, depletion and amortization expense. Table 7.1 presents the summary data on $C F M$ for merging firms and matched firms. The adjusted operating cash flow margin $(A C F M)$ in the years surrounding the acquisition, the 3 year-median $A C F M$ before and after acquisition (ACFMpre and ACFMpost) and the changes in adjusted cash flow margin $(\triangle$ 
$A C F M)$ are also summarized. Panel B shows the results of the cross-sectional regression model.

The results in panel A of table 7.1 show that the mean (median) adjusted cash flow margin in the pre-merger period is from $1.73(0.00)$ for year -3 down to $0.44(-0.20)$ for year -1. The mean and median measure over pre-acquisition years (ACFMpre) is 1.12 and 0.40 , respectively. While the median measure is only significant in year -3 , all the mean measures are statistically different from zero at the 10 percent level of significance except year t- 1 . In general, merging firms in the sample are performing better than their matched counterparts in the pre-acquisition period. These differences are more substantial in the post-acquisition period. Both mean $(2.68,2.52$, and 2.87 for year $+1,+2$, and +3 , respectively; 2.82 for ACFMpost $)$ and median $(2.29,2.08$, and 2.15 for year $+1,+2$, and +3 , respectively; 2.15 for ACFMpost) measures are significantly positive at the 1 percent annual level in the annual and over the three years after acquisition. Comparing the pre and post adjusted cash flow margins $(\triangle A C F M)$ also indicates that the mean and the median change of 1.70 and 1.94 are statistically significant.

The above findings are supported when the improvements are tested by regression. Panel B presents the regression results of median adjusted post-acquisition cash flow margins (ACFMpost) on median adjusted pre-acquisition measures (ACFMpre). The intercept $\alpha(0.023)$ is significantly different from zero at the 1 percent level, which indicates that after controlling for the effects of pre-merger cash flow margins, there is still a significant improvement of 2.3 percent in the post-acquisition period. Compared to the results of table 6.1, the adjusted cash flow returns in the post-acquisition period seem to be insignificantly positive while the cash flow margins are significantly positive. One possible reason for this is that the significant increase in adjusted operating cash flow margins is offset by the significant decrease in asset turnover. The following test on asset turnover confirms this point. Also, from the change in operating performance, both cash flow returns ( $\triangle A C F R$ ) and cash flow margins $(\triangle A C F M)$ prove that merging firms have significant improvements after transaction.

Overall, the merging firms in this sample earn higher adjusted operating cash flow margins $(A C F M)$ than their matched counterparts in the post-acquisition period; these improvements are not due to a persistence of superior pre-performance. These findings are 
similar to the conclusion in Healy, Palepu and Ruback (HPR, 1992) and Rahman and Limmack (2004). However, HPR (1992) hesitate to attribute the increase to the acquisition itself because even when they control for pre-acquisition adjusted operating cash flow margins, they are unable to find evidence of a significant change in the margins after transaction. In the Ghosh (2001) study, the mean adjusted cash flow margins are significantly positive in year $t+1, t+2$ and over the three-year post-acquisition. Nevertheless, Ghosh cannot prove the significant increase in the change of adjusted operating cash flow margins $(\triangle C F R M)$ following acquisition transactions.

\section{Table 7.1 Operating Cash Flow Margin}

Sample of 282 mergers and acquisitions by 222 acquiring firms in 11 English Origin countries (Australia, Canada, India, Ireland, Israel, Malaysia, New Zealand, Singapore, South Africa, Thailand and United Kingdom) between 1997 and 2001 for completed takeovers over US\$ 10 million are obtained from the Thomson Financial Securities Data's SDC PlatinumTM Worldwide Mergers \& Acquisitions Database. Operating cash flow margin $(C F M)$ is calculated as operating cash flow divided by Sales. Operating cash flow is defined as operating income before depreciation. Post-acquisition performance for each deal is measured by the operating cash flow margin of the surviving acquirer after transaction. Pre acquisition performance is calculated as a weighted-average of the operating cash flow margin for the bidder and the target included (MEGi pre and post). The weights are based on the market values of assets of both companies in the year before acquisition. Post- and pre-acquisition performances of the matched firms are measured as weighted-average of the operating cash flow margin (MATi pre and post). Industry, Size, and Pre performance Adjusted Operating Cash Flow Margin $(A C F M)$ is operating cash flow rates of merging firms minus those of matched firms. ACFMpost and ACFMpre are the 3 year-median ACFM before and after acquisition. The change in industry, size, and pre performance adjusted cash flow margin $(\triangle A C F M)$ is defined ACFMpost minus ACFMpre. Outliers have been winsorized using Huber's $\mathrm{M}$ estimator approach. ${ }^{* * *}$ denotes significance at the $1 \%$ level, ${ }^{* *}$ significance at the $5 \%$ level, * significance at the $10 \%$ level.

Panel A Operaitng Cash Flow Margin (CFM)

\begin{tabular}{|c|c|c|c|c|c|c|c|c|c|c|}
\hline \multirow{2}{*}{$\begin{array}{c}\text { Year Relative to } \\
\text { Acquisition }\end{array}$} & \multicolumn{3}{|c|}{ Mergering Firms (MEGi $)$} & \multicolumn{3}{|c|}{ Matched Firms (MATi ) } & \multicolumn{4}{|c|}{$\begin{array}{l}\text { Industry, Size, and Pre-performance Adjusted } \\
\text { (MEGi-MATi) }\end{array}$} \\
\hline & $\mathrm{N}$ & Mean & Median & $\mathrm{N}$ & Mean & Median & $\mathrm{N}$ & Mean & Median & Positive \\
\hline-3 & 194 & 14.22 & 13.14 & 194 & 12.49 & 12.29 & 194 & $1.73^{* *}$ & $0.00^{*}$ & $47 \%$ \\
\hline-2 & 260 & 15.33 & 14.39 & 260 & 14.27 & 14.16 & 260 & $1.06^{*}$ & 0.34 & $57 \%$ \\
\hline-1 & 282 & 15.75 & 14.49 & 282 & 15.30 & 15.24 & 282 & 0.44 & -0.20 & $45 \%$ \\
\hline 1 & 282 & 16.09 & 14.67 & 282 & 13.41 & 13.11 & 282 & 2.68 **** & $2.29^{* * * *}$ & $62 \%$ \\
\hline 2 & 280 & 15.55 & 14.25 & 280 & 13.03 & 12.77 & 280 & $2.52^{* * *}$ & $2.08^{* * *}$ & $63 \%$ \\
\hline 3 & 279 & 15.49 & 13.96 & 279 & 12.62 & 12.05 & 279 & $2.87^{* * * *}$ & $2.15^{* * *}$ & $64 \%$ \\
\hline \multicolumn{7}{|c|}{ ACFMpre: Median for years $(-3$ to -1$)$} & 282 & $1.12^{* *}$ & 0.40 & $53 \%$ \\
\hline \multicolumn{7}{|c|}{ ACFMpost: Median for years $(+1$ to +3$)$} & 282 & $2.82^{* * *}$ & $2.20^{* * *}$ & $63 \%$ \\
\hline \multicolumn{7}{|c|}{$\triangle \mathrm{ACFM}$ : change in operating cash flow rate (ACFMpost -ACFMpre) } & 282 & $1.70^{* * *}$ & $1.90^{* * *}$ & $64 \%$ \\
\hline
\end{tabular}

Panel B Regression of ACFMpost on ACFMpre

ACFMpost $=0.023^{* * *}+0.504^{* * *}$ ACFMpre

$\mathrm{F}=75.033^{* * *}$

adj. $R^{2}=20.9 \%$ 


\subsubsection{Asset Turnover $(A T)$}

The ratio of asset turnover $(A T)$ is calculated as sales divided by market value of assets $\left(S / M V_{A}\right)$ (the same definition as offered in HPR 1992). Market value of asset is computed by adding market value of equity at the beginning of each year and the book value of net debt. Table 7.2 presents the summary statistics on asset turnovers $(A T)$ for merging firms, matched firms and adjusted asset turnover (AAT) in the years surrounding the acquisition. The 3 year-median AAT before and after acquisition (AATpre and AATpost) and the change of adjusted asset turnover $(\triangle A A T)$ are also displayed in panel $\mathrm{A}$. Panel $\mathrm{B}$ provides the results of the change regression model.

The results in panel A of table 7.2 give details that both mean and median adjusted asset turnovers are significantly negative in all pre-acquisition periods (year $\mathrm{t}-3$ to $\mathrm{t}-1$ ). The median (mean) measure over three pre-acquisition years (AATpre) is $-0.130(-0.179)$ which indicates that merging firms generate 13.0 cent less in sales than benchmark firms for each dollar of assets in the pre-acquisition years. The results are close to those reported by HPR (1992) who find that median asset (sales) turnover of the merging firms is 0.2 lower than that of their competitors. Besides, Rahman and Limmack (2004) also report a -0.05 median adjusted asset turnover over the pre-acquisition period.

Evidence in this thesis shows that merging firms are still and even worse $(-0.206$ for mean and -0.172 for median) after merger while HPR (1992) document that merging firms close the gap and achieve a comparable adjusted asset turnover in the post-merger period. Merging firms consistently and stably underperform on asset turnover and it is reasonable to conjecture that poor post performance might be attributed to the poor pre performance. While the intercept regression model (table 7.2 panel B) still shows a significant decrease after controlling the pre performance, it might be more interesting to look at a change in asset turnover which is negative but non-significant. (median and mean measure is -0.027 and -0.038 , respectively).

From this analysis, it is clear that the improvement in adjusted operating cash flow returns is completely contributed by the increase of cash flow margins and not by using operating assets productively in the three years following acquisition. Due to the research limits, this thesis can only speculate about possible reasons for the decrease in asset turnover rates following the transactions. For instance, the disposal of the pre acquisition unwanted 
capacity is not as efficient as expected in the first three years after takeovers; the large increase in operating assets based in the combined firms actually worsens the idle property; or the benefits of sales growth are still not enough to be distributed because of the fast increase of market shares.

\section{Table 7.2 Asset Turnovers}

Sample of 282 mergers and acquisitions by 222 acquiring firms in 11 English Origin countries (Australia, Canada, India, Ireland, Israel, Malaysia, New Zealand, Singapore, South Africa, Thailand and United Kingdom) between 1997 and 2001 for completed takeovers over US\$ 10 million are obtained from the Thomson Financial Securities Data's SDC PlatinumTM Worldwide Mergers \& Acquisitions Database. Asset Turnover $(A T)$ is calculated as sales divided by market value of asset. Post-acquisition performance for each deal is measured by the asset turnover rates of the surviving acquirer after transaction. Pre acquisition performance is calculated as a weighted-average of the asset turnover rates for the bidder and the target included (MEGi pre and post). The weights are based on the market values of assets of both companies in the year before acquisition. Post- and pre -acquisition performances of the matched firms are measured as weighted-average of the asset turnover rates (MATi pre and post). Industry, Size, and Pre performance Adjusted Asset Turnover $(A A T)$ is asset turnover rates of merging firms minus those of matched firms. AAT and AATpre are the 3 year-median AAT before and after acquisition. The change in industry, size, and pre performance adjusted sales turnover $(\triangle A A T)$ is defined as 3-year median AATpost minus 3 year-median AATpre. Outliers have been winsorized using Huber's $M$ estimator approach. *** denotes significance at the $1 \%$ level, ** significance at the $5 \%$ level, * significance at the $10 \%$ level.

Panel A Asset Turnovers (AT)

\begin{tabular}{|c|c|c|c|c|c|c|c|c|c|c|c|c|}
\hline \multirow{2}{*}{$\begin{array}{c}\text { Year Relative to } \\
\text { Acquisition }\end{array}$} & \multicolumn{3}{|c|}{ Mergering Firms (MEGi ) } & \multicolumn{3}{|c|}{ Matched Firms (MAT $i$ ) } & \multicolumn{6}{|c|}{$\begin{array}{l}\text { Industry, Size, and Pre-performance Adjusted } \\
\text { (MEGi } i \text {-MAT } i)\end{array}$} \\
\hline & $\mathrm{N}$ & Mean & Median & $\mathrm{N}$ & Mean & Median & $\mathrm{N}$ & Mean & & Median & & Positive \\
\hline-3 & 194 & 0.653 & 0.534 & 194 & 0.863 & 0.709 & 194 & -0.210 & *** & -0.028 & $* * *$ & $30.30 \%$ \\
\hline-2 & 260 & 0.841 & 0.734 & 260 & 0.966 & 0.870 & 260 & -0.125 & $* * *$ & -0.074 & $* * *$ & $41.51 \%$ \\
\hline-1 & 282 & 0.769 & 0.665 & 282 & 0.996 & 0.925 & 282 & -0.227 & *** & -0.168 & $* * *$ & $39.02 \%$ \\
\hline 1 & 282 & 0.750 & 0.642 & 282 & 0.936 & 0.839 & 282 & -0.186 & $* * *$ & -0.173 & $* * *$ & $35.46 \%$ \\
\hline 2 & 280 & 0.787 & 0.680 & 280 & 0.996 & 0.858 & 280 & -0.209 & $* * *$ & -0.166 & $* * *$ & $35.71 \%$ \\
\hline 3 & 279 & 0.878 & 0.750 & 279 & 1.065 & 0.919 & 279 & -0.187 & $* * *$ & -0.200 & $* * *$ & $39.43 \%$ \\
\hline \multicolumn{7}{|c|}{ AATpre: Median for years $(-3$ to -1$)$} & 282 & -0.179 & $* * *$ & -0.130 & $* * *$ & $37.28 \%$ \\
\hline \multicolumn{7}{|c|}{ AATpost: Median for years $(+1$ to +3$)$} & 282 & -0.206 & & -0.172 & & $36.88 \%$ \\
\hline \multicolumn{7}{|c|}{$\triangle \mathrm{AAT}$ : change in operating cash flow rate (AATpost -AATpre) } & 282 & -0.027 & & -0.038 & & $45.39 \%$ \\
\hline
\end{tabular}

Panel B Regression of AATpost on AATpre

AATpost $=-0.100^{* * *}+0.591 * * *$ AATpre

$\mathrm{F}=174.293 * * *$

adj. $R^{2}=38.1 \%$

\subsubsection{Sales Growth Rate $(S G)$}

Sales are examined after realizing that the most important source of improved operating cash flow returns comes from the cash flow margins rather than from the efficient use of resources available in the post-bid period. The one-year sales growth rates $(S G)$ are obtained from the Thomson Financial database and are defined as the current year's net sales divided by the last year's total net sales $\left(S_{t} / S_{t-1}\right)$. Table 7.3 presents the summary statistics of 
sales growth rates (SG) for merging firms, matched firms, and adjusted sales growth rates $(A S G)$ in the years surrounding the acquisition; the 3 year-median $A S G$ before and after acquisition (ASGpre and ASGpost) and the change of adjusted asset turnover rate ( $\triangle A S G)$ are also presented. Again, panel B provides the results of the change regression model.

The results reveal information that parallels the cash flow margin results in table 7.3. Both mean (4.23, 4.66 and 1.12 for year t-3, t-2, and t-1, respectively; 3.13 for ASGpre) and median (1.61, 3.64 and 2.29 for year t-3, t-2, and t-1, respectively; 1.51 for ASGpre) measures are significantly positive in all but year $\mathrm{t}-1$ in the pre-acquisition period. Merging firms outperform their matched counterparts in sales growth rates during the pre-acquisition period. After merger, the mean (median) adjusted sales growth rate jumps to 18.43 (16.06) percent in year $\mathrm{t}+1$ and then decline to $3.65(4.42)$ percent in year $\mathrm{t}+2$ and $0.00(0.00)$ in year $t+3$. This result is similar to earlier findings in Ghosh (2001). According to the explanation offered in the Ghosh (2001) paper, the big jump in year $\mathrm{t}+1$ is probably due to accounting. Because the sales growth rate of year $t+1$ is calculated based on the sales of year 0 , for mid-year acquisition target firms' yearly sales are not fully reported in the combined statement at year 0 under purchase accounting, there is a sudden jump in the growth rate of year t+1. The mean (6.06) and median (5.43) $A S G$ post are significantly positive at one percent level and both measures of change in adjusted sales growth dates $(\triangle A S G)$ are economically significant (2.93 and 4.69).

The improvements of adjusted sales growth rates following the acquisition are further confirmed by the regression results. Panel B presents the regression results of median adjusted post-acquisition sales growth rates (ASGpost) on median adjusted pre-acquisition measures (ASGpre). The intercept $\alpha$ (5.678) is significantly different from zero at the one percent level, which indicates that even after controlling for the effects of pre-merger sales growth rates, there is still a significant improvement of 5.678 percent in the sales growth rates of merging firms following acquisition.

From this test, it is clear that sales make an important contribution to the improvements of cash flow. However, it is also clear that the advantage in sales growth rates dramatically declines year by year after transaction. The difference between merging firms and matched firms in sales growth rates becomes insignificant in year $\mathrm{t}+3$. 


\section{Table 7.3 Sales Growth Rates}

Sample of 282 mergers and acquisitions by 222 acquiring firms in 11 English Origin countries (Australia, Canada, India, Ireland, Israel, Malaysia, New Zealand, Singapore, South Africa, Thailand and United Kingdom) between 1997 and 2001 for completed takeovers over US\$ 10 million are obtained from the Thomson Financial Securities Data's SDC PlatinumTM Worldwide Mergers \& Acquisitions Database. Sales Growth rate $(S G)$ is calculated as current year's net sales divided by last year's total net sales. Post-acquisition performance for each deal is measured by the sales growth of the surviving acquirer after transaction. Pre acquisition performance is calculated as a weighted-average of the sales growth for the bidder and the target included (MEGi pre and post). The weights are based on the market values of assets of both companies in the year before acquisition. Post- and pre- acquisition performances of the matched firms are measured as weighted-average of the sales growth (MATi pre and post). Industry, Size, and Pre performance Adjusted Sales Growth $(A S G)$ is sales growth rates of merging firms minus those of matched firms. ASGpost and ASGpre are the 3 year-median ASG before and after acquisition. The change in industry, size, and pre performance adjusted sales growth $(\triangle A S G)$ is defined as 3-year median ASGpost minus 3 year-median ASGpre. Outliers have been winsorized using Huber's M estimator approach. ${ }^{* * *}$ denotes significance at the $1 \%$ level, ${ }^{* *}$ significance at the $5 \%$ level, * significance at the $10 \%$ level.

Panel A Sales Growth Rates (SG)

\begin{tabular}{|c|c|c|c|c|c|c|c|c|c|c|}
\hline \multirow{2}{*}{$\begin{array}{c}\text { Year Relative to } \\
\text { Acquisition }\end{array}$} & \multicolumn{3}{|c|}{ Mergering Firms (MEGi ) } & \multicolumn{3}{|c|}{ Matched Firms (MAT $i$ ) } & \multicolumn{4}{|c|}{$\begin{array}{l}\text { Industry, Size, and Pre-performance Adjusted } \\
\text { (MEGi }-\mathrm{MAT} i \text { ) }\end{array}$} \\
\hline & $\mathrm{N}$ & Mean & Median & $\mathrm{N}$ & Mean & Median & $\mathrm{N}$ & Mean & Median & 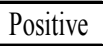 \\
\hline-3 & 194 & 10.72 & 9.72 & 194 & 6.50 & 5.15 & 194 & $4.23^{* * *}$ & $1.61^{* * *}$ & $53 \%$ \\
\hline-2 & 260 & 14.82 & 12.16 & 260 & 10.16 & 9.35 & 260 & $4.66^{* * *}$ & $3.64^{* * *}$ & $60 \%$ \\
\hline-1 & 282 & 15.28 & 13.07 & 282 & 14.16 & 12.65 & 282 & 1.12 & 2.29 & $57 \%$ \\
\hline 1 & 282 & 25.55 & 21.85 & 282 & 7.11 & 6.59 & 282 & $18.43^{* * *}$ & $16.06^{* * *}$ & $77 \%$ \\
\hline 2 & 280 & 8.02 & 6.63 & 280 & 4.37 & 3.84 & 280 & $3.65^{* * *}$ & $4.42^{* * *}$ & $59 \%$ \\
\hline 3 & 279 & 5.70 & 4.48 & 279 & 5.70 & 5.37 & 279 & 0.00 & 0.00 & $50 \%$ \\
\hline \multicolumn{7}{|c|}{ ASGpre: Median for years $(-3$ to -1$)$} & 282 & $3.13^{* * *}$ & $1.51^{* * *}$ & $57 \%$ \\
\hline \multicolumn{7}{|c|}{ ASGpost: Median for years $(+1$ to +3$)$} & 282 & $6.06^{* * *}$ & $5.43^{* * *}$ & $66 \%$ \\
\hline \multicolumn{7}{|c|}{$\triangle \mathrm{ASG}$ : change in sales growth rate (ASGpost -ASGpre) } & 282 & $2.93^{* *}$ & $4.69^{* * *}$ & $59 \%$ \\
\hline
\end{tabular}

\section{Panel B Regression of ASGpost on ASGpre}

ASGpost $=5.678 * * * 0.122 *$ ASGpre

$\mathrm{F}=2.895^{*}$

adj. $R^{2}=0.7 \%$ 


\subsection{Analysis of Type of Shareholders}

As reviewed in section 2.3.2 of chapter two, different types of shareholders have their own specific characteristics in the concentrated ownership structure. For family ownership, a line of previous literature suggests that a family's tenure can extend the firm's learning curve; families tend to have longer investment horizons (Stein 1989) and families often attempt to invest in positive projects to pass on to their descendants (James 1999). However, the other line of study argues that family may limit the top management positions to family members instead of hiring more qualified, external professional managers (Schulze, Lubatkin, Dino and Buchholtz 2001); the family also has more power to act on its own interests (Claessens, Djankov and Lang 2000); and the family may be unwilling to raise loans or to issue new stocks so as to make new positive investments (Zhang 1998). For institutional ownership, some research suggests that institutional investors may have more power and information for solving free-rider problems. But some articles argue that institutional investors are unable to effectively play their monitoring role because of their passivity, their myopic goals, or their interest conflicts (Duggal and Millar 1999). Financial institutional ownership is a specific type of institutional ownership. One stream of study represents the positive effect of bank involvement because financial institutions are assumed to provide superior monitoring capabilities, lower capital costs, or better financial supports (Lichtenberg and Pushner 1994). The other stream suggests negative effects since banks are usually risk-averse and are likely to use their monopoly power to expropriate minority shareholders (Weinstein and Yafeh 1998). State ownership is broadly considered an inefficient structure because this structure indicates a significant separation problem between control rights and cash flow rights; state firms do not attempt to pursue public interests more than private firms (Shleifer and Vishny 1997).

While the purpose of this thesis is not to examine various types of shareholders, it is still valuable to look at the specific benefits and costs of each type of ownership related to long-term acquisition operating performance. Therefore, following the classification of controlling shareholders in previous literature (La Porta, Lopez-de-Silanes and Shleifer 1999, Claessens et al. 2000, Faccio and Lang 2002), it is possible to identify four ultimate owners of concentrated firms in the sample and to then set four dummy variables for the four groups: 
LSH_FAM which equals to one if an acquiring firm has the ultimate owner who is individual or a member of family holding more than 10 percent of firm's voting shares;

LSH_FIN which equals to one if an acquiring firm has the ultimate owner who is widely held financial institution holding more than 10 percent of firm's voting shares;

LSH_NFIN which equals to one if an acquiring firms has the ultimate owner who is widely held corporation holding more than 10 percent of firm's voting shares;

LSH_GOV which equals to one if an acquiring firms has the ultimate owner who is the department of government holding more than 10 percent of firm's voting shares

A detailed explanation for the classification and characteristics of each type of concentrated firms is described in section 2.3.2 of chapter two..

\subsubsection{Statistics Description and Univariate Analysis}

To do univariate analysis, another variable (LSH_Type) is placed. It includes dispersed firms (DISPERSED) and four groups of concentrated firms as described above (LSH_FAM, LSH_FIN, LSH_NFIN, and LSH_GOV). Table 7.4 shows that in the sample companies, family controlled firms $(22.7 \%)$ and financial institutions controlled firms (23.0\%) have equal weight. There are 12.8 percent of acquiring firms controlled by a widely held corporation and 40 percent of samples are dispersed firms. Only three acquiring firms in the sample are identified as state firms; these are all controlled by the Singapore government.

In panel $\mathbf{A}$ for pre-acquisition performance (ACFRpre), the mean and median measures are higher in family controlled firms $(-0.53 \%$ and $0.09 \%)$ than in overall sample companies $(-1.51 \%$ and $-0.70 \%)$. While the median measure of the state controlled firms is better than that of family firms, the relatively high standard deviation due to the small sample size implies the likelihood of bias. Acquiring firms controlled by a widely held corporation have poorer pre-performance in both measures $(-2.85 \%$ for mean and $-3.36 \%$ for median). Nevertheless, the underperformance or outperformance among these subgroups within the whole sample is not significant either by using independent $t$ test to compare average performance between each type or by using ANOVA $F$ test to examine the differences.

Similar results might be derived from panel $\mathbf{B}$ for post-acquisition performance (ACFRpost). The state controlled firms have better mean and median performances $(2.76 \%$ and $3.96 \%$ ) but the results may be over interpreted because of the small sample size of the 
stated controlled firms. Widely held controlled firms still have the lowest mean $(-0.86 \%)$ and median $(-1.31 \%)$ measures. Family controlled firms (1.15\% for mean and $2.15 \%$ for median) again outperform the overall sample companies $(0.31 \%$ for mean and $0.59 \%$ for median). However, there is no significant evidence to support the outperformance of family firms either by independent $t$ test or by ANOVA F test.

From panel $\mathbf{C}$ for the change performance $(\triangle A C F R)$, the dispersed firms, except the stated controlled firms, create better abnormal returns through M\&A transactions ( $2.04 \%$ for mean and $2.44 \%$ for median) even they do no possess the same high post-acquisition performance as family controlled firms. However, this evidence is still not significant enough to form any conclusions. A relatively small sample size for each type of concentrated firm may affect the results. This thesis further applies a non-parametric Mann-Whitney $U$ test. The non-parametric results are qualitatively the same though they are not reported.

Table 7.4 Statistics description and Univariate test of Type of Shareholders

Sample of 282 mergers and acquisitions by 222 acquiring firms in 11 English Origin countries (Australia, Canada, India, Ireland, Israel, Malaysia, New Zealand, Singapore, South Africa, Thailand and United Kingdom) between 1997 and 2001 for completed takeovers over US\$ 10 million are obtained from the Thomson Financial Securities Data's SDC PlatinumTM Worldwide Mergers \& Acquisitions Database. ACFRpre and ACFRpost is the pre and post industry, size, and pre performance adjusted cash flow return. $\triangle A C F R$ is the change in industry, size, and pre performance adjusted cash flow return. LSH_FAM is defined when the largest shareholder is individual or member of family. LSH_FIN is defined when the largest shareholder is a financial institution. LSH_NFIN is defined when the largest shareholder is a non-financial institution. LSH_GOV is defined when the largest shareholder is government. Outliers have been winsorized using Huber's M estimator approach. T tests of differences are presented. $* * *$ denotes significant at the $1 \%$ level, $* *$ significant at the $5 \%$ level, * significant at the $10 \%$ level.

\begin{tabular}{|c|c|c|c|c|c|c|c|c|c|c|}
\hline \multirow{2}{*}{$\begin{array}{c}\text { Full Sample } \\
(\mathrm{N}=\mathbf{2 8 2})\end{array}$} & \multirow{2}{*}{\multicolumn{2}{|c|}{ Count }} & \multirow{2}{*}{$\begin{array}{c}\text { Mean } \\
(\%)\end{array}$} & \multirow{2}{*}{$\begin{array}{c}\text { Median } \\
(\%)\end{array}$} & \multirow{2}{*}{$\begin{array}{l}\mathrm{SD} \\
(\%)\end{array}$} & \multicolumn{4}{|c|}{ Indepent t Test } & \multirow{2}{*}{$\begin{array}{l}\text { ANOVA } \\
\text { (F test) }\end{array}$} \\
\hline & & & & & & FIN & NFIN & GOV & DIS & \\
\hline "LSH_FAM & 64 & $22.7 \%$ & -0.53 & 0.09 & 7.11 & 0.715 & 1.517 & 0.183 & 1.124 & \\
\hline LSH_FIN & 65 & $23.0 \%$ & -1.46 & -0.99 & 7.63 & - & 0.873 & 0.072 & 0.188 & \\
\hline LSH_NFIN & 36 & $12.8 \%$ & -2.85 & -3.36 & 7.75 & - & - & -0.093 & -0.838 & 0.662 \\
\hline LSH_GOV & 3 & $1.1 \%$ & -2.06 & 5.38 & 14.44 & - & - & - & -0.047 & \\
\hline DISPERSED & 114 & $40.4 \%$ & -1.66 & -0.72 & 6.10 & - & - & - & - & \\
\hline Overall & 282 & $100.0 \%$ & -1.51 & -0.70 & 7.00 & & & & & \\
\hline
\end{tabular}

\begin{tabular}{|c|c|c|c|c|c|c|c|c|c|c|}
\hline \multirow{2}{*}{$\begin{array}{c}\text { Full Sample } \\
(\mathrm{N}=\mathbf{2 8 2})\end{array}$} & \multirow{2}{*}{\multicolumn{2}{|c|}{ Count }} & \multirow{2}{*}{$\begin{array}{c}\text { Mean } \\
(\%)\end{array}$} & \multirow{2}{*}{$\begin{array}{c}\text { Median } \\
(\%)\end{array}$} & \multirow{2}{*}{$\begin{array}{l}\mathrm{SD} \\
(\%) \\
\end{array}$} & \multicolumn{4}{|c|}{ Indepent t Test } & \multirow{2}{*}{$\begin{array}{c}\text { ANOVA } \\
\text { (F test) }\end{array}$} \\
\hline & & & & & & FIN & NFIN & GOV & DIS & \\
\hline LSH_FAM & 64 & $22.7 \%$ & 1.15 & 2.15 & 8.67 & 0.949 & 1.143 & -0.312 & 0.618 & \\
\hline LSH_FIN & 65 & $23.0 \%$ & -0.11 & 0.34 & 6.27 & - & 0.482 & -0.759 & -0.485 & \\
\hline LSH_NFIN & 36 & $12.8 \%$ & -0.86 & -1.31 & 8.07 & - & - & -0.737 & -0.837 & 0.587 \\
\hline LSH_GOV & 3 & $1.1 \%$ & 2.76 & 3.96 & 9.71 & - & - & - & 0.603 & \\
\hline DISPERSED & 114 & $40.4 \%$ & 0.38 & 0.64 & 6.68 & - & - & - & - & \\
\hline Overall & 282 & $100.0 \%$ & 0.31 & 0.59 & 7.28 & & & & & \\
\hline
\end{tabular}

\begin{tabular}{|c|c|c|c|c|c|c|c|c|c|c|}
\hline \multirow{2}{*}{$\begin{array}{c}\text { Full Sample } \\
(\mathrm{N}=\mathbf{2 8 2})\end{array}$} & \multirow{2}{*}{\multicolumn{2}{|c|}{ Count }} & \multirow{2}{*}{$\begin{array}{c}\text { Mean } \\
(\%)\end{array}$} & \multirow{2}{*}{$\begin{array}{c}\text { Median } \\
(\%)\end{array}$} & \multirow{2}{*}{$\begin{array}{l}\text { SD } \\
(\%)\end{array}$} & \multicolumn{4}{|c|}{ Indepent t Test } & \multirow{2}{*}{$\begin{array}{l}\text { ANOVA } \\
\text { (F test) }\end{array}$} \\
\hline & & & & & & FIN & NFIN & GOV & DIS & \\
\hline 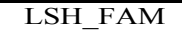 & 64 & $22.7 \%$ & 1.68 & 1.96 & 7.49 & 0.244 & -0.246 & -0.712 & -0.332 & \multirow{5}{*}{0.249} \\
\hline LSH FIN & 65 & $23.0 \%$ & 1.34 & -0.29 & 8.13 & - & -0.493 & 0.727 & -0.588 & \\
\hline LSH_NFIN & 36 & $12.8 \%$ & 1.99 & 2.66 & 4.98 & - & - & -0.930 & -0.046 & \\
\hline LSH_GOV & 3 & $1.1 \%$ & 4.82 & 4.67 & 6.31 & - & - & - & 0.706 & \\
\hline DISPERSED & 114 & $40.4 \%$ & 2.04 & 2.44 & 6.72 & - & - & - & - & \\
\hline Overall & 282 & $100.0 \%$ & 1.82 & 1.73 & 7.02 & & & & & \\
\hline
\end{tabular}




\subsubsection{Regression Results}

Based on the research structures used in the main analysis, four dummy variables for the type of large shareholders are first examined in regression models 10 of table 7.5. After controlling for those governance and deal factors that are expected to affect acquiring performance, it seems the coefficients of financial institutions controlled firms (LSH_FIN) for both performance measures are significantly negative at a 10 percent level $(-0.017$ in both panel A for ACFRpost and panel B for $\triangle A C F R$ ). Evidence here supports Weinstein and Yafeh's (1998) point by stating that financial institution large shareholders tend to pursue less risky projects that would result in lower profit investment returns. Results for the other control variables are consistent with the main findings. From panel A for ACFRpost, it is clear that separation problems still lead to value reduction; the existence of multi-bidders and the larger deviation between bidders' and targets' firm size are related to the poorer acquisition performance. Panel B for $\triangle A C F R$ evidences how CEO duality has a stronger negative impact on the average change performance; the presence of other blockholders plays an efficient monitoring role; and acquiring firms have higher levels of leverage that may be forced to miss a positive M\&A investment.

In model 11, 12, 11.1, and 12.1 of table 7.5, four dummy variables for the type of large shareholders are further examined by controlling for institutional variables. An interesting result shows that both financial institutions controlled firms and also family controlled firms have significantly poor post-acquisition performance. This means that when legal and extra-legal mechanisms are controlled, family controlling shareholders are likely to act on their own private benefits at the expense of firm performance through M\&A transactions. Besides, once institutional variables are controlled, the first generation governance mechanisms become significantly important. For example, in panel A for post operating performance (ACFRpost) controlling CEOs have higher incentive to make profitable M\&A decisions and smaller board size may function more efficiently. The other results for deal and institutional variables are the same as those held in the main analyses. Initial anti-director right and revised anti-director right indexes are stable proxies to represent how better investor protection leads to better acquisition performance. 
Table 7.5 Regression Results of Type of Large shareholders

Sample of 282 mergers and acquisitions by 222 acquiring firms in 11 English Origin countries (Australia, Canada, India, Ireland, Israel, Malaysia, New Zealand, Singapore, South Africa, Thailand and United Kingdom) between 1997 and 2001 for completed takeovers over US\$ 10 million are obtained from the Thomson Financial Securities Data's SDC PlatinumTM Worldwide Mergers \& Acquisitions Database. ACFRpre and ACFRpost is the pre and post industry, size, and pre performance adjusted cash flow return. $\triangle A C F R$ is the change in industry, size, and pre performance adjusted cash flow return. Outliers have been winsorized using Huber's $M$ estimator approach. T tests of differences are presented. Two tail tests *** denotes significant at the $1 \%$ level, ** significant at the $5 \%$ level, * significant at the $10 \%$ level. LSH FAM is defined when the largest shareholder is individual or member of family. LSH FIN is defined when the largest shareholder is a financial institution. LSH NFIN is defined when the largest shareholder is a non-financial institution. LSH_GOV is defined when the largest shareholder is government. See table 5.5 for the definitions of other variables.

Panel A Regression Results on Dependent Variable: ACFRpost

\begin{tabular}{|c|c|c|c|c|c|}
\hline Full Sample $(\mathrm{N}=282)$ & Model 10 & Model 11 & Model 11.1 & Model 12 & Model 12.1 \\
\hline$\overline{\text { Intercept }}$ & $0.052^{* *}$ & -0.196 & 0.056 & 0.008 & 0.102 \\
\hline LSH_FAM & -0.014 & $-0.024 *$ & $-0.023 *$ & $-0.026 *$ & $-0.024 *$ \\
\hline LSH_FIN & $-0.017^{*}$ & $-0.019^{*}$ & $-0.018 *$ & $-0.020 * *$ & $-0.019 *$ \\
\hline LSH_NFIN & -0.001 & -0.015 & -0.013 & -0.016 & -0.012 \\
\hline LSH_GOV & 0.015 & 0.023 & 0.021 & 0.004 & -0.023 \\
\hline SEP & $-0.020 *$ & $-0.027^{* *}$ & $-0.028^{* *}$ & $-0.028^{* *}$ & $-0.028 * *$ \\
\hline CEOLSH & 0.024 & $0.034^{* *}$ & $0.032 * *$ & $0.032 * *$ & $0.031^{* *}$ \\
\hline CEOdual & -0.015 & -0.012 & -0.014 & -0.013 & $-0.017 *$ \\
\hline BSIZE & -0.002 & $-0.003^{* *}$ & $-0.003^{* *}$ & $-0.003^{* *}$ & $-0.002 *$ \\
\hline INDDIR & -0.021 & -0.034 & -0.031 & -0.041 & -0.039 \\
\hline OTHLSH & 0.013 & 0.007 & 0.009 & 0.009 & 0.012 \\
\hline TGORI_English & 0.002 & -0.005 & -0.004 & -0.004 & -0.005 \\
\hline ATTI_Hostile & 0.006 & 0.017 & 0.012 & 0.003 & 0.009 \\
\hline PAY_stock & -0.012 & -0.011 & -0.013 & -0.013 & -0.015 \\
\hline COMPETE & $-0.037^{* *}$ & $-0.040^{* * *}$ & $-0.039^{* *}$ & $-0.040^{* *}$ & $-0.039^{* *}$ \\
\hline IND_rel & 0.001 & 0.000 & 0.000 & -0.001 & 0.002 \\
\hline TOEHOLD & 0.007 & 0.014 & 0.014 & 0.012 & 0.010 \\
\hline PREM_1day & 0.000 & 0.000 & 0.000 & 0.000 & 0.000 \\
\hline SIZE_rel & $-0.005^{* *}$ & $-0.004 *$ & $-0.005^{* *}$ & $-0.005 *$ & $-0.005^{* *}$ \\
\hline LEV & -0.001 & -0.001 & -0.002 & -0.002 & -0.003 \\
\hline ANTIDIR_high & & $0.095^{* *}$ & $0.070 * * *$ & & \\
\hline ENFORCE & & -0.001 & & & \\
\hline ACCTSTD & & $0.004 *$ & & & \\
\hline XLEG_high & & -0.031 & -0.024 & & \\
\hline ANTISDI & & & & 0.064 & -0.061 \\
\hline PUBENFORCE_high & & & & $-0.078^{* *}$ & \\
\hline NANTIDIR high & & & & $0.071^{* * *}$ & $0.056^{* * *}$ \\
\hline$U K$ & & -0.075 & -0.043 & $-0.075^{* * *}$ & $-0.042^{* *}$ \\
\hline$C A N$ & & -0.068 & $-0.046^{* * *}$ & $0.115^{* *}$ & 0.020 \\
\hline$A U S$ & & $0.059^{* *}$ & $0.055^{* *}$ & $0.036^{*}$ & 0.036 \\
\hline ACFRpre & $0.520 * * *$ & $0.506^{* * *}$ & $0.517 * * *$ & $0.515^{* * *}$ & $0.519^{* * *}$ \\
\hline $\begin{array}{c}\text { Adjust } R^{2}(\%) \\
F\end{array}$ & $\begin{array}{c}28.7 \\
6.667 * * *\end{array}$ & $\begin{array}{c}34.2 \\
6.405 * * *\end{array}$ & $\begin{array}{c}33.8 \\
6.736^{* * *}\end{array}$ & $\begin{array}{c}32.9 \\
6.290 * * *\end{array}$ & $\begin{array}{c}31.8 \\
6.250 * * *\end{array}$ \\
\hline
\end{tabular}


Table 7.5 (Continued)

Panel B Dependent Variable: $\triangle$ ACFR

\begin{tabular}{|c|c|c|c|c|c|}
\hline Full Sample $(\mathrm{N}=282)$ & Model 10 & Model 11 & Model 11.1 & Model 12 & Model 12.1 \\
\hline Intercept & $0.052^{* *}$ & -0.222 & 0.017 & -0.001 & 0.080 \\
\hline LSH_FAM & -0.014 & $-0.028 *$ & $-0.027 *$ & $-0.029 *$ & $-0.027^{*}$ \\
\hline LSH_FIN & $-0.017^{*}$ & $-0.022 *$ & $-0.021 *$ & $-0.022 *$ & $-0.020^{*}$ \\
\hline LSH_NFIN & -0.001 & -0.015 & -0.012 & -0.013 & -0.009 \\
\hline LSH_GOV & 0.015 & 0.031 & 0.025 & 0.016 & -0.007 \\
\hline SEP & -0.020 & -0.023 & -0.022 & -0.021 & -0.021 \\
\hline CEOLSH & 0.024 & $0.028 *$ & 0.024 & 0.024 & 0.022 \\
\hline CEOdual & $-0.015^{* *}$ & $-0.022 * *$ & $-0.023 * *$ & $-0.022 * *$ & $-0.025^{* *}$ \\
\hline BSIZE & -0.002 & -0.002 & -0.002 & -0.002 & -0.002 \\
\hline INDDIR & -0.021 & -0.019 & -0.014 & -0.021 & -0.019 \\
\hline OTHLSH & $0.013 *$ & 0.017 & $0.020 *$ & $0.021 *$ & $0.023^{*}$ \\
\hline TGORI_English & 0.002 & 0.003 & 0.002 & 0.002 & 0.001 \\
\hline ATTI_Hostile & 0.006 & 0.008 & 0.012 & 0.009 & 0.014 \\
\hline PAY_stock & -0.012 & -0.007 & -0.011 & -0.011 & -0.012 \\
\hline COMPETE & $-0.037^{* * *}$ & $-0.055^{* * *}$ & $-0.055^{* * *}$ & $-0.054^{* * *}$ & $-0.053^{* * *}$ \\
\hline IND_rel & 0.001 & 0.006 & 0.007 & 0.007 & 0.009 \\
\hline TOEHOLD & 0.007 & $0.024 * *$ & $0.022 *$ & $0.020 *$ & 0.018 \\
\hline PREM_1day & 0.000 & 0.000 & 0.000 & 0.000 & 0.000 \\
\hline SIZE_rel & -0.005 & -0.001 & -0.002 & -0.002 & -0.002 \\
\hline LEV & $-0.001^{* *}$ & $-0.007 *$ & $-0.008^{* *}$ & $-0.008^{* *}$ & $-0.008^{* *}$ \\
\hline ANTIDIR_high & & $0.137^{* * *}$ & $0.084^{* * *}$ & & \\
\hline ENFORCE & & 0.011 & & & \\
\hline ACCTSTD & & 0.000 & & & \\
\hline XLEG_high & & -0.017 & 0.003 & & \\
\hline ANTISDI & & & & 0.039 & -0.070 \\
\hline PUBENFORCE high & & & & $-0.068 *$ & \\
\hline NANTIDIR high & & & & $0.071^{* * *}$ & $0.059^{* *}$ \\
\hline$\overline{U K}$ & & $-0.134^{* *}$ & $-0.076^{* *}$ & $-0.074^{* * *}$ & $-0.045^{* *}$ \\
\hline$C A N$ & & $-0.145^{* *}$ & $-0.061^{* * *}$ & 0.089 & 0.007 \\
\hline$A U S$ & & 0.032 & 0.035 & 0.031 & 0.031 \\
\hline Adjust $R^{2}(\%)$ & 6.8 & 8.3 & 8.4 & 6.9 & 6.2 \\
\hline $\mathrm{F}$ & $2.222 * * *$ & $1.983 * * *$ & $2.073 * * *$ & $1.835 * *$ & $1.778 * *$ \\
\hline
\end{tabular}




\subsection{Analysis of Cross Effects of Type I and Type II Agency Problem}

As defined in section 4.3.3, the type I agency problem exists when a company with control devices which separate control rights from cash flow rights. The type II agency problem occurs when a company with an independent CEO owning few shares in the company; this causes the divergence-of-interest effects between ownership and management. Extending the evidence regarding to separation (SEP) and controlling CEO (CEOLSH) in the main analyses, this thesis also attempts to examine the interactive effects between these two types of agency problems on acquisition operating performance. That is, which type of these two agency problems is the more detrimental to acquisition performance? To what extent can one type of agency cost be offset by ameliorating the other type of agency cost, and vice versa? The results are presented in table 7.6.

From panel A of table 7.6 for full samples, there are 29 firms with both the type I and the type II agency problems, 18 firms with the type I but not the type II agency problem, 214 firms with the type II but not the type I problem, and 21 firms with neither the type I nor the type II agency problem. As expected, it is clear from these findings that the mean measure of post-acquisition performance (ACFRpost) in companies with the type I and the type II agency costs $(-3.64 \%)$ is significantly worse than in the other groups. Companies without the type II but with the type I ( $3.50 \%$ for ACFRpost), as compared to companies with the type II but without the type I ( $0.42 \%$ for ACFRpost), have statistically higher performance measures $(\mathrm{t}=1.814$ for ACFRpost). Moreover, in companies without the type II problems there is no significant difference ( $\mathrm{t}=0.647$ for ACFRpost) between companies with and without the type I agency costs. In sum, it is clear that the separation of ownership and management (the type II agency problem) has a dominant effect on acquisition performance for this sample. When the type II agency cost is curbed, the type I agency costs can be offset to the extent that performance in companies with a type I problem (3.50\% for ACFRpost) is made even better (but not more significant) than in companies without the type I agency costs $(1.86 \%$ for ACFRpost). The similarity of these cross effects is reflected in the change in adjusted operating cash flow returns $(\triangle A C F R)$. While the difference between the average performance of companies with the type I but without the type II (3.64\% for $\triangle A C F R)$ and the performance of companies with the type II but without the type I $(2.24 \%$ for $\triangle A C F R)$ is not as significant as that in the ACFRpost measure, it is clear in the group without the type II costs that 
companies even with the type I costs $(3.64 \%$ for $\triangle A C F R)$ still can significantly outperform companies without the type I agency costs $(-0.14 \%$ for $\triangle A C F R)$.

Note that the effects of the type II agency problem might be enforced since there are 114 dispersed firms in full samples and the CEOs in those firms are clearly not related to large shareholders. Therefore, in subsequent analyses the independent $t$ tests were carried out only for the 168 concentrated firms having large shareholders with more than 10 percent of company shares. Table 7.6 panel B reveals the results of these tests. After excluding the dispersed firms, there are 24 firms with both the type I and the type II agency problem, 18 firms with the type I but without the type II agency problem, 105 firms with the type II but without the type I problem, and 21 firms with neither the type I nor the type II agency problem. Similarity, the existence of both types of agency problem is still associated with the lowest average operating performance $(-4.22 \%$ for ACFRpost and $-0.50 \%$ for $\triangle A C F R)$ among the subgroups. Acquiring firms without the type II agency problem even with the type I agency costs (3.50\% for $A C F R p o s t, 3.64 \%$ for $\triangle A C F R$ ) still outperform the acquiring firms with type II agency problems no matter those firms with or without type I agency problems. Results again confirm that the type II agency costs have a stronger impact on both performance measures in the sample; this conclusion continues to hold even when the dispersed firms are excluded from the full sample.

Furthermore, to specifically identify the interactive effects on family firms, focus is placed on 64 family controlled firms in the sample. Table 7.6 panel $\mathbf{C}$ illustrates that there are seven family controlled firms with a separation policy and which are hiring independent CEOs; 16 family firms with a separation policy but which are run by family CEOs; 24 family firms without the type I but with the type II agency costs; and 17 family firms without both the type I and the type II agency costs. Neither the type I costs nor the type II costs significantly impact the post-acquisition performance (ACFRpost) of family controlled firms. Family CEOs do not have as strong a positive impact on the acquisition performance of a family firm as does the controlling CEOs of the concentrated firms. For the change in adjusted operating cash flow returns $(\triangle A C F R)$, family acquiring firms with both agency costs are related to the significant negative performance. There is no evidence to suggest which factor is the most detrimental to acquisition performance. Considering that the sample firms in each subgroup are relatively small, a non-parametric Mann-Whitney $U$ test is also conducted. The results are qualitatively similar and are reported in table 7.7. 
Villalonga and Amit (2006) examine the relative importance of the conflict of interest between managers and controlling large shareholders for US family firms. Their answers suggest that the interaction between family control and management generates significant value differences across firms but that such interaction relies crucially on whether the CEO is the family-founder or the family-descendent. A negative impact on the firm value of separation reduces the founder premium. Founder-CEO firms with separation, however, are more valuable than non-family firms, while minority shareholders in descendant-CEO family firms are worse off than they would have been in a non-family firm. These results are comparable to the findings of Villalonga and Amit (2006) but only for concentrated firms with controlling CEOs. The differences still exist when focusing on family firms but there is no statistical significance for making solid conclusions.

Table 7.6 Cross effects of Type I and Type II Agency Problems using Independent t Test

Sample of 282 mergers and acquisitions by 222 acquiring firms in 11 English Origin countries (Australia, Canada, India, Ireland, Israel, Malaysia, New Zealand, Singapore, South Africa, Thailand and United Kingdom) between 1997 and 2001 for completed takeovers over US\$ 10 million are obtained from the Thomson Financial Securities Data's SDC PlatinumTM Worldwide Mergers \& Acquisitions Database. ACFRpre and ACFRpost is the pre and post industry, size, and pre performance adjusted cash flow return. $\triangle A C F R$ is the change in industry, size, and pre performance adjusted cash flow return. Outliers have been winsorized using Huber's $M$ estimator approach. T tests of differences are presented. Two tail tests $* * *$ denotes significant at the $1 \%$ level, ** significant at the 5\% level, * significant at the $10 \%$ level. Type I agency problem is defined as company with separation problem $(\mathrm{SEP}=1)$ of ownership and voting shares. Type II agency problem is defined as company with independent $\mathrm{CEO}(\mathrm{CEOLSH}=0)$.

Panel A Cross effects of Type I and Type II agency problem for all samples ( $\mathrm{N}=\mathbf{2 8 2})$

\begin{tabular}{|c|c|c|c|}
\hline \multicolumn{3}{|c|}{ ACFRpost } & \begin{tabular}{|c|} 
Test of \\
\end{tabular} \\
\hline \begin{tabular}{|ll} 
Type I & Type II \\
\end{tabular} & \begin{tabular}{c|} 
YES \\
$(\mathrm{CEOLSH}=0)$
\end{tabular} & $\begin{array}{c}\mathrm{NO} \\
(\mathrm{CEOLSH}=1)\end{array}$ & $1.814^{*}$ \\
\hline YES $(\mathrm{SEP}=1)$ & $\begin{array}{r}29 \\
-3.64 \% \\
\end{array}$ & $\begin{array}{r}18 \\
3.50 \% \\
\end{array}$ & $3.023^{k * * * x}$ \\
\hline $\mathrm{NO}(\mathrm{SEP}=0)$ & $\begin{array}{r}214 \\
0.42 \%\end{array}$ & $\begin{array}{r}21 \\
1.86 \%\end{array}$ & 0.897 \\
\hline Test of difference ( $t$ ) & $-2.928^{k \neq * * *}$ & 0.647 & $-2.351^{* * *}$ \\
\hline
\end{tabular}

\begin{tabular}{|c|c|c|c|}
\hline \multicolumn{3}{|c|}{$\triangle \mathrm{ACFR}$} & $\begin{array}{c}\text { Test of } \\
\text { difference }(t)\end{array}$ \\
\hline $\begin{array}{ll}\text { Type I } & \text { Type II } \\
& \end{array}$ & $\begin{array}{c}\text { YES } \\
(\mathrm{CEOLSH}=0)\end{array}$ & $\begin{array}{c}\mathrm{NO} \\
(\mathrm{CEOLSH}=1)\end{array}$ & 0.817 \\
\hline YES (SEP=1) & $\begin{array}{r}29 \\
-0.93 \% \\
\end{array}$ & $\begin{array}{r}18 \\
3.64 \% \\
\end{array}$ & $2.307^{* * *}$ \\
\hline $\mathrm{NO}(\mathrm{SEP}=0)$ & $\begin{array}{r}214 \\
2.24 \% \\
\end{array}$ & $\begin{array}{r}21 \\
-0.14 \% \\
\end{array}$ & -1.475 \\
\hline Test of difference ( $t$ ) & $-2.287^{* * *}$ & $1.731^{*}$ & -0.404 \\
\hline
\end{tabular}

Panel B Cross effects of Type I and Type II agency problem for Concentrated Firms (N=168)

\begin{tabular}{|c|c|c|c|c|c|c|c|}
\hline \multicolumn{3}{|c|}{ ACFRpost } & \begin{tabular}{|c|} 
Test of \\
difference $(\mathrm{t})$
\end{tabular} & \multicolumn{3}{|c|}{$\triangle \mathrm{ACFR}$} & $\begin{array}{c}\text { Test of } \\
\text { difference }\end{array}$ \\
\hline \begin{tabular}{|ll} 
Type I & Type II \\
\end{tabular} & \begin{tabular}{|c|} 
YES \\
$(\mathrm{CEOLSH}=0)$ \\
\end{tabular} & $\begin{array}{c}\mathrm{NO} \\
(\mathrm{CEOLSH}=1) \\
\end{array}$ & $0.643^{*}$ & \begin{tabular}{|ll} 
Type I & Type II \\
\end{tabular} & $\begin{array}{c}\text { YES } \\
(\mathrm{CEOLSH}=0) \\
\end{array}$ & $\begin{array}{c}\mathrm{NO} \\
(\mathrm{CEOLSH}=1) \\
\end{array}$ & 0.630 \\
\hline YES $(\mathrm{SEP}=1)$ & $\begin{array}{r}24 \\
-4.22 \% \\
\end{array}$ & $\begin{array}{r}18 \\
3.50 \% \\
\end{array}$ & $3.131^{* * * x}$ & YES $(\mathrm{SEP}=1)$ & $\begin{array}{r}24 \\
-0.50 \% \\
\end{array}$ & $\begin{array}{r}18 \\
3.64 \% \\
\end{array}$ & $1.959^{* * *}$ \\
\hline $\mathrm{NO}(\mathrm{SEP}=0)$ & $\begin{array}{r}105 \\
0.41 \% \\
\end{array}$ & $\begin{array}{r}21 \\
1.86 \% \\
\end{array}$ & 0.830 & $\mathrm{NO}(\mathrm{SEP}=0)$ & $\begin{array}{r}105 \\
2.20 \% \\
\end{array}$ & $\begin{array}{r}21 \\
-0.14 \% \\
\end{array}$ & -1.333 \\
\hline Test of difference ( $t$ ) & $-2.796^{k \ldots * i}$ & 0.647 & $-2.471^{k * *}$ & Test of difference ( $t$ ) & -1.634 & $1.731^{*}$ & -0.175 \\
\hline
\end{tabular}

Panel C Cross effects of Type I and Type II agency problem for Family Firms (N=64)

\begin{tabular}{|c|c|c|c|}
\hline \multicolumn{3}{|c|}{ ACFRpost } & $\begin{array}{c}\text { Test of } \\
\text { differen }\end{array}$ \\
\hline \begin{tabular}{|ll} 
Type I & Type II \\
\end{tabular} & $\begin{array}{c}\text { YES } \\
(\mathrm{CEOLSH}=0) \\
\end{array}$ & $\begin{array}{c}\mathrm{NO} \\
(\mathrm{CEOLSH}=1) \\
\end{array}$ & 1.078 \\
\hline YES $(\mathrm{SEP}=1)$ & $\begin{array}{r}7 \\
-2.08 \% \\
\end{array}$ & $\begin{array}{r}16 \\
3.12 \% \\
\end{array}$ & 1.436 \\
\hline $\mathrm{NO}(\mathrm{SEP}=0)$ & $\begin{array}{r}24 \\
0.25 \% \\
\end{array}$ & $\begin{array}{r}17 \\
1.92 \% \\
\end{array}$ & 0.580 \\
\hline Test of difference ( $t)$ & -0.589 & 0.422 & 1.000 \\
\hline
\end{tabular}

\begin{tabular}{|c|c|c|c|}
\hline \multicolumn{3}{|c|}{$\triangle \mathrm{ACFR}$} & $\begin{array}{c}\text { Test of } \\
\text { difference (t) }\end{array}$ \\
\hline \begin{tabular}{|ll} 
Type I & Type II \\
\end{tabular} & $\begin{array}{c}\text { YES } \\
(\mathrm{CEOLSH}=0)\end{array}$ & $\begin{array}{c}\mathrm{NO} \\
(\mathrm{CEOLSH}=1)\end{array}$ & -0.225 \\
\hline YES $(\mathrm{SEP}=1)$ & $\begin{array}{r}7 \\
-3.33 \%\end{array}$ & $\begin{array}{r}16 \\
2.87 \%\end{array}$ & 2.008 \\
\hline $\mathrm{NO}(\mathrm{SEP}=0)$ & $\begin{array}{r}24 \\
3.37 \% \\
\end{array}$ & $\begin{array}{r}17 \\
0.23 \% \\
\end{array}$ & -1.303 \\
\hline Test of difference ( $t$ ) & -2.042 & 1.067 & 1.024 \\
\hline
\end{tabular}


Table 7.7 Cross effects of Type I and Type II Agency Problems using non-parametric Mann-Whitney U Test

Sample of 282 mergers and acquisitions by 222 acquiring firms in 11 English Origin countries (Australia, Canada, India, Ireland, Israel, Malaysia, New Zealand, Singapore, South Africa, Thailand and United Kingdom) between 1997 and 2001 for completed takeovers over US\$10 million are obtained from the Thomson Financial Securities Data's SDC PlatinumTM Worldwide Mergers \& Acquisitions Database. ACFRpre and ACFRpost is the pre and post industry, size, and pre performance adjusted cash flow return. $\triangle A C F R$ is for the change in industry, size, and pre performance adjusted cash flow return. Outliers have been winsorized using Huber's $M$ estimator approach. The absolute values of $Z$ statistics of Non-Parametric Mann-Whitney U Tests are presented. $* * *$ denotes significant at the $1 \%$ level, $* *$ significant at the $5 \%$ level, ${ }^{*}$ significant at the $10 \%$ level. Type I agency problem is defined as company with separation problem $(\mathrm{SEP}=1)$ of ownership and voting shares. Type II agency problem is defined as company with independent $\mathrm{CEO}(\mathrm{CEOLSH}=0)$.

Panel A Cross effects of Type I and Type II agency problem for all samples ( $\mathrm{N}=\mathbf{2 8 2})$

\begin{tabular}{|c|c|c|c|}
\hline \multicolumn{3}{|c|}{ ACFRpost } & Non-Par Test \\
\hline \begin{tabular}{|lll} 
Type I & Type II \\
\end{tabular} & $\begin{array}{c}\text { YES } \\
(\mathrm{CEOLSH}=0)\end{array}$ & $\begin{array}{c}\mathrm{NO} \\
(\mathrm{CEOLSH}=1)\end{array}$ & $1.773 *$ \\
\hline YES (SEP=1) & $\begin{array}{r}29 \\
-3.64 \% \\
\end{array}$ & $\begin{array}{r}18 \\
3.50 \%\end{array}$ & $2.998 * * *$ \\
\hline $\mathrm{NO}(\mathrm{SEP}=0)$ & $\begin{array}{r}214 \\
0.42 \% \\
\end{array}$ & $\begin{array}{r}21 \\
1.86 \%\end{array}$ & 1.044 \\
\hline Non-Par Test $(|Z|)$ & $2.859 * * *$ & 0.704 & $2.388^{* * *}$ \\
\hline
\end{tabular}

\begin{tabular}{|c|c|c|c|}
\hline \multicolumn{3}{|c|}{$\triangle \mathrm{ACFR}$} & Non-Par Test \\
\hline \begin{tabular}{|ll} 
Type I & Type II \\
\end{tabular} & $\begin{array}{c}\text { YES } \\
(\mathrm{CEOLSH}=0)\end{array}$ & $\begin{array}{c}\mathrm{NO} \\
(\mathrm{CEOLSH}=1)\end{array}$ & 1.031 \\
\hline YES (SEP=1) & $\begin{array}{r}29 \\
-0.93 \% \\
\end{array}$ & $\begin{array}{r}18 \\
3.64 \% \\
\end{array}$ & 2.090 ** \\
\hline $\mathrm{NO}(\mathrm{SEP}=0)$ & $\begin{array}{r}214 \\
2.24 \%\end{array}$ & $\begin{array}{r}21 \\
-0.14 \%\end{array}$ & 1.234 \\
\hline Non-Par Test (|Z|) & $2.248^{* * *}$ & $1.831^{*}$ & 0.678 \\
\hline
\end{tabular}

Panel B Cross effects of Type I and Type II agency problem for Concentrated Firms (N=168)

\begin{tabular}{|c|c|c|c|}
\hline \multicolumn{3}{|c|}{ ACFRpost } & Non-Par Test \\
\hline \begin{tabular}{|lll} 
Type I & Type II \\
\end{tabular} & $\begin{array}{c}\mathrm{YES} \\
(\mathrm{CEOLSH}=0) \\
\end{array}$ & $\begin{array}{c}\mathrm{NO} \\
(\mathrm{CEOLSH}=1) \\
\end{array}$ & $1.764 *$ \\
\hline YES (SEP=1) & $\begin{array}{r}24 \\
-4.22 \%\end{array}$ & $\begin{array}{r}18 \\
3.50 \%\end{array}$ & $3.076 * * *$ \\
\hline $\mathrm{NO}(\mathrm{SEP}=0)$ & $\begin{array}{r}105 \\
0.41 \%\end{array}$ & \begin{tabular}{r|}
21 \\
$1.86 \%$
\end{tabular} & 1.018 \\
\hline Non-Par Test (|Z|) & $2.645^{* * *}$ & 0.704 & $2.503^{* *}$ \\
\hline
\end{tabular}

\begin{tabular}{|c|c|c|c|}
\hline \multicolumn{3}{|c|}{$\triangle \mathrm{ACFR}$} & $\begin{array}{c}\text { Non-Par Test } \\
(\mid \mathrm{Z})\end{array}$ \\
\hline \begin{tabular}{|ll} 
Type I & Type II \\
\end{tabular} & $\begin{array}{c}\text { YES } \\
(\mathrm{CEOLSH}=0)\end{array}$ & $\begin{array}{c}\mathrm{NO} \\
(\mathrm{CEOLSH}=1)\end{array}$ & 1.116 \\
\hline YES (SEP=1) & $\begin{array}{r}2 \\
-0.50^{\circ}\end{array}$ & $\begin{array}{r}18 \\
3.64 \%\end{array}$ & $1.767 *$ \\
\hline $\mathrm{NO}(\mathrm{SEP}=0)$ & $\begin{array}{r}10 \% \\
2.20 \%\end{array}$ & $\begin{array}{r}21 \\
-0.14 \%\end{array}$ & 0.988 \\
\hline Non-Par Test (|Z) & 1.456 & $1.831^{*}$ & 0.410 \\
\hline
\end{tabular}

Panel C Cross effects of Type I and Type II agency problem for Family Firms (N=64)

\begin{tabular}{|c|c|c|c|}
\hline \multicolumn{3}{|c|}{ ACFRpost } & Non-Par Test \\
\hline \begin{tabular}{|lll} 
Type I & Type II \\
\end{tabular} & $\begin{array}{c}\begin{array}{c}\text { YES } \\
(\mathrm{CEOLSH}=0)\end{array} \\
\end{array}$ & $\begin{array}{c}\mathrm{NO} \\
(\mathrm{CEOLSH}=1)\end{array}$ & 1.146 \\
\hline YES (SEP $=1)$ & $\begin{array}{r}7 \\
-2.08 \%\end{array}$ & $\begin{array}{r}16 \\
3.12 \%\end{array}$ & 1.336 \\
\hline $\mathrm{NO}(\mathrm{SEP}=0)$ & $\begin{array}{r}24 \\
0.25 \%\end{array}$ & $\begin{array}{r}17 \\
1.92 \%\end{array}$ & 0.662 \\
\hline Non-Par Test $(|Z|)$ & 0.378 & 0.504 & 0.984 \\
\hline
\end{tabular}

\begin{tabular}{|c|c|c|c|}
\hline \multicolumn{3}{|c|}{$\triangle \mathrm{ACFR}$} & Non-Par Test \\
\hline \begin{tabular}{|l} 
Type I \\
\end{tabular} & $\begin{array}{c}\text { YES } \\
(\mathrm{CEOLSH}=0)\end{array}$ & \begin{tabular}{|c|}
$\mathrm{NO}$ \\
$(\mathrm{CEOLSH}=1)$ \\
\end{tabular} & 0.166 \\
\hline YES (SEP=1) & $\begin{array}{r}7 \\
-3.33 \% \\
\end{array}$ & $\begin{array}{r}16 \\
2.87 \% \\
\end{array}$ & $1.804 *$ \\
\hline $\mathrm{NO}(\mathrm{SEP}=0)$ & $\begin{array}{r}24 \\
3.37 \%\end{array}$ & $\begin{array}{r}17 \\
0.23 \% \\
\end{array}$ & 0.794 \\
\hline Non-Par Test $(|\mathrm{Z}|)$ & $1.843^{*}$ & 0.937 & 1.111 \\
\hline
\end{tabular}




\subsection{Analysis of Different Definition of Independent Variables}

This section reports the results on acquisition performance using different definitions of independent variables. It investigates cross border deals instead of cross origin transactions; it uses a definition of industry relatedness by two-digit and three-digit SIC codes; it extends the pre-bid period for premium measure from 1-day to 1-week and 4-week; and finally it adds in a year dummy to capture year differences. Table 7.8 summarizes the univariate statistics of all additional explanatory variables with different definition. Table

7.9 to table 7.14 displays separate regression results for each variable.

Table 7.8 Univariate Statistics of Additional Independent Variables

Sample of 282 mergers and acquisitions by 222 acquiring firms in 11 English Origin countries (Australia, Canada, India, Ireland, Israel, Malaysia, New Zealand, Singapore, South Africa, Thailand and United Kingdom) between 1997 and 2001 for completed takeovers over US\$ 10 million are obtained from the Thomson Financial Securities Data's SDC PlatinumTM Worldwide Mergers \& Acquisitions Database. ACFRpre and ACFRpost is the pre and post industry, size, and pre performance adjusted cash flow return. $\triangle A C F R$ is the change in industry, size, and pre performance adjusted cash flow return. CROSSBD is defined as the nation of acquiring firm is different from that of target firms. IND_rel_2D is defined as the acquiring and target firms had equivalent 2-digit primary SIC code at transaction year. IND rel 3D is defined as the acquiring and target firms had equivalent 3-digit primary SIC code at transaction year. PREM_1W is the premium of offer price to target trading price one week prior to the announcement date. PREM 4W is the premium of offer price to target trading price four week prior to the announcement date. The year of acquisition completed in 1998, 1999, 2000 and 2001 is defined as YR98, YR99, YR00 and YR01, respectively. Outliers have been winsorized using Huber's M estimator approach. T tests of differences and Pearson correlation are presented. $* * *$ denotes significant at the $1 \%$ level, $* *$ significant at the $5 \%$ level, $*$ significant at the $10 \%$ level.

\begin{tabular}{|c|c|c|c|c|c|c|c|c|c|c|c|}
\hline \multirow{2}{*}{\multicolumn{2}{|c|}{ Full Sample (N=282) }} & \multirow{2}{*}{\multicolumn{2}{|c|}{ Count }} & \multicolumn{4}{|c|}{ ACFRpost } & \multicolumn{4}{|c|}{$\triangle \mathrm{ACFR}$} \\
\hline & & & & \multirow{3}{*}{$\begin{array}{c}\begin{array}{c}\text { Mean } \\
(\%)\end{array} \\
-0.84 \\
1.25 \\
\end{array}$} & \multirow{3}{*}{\begin{tabular}{|c|}
$\begin{array}{c}\text { Median } \\
(\%)\end{array}$ \\
-0.65 \\
1.32 \\
\end{tabular}} & \multirow{3}{*}{\begin{tabular}{|l|}
$\begin{array}{l}\text { SD } \\
(\%)\end{array}$ \\
6.97 \\
7.41 \\
\end{tabular}} & \multirow{3}{*}{$\begin{array}{c}\begin{array}{c}\mathrm{T} \text { test/ } \\
\text { Pearson }\end{array} \\
\mathbf{- 2 . 4 3 0 * *}\end{array}$} & \multirow{3}{*}{$\begin{array}{c}\begin{array}{c}\text { Mean } \\
(\%)\end{array} \\
1.42 \\
2.15 \\
\end{array}$} & \multirow{3}{*}{\begin{tabular}{|c|}
$\begin{array}{c}\text { Median } \\
(\%)\end{array}$ \\
1.31 \\
2.47 \\
\end{tabular}} & \multirow{3}{*}{\begin{tabular}{c|}
$\begin{array}{c}\mathrm{SD} \\
(\%)\end{array}$ \\
6.98 \\
7.06 \\
\end{tabular}} & \multirow{3}{*}{$\begin{array}{c}\begin{array}{c}\mathrm{T} \text { test/ } \\
\text { Pearson }\end{array} \\
-0.870\end{array}$} \\
\hline \multirow{2}{*}{ CROSSBD } & $\bar{Y}$ & 127 & $45 \%$ & & & & & & & & \\
\hline & $\mathrm{N}$ & 155 & $55 \%$ & & & & & & & & \\
\hline \multirow{2}{*}{ IND_rel_2D } & $\mathrm{Y}$ & 175 & $62 \%$ & -0.14 & 0.30 & 7.32 & \multirow{2}{*}{-1.330} & 1.66 & 1.02 & 7.51 & \multirow{2}{*}{-0.527} \\
\hline & $\mathrm{N}$ & 107 & $38 \%$ & 1.05 & 1.11 & 7.18 & & 2.09 & 2.92 & 6.18 & \\
\hline \multirow{2}{*}{ IND_rel_3D } & $\mathrm{Y}$ & 138 & $49 \%$ & -0.17 & -0.16 & 7.37 & \multirow{2}{*}{-1.088} & 1.99 & 1.60 & 7.34 & \multirow{2}{*}{0.397} \\
\hline & $\mathrm{N}$ & 144 & $51 \%$ & 0.77 & 1.10 & 7.19 & & 1.66 & 2.08 & 6.73 & \\
\hline PREM 1W (\%) & - & 250 & $89 \%$ & - & - & - & -0.051 & - & - & - & -0.014 \\
\hline PREM_4W (\%) & - & 260 & $92 \%$ & - & - & - & -0.008 & - & - & - & 0.020 \\
\hline \multirow{2}{*}{ YR98 } & $\mathrm{Y}$ & 43 & $15 \%$ & 2.11 & 2.37 & 6.17 & \multirow{2}{*}{$2.007 * *$} & 3.14 & 3.12 & 7.11 & \multirow{2}{*}{1.336} \\
\hline & $\mathrm{N}$ & 239 & $85 \%$ & -0.01 & 0.30 & 7.43 & & 1.59 & 1.39 & 7.00 & \\
\hline \multirow{2}{*}{ YR99 } & $\mathrm{Y}$ & 74 & $26 \%$ & 0.15 & 0.56 & 6.16 & \multirow{2}{*}{-0.243} & 2.19 & 2.09 & 6.17 & \multirow{2}{*}{0.561} \\
\hline & $\mathrm{N}$ & 208 & $74 \%$ & 0.37 & 0.59 & 7.65 & & 1.69 & 1.63 & 7.31 & \\
\hline \multirow{2}{*}{ YR00 } & $\mathrm{Y}$ & 88 & $31 \%$ & 0.22 & 0.09 & 8.48 & \multirow{2}{*}{-0.131} & 0.74 & 1.07 & 7.75 & \multirow{2}{*}{$-1.749 *$} \\
\hline & $\mathrm{N}$ & 194 & $69 \%$ & 0.35 & 0.76 & 6.68 & & 2.31 & 2.20 & 6.63 & \\
\hline \multirow{2}{*}{ YR01 } & $\mathrm{Y}$ & & $24 \%$ & -0.02 & 0.54 & 7.26 & \multirow{2}{*}{-0.426} & 1.92 & 0.28 & 7.13 & \multirow{2}{*}{0.133} \\
\hline & $\mathrm{N}$ & 215 & $76 \%$ & 0.41 & 0.68 & 7.30 & & 1.79 & 1.76 & 7.01 & \\
\hline
\end{tabular}




\subsubsection{Cross Border}

Cross border mergers are generally expected to create synergies from business diversification as well as less systematic risks and stronger market power (Seth, Song and Pettit 2002). However, this type of deals suffers from different cultural, legal, and transactional barriers (Campa and Hernando 2004). In the main analyses, focus is upon cross origin deals that have more severe challenges for those different natures. Here, additional analysis is presented in order to obtain more information about the expected costs and potential advantages of cross border deals. One dummy variable (CROSSBD) is equal to one when the nation of the acquiring firm is different from that of target firm.

It is clear from table 7.8 that the average adjusted cash flow returns of cross border deals is significantly negative in the post-merger period. The potential advantages of cross border transactions are offset by high entry costs. This result supports previous research which finds that acquiring firms obtain lower abnormal returns in cross-border deals than in domestic deals (André, Kooli and L'Her 2004, Campa and Hernando 2004, Moeller and Schlingemann 2005). Regression results in table 7.9, however, indicate that the nature problems of cross border deals are not the major factors which destroy acquisition values; their significant negative effects can be explained by the other control variables.

\subsubsection{Industry Relatedness: two-digit and three- digit SIC codes}

The choice of industry definition to classify industry related versus non-related acquisitions is a critical issue. Two-digit codes are defined as firms in different industrial groups; three- or four-digit codes are simply defined as being related to firms in different product lines. Two-digit SIC codes are employed by Ghosh (2001) and Ben-Amar and André (2006). Tighter definitions of three- or four-digit codes are employed by Eckbo $(1983,1985)$, Lang and Stulz (1994) and Gugler, Mueller, Yurtoglu and Zulehner (2003). Ghosh (2004) defines related industry based on a four-digit SIC code but also provides comparisons for a three and a two-digit SIC code definition. He argues that "merging firms are likely to benefit mostly from economies of scale when the industry definition is based on a four-digit SIC code (horizontal acquisitions). The sources of benefits for mergers within a three-digit SIC code possibly include economies of technical scope and economies of scale (vertical acquisitions). Mergers within a two-digit SIC code are most likely to benefit from economies of scope (conglomerate acquisitions) and are less likely to benefit from economies of scale". 
Therefore, in this additional analysis two dummy variables are used in order to test the effects of the choice of industry definition: (1) IND_rel_2D equals to one when the acquiring firms and target firms had equivalent 2-digit primary SIC code at transaction year. (2) IND_rel_3D equals to one when the acquiring firms and target firms have an equivalent 3-digit primary SIC code at the transaction year. In table 7.8, there is no significant difference between related and non-related mergers, no matter whether using a two-digit or a three-digit SIC code to define business relatedness. Regression results in table $\mathbf{7 . 1 0}$ for two-digit SIC codes and in table $\mathbf{7 . 1 1}$ for three-digit SIC codes also confirm the non-significant difference as the results in univariate analysis. This finding is consistent with the findings of Limmack and McGregor (1995) and André et al. (2004) who document that there is no significant difference between conglomerate and non-conglomerate mergers.

\subsubsection{Pre- bid Period for Premium Measure: one week and four weeks}

Schwert (1996) shows that any abnormal movement of the target's stock price in pre-bid period (called the pre-bid runup) is an added cost for the bidders. If this argument can be sustained, then a longer pre-bid period may be more relevant to premium measure since it includes most runup costs. To control this possible pre-bid runup effect, this thesis replaces the 1-day premium by a 1-week and 4-week premium, respectively. Thus, two explanatory variables are added: (1) PREM_1W is the difference in the bid price and the target's market value one week before announcement. (2) PREM_4W is the difference in the bid price and the target's market value four weeks prior to the announcement.

From table 7.8, it is clear that neither a 1-week premium nor a 4 -week premium has a significant relationship with post-acquisition performance (both ACFRpost and $\triangle A C F R$ ). Regression results in table $\mathbf{7 . 1 2}$ for a 1-week premium and in table $\mathbf{7 . 1 3}$ for a 4-week premium are in agreement with previously published studies which suggest that focusing on an assessment of the relationship between bid premium and other deal characteristics is more meaningful than directly discussing the impact of the bid premium on acquisition performance (Walkling and Edmister 1985, Goergen and Renneboog 2004)

\subsubsection{Year Dummy}

From table 5.2 in the main analysis, it is clear that most deals (61.2\%) are completed in year 2000; only 0.5 percent of transactions belong to year 1997. As sample deals are not proportionally distributed among five event years (1997-2001), this thesis sets another four 
dummy variables in order to capture similarities or discrepancies among acquisition years with respect to acquisition performance. YR98, YR99, YR00 and YR01 are set to equal to one when the year of acquisition completed is in 1998, 1999, 2000 and 2001 respectively.

From table 7.8, it is evident that transactions completed in year 1998 have significantly higher average adjusted cash flow returns in the post-merger periods (ACFRpost). Instead, deals completed in year 2000 have significant underperformance by the change performance measure $(\triangle A C F R)$. However, table 7.14 presents evidence that when these four- year dummy variables are considered into regression models as control variables, the significant effects of year difference disappear in both performance measures (ACFRpost and $\triangle A C F R$ ). The other variables including ownership variables, governance variables, institutions variables, and deal variables have consistent and stable results as those in the main analyses. Year difference therefore has no explanation power for the improvements of acquisition in the sample. 
Table 7.9 Regression Results of Cross Border Deals

Sample of 282 mergers and acquisitions by 222 acquiring firms in 11 English Origin countries (Australia, Canada, India, Ireland, Israel, Malaysia, New Zealand, Singapore, South Africa, Thailand and United Kingdom) between 1997 and 2001 for completed takeovers over US\$ 10 million are obtained from the Thomson Financial Securities Data's SDC PlatinumTM Worldwide Mergers \& Acquisitions Database. ACFRpre and ACFRpost is the pre and post industry, size, and pre performance adjusted cash flow return. $\triangle \mathrm{ACFR}$ is the change in industry, size, and pre performance adjusted cash flow return. Outliers have been winsorized using Huber's M estimator approach. T tests of differences are presented. With OLS standard errors. Two tail tests *** denotes significant at the $1 \%$ level, ** significant at the $5 \%$ level, * significant at the $10 \%$ level. CROSSBD is defined as the nation of acquiring firm is different from that of target firms. See table 5.5 for other variables definitions.

\begin{tabular}{|c|c|c|c|c|c|c|c|c|c|c|c|}
\hline Full Sample $(\mathrm{N}=282)$ & Model 1 & Model 2 & Model 3 & Model 4 & Model 5 & Model 6 & Model 7 & Model 8 & Model 8.1 & Model 9 & Model 9.1 \\
\hline Intercept & ב-055 & $\begin{array}{ll}0.048 \\
\end{array}$ & P0.071 & 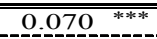 & (20.043 & $\begin{array}{ll}0.045 \\
-\end{array}$ & $\begin{array}{ll}0.059 \\
\end{array}$ & 年-0.170 & -0.055 & $\begin{array}{l}0.019 \\
-\end{array}$ & $\begin{array}{ll}0.109 \\
\end{array}$ \\
\hline CONCEN 10 & -0.013 & & & & & & & & & & \\
\hline CONCEN 1020 & & & $-0.027^{* * * *}$ & $-0.027^{* * *}$ & & & & & & & \\
\hline CONCEN2O & & $0.023^{* *}$ & 0.009 & & & & & & & & \\
\hline $\begin{array}{l}\text { CONCEN2050 } \\
\text { CONCEN50 }\end{array}$ & & & & 0.008 & & & & & & & \\
\hline CONCEN5O & & & & 0.010 & & & & & & & \\
\hline LSH1P & & & & & 0.021 & -0.005 & $-0.252^{* * *}$ & $-0.212^{* *}$ & $-0.214^{* * *}$ & $-0.238^{* *}$ & $-0.215^{* * *}$ \\
\hline LSH1PSQ & & & & & & 0.038 & $1.045^{* * * *}$ & $0.716^{* *}$ & $0.760^{* *}$ & $0.813^{* *}$ & $0.760^{* *}$ \\
\hline LSH1PCUBE & & & & & & & $-0.910^{* * *}$ & $-0.584^{*}$ & _-0.632 ** & $-0.668^{* *}$ & $-0.635^{*}$ \\
\hline SEP & $-0.020^{*}$ & $-0.028^{* *}$ & $-0.027^{* *}$ & $-0.027^{* *}$ & $-0.026^{* *}$ & $-0.027^{* *}$ & $-0.030^{* *}$ & $-0.033^{* *}$ & $-0.034^{*}$ & $-0.034^{*}$ & $-0.033^{*}$ \\
\hline CEOLSH & $0.025^{* *}$ & 0.013 & 0.017 & 0.017 & 0.018 & 0.020 & 0.016 & $0.026 *$ & $0.023 *$ & $0.022 *$ & 0.021 \\
\hline CEOdual & -0.013 & -0.012 & -0.013 & -0.013 & -0.013 & -0.014 & -0.012 & -0.010 & -0.012 & -0.010 & -0.014 \\
\hline$\overline{\mathrm{BSIZE}}$ & -0.001 & $-0.002 *$ & $-0.003^{* * *}$ & $-0.003^{* *}$ & -0.002 & -0.002 & $-0.003^{* *}$ & $-0.003 * *$ & $-0.003^{* * *}$ & $-0.003 * *$ & $-0.002 *$ \\
\hline INDDIR & -0.021 & -0.012 & -0.020 & -0.020 & -0.011 & -0.012 & -0.011 & -0.026 & -0.022 & -0.030 & -0.027 \\
\hline OTHLSH & _.012 & _o.001 & O.006 & _o.006 & O.006 & 0.008 & 0.010 & 0.006 & 0.008 & 0.008 & 0.011 \\
\hline CROSSBD & -0.011 & -0.008 & -0.010 & -0.010 & -0.009 & -0.010 & -0.011 & -0.007 & -0.007 & -0.007 & -0.006 \\
\hline ATTI_Hostile & 0.009 & 0.007 & 0.006 & 0.006 & 0.009 & 0.010 & 0.008 & 0.016 & 0.013 & 0.005 & 0.011 \\
\hline PAY_stock & -0.010 & -0.013 & -0.013 & -0.012 & -0.011 & -0.011 & -0.011 & -0.010 & -0.012 & -0.012 & -0.013 \\
\hline СОМРЕТЕ & $-0.036^{* *}$ & $-0.033^{* *}$ & $-0.036^{* *}$ & $-0.036^{* *}$ & $-0.034^{* *}$ & $-0.034^{* *}$ & $-0.036^{* *}$ & $-0.039^{* *}$ & $-0.038 * *$ & $-0.038^{* *}$ & $-0.037^{* *}$ \\
\hline IND_rel & 0.001 & 0.003 & 0.001 & 0.001 & 0.002 & 0.002 & 0.002 & 0.001 & 0.001 & 0.000 & 0.002 \\
\hline TOËHOLD & 0.005 & 0.006 & 0.006 & 0.006 & 0.006 & 0.006 & 0.005 & 0.012 & 0.012 & 0.010 & 0.009 \\
\hline PREM_1 day & 0.000 & 0.000 & 0.000 & 0.000 & 0.000 & 0.000 & 0.000 & 0.000 & 0.000 & 0.000 & 0.000 \\
\hline SIZE_ & $-0.004 *$ & $-0.005^{* *}$ & $-0.005 * *$ & $-0.005^{* *}$ & $-0.005 *$ & $-0.005 *$ & $-0.005^{* *}$ & $-0.004 *$ & $-0.004 *$ & $-0.004 *$ & $-0.005^{* *}$ \\
\hline LEV & -0.001 & 0.000 & -0.001 & -0.001 & -0.001 & -0.001 & -0.002 & -0.001 & -0.002 & -0.002 & -0.003 \\
\hline ANTIDIR_high & & & & & & & & $0.085^{*}$ & $0.056^{* * 1 *}$ & & \\
\hline ENFORCE & & & & & & & & 0.001 & & & \\
\hline ACCTSTD & & & & & & & & 0.003 & & & \\
\hline XLEG_high & & & & & & & & -0.033 & -0.027 & & \\
\hline ANTISDI & & & & & & & & & & 0.048 & -0.076 \\
\hline PUBENFORCE_high & & & & & & & & & & $-0.072^{* * *}$ & \\
\hline NANTIDIR high & & & & & & & & & & $0.056^{* * *}$ & $0.041 *$ \\
\hline$U K$ & & & & & & & & -0.065 & -0.028 & $-0.060^{*}$ & -0.026 \\
\hline$C A N$ & & & & & & & & -0.071 & $-0.039^{* *}$ & $0.099^{* *}$ & 0.011 \\
\hline$A U S$ & & & & & & & & $0.054^{* *}$ & $0.053 * *$ & 0.031 & 0.030 \\
\hline ACFRpre & $0.511_{* * *}^{* * *}$ & $0.516 * * *$ & $0.519^{* * *}$ & $0.518^{* * * *}$ & $0.511^{* * *}$ & $0.511^{* * *}$ & $0.513^{* * *}$ & $0.503^{*}$ & $0.510^{* \cdots *}$ & $0.510^{* \cdots *}$ & $0.516^{* N \times}$ \\
\hline Adjust $R^{2}(\%)$ & 29.6 & 30.2 & 32.0 & 31.7 & 29.2 & 29.0 & 31.0 & 34.0 & 33.9 & 33.0 & 32.1 \\
\hline $\mathrm{F}$ & $7.935 * * *$ & $8.164 * * *$ & $8.339 * * *$ & $7.872 * * *$ & $7.821 * * *$ & $7.378 * * *$ & $7.657 * * *$ & $6.569 * * *$ & $7.011 * * *$ & $6.537 * * *$ & $6.523 * * *$ \\
\hline
\end{tabular}


Table 7.9 (Continued)

Panel B Dependent Variable: $\triangle$ ACFR

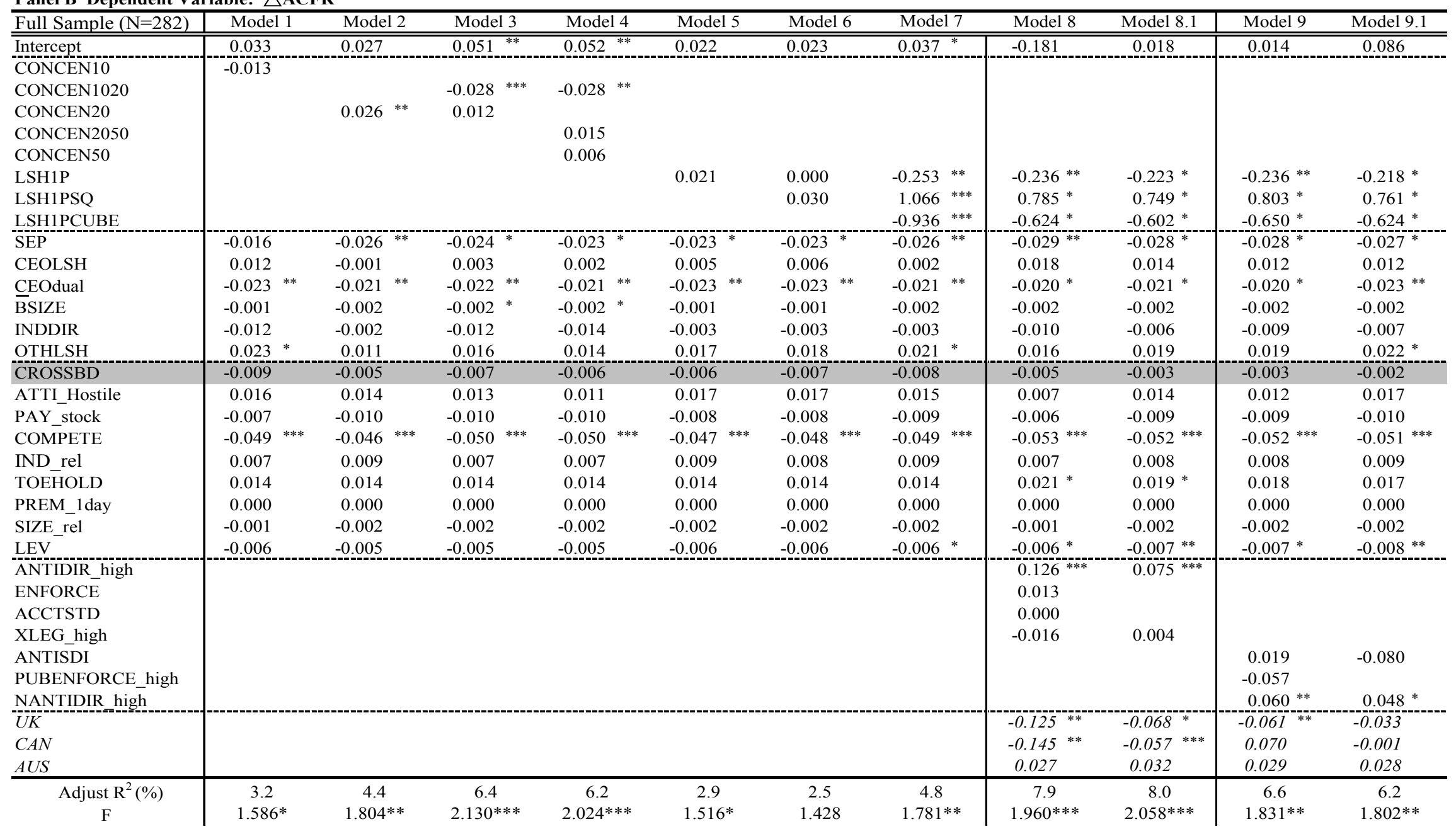


Table 7.10 Regression Results of Industry Relatedness: Two- digit Primary SIC Code

Sample of 282 mergers and acquisitions by 222 acquiring firms in 11 English Origin countries (Australia, Canada, India, Ireland, Israel, Malaysia, New Zealand, Singapore, South Africa, Thailand and United Kingdom) between 1997 and 2001 for completed takeovers over US\$ 10 million are obtained from the Thomson Financial Securities Data's SDC PlatinumTM Worldwide Mergers \& Acquisitions Database. ACFRpre and ACFRpost is the pre and post industry, size, and pre performance adjusted cash flow return. $\triangle \mathrm{ACFR}$ is the change in industry, size, and pre performance adjusted cash flow return. Outliers have been winsorized using Huber's M estimator approach. T tests of differences are presented. With OLS standard errors. Two tail tests *** denotes significant at the $1 \%$ level, ** significant at the $5 \%$ level, * significant at the $10 \%$ level. IND_rel_2D is defined as the acquiring and target firms had equivalent 2-digit primary SIC code at transaction year. See table 5.5 for other variables definitions.

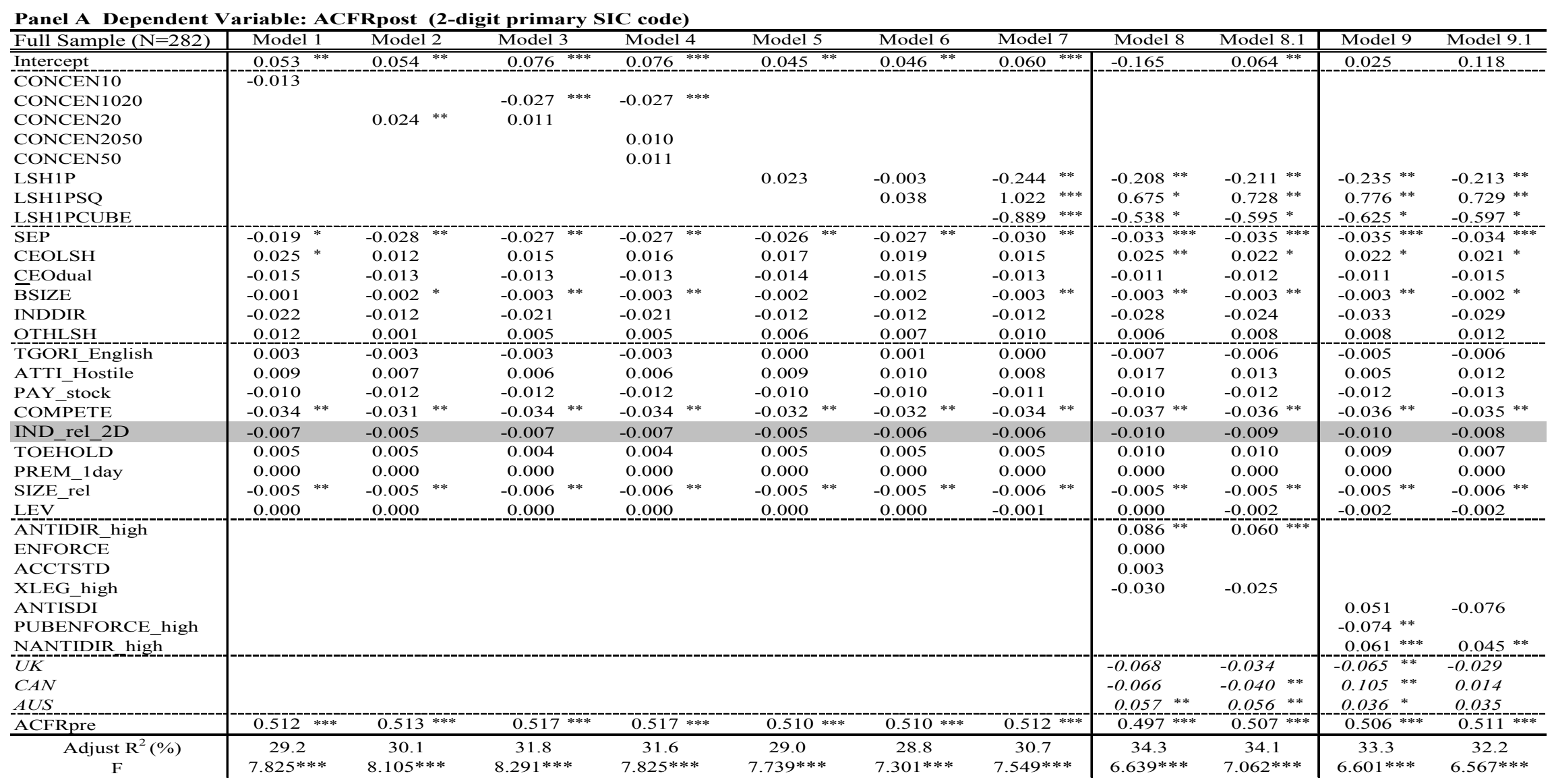


Table 7.10 (Continued)

Panel B Dependent Variable: $\triangle$ ACFR (2-digit primary SIC code)

\begin{tabular}{|c|c|c|c|c|c|c|c|c|c|c|c|c|c|}
\hline Full Sample $(\mathrm{N}=282)$ & Model 1 & Model 2 & Model & 3 & Model & & Model 5 & Model 6 & Model 7 & Model 8 & Model 8.1 & Model 9 & Model 9.1 \\
\hline$\overline{\text { Intercept }}$ & "0.027 & $\begin{array}{ll}0.028 \\
\end{array}$ & 0.051 & & "0.053 & "** & $\begin{array}{ll}0.018 \\
\end{array}$ & $\begin{array}{ll}0.019 \\
\end{array}$ & (20.034 & $\begin{array}{ll}-0.191 \\
\end{array}$ & $\begin{array}{ll}0.021 \\
\end{array}$ & 0.012 & 0.090 \\
\hline CONCEN10 & -0.014 & & & & & & & & & & & & \\
\hline CONCEN1020 & & & -0.029 & *** & -0.029 & $* * *$ & & & & & & & \\
\hline CONCEN20 & & $0.025^{* *}$ & 0.011 & & & & & & & & & & \\
\hline CONCEN50 & & & & & 0.006 & & & & & & & & \\
\hline LSH1P & & & & & & & 0.020 & -0.007 & $-0.255^{* *}$ & $-0.241^{* *}$ & $-0.231^{* *}$ & $-0.245^{* *}$ & $-0.227^{* *}$ \\
\hline LSH1PSQ & & & & & & & & 0.040 & $1.053^{* * *}$ & $0.769 *$ & $0.741 *$ & $0.798 *$ & $0.758 *$ \\
\hline LSH1PCUBE & & & & & & & & & $-0.916^{* * *}$ & -0.596 & -0.580 & $-0.629 *$ & $-0.606^{*}$ \\
\hline$\overline{\mathrm{SEP}}$ & -0.015 & $-0.025 *$ & -0.024 & $*$ & -0.022 & * & $-0.022 *$ & $-0.023 *$ & $-0.026^{*}$ & $-0.029^{* *}$ & $-0.028 *$ & $-0.028^{*}$ & $-0.027^{*}$ \\
\hline CEOLSH & 0.012 & -0.002 & 0.002 & & 0.002 & & 0.004 & 0.006 & 0.002 & 0.018 & 0.014 & 0.012 & 0.011 \\
\hline CEOdual & $-0.024^{* *}$ & $-0.022^{* *}$ & -0.022 & ** & -0.022 & ** & $-0.023^{* *}$ & $-0.024^{* *}$ & $-0.022^{* *}$ & $-0.021 *$ & $-0.021 *$ & $-0.020 *$ & $-0.023^{* *}$ \\
\hline$\overline{\mathrm{BS}} \mathrm{SIZE}$ & -0.001 & -0.002 & -0.002 & * & -0.002 & * & -0.001 & -0.001 & -0.002 & -0.002 & -0.002 & -0.002 & -0.002 \\
\hline INDDIR & -0.013 & -0.003 & -0.012 & & -0.014 & & -0.003 & -0.003 & -0.003 & -0.012 & -0.007 & -0.011 & -0.008 \\
\hline OTHLSH & $0.023 *$ & 0.011 & 0.016 & & 0.014 & & 0.017 & 0.018 & 0.021 & 0.016 & 0.019 & 0.020 & $0.023 *$ \\
\hline TGORI English & 0.011 & 0.003 & 0.004 & & 0.003 & & 0.007 & 0.008 & 0.007 & 0.003 & 0.001 & 0.001 & 0.001 \\
\hline ATTI_Hostile & 0.017 & 0.015 & 0.014 & & 0.012 & & 0.018 & 0.018 & 0.016 & 0.008 & 0.015 & 0.013 & 0.019 \\
\hline PAY_stock & -0.006 & -0.009 & -0.009 & & -0.009 & & -0.007 & -0.006 & -0.007 & -0.005 & -0.008 & -0.008 & -0.009 \\
\hline СОМРЕТЕ & $-0.049^{* * *}$ & $-0.045^{* * *}$ & -0.048 & $* * *$ & -0.049 & $* * *$ & $-0.047^{* * *}$ & $-0.047^{* * *}$ & $-0.048^{* * *}$ & $-0.052 * * *$ & $-0.051^{* * *}$ & $-0.051^{* * *}$ & $-0.050 * * *$ \\
\hline IND rel $2 \mathrm{D}$ & -0.003 & 0.000 & -0.003 & & -0.003 & & -0.001 & -0.002 & -0.001 & -0.005 & -0.004 & -0.005 & -0.003 \\
\hline SIZE_rel & -0.002 & -0.002 & -0.003 & & -0.003 & & -0.002 & -0.002 & -0.002 & -0.001 & -0.002 & -0.002 & -0.002 \\
\hline LEV & -0.005 & -0.005 & -0.005 & & -0.005 & & -0.005 & -0.005 & -0.006 & $-0.006 *$ & $-0.007 *$ & $-0.007^{*}$ & $-0.008^{* *}$ \\
\hline ANTIDIR_high & & & & & & & & & & $0.132^{* * *}$ & $0.078^{* * *}$ & & \\
\hline ENFORCE & & & & & & & & & & 0.013 & & & \\
\hline ACCTSTD & & & & & & & & & & 0.000 & & & \\
\hline XLEG_high & & & & & & & & & & -0.014 & 0.006 & & \\
\hline ANTISDI & & & & & & & & & & & & 0.028 & -0.080 \\
\hline PUBENFORCE_high & & & & & & & & & & & & -0.062 & \\
\hline NANTIDIR high & & & & & & & & & & & & $0.063^{* *}$ & $0.049^{* *}$ \\
\hline$U K$ & & & & & & & & & & $-0.132^{* *}$ & $-0.072 *$ & $-0.064^{* *}$ & -0.034 \\
\hline$C A N$ & & & & & & & & & & $-0.148 * *$ & $-0.057 * * *$ & 0.078 & 0.002 \\
\hline$A U S$ & & & & & & & & & & 0.028 & 0.033 & 0.031 & 0.030 \\
\hline Adjust $\mathrm{R}^{2}(\%)$ & 2.9 & 3.9 & 6.0 & & 5.8 & & 2.4 & 2.1 & 4.2 & 7.7 & 7.7 & 6.4 & 5.8 \\
\hline $\mathrm{F}$ & $1.516^{*}$ & $1.708^{* *}$ & $2.067 * *$ & & $1.959^{\prime}$ & & 1.431 & 1.354 & $1.690^{* *}$ & $1.936^{* * *}$ & $2.024 * * *$ & $1.802 * *$ & $1.750 * *$ \\
\hline
\end{tabular}


Table 7.11 Regression Results of Industry Relatedness: Three- digit Primary SIC Code

Sample of 282 mergers and acquisitions by 222 acquiring firms in 11 English Origin countries (Australia, Canada, India, Ireland, Israel, Malaysia, New Zealand, Singapore, South Africa, Thailand and United Kingdom) between 1997 and 2001 for completed takeovers over US\$ 10 million are obtained from the Thomson Financial Securities Data's SDC PlatinumTM Worldwide Mergers \& Acquisitions Database. ACFRpre and ACFRpost is the pre and post industry, size, and pre performance adjusted cash flow return. $\triangle \mathrm{ACFR}$ is the change in industry, size, and pre performance adjusted cash flow return. Outliers have been winsorized using Huber's M estimator approach. T tests of differences are presented. With OLS standard errors. Two tail tests *** denotes significant at the $1 \%$ level, ** significant at the $5 \%$ level, * significant at the $10 \%$ level. IND_rel_3D is defined as the acquiring and target firms had equivalent 3-digit primary SIC code at transaction year. See table 5.5 for other variables definitions.

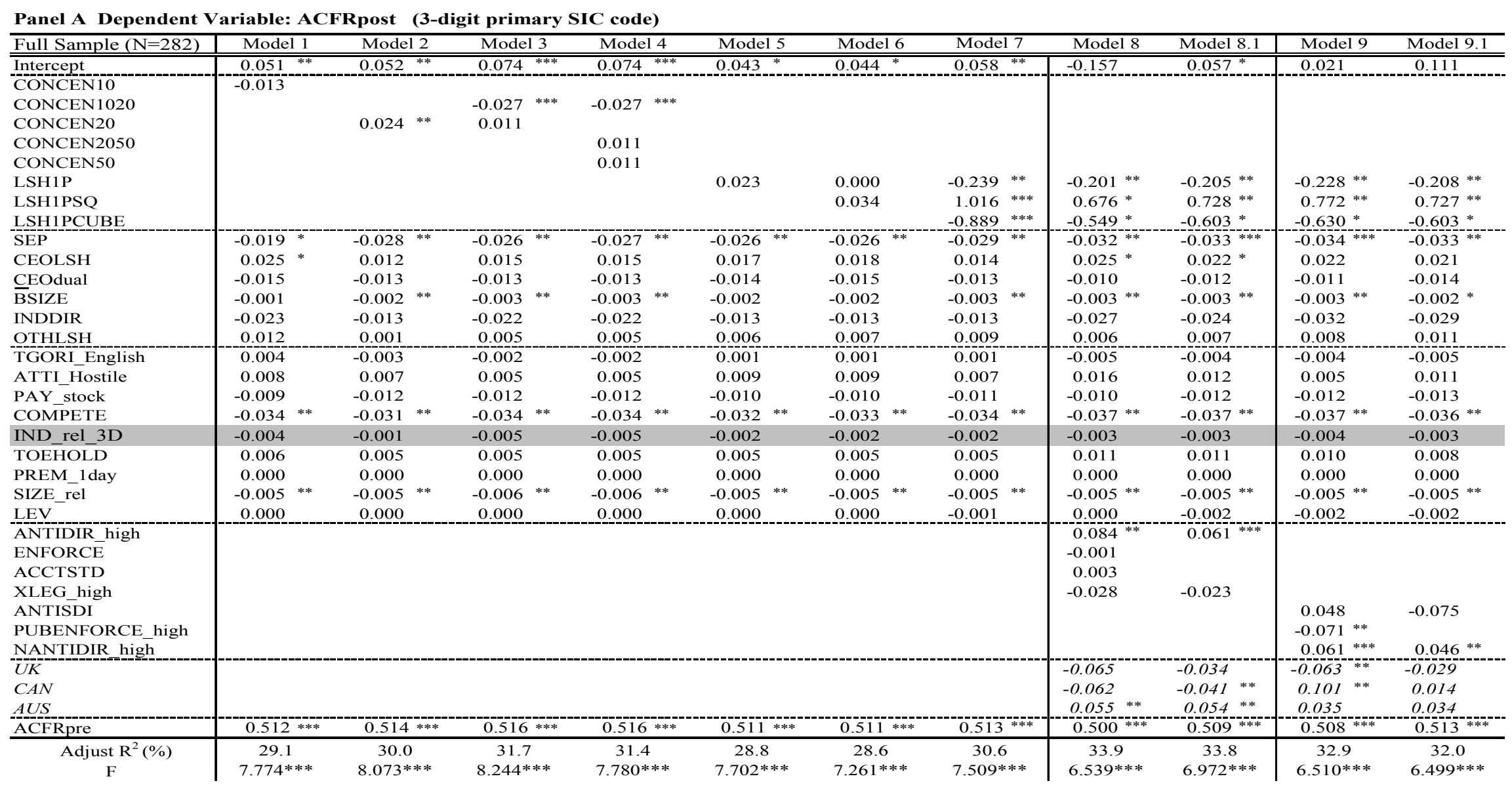


Table 7.11 (Continued)

Panel B Dependent Variable: $\triangle A C F R$ (3-digit primary SIC code)

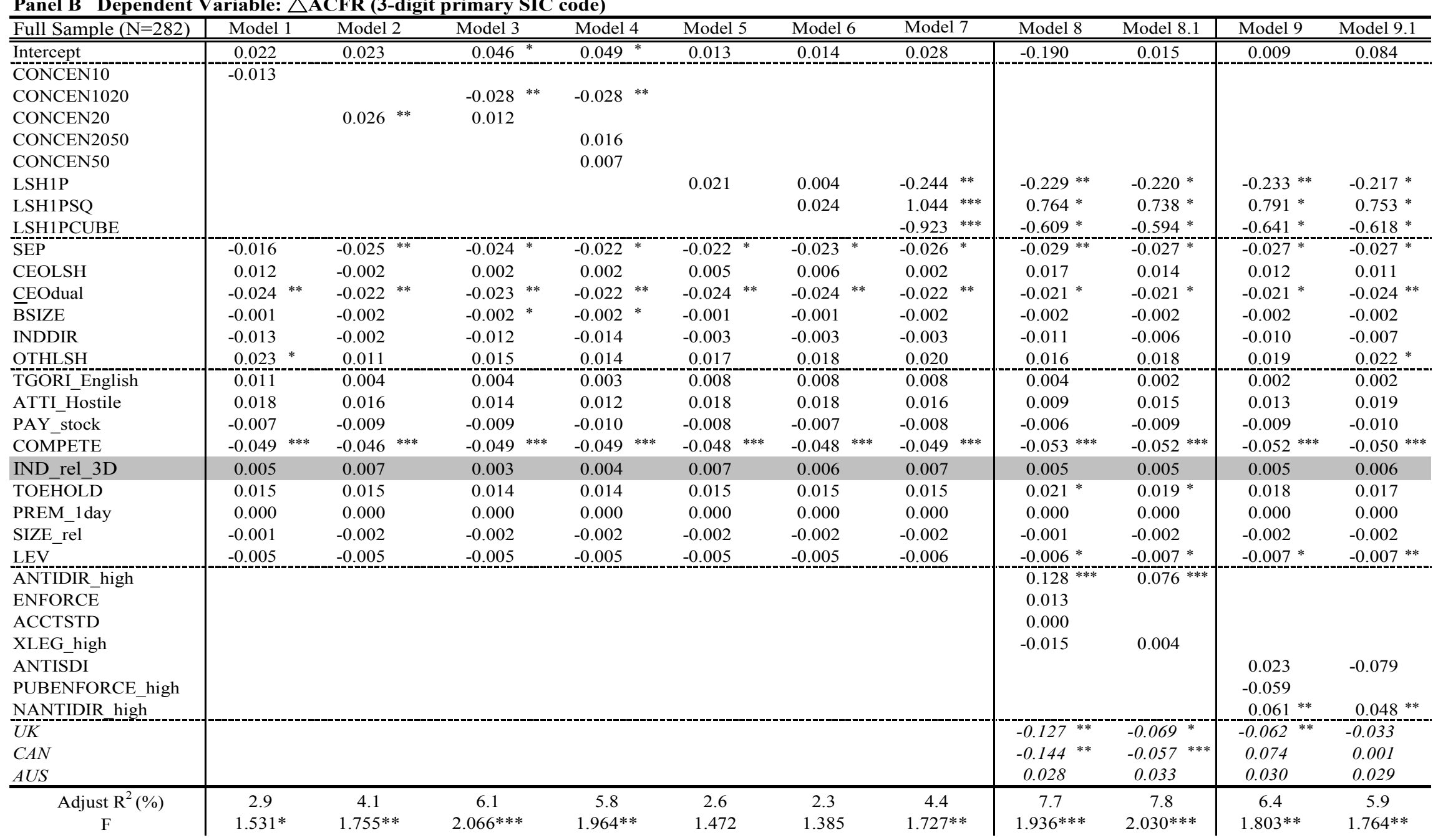


Table 7.12 Regression Results of Pre Bid Period for Premium Measure: One- Week

Sample of 282 mergers and acquisitions by 222 acquiring firms in 11 English Origin countries (Australia, Canada, India, Ireland, Israel, Malaysia, New Zealand, Singapore, South Africa, Thailand and United Kingdom) between 1997 and 2001 for completed takeovers over US\$ 10 million are obtained from the Thomson Financial Securities Data's SDC PlatinumTM Worldwide Mergers \& Acquisitions Database. ACFRpre and ACFRpost is the pre and post industry, size, and pre performance adjusted cash flow return. $\triangle \mathrm{ACFR}$ is the change in industry, size, and pre performance adjusted cash flow return. Outliers have been winsorized using Huber's M estimator approach. Pearson Correlation test are presented. With OLS standard errors. Two tail tests *** denotes significant at the $1 \%$ level, ** significant at the $5 \%$ level, * significant at the $10 \%$ level. PREM_1W is the premium of offer price to target trading price one week prior to the announcement date. See table 5.5 for other variables definitions.

\begin{tabular}{|c|c|c|c|c|c|c|c|c|c|c|c|}
\hline Full Sample $(\mathrm{N}=282)$ & Model 1 & Model 2 & Model 3 & Model 4 & Model 5 & Model 6 & Model 7 & Model 8 & Model 8.1 & Model 9 & Model 9.1 \\
\hline Intercept & "0.049 & (20.050 ${ }^{* *}$ & (20.070 ${ }^{* * * *}$ & (20.070 ${ }^{* * * *}$ & ( & ב-0.042 * & ( & 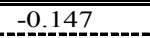 & 然 & $\begin{array}{l}0.023 \\
-2\end{array}$ & (20.110. \\
\hline CONCEN10 & -0.012 & & & & & & & & & & \\
\hline CONCEN 1020 & & & $-0.025^{* * *}$ & $-0.025^{* * *}$ & & & & & & & \\
\hline CONCEN2O & & $0.023^{* *}$ & 0.011 & & & & & & & & \\
\hline CONCEN2050 & & & & 0.010 & & & & & & & \\
\hline CONCEN50 & & & & 0.012 & & & & & & & \\
\hline LSH1P & & & & & 0.022 & 0.005 & $-0.240 * *$ & $-0.203^{* *}$ & $-0.207 * *$ & $-0.229 * *$ & $-0.209^{* *}$ \\
\hline LSH1PSQ & & & & & & 0.026 & $1.028^{* * *}$ & $0.710^{* *}$ & $0.760^{* *}$ & $0.804^{* *}$ & $0.759^{* *}$ \\
\hline LSH1PCUBE & & & & & & & $-0.906^{* * *}$ & $-0.590 *$ & $-0.642 * *$ & $-0.670 * *$ & $-0.643 *$ \\
\hline S- & $-0.020^{*}$ & $-0.029^{* *}$ & $-0.027^{* *}$ & $-0.028^{* *}$ & $-0.027^{* *}$ & $-0.027^{* * 4}$ & $-0.030^{* *}$ & $-0.032^{* *}$ & $-0.034^{* * * *}$ & $-0.034^{* * *}$ & $-0.033^{* *}$ \\
\hline CEOdual & -0.014 & -0.012 & -0.013 & -0.013 & -0.014 & -0.014 & -0.012 & -0.010 & -0.011 & -0.010 & -0.014 \\
\hline$\overline{\mathrm{BSIZE}}$ & -0.001 & $-0.002 *$ & $-0.003^{* *}$ & $-0.003^{* *}$ & -0.002 & -0.002 & $-0.003^{* *}$ & $-0.003^{* *}$ & $-0.003^{* *}$ & $-0.003^{* *}$ & $-0.002 *$ \\
\hline INDDIR & -0.023 & -0.013 & -0.022 & -0.022 & -0.013 & -0.013 & -0.013 & -0.026 & -0.022 & -0.030 & -0.027 \\
\hline OTHLSH & 0.013 & 0.002 & _.006 & 0.006 & 0.007 & 0.008 & 0.010 & 0.006 & 0.008 & 0.009 & 0.012 \\
\hline TGORI_English & 0.007 & 0.000 & 0.001 & 0.001 & 0.003 & 0.004 & 0.003 & -0.002 & -0.001 & -0.001 & -0.001 \\
\hline ATTI_Hostile & 0.010 & 0.008 & 0.007 & 0.007 & 0.011 & 0.011 & 0.009 & 0.019 & 0.015 & 0.007 & 0.013 \\
\hline PAY_stock & -0.010 & -0.013 & -0.013 & -0.013 & -0.011 & -0.011 & -0.012 & -0.011 & -0.013 & -0.013 & -0.014 \\
\hline COMPETE & $-0.034^{* *}$ & $-0.031^{* *}$ & $-0.034^{* *}$ & $-0.034^{* *}$ & $-0.032^{* *}$ & $-0.032^{* *}$ & $-0.034^{* *}$ & $-0.036^{* *}$ & $-0.036^{* *}$ & $-0.036^{* *}$ & $-0.035^{* *}$ \\
\hline IND_rel & 0.001 & 0.003 & 0.001 & 0.001 & 0.003 & 0.002 & 0.002 & 0.001 & 0.001 & 0.001 & 0.002 \\
\hline TOËHOLD & 0.006 & 0.005 & 0.005 & 0.005 & 0.005 & 0.005 & 0.005 & 0.011 & 0.011 & 0.009 & 0.008 \\
\hline PREM_1W & 0.000 & 0.000 & 0.000 & 0.000 & 0.000 & 0.000 & 0.000 & 0.000 & 0.000 & 0.000 & 0.000 \\
\hline SIZE_rel & $-0.004 *$ & $-0.005^{* *}$ & $-0.005^{* *}$ & $-0.005^{* *}$ & $-0.005^{* *}$ & $-0.005^{* *}$ & $-0.005^{* *}$ & $-0.004 *$ & $-0.005 *$ & $-0.005 *$ & $-0.005^{* *}$ \\
\hline ENFORCE & & & & & & & & -0.001 & & & \\
\hline ACCTSTD & & & & & & & & 0.003 & & & \\
\hline XLEG_high & & & & & & & & -0.030 & -0.026 & & \\
\hline ANTISDI & & & & & & & & & & 0.041 & -0.078 \\
\hline PUBENFORCE_high & & & & & & & & & & $-0.069 *$ & \\
\hline NANTIDIR_high & & & & & & & & & & $0.058^{* *}$ & $0.043^{* *}$ \\
\hline $\bar{U}$ & & & & & & & & -0.057 & -0.028 & $-0.059^{* *}$ & -0.026 \\
\hline$C A N$ & & & & & & & & -0.057 & $-0.039^{* *}$ & $0.097^{* *}$ & 0.013 \\
\hline$A U S$ & & & & & & & & $0.055^{* *}$ & $0.054^{* *}$ & 0.033 & 0.032 \\
\hline ACFRpre & $0.515^{* * * *}$ & $0.517 * * *$ & $0.520^{* * * *}$ & $0.520^{* * *}$ & $0.514 * * *$ & $0.513^{* * *}$ & $0.515^{* * *}$ & $0.501^{* * *}$ & $0.511^{* * *}$ & $0.511^{* * *}$ & $0.516^{* * *}$ \\
\hline Adjust $\mathrm{R}^{2}(\%)$ & 28.9 & 29.8 & 31.4 & 31.1 & 28.7 & 28.4 & 30.5 & 33.5 & 33.4 & 32.5 & 3 \\
\hline $\mathrm{F}$ & $7.718^{* * *}$ & $8.008 * * *$ & $8.113^{* * *}$ & $7.667 * * *$ & $7.651 * * *$ & $7.207 * * *$ & $7.482 * * *$ & $6.440 * * *$ & $6.876 * * *$ & $6.404 * * *$ & $6.416^{* * *}$ \\
\hline
\end{tabular}


Table 7.12 (Continued)

Panel B Dependent Variable: $\triangle \operatorname{ACFR}$ (One-week Premium)

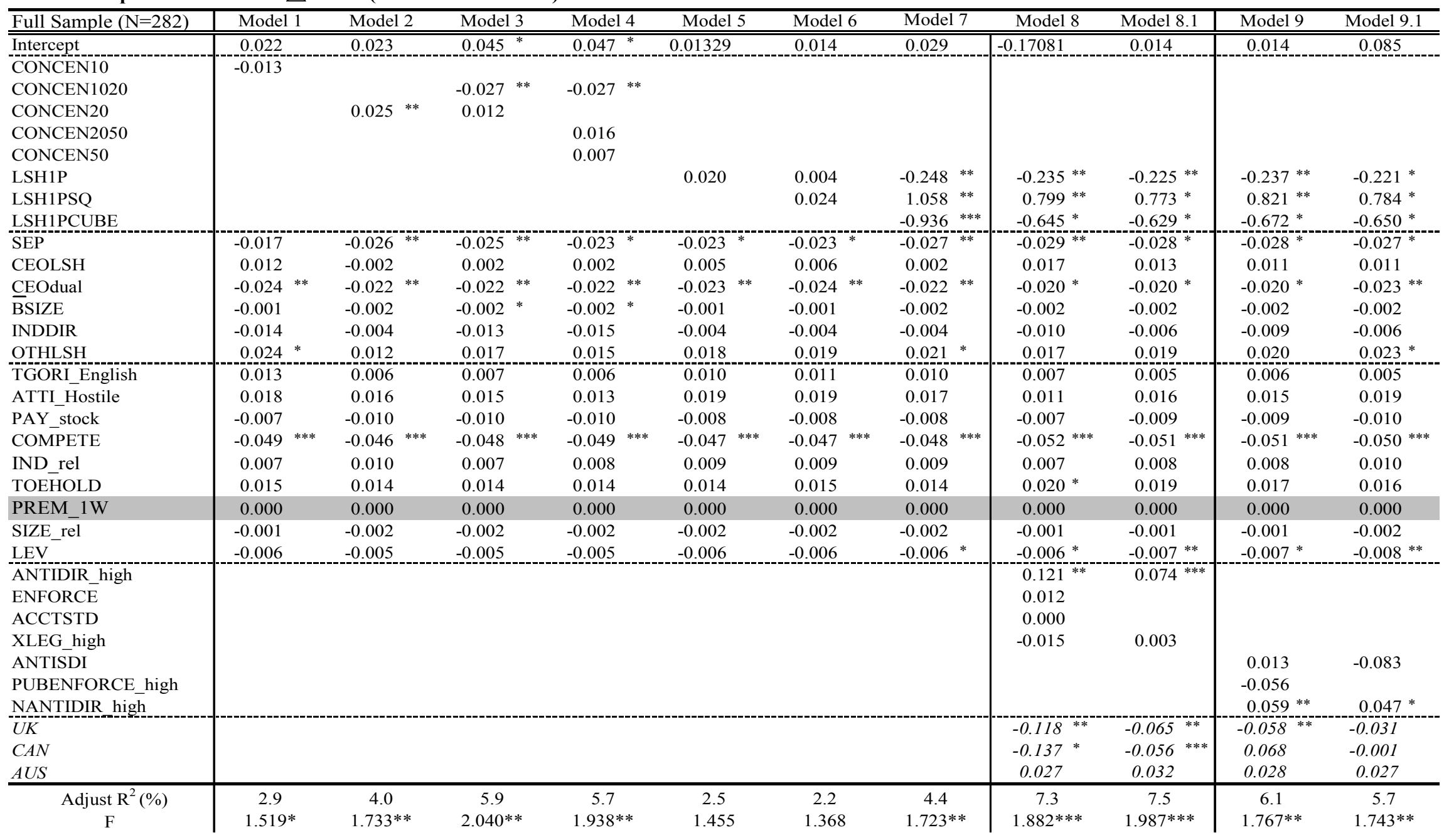


Table 7.13 Regression Results of Pre Bid Period for Premium Measure: Four- Weeks

Sample of 282 mergers and acquisitions by 222 acquiring firms in 11 English Origin countries (Australia, Canada, India, Ireland, Israel, Malaysia, New Zealand, Singapore, South Africa, Thailand and United Kingdom) between 1997 and 2001 for completed takeovers over US\$ 10 million are obtained from the Thomson Financial Securities Data's SDC PlatinumTM Worldwide Mergers \& Acquisitions Database. ACFRpre and ACFRpost is the pre and post industry, size, and pre performance adjusted cash flow return. $\triangle \mathrm{ACFR}$ is the change in industry, size, and pre performance adjusted cash flow return. Outliers have been winsorized using Huber's M estimator approach. Pearson Correlation test are presented. With OLS standard errors. Two tail tests *** denotes significant at the $1 \%$ level, ** significant at the $5 \%$ level, * significant at the $10 \%$ level. PREM_4W is the premium of offer price to target trading price four week prior to the announcement date. See table 5.5 for other variables definitions.

\begin{tabular}{|c|c|c|c|c|c|c|c|c|c|c|c|}
\hline Full Sample $(\mathrm{N}=282)$ & Model 1 & Model 2 & Model 3 & Model 4 & Model 5 & Model 6 & Model 7 & Model 8 & Model 8.1 & Model 9 & Model 9.1 \\
\hline Intercept & $0.048^{* *}$ & $0.049^{* *}$ & (20.070 ${ }^{* * * *}$ & $0.070^{* * *}$ & $0.041^{*}$ & $0.041^{*}$ & $0.055^{* *}$ & (-0.166 & $0.054^{*}$ & 0.025 & 0.109 \\
\hline CONCEN10 & -0.012 & & & & & & & & & & \\
\hline CONCEN 1020 & & & $-0.026^{* * *}$ & $-0.026^{* * *}$ & & & & & & & \\
\hline CONCEN20 & & $0.024^{* *}$ & 0.011 & & & & & & & & \\
\hline CONCEN2050 & & & & 0.011 & & & & & & & \\
\hline CONCEN50 & & & & 0.012 & & & & & & & \\
\hline LSH1P & & & & & 0.023 & 0.005 & $-0.240 * *$ & $-0.208^{* *}$ & $-0.210 * *$ & $-0.232^{* *}$ & $-0.212^{* *}$ \\
\hline LSH1PSQ & & & & & & 0.026 & $1.032 * * *$ & $0.725 * *$ & $0.770 * *$ & $0.813 * *$ & $0.767^{* *}$ \\
\hline LSH1PCUBE & & & & & & & $-0.910^{* * *}$ & $-0.599 *$ & $-0.648^{* *}$ & $-0.675^{* *}$ & $-0.647^{* *}$ \\
\hline $\mathrm{SEP}$ & $-0.020^{*}$ & $-0.028^{* *}$ & $-0.027^{* x_{*}}$ & $-0.027^{* *}$ & -0.026 & -0.027 & $-0.030^{* *}$ & $-0.032^{* *}$ & $-0.034^{* * *}$ & $-0.034^{* * *}$ & -0.033 * \\
\hline CEOdual & -0.014 & -0.012 & -0.013 & -0.013 & -0.014 & -0.014 & -0.012 & -0.009 & -0.011 & -0.010 & -0.013 \\
\hline$\overline{\mathrm{BSIZE}}$ & -0.001 & $-0.002 *$ & $-0.003^{* *}$ & $-0.003^{* *}$ & -0.002 & -0.002 & $-0.003^{* *}$ & $-0.003^{* *}$ & $-0.003^{* *}$ & $-0.003^{* *}$ & $-0.002 *$ \\
\hline INDDIR & -0.023 & -0.013 & -0.022 & -0.022 & -0.013 & -0.013 & -0.013 & -0.026 & -0.022 & -0.030 & -0.026 \\
\hline OTHLSH & 0.012 & 0.002 & 0.006 & 0.006 & 0.006 & 0.008 & _.010 & 0.006 & 0.008 & 0.008 & 0.012 \\
\hline TGORI English & 0.005 & -0.001 & -0.001 & -0.001 & 0.002 & 0.002 & 0.001 & -0.004 & -0.003 & -0.002 & -0.003 \\
\hline ATTI_Hostile & 0.010 & 0.008 & 0.007 & 0.007 & 0.010 & 0.011 & 0.008 & 0.017 & 0.014 & 0.007 & 0.013 \\
\hline PAY_stock & -0.010 & -0.013 & -0.013 & -0.013 & -0.011 & -0.011 & -0.011 & -0.011 & -0.013 & -0.012 & -0.014 \\
\hline COMPETE & $-0.034^{* *}$ & $-0.031^{* *}$ & $-0.034^{* *}$ & $-0.034^{* *}$ & $-0.032^{* *}$ & $-0.033^{* *}$ & $-0.034^{* *}$ & $-0.037^{* *}$ & $-0.037^{* *}$ & $-0.037^{* *}$ & $-0.036^{* *}$ \\
\hline IND_rel & 0.001 & 0.003 & 0.001 & 0.001 & 0.003 & 0.002 & 0.003 & 0.001 & 0.001 & 0.001 & 0.003 \\
\hline TOËHOLD & 0.006 & 0.005 & 0.005 & 0.005 & 0.005 & 0.005 & 0.005 & 0.010 & 0.011 & 0.009 & 0.008 \\
\hline PREM_4W & 0.000 & 0.000 & 0.000 & 0.000 & 0.000 & 0.000 & 0.000 & 0.000 & 0.000 & 0.000 & 0.000 \\
\hline SIZE_rel & $-0.005 *$ & $-0.005^{* *}$ & $-0.005^{* *}$ & $-0.005^{* *}$ & $-0.005^{* *}$ & $-0.005^{* *}$ & $-0.005^{* *}$ & $-0.004 *$ & $-0.005^{* *}$ & $-0.005^{* *}$ & $-0.005^{* *}$ \\
\hline ENFORCE $\bar{E}$ & & & & & & & & 0.000 & & & \\
\hline ACCTSTD & & & & & & & & 0.003 & & & \\
\hline XLEG_high & & & & & & & & -0.030 & -0.025 & & \\
\hline ANTISDI & & & & & & & & & & 0.038 & -0.078 \\
\hline PUBENFORCE_high & & & & & & & & & & $-0.067 * *$ & \\
\hline NANTIDIR high & & & & & & & & & & $0.059^{* * *}$ & $0.044^{* *}$ \\
\hline$U \bar{U}$ & & & & & & & & -0.065 & -0.031 & $-0.059^{*}$ & -0.027 \\
\hline$C A N$ & & & & & & & & -0.067 & $-0.041^{* *}$ & $0.095^{* *}$ & 0.012 \\
\hline AUS & & & & & & & & $0.054^{* *}$ & $0.053 * *$ & 0.033 & 0.033 \\
\hline ACFRpre & $0.515 * * *$ & $0.517^{* * * * *}$ & $0.520^{* * *}$ & $0.520 * * *$ & $0.513^{* * *}$ & $0.513^{* * * *}$ & $0.515^{* * * *}$ & $0.503^{* * *}$ & $0.511^{* * *}$ & $0.511^{* * *}$ & $0.516^{* * *}$ \\
\hline Adjust $\mathrm{R}^{2}(\%)$ & 28.9 & 29.9 & 31.5 & 31.2 & 28.8 & 28.5 & 30.6 & 33.1 & 33.6 & 32.0 & 31.8 \\
\hline & & & & & $7.675 * * *$ & $7.230^{* * * *}$ & $.511 * *$ & $5.489^{* *}$ & $.921 *$ & $445 *$ & \\
\hline
\end{tabular}


Table 7.13 (Continued)

Panel B Dependent Variable: $\triangle$ ACFR (Four-Weeks Premium)

\begin{tabular}{|c|c|c|c|c|c|c|c|c|c|c|c|}
\hline Full Sample $(\mathrm{N}=282)$ & Model 1 & Model 2 & Model 3 & Model 4 & Model 5 & Model 6 & Model 7 & Model 8 & Model 8.1 & Model 9 & Model 9.1 \\
\hline$\overline{\overline{\text { Intercept }}}$ & (20.021 & 0.023 & "0.045 ${ }^{*}$ & 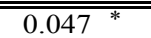 & 0.013 & 0.014 & 0.028 & $\begin{array}{l}-0.195 \\
\end{array}$ & "0.013 & "0.016 & (0.084 \\
\hline CONCEN10 & -0.013 & & & & & & & & & & \\
\hline CONCEN 1020 & & & $-0.027^{* *}$ & $-0.027^{* *}$ & & & & & & & \\
\hline CONCEN20 & & $0.026^{* *}$ & 0.012 & & & & & & & & \\
\hline CONCEN2050 & & & & 0.016 & & & & & & & \\
\hline CONCEN50 & & & & 0.007 & & & & & & & \\
\hline LSH1P & & & & & 0.021 & 0.004 & $-0.249^{* *}$ & $-0.243^{* *}$ & $-0.230^{* *}$ & $-0.241^{* *}$ & $-0.225 *$ \\
\hline LSH1PSQ & & & & & & 0.024 & $1.065^{* * *}$ & $0.825^{* *}$ & $0.790^{* *}$ & $0.835^{* *}$ & $0.798 *$ \\
\hline LSH1PCUBE & & & & & & & $-0.941^{* * * *}$ & $-0.663 *$ & $-0.641 *$ & $-0.682 *$ & $-0.659 *$ \\
\hline $\mathrm{SEP}$ & -0.016 & $-0.026^{* *}$ & $-0.025^{*}$ & $-0.023^{*}$ & $-0.023^{*}$ & $-0.023^{*}$ & $-0.026^{* *}$ & $-0.029^{* *}$ & $-0.028^{*}$ & $-0.028^{*}$ & $-0.027^{*}$ \\
\hline CEOdual & $-0.024^{* *}$ & $-0.021^{* *}$ & $-0.022^{* *}$ & $-0.021 * *$ & $-0.023^{* *}$ & $-0.023 * *$ & $-0.021 * *$ & $-0.019 *$ & $-0.020 *$ & $-0.019 *$ & $-0.022 * *$ \\
\hline$\overline{\mathrm{BSIZE}}$ & -0.001 & -0.002 & $-0.002 *$ & $-0.002 *$ & -0.001 & -0.001 & -0.002 & -0.002 & -0.002 & -0.002 & -0.002 \\
\hline INDDIR & -0.014 & -0.004 & -0.013 & -0.015 & -0.004 & -0.004 & -0.004 & -0.010 & -0.005 & -0.008 & -0.006 \\
\hline OTHLSH & $0.024^{*}$ & 0.012 & 0.016 & 0.015 & 0.018 & 0.019 & $0.021 *$ & 0.017 & 0.019 & 0.020 & $0.023 *$ \\
\hline TGORI_English & 0.013 & 0.006 & 0.006 & 0.006 & 0.009 & 0.010 & 0.009 & 0.005 & 0.004 & 0.004 & 0.003 \\
\hline ATTI Hostile & 0.018 & 0.016 & 0.015 & 0.013 & 0.019 & 0.019 & 0.016 & 0.009 & 0.016 & 0.015 & 0.019 \\
\hline PAY_stock & -0.007 & -0.010 & -0.010 & -0.010 & -0.008 & -0.008 & -0.008 & -0.006 & -0.009 & -0.009 & -0.010 \\
\hline COMPETE & $-0.049^{* * *}$ & $-0.046^{* * * *}$ & $-0.049^{* * * *}$ & $-0.049^{* * *}$ & $-0.047^{* * * *}$ & $-0.047 * * *$ & $-0.049^{* * * *}$ & $-0.053 * * *$ & $-0.052 * * *$ & $-0.051^{* * * *}$ & $-0.050 * * *$ \\
\hline IND_rel & 0.007 & 0.010 & 0.007 & 0.008 & 0.009 & 0.009 & 0.009 & 0.007 & 0.008 & 0.008 & 0.010 \\
\hline TOEḦHLD & 0.015 & 0.014 & 0.014 & 0.014 & 0.014 & 0.014 & 0.014 & $0.020 *$ & 0.018 & 0.017 & 0.016 \\
\hline SIZE_rel & $\begin{array}{l}-0.001 \\
-0.006\end{array}$ & $\begin{array}{l}-0.002 \\
-0.005\end{array}$ & $\begin{array}{l}-0.002 \\
-0.005\end{array}$ & $\begin{array}{l}-0.002 \\
-0.005\end{array}$ & $\begin{array}{l}-0.002 \\
-0.006\end{array}$ & $\begin{array}{l}-0.002 \\
-0.006\end{array}$ & 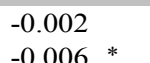 & -0.001 & $\begin{array}{l}-0.001 \\
-0.007\end{array} * *$ & $\begin{array}{l}-0.002 \\
-0.007\end{array} *$ & $\begin{array}{l}-0.002 \\
-0.008 \text { ** }\end{array}$ \\
\hline ANTIDIR high & -0.006 & -0.005 & -0.005 & & -0.006 & -0.006 & $-0.006{ }^{*}$ & 0.0 .130 **** & $0.075^{* * * *}$ & $-0.007^{*}$ & -0.008 \\
\hline ENFORCE & & & & & & & & 0.013 & & & \\
\hline ACCTSTD & & & & & & & & 0.000 & & & \\
\hline XLEG_high & & & & & & & & -0.015 & 0.005 & & \\
\hline ANTISDI & & & & & & & & & & 0.010 & -0.083 \\
\hline PUBENFORCE_high & & & & & & & & & & -0.054 & \\
\hline NANTIDIR high & & & & & & & & & & $0.060^{* *}$ & $0.048^{* *}$ \\
\hline $\bar{U} \bar{U}$ & & & & & & & & $-0.128 *$ & $-0.068 *$ & $-0.057^{* *}$ & -0.032 \\
\hline$C A N$ & & & & & & & & $-0.150^{* *}$ & $-0.057^{* * *}$ & 0.065 & -0.001 \\
\hline$A U S$ & & & & & & & & 0.025 & 0.031 & 0.029 & 0.028 \\
\hline Adjust $\mathrm{R}^{2}(\%)$ & 2.9 & 4.1 & 6.0 & 5.8 & 2.6 . & 2.2 & 4.5 & 7.6 & 7.7 & 6.3 & 5.9 \\
\hline $\mathrm{F}$ & $1.525 *$ & $1.744 * *$ & $2.056 * * *$ & $1.953 * *$ & 1.464 & 1.377 & $1.737 * *$ & $1.926 * * *$ & $2.015^{* * *}$ & $1.789 * *$ & $1.772 * *$ \\
\hline
\end{tabular}


Table 7.14 Regression Results of Acquisition Years

Sample of 282 mergers and acquisitions by 222 acquiring firms in 11 English Origin countries (Australia, Canada, India, Ireland, Israel, Malaysia, New Zealand, Singapore, South Africa, Thailand and United Kingdom) between 1997 and 2001 for completed takeovers over US\$ 10 million are obtained from the Thomson Financial Securities Data's SDC PlatinumTM Worldwide Mergers \& Acquisitions Database. ACFRpre and ACFRpost is the pre and post industry, size, and pre performance adjusted cash flow return. $\triangle \mathrm{ACFR}$ is the change in industry, size, and pre performance adjusted cash flow return. Outliers have been winsorized using Huber's M estimator approach. Pearson Correlation test are presented. With OLS standard errors. Two tail tests *** denotes significant at the $1 \%$ level, ** significant at the $5 \%$ level, * significant at the $10 \%$ level. PREM $1 \mathrm{~W}$ is the premium of offer price to target trading price one week prior to the announcement date. The year of acquisition completed at 1998 , 1999,2000 and 2001 is defined as YR98, YR99, YR00 and YR0, respectively. See table 5.5 for other variables definitions

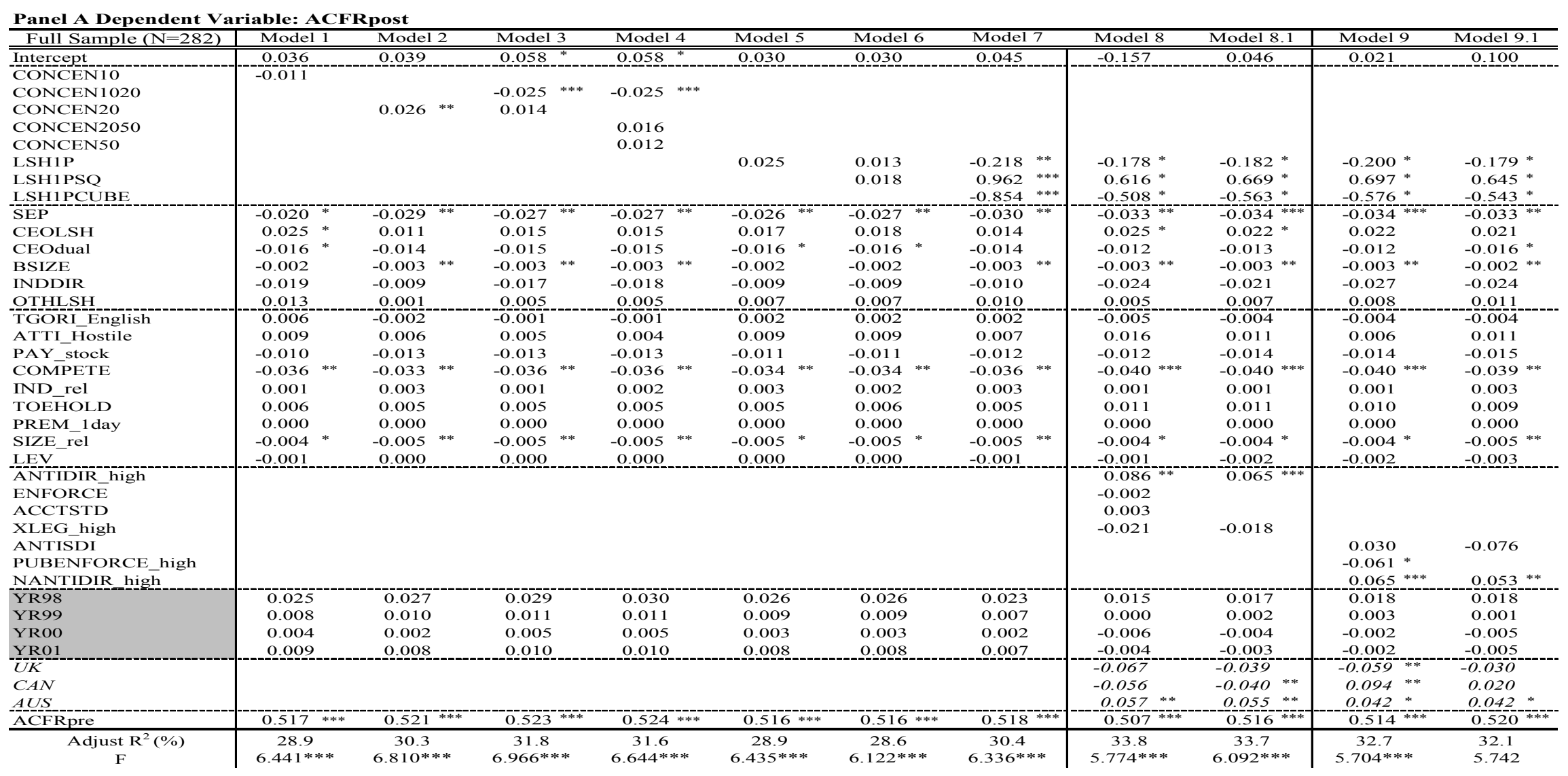


Table 7.14 (Continued)

Panel B Dependent Variable: $\triangle \mathrm{ACFR}$

\begin{tabular}{|c|c|c|c|c|c|c|c|c|c|c|c|}
\hline Full Sample $(\mathrm{N}=282)$ & Model 1 & Model 2 & Model 3 & Model 4 & Model 5 & Model 6 & Model 7 & Model 8 & Model 8.1 & Model 9 & Model 9.1 \\
\hline Intercept & $\begin{array}{l}0.028 \\
\end{array}$ & 0.032 & 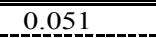 & 20.053 & 0.022 & 0.022 & 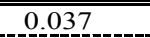 & 0.165 & 0.023 & 0.039 & 然.096 \\
\hline CONCEN10 & -0.011 & & & & & & & & & & \\
\hline CONCEN1020 & & & $-0.026^{* *}$ & $-0.026^{* *}$ & & & & & & & \\
\hline CONCEN20 & & $0.029^{* *}$ & 0.016 & & & & & & & & \\
\hline CONCEN2050 & & & & 0.022 & & & & & & & \\
\hline CONCEN50 & & & & 0.007 & & & & & & & \\
\hline LSH1P & & & & & 0.023 & 0.018 & $-0.221 *$ & $-0.203 *$ & $-0.194 *$ & $-0.200 *$ & $-0.184^{* *}$ \\
\hline LSH1PSQ & & & & & & 0.007 & $0.985^{* *}$ & $0.692 *$ & $0.672 *$ & $0.695 *$ & $0.658 *$ \\
\hline LSH1PCUBE & & & & & & & $-0.884^{* * *}$ & -0.560 & -0.549 & -0.571 & $-0.547^{*}$ \\
\hline SEP & -0.018 & $-0.028 * *$ & $-0.026 *$ & -0.024 & -0.025 & $-0.025 *$ & -0.028 & $-0.031^{* *}$ & $-0.030^{* *}$ & $-0.029^{* *}$ & $-0.029^{* *}$ \\
\hline CEOLSH & 0.012 & -0.002 & 0.002 & 0.001 & 0.005 & 0.006 & 0.002 & 0.017 & 0.014 & 0.012 & 0.012 \\
\hline BSIZE & -0.001 & -0.002 & $-0.003 *$ & $-0.003 *$ & -0.001 & -0.001 & -0.002 & -0.002 & -0.002 & -0.002 & -0.002 \\
\hline INDDIR & -0.011 & -0.001 & -0.010 & -0.013 & -0.002 & -0.002 & -0.002 & -0.010 & -0.006 & -0.008 & -0.006 \\
\hline OTHLSH & $0.024^{*}$ & 0.011 & 0.016 & 0.013 & 0.018 & 0.018 & 0.021 & 0.016 & 0.018 & 0.019 & $0.021 *$ \\
\hline TGORI_English & 0.013 & 0.005 & 0.006 & 0.005 & 0.010 & 0.010 & 0.010 & 0.005 & 0.003 & 0.003 & 0.002 \\
\hline ATTI_Hostile & 0.018 & 0.016 & 0.015 & 0.012 & 0.019 & 0.019 & 0.017 & 0.010 & 0.015 & 0.016 & 0.020 \\
\hline PAY_stock & -0.007 & -0.011 & -0.011 & -0.011 & -0.008 & -0.008 & -0.009 & -0.008 & -0.011 & -0.011 & -0.012 \\
\hline COMPETE & $-0.050^{* * *}$ & $-0.047^{* * * *}$ & $-0.050^{* * * *}$ & $-0.051^{* * *}$ & $-0.049^{* * * *}$ & $-0.049^{* * *}$ & $-0.050^{* * *}$ & $-0.055^{* * *}$ & $-0.055^{* * *}$ & $-0.054^{* * *}$ & $-0.053^{* * *}$ \\
\hline IND_rel & 0.007 & 0.009 & 0.007 & 0.007 & 0.008 & 0.008 & 0.008 & 0.007 & 0.008 & 0.008 & 0.009 \\
\hline TOEHOLD & 0.014 & 0.013 & 0.013 & 0.013 & 0.014 & 0.014 & 0.013 & $0.020 *$ & 0.018 & 0.017 & 0.016 \\
\hline PREM_1day & 0.000 & 0.000 & 0.000 & 0.000 & 0.000 & 0.000 & 0.000 & 0.000 & 0.000 & 0.000 & 0.000 \\
\hline ANTIDIR_high & & & & & & & & $0.126^{* * *}$ & $0.081^{* * 1}$ & & \\
\hline ENFORCE & & & & & & & & 0.010 & & & \\
\hline ACCTSTD & & & & & & & & 0.000 & & & \\
\hline XLEG_high & & & & & & & & -0.007 & 0.009 & & \\
\hline ANTISDI & & & & & & & & & & -0.009 & -0.085 \\
\hline PUBENFORCE_high & & & & & & & & & & -0.044 & \\
\hline NANTIDIR high & & & & & & & & & & $0.067^{* *}$ & $0.058^{* *}$ \\
\hline YR98 & 0.007 & 0.010 & 0.012 & 0.014 & 0.008 & 0.008 & 0.004 & 0.003 & 0.001 & 0.000 & 0.000 \\
\hline YR99 & -0.010 & -0.008 & -0.007 & -0.006 & -0.009 & -0.009 & -0.012 & -0.014 & -0.015 & -0.016 & -0.017 \\
\hline YROO & -0.020 & -0.021 & -0.018 & -0.017 & -0.021 & -0.020 & -0.021 & -0.024 & -0.026 & -0.026 & -0.028 \\
\hline YR01 & -0.008 & -0.008 & -0.006 & -0.005 & -0.008 & -0.008 & -0.009 & -0.016 & -0.018 & -0.020 & -0.022 \\
\hline$U K$ & & & & & & & & $-0.123^{* * *}$ & $-0.074 *$ & $-0.055^{*}$ & -0.035 \\
\hline$C A N$ & & & & & & & & $-0.130 *$ & $-0.056^{* * *}$ & 0.062 & 0.008 \\
\hline$A U S$ & & & & & & & & 0.031 & 0.036 & 0.039 & 0.039 \\
\hline Adjust $\mathrm{R}^{2}(\%)$ & 3.2 & 5.0 & 6.8 & 6.7 & 3.1 & 2.7 & 4.7 & 8.0 & 8.2 & 6.8 & 6.6 \\
\hline $\mathrm{F}$ & $1.465^{*}$ & $1.740^{* *}$ & $1.970^{* * *}$ & $1.915 * * *$ & $1.449^{*}$ & 1.375 & $1.630^{* *}$ & $1.840 * * *$ & $1.935^{* * *}$ & $1.728^{* *}$ & $1.741^{* *}$ \\
\hline
\end{tabular}




\section{Chapter Eight \\ Sensitivity Analysis}

\subsection{Introduction}

This chapter presents robustness tests on three aspects. First, as stated in section 5.3.2 of chapter five, the original operating cash flow data of both merging and matched firms have heavy tailed distribution. In the main analyses, Huber's M-estimator with k=1.28 is used to estimate and winsorize outliers. In section 8.2, other estimators are presented including $\mu \pm 2 \sigma$ and 20 percent breakdown point and the sensitivity of results is tested using both trimming and winsorizing approaches. Second, as described in section 5.2.1 of chapter five, the sample comprises 282 acquisitions conducted by 222 acquiring firms. To investigate whether the clustering problems caused by multiple acquirers have an impact on basic results, section 8.3 displays the simulation regressions under the clustered- robust and the bootstrap standard errors. Third, with respect to the approaches used in Denis and Denis (1995) and Ghosh (2001), section 8.4 examines two operating performance measures (based on the last year prior to the transactions, year t-1) to each of the three following years. Since the methodology behind such sensitivity analysis is not the focus of this thesis, the following sections introduce the theoretical background and test the sensitivity of results in chapter six.

\subsection{Robustness Analysis on Outliers}

\subsubsection{Background Introduction}

Classical statistical procedures rely heavily on assumptions that data is normally distributed, at least approximately. In practice, the real data usually does not satisfy a normal distribution. Outliers generally have influential effects on the performance of the classical statistical analysis. Barnett and Lewis (1984) define outliers as observations that appear to be inconsistent with other observations in the data set. These outliers have a large effect on the mean, dragging it towards them and away from the center of the data set. Obviously, the mean measure is biased for estimating the location of the center of the data and even badly affects the standard deviation because the squares of the deviations from the mean go into 
the calculation. Earlier statistical journals indicate that slight deviations away from normality could have a large negative impact on power whenever means are being compared (Tukey 1960). A theory of robustness has since been developed by Huber (1964) and Hample, Ronchetti, Rousseeuw and Stahel (1986). In recent research, a useful mathematical foundation and computer software have been established to detect the outliers and to estimate the location and scale of data (Huber 1981, Rousseeuw and Leroy 1987, Wilcox 2001).

Once the outliers are identified in the data set, the next step is to decide which estimator could prove a better measure instead of the sample mean. It is well known that the breakdown point ${ }^{38}$ of the sample mean is zero. That means a single contaminated observation may have an unbounded influence on the estimator. The higher the breakdown point of an estimator, the more robust it is. Numerous studies examine those cases in which a 50 percent breakdown point can be achieved. The trimmed mean is a simple robust estimator of location that deletes a certain percentage of observations in each tail of the data, and then computes the mean out of the remainder. Formally, given a sample of ordered $\mathrm{n}$ data values, $X_{(1)} \leq \ldots, \leq X_{(n)}$, the $\alpha$-trimmed mean is expressed as

$$
\bar{X}_{t g}=\frac{1}{n-2 g}\left[X_{g+1}+X_{g+2}+\ldots . .+X_{n-g-1}+X_{n-g}\right]
$$

where $\mathrm{g}=[\mathrm{n} \alpha]$. Generally, the so called $\alpha$-trimmed mean $^{39}$ has the outlier observations removed from each end and indicates a breakdown point at $\alpha$ level. Since the $\alpha$-trimmed mean is based on a given level, the choice of a higher breakdown point might be made arbitrarily so as to give data more of a chance to avoid the masking problem ${ }^{40}$. But if the level of trimming is too high, power will be low when sampling from a light tailed

${ }^{38}$ Breakdown is a measure of the largest percentage of contaminating data which can be present before overwhelming the remaining data. The maximum breakdown point is $50 \%$ because if more than half of the observations are contaminated, it is not possible to distinguish between the underlying distribution and the contaminating distribution.

${ }^{39}$ For example, the $20 \%$ trimmed mean is computed by removing the $0.2 \mathrm{n}$ smallest and $0.2 \mathrm{n}$ largest of the sample and averaging those that remain (Wilcox 2001/2003), and this 20 percent trimmed mean estimator has breakdown point at roughly $20 \%$ level. However, be cautious that some study define $\alpha$-trimmed mean by trimming $\alpha^{*} \mathrm{n} / 2$ level each side and having breakdown point $\alpha / 2$. For instance, if the $10 \%$ upper and lower of the data are removed, then it creates a $20 \%$ trimmed mean (Singh 1998).

${ }^{40}$ Masking problem occurs because the trimming level $\alpha$ is too low, outliers have chance to mask each other. As a simple example, when a data set includes one modest and one large outlier, the procedure of detecting with too low trimming level will make the modest outlier look relatively normal and only identify the large outlier. As soon as the large outlier is removed, the estimated standard deviation shrinks, and the modest outlier becomes unusual. This masking problem gets worse as the complexity of the data increases. 
distribution or even from a good data set (Wilcox 2003). In fact, the mean and the median are extreme values of the trimmed mean with $\alpha=0$ and $\alpha=0.5$ respectively.

According to Tukey (1970), the resistant rule of thumb for identifying extreme values is to set the breakdown point at roughly 25 percent (Hoaglin, Iglewicz and Tukey 1986). Besides, Thomas (2000) suggests a value in the range between 0.1 and 0.3 . While the trimmed mean performs well relative to the sample mean in the presence of outliers, the method of trimmed means is criticized when sampling from a heavy one-tail skewed distribution since the proportion of observations is pre-determined and the trimming is applied in both tails. The other alternative, M-estimators, has been highly recommended to improve this deficiency.

M-estimators are a generalization of the maximum likelihood estimators (MLEs) as first introduced by Huber (1964). The pair $(\theta, \hat{\sigma})$ of the two estimators is defined by the equations:

$$
\sum_{\mathrm{i}=1}^{n} \psi\left(\frac{x_{i}-\theta}{\hat{\sigma}}\right)=0
$$

where $\psi$ is some odd function. A complete theoretical description regarding this approach is not the major issue in this thesis and it can be found in related statistics literature (Huber 1981, Rousseeuw and Leroy 1987, Wilcox 2001/ 2003, Pitselis 2005). In practical situations, the choice of the $\psi$ function is not critical for gaining a good robust estimate and many choices give similar results that offer great improvements (in terms of efficiency and bias) over classical estimates in the presence of outliers (Huber 1981).

Among the many choices for $\psi$, Huber's $\psi$ - called a one-step M-estimator ${ }^{41}$ - has been broadly applied in a practical and theoretical field by using the constant $\mathrm{K}=1.28$ (Staudte and Sheather 1990, Wilcox 2003).

$$
\psi(x)=\max [-K, \min (K, x)]
$$

Considering that the median (M) and the median absolute deviation ${ }^{42}$ (MAD) are more suited

${ }^{41}$ That is using a single iteration in the Newton-Raphson method to solve equation (1).

42 The median absolute deviation (MAD) is computed by subtracting the median from each observation and then taking absolute values. The median of the $\mathrm{n}$ values just computed is MAD (Wilcox 2001: p35). The constant 0.6745 is needed because for a large sample from normal distribution curve $\mathrm{N}\left(0, \sigma^{2}\right), \mathrm{E}(\mathrm{MAD} / 0.6745)=\sigma$. While MAD is a less accurate estimator than the sample standard deviation $(\sigma)$, it is much less sensitive to outliers because of its high breakdown point. 
for detecting outliers because of the higher breakdown point (approximately 0.5 ), they are widely accepted as the efficient robust estimators of the location $(\theta)$ and scale $(\hat{\sigma})$ of data with outliers. After a slight modification performed on the Huber's one-step M-estimator, a more practical equation (3) has been proposed. Here, any observed value, $\mathrm{X}$, is regarded as an outlier if

$$
\frac{|X-M|}{M A D / 0.6745}>K=1.28
$$

The idea of flexibility for the trimming ratio leads to the interest in the M-estimator. This estimator is appealing due to its higher breakdown point than that of sample mean and its more accurate variance than that of median from a normal distribution or that of trimmed means from a heavy tailed probability curve (Wilcox 2001). However, M-estimate is not necessarily unique; $\mathrm{K}$ virtually determines the degree of trimming. Arguments for choosing K have been made in several quantitative studies (Staudte and Sheather 1990, Singh 1998, Wilcox 2003). In Wilcox's (2001) book, he develops an experiment to compare a 20 percent trimmed mean and Huber's one-step M-estimator $(\mathrm{K}=1.28)$. His conclusions suggest that there is little separating the two, especially when the samples are not too small (more than 20). The trimmed means might be better for small sample sizes and individual tests, but M-estimators play a more dominant role when dealing with regression.

A winsorized mean, a development of the trimming approach, is another measure of the central tendency which is proposed by Dixon and Tukey (1968). Unlike the trimmed mean, a $\beta$-winsorized mean does not need to remove the end points completely but shrinks the most extreme $\mathrm{g}=[\mathrm{n} \beta]$ data values at each end to the smallest $\mathrm{g}$ by $X_{(\mathrm{g}+1)}$ and the largest $\mathrm{g}$ by $X_{(\mathrm{n}-\mathrm{g})}$. Assume that $X_{(1)} \leq \ldots, \leq X_{(n)}$ are the usual order statistics. Let

$$
\widetilde{W}_{i}= \begin{cases}X_{(g+1),} & \text { if } X_{i}<X_{(g+1)} \\ X_{i}, & \text { if } X_{(g+1)} \leq X_{i} \leq X_{(n-g)} \\ X_{(n-g),} & \text { if } X_{i}>X_{(n-g)}\end{cases}
$$

Then the $\beta$-winsorized mean is defined as

$$
\bar{X}_{w g}=\frac{1}{n}\left[(g+1) X_{g+1}+X_{g+2}+\ldots .+X_{n-g-1}+(g+1) X_{n-g}\right],
$$

and the winsorized sample variance is given by

$$
S S D_{w g}=(g+1)\left(X_{g+1}-\bar{X}_{w g}\right)^{2}+\left(X_{g+2}-\bar{X}_{w g}\right)^{2}+\ldots+\left(X_{n-g-1}-\bar{X}_{w g}\right)^{2}+(g+1)\left(X_{n-g}-\bar{X}_{w g}\right)^{2}
$$


Yuen (1975) conducts a power comparison of winsorized t, trimmed t, and student's t. The evidence proves that when the parent population is long-tailed, trimmed $t$ and winsorized $t$ are proposed as better robust estimators of location. However, based on a long-tailed underling distribution, this study further compares the performance of winsorized $t$ and trimmed $t$; the results show small difference between these two estimators. Winsorized mean has been regarded as an attractive alternative to the skewed populations not only because it is a nearly unbiased estimator of the population mean, but also because it improves the sample mean even in small samples (Rivest 1994).

\subsubsection{Application to Data}

Turning to the sample in this thesis, the statistics in table 8.1 show that the original data of operating cash flow returns for both merging (MEG_CFR ${ }_{i}$ ) and matched firms (MAT_CFR ${ }_{i}$ ) comes from heavy tailed distributions. For example, the standard deviation of MEG_CFR $_{\mathrm{t}+3}(135.15 \%)$, MEG_CFR $_{\mathrm{t}-2}(70.25 \%), \mathrm{MEG}_{-} \mathrm{CFR}_{\mathrm{t}-3}(193.74 \%), \mathrm{MAT}_{-} \mathrm{CFR}_{\mathrm{t}-1}$ (115.01\%), MAT_CFR $\mathrm{t-2}(73.33 \%)$ and MAT_CFR $\mathrm{t}-3$ (948.62\%) is incredibly large and indicates that data points are far from the mean. In addition, from figure 8.1 many extreme values are spotted in all data sets. While in sets MEG_CFR ${ }_{t+3}, \mathrm{MEG}_{-} \mathrm{CFR}_{\mathrm{t}-2}, \mathrm{MAT}_{-} \mathrm{CFR}_{\mathrm{t}+2}$ and MAT_CFR $\mathrm{t}_{\mathrm{t}-3}$ distribution appears to be contaminated by extreme values in both tails, most data sets have outliers falling on the right tail. Obviously, the sample mean is strongly altered by the large values and the standard deviation tends to overstate the variation.

When outliers are encountered, special checks are conducted to ensure that the values are genuine and not subject to computing or other errors. Outliers are not always bad data but the major interest of this thesis is not to track the behavior of these unusual signs. This thesis simply hopes to assess which approach, provided by the earlier literature, is more suited for testing the relationship between the response and explanatory variables in the sample, and for deciding which will provide more reliable results. A sensitive analysis is applied at several estimators including $2 \sigma$-winsorized, 20 percent- winsorized, $2 \sigma$-trimmed, M-estimator with $\mathrm{K}=1.28$ - trimmed and 20 percent-trimmed. 


\section{Table 8.1 Outlier Robustness Test: Original Data}

Sample of 282 mergers and acquisitions by 222 acquiring firms in 11 English Origin countries (Australia, Canada, India, Ireland, Israel, Malaysia, New Zealand, Singapore, South Africa, Thailand and United Kingdom) between 1997 and 2001 for completed transactions over US\$10 million are obtained from the Thomson Financial Securities Data's SDC PlatinumTM Worldwide Mergers \& Acquisitions Database. Operating cash flow return (OCFR) is calculated as operating cash flow divided by market value of asset. Operating cash flow is defined as operating income before depreciation. Post acquisition performance for each deal is measured by the operating cash flow return of the surviving acquirer after transaction. Pre acquisition performance is calculated as a weighted-average of the operating cash flow return for the bidder and the target included (MEGi pre and post). The weights are based on the market values of assets of both companies in the year before acquisition. Post and pre acquisition performances of the matched firms are measured as weighted-average of the operating cash flow rates (MATi pre and post). ACFRpre and ACFRpost is the pre and post industry, size, and pre performance adjusted cash flow return. $\triangle \mathrm{ACFR}$ is for the change in industry, size, and pre performance adjusted cash flow return.

Summary statistics for the Original data set

\begin{tabular}{|c|c|c|c|c|c|c|c|c|c|c|c|}
\hline & Count & Missing & Valid (N) & Mean & Median & $\begin{array}{l}\text { Standard } \\
\text { Deviation }\end{array}$ & $\begin{array}{c}\text { Percentile } \\
05\end{array}$ & $\begin{array}{c}\text { Percentile } \\
25\end{array}$ & $\begin{array}{c}\text { Percentile } \\
75\end{array}$ & $\begin{array}{c}\text { Percentile } \\
95\end{array}$ & $\begin{array}{c}\text { Percentile } \\
99\end{array}$ \\
\hline $\mathrm{MEG}_{-} \mathrm{CFR}_{\mathrm{t}+3}$ & 282 & 3 & 279 & $4.20 \%$ & $12.47 \%$ & $135.15 \%$ & $-6.15 \%$ & $8.67 \%$ & $17.62 \%$ & $29.37 \%$ & $77.84 \%$ \\
\hline $\mathrm{MEG}_{-} \mathrm{CFR}_{\mathrm{t}+2}$ & 282 & 2 & 280 & $13.45 \%$ & $11.72 \%$ & $31.24 \%$ & $-3.49 \%$ & $7.35 \%$ & $16.19 \%$ & $29.39 \%$ & $41.58 \%$ \\
\hline MEG_CFR $_{t+1}$ & 282 & 0 & 282 & $12.75 \%$ & $11.05 \%$ & $14.15 \%$ & $-3.20 \%$ & $6.47 \%$ & $16.53 \%$ & $29.77 \%$ & $65.71 \%$ \\
\hline MEG_CFR $_{\mathrm{t}-1}$ & 282 & 0 & 282 & $12.50 \%$ & $11.22 \%$ & $21.78 \%$ & $0.00 \%$ & $7.14 \%$ & $15.34 \%$ & $34.41 \%$ & $74.36 \%$ \\
\hline $\mathrm{MEG}_{-} \mathrm{CFR}_{\mathrm{t}-2}$ & 282 & 22 & 260 & $14.32 \%$ & $11.91 \%$ & $70.25 \%$ & $-1.32 \%$ & $8.33 \%$ & $16.78 \%$ & $34.52 \%$ & $303.72 \%$ \\
\hline $\mathrm{MEG}_{\mathrm{CFR}} \mathrm{t}-3$ & 282 & 88 & 194 & $32.13 \%$ & $12.56 \%$ & $193.74 \%$ & $2.38 \%$ & $8.54 \%$ & $17.50 \%$ & $38.53 \%$ & $406.03 \%$ \\
\hline MAT_CFR ${ }_{t+3}$ & 282 & 3 & 279 & $14.54 \%$ & $12.15 \%$ & $23.82 \%$ & $-6.62 \%$ & $7.22 \%$ & $18.98 \%$ & $37.76 \%$ & $122.26 \%$ \\
\hline MAT_CFR ${ }_{t+2}$ & 282 & 2 & 280 & $13.41 \%$ & $11.12 \%$ & $28.09 \%$ & $-2.73 \%$ & $6.24 \%$ & $17.49 \%$ & $42.62 \%$ & $107.04 \%$ \\
\hline MAT_CFR ${ }_{t+1}$ & 282 & 0 & 282 & $12.21 \%$ & $10.52 \%$ & $29.03 \%$ & $-6.82 \%$ & $5.81 \%$ & $16.67 \%$ & $36.75 \%$ & $137.79 \%$ \\
\hline MAT_CFR $_{\mathrm{t}-1}$ & 282 & 0 & 282 & $16.40 \%$ & $12.85 \%$ & $115.01 \%$ & $-9.54 \%$ & $8.88 \%$ & $18.33 \%$ & $45.50 \%$ & $570.70 \%$ \\
\hline MAT_CFR ${ }_{t-2}$ & 282 & 22 & 260 & $20.24 \%$ & $13.32 \%$ & $73.33 \%$ & $-10.90 \%$ & $8.56 \%$ & $19.15 \%$ & $76.97 \%$ & $505.31 \%$ \\
\hline MAT_CFR $_{t-3}$ & 282 & 88 & 194 & $59.68 \%$ & $14.21 \%$ & $948.62 \%$ & $-63.20 \%$ & $8.90 \%$ & $20.44 \%$ & $96.37 \%$ & $365.92 \%$ \\
\hline $\mathrm{ACFR}_{\mathrm{t}+3}$ & 282 & 3 & 279 & $-10.34 \%$ & $0.17 \%$ & $136.84 \%$ & $-43.99 \%$ & $-7.77 \%$ & $7.29 \%$ & $28.41 \%$ & $90.68 \%$ \\
\hline ACFR $_{t+2}$ & 282 & 2 & 280 & $0.04 \%$ & $0.33 \%$ & $41.26 \%$ & $-28.46 \%$ & $-7.03 \%$ & $7.06 \%$ & $26.34 \%$ & $72.10 \%$ \\
\hline $\mathrm{ACFR}_{\mathrm{t}+1}$ & 282 & 0 & 282 & $0.54 \%$ & $0.49 \%$ & $31.44 \%$ & $-26.71 \%$ & $-6.86 \%$ & $6.68 \%$ & $31.67 \%$ & $123.47 \%$ \\
\hline $\operatorname{ACFR}_{t-1}$ & 282 & 0 & 282 & $-3.90 \%$ & $-0.57 \%$ & $117.79 \%$ & $-33.83 \%$ & $-7.74 \%$ & $4.79 \%$ & $34.96 \%$ & $156.08 \%$ \\
\hline $\mathrm{ACFR}_{\mathrm{t}-2}$ & 282 & 22 & 260 & $-5.91 \%$ & $-0.85 \%$ & $99.77 \%$ & $-91.40 \%$ & $-9.02 \%$ & $4.67 \%$ & $47.08 \%$ & $420.41 \%$ \\
\hline $\mathrm{ACFR}_{\mathrm{t}-3}$ & 282 & 88 & 194 & $-27.55 \%$ & $-0.80 \%$ & $769.01 \%$ & $-90.51 \%$ & $-9.85 \%$ & $5.54 \%$ & $149.39 \%$ & $657.64 \%$ \\
\hline ACFRpost & 282 & 0 & 282 & $-0.80 \%$ & $0.53 \%$ & $19.44 \%$ & $-22.38 \%$ & $-6.95 \%$ & $7.18 \%$ & $19.79 \%$ & $55.58 \%$ \\
\hline ACFRpre & 282 & 0 & 282 & $-4.94 \%$ & $-0.70 \%$ & $78.04 \%$ & $-48.84 \%$ & $-6.71 \%$ & $5.66 \%$ & $49.87 \%$ & $216.88 \%$ \\
\hline$\triangle \mathrm{ACFR}$ & 282 & 0 & 282 & $4.14 \%$ & $0.98 \%$ & $79.36 \%$ & $-56.90 \%$ & $-5.17 \%$ & $7.80 \%$ & $49.58 \%$ & $529.96 \%$ \\
\hline
\end{tabular}



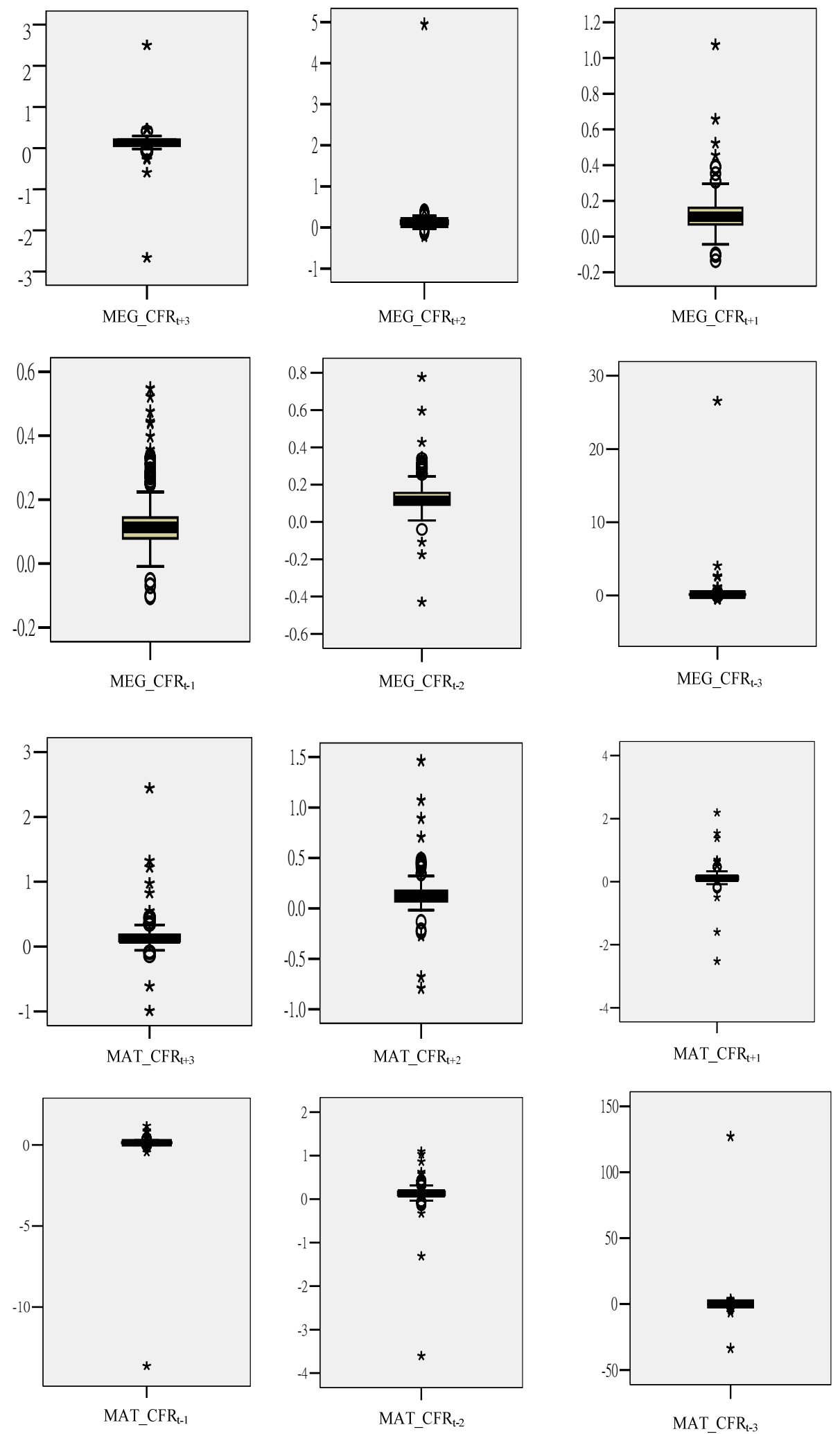

Figure 8.1 Box Plots for the Data Set of Operating Cash Flow of Merging $\left(\mathrm{MEG}_{-} \mathrm{CFR}_{\mathrm{i}}\right)$ and Matched (MAT_CFR $_{\mathrm{i}}$ Firms 
According to the empirical rules for a normal distribution, if the data are normally distributed, then about 95.44 percent of the values are within 2 standard deviations (see figure 8.2). Therefore, testing starts with the traditional method of winsorizing the data at $\mu \pm 2 \sigma$ level. Huber's M-estimator with $\mathrm{K}=1.28$ winsorized is applied in the main analysis. If the data set is under the normal distribution, this approach should be similar to winsorized data at $\mu \pm 1.28 \sigma$ or using a 10 percent-winsorized mean estimator that keeps about 80 percent of the values within 1.28 standard deviations. 20 percent- winsorized is another alternative that is broadly accepted as an efficient robust estimator and that is usually used to compare the Huber's M-estimator (Yuen 1974/ 1975, Singh 1998, Thomas 2000, Wilcox 2003). Therefore, the 20 percent- winsorized mean is also tested as a comparison. In addition, further tests are conducted (using trimming approach) on all of the above robust estimators, including the $\mathrm{M}$-estimator with $\mathrm{K}=1.28$. Importantly, trimming from the data set of operating cash flows for both merging $\left(\mathrm{MEG}_{i}\right)$ and matched (MATi) firms will lose too many samples. Therefore, in this part trimming is done directly from the data set of ACFRpost, ACFRpre and $\triangle \mathrm{ACFR}$. The statistics results are presented in table 8.2a and 8.2b.

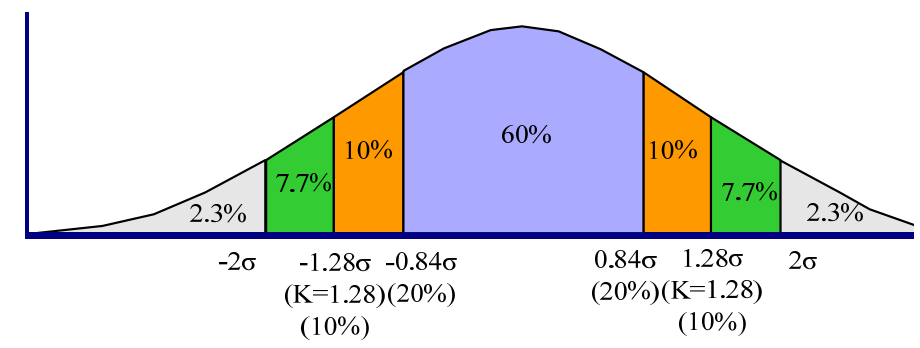

Figure 8.2 Probability of Standard Normal Distribution (0.84 standard deviation from the mean accounts for $60 \%$ of the set; 1.28 standard deviations from the mean account for $80 \%$; and 2 standard deviations account for $95.44 \%$ )

Statistical results for three breakdown levels of winsorizing are presented in table 8.2a: $\mu \pm 2 \sigma(\approx 2.5 \%)$, M-estimator with $\mathrm{K}=1.28(\approx 10 \%)$ and 20 percent-winsorized mean $(20 \%)$. The distribution of all operating performance measures is clearly improved. However, Panel A shows that the robust standard deviation of data set MEG_CFRt+3 (34.79\%), MEG_CFRt-2 (25.21\%), MEG_CFRt-3 (50.2\%), MAT_CFRt-1 (41.76\%), MAT_CFRt-2 (34.43\%) and MAT_CFRt-3 (207.38\%) is still substantial, that the masking problems are still there, and that the breakdown point is too low when using a $\mu \pm 2 \sigma$ approach.

By comparison, panel B shows that winsorizing using Huber's M-estimator with $\mathrm{K}=1.28$ is fairly appropriate. The robust estimators of mean and standard deviation are rather 
reliable in all data sets and the masking problems are markedly improved. Besides, the level of winsorizing in each tail is flexible. Here the average level of right tail and left tail is 17.51 and 10.43 percent, respectively. In panel $\mathrm{C}$, using a 20 percent winsorized-mean to detect outliers provides similar results as an M-estimator approach does, but it arbitrarily replaces data at a given and higher level in both tails. A similar comparison is made on the trimming approach for the same three breakdown levels. To keep more data and simplify the computing procedure, the outliers are tackled from the data set ACFRpost, ACFRpre and $\triangle \mathrm{ACFR}$. Table $8.2 \mathrm{~b}$ reveals a consistent conclusion as made for the winsorizing

Table 8.2 a Outlier Robustness Test: Winsorizing at different estimators

Sample of 282 mergers and acquisitions by 222 acquiring firms in 11 English Origin countries (Australia, Canada, India, Ireland, Israel, Malaysia, New Zealand, Singapore, South Africa, Thailand and United Kingdom) between 1997 and 2001 for completed transactions over US\$ 10 million are obtained from the Thomson Financial Securities Data's SDC PlatinumTM Worldwide Mergers \& Acquisitions Database. Operating cash flow return (OCFR) is calculated as operating cash flow divided by market value of asset. Operating cash flow is defined as operating income before depreciation. Post acquisition performance for each deal is measured by the operating cash flow return of the surviving acquirer after transaction. Pre acquisition performance is calculated as a weighted-average of the operating cash flow return for the bidder and the target included (MEGi pre and post). The weights are based on the market values of assets of both companies in the year before acquisition. Post and pre acquisition performances of the matched firms are measured as weighted-average of the operating cash flow rates (MATi pre and post). ACFRpre and ACFRpost is the pre and post industry, size, and pre performance adjusted cash flow return. $\triangle \mathrm{ACFR}$ is for the change in industry, size, and pre performance adjusted cash flow return.

Panel A $\mu \pm 2 \sigma$ - winsorized (probability around $95.44 \%$ )

\begin{tabular}{|c|c|c|c|c|c|c|c|c|c|c|c|c|c|}
\hline & \multirow{2}{*}{ Count } & \multirow{2}{*}{ Missing } & \multirow{2}{*}{ Valid } & \multirow{2}{*}{ Mean } & \multirow{2}{*}{ Median } & \multirow{2}{*}{$\begin{array}{l}\text { Standard } \\
\text { Deviation }\end{array}$} & \multirow{2}{*}{$\begin{array}{c}\text { Percentile } \\
05\end{array}$} & \multirow{2}{*}{$\begin{array}{c}\text { Percentile } \\
25\end{array}$} & \multirow{2}{*}{$\begin{array}{c}\text { Percentile } \\
75\end{array}$} & \multirow{2}{*}{$\begin{array}{c}\text { Percentile } \\
95\end{array}$} & \multirow{2}{*}{$\begin{array}{c}\text { Percentile } \\
99\end{array}$} & \multicolumn{2}{|c|}{ level of winsorizing } \\
\hline & & & & & & & & & & & & right tail & left tail \\
\hline$\overline{\text { MEG_CFR }_{t+3}}$ & 282 & 3 & 279 & $11.08 \%$ & $12.47 \%$ & $34.79 \%$ & $-6.15 \%$ & $8.67 \%$ & $17.62 \%$ & $29.37 \%$ & $77.84 \%$ & $0.00 \%$ & $0.72 \%$ \\
\hline MEG_CFR $_{t+2}$ & 282 & 2 & 280 & $12.12 \%$ & $11.72 \%$ & $11.41 \%$ & $-3.49 \%$ & $7.35 \%$ & $16.19 \%$ & $29.39 \%$ & $41.58 \%$ & $0.36 \%$ & $0.71 \%$ \\
\hline MEG_CFR ${ }_{t+1}$ & 282 & 0 & 282 & $12.10 \%$ & $11.05 \%$ & $10.18 \%$ & $-3.20 \%$ & $6.47 \%$ & $16.53 \%$ & $29.77 \%$ & $41.06 \%$ & $2.84 \%$ & $1.42 \%$ \\
\hline $\mathrm{MEG}_{-} \mathrm{CFR}_{\mathrm{t}-1}$ & 282 & 0 & 282 & $12.76 \%$ & $11.22 \%$ & $11.72 \%$ & $0.00 \%$ & $7.14 \%$ & $15.34 \%$ & $34.41 \%$ & $55.66 \%$ & $1.05 \%$ & $1.05 \%$ \\
\hline $\mathrm{MEG}_{-} \mathrm{CFR}_{\mathrm{t}-2}$ & 282 & 22 & 260 & $13.23 \%$ & $11.91 \%$ & $25.21 \%$ & $-1.32 \%$ & $8.33 \%$ & $16.78 \%$ & $34.52 \%$ & $153.48 \%$ & $1.13 \%$ & $1.13 \%$ \\
\hline MEG_CFR ${ }_{t-3}$ & 282 & 88 & 194 & $20.54 \%$ & $12.56 \%$ & $50.23 \%$ & $1.61 \%$ & $8.44 \%$ & $17.50 \%$ & $38.53 \%$ & $406.03 \%$ & $0.51 \%$ & $0.00 \%$ \\
\hline MAT_CFR $_{t+3}$ & 282 & 3 & 279 & $13.58 \%$ & $12.15 \%$ & $14.66 \%$ & $-6.62 \%$ & $7.22 \%$ & $18.98 \%$ & $37.76 \%$ & $62.17 \%$ & $2.15 \%$ & $1.79 \%$ \\
\hline MAT_CFR $_{t+2}$ & 282 & 2 & 280 & $\%$ & $11.12 \%$ & $15.89 \%$ & $-2.73 \%$ & $6.24 \%$ & $17.49 \%$ & $42.62 \%$ & $69.60 \%$ & $2.50 \%$ & $1.43 \%$ \\
\hline MAT_CFR $_{t+1}$ & 282 & 0 & 282 & $06 \%$ & $10.52 \%$ & $15.21 \%$ & $-6.82 \%$ & $5.81 \%$ & $16.67 \%$ & $36.75 \%$ & $70.26 \%$ & $1.77 \%$ & $1.06 \%$ \\
\hline MAT_CFR $_{\mathrm{t}-1}$ & 282 & 0 & 282 & $8 \%$ & $12.85 \%$ & $41.76 \%$ & $-9.54 \%$ & $8.88 \%$ & $18.33 \%$ & $45.50 \%$ & $244.65 \%$ & $1.05 \%$ & $0.70 \%$ \\
\hline MAT_CFR ${ }_{t-2}$ & 282 & 22 & 260 & $17.45 \%$ & $13.32 \%$ & $34.43 \%$ & $-10.90 \%$ & $8.56 \%$ & $19.15 \%$ & $76.97 \%$ & $166.01 \%$ & $2.26 \%$ & $1.13 \%$ \\
\hline MAT_CFR ${ }_{t-3}$ & 282 & 88 & 194 & $12.09 \%$ & $14.30 \%$ & $207.38 \%$ & $-63.20 \%$ & $8.90 \%$ & $20.44 \%$ & $96.37 \%$ & $365.92 \%$ & $0.51 \%$ & $0.51 \%$ \\
\hline & & & & & & & & & & & & $1.34 \%$ & $0.97 \%$ \\
\hline $\mathrm{ACFR}_{\mathrm{t}+3}$ & 282 & 3 & 279 & $-2.50 \%$ & $0.17 \%$ & $37.28 \%$ & $-40.62 \%$ & $-7.77 \%$ & $7.29 \%$ & $28.03 \%$ & $78.77 \%$ & & \\
\hline ACFR $_{t+2}$ & 282 & 2 & 280 & $-0.58 \%$ & $0.33 \%$ & $18.04 \%$ & $-28.46 \%$ & $-7.03 \%$ & $7.06 \%$ & $26.34 \%$ & $55.15 \%$ & & \\
\hline $\mathrm{ACFR}_{\mathrm{t}+1}$ & 282 & 0 & 282 & $0.04 \%$ & $0.49 \%$ & $16.55 \%$ & $-23.32 \%$ & $-6.86 \%$ & $6.68 \%$ & $24.77 \%$ & $41.73 \%$ & & \\
\hline $\mathrm{ACFR}_{\mathrm{t}-1}$ & 282 & 0 & 282 & $-3.03 \%$ & $-0.57 \%$ & $41.92 \%$ & $-33.83 \%$ & $-7.74 \%$ & $4.79 \%$ & $32.37 \%$ & $156.08 \%$ & & \\
\hline $\mathrm{ACFR}_{\mathrm{t}-2}$ & 282 & 22 & 260 & $-4.22 \%$ & $-0.85 \%$ & $41.73 \%$ & $-91.40 \%$ & $-9.02 \%$ & $4.67 \%$ & $47.08 \%$ & $143.23 \%$ & & \\
\hline $\mathrm{ACFR}_{\mathrm{t}-3}$ & 282 & 88 & 194 & $8.53 \%$ & $-0.80 \%$ & $194.20 \%$ & $-90.51 \%$ & $-9.85 \%$ & $5.54 \%$ & $149.39 \%$ & $657.64 \%$ & & \\
\hline ACFRpost & 282 & 0 & 282 & $-0.27 \%$ & $0.53 \%$ & $14.74 \%$ & $-22.38 \%$ & $-6.95 \%$ & $7.18 \%$ & $19.79 \%$ & $41.73 \%$ & & \\
\hline ACFRpre & 282 & 0 & 282 & $-2.33 \%$ & $-0.70 \%$ & $36.72 \%$ & $-40.27 \%$ & $-6.71 \%$ & $5.66 \%$ & $39.10 \%$ & $131.11 \%$ & & \\
\hline$\triangle \mathrm{ACFR}$ & 282 & 0 & 282 & $2.06 \%$ & $0.98 \%$ & $37.33 \%$ & $-38.92 \%$ & $-5.14 \%$ & $7.73 \%$ & $40.73 \%$ & $197.28 \%$ & & \\
\hline
\end{tabular}


Table 8.2 a (Continued)

Panel B M-estimator K=1.28- winsorized (Probability around 80\%)

\begin{tabular}{|c|c|c|c|c|c|c|c|c|c|c|c|c|c|}
\hline & \multirow{2}{*}{ Count } & \multirow{2}{*}{ Missing } & \multirow{2}{*}{ Valid } & \multirow{2}{*}{ Mean } & \multirow{2}{*}{ Median } & \multirow{2}{*}{$\begin{array}{c}\text { Standard } \\
\text { Deviation }\end{array}$} & \multirow{2}{*}{$\begin{array}{c}\text { Percentile } \\
05\end{array}$} & \multirow{2}{*}{$\begin{array}{c}\text { Percentile } \\
25\end{array}$} & \multirow{2}{*}{$\begin{array}{c}\text { Percentile } \\
75\end{array}$} & \multirow{2}{*}{$\begin{array}{c}\text { Percentile } \\
95\end{array}$} & \multirow{2}{*}{$\begin{array}{c}\text { Percentile } \\
99 \\
\end{array}$} & \multicolumn{2}{|c|}{ level of winsorizing } \\
\hline & & & & & & & & & & & & right tail & left tail \\
\hline MEG_CFR $_{t+3}$ & 282 & 3 & 279 & $12.87 \%$ & $12.47 \%$ & $5.77 \%$ & $3.74 \%$ & $8.67 \%$ & $17.62 \%$ & $21.20 \%$ & $21.20 \%$ & $15.77 \%$ & $11.11 \%$ \\
\hline MEG_CFR $_{t+2}$ & 282 & 2 & 280 & $11.81 \%$ & $11.72 \%$ & $5.60 \%$ & $3.33 \%$ & $7.35 \%$ & $16.19 \%$ & $20.21 \%$ & $20.21 \%$ & $15.71 \%$ & $12.86 \%$ \\
\hline MEG_CFR $_{t+1}$ & 282 & 0 & 282 & $11.41 \%$ & $11.05 \%$ & $5.99 \%$ & $2.00 \%$ & $6.47 \%$ & $16.53 \%$ & $20.22 \%$ & $20.22 \%$ & $14.89 \%$ & $9.57 \%$ \\
\hline MEG_CFR ${ }_{t-1}$ & 282 & 0 & 282 & $11.35 \%$ & $11.22 \%$ & $5.17 \%$ & $3.44 \%$ & $7.14 \%$ & $15.34 \%$ & $19.00 \%$ & $19.00 \%$ & $15.33 \%$ & $9.76 \%$ \\
\hline $\mathrm{MEG}_{-} \mathrm{CFR} \mathrm{t}_{\mathrm{t}-2}$ & 282 & 22 & 260 & $12.27 \%$ & $11.91 \%$ & $5.32 \%$ & $3.86 \%$ & $8.33 \%$ & $16.78 \%$ & $20.09 \%$ & $20.09 \%$ & $16.60 \%$ & $7.55 \%$ \\
\hline MEG_CFR ${ }_{t-3}$ & 282 & 88 & 194 & $13.09 \%$ & $12.56 \%$ & $5.75 \%$ & $3.63 \%$ & $8.54 \%$ & $17.50 \%$ & $21.93 \%$ & $21.93 \%$ & $19.19 \%$ & $10.61 \%$ \\
\hline MAT_CFR ${ }_{t+3}$ & 282 & 3 & 279 & $12.71 \%$ & $12.15 \%$ & $7.34 \%$ & $0.95 \%$ & $7.22 \%$ & $18.98 \%$ & $23.35 \%$ & $23.35 \%$ & $17.20 \%$ & $8.96 \%$ \\
\hline MAT_CFR ${ }_{t+2}$ & 282 & 2 & 280 & $11.61 \%$ & $11.12 \%$ & $7.00 \%$ & $0.32 \%$ & $6.24 \%$ & $17.49 \%$ & $21.92 \%$ & $21.92 \%$ & $15.00 \%$ & $7.50 \%$ \\
\hline MAT_CFR ${ }_{t+1}$ & 282 & 0 & 282 & $10.88 \%$ & $10.52 \%$ & $6.43 \%$ & $0.91 \%$ & $5.81 \%$ & $16.67 \%$ & $20.13 \%$ & $20.13 \%$ & $17.38 \%$ & $11.35 \%$ \\
\hline MAT_CFR ${ }_{t-1}$ & 282 & 0 & 282 & $13.46 \%$ & $12.85 \%$ & $6.10 \%$ & $3.65 \%$ & $8.88 \%$ & $18.33 \%$ & $22.14 \%$ & $22.14 \%$ & $17.77 \%$ & $9.41 \%$ \\
\hline MAT_CFR $t_{t-2}$ & 282 & 22 & 260 & $13.84 \%$ & $13.32 \%$ & $6.82 \%$ & $3.64 \%$ & $8.56 \%$ & $19.15 \%$ & $24.10 \%$ & $24.10 \%$ & $20.00 \%$ & $12.83 \%$ \\
\hline MAT_CFR ${ }_{t-3}$ & 282 & 88 & 194 & $14.38 \%$ & $14.21 \%$ & $6.85 \%$ & $3.73 \%$ & $8.90 \%$ & $20.44 \%$ & $24.11 \%$ & $24.11 \%$ & $25.25 \%$ & $13.64 \%$ \\
\hline & & & & & & & & & & & & $17.51 \%$ & $10.43 \%$ \\
\hline $\mathrm{ACFR}_{\mathrm{t}+3}$ & 282 & 3 & 279 & $0.16 \%$ & $0.17 \%$ & $8.31 \%$ & $-13.09 \%$ & $-4.93 \%$ & $5.57 \%$ & $14.61 \%$ & $20.25 \%$ & & \\
\hline $\operatorname{ACFR}_{\mathrm{t}+2}$ & 282 & 2 & 280 & $0.20 \%$ & $0.54 \%$ & $8.09 \%$ & $-13.29 \%$ & $-5.15 \%$ & $4.80 \%$ & $14.36 \%$ & $19.89 \%$ & & \\
\hline $\operatorname{ACFR}_{t+1}$ & 282 & 0 & 282 & $0.53 \%$ & $0.23 \%$ & $7.70 \%$ & $-12.54 \%$ & $-4.83 \%$ & $5.17 \%$ & $14.21 \%$ & $19.31 \%$ & & \\
\hline $\mathrm{ACFR}_{\mathrm{t}-1}$ & 282 & 0 & 282 & $-2.11 \%$ & $-1.37 \%$ & $7.24 \%$ & $-13.82 \%$ & $-6.91 \%$ & $2.24 \%$ & $9.94 \%$ & $15.35 \%$ & & \\
\hline $\mathrm{ACFR}_{\mathrm{t}-2}$ & 282 & 22 & 260 & $-1.57 \%$ & $-0.70 \%$ & $8.21 \%$ & $-16.24 \%$ & $-6.94 \%$ & $3.94 \%$ & $11.62 \%$ & $16.45 \%$ & & \\
\hline $\mathrm{ACFR}_{\mathrm{t}-3}$ & 282 & 88 & 194 & $-1.29 \%$ & $-0.90 \%$ & $8.47 \%$ & $-15.47 \%$ & $-6.74 \%$ & $3.88 \%$ & $12.64 \%$ & $18.20 \%$ & & \\
\hline ACFRpost & 282 & 0 & 282 & $0.31 \%$ & $0.59 \%$ & $7.28 \%$ & $-11.94 \%$ & $-4.83 \%$ & $5.23 \%$ & $12.24 \%$ & $19.31 \%$ & & \\
\hline ACFRpre & 282 & 0 & 282 & $-1.51 \%$ & $-0.70 \%$ & $7.00 \%$ & $-13.74 \%$ & $-5.72 \%$ & $3.18 \%$ & $9.80 \%$ & $13.99 \%$ & & \\
\hline$\triangle \mathrm{ACFR}$ & 282 & 0 & 282 & $1.82 \%$ & $1.73 \%$ & $7.02 \%$ & $-9.97 \%$ & $-2.71 \%$ & $6.49 \%$ & $12.99 \%$ & $18.31 \%$ & & \\
\hline
\end{tabular}

Panel C 20\%- winsorized mean (Probability around 60\%)

\begin{tabular}{|c|c|c|c|c|c|c|c|c|c|c|c|c|c|}
\hline & \multirow{2}{*}{ Count } & \multirow{2}{*}{ Missing } & \multirow{2}{*}{ Valid } & \multirow{2}{*}{ Mean } & \multirow{2}{*}{ Median } & \multirow{2}{*}{$\begin{array}{c}\text { Standard } \\
\text { Deviation }\end{array}$} & \multirow{2}{*}{$\begin{array}{c}\text { Percentile } \\
05 \\
\end{array}$} & \multirow{2}{*}{$\begin{array}{c}\text { Percentile } \\
25 \\
\end{array}$} & \multirow{2}{*}{$\begin{array}{c}\text { Percentile } \\
75 \\
\end{array}$} & \multirow{2}{*}{$\begin{array}{c}\text { Percentile } \\
95 \\
\end{array}$} & \multirow{2}{*}{$\begin{array}{c}\text { Percentile } \\
99 \\
\end{array}$} & \multicolumn{2}{|c|}{ level of winsorizing } \\
\hline & & & & & & & & & & & & right tail & left tail \\
\hline MEG_CFR $_{t+3}$ & 282 & 3 & 279 & $13.12 \%$ & $12.47 \%$ & $4.66 \%$ & $7.32 \%$ & $8.67 \%$ & $17.62 \%$ & $19.72 \%$ & $19.72 \%$ & $20.00 \%$ & $20.00 \%$ \\
\hline MEG_CFR $_{\mathrm{t}+2}$ & 282 & 2 & 280 & $11.83 \%$ & $11.72 \%$ & $4.54 \%$ & $5.79 \%$ & $7.35 \%$ & $16.19 \%$ & $18.09 \%$ & $18.09 \%$ & $20.00 \%$ & $20.00 \%$ \\
\hline MEG_CFR $_{t+1}$ & 282 & 0 & 282 & $11.59 \%$ & $11.05 \%$ & $4.82 \%$ & $5.61 \%$ & $6.47 \%$ & $16.53 \%$ & $18.29 \%$ & $18.29 \%$ & $20.00 \%$ & $20.00 \%$ \\
\hline MEG_CFR $_{t-1}$ & 282 & 0 & 282 & $11.52 \%$ & $11.22 \%$ & $4.24 \%$ & $6.22 \%$ & $7.14 \%$ & $15.34 \%$ & $17.61 \%$ & $17.61 \%$ & $20.00 \%$ & $20.00 \%$ \\
\hline MEG_CFR $_{\mathrm{t}-2}$ & 282 & 22 & 260 & $12.50 \%$ & $11.91 \%$ & $4.29 \%$ & $7.09 \%$ & $8.33 \%$ & $16.78 \%$ & $18.72 \%$ & $18.72 \%$ & $20.00 \%$ & $20.00 \%$ \\
\hline MEG_CFR ${ }_{t-3}$ & 282 & 88 & 194 & $13.17 \%$ & $12.56 \%$ & $4.47 \%$ & $7.68 \%$ & $8.54 \%$ & $17.50 \%$ & $19.55 \%$ & $19.55 \%$ & $20.00 \%$ & $20.00 \%$ \\
\hline MAT_CFR $_{t+3}$ & 282 & 3 & 279 & $12.94 \%$ & $12.15 \%$ & $5.75 \%$ & $5.92 \%$ & $7.22 \%$ & $18.98 \%$ & $20.91 \%$ & $20.91 \%$ & $20.00 \%$ & $20.00 \%$ \\
\hline MAT_CFR $_{t+2}$ & 282 & 2 & 280 & $11.77 \%$ & $11.12 \%$ & $5.64 \%$ & $4.70 \%$ & $6.24 \%$ & $17.49 \%$ & $19.67 \%$ & $19.67 \%$ & $20.00 \%$ & $20.00 \%$ \\
\hline MAT_CFR $_{t+1}$ & 282 & 0 & 282 & $11.32 \%$ & $10.52 \%$ & $5.41 \%$ & $4.88 \%$ & $5.81 \%$ & $16.67 \%$ & $19.32 \%$ & $19.32 \%$ & $20.00 \%$ & $20.00 \%$ \\
\hline MAT_CFR $_{t-1}$ & 282 & 0 & 282 & $13.80 \%$ & $12.85 \%$ & $5.02 \%$ & $7.77 \%$ & $8.88 \%$ & $18.33 \%$ & $20.97 \%$ & $20.97 \%$ & $20.00 \%$ & $20.00 \%$ \\
\hline MAT_CFR $_{t-2}$ & 282 & 22 & 260 & $14.02 \%$ & $13.32 \%$ & $5.71 \%$ & $6.97 \%$ & $8.56 \%$ & $19.15 \%$ & $22.41 \%$ & $22.41 \%$ & $20.00 \%$ & $20.00 \%$ \\
\hline \multirow[t]{2}{*}{ MAT_CFR $_{t-3}$} & 282 & 88 & 194 & $15.15 \%$ & $14.21 \%$ & $6.24 \%$ & $8.11 \%$ & $8.90 \%$ & $20.44 \%$ & $24.85 \%$ & $24.85 \%$ & $20.00 \%$ & $20.00 \%$ \\
\hline & & & & & & & & & & & & $20.00 \%$ & $20.00 \%$ \\
\hline $\mathrm{ACFR}_{\mathrm{t}+3}$ & 282 & 3 & 279 & $0.19 \%$ & $0.47 \%$ & $6.64 \%$ & $-11.24 \%$ & $-3.53 \%$ & $4.36 \%$ & $12.22 \%$ & $13.80 \%$ & & \\
\hline $\mathrm{ACFR}_{\mathrm{t}+2}$ & 282 & 2 & 280 & $0.05 \%$ & $0.53 \%$ & $6.59 \%$ & $-11.38 \%$ & $-4.85 \%$ & $4.11 \%$ & $12.04 \%$ & $13.39 \%$ & & \\
\hline $\operatorname{ACFR}_{t+1}$ & 282 & 0 & 282 & $0.27 \%$ & $0.52 \%$ & $6.47 \%$ & $-11.64 \%$ & $-3.43 \%$ & $4.70 \%$ & $11.95 \%$ & $13.41 \%$ & & \\
\hline $\mathrm{ACFR}_{\mathrm{t}-1}$ & 282 & 0 & 282 & $-2.29 \%$ & $-1.55 \%$ & $6.14 \%$ & $-13.17 \%$ & $-6.16 \%$ & $1.86 \%$ & $8.42 \%$ & $9.84 \%$ & & \\
\hline $\mathrm{ACFR}_{\mathrm{t}-2}$ & 282 & 22 & 260 & $-1.52 \%$ & $-0.56 \%$ & $6.86 \%$ & $-14.51 \%$ & $-6.23 \%$ & $3.38 \%$ & $9.96 \%$ & $11.75 \%$ & & \\
\hline $\mathrm{ACFR}_{\mathrm{t}-3}$ & 282 & 88 & 194 & $-1.98 \%$ & $-0.90 \%$ & $7.30 \%$ & $-15.41 \%$ & $-6.43 \%$ & $2.79 \%$ & $10.54 \%$ & $11.43 \%$ & & \\
\hline ACFRpost & 282 & 0 & 282 & $0.10 \%$ & $0.72 \%$ & $6.05 \%$ & $-10.79 \%$ & $-3.63 \%$ & $3.85 \%$ & $10.16 \%$ & $13.41 \%$ & & \\
\hline ACFRpre & 282 & 0 & 282 & $-1.70 \%$ & $-1.37 \%$ & $5.88 \%$ & $-11.98 \%$ & $-5.51 \%$ & $2.43 \%$ & $7.60 \%$ & $10.26 \%$ & & \\
\hline$\triangle \mathrm{ACFR}$ & 282 & 0 & 282 & $1.80 \%$ & $1.79 \%$ & $5.79 \%$ & $-7.60 \%$ & $-1.76 \%$ & $5.42 \%$ & $10.76 \%$ & $15.75 \%$ & & \\
\hline
\end{tabular}


Table 8.2 b Outlier Robustness Test: Trimming at different estimators

Sample of 282 mergers and acquisitions by 222 acquiring firms in 11 English Origin countries (Australia, Canada, India, Ireland, Israel, Malaysia, New Zealand, Singapore, South Africa, Thailand and United Kingdom) between 1997 and 2001 for completed transactions over US\$10 million are obtained from the Thomson Financial Securities Data's SDC PlatinumTM Worldwide Mergers \& Acquisitions Database. Operating cash flow return (OCFR) is calculated as operating cash flow divided by market value of asset. Operating cash flow is defined as operating income before depreciation. Post acquisition performance for each deal is measured by the operating cash flow return of the surviving acquirer after transaction. Pre acquisition performance is calculated as a weighted-average of the operating cash flow return for the bidder and the target included (MEGi pre and post). The weights are based on the market values of assets of both companies in the year before acquisition. Post and pre acquisition performances of the matched firms are measured as weighted-average of the operating cash flow rates (MATi pre and post). ACFRpre and ACFRpost is the pre and post industry, size, and pre performance adjusted cash flow return. $\triangle \mathrm{ACFR}$ is for the change in industry, size, and pre performance adjusted cash flow return.

Panel A $\mu \pm 2 \sigma$ - trimmed (probability around $95.44 \%$ )

\begin{tabular}{|c|c|c|c|c|c|c|c|c|c|c|c|c|c|}
\hline & \multirow{2}{*}{ Count } & \multirow{2}{*}{ Missing } & \multirow{2}{*}{ Valid } & \multirow{2}{*}{ Mean } & \multirow{2}{*}{ Median } & \multirow{2}{*}{$\begin{array}{l}\text { Standarc } \\
\text { Deviatio }\end{array}$} & \multirow{2}{*}{$\begin{array}{c}\text { Percentile } \\
05 \\
\end{array}$} & \multirow{2}{*}{$\begin{array}{c}\text { Percentile } \\
25 \\
\end{array}$} & \multirow{2}{*}{$\begin{array}{c}\text { Percentile } \\
75 \\
\end{array}$} & \multirow{2}{*}{$\begin{array}{c}\text { Percentile } \\
95 \\
\end{array}$} & \multirow{2}{*}{$\begin{array}{c}\text { Percentile } \\
99 \\
\end{array}$} & \multicolumn{2}{|c|}{ level of trimming } \\
\hline & & & & & & & & & & & & right tail & left tail \\
\hline ACFRpost & 258 & 0 & 258 & $-0.08 \%$ & $0.53 \%$ & $10.53 \%$ & $-16.37 \%$ & $-6.71 \%$ & $6.22 \%$ & $16.56 \%$ & $21.70 \%$ & $2.48 \%$ & $2.13 \%$ \\
\hline ACFRpre & 258 & 0 & 258 & $-0.82 \%$ & $-0.68 \%$ & $26.45 \%$ & $-31.51 \%$ & $-5.85 \%$ & $4.90 \%$ & $26.37 \%$ & $98.68 \%$ & $2.09 \%$ & $2.44 \%$ \\
\hline$\triangle \mathrm{ACFR}$ & 270 & 0 & 270 & $-0.31 \%$ & $0.94 \%$ & $29.61 \%$ & $-31.65 \%$ & $-4.95 \%$ & $7.54 \%$ & $31.77 \%$ & $94.87 \%$ & $2.48 \%$ & $1.77 \%$ \\
\hline
\end{tabular}

Panel B M-estimator K=1.28- trimmed (Probability around 80\%)

\begin{tabular}{|c|c|c|c|c|c|c|c|c|c|c|c|c|c|}
\hline & \multirow{2}{*}{ Count } & \multirow{2}{*}{ Missing } & \multirow{2}{*}{ Valid } & \multirow{2}{*}{ Mean } & \multirow{2}{*}{ Median } & \multirow{2}{*}{$\begin{array}{c}\text { Standard } \\
\text { Deviatio } \\
\end{array}$} & \multirow{2}{*}{$\begin{array}{c}\text { Percentile } \\
05\end{array}$} & \multirow{2}{*}{$\begin{array}{c}\text { Percentile } \\
25 \\
\end{array}$} & \multirow{2}{*}{$\begin{array}{c}\text { Percentile } \\
75 \\
\end{array}$} & \multirow{2}{*}{$\begin{array}{c}\text { Percentile } \\
95 \\
\end{array}$} & \multirow{2}{*}{$\begin{array}{c}\text { Percentile } \\
99 \\
\end{array}$} & \multicolumn{2}{|c|}{\begin{tabular}{|l|} 
level of winsorizing \\
\end{tabular}} \\
\hline & & & & & & & & & & & & right tail & left tail \\
\hline ACFRpost & 169 & 0 & 169 & $0.62 \%$ & $0.80 \%$ & $6.30 \%$ & $-10.35 \%$ & $-3.82 \%$ & $5.31 \%$ & $11.47 \%$ & $13.65 \%$ & $10.64 \%$ & $12.06 \%$ \\
\hline ACFRpre & 169 & 0 & 169 & $-0.26 \%$ & $-0.65 \%$ & $5.21 \%$ & $-9.75 \%$ & $-3.92 \%$ & $3.36 \%$ & $8.23 \%$ & $10.75 \%$ & $13.24 \%$ & $17.42 \%$ \\
\hline$\triangle \mathrm{ACFR}$ & 241 & 0 & 241 & $1.08 \%$ & $0.78 \%$ & $5.62 \%$ & $-8.61 \%$ & $-2.41 \%$ & $5.19 \%$ & $10.65 \%$ & $13.00 \%$ & $6.74 \%$ & $7.80 \%$ \\
\hline
\end{tabular}

Panel C 20\%-trimmed mean (Probability around 60\%)

\begin{tabular}{|c|c|c|c|c|c|c|c|c|c|c|c|c|c|}
\hline & \multirow{2}{*}{ Count } & \multirow{2}{*}{ Missing } & \multirow{2}{*}{ Valid } & \multirow{2}{*}{ Mean } & \multirow{2}{*}{ Median } & \multirow{2}{*}{$\begin{array}{l}\text { Standarc } \\
\text { Deviatio }\end{array}$} & \multirow{2}{*}{$\begin{array}{c}\text { Percentile } \\
05\end{array}$} & \multirow{2}{*}{$\begin{array}{c}\text { Percentile } \\
25\end{array}$} & \multirow{2}{*}{$\begin{array}{c}\text { Percentile } \\
75\end{array}$} & \multirow{2}{*}{$\begin{array}{c}\text { Percentile } \\
95\end{array}$} & \multirow{2}{*}{$\begin{array}{c}\text { Percentile } \\
99\end{array}$} & \multicolumn{2}{|c|}{ level of winsorizing } \\
\hline & & & & & & & & & & & & right tail & left tail \\
\hline ACFRpost & 119 & 0 & 119 & $0.34 \%$ & $0.68 \%$ & $4.65 \%$ & $-7.02 \%$ & $-3.18 \%$ & $3.64 \%$ & $7.47 \%$ & $8.34 \%$ & $20 \% \%$ & $20.0 \%$ \\
\hline ACFRpre & 119 & 0 & 119 & $-0.88 \%$ & $-1.21 \%$ & $4.00 \%$ & $-6.89 \%$ & $-3.96 \%$ & $2.48 \%$ & $6.24 \%$ & $7.06 \%$ & $20.0 \%$ & $20.0 \%$ \\
\hline$\triangle \mathrm{ACFR}$ & 170 & 0 & 170 & $1.17 \%$ & $0.98 \%$ & $4.79 \%$ & $-6.51 \%$ & $-2.39 \%$ & $5.39 \%$ & $9.10 \%$ & $9.85 \%$ & $20.0 \%$ & $20.0 \%$ \\
\hline
\end{tabular}

Subsequently, the whole set of regression models (model 1 to model 9.1) is re-run in order to test the effects of these various estimators and methods. To make the comparison easier, table 8.3 summarizes the variables according to the significance in regression results; table 8.4 to table 8.8 displays the details. First of all, it is clear that no matter whether applying the measures of $\mu \pm 2 \sigma$, M-estimator with $K=1.28$ or 20 percent to deal with the outliers, the regression results of most empirical models are relatively stable through the winsorizing method. That is, all models stay with significance in table 8.4 for $\mu \pm 2 \sigma$ winsorized, in table 8.5 for 20-percent winsorized (except model 1,5 and 6 for $\triangle \mathrm{ACFR}$ ), and in table 6.4-6.7 as main analysis. But the explanatory power of models lose significance by using $\mu \pm 2 \sigma$ trimmed for $\triangle \mathrm{ACFR}$ (all models in table 8.6 , panel B), M-estimator with $\mathrm{K}=1.28$ trimmed for $\triangle \mathrm{ACFR}$ (model 2, 5, 6 in table 8.7, panel B) and 20-percent trimmed for $\triangle$ ACFR (all models except model 7, 8, 8,1 in table 8.8, panel B). 
Secondly, setting the breakdown point at $\mu \pm 2 \sigma$, as the statistics results show, is simply not enough to eliminate the contaminating data. Therefore, even though there are some signals for the ownership variables (CONCEN20, CONCEN1020 in table 8.4), the non-linear relationship (model 5-8) between ownership and both performance measures is hard to realize until using M-estimator with $\mathrm{K}=1.28$ or 20 percent- winsorized /trimmed mean estimator. Third, unlike the stable cube relationship between ownership and both performance measures by using the winsorizing method (model 7 in table 6.4-6.6 and table 8.5 for 20 percent-winsorized), a particular square relationship is observed between ownership and only post operating performance (ACFRpost) by using the trimming approach (model 6 in panel A for ACFRpost in table 8.6 M-estimator with $\mathrm{K}=1.28$ trimmed and 8.720 percent-trimmed).

Fourth, for governance mechanisms, separation (-), controlling CEO (+) and board size (-) are still the three major governance variables having an impact on acquisition performance as the basic results. For deal characteristics, trimming data may further release information regarding the positive effect of stock payment. Trimming at the 20 percent level can even see that merging with targets from English original countries leads to a better operating performance. Finally, for institutional variables, the initial and revised anti-director right indexes (ANTIDIR, NANTIDIR) generally hold the significantly positive effects on performance measures.

In sum, inferring or declaring a best robust estimator or approach is not the major purpose of this sensitivity test. These experiments are primarily conducted so as to examine the reliability of the basic results. While some differentiation is evident when using a different approach (winsorizing or trimming) to chuck out the different proportion of outliers there are still robust findings in the results. 
Table 8.3 Summary Results of Variables in Regressions with Significance for Outliers Robustness Tests

\begin{tabular}{|c|c|c|c|c|c|c|}
\hline & \multicolumn{2}{|c|}{$\mu \pm 2 \sigma$} & \multicolumn{2}{|c|}{ M-est } & \multicolumn{2}{|c|}{$20 \%$} \\
\hline & ACFR post & $\triangle \mathrm{ACFR}$ & ACFR post & $\triangle \mathrm{ACFR}$ & ACFR post & $\triangle \mathrm{ACFR}$ \\
\hline Winsoried & \multicolumn{2}{|c|}{ Table 8.4} & \multicolumn{2}{|c|}{ Basic (Table 6.4-6.6) } & \multicolumn{2}{|c|}{ Table 8.5} \\
\hline OWN & $\begin{array}{l}\text { CONCEN1020 } \\
\text { CONCEN20 }\end{array}$ & $\begin{array}{l}\text { CONCEN20 } \\
\text { CONCEN2050 }\end{array}$ & $\begin{array}{l}\text { CONCEN1020 } \\
\text { CONCEN20 } \\
\text { CUBE }\end{array}$ & $\begin{array}{l}\text { CONCEN1020 } \\
\text { CONCEN20 } \\
\text { CUBE }\end{array}$ & $\begin{array}{l}\text { CONCEN1020 } \\
\text { CONCEN20 } \\
\text { CUBE }\end{array}$ & $\begin{array}{l}\text { CONCEN1020 } \\
\text { CONCEN20 } \\
\text { CUBE }\end{array}$ \\
\hline GOV & \begin{tabular}{|l|} 
SEP \\
CEOLSH \\
BSIZE
\end{tabular} & $\begin{array}{l}\text { CEOdual } \\
\text { OTHLSH }\end{array}$ & \begin{tabular}{|l} 
SEP \\
CEOLSH \\
BSIZE
\end{tabular} & \begin{tabular}{|l} 
SEP \\
CEOdual \\
BSIZE
\end{tabular} & \begin{tabular}{|l} 
SEP \\
CEOLSH \\
BSIZE
\end{tabular} & \begin{tabular}{|l} 
SEP \\
CEOdual \\
BSIZE
\end{tabular} \\
\hline DEAL & $\begin{array}{l}\text { PAY_stock } \\
\text { SIZE_rel }\end{array}$ & \begin{tabular}{|l} 
IND_rel \\
LEV
\end{tabular} & $\begin{array}{l}\text { COMPETE } \\
\text { SIZE rel }\end{array}$ & $\begin{array}{l}\text { COMPETE } \\
\text { LEV }\end{array}$ & $\begin{array}{l}\text { COMPETE } \\
\text { SIZE rel }\end{array}$ & COMPETE \\
\hline INSTI & $\begin{array}{l}\text { ANTIDIR } \\
\text { ACCTSTD } \\
\text { ANTISDI } \\
\text { PUBENFORCE } \\
\text { NANTIDIR } \\
\end{array}$ & NANTIDIR & \begin{tabular}{|l} 
ANTIDIR \\
PUBENFORCE \\
NANTIDIR
\end{tabular} & \begin{tabular}{|l} 
ANTIDIR \\
NANTIDIR
\end{tabular} & $\begin{array}{l}\text { ANTIDIR } \\
\text { NANTIDIR }\end{array}$ & $\begin{array}{l}\text { ANTIDIR } \\
\text { NANTIDIR }\end{array}$ \\
\hline Trimmed & \multicolumn{2}{|c|}{ Table 8.6} & \multicolumn{2}{|c|}{ Table 8.7} & \multicolumn{2}{|c|}{ Table 8.8} \\
\hline OWN & - & - & SQ & $\begin{array}{l}\text { CONCEN10 } \\
\text { CONCEN1020 } \\
\text { CUBE }\end{array}$ & $\begin{array}{l}\text { CONCEN2050 } \\
\text { SQ }\end{array}$ & CUBE \\
\hline GOV & \begin{tabular}{|l} 
SEP \\
CEOLSH \\
BSIZE
\end{tabular} & - & BSIZE & \begin{tabular}{|l} 
SEP \\
CEOLSH \\
CEOdual \\
BSIZE
\end{tabular} & \begin{tabular}{|l} 
CEOLSH \\
CEOdual \\
BSIZE
\end{tabular} & $\begin{array}{l}\text { CEOdual } \\
\text { BSIZE }\end{array}$ \\
\hline DEAL & PAY_stock & - & - & $\begin{array}{l}\text { PAY_stock } \\
\text { SIZE_rel } \\
\text { LEV }\end{array}$ & \begin{tabular}{|l|} 
TGORI \\
COMPETE \\
SIZE_rel
\end{tabular} & $\begin{array}{l}\text { TGORI } \\
\text { SIZE_rel }\end{array}$ \\
\hline INSTI & $\begin{array}{l}\text { ANTIDIR } \\
\text { ENFORCE } \\
\text { ACCTSTD } \\
\text { PUBENFORCE } \\
\text { NANTIDIR }\end{array}$ & - & |NANTIDIR & $\begin{array}{l}\text { ANTIDIR } \\
\text { XLEG_high } \\
\text { NANTIDIR }\end{array}$ & $\begin{array}{l}\text { ANTIDIR } \\
\text { NANTIDIR }\end{array}$ & $\begin{array}{l}\text { ANTIDIR } \\
\text { NANTIDIR }\end{array}$ \\
\hline
\end{tabular}

See table 5.5 for variable definitions. 
Table 8.4 Ownership Structure, Institutional Mechanisms and Acquiring Firm Performance: Outlier Robustness Test on $\mu \pm 2 \sigma-$ Winsorized

Sample of 282 mergers and acquisitions by 222 acquiring firms in 11 English Origin countries (Australia, Canada, India, Ireland, Israel, Malaysia, New Zealand, Singapore, South Africa, Thailand and United Kingdom) between 1997 and 2001 for completed transactions over US\$ 10 million are obtained from the Thomson Financial Securities Data's SDC PlatinumTM Worldwide Mergers \& Acquisitions Database. ACFRpre and ACFRpost is the pre and post industry, size, and pre performance adjusted cash flow return. $\triangle \mathrm{ACFR}$ is for the change in industry, size, and pre performance adjusted cash flow return. Outliers have been winsorized using $\mu \pm 2 \sigma$ approach. With OLS standard errors. Two tail tests *** denotes significant at the $1 \%$ level, ** significant at the $5 \%$ level, * significant at the $10 \%$ level. See table 5.5 for variable definitions.

Panel A Regressions on Dependent Variable: ACFRpost

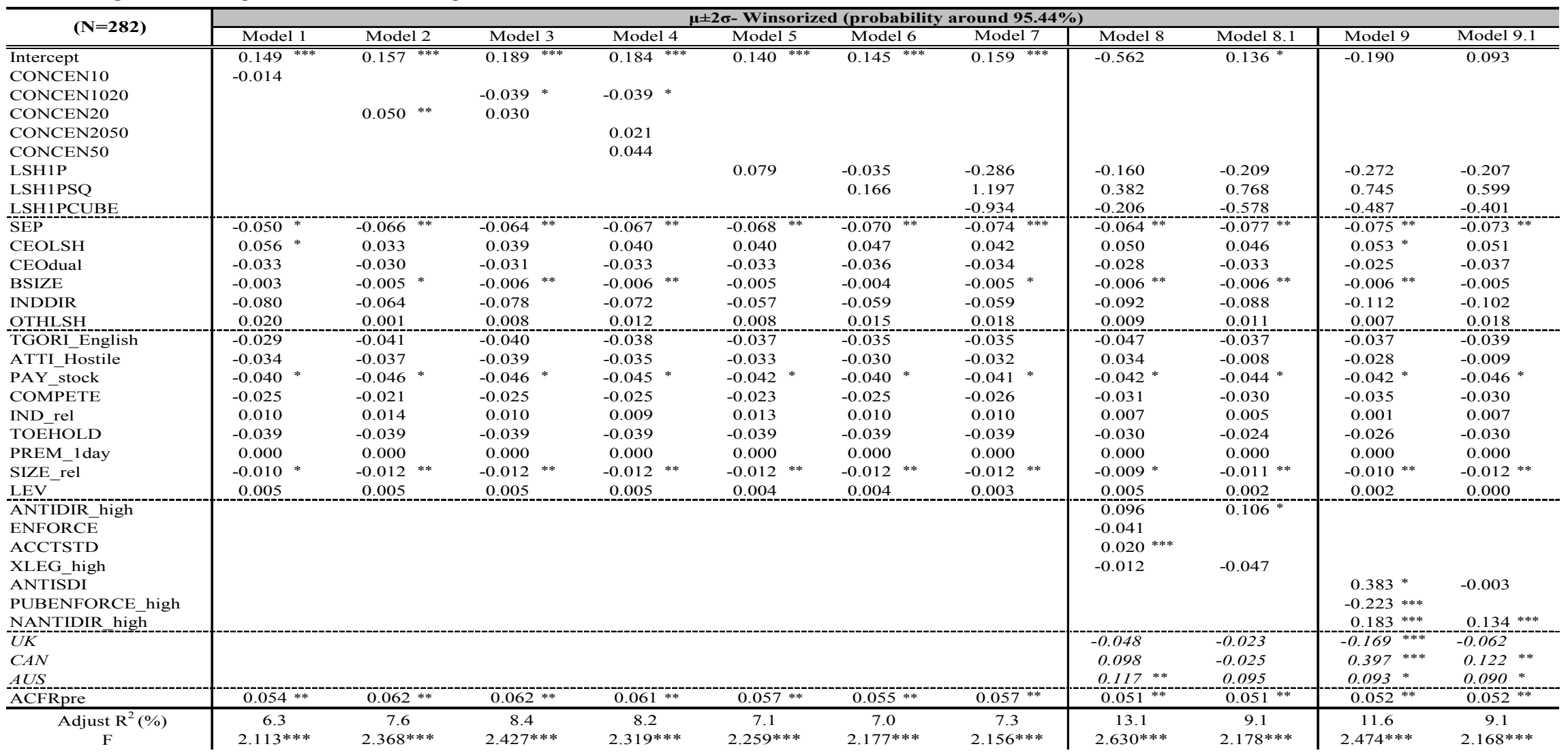


Table 8.4 (Continued)

Panel B Regressions on Dependent Variable: $\triangle$ ACFR

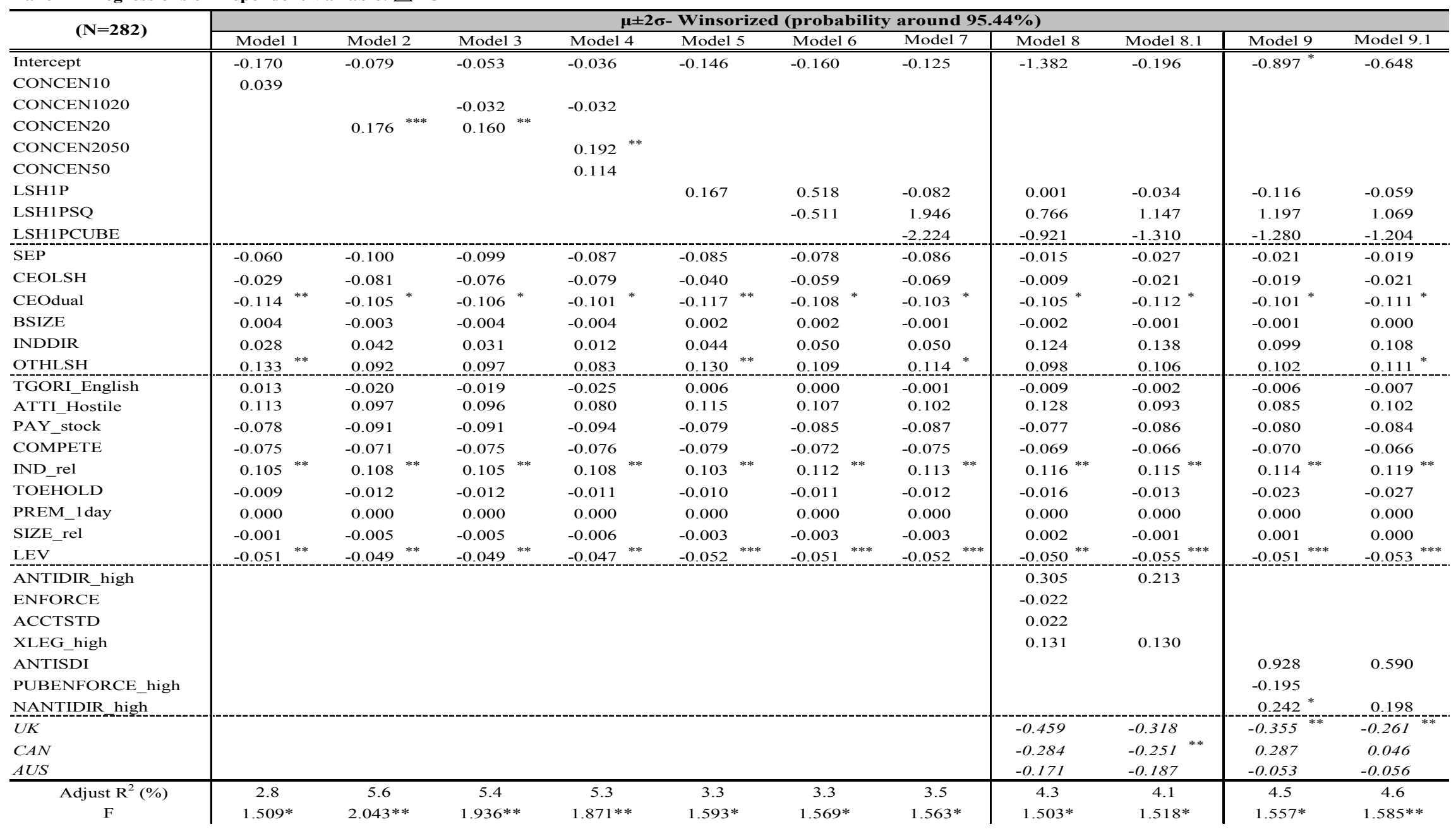


Table 8.5 Ownership Structure, Institutional Mechanisms, and Acquiring Firm Performance: Outlier Robustness Test on 20\%- Winsorized Mean Sample of 282 mergers and acquisitions by 222 acquiring firms in 11 English Origin countries (Australia, Canada, India, Ireland, Israel, Malaysia, New Zealand, Singapore, South Africa, Thailand and United Kingdom) between 1997 and 2001 for completed transactions over US\$ 10 million are obtained from the Thomson Financial Securities Data's SDC PlatinumTM Worldwide Mergers \& Acquisitions Database. ACFRpre and ACFRpost is the pre and post industry, size, and pre performance adjusted cash flow return. $\triangle \mathrm{ACFR}$ is for the change in industry, size, and pre performance adjusted cash flow return. Outliers have been trimmed using $\mu \pm 2 \sigma$ approach. With OLS standard errors. Two tail tests *** denotes significant at the $1 \%$ level, ** significant at the $5 \%$ level, * significant at the $10 \%$ level. See table 5.5 for variable definitions.

Panel A Regressions on Dependent Variable: ACFRpost

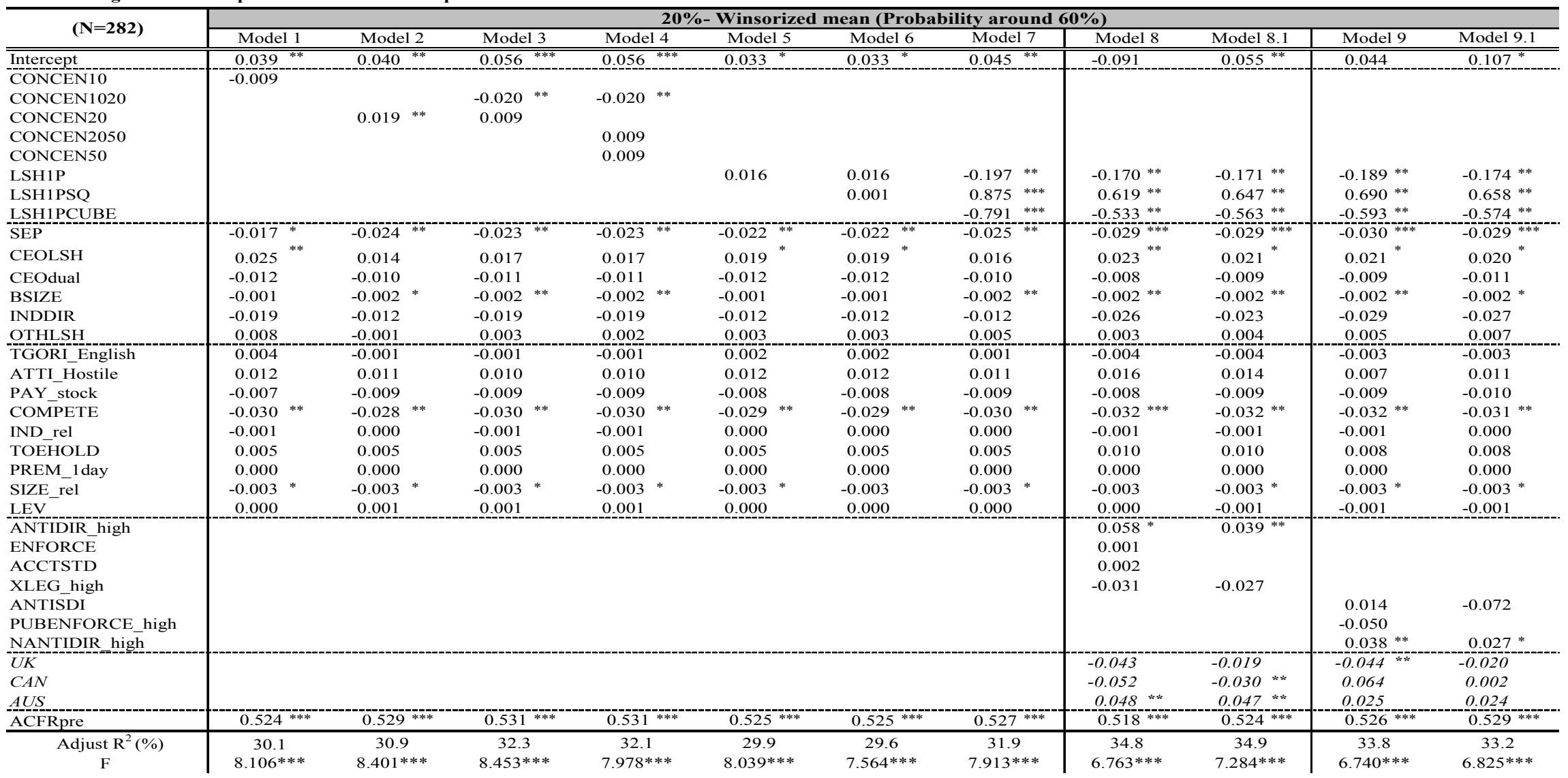


Table 8.5 (Continued)

Panel B Regressions on Dependent Variable: $\triangle$ ACFR

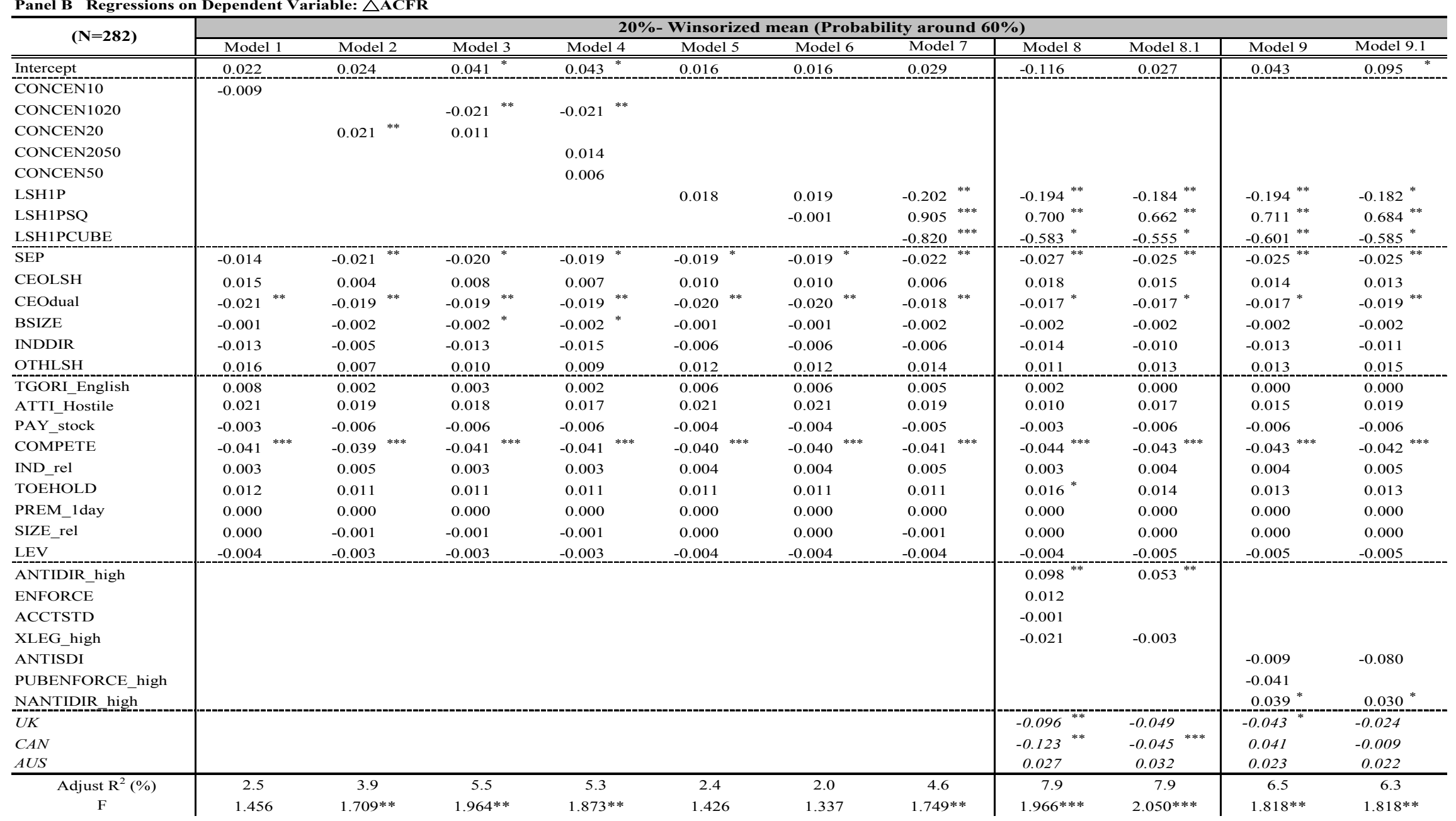


Table 8.6 Ownership Structure, Institutional Mechanisms and Acquiring Firm Performance: Outlier Robustness Test on $\mu \pm 2 \sigma-$ Trimmed

Sample of 282 mergers and acquisitions by 222 acquiring firms in 11 English Origin countries (Australia, Canada, India, Ireland, Israel, Malaysia, New Zealand, Singapore, South Africa, Thailand and United Kingdom) between 1997 and 2001 for completed transactions over US\$ 10 million are obtained from the Thomson Financial Securities Data's SDC PlatinumTM Worldwide Mergers \& Acquisitions Database. ACFRpre and ACFRpost is the pre and post industry, size, and pre performance adjusted cash flow return. $\triangle \mathrm{ACFR}$ is for the change in industry, size, and pre performance adjusted cash flow return. Outliers have been trimmed using $\mu \pm 2 \sigma$ approach. With OLS standard errors. Two tail tests *** denotes significant at the $1 \%$ level, ** significant at the $5 \%$ level, * significant at the $10 \%$ level. See table 5.5 for variable definitions.

\begin{tabular}{|c|c|c|c|c|c|c|c|c|c|c|c|}
\hline \multirow{2}{*}{$\begin{array}{c}\text { (After trimming, } \\
\mathbf{N}=\mathbf{2 5 8} \text { ) }\end{array}$} & \multicolumn{11}{|c|}{$\mu \pm 2 \sigma$ - Trimmed (probability around $95.44 \%$ ) } \\
\hline & Model 1 & Model 2 & Model 3 & Model 4 & Model 5 & Model 6 & Model 7 & Model 8 & Model 8.1 & Model 9 & Model 9.1 \\
\hline Intercept & $0.112^{* * *}$ & $0.115^{* * *}$ & $0.135^{* * *}$ & $0.129^{* * * *}$ & 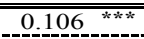 & $0.110^{* * 2}$ & $\begin{array}{c}0.119 \\
-19\end{array}$ & $\begin{array}{ll}-0.386 \\
-3\end{array}$ & $0.114^{* * *}$ & $\begin{array}{ll}-0.098 \\
-2\end{array}$ & (20.128 \\
\hline CONCEN10 & -0.008 & & & & & & & & & & \\
\hline CONCEN1020 & & & -0.023 & -0.022 & & & & & & & \\
\hline CONCEN2O & & 0.025 & 0.014 & & & & & & & & \\
\hline CONCEN2050 & & & & 0.004 & & & & & & & \\
\hline CONCEN50 & & & & 0.031 & & & & & & & \\
\hline LSH1P & & & & & 0.045 & -0.031 & -0.194 & -0.036 & -0.124 & -0.136 & -0.124 \\
\hline LSH1PSQ & & & & & & 0.110 & 0.777 & 0.010 & 0.486 & 0.332 & 0.333 \\
\hline LSH1PCUBE & & & & & & & -0.602 & 0.083 & -0.348 & -0.165 & -0.183 \\
\hline $\mathrm{SEP}$ & -0.011 & -0.020 & -0.020 & -0.024 & -0.021 & -0.023 & -0.026 & -0.028 & $-0.040 *$ & $-0.037 *$ & -0.036 \\
\hline CEOdual & -0.011 & -0.009 & -0.008 & -0.010 & -0.011 & -0.013 & -0.011 & -0.004 & -0.006 & -0.006 & -0.011 \\
\hline BSIZE & $-0.004^{* * *}$ & $-0.005 * *$ & $-0.006^{* * *}$ & $-0.006^{* * * *}$ & $-0.005^{* *}$ & $-0.005^{* *}$ & $-0.005^{* *}$ & $-0.006^{* * * *}$ & $-0.006 * * *$ & $-0.005^{* *}$ & $-0.005^{* *}$ \\
\hline INDDIR & -0.035 & -0.027 & -0.038 & -0.031 & -0.022 & -0.024 & -0.025 & -0.016 & -0.022 & -0.039 & -0.037 \\
\hline OTHLSH & -0.012 & -0.022 & -0.019 & -0.014 & -0.018 & -0.014 & -0.012 & -0.017 & -0.016 & -0.017 & -0.009 \\
\hline TGORI English & -0.016 & -0.023 & -0.022 & -0.020 & -0.021 & -0.020 & -0.020 & -0.035 & -0.026 & -0.027 & -0.028 \\
\hline ATTI Hostile & -0.036 & -0.038 & -0.040 & -0.034 & -0.035 & -0.034 & -0.035 & 0.016 & -0.022 & -0.039 & -0.029 \\
\hline PAY_stock & $-0.035 *$ & $-0.036^{* *}$ & $-0.037^{* * *}$ & $-0.035 *$ & $-0.035^{* *}$ & $-0.034 *$ & $-0.034 *$ & $-0.036 * *$ & $-0.036^{* *}$ & -0.034 * & $-0.038^{* * *}$ \\
\hline COMPETE & -0.005 & -0.002 & -0.005 & -0.003 & -0.002 & -0.004 & -0.005 & -0.007 & -0.009 & -0.012 & -0.011 \\
\hline IND_rel & -0.011 & -0.008 & -0.010 & -0.011 & -0.009 & -0.011 & -0.010 & -0.010 & -0.013 & -0.014 & -0.012 \\
\hline TOEHOLD & -0.023 & -0.024 & -0.023 & -0.023 & -0.024 & -0.023 & -0.023 & -0.020 & -0.013 & -0.017 & -0.019 \\
\hline PREM_1day & 0.000 & 0.000 & 0.000 & 0.000 & 0.000 & 0.000 & 0.000 & 0.000 & 0.000 & 0.000 & 0.000 \\
\hline SIZE_rel & -0.004 & -0.005 & -0.005 & -0.005 & -0.005 & -0.005 & -0.005 & -0.005 & -0.006 & -0.005 & -0.006 \\
\hline ENFORCE & & & & & & & & & & & \\
\hline ACCTSTD & & & & & & & & $0.017^{* * *}$ & & & \\
\hline XLEG_high & & & & & & & & -0.042 & -0.089 & & \\
\hline ANTISDI & & & & & & & & & & 0.201 & -0.080 \\
\hline PUBENFORCE_high & & & & & & & & & & $-0.143 *$ & \\
\hline NANTIDIR high & & & & & & & & & & $0.143^{* * *}$ & $0.089^{* *}$ \\
\hline$U K$ & & & & & & & & 0.009 & 0.030 & $-0.113 \%$ & -0.031 \\
\hline CAN & & & & & & & & 0.083 & -0.044 & $0.248^{* *}$ & 0.057 \\
\hline AUS & & & & & & & & $0.159^{* * *}$ & 0.136 & $0.106^{* * *}$ & $0.093^{* *}$ \\
\hline ACFRpre & $0.083^{* * * k}$ & $0.083^{* \cdots *}$ & $0.082^{* * * k}$ & $0.081^{* \cdots \cdots k}$ & $0.083^{* * x}$ & $0.082^{* * * k}$ & $0.083^{* \cdots k}$ & $0.062 * \cdots$ & $0.068^{* \cdots x}$ & $0.077 * \cdots$ & $0.075^{* * *}$ \\
\hline Adjust $\mathrm{R}^{2}(\%)$ & 6.9 & 7.5 & 7.8 & 7.9 & 7.4 & 7.3 & 7.4 & 16.5 & 11.0 & 9.8 & 9.0 \\
\hline $\mathrm{F}$ & $2.123^{* * *}$ & $2.235^{* * *}$ & $2.214^{* * *}$ & $2.161^{* * *}$ & $2.212^{* * *}$ & $2.122 * * *$ & $2.079^{* * *}$ & $2.957^{* * * *}$ & $2.324 * * *$ & $2.121^{* * *}$ & $2.057 * * *$ \\
\hline
\end{tabular}


Table 8.6 (Continued)

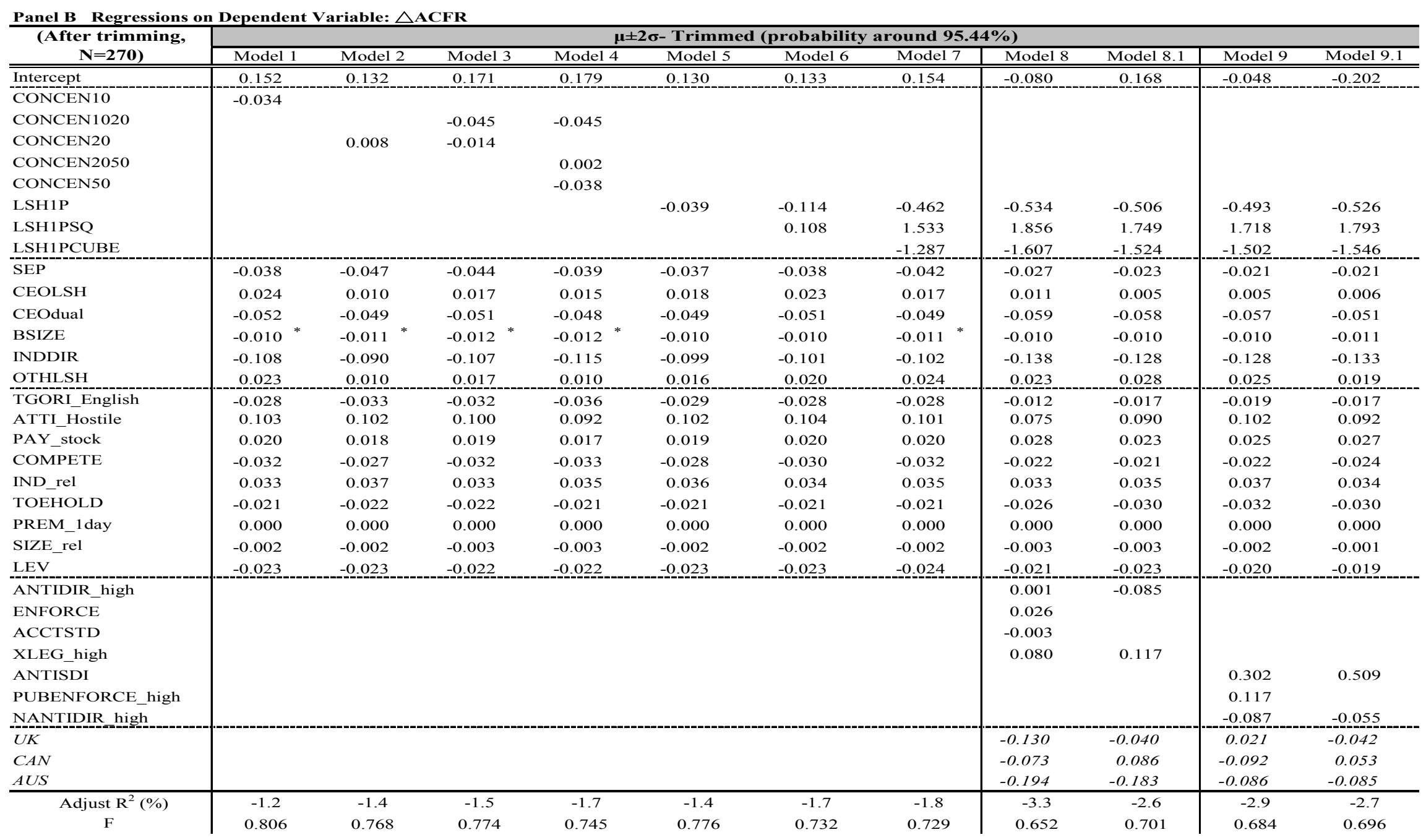


Table 8.7 Ownership Structure, Institutional Mechanisms and Acquiring Firm Performance: Outlier Robustness Test on M-estimator K=1.28 Trimmed Sample of 282 mergers and acquisitions by 222 acquiring firms in 11 English Origin countries (Australia, Canada, India, Ireland, Israel, Malaysia, New Zealand, Singapore, South Africa, Thailand and United Kingdom) between 1997 and 2001 for completed transactions over US\$ 10 million are obtained from the Thomson Financial Securities Data's SDC PlatinumTM Worldwide Mergers \& Acquisitions Database. ACFRpre and ACFRpost is the pre and post industry, size, and pre performance adjusted cash flow return. $\triangle \mathrm{ACFR}$ is for the change in industry, size, and pre performance adjusted cash flow return. Outliers have been trimmed using Huber's M-estimator $\mathrm{K}=1.28$ approach. With OLS standard errors. Two tail tests *** denotes significant at the $1 \%$ level, ** significant at the $5 \%$ level, * significant at the $10 \%$ level. See table 5.5 for variable definitions.

\begin{tabular}{|c|c|c|c|c|c|c|c|c|c|c|c|}
\hline \multirow{2}{*}{$\begin{array}{c}\text { (After trimming, } \\
\mathbf{N}=169)\end{array}$} & \multicolumn{11}{|c|}{ M-estimator K=1.28- Trimmed (Probability around 80\%) } \\
\hline & Model 1 & Model 2 & Model 3 & Model 4 & Model 5 & Model 6 & Model 7 & Model 8 & Model 8.1 & Model 9 & Model 9.1 \\
\hline Intercept & 0.039 & 0.034 & 0.051 & 0.040 & 0.032 & 0.039 & 0.038 & -0.362 & 0.018 & -0.150 & 0.043 \\
\hline CONCEN1O & -0.013 & & & & & & & & & & \\
\hline CONCEN1020 & & & -0.020 & -0.018 & & & & & & & \\
\hline CONCEN2O & & 0.005 & -0.003 & & & & & & & & \\
\hline CONCEN2050 & & & & -0.020 & & & & & & & \\
\hline CONCEN50 & & & & 0.029 & & & & & & & \\
\hline LSH1P & & & & & 0.026 & $-0.203^{* * *}$ & -0.185 & -0.191 & -0.185 & -0.174 & -0.180 \\
\hline LSH1PSQ & & & & & & $0.361^{* * *}$ & 0.283 & 0.167 & 0.168 & 0.101 & 0.166 \\
\hline LSH1PCUBE & & & & & & & 0.074 & 0.215 & 0.206 & 0.265 & 0199 \\
\hline SEP & 0.006 & 0.003 & 0.002 & -0.010 & -0.001 & -0.010 & -0.009 & -0.015 & -0.015 & -0.013 & -0.014 \\
\hline CEOdual & 0.003 & 0.004 & 0.004 & 0.001 & 0.003 & -0.003 & -0.004 & -0.001 & -0.002 & -0.001 & -0.002 \\
\hline BSIZE & $-0.003 *$ & $-0.003^{*}$ & $-0.003^{* * *}$ & $-0.003^{* *}$ & $-0.003 *$ & $-0.003 *$ & $-0.003 *$ & -0.003 & -0.002 & -0.002 & -0.002 \\
\hline INDDIR & 0.038 & 0.045 & 0.036 & $0.047^{*}$ & $0.049^{*}$ & 0.041 & 0.041 & 0.028 & 0.033 & 0.028 & 0.031 \\
\hline OTHLSH & O.005 & _.ooo & O.001 & _.009 & _o.000 & 0.011 & _0.010 & -0.010 & 0.011 & _o.011 & 0.011 \\
\hline TGORI_English & -0.002 & -0.005 & -0.002 & 0.001 & -0.006 & 0.001 & 0.001 & 0.000 & 0.000 & 0.000 & 0.000 \\
\hline ATTI_Hostile & 0.029 & 0.032 & 0.029 & 0.040 & 0.034 & 0.034 & 0.035 & 0.027 & 0.028 & 0.028 & 0.029 \\
\hline PAY_stock & -0.011 & -0.012 & -0.013 & -0.010 & -0.012 & -0.007 & -0.006 & -0.006 & -0.008 & -0.007 & -0.009 \\
\hline COMPETE & 0.005 & 0.008 & 0.004 & 0.007 & 0.008 & -0.004 & -0.004 & -0.009 & -0.009 & -0.008 & -0.008 \\
\hline IND_rel & -0.009 & -0.007 & -0.009 & -0.010 & -0.007 & -0.014 & -0.014 & -0.015 & -0.014 & -0.015 & -0.014 \\
\hline TOEHOLD & -0.002 & -0.005 & -0.003 & -0.005 & -0.005 & -0.002 & -0.002 & -0.001 & -0.001 & -0.001 & -0.002 \\
\hline PREM_1day & 0.000 & 0.000 & 0.000 & 0.000 & 0.000 & 0.000 & 0.000 & 0.000 & 0.000 & 0.000 & 0.000 \\
\hline SIZE_rel & -0.004 & -0.004 & -0.005 & -0.004 & -0.005 & -0.005 & -0.005 & -0.004 & -0.004 & -0.004 & -0.005 \\
\hline ANTIDIR_high & & & & & & & & 0.140 & 0.057 & & \\
\hline ENFORCE & & & & & & & & 0.010 & & & \\
\hline ACCTSTD & & & & & & & & 0.003 & & & \\
\hline XLEG_high & & & & & & & & 0.018 & 0.030 & & \\
\hline ANTISDI & & & & & & & & & & & -0.029 \\
\hline PUBENFORCE_high & & & & & & & & & & -0.111 & \\
\hline NANTIDIR_high̄ & & & & & & & & & & $0.081 *$ & 0.037 \\
\hline$\overline{U K}$ & & & & & & & & -0.162 & -0.070 & -0.097 & -0.017 \\
\hline$C A N$ & & & & & & & & -0.130 & -0.029 & 0.168 & 0.022 \\
\hline AUS & & & & & & & & 0.008 & 0.008 & 0.036 & 0.035 \\
\hline ACFRpre & $0.303^{* * 4 *}$ & $0.291^{* * * *}$ & $0.313^{* * * *}$ & $0.301^{* * * *}$ & $0.290^{* * * * *}$ & $0.321^{* * *}$ & $0.320^{-* * * *}$ & 0.358 **** & $0.359^{* * * *}$ & $0.347^{* * *}$ & $0.347^{* * * *}$ \\
\hline Adjust R $^{2}(\%)$ & 11.1 & 10.4 & 11.2 & 14.3 & 10.7 & 15.9 & 15.4 & 13.9 & 14.5 & 14.3 & 13.9 \\
\hline $\mathrm{F}$ & $2.237 * * *$ & $2.143 * * *$ & $2.180^{* * *}$ & $2.471 * * *$ & $2.188 * * *$ & $2.771 * * *$ & $2.609 * * *$ & $2.039 * * *$ & $2.192 * * *$ & $2.120 * * *$ & $2.129 * * *$ \\
\hline
\end{tabular}


Table 8.7 (Continued)

\begin{tabular}{|c|c|c|c|c|c|c|c|c|c|c|c|}
\hline \multirow{2}{*}{$\begin{array}{c}\text { (After trimming, } \\
\mathbf{N}=\mathbf{2 4 1} \text { ) } \\
\end{array}$} & \multicolumn{11}{|c|}{ M-estimator $\mathrm{K}=1.28$ - Trimmed (Probability around $80 \%$ ) } \\
\hline & Model 1 & Model 2 & Model 3 & Model 4 & Model 5 & Model 6 & Model 7 & Model 8 & Model 8.1 & Model 9 & Model 9.1 \\
\hline Intercept & 0.024 & $\begin{array}{llll}0.017 \\
-2\end{array}$ & (0.042 ${ }^{*}$ & (0.039 * & 0.012 & (0.016 & 0.033 & (0.031 & (-0.006 & (0.023 & 0.042 \\
\hline CONCEN10 & -0.022 & & & & & & & & & & \\
\hline CONCEN1020 & & & $-0.032^{* * *}$ & $-0.032^{* * *}$ & & & & & & & \\
\hline CONCEN2O & & 0.011 & -0.004 & & & & & & & & \\
\hline CONCEN2050 & & & & -0.010 & & & & & & & \\
\hline CONCEN50 & & & & 0.005 & & & & & & & \\
\hline LSH1P & & & & & 0.006 & -0.092 & $-0.366^{* * * *}$ & $-0.372^{* * * *}$ & $-0.373^{* * * *}$ & $-0.345^{* * *}$ & $-0.340^{* * * *}$ \\
\hline LSH1PSQ & & & & & & $0.145^{*}$ & $1.268^{* * * *}$ & $1.169^{* * *}$ & $1.167^{* * * *}$ & $1.099^{* * *}$ & $1.084^{* * * *}$ \\
\hline SEP & -0.005 & -0.013 & -0.011 & -0.013 & -0.011 & -0.012 & -0.015 & $-0.024^{*}$ & $-0.024^{*}$ & $-0.022 *$ & $-0.022 *$ \\
\hline CEOLSH & $0.026^{* *}$ & 0.014 & 0.019 & 0.019 & 0.018 & $0.022^{*}$ & 0.018 & $0.026^{*}$ & $0.026^{* *}$ & $0.023^{*}$ & $0.023^{*}$ \\
\hline CEOdual & $-0.024^{* *}$ & $-0.021^{* *}$ & $-0.023^{* *}$ & $-0.023^{* *}$ & $-0.021^{* *}$ & $-0.024^{* *}$ & $-0.023^{* * *}$ & $-0.020^{* *}$ & $-0.019^{* *}$ & $-0.021^{* *}$ & $-0.021^{* *}$ \\
\hline BSIZE & -0.002 & $-0.002^{*}$ & $-0.003^{* *}$ & $-0.003^{* *}$ & -0.002 & -0.002 & $-0.003^{* * *}$ & $-0.002 *$ & $-0.002 *$ & $-0.003^{* *}$ & $-0.002^{* *}$ \\
\hline INDDIR & 0.018 & 0.030 & 0.018 & 0.021 & 0.029 & 0.028 & 0.024 & 0.012 & 0.011 & 0.017 & 0.018 \\
\hline OTHLSH & 0.007 & -0.002 & 0.004 & 0.006 & 0.000 & 0.006 & 0.009 & 0.010 & 0.009 & 0.010 & 0.011 \\
\hline TGORI_English & 0.014 & 0.009 & 0.011 & 0.012 & 0.010 & 0.012 & 0.013 & 0.011 & 0.011 & 0.010 & 0.009 \\
\hline ATTI_Hostile & 0.015 & 0.014 & 0.013 & 0.015 & 0.015 & 0.017 & 0.015 & 0.007 & 0.007 & 0.018 & 0.020 \\
\hline PAY_stock & $-0.020^{* *}$ & $-0.022^{* *}$ & $-0.021^{* *}$ & $-0.021^{* *}$ & $-0.021^{* *}$ & $-0.019^{*}$ & $-0.019^{*}$ & $-0.020^{* * *}$ & $-0.019^{* *}$ & $-0.021^{* *}$ & $-0.021^{* *}$ \\
\hline COMPETE & -0.006 & -0.002 & -0.005 & -0.004 & -0.003 & -0.003 & -0.008 & -0.015 & -0.015 & -0.013 & -0.013 \\
\hline IND_rel & -0.007 & -0.005 & -0.008 & -0.008 & -0.006 & -0.007 & -0.007 & -0.009 & -0.009 & -0.008 & -0.008 \\
\hline PREM_1day & 0.000 & 0.000 & 0.000 & 0.000 & 0.000 & 0.000 & 0.000 & 0.000 & 0.000 & 0.000 & 0.000 \\
\hline SIZE_rel & $-0.004^{*}$ & $-0.004^{*}$ & $-0.004^{*}$ & $-0.004^{*}$ & $-0.004 *$ & $-0.004 *$ & $-0.004 *$ & $-0.004 *$ & $-0.004^{*}$ & $-0.004 *$ & $-0.004^{*}$ \\
\hline LEV & -0.004 & -0.004 & -0.004 & -0.004 & -0.004 & -0.005 & -0.005 & $-0.006^{* *}$ & $-0.006^{* * *}$ & $-0.006^{* *}$ & $-0.006 * *$ \\
\hline ANTIDIR_high & & & & & & & & 0.056 & 0.064 & & \\
\hline ENFORCE & & & & & & & & -0.001 & & & \\
\hline ACCTSTD & & & & & & & & 0.000 & & & \\
\hline XLEG_high & & & & & & & & 0.053 & 0.050 * & & \\
\hline ANTISDI & & & & & & & & & & -0.023 & -0.050 \\
\hline PUBENFORCE_high & & & & & & & & & & -0.017 & \\
\hline NANTIDIR high & & & & & & & & & & $0.051^{* *}$ & $0.047^{\text {*** }}$ \\
\hline$U K$ & & & & & & & & -0.067 & -0.075 & -0.020 & -0.012 \\
\hline$C A N$ & & & & & & & & -0.003 & -0.015 & 0.051 & 0.031 \\
\hline$A U S$ & & & & & & & & 0.014 & 0.014 & $0.049^{* * *}$ & $0.049^{* *}$ \\
\hline Adjust $\mathrm{R}^{2}(\%)$ & 4.3 & 2.0 & 6.3 & 6.5 & 1.5 & 2.6 & 6.9 & 9.0 & 9.8 & 8.3 & 8.6 \\
\hline $\mathrm{F}$ & $1.681^{*}$ & 1.303 & $1.961^{* *}$ & $1.920^{* *}$ & 1.234 & 1.381 & $1.992 * *$ & $1.944 * * *$ & $2.129 * * *$ & $1.902 * * *$ & $1.980^{* * *}$ \\
\hline
\end{tabular}


Table 8.8 Ownership Structure, Institutional Mechanisms and Acquiring Firm Performance: Outlier Robustness Test on 20\%- Trimmed Mean

Sample of 282 mergers and acquisitions by 222 acquiring firms in 11 English Origin countries (Australia, Canada, India, Ireland, Israel, Malaysia, New Zealand, Singapore, South Africa, Thailand and United Kingdom) between 1997 and 2001 for completed transactions over US\$ 10 million are obtained from the Thomson Financial Securities Data's SDC PlatinumTM Worldwide Mergers \& Acquisitions Database. ACFRpre and ACFRpost is the pre and post industry, size, and pre performance adjusted cash flow return. $\triangle \mathrm{ACFR}$ is for the change in industry, size, and pre performance adjusted cash flow return. Outliers have been trimmed using $20 \%$-mean approach. With OLS standard errors. Two tail tests *** denotes significant at the $1 \%$ level, ** significant at the $5 \%$ level, * significant at the $10 \%$ level. See table 5.5 for variable definitions.

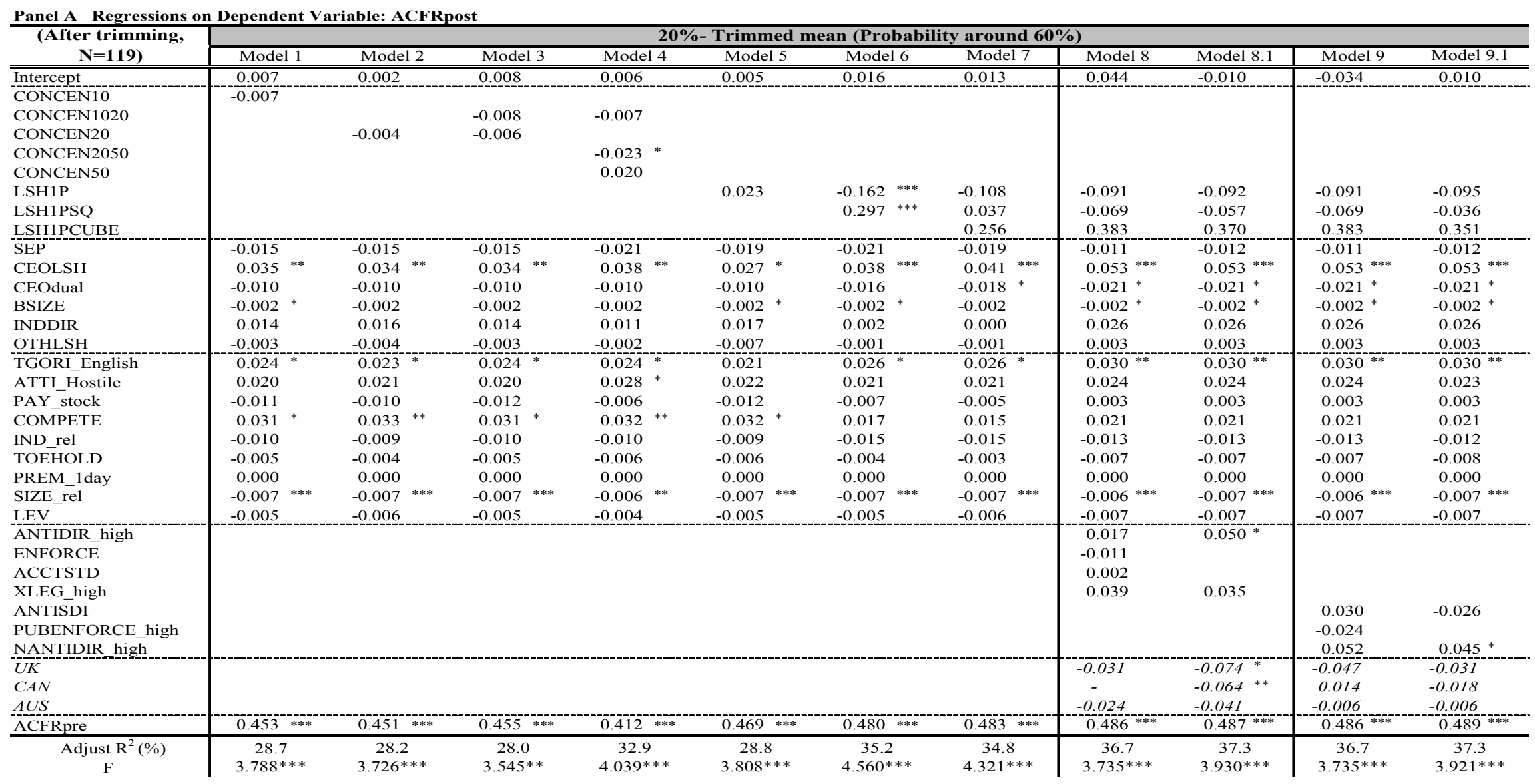


Table 8.8 (Continued)

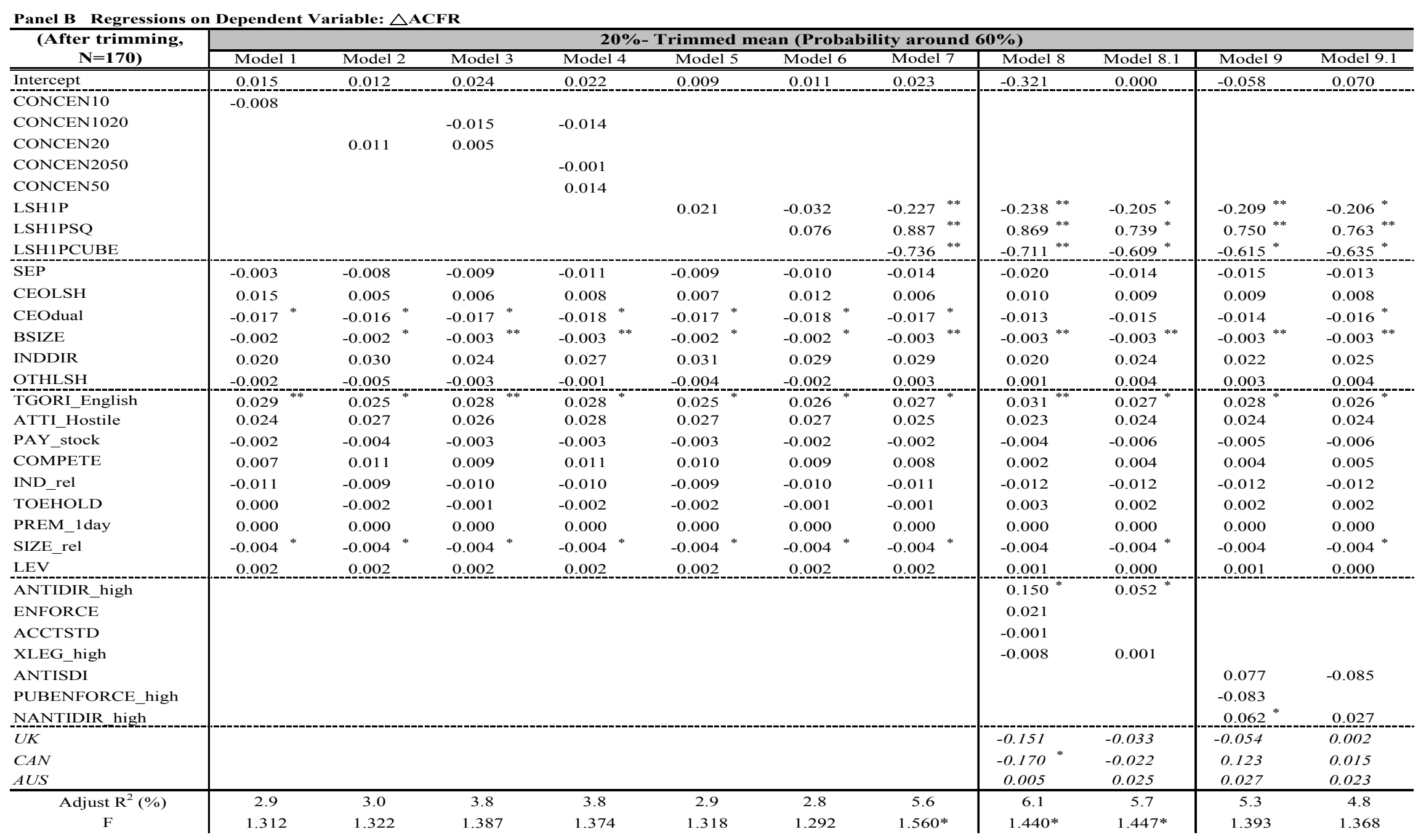




\subsection{Robustness Analysis on Clustering}

\subsubsection{Background Introduction}

Traditional statistical methods for fitting regression models generally assume each observation in the data set is independent. In a sense, this assumption may give substantial bias in parameter and variance estimates when sampling model populations with clustering characteristics. More specifically, when a number of objects are drawn closer to each other than to the rest of the objects, each observation may contain less unique information and the effective sample size can be diminished. If the standard errors are still normally reported, then the unequal probability of selection may distress the size of standard errors because the intra-class correlation (correlation between observations) is different from a Pearson correlation, which exists between two variables. Formally, Rand (1971: p846) defined clustering as of follows.

[[... $\mathrm{X}$ represents the set of $\mathrm{N}$ objects (or points) to be clustered, $X=\left\{X_{1}, X_{2} \cdots, X_{N}\right\}$, and $\mathrm{Y}$, a specific partitioning of these objects into $\mathrm{K}$ disjoint sets. This portioning will be called a clustering and written as a set of clusters, $Y=\left\{Y_{1}, Y_{2} \cdots, Y_{K}\right\}$, where each cluster is a set of the given points, $Y_{k}=\left\{X_{k_{1}}, X_{k_{2}}, \cdots, X_{k_{n}}\right\}$, with $\Sigma n k=N$ and $n k \geqq 1$ for $k=1,2, \cdots K$. The set of all such partitions, for all $k=1,2, \cdots N$, of a given set of $N$ points will be denoted by $Y$.

Wooldridge (2003) gives a more detailed description for the goal of clustering analysis as follows. The goal is to estimate the parameters in the following linear model:

$$
\begin{aligned}
& y_{g m}=\alpha+x_{g} \beta+z_{g m} \gamma+v_{g m} \\
& \qquad m=1, \cdots, M_{g}, g=1, \cdots, G
\end{aligned}
$$

where $g$ indexes the "group" or "cluster," $m$ indexes observations within the group, $\mathrm{M}_{\mathrm{g}}$ is the group size, and $\mathrm{G}$ is the number of groups. [...] The approach to estimation and inference in equation (1) depends on several factors, including whether one is interested in the effects of aggregate variables $(\beta)$ or individual specific $(\gamma)$. Plus, it is necessary to make assumptions about the error terms. An important issue is whether $\mathrm{v}_{\mathrm{gm}}$ contains a common group effect, as in

$$
v_{g m}=c_{g}+u_{g m}
$$

where $c_{\mathrm{g}}$ is an unobserved cluster effect and $\mathrm{u}_{\mathrm{gm}}$ is the idiosyncratic error.

In previous studies, statistics research has attempted to correct standard errors and to develope robust standard error estimators (Quenouille 1949, Huber 1967, White 1980, Efron and Tibshirani 1986, Wu 1986, Greene 1998, Shao and Tu 1995). In general, investigators face two basic questions: how to set up a natural criterion for assigning each clustering a numerical value to indicate its relative appropriateness? And what is the best clustering approach for selecting a suitable subset and for providing estimators with better performance? (Rand 1971) Considering that the mathematical exposition, theoretical estimation or 
performance evaluation has been rigorously discussed and the results made available in many statistical works, the main purpose of doing clustering analysis in this thesis is to examine whether the basic regression results based on an original population with the existence of multiple bidders are still efficient by using the default ordinary least square (OLS) standard errors.

OLS estimators are so called naive estimates that minimize the sum of squared errors and give efficient estimators in ideal conditions under the assumption of homoskedastic errors. However, clustered or correlated data frequently happen in empirical social science research. The population can be separated into several groups (clusters) according to sample characteristics. The clusters are individually independent, but observations within a cluster are internally more homogenous. A typical method used to account for the within-group dependence is to compute Weighted Least Squares (WLS) that may correct the problem of bias in the standard errors and thereby provide reasonably accurate confidence intervals and $\mathrm{p}$ values. However, WLS requires more assumptions and is more difficult to implement (Pfeffermann, Skinner, Holmes and Goldstein 1997, Goldstein 1995). Huber (1967) and White (1980) originally introduced the Huber-White standard error, a more general preferred estimate for corrections of the standard errors. The Huber-White standard error is also called sandwich (Zeger and Liang 1986) or the robust or empirical standard error in the SAS documentation. The clustered robust standard errors are standard errors that are adjusted for the correlation of error terms across observations. The formulas are

$$
V_{\text {cluster }}=\left(X^{\prime} X\right)^{-l} \sum_{j=1}^{n_{c}} \mu_{j}^{\prime} \mu_{j}\left(X^{\prime} X\right)^{-1}
$$

where $\mathrm{n}_{\mathrm{c}}$ is the total number of clusters, $\mu_{j}=\sum_{\text {jcluster }} \mathrm{e}^{\mathrm{i}^{*} \mathrm{Xi}}$ and $\mathrm{e}_{\mathrm{i}}$ is the residual for the $i$ th observation and $\mathrm{xi}$ is a row vector of predictors including the constant.

Since this type of standard error can be applied to estimate the variance of the MLE even when the error structure is non-constant or has more than two levels, they are more popular, once obtained, than other traditional standard error estimates for inferences and hypothesis testing of the econometric mode (Zeger and Liang 1986, Mancl and Leroux 1996, Wooldridge 2003). Fortunately, it is getting easier and faster to compute these standard error estimators with the enhancement of computing power in the last decades. This is true, for example, when using the clustered robust option of standard errors/ robust for linear regression in Stata 9.0, as available in commercial statistical software package. 
The clustered robust standard errors are preferred because they allow general heteroskedasticity and within-cluster error correlation, but at the same time are limited by the cluster size (Wooldridge 2003). In some applications with a small number of clusters (5-30, even 40 or 50 in Angrist and Lavy 2002 study), the clustered robust standard errors are proven to be downwards biased and hypothesis testing based on theses estimators is likely to be over-rejected (Kauermann and Carroll 2001, Bell and McCaffrey 2002). In addition, Freedman (2005) criticizes the use of clustered robust estimators because of underspecification. More clearly, the inferences of clustered robust standard errors are based on an OLS model that is admittedly incorrect. If the model were correct, or nearly correct, there would be no need for sandwiches. This is bias due to specification error. Therefore, when using the robust cluster variance estimator, it's still important for the specification of the model to be reasonable so that the model has a reasonable interpretation and yields good predictions.

Benefiting from the development of high-speed computer technology, several different methods - that are computer-intensive and more reliable - have been introduced for estimating standard errors. The jackknife and the bootstrap are two of the methods that are nowadays widely used in clustering analysis. Again, a large number of theoretical articles have provided statistical inferences built upon these two techniques. Here, this thesis simply reviews some fundamental concepts on the basis of application. The jackknife (Quenouille-Tukey jackknife) was initially proposed by Quenouille (1949) and Tukey (1958). This statistical method is less dependent on model assumptions and does not need the theoretical formula to construct robust standard errors estimators and confidence intervals. Jackknifed statistics are created by systematically dropping out a subset of original data (one at a time) and by assessing the resulting variation in the studied parameter. Rodgers (1999) emphasizes the jackknife procedure that requires randomly re-sampling from the population without any replacement so as to fill the groups with a smaller number of observations in the subset than in the original sample. Sampling n-1 of the original observations generates a basic jackknife estimator called delete-one jackknife. The delete-one jackknife is well known and provides consistent variance estimation for the case of smooth estimators; it does not provide consistent variance estimation for estimators such as the sample quantiles that are generated in functionals which are not smooth enough (Miller 1974, Wu 1986, Shao and Tu 1995). The bootstrap clearly holds a major advantage over the jackknife. 
The Bootstrap is the most recent computer-based method originally referenced by Efron (1979). Like the jackknife, the bootstrap obtains robust standard errors through resampling from the original data. However, instead of recomputing the estimators by deleting observations each time, the bootstrap procedure requires resampling with replacement so as to create samples of the original size (Efron and Tibshirani 1986, Rodgers 1999). While more computation and expensive than the jackknife, the bootstrap can be conveniently applied to nonsmooth functions under general designs (Shao and Tu 1995). In some cases, the jackknife can be used to estimate the accuracy of bootstrap estimates (Efron 1992). The bootstrap is useful, particularly in small size populations, to estimate the entire distribution of an estimator, to correct the bias in a clustering problem, to construct confidence intervals and to test hypotheses (Shao and Tu 1995, Basford and McLachlan 1985). While some critics do not agree that larger sampling frames might improve performance, it is still generally accepted that discontinuities in the distributions around the critical points or the ends of confidence intervals may lead to uncertainty and imprecision (Rodgers 1999). But note that bootstrapping is, like other methods, not a "cure" for small sample sizes. If the sample is too small or un-preventative, resampling with replacement may actually enlarge the problems (Rodgers 1999).

It is not a straightforward process to assess different approaches that are developed at different times with different purposes. Also, there is no absolute scheme with which to measure clustering. The common solution to date is to calculate the clustered robust standard errors, but this method requires a premise that is the number of clusters should be large enough. With the help of a new generation of statistics software, the jackknife and bootstrap techniques have become more appealing and more computationally intensive than the robust option used to approximate standard errors. Since these two methods estimate the variability of a statistic from the variability of that statistic between subsamples, the performance of the jackknife and bootstrap estimators are less susceptible to the violation of model assumptions than the other traditional approach. The jackknife with its flexible sampling weights is easier to apply to complex sampling schemes, such as multi-stage sampling, than the bootstrap. But the bootstrap is a more preferred tool because it gives more accurate distribution estimators than the jackknife histogram, especially for more complicated problems such as estimating sampling distributions and constructing confidence sets. Previous studies have done numerous theoretical and empirical comparisons among different types of standard errors estimators. Much of that work has recommended the bootstrap rather than the others (Beran 
1988, Efron and Gong 1983, Rasmussen 1989, Good 1994). The sensitivity analysis of clustering in this thesis is aimed not at the winner but at whoever has more of an interest in how the results under the different schemes support or challenge the basic conclusions.

\subsubsection{Application to Data}

As mentioned in section 5.2.1 of chapter five, the sample is comprised of 282 deals by 222 acquirers. This means that in the sample there are several transactions created by the same acquiring firms that are called multiple acquirers. In order to control for this, regression models are rerun through estimating cluster robust standard errors. This is a more common correction and can be easily realized by the wide audience. For the convenience of computing facilities, investigation then turns towards whether or not bootstrapping ${ }^{43}$ improves the OLS estimation with cluster standard errors - even when there aren't enough clusters. Both approaches can now be implemented in Stata. Table 8.9 displays the regression results with the default OLS standard errors and these serve as the preliminary regression results as well. Table 8.10 and table 8.11 present the simulations under the clustered-robust and the bootstrap respectively.

In Stata, the regress command includes a robust option for estimating the standard errors using the Huber-White sandwich estimators. With the clustered-robust option, the standard errors account for the intraclass correlation while the estimates of the coefficients are exactly the same as in ordinary OLS. This is because Stata uses a constant similar to a finite population correction (fpc) called a finite sample correction when calculating robust standard errors, while SAS does not. Therefore, when comparing the results of regression with clustered-robust standard errors as it appears in table 8.10 with OLS regression in table 8.9, it seems that slight changes are evident in the standard errors but no changes at all in the coefficients $^{44}$. For example, the coefficient of CONEN20 is 0.024 in OLS regression (panel A of table 8.9) is exactly same as that in regression with clustered-robust standard errors (panel A of table 8.10), but the standard error has a minor increase from 0.0102 in OLS regression to 0.0115 in regression with clustered-robust standard errors.

Considering the assumption of the sample with heteroskedasticity, the robust standard errors may be preferred but with little difference. While the F statistic has also mildly

\footnotetext{
43 Considering the features of jackknife and the numbers of subset sample, this thesis did simulation using the jackknife. The results are not reported but presented in appendix $F$ for reference.

44 The $t$ values and $p$ values are also similar as well but not reported in the table.
} 
changed (e.g. 7.76 of model 1 in panel A table 8.9 to 6.59 in panel A table 8.10), it is not appropriate to make a comparison because it is no longer based on the sum of squares. It becomes a Wald test based on the robustly estimated variance matrix. At the same time, adjust R square is hold (e.g. 29.01 of model 1 in panel of both tables) and still function as a goodness-of-fit statistic but can't use it to obtain F statistics. The root MSE (mean squared error) is also valid but is no longer an estimate of $\sigma$ because there is no single $\sigma$. The signs of control variables in each specification in table 8.9 are all consistent with those in table 8.10. In sum, using robust standard errors in the example does not change any of the conclusions from the original OLS regression; clustering problems caused by dependent acquirers are therefore negligible in the sample.

It is getting relatively simple to run bootstrapping regression using the bootstrap built-in command in new Stata 9.0. All that needed is to identify the cluster variable (set "acquirer" as cluster variable) and then the sample drawn during each replication is a bootstrap sample of clusters. The default number of bootstrap replications to be performed is 50. While 50-200 replications are generally adequate to give a good estimate of standard error, it is necessary to specify the size of clusters in the sample (222) (as in the jackknife regressions report) according to the number of bootstrap replications. Notice that the Stata program here treats bootstrapping regression as random. Simply to say, the program selects bootstrap samples directly from the observations, calculates the statistics for each bootstrap sample, saves the results and do repeats the sequence a large number of times. Finally there are results from each individual replication. This allows bootstrapping regression to be run again and again, and allows standard errors to be recalculated. However, there are slightly different results when bootstrapping runs again; this is because that there is no reason to select the same random samples. Regression here is tested twice and the outcomes are basically similar with little difference. Table 8.11 presents the bootstrapping results obtained on the second run.

Similar to the regressions with clustered-robust standard errors, bootstrapping regression models in Stata are tested by a Wald style test that is based on the chi squared distribution instead of the t-distribution. The program is designed to prevent researchers from running F-tests, which in any event would be incorrect due to the asymptotic nature of the bootstrapping technique. Thus, from table 8.11 it is clear that Wald chi square value for ACFRpost measure ranges between 102.73 of model 7 to 173.24 of model 8.1 and for $\triangle A C F R$ measure ranges between 25.93 of model 5 to 56.85 of model 8.1. All the statistics 
are significant at the 5 percent level, but the values are not compatible with $\mathrm{F}$ statistics in OLS regressions or with regressions with clustered robust standard errors. The bootstrapping regression analysis yields rather similar results to indicate that the basic conclusions are still held even after standard errors are corrected using the bootstrap standard error estimators.

There is a major difference in that the cube relationship between continuous ownership variables and the change operating performance $(\triangle A C F R)$ is losing its importance after controlling institutional variables (i.e. model 8, 9, 8.1 and 9.1 in panel B). This means that controlling shareholders having over a certain amount of voting shares are finding it difficult to expropriate minority shareholders through M\&A transactions when in countries with good legal protection. Indeed, this result is not a surprising find but does more strongly support the trend spotted in the preliminary analyses (see section 6.5.2 for full model results). In statistics technique, a possible reason may because that the bootstrap approach is trying to estimate a population distribution from the sample data; the performance may be not accurate when simulations depend crucially on particular observations.

In table 8.11 the ownership dummy variables still have an effect on both measures. The significance of the cube relationship fade-off may be due to the essential extreme data in both tails as they are generally comprised in continuous variables. Overall, these standard error robustness tests provide results that are equivalent to the basic analysis. Clustering problems caused by multiple acquirers in the sample might be not necessary for consideration because standard linear regression already provides a very good approximation concerning the joint distribution of the regression coefficients. 
Table 8.9 Standard Errors Robustness Test on Default OLS estimators

Sample of 282 mergers and acquisitions by 222 acquiring firms in 11 English Origin countries (Australia, Canada, India, Ireland, Israel, Malaysia, New Zealand, Singapore, South Africa, Thailand and United Kingdom) between 1997 and 2001 for completed transactions over US\$ 10 million are obtained from the Thomson Financial Securities Data's SDC PlatinumTM Worldwide Mergers \& Acquisitions Database. ACFRpre and ACFRpost is the pre and post industry, size, and pre performance adjusted cash flow return. $\triangle$ ACFR is for the change in industry, size, and pre performance adjusted cash flow return. Outliers have been winsorized using Huber's M estimator approach. With the default OLS standard errors below (Italics). Two tail tests *** denotes significant at the $1 \%$ level, $* *$ significant at the $5 \%$ level, * significant at the $10 \%$ level. See table 5.5 for variable definitions.

Panel A Dependent Variable: ACFRpost

\begin{tabular}{|c|c|c|c|c|c|c|c|c|c|c|c|}
\hline \multirow{2}{*}{$(\mathrm{N}=\mathbf{2 8 2})$} & \multicolumn{11}{|c|}{ Default Ordinary Least Square (OLS) estimators } \\
\hline & Model 1 & Model 2 & Model 3 & Model 4 & Model 5 & Model 6 & Model 7 & Model 8 & Model 8.1 & Model 9 & Model 9.1 \\
\hline Intercept & $\begin{array}{l}0.048 \\
0.0230\end{array}$ & $\begin{array}{l}0.050^{* *} \\
0.0225\end{array}$ & $\begin{array}{r}0.070^{* * *} \\
0.0235\end{array}$ & $\begin{array}{r}0.070^{* * *} \\
0.0238\end{array}$ & $\begin{array}{c}0.041 \\
0.0224\end{array}{ }^{*}$ & $\begin{array}{c}0.042 \\
0.0225\end{array}$ & $\begin{array}{l}0.056^{* *} \\
0.0227\end{array}$ & $\begin{array}{c}-0.158 \\
0.1660\end{array}$ & $\begin{array}{l}0.055^{*} \\
0.0303\end{array}$ & $\begin{array}{c}0.020 \\
0.0797\end{array}$ & $\begin{array}{c}0.108 \\
0.0681\end{array}$ \\
\hline CONCEN10 & $\begin{array}{l}-0.012 \\
0.0087\end{array}$ & & & & & & & & & & \\
\hline CONCEN1020 & & & $\begin{array}{l}-0.025^{* * *} \\
0.0095\end{array}$ & $\begin{array}{l}-0.025^{* * *} \\
0.0095\end{array}$ & & & & & & & \\
\hline CONCEN20 & & $\begin{array}{c}0.0244^{* *} \\
0.0102\end{array}$ & $\begin{array}{r}0.012 \\
0.0111\end{array}$ & & & & & & & & \\
\hline CONCEN2050 & & & & $\begin{array}{r}0.012 \\
0.0126\end{array}$ & & & & & & & \\
\hline CONCEN50 & & & & $\begin{array}{r}0.012 \\
0.0141\end{array}$ & & & & & & & \\
\hline LSH1P & & & & & $\begin{array}{r}0.023 \\
0.0209\end{array}$ & $\begin{array}{r}0.006 \\
0.0583\end{array}$ & $\begin{array}{l}-0.234^{* *} \\
0.1011\end{array}$ & $\begin{array}{l}-0.197^{* *} \\
0.0999\end{array}$ & $\begin{array}{l}-0.2011^{* *} \\
0.0996\end{array}$ & $\begin{array}{l}-0.2222^{* *} \\
0.1011\end{array}$ & $\begin{array}{l}-0.202^{* *} \\
0.1013\end{array}$ \\
\hline LSH1PSQ & & & & & & $\begin{array}{r}0.025 \\
0.0794\end{array}$ & $\begin{array}{r}1.012 \\
0.3494\end{array}$ & $\begin{array}{c}0.673 \\
0.3568\end{array}$ & $\begin{array}{l}0.726^{\text {** }} \\
0.3538\end{array}$ & $\begin{array}{l}0.768^{* *} \\
0.3603\end{array}$ & $\begin{array}{l}0.723 \\
0.3620\end{array}$ \\
\hline LSH1PCUBE & & & & & & & $\begin{array}{l}-0.893^{* * *} \\
0.3081\end{array}$ & $\begin{array}{l}-0.553^{*} \\
0.3175\end{array}$ & $\begin{array}{l}-0.609 \text { * } \\
0.3147\end{array}$ & $\begin{array}{l}-0.635^{* *} \\
0.3203\end{array}$ & $\begin{array}{l}-0.608 * \\
0.3221\end{array}$ \\
\hline SEP & $-0.019 *$ & $-0.028^{* *}$ & $-0.027^{* *}$ & $-0.027^{* *}$ & $-0.026^{* *}$ & $-0.026^{* *}$ & $-0.030^{* *}$ & $-0.032^{* *}$ & $-0.033^{* * *}$ & $-0.033^{* * *}$ & $-0.033^{* *}$ \\
\hline CEOLSH & $\begin{array}{r}0.0110 \\
0.025\end{array}$ ** & $\begin{array}{r}0.0112 \\
0.012\end{array}$ & $\begin{array}{r}0.0110 \\
0.016\end{array}$ & $\begin{array}{r}0.0113 \\
0.016\end{array}$ & $\begin{array}{r}0.0117 \\
0.018\end{array}$ & $\begin{array}{r}0.0117 \\
0.019\end{array}$ & $\begin{array}{r}0.0116 \\
0.015\end{array}$ & $\begin{array}{l}0.0127 \\
0.025\end{array}$ & $\begin{array}{c}0.0126 \\
0.022\end{array}$ & $\begin{array}{r}0.0128 \\
0.022\end{array}$ & $\begin{array}{r}0.0129 \\
0.021\end{array}$ \\
\hline & 0.0128 & 0.0130 & 0.0129 & 0.0129 & 0.0128 & 0.0132 & 0.0131 & 0.0135 & 0.0133 & 0.0134 & 0.0134 \\
\hline CEOdual & $\begin{array}{l}-0.015 \\
0.0094\end{array}$ & $\begin{array}{l}-0.013 \\
0.0093\end{array}$ & $\begin{array}{l}-0.013 \\
0.0092\end{array}$ & $\begin{array}{l}-0.013 \\
0.0093\end{array}$ & $\begin{array}{l}-0.014 \\
0.0094\end{array}$ & $\begin{array}{r}-0.015 \\
0.0095\end{array}$ & $\begin{array}{l}-0.013 \\
0.0094\end{array}$ & $\begin{array}{c}-0.011 \\
0.0094\end{array}$ & $\begin{array}{l}-0.012 \\
0.0094\end{array}$ & $\begin{array}{c}-0.011 \\
0.0096\end{array}$ & $\begin{array}{l}-0.015 \\
0.0095\end{array}$ \\
\hline BSIZE & $\begin{array}{l}-0.001 \\
0.0012\end{array}$ & $\begin{array}{l}-0.002 \\
0.0012\end{array}$ & $\begin{array}{l}-0.003 \\
0.0012\end{array}$ & $\begin{array}{l}-0.003 \\
0.0012\end{array}$ ** & $\begin{array}{l}-0.002 \\
0.0012\end{array}$ & $\begin{array}{l}-0.002 \\
0.0012\end{array}$ & $\begin{array}{l}-0.003 \\
0.0012\end{array}$ ** & $\begin{array}{l}-0.003 \text { ** } \\
0.0013\end{array}$ & $\begin{array}{l}-0.003^{* *} \\
0.0013\end{array}$ & $\begin{array}{l}-0.003^{* *} \\
0.0013\end{array}$ & $\begin{array}{l}-0.002 \\
0.0012\end{array}$ \\
\hline INDDIR & -0.023 & -0.013 & -0.022 & -0.022 & -0.013 & -0.013 & -0.013 & -0.027 & -0.023 & -0.031 & -0.028 \\
\hline OTHLSH & $\begin{array}{r}0.0215 \\
0.012 \\
0.0109\end{array}$ & $\begin{array}{r}0.0211 \\
0.001 \\
0.0109\end{array}$ & $\begin{array}{r}0.0211 \\
0.005 \\
0.0109\end{array}$ & $\begin{array}{r}0.0214 \\
0.005 \\
0.0112\end{array}$ & $\begin{array}{r}0.0216 \\
0.006 \\
0.0107\end{array}$ & $\begin{array}{r}0.0216 \\
0.007 \\
0.0112\end{array}$ & $\begin{array}{r}0.0213 \\
0.009 \\
0.0111\end{array}$ & $\begin{array}{c}0.0254 \\
0.005 \\
0.0111\end{array}$ & $\begin{array}{c}0.0252 \\
0.007 \\
0.0109\end{array}$ & $\begin{array}{c}0.0255 \\
0.008 \\
0.0111\end{array}$ & $\begin{array}{c}0.0257 \\
0.011 \\
0.0110\end{array}$ \\
\hline
\end{tabular}




\begin{tabular}{|c|c|c|c|c|c|c|c|c|c|c|c|}
\hline \multirow{2}{*}{ TGORI_English } & 0.004 & -0.003 & -0.002 & -0.002 & 0.001 & 0.001 & 0.001 & -0.005 & -0.004 & -0.004 & -0.004 \\
\hline & 0.0145 & 0.0145 & 0.0143 & 0.0144 & 0.0145 & 0.0146 & 0.0144 & 0.0143 & 0.0142 & 0.0143 & 0.0144 \\
\hline \multirow[t]{2}{*}{ ATTI_Hostile } & 0.009 & 0.007 & 0.006 & 0.006 & 0.009 & 0.009 & 0.007 & 0.016 & 0.012 & 0.005 & 0.011 \\
\hline & 0.0211 & 0.0210 & 0.0208 & 0.0210 & 0.0212 & 0.0212 & 0.0210 & 0.0222 & 0.0213 & 0.0215 & 0.0215 \\
\hline \multirow[t]{2}{*}{ PAY_stock } & -0.010 & -0.013 & -0.013 & -0.013 & -0.011 & -0.011 & -0.011 & -0.011 & -0.013 & -0.012 & -0.013 \\
\hline & 0.0101 & 0.0101 & 0.0099 & 0.0100 & 0.0101 & 0.0102 & 0.0100 & 0.0100 & 0.0098 & 0.0099 & 0.0100 \\
\hline \multirow[t]{2}{*}{ COMPETE } & $-0.035^{* *}$ & $-0.032^{* *}$ & $-0.035^{* *}$ & $-0.035^{* *}$ & $-0.033^{* *}$ & $-0.033^{* *}$ & $-0.035^{* *}$ & $-0.038^{* *}$ & $-0.037^{* *}$ & $-0.037^{* *}$ & $-0.036 * *$ \\
\hline & 0.0153 & 0.0151 & 0.0150 & 0.0150 & 0.0152 & 0.0153 & 0.0151 & 0.0149 & 0.0149 & 0.0150 & 0.0151 \\
\hline \multirow[t]{2}{*}{ IND_rel } & 0.001 & 0.003 & 0.001 & 0.001 & 0.002 & 0.002 & 0.002 & 0.001 & 0.001 & 0.000 & 0.002 \\
\hline & 0.0079 & 0.0077 & 0.0077 & 0.0078 & 0.0078 & 0.0079 & 0.0078 & 0.0077 & 0.0077 & 0.0078 & 0.0078 \\
\hline \multirow[t]{2}{*}{ TOEHOLD } & 0.006 & 0.006 & 0.006 & 0.006 & 0.006 & 0.006 & 0.006 & 0.012 & 0.012 & 0.010 & 0.009 \\
\hline & 0.0104 & 0.0104 & 0.0102 & 0.0103 & 0.0104 & 0.0105 & 0.0103 & 0.0104 & 0.0103 & 0.0103 & 0.0104 \\
\hline \multirow[t]{2}{*}{ PREM_1day } & 0.000 & 0.000 & 0.000 & 0.000 & 0.000 & 0.000 & 0.000 & 0.000 & 0.000 & 0.000 & 0.000 \\
\hline & 0.0001 & 0.0001 & 0.0001 & 0.0001 & 0.0001 & 0.0001 & 0.0001 & 0.0001 & 0.0001 & 0.0001 & 0.0001 \\
\hline \multirow[t]{2}{*}{ SIZE_rel } & $-0.005^{* *}$ & $-0.005^{* *}$ & $-0.006^{* *}$ & $-0.006^{* *}$ & $-0.005^{* *}$ & $-0.005^{* *}$ & $-0.005^{* *}$ & $-0.005^{*}$ & $-0.005 * *$ & $-0.005 * *$ & $-0.005 * *$ \\
\hline & 0.0024 & 0.0024 & 0.0023 & 0.0023 & 0.0024 & 0.0024 & 0.0024 & 0.0023 & 0.0023 & 0.0023 & 0.0024 \\
\hline \multirow[t]{2}{*}{ LEV } & 0.000 & 0.000 & 0.000 & 0.000 & 0.000 & 0.000 & -0.001 & -0.001 & -0.002 & -0.002 & -0.003 \\
\hline & 0.0032 & 0.0032 & 0.0032 & 0.0032 & 0.0032 & 0.0033 & 0.0032 & 0.0033 & 0.0032 & 0.0033 & 0.0033 \\
\hline ANTIDIR_high & & & & & & & & $\begin{array}{l}0.083^{* *} \\
0.0421\end{array}$ & $\begin{array}{l}0.060^{\text {** }} \\
0.0233\end{array}$ & & \\
\hline ENFORCE & & & & & & & & $\begin{array}{l}-0.001 \\
0.0095\end{array}$ & & & \\
\hline ACCTSTD & & & & & & & & $\begin{array}{r}0.003 \\
0.0024\end{array}$ & & & \\
\hline XLEG_high & & & & & & & & -0.028 & -0.024 & & \\
\hline ANTISDI & & & & & & & & & & $\begin{array}{r}0.046 \\
0.0963\end{array}$ & -0.075 \\
\hline PUBENFORCE_high & & & & & & & & & & $\begin{array}{l}0.0963 \\
-0.070 * \\
0.0332\end{array}$ & \\
\hline NANTIDIR_high & & & & & & & & & & $\begin{array}{l}0.061 \\
0.0225 *\end{array}$ & $\begin{array}{l}0.045^{* *} \\
0.0214\end{array}$ \\
\hline$U K^{-}$ & & & & & & & & -0.064 & $-0.033^{-}$ & $-0.062^{* *}$ & -0.029 \\
\hline & & & & & & & & 0.0518 & 0.0338 & 0.0250 & 0.0193 \\
\hline$C A N$ & & & & & & & & -0.061 & $-0.041^{* *}$ & $0.099^{* *}$ & 0.013 \\
\hline & & & & & & & & 0.0625 & 0.0176 & 0.0467 & 0.0225 \\
\hline$A U S$ & & & & & & & & $0.055 *$ & $0.054^{* *}$ & $0.035^{*}$ & $\begin{array}{r}0.034 \\
0.0218\end{array}$ \\
\hline ACFRpre & $0.516^{* * *}$ & $0.518^{* * *}$ & $0.521^{* * *}$ & $0.521^{* * *}$ & $0.514^{* * *}$ & $0.514^{* * *}$ & $0.516^{* * *}$ & $0.503^{* * *}$ & $0.512^{* * *}$ & $0.512 * * *$ & $0.517^{* * *}$ \\
\hline & 0.0566 & 0.0563 & 0.0556 & 0.0559 & 0.0567 & 0.0568 & 0.0560 & 0.0565 & 0.0556 & 0.0557 & 0.0560 \\
\hline Adjust $\mathrm{R}^{2}(\%)$ & 29.01 & 30.00 & 31.59 & 31.33 & 28.86 & 28.62 & 30.57 & 33.85 & 33.74 & 32.82 & 31.94 \\
\hline $\mathrm{F}$ & $7.76^{* * *}$ & $8.08^{* * * *}$ & $8.21^{* * * *}$ & $7.75^{* * * *}$ & $7.71^{* * * *}$ & $7.26^{* * * *}$ & $7.51^{* * * *}$ & $6.53^{* * * *}$ & $6.96^{* * *}$ & $6.49^{* * * *}$ & $6.49^{* * *}$ \\
\hline Root MSE & 0.06132 & 0.06089 & 0.06019 & 0.06031 & 0.06139 & 0.06149 & 0.06064 & 0.05919 & 0.05924 & 0.05965 & 0.06004 \\
\hline
\end{tabular}


Table 8.9 (Continued)

Panel B Dependent Variable: $\triangle \mathrm{ACFR}$

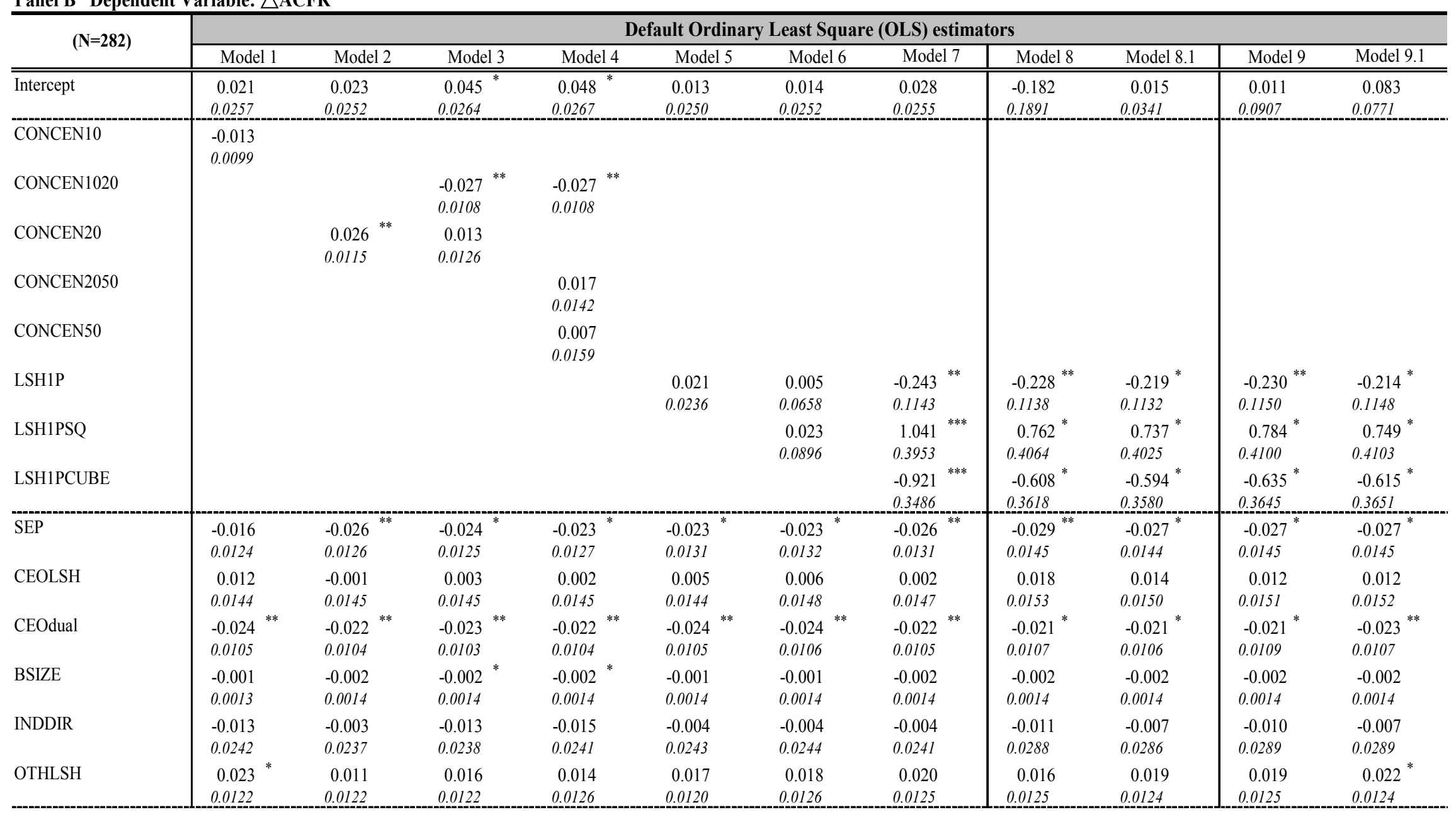




\begin{tabular}{|c|c|c|c|c|c|c|c|c|c|c|c|}
\hline TGORI_English & $\begin{array}{r}0.011 \\
0.0163\end{array}$ & $\begin{array}{r}0.004 \\
0.0163\end{array}$ & $\begin{array}{r}0.004 \\
0.0162\end{array}$ & $\begin{array}{r}0.004 \\
0.0163\end{array}$ & $\begin{array}{r}0.008 \\
0.0164\end{array}$ & $\begin{array}{r}0.008 \\
0.0164\end{array}$ & $\begin{array}{r}0.008 \\
0.0163\end{array}$ & $\begin{array}{r}0.004 \\
0.0163\end{array}$ & $\begin{array}{r}0.002 \\
0.0162\end{array}$ & $\begin{array}{r}0.002 \\
0.0163\end{array}$ & 0.002 \\
\hline ATTI_Hostile & $\begin{array}{r}0.017 \\
0.0238\end{array}$ & $\begin{array}{r}0.014 \\
0.0237\end{array}$ & $\begin{array}{r}0.013 \\
0.0235\end{array}$ & $\begin{array}{r}0.011 \\
0.0237\end{array}$ & $\begin{array}{r}0.017 \\
0.0239\end{array}$ & $\begin{array}{r}0.017 \\
0.0240\end{array}$ & $\begin{array}{r}0.015 \\
0.0237\end{array}$ & $\begin{array}{c}0.008 \\
0.0253\end{array}$ & $\begin{array}{c}0.014 \\
0.0243\end{array}$ & $\begin{array}{l}0.012 \\
0.0245\end{array}$ & $\begin{array}{c}0.017 \\
0.0243\end{array}$ \\
\hline PAY_stock & $\begin{array}{l}-0.007 \\
0.0114\end{array}$ & $\begin{array}{l}-0.010 \\
0.0113\end{array}$ & $\begin{array}{l}-0.010 \\
0.0112\end{array}$ & $\begin{array}{l}-0.010 \\
0.0113\end{array}$ & $\begin{array}{l}-0.008 \\
0.0114\end{array}$ & $\begin{array}{l}-0.007 \\
0.0115\end{array}$ & $\begin{array}{l}-0.008 \\
0.0114\end{array}$ & $\begin{array}{l}-0.006 \\
0.0114\end{array}$ & $\begin{array}{c}-0.009 \\
0.0112\end{array}$ & $\begin{array}{c}-0.009 \\
0.0113\end{array}$ & $\begin{array}{l}-0.010 \\
0.0113\end{array}$ \\
\hline COMPETE & $\begin{array}{l}-0.050 \\
0.0171\end{array}$ & $\begin{array}{l}-0.046^{* * *} \\
0.0170\end{array}$ & $\begin{array}{l}-0.049^{* * *} \\
0.0168\end{array}$ & $\begin{array}{l}-0.050 \\
0.0168\end{array}$ & $\begin{array}{l}-0.048 \\
0.0171\end{array}$ & $\begin{array}{l}-0.048^{* * *} \\
0.0172\end{array}$ & $\begin{array}{l}-0.049^{* * *} \\
0.0170\end{array}$ & $\begin{array}{l}-0.053^{* * *} \\
0.0169^{*}\end{array}$ & $\begin{array}{l}-0.052^{* * *} \\
0.0168\end{array}$ & $\begin{array}{l}-0.052^{* * *} \\
0.0170\end{array}$ & $\begin{array}{l}-0.051^{* * *} \\
0.0170\end{array}$ \\
\hline IND_rel & $\begin{array}{r}0.007 \\
0.0088\end{array}$ & $\begin{array}{r}0.009 \\
0.0087\end{array}$ & $\begin{array}{r}0.007 \\
0.0087\end{array}$ & $\begin{array}{r}0.007 \\
0.0087\end{array}$ & $\begin{array}{r}0.009 \\
0.0088\end{array}$ & $\begin{array}{r}0.008 \\
0.0089\end{array}$ & $\begin{array}{r}0.009 \\
0.0088\end{array}$ & $\begin{array}{c}0.007 \\
0.0088\end{array}$ & $\begin{array}{c}0.008 \\
0.0087\end{array}$ & $\begin{array}{c}0.008 \\
0.0088\end{array}$ & $\begin{array}{c}0.009 \\
0.0088\end{array}$ \\
\hline TOEHOLD & $\begin{array}{r}0.015 \\
0.0117\end{array}$ & $\begin{array}{r}0.015 \\
0.0116\end{array}$ & $\begin{array}{r}0.015 \\
0.0115\end{array}$ & $\begin{array}{r}0.015 \\
0.0115\end{array}$ & $\begin{array}{r}0.015 \\
0.0117\end{array}$ & $\begin{array}{r}0.015 \\
0.0117\end{array}$ & $\begin{array}{r}0.015 \\
0.0116\end{array}$ & $\begin{array}{l}0.021 \\
0.0117\end{array}$ & $\begin{array}{l}0.019^{*} \\
0.0116\end{array}$ & $\begin{array}{l}0.018 \\
0.0117\end{array}$ & $\begin{array}{l}0.017 \\
0.0117\end{array}$ \\
\hline PREM_1day & $\begin{array}{r}0.000 \\
0.0001\end{array}$ & $\begin{array}{r}0.000 \\
0.0001\end{array}$ & $\begin{array}{r}0.000 \\
0.0001\end{array}$ & $\begin{array}{r}0.000 \\
0.0001\end{array}$ & $\begin{array}{r}0.000 \\
0.0001\end{array}$ & $\begin{array}{r}0.000 \\
0.0001\end{array}$ & $\begin{array}{r}0.000 \\
0.0001\end{array}$ & $\begin{array}{c}0.000 \\
0.0001\end{array}$ & $\begin{array}{c}0.000 \\
0.0001\end{array}$ & $\begin{array}{c}0.000 \\
0.0001\end{array}$ & $\begin{array}{c}0.000 \\
0.0001\end{array}$ \\
\hline SIZE_rel & $\begin{array}{l}-0.002 \\
0.0026\end{array}$ & $\begin{array}{l}-0.002 \\
0.0026\end{array}$ & $\begin{array}{l}-0.002 \\
0.0026\end{array}$ & $\begin{array}{l}-0.002 \\
0.0026\end{array}$ & $\begin{array}{l}-0.002 \\
0.0027\end{array}$ & $\begin{array}{l}-0.002 \\
0.0027\end{array}$ & $\begin{array}{l}-0.002 \\
0.0026\end{array}$ & $\begin{array}{l}-0.001 \\
0.0026\end{array}$ & $\begin{array}{l}-0.002 \\
0.0026\end{array}$ & $\begin{array}{l}-0.002 \\
0.0026\end{array}$ & $\begin{array}{l}-0.002 \\
0.0026\end{array}$ \\
\hline LEV & $\begin{array}{r}-0.005 \\
0.0036 \\
\end{array}$ & $\begin{array}{l}-0.005 \\
0.0036\end{array}$ & $\begin{array}{l}-0.005 \\
0.0035 \\
\end{array}$ & $\begin{array}{l}-0.005 \\
0.0036\end{array}$ & $\begin{array}{r}-0.005 \\
0.0036 \\
\end{array}$ & $\begin{array}{r}-0.006 \\
0.0036 \\
\end{array}$ & ${ }^{-0.006^{*}}{ }^{*}$ & $\begin{array}{c}-0.006 \\
0.0037\end{array}$ & ${ }^{-0.007^{* *}}{ }^{*}$ & $\begin{array}{c}-0.007^{*} \\
0.0036\end{array}$ & $-0.008^{* *}$ \\
\hline ANTIDIR_high & & & & & & & & $\begin{array}{l}0.126^{* * *} \\
0.0476\end{array}$ & $\begin{array}{l}0.076^{* * *} \\
0.0265\end{array}$ & & \\
\hline ENFORCE & & & & & & & & $\begin{array}{l}0.012 \\
0.0107\end{array}$ & & & \\
\hline ACCTSTD & & & & & & & & $\begin{array}{c}0.000 \\
0.0026\end{array}$ & & & \\
\hline XLEG_high & & & & & & & & $\begin{array}{c}-0.013 \\
0.0351\end{array}$ & $\begin{array}{l}0.005 \\
0.0316\end{array}$ & & \\
\hline ANTISDI & & & & & & & & & & $\begin{array}{c}0.018 \\
0.1095\end{array}$ & $\begin{array}{c}-0.079 \\
0.0880\end{array}$ \\
\hline PUBENFORCE_high & & & & & & & & & & $\begin{array}{l}-0.056 \\
0.0378\end{array}$ & \\
\hline NANTIDIR_high & & & & & & & & & & $\begin{array}{c}0.062^{* *} \\
0.0256\end{array}$ & $\begin{array}{c}0.049^{* *} \\
0.0243\end{array}$ \\
\hline UK & & & & & & & & $\begin{array}{l}-0.125 \\
0.0584\end{array}$ & $\begin{array}{l}-0.070^{*} \\
0.0381\end{array}$ & $\begin{array}{l}-0.061^{* *} \\
0.0284\end{array}$ & $\begin{array}{l}-0.034 \\
0.0218\end{array}$ \\
\hline$C A N$ & & & & & & & & $\begin{array}{l}-0.141 \\
0.0704\end{array}$ & $\begin{array}{l}-0.058^{* * *} \\
0.0200\end{array}$ & $\begin{array}{c}0.070 \\
0.0530\end{array}$ & $\begin{array}{c}0.000 \\
0.0254\end{array}$ \\
\hline$A U S$ & & & & & & & & $\begin{array}{r}0.027 \\
0.0289 \\
\end{array}$ & $\begin{array}{r}0.032 \\
0.0285\end{array}$ & $\begin{array}{r}0.030 \\
0.0246\end{array}$ & $\begin{array}{r}0.029 \\
0.0247\end{array}$ \\
\hline Adjust $R^{2}(\%)$ & 3.06 & 4.30 & 6.23 & 6.01 & 2.76 & 2.41 & 4.58 & 7.79 & 7.90 & 6.58 & 6.10 \\
\hline F & $1.55^{*}$ & $1.79 * *$ & $2.10 * * *$ & $2.00 * *$ & $1.50^{*}$ & $1.41 *$ & $1.75^{* *}$ & $1.95 * * *$ & $2.05 * * *$ & $1.83 * *$ & $1.80^{* *}$ \\
\hline Root MSE & 0.06916 & 0.06871 & 0.06802 & 0.0681 & 0.06926 & 0.06939 & 0.06861 & 0.06745 & 0.06739 & 0.06789 & 0.06805 \\
\hline
\end{tabular}


Table8.10 Standard Errors Robustness Test on Clustered-Robust Standard Errors Estimators

Sample of 282 mergers and acquisitions by 222 acquiring firms in 11 English Origin countries (Australia, Canada, India, Ireland, Israel, Malaysia, New Zealand, Singapore, South Africa, Thailand and United Kingdom) between 1997 and 2001 for completed transactions over US\$ 10 million are obtained from the Thomson Financial Securities Data's SDC PlatinumTM Worldwide Mergers \& Acquisitions Database. ACFRpre and ACFRpost is the pre and post industry, size, and pre performance adjusted cash flow return. $\triangle \mathrm{ACFR}$ is for the change in industry, size, and pre performance adjusted cash flow return. Outliers have been winsorized using Huber's M estimator approach. With clustered (Robust) standard errors below (Italics). Two tail tests *** denotes significant at the $1 \%$ level, ** significant at the $5 \%$ level, * significant at the $10 \%$ level. See table 5.5 for variable definitions.

Panel A Dependent Variable: ACFRpost

\begin{tabular}{|c|c|c|c|c|c|c|c|c|c|c|c|}
\hline \multirow{2}{*}{$(\mathrm{N}=\mathbf{2 8 2})$} & \multicolumn{11}{|c|}{ Clustered-Robust Standard Errors Estimators } \\
\hline & Model 1 & Model 2 & Model 3 & Model 4 & Model 5 & Model 6 & Model 7 & Model 8 & Model 8.1 & Model 9 & Model 9.1 \\
\hline \multirow[t]{2}{*}{ Intercept } & $0.048^{* *}$ & $0.050^{* *}$ & $0.070^{* * *}$ & $0.070^{* * *}$ & $0.041^{* *}$ & $0.042^{* *}$ & $0.056^{* * *}$ & -0.158 & $0.055^{* *}$ & 0.020 & 0.108 \\
\hline & 0.0222 & 0.0210 & 0.0232 & 0.0231 & 0.0206 & 0.0209 & 0.0216 & 0.1488 & & 0.0966 & 0.0795 \\
\hline CONCEN10 & $\begin{array}{l}-0.012 \\
0.0087\end{array}$ & & & & & & & & & & \\
\hline CONCEN1020 & & & $\begin{array}{l}-0.025^{* * *} \\
0.0093\end{array}$ & $\begin{array}{l}-0.025^{* * *} \\
0.0093\end{array}$ & & & & & & & \\
\hline CONCEN20 & & $\begin{array}{c}0.024^{* *} \\
0.0115\end{array}$ & $\begin{array}{r}0.012 \\
0.0121\end{array}$ & & & & & & & & \\
\hline CONCEN2050 & & & & $\begin{array}{r}0.012 \\
0.0127\end{array}$ & & & & & & & \\
\hline CONCEN50 & & & & $\begin{array}{r}0.012 \\
0.0162\end{array}$ & & & & & & & \\
\hline LSH1P & & & & & 0.023 & 0.006 & $-0.234^{* *}$ & $-0.197 *$ & $-0.200^{* *}$ & $-0.222^{* *}$ & $-0.202 * *$ \\
\hline LSH1PSQ & & & & & 0.0238 & $\begin{array}{r}0.0607 \\
0.025\end{array}$ & $\begin{array}{r}0.1016 \\
1.011^{* * *}\end{array}$ & $\begin{array}{l}0.1021 \\
0.673\end{array}$ & $\begin{array}{l}0.1002 \\
0.725 *\end{array}$ & $\begin{array}{l}0.1012 \\
0.768^{* *}\end{array}$ & $\begin{array}{l}0.1014 \\
0.723 *\end{array}$ \\
\hline LSH1PCUBE & & & & & & 0.0851 & $\begin{array}{r}0.3744 \\
-0.892 \\
0.338\end{array}{ }^{* * *}$ & $\begin{array}{c}0.3895 \\
-0.553 \\
0.355\end{array}$ & $\begin{array}{c}0.3800 \\
-0.608 \\
0.346\end{array}$ & $\begin{array}{c}0.3871 \\
-0.635 \\
0.353\end{array}$ & $\begin{array}{c}0.3844 \\
-0.608 \\
0.350\end{array}$ \\
\hline SEP & -0.019 & $-0.028^{* *}$ & $-0.027^{* *}$ & $-0.027^{* *}$ & $-0.026^{* *}$ & $-0.026^{* *}$ & $-0.030^{* *}$ & $-0.032^{* *}$ & $-0.033^{* *}$ & $-0.033^{* *}$ & $-0.033^{* *}$ \\
\hline CEOLSH & 0.0145 & 0.0152 & 0.0150 & 0.0150 & 0.0150 & 0.0151 & 0.0151 & 0.0162 & 0.0156 & 0.0158 & 0.0157 \\
\hline \multirow[t]{2}{*}{ CEOdual } & -0.015 & -0.013 & -0.013 & -0.013 & -0.014 & -0.015 & -0.013 & -0.011 & -0.012 & -0.011 & -0.015 \\
\hline & 0.0098 & 0.0098 & 0.0098 & 0.0097 & 0.0099 & 0.0098 & 0.0097 & 0.0095 & 0.0096 & 0.0098 & 0.0100 \\
\hline \multirow[t]{2}{*}{ BSIZE } & -0.001 & $-0.002 *$ & $-0.003^{* *}$ & $-0.003^{* *}$ & -0.002 & -0.002 & $-0.003 *$ & $-0.003^{* *}$ & $-0.003^{* *}$ & $-0.003^{* *}$ & $-0.002 *$ \\
\hline & 0.0012 & 0.0014 & 0.0014 & 0.0014 & 0.0013 & 0.0013 & 0.0014 & 0.0014 & 0.0014 & 0.0014 & 0.0014 \\
\hline \multirow[t]{2}{*}{ INDDIR } & -0.023 & -0.013 & -0.022 & -0.022 & -0.013 & -0.013 & -0.013 & -0.027 & -0.023 & -0.031 & -0.028 \\
\hline & 0.0239 & 0.0235 & 0.0234 & 0.0236 & 0.0238 & 0.0239 & 0.0236 & 0.0260 & 0.0262 & 0.0267 & 0.0271 \\
\hline \multirow[t]{2}{*}{ OTHLSH } & 0.012 & 0.001 & 0.005 & 0.005 & 0.006 & 0.007 & 0.009 & 0.005 & 0.007 & 0.008 & 0.011 \\
\hline & 0.0121 & 0.0113 & 0.0115 & 0.0115 & 0.0118 & 0.0118 & 0.0121 & 0.0121 & 0.0119 & 0.0120 & 0.0118 \\
\hline
\end{tabular}




\begin{tabular}{|c|c|c|c|c|c|c|c|c|c|c|c|}
\hline \multirow[t]{2}{*}{ TGORI_English } & 0.004 & -0.003 & -0.002 & -0.002 & 0.001 & 0.001 & 0.001 & -0.005 & -0.004 & -0.004 & -0.004 \\
\hline & 0.0127 & 0.0121 & 0.0124 & 0.0123 & 0.0122 & 0.0122 & 0.0115 & 0.0118 & 0.0115 & 0.0115 & 0.0115 \\
\hline \multirow[t]{2}{*}{ ATTI_Hostile } & 0.009 & 0.007 & 0.006 & 0.006 & 0.009 & 0.009 & 0.007 & 0.016 & 0.012 & 0.005 & 0.011 \\
\hline & 0.0141 & 0.0175 & 0.0170 & 0.0170 & 0.0158 & 0.0155 & 0.0150 & 0.0115 & 0.0125 & 0.0133 & 0.0124 \\
\hline \multirow[t]{2}{*}{ PAY_stock } & -0.010 & -0.013 & -0.013 & -0.013 & -0.011 & -0.011 & -0.011 & -0.011 & -0.013 & -0.012 & -0.013 \\
\hline & 0.0101 & 0.0091 & 0.0093 & 0.0093 & 0.0094 & 0.0097 & 0.0094 & 0.0097 & 0.0094 & 0.0095 & 0.0099 \\
\hline \multirow[t]{2}{*}{ COMPETE } & $-0.035^{* *}$ & $-0.032^{* *}$ & $-0.035^{* *}$ & $-0.035^{* *}$ & $-0.033^{* *}$ & $-0.033^{* *}$ & $-0.035^{* *}$ & $-0.038^{* *}$ & $-0.037^{* *}$ & $-0.037^{* *}$ & $-0.036^{* *}$ \\
\hline & 0.0148 & 0.0142 & 0.0143 & 0.0144 & 0.0143 & 0.0143 & 0.0149 & 0.0149 & 0.0147 & 0.0147 & 0.0147 \\
\hline \multirow[t]{2}{*}{ IND_rel } & 0.001 & 0.003 & 0.001 & 0.001 & 0.002 & 0.002 & 0.002 & 0.001 & 0.001 & 0.000 & 0.002 \\
\hline & 0.0078 & 0.0076 & 0.0075 & 0.0076 & 0.0077 & 0.0080 & 0.0078 & 0.0075 & 0.0075 & 0.0076 & 0.0077 \\
\hline \multirow[t]{2}{*}{ TOEHOLD } & 0.006 & 0.006 & 0.006 & 0.006 & 0.006 & 0.006 & 0.006 & 0.012 & 0.012 & 0.010 & 0.009 \\
\hline & 0.0081 & 0.0082 & 0.0081 & 0.0081 & 0.0082 & 0.0083 & 0.0079 & 0.0081 & 0.0078 & 0.0079 & 0.0080 \\
\hline \multirow[t]{2}{*}{ PREM_1day } & 0.000 & 0.000 & 0.000 & 0.000 & 0.000 & 0.000 & 0.000 & 0.000 & 0.000 & 0.000 & 0.000 \\
\hline & 0.0001 & 0.0002 & 0.0002 & 0.0002 & 0.0001 & 0.0001 & 0.0002 & 0.0001 & 0.0002 & 0.0002 & 0.0002 \\
\hline \multirow[t]{2}{*}{ SIZE_rel } & $-0.005^{* *}$ & $-0.005^{* *}$ & $-0.006^{* *}$ & $-0.006^{* *}$ & $-0.005^{* *}$ & $-0.005^{* *}$ & $-0.005^{* *}$ & $-0.005^{* *}$ & $-0.005^{* *}$ & $-0.005^{* *}$ & $-0.005 * *$ \\
\hline & 0.0023 & 0.0023 & 0.0022 & 0.0022 & 0.0023 & 0.0023 & 0.0022 & 0.0022 & 0.0021 & 0.0022 & 0.0022 \\
\hline \multirow[t]{2}{*}{ LEV } & 0.000 & 0.000 & 0.000 & 0.000 & 0.000 & 0.000 & -0.001 & -0.001 & -0.002 & -0.002 & -0.003 \\
\hline & 0.0034 & 0.0032 & 0.0033 & 0.0033 & 0.0033 & 0.0033 & 0.0034 & 0.0034 & 0.0031 & 0.0033 & 0.0032 \\
\hline ANTIDIR_high & & & & & & & & $\begin{array}{c}0.083^{* *} \\
0.0334\end{array}$ & $\begin{array}{l}0.060^{* * *} \\
0.0203\end{array}$ & & \\
\hline ENFORCE & & & & & & & & $\begin{array}{l}-0.001 \\
0.0067\end{array}$ & & & \\
\hline \multirow{2}{*}{ ACCTSTD } & & & & & & & & 0.003 & & & \\
\hline & & & & & & & & 0.0021 & & & \\
\hline XLEG_high & & & & & & & & $\begin{array}{l}-0.028 \\
0.0283\end{array}$ & $\begin{array}{l}-0.024 \\
0.0240\end{array}$ & & \\
\hline ANTISDI & & & & & & & & & & 0.046 & -0.075 \\
\hline PUBENFORCE_high & & & & & & & & & & $\begin{array}{l}0.1161 \\
-0.070 *\end{array}$ & 0.0933 \\
\hline NANTIDIR_high & & & & & & & & & & $\begin{array}{c}0.0415 \\
0.061 \\
0.0237\end{array}$ & $\begin{array}{l}0.045^{* *} \\
0.0207\end{array}$ \\
\hline \multirow[t]{2}{*}{$\bar{U}$} & & & & & & & & -0.064 & -0.033 & $-0.062^{* *}$ & -0.029 \\
\hline & & & & & & & & 0.0429 & 0.0309 & 0.0288 & 0.0229 \\
\hline \multirow[t]{2}{*}{ CAN } & & & & & & & & -0.061 & $-0.041^{* *}$ & $0.099^{*}$ & 0.013 \\
\hline & & & & & & & & 0.0468 & 0.0194 & 0.0600 & 0.0210 \\
\hline$A U S$ & & & & & & & & $\begin{array}{l}0.055^{* *} \\
0.0240\end{array}$ & $\begin{array}{l}0.054^{* *} \\
0.0243\end{array}$ & $\begin{array}{l}0.035 \\
0.0201\end{array}$ & $\begin{array}{c}0.034^{*} \\
0.0190\end{array}$ \\
\hline ACFRpre & $\begin{array}{l}0.516^{\text {*** }} \\
0.061\end{array}$ & $\begin{array}{l}0.518^{* * *} \\
0.059\end{array}$ & $\begin{array}{l}0.521^{* * *} \\
0.060\end{array}$ & $\begin{array}{l}0.521^{* * *} \\
0.060\end{array}$ & $\begin{array}{l}0.514^{* * *} \\
0.061\end{array}$ & $\begin{array}{l}0.514^{* * *} \\
0.061\end{array}$ & $\begin{array}{l}0.516^{* * *} \\
0.061\end{array}$ & $\begin{array}{l}0.503^{* * *} \\
0.058\end{array}$ & $\begin{array}{l}0.512^{\text {*** }} \\
0.058\end{array}$ & $\begin{array}{l}0.512^{* * *} \\
0.057\end{array}$ & $\begin{array}{l}0.517^{* * *} \\
0.059\end{array}$ \\
\hline Adjust $R^{2}(\%)$ & 29.01 & 30.00 & 31.59 & 31.33 & 28.86 & 28.62 & 30.57 & 33.85 & 33.74 & 32.82 & 31.94 \\
\hline $\mathrm{F}$ & $6.59 * * *$ & $7.02^{* * * *}$ & $7.25^{* * * *}$ & $6.85 * * *$ & $6.56^{* * * *}$ & $6.32 * * *$ & $6.27^{* * *}$ & $7.90^{* * *}$ & $6.97 * * *$ & $6.45^{* * *}$ & $6.72 * * *$ \\
\hline Root MSE & 0.06132 & 0.06089 & 0.06019 & 0.06031 & 0.06139 & 0.06149 & 0.06064 & 0.05919 & 0.05924 & 0.05965 & 0.06004 \\
\hline
\end{tabular}


Table8.10 (Continued)

Panel B Dependent Variable: $\triangle \mathrm{ACFR}$

\begin{tabular}{|c|c|c|c|c|c|c|c|c|c|c|c|}
\hline \multirow{2}{*}{$(\mathrm{N}=\mathbf{2 8 2})$} & \multicolumn{11}{|c|}{ Clustered-Robust Standard Errors Estimators } \\
\hline & Model 1 & Model 2 & Model 3 & Model 4 & Model 5 & Model 6 & Model 7 & Model 8 & Model 8.1 & Model 9 & Model 9.1 \\
\hline \multirow[t]{2}{*}{ Intercept } & 0.021 & 0.023 & 0.045 & 0.048 & 0.013 & 0.014 & 0.028 & -0.182 & 0.015 & 0.011 & 0.083 \\
\hline & 0.0295 & 0.0278 & 0.0305 & 0.0304 & 0.0278 & 0.0282 & 0.0286 & 0.1711 & 0.0326 & 0.1105 & 0.0844 \\
\hline CONCEN10 & 0.0099 & & & & & & & & & & \\
\hline \multirow[t]{2}{*}{ CONCEN1020 } & & & $-0.027^{* *}$ & $-0.027^{* *}$ & & & & & & & \\
\hline & & & 0.0106 & 0.0106 & & & & & & & \\
\hline \multirow[t]{2}{*}{ CONCEN20 } & & $0.026^{* *}$ & 0.013 & & & & & & & & \\
\hline & & 0.0128 & 0.0135 & & & & & & & & \\
\hline \multirow[t]{2}{*}{ CONCEN2050 } & & & & 0.017 & & & & & & & \\
\hline & & & & 0.0149 & & & & & & & \\
\hline \multirow[t]{2}{*}{ CONCEN50 } & & & & 0.007 & & & & & & & \\
\hline & & & & 0.0167 & & & & & & & \\
\hline \multirow[t]{2}{*}{ LSH1P } & & & & & 0.021 & 0.005 & $-0.243^{* *}$ & $-0.228 *$ & $-0.218^{*}$ & $-0.230^{*}$ & $-0.214^{*}$ \\
\hline & & & & & 0.0253 & 0.0669 & 0.1170 & 0.1172 & 0.1164 & 0.1178 & 0.1183 \\
\hline \multirow[t]{2}{*}{ LSH1PSQ } & & & & & & 0.023 & $1.041^{* *}$ & $0.760^{*}$ & 0.735 * & $0.784^{*}$ & $0.747^{*}$ \\
\hline & & & & & & 0.0915 & 0.4166 & 0.4277 & 0.4201 & 0.4299 & 0.4292 \\
\hline LSH1PCUBE & & & & & & & 0.3673 & 0.3787 & 0.3704 & 0.3800 & 0.3786 \\
\hline \multirow[t]{2}{*}{ SEP } & -0.016 & -0.026 & $-0.024 *$ & $-0.023^{*}$ & $-0.023^{*}$ & $-0.023^{*}$ & $-0.026{ }^{* *}$ & -0.029 * & $-0.027^{*}$ & -0.027 * & -0.027 * \\
\hline & 0.0131 & 0.0131 & 0.0130 & 0.0127 & 0.0132 & 0.0130 & 0.0133 & 0.0146 & 0.0144 & 0.0147 & 0.0147 \\
\hline \multirow[t]{2}{*}{ CEOLSH } & 0.012 & -0.001 & 0.003 & 0.002 & 0.005 & 0.006 & 0.002 & 0.018 & 0.014 & 0.012 & 0.012 \\
\hline & 0.0148 & 0.0158 & 0.0156 & 0.0156 & 0.0153 & 0.0157 & 0.0157 & 0.0165 & 0.0158 & 0.0161 & 0.0162 \\
\hline \multirow[t]{2}{*}{ CEOdual } & $-0.024^{* *}$ & $-0.022^{* *}$ & $-0.023^{* *}$ & $-0.022^{* *}$ & $-0.024^{* *}$ & $-0.024^{* *}$ & $-0.022^{* *}$ & $-0.021^{*}$ & $-0.021 *$ & $-0.021 *$ & $-0.023^{* *}$ \\
\hline & 0.0104 & 0.0105 & 0.0105 & 0.0103 & 0.0105 & 0.0105 & 0.0106 & 0.0107 & 0.0107 & 0.0110 & 0.0110 \\
\hline \multirow[t]{2}{*}{ BSIZE } & -0.001 & -0.002 & -0.002 & -0.002 & -0.001 & -0.001 & -0.002 & -0.002 & -0.002 & -0.002 & -0.002 \\
\hline & 0.0014 & 0.0016 & 0.0016 & 0.0016 & 0.0015 & 0.0015 & 0.0016 & 0.0015 & 0.0015 & 0.0015 & 0.0015 \\
\hline \multirow[t]{2}{*}{ INDDIR } & -0.013 & -0.003 & -0.013 & -0.015 & -0.004 & -0.004 & -0.004 & -0.011 & -0.007 & -0.010 & -0.007 \\
\hline & 0.0267 & 0.0260 & 0.0262 & 0.0266 & 0.0268 & 0.0269 & 0.0265 & 0.0312 & 0.0308 & 0.0309 & 0.0314 \\
\hline \multirow[t]{2}{*}{ OTHLSH } & 0.023 & 0.011 & 0.016 & 0.014 & 0.017 & 0.018 & 0.020 & 0.016 & 0.019 & 0.019 & 0.022 \\
\hline & 0.0141 & 0.0136 & 0.0136 & 0.0137 & 0.0139 & 0.0137 & 0.0138 & 0.0136 & 0.0133 & 0.0135 & 0.0135 \\
\hline
\end{tabular}




\begin{tabular}{|c|c|c|c|c|c|c|c|c|c|c|c|}
\hline TGORI_English & 0.011 & 0.004 & 0.004 & 0.004 & 0.008 & 0.008 & 0.008 & 0.004 & 0.002 & 0.002 & 0.002 \\
\hline \multirow{3}{*}{ ATTI_Hostile } & 0.0156 & 0.0149 & 0.0152 & 0.0153 & 0.0152 & 0.0152 & 0.0148 & 0.0150 & 0.0149 & 0.0149 & 0.0150 \\
\hline & 0.017 & 0.014 & 0.013 & 0.011 & 0.017 & 0.017 & 0.015 & 0.008 & 0.014 & 0.012 & 0.017 \\
\hline & 0.0165 & 0.0184 & 0.0189 & 0.0190 & 0.0170 & 0.0169 & 0.0167 & 0.0180 & 0.0181 & 0.0173 & 0.0176 \\
\hline \multirow[t]{2}{*}{ PAY_stock } & -0.007 & -0.010 & -0.010 & -0.010 & -0.008 & -0.007 & -0.008 & -0.006 & -0.009 & -0.009 & -0.010 \\
\hline & 0.0120 & 0.0113 & 0.0114 & 0.0114 & 0.0116 & 0.0118 & 0.0117 & 0.0121 & 0.0117 & 0.0118 & 0.0121 \\
\hline \multirow[t]{2}{*}{ COMPETE } & $-0.050^{* * *}$ & $-0.046^{* * * *}$ & $-0.049^{* * *}$ & $-0.050^{* * * *}$ & $-0.048^{* * * *}$ & $-0.048^{* * * *}$ & $-0.049^{* * *}$ & $-0.053^{* * * *}$ & $-0.052^{* * * *}$ & $-0.052^{* * * *}$ & $-0.051^{* * * *}$ \\
\hline & 0.0174 & 0.0162 & 0.0161 & 0.0161 & 0.0168 & 0.0168 & 0.0171 & 0.0169 & 0.0169 & 0.0170 & 0.0171 \\
\hline \multirow[t]{2}{*}{ IND_rel } & 0.007 & 0.009 & 0.007 & 0.007 & 0.009 & 0.008 & 0.009 & 0.007 & 0.008 & 0.008 & 0.009 \\
\hline & 0.0088 & 0.0086 & 0.0085 & 0.0086 & 0.0087 & 0.0090 & 0.0088 & 0.0088 & 0.0087 & 0.0088 & 0.0088 \\
\hline TOEHOLD & 0.015 & 0.015 & 0.015 & 0.015 & 0.015 & 0.015 & 0.015 & $0.021^{* *}$ & $0.019^{*}$ & $0.018^{*}$ & $0.017^{*}$ \\
\hline \multirow[t]{2}{*}{ PREM_1day } & 0.000 & 0.000 & 0.000 & 0.000 & 0.000 & 0.000 & 0.000 & 0.000 & 0.000 & 0.000 & 0.000 \\
\hline & 0.0002 & 0.0002 & 0.0002 & 0.0002 & 0.0002 & 0.0002 & 0.0002 & 0.0002 & 0.0002 & 0.0002 & 0.0002 \\
\hline \multirow[t]{2}{*}{ SIZE_rel } & -0.002 & -0.002 & -0.002 & -0.002 & -0.002 & -0.002 & -0.002 & -0.001 & -0.002 & -0.002 & -0.002 \\
\hline & 0.0025 & 0.0025 & 0.0024 & 0.0024 & 0.0026 & 0.0026 & 0.0025 & 0.0025 & 0.0024 & 0.0024 & 0.0024 \\
\hline \multirow[t]{2}{*}{ LEV } & -0.005 & -0.005 & -0.005 & -0.005 & -0.005 & -0.006 & -0.006 & -0.006 & $-0.007^{*}$ & -0.007 * & -0.008 * \\
\hline & 0.0042 & 0.0040 & 0.0042 & 0.0041 & -0.0040 & 0.0040 & 0.0041 & 0.0041 & 0.0038 & 0.0040 & 0.0040 \\
\hline \multirow{2}{*}{ ANTIDIR_high } & & & & & & & & 0.126 & $0.076^{* * * *}$ & & \\
\hline & & & & & & & & 0.0402 & 0.0232 & & \\
\hline \multirow[t]{2}{*}{ ENFORCE } & & & & & & & & 0.012 & & & \\
\hline & & & & & & & & 0.0079 & & & \\
\hline ACCTSTD & & & & & & & & 0.0025 & & & \\
\hline \multirow[t]{2}{*}{ XLEG_high } & & & & & & & & -0.013 & 0.005 & & \\
\hline & & & & & & & & 0.0353 & 0.0316 & & \\
\hline \multirow[t]{2}{*}{ ANTISDI } & & & & & & & & & & 0.018 & -0.079 \\
\hline & & & & & & & & & & 0.1270 & 0.0963 \\
\hline \multirow{2}{*}{ PUBENFORCE_high } & & & & & & & & & & -0.056 & \\
\hline & & & & & & & & & & 0.0533 & \\
\hline \multirow[t]{2}{*}{ NANTIDIR_high } & & & & & & & & & & $0.062^{* *}$ & $0.049^{* *}$ \\
\hline & & & & & & & & & & 0.0295 & 0.0245 \\
\hline \multirow[t]{2}{*}{$U K$} & & & & & & & & $-0.125^{* *}$ & $-0.070^{*}$ & -0.061 & -0.034 \\
\hline & & & & & & & & 0.0510 & 0.0386 & 0.0356 & 0.0274 \\
\hline \multirow[t]{2}{*}{$C A N$} & & & & & & & & $-0.141^{* *}$ & $-0.058^{* * *}$ & 0.070 & 0.000 \\
\hline & & & & & & & & 0.0535 & 0.0212 & 0.0745 & 0.0225 \\
\hline \multirow{2}{*}{$A U S$} & & & & & & & & 0.027 & 0.032 & 0.030 & 0.029 \\
\hline & & & & & & & & 0.0297 & 0.0317 & 0.0239 & 0.0229 \\
\hline Adjust R R $\left.^{2} \%\right)$ & 3.06 & 4.30 & 6.23 & 6.01 & 2.76 & 2.41 & 4.58 & 7.79 & 7.90 & 6.58 & 6.10 \\
\hline$F$ & $1.81 * *$ & $1.75^{* *}$ & $2.24 * * *$ & $2.12 * * *$ & $1.65^{*}$ & $1.66^{*}$ & $1.77^{* *}$ & $2.44 * * *$ & $2.50^{* * * *}$ & $2.22 * * *$ & $2.17 * * *$ \\
\hline Root $\mathrm{I}$ & 0.06916 & 0.06871 & 0.06802 & 0.0681 & 0.06926 & 0.06939 & 0.06861 & 0.06745 & 0.06739 & 0.06789 & 0.06805 \\
\hline
\end{tabular}


Table 8.11 Standard Error Robustness Test on Bootstrap Standard Errors Estimators

Sample of 282 mergers and acquisitions by 222 acquiring firms in 11 English Origin countries (Australia, Canada, India, Ireland, Israel, Malaysia, New Zealand, Singapore, South Africa, Thailand and United Kingdom) between 1997 and 2001 for completed transactions over US\$ 10 million are obtained from the Thomson Financial Securities Data's SDC PlatinumTM Worldwide Mergers \& Acquisitions Database. ACFRpre and ACFRpost is the pre and post industry, size, and pre performance adjusted cash flow return. $\triangle$ ACFR is for the change in industry, size, and pre performance adjusted cash flow return. Outliers have been winsorized using Huber's M estimator approach. With clustered (Bootstrap) standard errors below (Italics). Two tail tests *** denotes significant at the $1 \%$ level, ** significant at the 5\% level, * significant at the $10 \%$ level. See table 5.5 for variable definitions.

\section{Panel A Dependent Variable: ACFRpost}

\begin{tabular}{|c|c|c|c|c|c|c|c|c|c|c|c|}
\hline \multirow{2}{*}{$\begin{array}{c}\mathbf{N}=282, \text { Clusters }=222 \\
\text { Replications }=222\end{array}$} & \multicolumn{11}{|c|}{ Bootstrap Standard Errors Estimators } \\
\hline & Model 1 & Model 2 & Model 3 & Model 4 & Model 5 & Model 6 & Model & Model 8 & Model 8.1 & Model 9 & Model 9.1 \\
\hline$\overline{\text { Intercept }}$ & $\begin{array}{l}\mathbf{0 . 0 4 8} \\
0.0199\end{array}$ & $\begin{array}{l}\mathbf{0 . 0 5 0} \\
0.0204\end{array}$ & $\begin{array}{l}\mathbf{0 . 0 7 0} \\
0.0242^{* * * *}\end{array}$ & $\begin{array}{l}\mathbf{0 . 0 7 0} \\
0.0244\end{array}$ & $\begin{array}{c}\mathbf{0 . 0 4 1} \\
0.0199\end{array}$ & $\begin{array}{l}\mathbf{0 . 0 4 2} \\
0.0216\end{array}$ & $\begin{array}{c}\mathbf{0 . 0 5 6} \\
0.0222\end{array}$ & $\begin{array}{l}-0.158 \\
0.1896\end{array}$ & $\begin{array}{l}\mathbf{0 . 0 5 5} \text { ** } \\
0.0249\end{array}$ & $\begin{array}{c}0.020 \\
0.1131\end{array}$ & $\begin{array}{c}0.108 \\
0.0910\end{array}$ \\
\hline CONCEN10 & $\begin{array}{l}-0.012 \\
0.0077\end{array}$ & & & & & & & & & & \\
\hline CONCEN 1020 & & & $\begin{array}{l}-0.025^{* * *} \\
0.0095^{*}\end{array}$ & $\begin{array}{l}-0.025 \\
0.0096\end{array}$ & & & & & & & \\
\hline CONCEN20 & & $\begin{array}{l}0.024^{* *} \\
0.0123\end{array}$ & $\begin{array}{r}0.012 \\
0.0129\end{array}$ & & & & & & & & \\
\hline CONCEN2050 & & & & $\begin{array}{r}0.012 \\
0.0131\end{array}$ & & & & & & & \\
\hline CONCEN50 & & & & $\begin{array}{r}0.012 \\
0.0176\end{array}$ & & & & & & & \\
\hline LSH1P & & & & & $\begin{array}{r}0.023 \\
0.0253\end{array}$ & $\begin{array}{r}0.006 \\
0.0632\end{array}$ & $\begin{array}{l}-0.234 \text { * } \\
0.1140\end{array}$ & $\begin{array}{l}-0.197 * \\
0.1129\end{array}$ & $\begin{array}{l}-0.200 \\
0.1001\end{array}$ & $\begin{array}{l}-0.222 * * \\
0.1029\end{array}$ & $\begin{array}{l}-0.202 * * \\
0.0920\end{array}$ \\
\hline LSH1PSQ & & & & & & $\begin{array}{r}0.025 \\
0.0942\end{array}$ & $\begin{array}{l}1.011 \\
0.4326\end{array}$ & $\begin{array}{l}0.673 \text { * } \\
0.4501\end{array}$ & $\begin{array}{l}0.725 \text { * } \\
0.3787\end{array}$ & $\begin{array}{l}0.768 \text { * } \\
0.4438\end{array}$ & $\begin{array}{l}0.723 * \\
0.3706\end{array}$ \\
\hline LSH1PCUBE & & & & & & & $\begin{array}{r}-0.892 * \\
0.399\end{array}$ & $\begin{array}{c}-0.553 \\
0.417\end{array}$ & $\begin{array}{c}-0.608 \\
0.354\end{array}$ & $\begin{array}{c}-0.635 \\
0.417\end{array}$ & $\begin{array}{c}-0.608 \\
0.362\end{array}$ \\
\hline \multirow[t]{2}{*}{ SEP } & -0.019 & $-0.028 * *$ & $-0.027^{* *}$ & $-0.027^{* *}$ & $-0.026^{*}$ & $-0.026^{* *}$ & -0.030 & $-0.032^{* *}$ & $-0.033^{* *}$ & $-0.033^{* *}$ & $-0.033^{* *}$ \\
\hline & 0.0133 & 0.0127 & 0.0112 & 0.0123 & 0.0141 & 0.0121 & 0.0129 & 0.0148 & 0.0149 & 0.0141 & 0.0149 \\
\hline CEOLSH & 0.0150 & 0.0154 & 0.0151 & 0.0145 & 0.0150 & 0.0149 & 0.0155 & 0.0165 & 0.0170 & 0.0166 & 0.0163 \\
\hline CEOdual & $\begin{array}{l}-0.015 \\
0.0099\end{array}$ & $\begin{array}{l}-0.013 \\
0.0095\end{array}$ & $\begin{array}{l}-0.013 \\
0.0101\end{array}$ & $\begin{array}{l}-0.013 \\
0.0089\end{array}$ & $\begin{array}{l}-0.014 \\
0.0099\end{array}$ & $\begin{array}{r}-0.015 \\
0098\end{array}$ & -0.013 & -0.011 & -0.012 & -0.011 & -0.015 \\
\hline \multirow[t]{2}{*}{ BSIZE } & -0.001 & $-0.002 *$ & $-0.003^{* *}$ & $-0.003 * *$ & -0.002 & $\begin{array}{r}0.0000 \\
-0.002\end{array}$ & $-0.003 *$ & $-0.003 * *$ & -0.003 ** & $-0.003 *$ & $-0.002 *$ \\
\hline & 0.0012 & 0.0014 & 0.0014 & 0.0015 & 0.0014 & 0.0013 & 0.0014 & 0.0013 & 0.0014 & 0.0015 & 0.0013 \\
\hline \multirow[t]{2}{*}{ INDDIR } & -0.023 & -0.013 & -0.022 & -0.022 & -0.013 & -0.013 & -0.013 & -0.027 & -0.023 & -0.031 & -0.028 \\
\hline & 0.0231 & 0.0243 & 0.0244 & 0.0210 & 0.0218 & 0.0261 & 0.0233 & 0.0299 & 0.0281 & 0.0276 & 0.0293 \\
\hline \multirow{2}{*}{ OTHLSH } & 0.012 & 0.001 & 0.005 & 0.005 & 0.006 & 0.007 & 0.009 & 0.005 & 0.007 & 0.008 & 0.011 \\
\hline & 0.0120 & 0.0113 & 0.0123 & 0.0117 & 0.0120 & 0.0126 & 0.0125 & 0.0117 & 0.0117 & 0.0129 & 0.0121 \\
\hline
\end{tabular}




\begin{tabular}{|c|c|c|c|c|c|c|c|c|c|c|c|}
\hline \multirow[t]{2}{*}{ TGORI_English } & 0.004 & -0.003 & -0.002 & -0.002 & 0.001 & 0.001 & 0.001 & -0.005 & -0.004 & -0.004 & -0.004 \\
\hline & 0.0120 & 0.0136 & 0.0125 & 0.0126 & 0.0134 & 0.0126 & 0.0118 & 0.0117 & 0.0111 & 0.0120 & 0.0119 \\
\hline \multirow[t]{2}{*}{ ATTI_Hostile } & 0.009 & 0.007 & 0.006 & 0.006 & 0.009 & 0.009 & 0.007 & 0.016 & 0.012 & 0.005 & 0.011 \\
\hline & 0.0152 & 0.0171 & 0.0181 & 0.0186 & 0.0178 & 0.0158 & 0.0185 & 0.0134 & 0.0135 & 0.0178 & 0.0131 \\
\hline \multirow[t]{2}{*}{ PAY_stock } & -0.010 & -0.013 & -0.013 & -0.013 & -0.011 & -0.011 & -0.011 & -0.011 & -0.013 & -0.012 & -0.013 \\
\hline & 0.0107 & 0.0095 & 0.0096 & 0.0097 & 0.0097 & 0.0092 & 0.0104 & 0.0109 & 0.0106 & 0.0102 & 0.0104 \\
\hline \multirow[t]{2}{*}{ COMPETE } & $-0.035^{* *}$ & $-0.032^{* *}$ & $-0.035^{* *}$ & $-0.035^{* *}$ & $-0.033^{* *}$ & $-0.033^{* *}$ & $-0.035^{* *}$ & $-0.038^{* *}$ & $-0.037^{* *}$ & $-0.037^{* *}$ & $-0.036^{* *}$ \\
\hline & 0.0151 & 0.0144 & 0.0163 & 0.0142 & 0.0143 & 0.0153 & 0.0138 & 0.0149 & 0.0144 & 0.0174 & 0.0153 \\
\hline \multirow[t]{2}{*}{ IND_rel } & 0.001 & 0.003 & 0.001 & 0.001 & 0.002 & 0.002 & 0.002 & 0.001 & 0.001 & 0.000 & 0.002 \\
\hline & 0.0078 & 0.0074 & 0.0080 & 0.0070 & 0.0076 & 0.0083 & 0.0080 & 0.0070 & 0.0082 & 0.0072 & 0.0079 \\
\hline TOEHOLD & 0.006 & 0.006 & 0.006 & 0.006 & 0.006 & 0.006 & 0.006 & 0.012 & 0.012 & 0.010 & 0.009 \\
\hline \multirow[t]{2}{*}{ PREM_1day } & 0.000 & 0.000 & 0.000 & 0.000 & 0.000 & 0.000 & 0.000 & 0.000 & 0.000 & 0.000 & 0.000 \\
\hline & 0.0001 & 0.0002 & 0.0001 & 0.0002 & 0.0001 & 0.0002 & 0.0001 & 0.0002 & 0.0002 & 0.0002 & 0.0002 \\
\hline \multirow[t]{2}{*}{ SIZE_rel } & $-0.005^{* *}$ & $-0.005^{* *}$ & $-0.006^{* *}$ & $-0.006^{* * *}$ & $-0.005^{* *}$ & $-0.005^{* *}$ & $-0.005^{* *}$ & $-0.005^{*}$ & $-0.005^{* *}$ & $-0.005^{* *}$ & $-0.005^{* *}$ \\
\hline & 0.0023 & 0.0025 & 0.0022 & 0.0024 & 0.0024 & 0.0025 & 0.0024 & 0.0023 & 0.0021 & 0.0022 & 0.0023 \\
\hline \multirow{2}{*}{ LEV } & 0.000 & 0.000 & 0.000 & 0.000 & 0.000 & 0.000 & -0.001 & -0.001 & -0.002 & -0.002 & -0.003 \\
\hline & 0.0032 & 0.0033 & 0.0032 & 0.0033 & 0.0034 & 0.0034 & 0.0034 & 0.0036 & 0.0033 & 0.0033 & 0.0033 \\
\hline ANTIDIR_high & & & & & & & & $\begin{array}{l}0.083^{*} \\
0.0478\end{array}$ & ${ }_{0.060^{* *}}$ & & \\
\hline ENFORCE & & & & & & & & $\begin{array}{l}-0.001 \\
0.0107\end{array}$ & & & \\
\hline ACCTSTD & & & & & & & & 0.003 & & & \\
\hline XLEG_high & & & & & & & & -0.028 & -0.024 & & \\
\hline ANTISDI & & & & & & & & & & 0.046 & -0.075 \\
\hline PUBENFORCE high & & & & & & & & & & $\begin{array}{l}0.1334 \\
-0.070\end{array}$ & 0.1072 \\
\hline 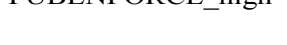 & & & & & & & & & & 0.0513 & \\
\hline NANTIDIR_high & & & & & & & & & & $\begin{array}{c}0.061 \\
0.0296\end{array}$ & $\begin{array}{c}0.045^{* *} \\
0.0218\end{array}$ \\
\hline $\bar{U}$ & & & & & & & & -0.064 & -0.033 & $-0.062^{*}$ & -0.029 \\
\hline & & & & & & & & 0.0617 & 0.0338 & 0.0349 & 0.0245 \\
\hline$C A N$ & & & & & & & & -0.061 & $-0.041^{*}$ & 0.099 & 0.013 \\
\hline & & & & & & & & 0.0708 & 0.0214 & 0.0731 & 0.0249 \\
\hline$A U S$ & & & & & & & & $\begin{array}{r}0.055 \\
0.0261\end{array}$ & $\begin{array}{r}0.054 \\
0.0250\end{array}$ & $\begin{array}{r}0.035 \\
0.0224 \\
\end{array}$ & $\begin{array}{r}0.034 \\
0.0202\end{array}$ \\
\hline ACFRpre & $\begin{array}{l}0.516^{* * *} \\
0.059\end{array}$ & $\begin{array}{l}0.518^{* * *} \\
0.058\end{array}$ & $\begin{array}{l}0.521^{* * *} \\
0.060\end{array}$ & $\begin{array}{l}0.521^{* * *} \\
0.061\end{array}$ & $\begin{array}{l}0.514^{* * *} \\
0.066\end{array}$ & $\begin{array}{l}0.514^{* * *} \\
0.063\end{array}$ & $\begin{array}{l}0.516^{* * *} \\
0.067\end{array}$ & $\begin{array}{l}0.503^{* * *} \\
0.058\end{array}$ & $\begin{array}{l}0.512^{* * *} \\
0.065\end{array}$ & $\begin{array}{l}0.512^{* * *} \\
0.063\end{array}$ & $\begin{array}{l}0.517^{* * * *} \\
0.060\end{array}$ \\
\hline Adjust $\mathrm{R}^{2}(\%)$ & 29.01 & 30.00 & 31.59 & 31.33 & 28.86 & 28.62 & 30.57 & 33.85 & 33.74 & 32.82 & 31.94 \\
\hline${\text { Wald } \mathrm{Chi}^{2}}^{2}$ & $125.57 * * *$ & $126.33^{* * *}$ & $147.95 * * *$ & $115.14 * * *$ & $104.30 * * *$ & $108.22 * * *$ & $102.73 * * *$ & $173.24 * * *$ & $161.87 * * *$ & $153.84 * * *$ & $155.70 * * *$ \\
\hline Root MSE & 0.0613 & 0.06089 & 0.06019 & 0.06031 & 0.06139 & 0.06149 & 0.06064 & 0.05919 & 0.05924 & 0.05965 & 0.06004 \\
\hline
\end{tabular}


Table 8.11 (Continued)

\begin{tabular}{|c|c|c|c|c|c|c|c|c|c|c|c|}
\hline \multirow{2}{*}{$\begin{array}{c}\mathrm{N}=282, \text { Clusters }=222 \\
\text { Replications }=222\end{array}$} & \multicolumn{11}{|c|}{ Bootstrap Standard Errors Estimators } \\
\hline & Model 1 & Model 2 & Model 3 & Model 4 & Model 5 & Model 6 & Model 7 & Model 8 & Model 8.1 & Model 9 & Model 9.1 \\
\hline Intercept & $\begin{array}{r}0.021 \\
0.0303\end{array}$ & $\begin{array}{r}0.023 \\
0.0283\end{array}$ & $\begin{array}{r}0.045 \\
0.0311\end{array}$ & $\begin{array}{r}0.048 \\
0.0301\end{array}$ & $\begin{array}{r}0.013 \\
0.0284\end{array}$ & $\begin{array}{r}0.014 \\
0.0247\end{array}$ & $\begin{array}{r}0.028 \\
0.0293\end{array}$ & $\begin{array}{l}-0.182 \\
0.2479\end{array}$ & $\begin{array}{c}0.015 \\
0.0330\end{array}$ & $\begin{array}{l}0.011 \\
0.1295\end{array}$ & $\begin{array}{c}0.083 \\
0.0983\end{array}$ \\
\hline CONCEN10 & $\begin{array}{l}-0.013 \\
0.0101\end{array}$ & & & & & & & & & & \\
\hline CONCEN1020 & & & $\begin{array}{l}-0.027^{* * *} \\
0.0100\end{array}$ & $\begin{array}{l}-0.027^{* * *} \\
0.0101^{*}\end{array}$ & & & & & & & \\
\hline CONCEN20 & & $0_{0.026}^{*}$ & $\begin{array}{r}0.013 \\
0.0134\end{array}$ & & & & & & & & \\
\hline CONCEN2050 & & & & $\begin{array}{r}0.017 \\
0.0149\end{array}$ & & & & & & & \\
\hline CONCEN50 & & & & $\begin{array}{r}0.007 \\
0.0168\end{array}$ & & & & & & & \\
\hline LSH1P & & & & & 0.021 & 0.005 & $-0.243 *$ & $-0.228^{*}$ & $-0.218^{*}$ & -0.230 * & $-0.214^{*}$ \\
\hline LSH1PSQ & & & & & 0.0287 & $\begin{array}{r}0.0726 \\
0.023\end{array}$ & $\begin{array}{r}0.1301 \\
1.041\end{array}$ ** & $\begin{array}{l}0.1251 \\
0.760\end{array}$ & $\begin{array}{r}0.1149 \\
0.735\end{array}$ & $\begin{array}{c}0.1198 \\
0.784\end{array}$ & $\begin{array}{r}0.1355 \\
0.747\end{array}$ \\
\hline LSH1PCUBE & & & & & & 0.1023 & $\begin{array}{l}0.4800 \\
-0.921 \\
0.4433\end{array}$ ** & $\begin{array}{c}0.4830 \\
-0.606 \\
0.4481\end{array}$ & $\begin{array}{c}0.4523 \\
-0.593 \\
0.4332\end{array}$ & $\begin{array}{c}0.4242 \\
-0.635 \\
0.3801\end{array}$ * & $\begin{array}{c}0.4873 \\
-0.613 \\
0.4340\end{array}$ \\
\hline SEP & -0.016 & -0.026 ** & $-0.024 *$ & $-0.023 *$ & $-0.023^{*}$ & $-0.023{ }^{*}$ & -0.026 & $-0.029^{* *}$ & $-0.027^{*}$ & $-0.027^{*}$ & $-0.027^{*}$ \\
\hline & 0.0139 & 0.0127 & 0.0138 & 0.0127 & 0.0132 & 0.0135 & 0.0145 & 0.0145 & 0.0154 & 0.0159 & 0.0162 \\
\hline CEOLSH & 0.012 & -0.001 & 0.003 & 0.002 & 0.005 & 0.006 & 0.002 & 0.018 & 0.014 & 0.012 & 0.012 \\
\hline CEOdual & $\begin{array}{l}0.0156 \\
-0.024\end{array}$ ** & $\begin{array}{l}0.0144 \\
-0.022\end{array} *$ & $\begin{array}{l}0.0167 \\
-0.023\end{array}$ ** & $\begin{array}{l}0.0158 \\
-0.022\end{array} * *$ & $\begin{array}{l}0.0156 \\
-0.024\end{array}$ ** & $\begin{array}{l}0.0162 \\
-0.024\end{array}$ ** & $\begin{array}{l}0.0166 \\
-0.022\end{array}$ * & $\begin{array}{l}0.0188 \\
-0.021\end{array}$ * & $\begin{array}{l}0.0166 \\
-0.021\end{array}$ & $\begin{array}{c}0.0172 \\
-0.021\end{array}$ * & $\begin{array}{l}0.0168 \\
-0.023\end{array}$ ** \\
\hline & 0.0099 & 0.0114 & 0.0107 & 0.0112 & 0.0103 & 0.0099 & 0.0114 & 0.0111 & 0.0119 & 0.0111 & 0.0110 \\
\hline BSIZE & -0.001 & -0.002 & -0.002 & -0.002 & -0.001 & -0.001 & -0.002 & -0.002 & -0.002 & -0.002 & -0.002 \\
\hline & 0.0014 & 0.0015 & 0.0016 & 0.0017 & 0.0015 & 0.0015 & 0.0017 & 0.0015 & 0.0015 & 0.0015 & 0.0016 \\
\hline INDDIR & -0.013 & -0.003 & -0.013 & -0.015 & -0.004 & -0.004 & -0.004 & -0.011 & -0.007 & -0.010 & -0.007 \\
\hline & 0.0268 & 0.0277 & 0.0272 & 0.0256 & 0.0271 & 0.0247 & 0.0258 & 0.0289 & 0.0334 & 0.0309 & 0.0347 \\
\hline OTHLSH & 0.023 & 0.011 & 0.016 & 0.014 & 0.017 & 0.018 & 0.020 & 0.016 & 0.019 & 0.019 & $0.022^{*}$ \\
\hline & 0.0141 & 0.0139 & 0.0136 & 0.0138 & 0.0135 & 0.0135 & 0.0147 & 0.0136 & 0.0136 & 0.0129 & 0.0132 \\
\hline
\end{tabular}




\begin{tabular}{|c|c|c|c|c|c|c|c|c|c|c|c|}
\hline TGORI_English & 0.011 & 0.004 & 0.004 & 0.004 & 0.008 & 0.008 & 0.008 & 0.004 & 0.002 & 0.002 & 0.002 \\
\hline \multirow{3}{*}{ ATTI_Hostile } & 0.0176 & 0.0158 & 0.0149 & 0.0147 & 0.0151 & 0.0144 & 0.0146 & 0.0147 & 0.0151 & 0.0158 & 0.0165 \\
\hline & 0.017 & 0.014 & 0.013 & 0.011 & 0.017 & 0.017 & 0.015 & 0.008 & 0.014 & 0.012 & 0.017 \\
\hline & 0.0164 & 0.0216 & 0.0210 & 0.0225 & 0.0181 & 0.0160 & 0.0181 & 0.0219 & 0.0192 & 0.0203 & 0.0221 \\
\hline \multirow[t]{2}{*}{ PAY_stock } & -0.007 & -0.010 & -0.010 & -0.010 & -0.008 & -0.007 & -0.008 & -0.006 & -0.009 & -0.009 & -0.010 \\
\hline & 0.0126 & 0.0114 & 0.0116 & 0.0131 & 0.0117 & 0.0120 & 0.0112 & 0.0126 & 0.0131 & 0.0127 & 0.0120 \\
\hline \multirow[t]{2}{*}{ COMPETE } & $-0.050^{* * * *}$ & $-0.046^{* * *}$ & $-0.049^{* * * *}$ & $-0.050^{* * *}$ & $-0.048^{* * * *}$ & $-0.048^{* * *}$ & $-0.049^{* * *}$ & $-0.053^{* * * *}$ & $-0.052^{* * *}$ & $-0.052^{* * *}$ & $-0.051^{* * * *}$ \\
\hline & 0.0181 & 0.0176 & 0.0167 & 0.0174 & 0.0177 & 0.0171 & 0.0176 & 0.0186 & 0.0181 & 0.0179 & 0.0166 \\
\hline \multirow[t]{2}{*}{ IND_rel } & 0.007 & 0.009 & 0.007 & 0.007 & 0.009 & 0.008 & 0.009 & 0.007 & 0.008 & 0.008 & 0.009 \\
\hline & 0.0084 & 0.0086 & 0.0084 & 0.0088 & 0.0080 & 0.0094 & 0.0092 & 0.0090 & 0.0084 & 0.0090 & 0.0082 \\
\hline TOEHOLD & 0.015 & 0.015 & 0.015 & 0.015 & 0.015 & 0.015 & 0.015 & $0.021 *$ & $0.019^{*}$ & $0.018^{*}$ & 0.017 \\
\hline \multirow[t]{2}{*}{ PREM_1day } & 0.000 & 0.000 & 0.000 & 0.000 & 0.000 & 0.000 & 0.000 & 0.000 & 0.000 & 0.000 & 0.000 \\
\hline & 0.0002 & 0.0002 & 0.0002 & 0.0002 & 0.0001 & 0.0002 & 0.0002 & 0.0002 & 0.0002 & 0.0002 & 0.0002 \\
\hline \multirow[t]{2}{*}{ SIZE_rel } & -0.002 & -0.002 & -0.002 & -0.002 & -0.002 & -0.002 & -0.002 & -0.001 & -0.002 & -0.002 & -0.002 \\
\hline & 0.0027 & 0.0026 & 0.0025 & 0.0023 & 0.0027 & 0.0025 & 0.0025 & 0.0026 & 0.0027 & 0.0027 & 0.0024 \\
\hline \multirow[t]{2}{*}{ LEV } & -0.005 & -0.005 & -0.005 & -0.005 & -0.005 & -0.006 & -0.006 & -0.006 & $-0.007 *$ & $-0.007^{*}$ & -0.008 * \\
\hline & 0.0041 & _o.0039 & 0.0040 & 0.0040 & 0.0040 & 0.0042 & 0.0040 & 0.0041 & 0.0040 & 0.0040 & 0.0041 \\
\hline \multirow[t]{2}{*}{ ANTIDIR_high } & & & & & & & & 0.126 * & $0.076^{* * *}$ & & \\
\hline & & & & & & & & 0.0717 & 0.0249 & & \\
\hline \multirow[t]{2}{*}{ ENFORCE } & & & & & & & & 0.012 & & & \\
\hline & & & & & & & & 0.0179 & & & \\
\hline ACCTSTD & & & & & & & & 0.0037 & & & \\
\hline \multirow[t]{2}{*}{ XLEG_high } & & & & & & & & -0.013 & 0.005 & & \\
\hline & & & & & & & & 0.0462 & 0.0354 & & \\
\hline \multirow[t]{2}{*}{ ANTISDI } & & & & & & & & & & 0.018 & -0.079 \\
\hline & & & & & & & & & & 0.1517 & 0.1160 \\
\hline PUBENFORCE_high & & & & & & & & & & -0.056 & \\
\hline NANTIDIR_high & & & & & & & & & & $\begin{array}{c}0.0631 \\
0.062\end{array} *$ & $\begin{array}{l}0.049^{* *} \\
0.0240\end{array}$ \\
\hline \multirow[t]{2}{*}{$U K$} & & & & & & & & -0.125 & $-0.070^{*}$ & $\begin{array}{l}0.0331 \\
-0.061\end{array}$ & $\begin{array}{l}0.0240 \\
-0.034 \\
-0.034\end{array}$ \\
\hline & & & & & & & & 0.0817 & 0.0390 & 0.0413 & 0.0285 \\
\hline \multirow[t]{2}{*}{$C A N$} & & & & & & & & -0.141 & $-0.058^{* *}$ & 0.070 & 0.000 \\
\hline & & & & & & & & 0.1108 & 0.0242 & 0.0896 & 0.0252 \\
\hline \multirow[t]{2}{*}{$A U S$} & & & & & & & & 0.027 & 0.032 & 0.030 & 0.029 \\
\hline & & & & & & & & 0.0343 & 0.0327 & 0.0245 & 0.0249 \\
\hline Adjust R ${ }^{2}(\%)$ & 3.06 & 4.30 & 6.23 & 6.01 & 2.76 & 2.41 & 4.58 & 7.79 & 7.90 & 6.58 & 6.10 \\
\hline Wald $\mathrm{chi}^{2}$ & $27.98^{* *}$ & $27.07 * *$ & $38.57 * * *$ & $40.23 * * *$ & $25.93 *$ & $28.52 * *$ & $30.48^{* *}$ & $56.85 * * *$ & $53.37 * * *$ & $49.73 * * *$ & $55.90 * * *$ \\
\hline Root MSE & 0.06916 & 0.06871 & 0.06802 & 0.06810 & 0.06926 & 0.06939 & 0.06861 & 0.06745 & 0.06739 & 0.06789 & 0.06805 \\
\hline
\end{tabular}




\subsection{Robustness Analysis on Windows of Measuring Performance}

The basic regressions attempt to explain the change in pre and post median performance over years $\mathrm{t}-3$ to $\mathrm{t}-1$ and $\mathrm{t}+1$ to $\mathrm{t}+3(\triangle A C F R)$ and the level of post median performance over $\mathrm{t}+1$ to $\mathrm{t}+3$ (ACFRpost). They also attempt to control for pre median performance over t-3 to t-1 operating performance (ACFRpre) (HPR 1992/ 1997, Linn and Switzer 2001, Ghosh 2001). However, one stream of academic literature argues that the changes in performance $(\triangle A C F R)$ surrounding corporate events should be examined based on a set year (commonly the last year prior to the event) before the event and each of the years after the transaction (Denis and Denis 1995). Ghosh (2001) and Powell and Stark (2005) partially examine the change between year $t-1$ and the median post performance over $t+1$ to $t+3$ year. The operating performance in the year surrounding the transactions is examined in a further robustness test and then the benchmark regression model (model 7) is rerun along with the modified regression models (model 8.1 and 9.1) as representatives over these different measuring windows. The robustness results are reported in tables 8.12 and 8.13 .

Table 8.12 is set just like table 6.1 but the part of change in operating cash flow return $(\triangle A C F R)$ is presented in panel $\mathbf{B}$ with a different set of measuring windows instead. The results in panel A of table $\mathbf{8 . 1 2}$ are exactly same as those in panel A of table 6.1. It is clear that firms with acquisitions significantly underperform as compared with their matched peers in the level of adjusted operating performance (ACFRi) among the prior years of transactions (median measure $-0.91,-0.70$ and -1.37 percent at year $\mathrm{t}-3, \mathrm{t}-2$ and $\mathrm{t}-1$, respectively) but the ratio of the change in adjusted operating performance $(\triangle A C F R)$ declines from year t-3 to year $\mathrm{t}-1$ by an median (mean) measure $-0.22(-0.86)$ percent which is not a statistically decrease. Following the acquisitions, merging firms exhibit a comparable performance with their benchmark firms in the level of adjusted operating cash flow returns (ACFRi) (median measure $+0.23,+0.54$ and +0.17 percent at year $t+1, t+2$ and $t+3$, respectively). However, there is a statistically significant increase in the ratio of the change in adjusted performance $\left(\triangle A C F R_{3}\right)$ by a median (mean) measure 2.25 (2.27) percent from year $\mathrm{t}-1$ through year $\mathrm{t}+3$. This evidence remains in $\triangle A C F R_{1}$ and $\triangle A C F R_{2}$ by median measure 2.03 and 2.28 through year $\mathrm{t}+1$ and year $\mathrm{t}+2$, respectively, and also stands in the median post performance (ACFRpost, median measure is 2.15) as applied in Ghosh (2001). All the mean and median 
measures of the change performance are significantly distinguishable from zero at the $1 \%$ level.

In the same way, improvements in post acquisition performance are tested using the regression approach. Panel $\mathbf{C}$ presents the regression results of adjusted returns at each postacquisition year $\left(A C F R_{t+i}, i=1,2,3\right)$ and the adjusted returns at the last year prior to the transaction $\left(A C F R_{t-1}\right)$. The intercept $\alpha$ is positive and significant at least at the 5 percent level in all regression models $(0.016,0.013,0.012$ and 0.014 at $\mathrm{t}+1, \mathrm{t}+2, \mathrm{t}+3$ and median over 3 year, respectively) which indicates that adjusted operating performance has a significant improvement in each post-acquisition year after controlling for the effects of pre-performance at year $\mathrm{t}-1$. The slope coefficient $\beta$ is also positive and statistically different from zero $(0.494,0.527,0.483$ and 0.504 at $\mathrm{t}+1, \mathrm{t}+2, \mathrm{t}+3$ and median over 3 - year, respectively) which specifies that the correlation in operating cash flow between the pre and post acquisition years is positive effect per year and that the adjusted cash flow returns tend to persist over time. These results certainly confirm the basic conclusions in table 6.1. There is no difference seen by using different windows to measure the change in operating cash flow returns.

Major regression models are rerun in the following step. The metrics over these windows are displayed in table 8.13. Panel A reflects the level of operating performance at each post acquisition year $(A C F R p o s t=A C F R t+i)$ by controlling the pre-performance at the last year prior to the event (ACFRpre $=A C F R t-1)$. Panel B reflects the change in operating performance based on the last year prior to the event as well. 
Table 8.12 Operating Cash Flows Returns: Robustness Test on Year Window of Measuring Performance

Sample of 282 mergers and acquisitions by 222 acquiring firms in 11 English Origin countries (Australia, Canada, India, Ireland, Israel, Malaysia, New Zealand, Singapore, South Africa, Thailand and United Kingdom) between 1997 and 2001 for completed transactions over US\$10 million are obtained from the Thomson Financial Securities Data's SDC PlatinumTM Worldwide Mergers \& Acquisitions Database. Operating cash flow return (OCFR) is calculated as operating cash flow divided by market value of asset. Operating cash flow is defined as operating income before depreciation. Post acquisition performance for each deal is measured by the operating cash flow return of the surviving acquirer after transaction. Pre acquisition performance is calculated as a weighted-average of the operating cash flow return for the bidder and the target included (MEGi pre and post). The weights are based on the market values of assets of both companies in the year before acquisition. Post and pre acquisition performances of the matched firms are measured as weighted-average of the operating cash flow rates (MATi pre and post). Industry, Size, and Pre performance Adjusted Operating Cash Flow Rates (ACFRt $+i$ ) is operating cash flow rates of merged firms minus those of matched firms at the year $\mathrm{i}(\mathrm{i}=-1,-2,-3,1,2,3)$. The change in industry, size, and pre performance adjusted cash flow rate ( $\triangle \mathrm{ACFRpre}$ ) is defined as ACFR at the third year before transaction minus ACFR at the last year prior to transaction. The change in industry, size, and pre performance adjusted cash flow rate $(\triangle \mathrm{ACFR}+\mathrm{i})$ is defined as ACFRi at each post year $(\mathrm{i}=1,2,3)$ minus the last year prior to transaction $(\mathrm{i}=-1)$. The change in industry, size, and pre performance adjusted cash flow rate $(\triangle \mathrm{ACFRmd})$ is defined as 3-year median ACFR (ACFRpost) minus the last year prior to transaction (ACFRt-1). Outliers have been winsorized using Huber's M estimator approach. Significance of mean and median are measured using a standard two-tailed t- test and a two-tailed Wilcoxon signed rank test, respectively. $* * *$ denotes significance at the $1 \%$ level, $* *$ significance at the $5 \%$ level, * significance at the $10 \%$ level.

Panel A Operating Cash Flows

\begin{tabular}{|c|c|c|c|c|c|c|c|c|c|c|c|c|}
\hline \multirow{2}{*}{$\begin{array}{l}\text { Year Relative to } \\
\text { Acquisition }\end{array}$} & \multicolumn{3}{|c|}{ Mergering Firms (MEGi $)$} & \multicolumn{3}{|c|}{ Matched Firms (MAT $i$ ) } & \multicolumn{6}{|c|}{$\begin{array}{c}\text { Industry, Size, and Pre-performance Adjusted } \\
(\text { MEGi-MATi=ACFRt+i) }\end{array}$} \\
\hline & $\mathrm{N}$ & Mean $\%$ & Median $\%$ & $\mathrm{~N}$ & Mean $\%$ & Median \% & $\overline{\mathrm{N}}$ & $\mathrm{Me}$ & & Med & $\overline{a n} \%$ & Positive \\
\hline-3 & 194 & 13.09 & 12.57 & 194 & 14.38 & 14.21 & 194 & -1.29 & $* *$ & -0.91 & $* *$ & $43.81 \%$ \\
\hline-2 & 260 & 12.27 & 11.91 & 260 & 13.84 & 13.32 & 260 & -1.57 & $* * *$ & -0.70 & $* * *$ & $47.31 \%$ \\
\hline-1 & 282 & 11.35 & 11.22 & 282 & 13.46 & 12.85 & 282 & -2.11 & $* * *$ & -1.37 & $* * *$ & $39.01 \%$ \\
\hline 1 & 282 & 11.41 & 11.06 & 282 & 10.88 & 10.52 & 282 & 0.53 & & 0.23 & & $54.61 \%$ \\
\hline 2 & 280 & 11.81 & 11.72 & 280 & 11.61 & 11.12 & 280 & 0.20 & & 0.54 & & $52.14 \%$ \\
\hline 3 & 279 & 12.87 & 12.47 & 279 & 12.71 & 12.15 & 279 & 0.16 & & 0.17 & & $50.18 \%$ \\
\hline \multicolumn{7}{|c|}{ ACFRpre: Median for years ( -3 to -1$)$} & 282 & -1.51 & $* * *$ & -0.70 & $* * *$ & $43.26 \%$ \\
\hline \multicolumn{7}{|c|}{ ACFRpost: Median for years $(+1$ to +3$)$} & 282 & 0.31 & & 0.59 & & $53.19 \%$ \\
\hline
\end{tabular}

Panel B Change in Operating Cash Flow Rate

\begin{tabular}{|c|c|c|c|c|c|c|}
\hline \multirow[t]{2}{*}{ Year } & \multicolumn{6}{|c|}{$\begin{array}{l}\text { Industry, Size, and Pre-performance Adjusted } \\
\quad(\text { MEGi-MATi=ACFRt }+\mathrm{i})\end{array}$} \\
\hline & $\mathrm{N}$ & Mea & & & edian $\%$ & Positive \\
\hline$\triangle \mathrm{ACFR}_{\mathrm{pre}}:\left(\mathrm{ACFR}_{\mathrm{t}-1}-\mathrm{ACFR}_{\mathrm{t}-3}\right)$ & 194 & -0.86 & & -0.22 & & $42.27 \%$ \\
\hline$\triangle \operatorname{ACFR}_{1}:\left(\operatorname{ACFR}_{t+1}-\operatorname{ACFR}_{t-1}\right)$ & 282 & 2.64 & *** & 2.03 & $* * *$ & $63.48 \%$ \\
\hline$\triangle \mathrm{ACFR}_{2}:\left(\mathrm{ACFR}_{\mathrm{t}+2}-\mathrm{ACFR}_{\mathrm{t}-1}\right)$ & 280 & 2.36 & *** & 2.28 & $* * *$ & $58.57 \%$ \\
\hline$\triangle \mathrm{ACFR}_{3}:\left(\mathrm{ACFR}_{\mathrm{t}+3}-\mathrm{ACFR}_{\mathrm{t}-1}\right)$ & 279 & 2.27 & *** & 2.25 & ${ }^{* * *}$ & $58.06 \%$ \\
\hline$\triangle \mathrm{ACFR}_{\text {md }}:\left(\mathrm{ACFR}_{\text {post }}-\mathrm{ACFR}_{\mathrm{t}-1}\right)$ & 282 & 2.42 & *** & 2.15 & ${ }^{* * *}$ & $62.06 \%$ \\
\hline
\end{tabular}

Panel C Regression of $\mathrm{ACFR}_{\mathrm{t}=+1,+2,+3}$ on $\mathrm{ACFR}_{\mathrm{t}-1}$

\begin{tabular}{l|c|c}
\hline \multicolumn{1}{c|}{ Regression } & $\mathrm{F}$ & adj. $\mathrm{R}^{2}$ \\
\hline $\mathrm{ACFR}_{\mathrm{t}+1}=0.016^{* * *}+0.494^{* * *} \mathrm{ACFR}_{\mathrm{t}-1}$ & $76.781^{* * *}$ & $21.2 \%$ \\
$\mathrm{ACFR}_{\mathrm{t}+2}=0.013^{* * *}+0.527 * * * \mathrm{ACFR}_{\mathrm{t}-1}$ & $77.915^{* * *}$ & $21.6 \%$ \\
$\mathrm{ACFR}_{\mathrm{t}+3}=0.012^{* *}+0.483^{* * *} \mathrm{ACFR}_{\mathrm{t}-1}$ & $57.604^{* * *}$ & $16.9 \%$ \\
$\mathrm{ACFR}_{\text {median }(\mathrm{t}+1 \sim+3)}=0.014^{* * *}+0.504^{* * *} \mathrm{ACFR}_{\mathrm{t}-1}$ & $93.849^{* * *}$ & $24.8 \%$
\end{tabular}


Interestingly, the ownership variables have no effect on the first two years $(A C F R t+1$ and $A C F R t+2$ in panel A of Table 8.13), but the institutional variables are significantly positive when related to the post performance at the first year $(\mathrm{ACFR} t+1)$ alone. This result is rather consistent with intuition. Since this thesis is examining a specific corporate event, it is reasonable to conclude that good legal protection plays an important role in creating better corporate performance for acquiring firms at the beginning. By contrast, the strong influence (good or bad) of controlling shareholders takes time to come into play. Besides, when merely comparing to the pre performance at the single last year prior to the event, it is clear that a significant non-linear relationship still exists between the median post operating performance (ACFRpost) and the voting shares of controlling shareholders without controlling the institutional variables (model 7). Once the legal protection is put into consideration (model 8.1 and 9.1), controlling shareholders seem to lose their influence over the median of post performance (ACFRpost) through acquisitions. This result was also found in the main analyses as basic conclusion and in the robustness test by bootstrap standard error estimators.

For governance variables, separation has the strongest effect on the first year adjusted post performance $\left(A C F R_{t^{+1}}\right)$; this indicates that controlling shareholders in acquisition firms are still likely to expropriate minority shareholders through acquisitions by separating their voting rights from cash flow rights, even in the countries with strong shareholder protection. In the tradition of years past, other governance variables like controlling CEO, CEO duality and board size, play a much more important role.

For deal variables, if those factors are further classified into variables with transaction characteristics (deal- specific variables) and variables with company characteristics (firmspecific variables), deal- specific variables emerge such as payment type (PAY_stock) and multiple bidders (COMPETE); their significance becomes clear at the first two years and when the firm- specific variables like size relatedness (SIZE_rel) and acquirers leverage (LEV) stay to the end. Moreover, when this study regressed on the smooth median post performance (ACFRpost) instead of $\mathrm{ACFR}_{t+i}$, the results are similar to the basic conclusions in table 6.4 to table 6.6 those are controlled by the median pre performance over a three-year window (ACFRpre).

In terms of the change performance measure $\left(\triangle A C F R_{i}\right)$ in table 8.13 panel $\mathbf{B}$, it seems that model 7 loses its explanatory power on $\triangle A C F R_{t+1}, \triangle A C F R_{t+2}$ and $\triangle A C F R_{m d}$. This means 
that those independent variables are not strong enough to explain the abnormal adjusted returns. While the explanatory power of model 8.1 and model 9.1 improves after putting institutional variables into consideration, it is still weakly significant at a 10 percent level. Until year $\mathrm{t}+3$, the consistent patterns for post operating performance (as stated above) are observed. These results verify Ghosh's (2001: p167) concern regarding the use of the mean or the median post year performance in comparison with data from year $\mathrm{t}-1$. As he suggested, a possible alternative is "to take the mean of year 2 and 3, ignoring year $t+1$ information because of possible integration costs." In this thesis, it becomes clear that even when using the median performance of post three years, the results are still influenced at the first beginning years once the year $\mathrm{t}-1$ is adopted as the benchmark of pre-performance. This thesis postulates the benchmark on a set of year $\mathrm{t}-1$; the results are easily prejudiced due to the presence of extreme observations, and this influence takes a much longer time to offset. This problem is even worse when the abnormal returns are measured by the change in adjusted cash flow returns. In summary, this thesis finds that some valuable information may be specifically released and the change performance measures may be biased at the first beginning years by using the different year window to examine operating performance. Fortunately, the basic conclusions for ownership structure, governance mechanisms, institutional functions and legal characteristics are still qualitatively similar. 
Table 8.13 Ownership Structure, Institutional Mechanisms and Acquiring Firm Performance: Robustness Test on Year Window of Measuring Performance

Sample of 282 mergers and acquisitions by 222 acquiring firms in 11 English Origin countries (Australia, Canada, India, Ireland, Israel, Malaysia, New Zealand, Singapore, South Africa, Thailand and United Kingdom) between 1997 and 2001 for completed transactions over US\$ 10 million are obtained from the Thomson Financial Securities Data's SDC PlatinumTM Worldwide Mergers \& Acquisitions Database. Industry, Size, and Pre performance Adjusted Operating Cash Flow Rates (ACFRt $+\mathrm{i})$ is operating cash flow rates of merged firms minus those of matched firms at the year i (i=-1,-2,-3,1,2,3). ACFRpost is the 3-year median post industry, size, and pre performance adjusted cash flow return. The change in industry, size, and pre performance adjusted cash flow rate ( $\triangle \mathrm{ACFRt}+\mathrm{i})$ is defined as ACFRi at each post year $(\mathrm{i}=1,2,3)$ minus the last year prior to transaction $(\mathrm{i}=-1)$. The change in industry, size, and pre performance adjusted cash flow rate $(\triangle \mathrm{ACFRmd})$ is defined as 3 -year median posst ACFR (ACFRpost) minus the last year prior to transaction (ACFRt-1). Outliers have been winsorized using Huber's M estimator approach. Two tail tests *** denotes significant at the 1\% level, ** significant at the $5 \%$ level, * significant at the $10 \%$ level. See table 5.5 for variable definitions.

\section{Panel A: Regression on Adjusted Post Operating Performance (ACFR $\left.{ }_{t+i}, \mathrm{i}=1,2,3\right)$}

\begin{tabular}{|c|c|c|c|c|c|c|c|c|c|c|c|c|}
\hline \multirow{2}{*}{$(\mathrm{N}=\mathbf{2 8 2})$} & \multicolumn{3}{|c|}{$\overline{\mathbf{A C F R}_{\mathrm{t}+1}}$} & \multicolumn{3}{|c|}{$\mathbf{A C F R}_{\mathrm{t}+2}$} & \multicolumn{3}{|c|}{$\mathbf{A C F R}_{t+3}$} & \multicolumn{3}{|c|}{ ACFRpost } \\
\hline & Model 7 & $\begin{array}{l}\text { Model } 8.1 \\
\end{array}$ & \begin{tabular}{|l|} 
Model 9.1 \\
\end{tabular} & Model 7 & $\begin{array}{l}\text { Model } 8.1 \\
\end{array}$ & $\begin{array}{l}\text { Model 9.1 } \\
\end{array}$ & $\begin{array}{l}\text { Model } 7 \\
\end{array}$ & \begin{tabular}{|l|} 
Model 8.1 \\
\end{tabular} & $\begin{array}{l}\text { Model 9.1 } \\
\end{array}$ & $\begin{array}{l}\text { Model } 7 \\
\end{array}$ & Model 8.1 & $\begin{array}{l}\text { Model 9.1 } \\
\end{array}$ \\
\hline Intercept & (0.056** & (0.046 & - & (0.064** & (0.091* & $0.174^{* * *}$ & (0.026 & (0.043 & (0.016 & $0.055^{* * *}$ & (0.070** & (20.110 \\
\hline LSH1P & -0.057 & -0.035 & -0.032 & -0.125 & -0.085 & -0.080 & $-0.316^{* *}$ & -0.310 & $-0.319^{* *}$ & $-0.181^{*}$ & -0.145 & -0.146 \\
\hline LSH1PSQ & 0.445 & 0.115 & 0.054 & 0.563 & 0.296 & 0.266 & $1.042^{* *}$ & $0.932^{* *}$ & 0.916 ** & $0.794^{* *}$ & 0.504 & 0.484 \\
\hline LSH1PCUBE & -0.497 & -0.149 & -0.088 & $\ldots$ & -0.245 & -0.219 & $-0.791^{* *}$ & $-0.657^{*}$ & $-0.631^{*}$ & $-0.697^{* *}$ & - & -0.398 \\
\hline SEP & $-0.039^{* * *}$ & $-0.040^{* * * *}$ & $-0.037^{* * * *-}$ & $-0.034^{-* * *}$ & $-0.039^{\text {**** }}$ & $-0.039^{* *}$ & -0.016 & -0.025 & -0.024 & $-0.023^{*}$ & $-0.027^{* * 4}$ & -0.026 \\
\hline CEOLSH & 0.013 & $0.024^{*}$ & $0.025^{*}$ & 0.025 & 0.025 & 0.025 & $0.032^{* *}$ & $0.037^{* *}$ & $0.038^{* *}$ & 0.017 & 0.022 & 0.022 \\
\hline CEOdual & 0.014 & 0.013 & 0.013 & -0.008 & -0.010 & -0.012 & $-0.025^{* *}$ & $-0.023^{* *}$ & $-0.024 * *$ & -0.005 & -0.006 & -0.008 \\
\hline BSIZE & 0.000 & 0.000 & 0.000 & $-0.003 *$ & $-0.003^{* *}$ & $-0.003^{* *}$ & $-0.004 * * *$ & $-0.004^{* * * *}$ & $-0.004 * *$ & $-0.003^{* *}$ & $-0.003^{* *}$ & -0.002 * \\
\hline INDDIR & -0.020 & -0.037 & -0.042 & -0.027 & $-0.060^{* *}$ & $-0.061^{* *}$ & 0.007 & 0.002 & -0.005 & -0.018 & -0.037 & -0.042 \\
\hline TGORI_English & 0.012 & 0.007 & 0.006 & 0.001 & -0.003 & -0.002 & 0.024 & 0.018 & 0.018 & 0.007 & 0.001 & 0.002 \\
\hline ATTI_Hostile & -0.014 & -0.020 & -0.015 & 0.003 & 0.012 & 0.011 & 0.029 & 0.026 & 0.021 & 0.006 & 0.011 & 0.009 \\
\hline PAY_stock & $-0.019^{*}$ & $-0.021 *$ & $-0.021 *$ & -0.015 & -0.017 & -0.018 & -0.010 & -0.010 & -0.010 & $-0.021^{* *}$ & $-0.022^{* *}$ & $-0.023^{* * *}$ \\
\hline COMPETE & -0.016 & -0.018 & -0.018 & $-0.036^{* *}$ & $-0.036{ }^{* *}$ & $-0.036^{* *}$ & -0.025 & -0.028 & -0.028 & $-0.033^{* *}$ & $-0.034^{* *}$ & $-0.034^{* * *}$ \\
\hline IND_rel & -0.002 & -0.003 & -0.002 & 0.005 & 0.002 & 0.003 & 0.008 & 0.008 & 0.008 & 0.000 & -0.002 & -0.001 \\
\hline TOEHOLD & -0.004 & 0.000 & -0.004 & 0.014 & $0.020^{*}$ & 0.019 & 0.009 & 0.011 & 0.009 & 0.005 & 0.011 & 0.009 \\
\hline PREM_1day & 0.000 * & 0.000 & 0.000 & 0.000 & 0.000 & 0.000 & 0.000 & 0.000 & 0.000 & 0.000 & 0.000 & 0.000 \\
\hline SIZE_rel & $-0.006^{* *}$ & $-0.005^{* *}$ & $-0.005^{* *}$ & -0.004 & -0.004 & -0.004 & $-0.007^{* *}$ & $-0.007^{* *}$ & $-0.007^{* *}$ & $-0.005^{* *}$ & $-0.005^{* *}$ & $-0.005^{* *}$ \\
\hline LEV & $0.008^{* *}$ & $0.007^{*}$ & $0.007^{*}$ & 0.000 & 0.000 & -0.002 & $-0.009^{* *}$ & $-0.008^{* * *}$ & $-0.009^{*}$ & $\ldots$ & -0.002 & -0.003 \\
\hline $\begin{array}{l}\text { ANTIDIR_high } \\
\text { XLEG high }\end{array}$ & & $\begin{array}{l}0.071 \\
0.032\end{array}$ & & & $\begin{array}{r}0.029 \\
-0.038\end{array}$ & & & $\begin{array}{r}0.014 \\
-0.031\end{array}$ & & & $\begin{array}{r}0.046 \\
-0.031\end{array}$ & \\
\hline NANTIDIR high & & & -0.071 *** & & & 0.027 & & & 0.019 & & & $0.039^{*}$ \\
\hline$U K$ & & -0.094 & $-0.072^{*}$ & & -0.005 & -0.015 & & 0.002 & -0.026 & & -0.024 & -0.032 \\
\hline CAN & & $-0.044^{* *}$ & $0.044^{*}$ & & -0.006 & 0.016 & & -0.025 & 0.004 & & -0.031 & 0.015 \\
\hline$A U S$ & & 0.005 & $0.042^{*}$ & & 0.049 & 0.021 & & $0.054^{*}$ & 0.036 & & $0.049^{*}$ & 0.027 \\
\hline $\mathrm{ACFR}_{t-1}$ & $0.412^{* * *}$ & 0.420 & $0.419^{* * * *}$ & $0.481^{* * * * *}$ & $0.465^{-6 * * * *}$ & $0.476^{* * * a}$ & $0.452^{* * * *}$ & $0.448^{* * * *}$ & $0.457^{* * * *-1}$ & $0.472^{* * * *}$ & $0.463^{* * * *}$ & 0.474 \\
\hline $\begin{array}{l}\text { adjusted } R^{2} \\
F\end{array}$ & $\begin{array}{c}27.6 \\
6.651^{* * *}\end{array}$ & $\begin{array}{c}29.9 \\
5.993^{* * * *}\end{array}$ & $\begin{array}{c}30.6 \\
6.152^{* * *}\end{array}$ & $\begin{array}{c}23.8 \\
5.618^{* * *}\end{array}$ & $\begin{array}{c}25.9 \\
5.099 * * *\end{array}$ & $\begin{array}{c}25.5 \\
5.003^{* * *}\end{array}$ & $\begin{array}{c}22.3 \\
5.253^{* * *}\end{array}$ & $\begin{array}{c}22.9 \\
4.447^{* * *}\end{array}$ & $\begin{array}{c}22.5 \\
4.391 * * *\end{array}$ & $\begin{array}{c}28.6 \\
6.910^{* * *}\end{array}$ & $\begin{array}{c}31.4 \\
6.355^{* * *}\end{array}$ & $\begin{array}{c}30.0 \\
6.027^{* * *}\end{array}$ \\
\hline
\end{tabular}


Table 8.13 (Continued)

Panel B: Regression on the Change Operating Performance ( $\triangle \mathrm{ACFR}$ )

\begin{tabular}{|c|c|c|c|c|c|c|c|c|c|c|c|c|}
\hline \multirow{2}{*}{$(\mathrm{N}=\mathbf{2 8 2})$} & \multicolumn{3}{|c|}{$\triangle \mathrm{ACFR}_{1}=\mathrm{ACFR}_{t+1}-\mathrm{ACFR}_{\mathrm{t}-1}$} & \multicolumn{3}{|c|}{$\triangle \mathrm{ACFR}_{2}=\mathrm{ACFR}_{\mathrm{t}+2}-\mathrm{ACFR}_{\mathrm{t}-1}$} & \multicolumn{3}{|c|}{$\triangle \mathrm{ACFR}_{3}=\mathrm{ACFR}_{\mathrm{t}+3}-\mathrm{ACFR}_{\mathrm{t}-1}$} & \multicolumn{3}{|c|}{$\triangle \mathrm{ACFR}_{\mathrm{md}}=\mathrm{ACFR}_{\mathrm{md}(\mathrm{t}+1 \sim t+3)^{-}} \mathrm{ACFR}_{\mathrm{t}-1}$} \\
\hline & Model 7 & Model 8.1 & Model 9.1 & Model 7 & Model 8.1 & Model 9.1 & Model 7 & Model 8.1 & Model 9.1 & Model 7 & Model 8.1 & Model 9.1 \\
\hline$\overline{\text { Intercept }}$ & 0.020 & 0.011 & -0.062 & 0.034 & 0.058 & $0.143^{*}$ & $\begin{array}{c}-0.007 \\
\end{array}$ & 0.009 & 0.020 & 0.023 & 0.038 & 0.081 \\
\hline LSH1P & -0.002 & 0.011 & 0.021 & -0.078 & -0.040 & -0.031 & $-0.278^{* *}$ & $-0.272^{* *}$ & $-0.279^{* *}$ & -0.131 & -0.102 & -0.098 \\
\hline LSH1PSQ & 0.215 & -0.148 & -0.207 & 0.425 & 0.085 & 0.065 & $0.886^{*}$ & 0.718 & 0.737 & 0.588 & 0.260 & 0.248 \\
\hline LSH1PCUBE & -0.293 & 0.108 & 0.161 & -0.368 & -0.048 & -0.038 & -0.653 & -0.444 & -0.460 & -0.513 & -0.180 & -0.173 \\
\hline SEP & $-0.026^{*}$ & -0.024 & -0.022 & -0.024 & -0.025 & -0.025 & -0.004 & -0.010 & -0.010 & -0.012 & -0.012 & -0.012 \\
\hline CEOLSH & 0.000 & 0.013 & 0.013 & 0.011 & 0.015 & 0.014 & 0.019 & 0.028 & 0.027 & 0.004 & 0.012 & 0.011 \\
\hline CEOdual & 0.011 & 0.009 & 0.009 & -0.011 & -0.014 & -0.016 & $-0.028^{* *}$ & $-0.026^{* *}$ & $-0.027^{* *}$ & -0.008 & -0.010 & -0.012 \\
\hline INDDIR & -0.015 & -0.032 & -0.033 & -0.022 & -0.054 & -0.052 & 0.011 & 0.012 & 0.007 & -0.013 & -0.032 & -0.033 \\
\hline OTHLSH & 0.004 & 0.004 & 0.006 & 0.008 & 0.008 & 0.010 & $0.029^{*}$ & $0.030^{* *}$ & $0.032^{* *}$ & 0.013 & 0.012 & 0.015 \\
\hline TGORI_English & 0.029 & 0.023 & 0.021 & 0.016 & 0.012 & 0.012 & $0.038^{*}$ & 0.031 & 0.031 & 0.021 & 0.016 & 0.016 \\
\hline ATTI_Hostile & -0.006 & -0.019 & -0.009 & 0.009 & 0.013 & 0.016 & 0.037 & 0.031 & 0.028 & 0.013 & 0.012 & 0.015 \\
\hline PAY_stock & $-0.027^{* *}$ & $-0.028^{* *}$ & $-0.028^{* *}$ & $-0.023^{*}$ & $-0.025^{*}$ & $-0.026^{* *}$ & -0.018 & -0.018 & -0.018 & $-0.028^{* *}$ & $-0.029^{* *}$ & $-0.029^{* *}$ \\
\hline COMPETE & $-0.033^{*}$ & $-0.034^{*}$ & $-0.034^{*}$ & $-0.052^{* * *}$ & $-0.051^{* * *}$ & $-0.050^{* * *}$ & $-0.042^{* *}$ & $-0.044^{* *}$ & $-0.043^{* *}$ & $-0.048^{* * *}$ & $-0.049^{* * *}$ & $-0.048^{* * *}$ \\
\hline IND_rel & 0.003 & 0.003 & 0.004 & 0.009 & 0.007 & 0.008 & 0.012 & 0.013 & 0.013 & 0.004 & 0.004 & 0.005 \\
\hline TOEHOLD & 0.007 & 0.008 & 0.006 & $0.023^{*}$ & $0.028^{* *}$ & $0.028^{* *}$ & 0.016 & 0.017 & 0.014 & 0.015 & 0.019 & 0.017 \\
\hline SIZE_rel & -0.002 & -0.001 & -0.001 & 0.000 & 0.000 & 0.000 & -0.003 & -0.003 & -0.003 & -0.002 & -0.001 & -0.002 \\
\hline LEV & 0.001 & -0.001 & -0.001 & -0.006 & $-0.008^{*}$ & $-0.008^{* *}$ & $-0.015^{* * *}$ & $-0.015^{* * *}$ & $-0.016^{* * *}$ & $-0.008^{* *}$ & $-0.009^{* *}$ & $-0.009^{* *}$ \\
\hline ANTIDIR_high & & $0.074^{* *}$ & & & 0.040 & & & 0.026 & & & $0.049^{*}$ & \\
\hline XLEG_high & & $0.064^{*}$ & & & -0.010 & & & -0.020 & & & -0.002 & \\
\hline ANTISDI & & & 0.102 & & & -0.114 & & & -0.016 & & & -0.056 \\
\hline NANTIDIR high & & & $0.070^{* *}$ & & & 0.031 & & & 0.016 & & & $0.038^{*}$ \\
\hline UK & & $-0.132^{* * *}$ & $-0.084^{* * *}$ & & $-0.046^{*}$ & -0.031 & & -0.023 & -0.030 & & -0.059 & -0.043 \\
\hline$C A N$ & & $-0.054^{* *}$ & 0.029 & & -0.023 & 0.003 & & $-0.044^{*}$ & -0.018 & & $-0.040^{*}$ & 0.001 \\
\hline AUS & & -0.029 & 0.028 & & 0.019 & 0.008 & & 0.039 & 0.022 & & 0.017 & 0.015 \\
\hline$\overline{\text { adjusted } \mathrm{R}^{2}}$ & 0.9 & 4.0 & 4.2 & 2.2 & 3.8 & 3.7 & 6.5 & 7.5 & 6.9 & 2.7 & 4.7 & 4.1 \\
\hline $\mathrm{F}$ & 1.136 & $1.505^{*}$ & $1.540 *$ & 1.354 & $1.480 *$ & $1.473 *$ & $2.088^{* * *}$ & $1.986 * * *$ & $1.911 * * *$ & 1.427 & $1.600^{* *}$ & $1.526^{*}$ \\
\hline
\end{tabular}




\section{Chapter Nine \\ Conclusions}

\subsection{Introduction}

This thesis provides empirical evidence concerning the relationship between concentrated ownership structures and the long-term operating performance of acquiring firms in English origin countries other than the US. The primary agency problems in concentrated ownership structures are not between owners and managers, but between large shareholders and minority shareholders. Large shareholders are generally viewed as beneficial monitors of corporate performance. High levels of concentration, however, can lead to potential expropriation from minority shareholders via managerial entrenchment, tunneling, or sub-optimal investment decisions. This problem is potentially greater in firms with a separation of voting and cash flow rights. Corporate governance research mostly relies on the effectiveness of internal and external monitoring mechanisms to mitigate agency costs; recent studies focus more heavily on legal institutions.

According to the classification and investigation of La Porta, Lopez-de-Silanes, Shleifer and Vishny (LLSV, 1998), countries in English origin families are generally lumped together and viewed as possessing the strongest legal protections for minority shareholders. Companies in these countries are also shown to have higher firm performance. However, the levels of shareholders protection, either proxied by anti-director right indexes in LLSV (1998), extra-legal institutions in Dyck and Zinglaes (2003), or the new anti-self dealing measure in Djankov, La Porta, Lopez-de-Silanes and Shleifer (DLLV, 2006) vary among the countries in English common law families. One line of M\&A studies provides evidence to suggest that controlling shareholders in countries with poor legal systems generally expropriate minority shareholders through acquisition transactions. Another line of study, however, shows that in countries with higher levels of investor protection the tunneling costs may be too high for controlling shareholders to entertain expropriation via M\&As deals.

Compared to most governance literature that tests general corporate performance, this thesis investigates the impact of ownership structures on firm performance around specific mergers and acquisitions because these transactions are large and significant investments in a 
firm's life. Whereas most M\&A research adopts an event study methodology to evaluate the short-term market performance, this thesis examines the improvement of acquisition performance by measuring long-term accounting based performance to better captures the economic consequences and the underlying drivers. This thesis presents Healy, Palepu and Ruback (HPR, 1992) regression-based results and the results of a change model (Ghosh 2001). Furthermore, it matches benchmark firms based on industry, size and pre-performance, similar to the technique of Barber and Lyon (1996).

The existing international governance literature generally compares corporate performance among different legal origins under the assumption that companies in countries with same legal origins are homogeneous: this is not true. Hence, this thesis proves that the levels of legal/ extra- legal investor protection are different even in countries with the same legal origins and that they have a significant impact on firm performance. This thesis also evaluates the effectiveness of monitoring mechanisms in corporate governance and completes the debate about deal characteristics.

\subsection{Main Findings}

First of all, for the improvement of acquisition performance this thesis finds that the changes in adjusted operating cash flow rates are significantly improved after M\&A events. It also finds that after controlling the effects of pre-acquisition performance, the operating performance of merging firms is significantly improved in post-merger periods. These evidence confirms the synergy hypothesis which states that M\&A transactions should improve the long-term financial and operating performance of merging firms to reflect that accounting performance can capture real economic creations (HPR 1992). In addition, this thesis finds that improvement in the operating performance of sample firms is primarily achieved by an increase in cash flow margins rather than by asset turnover. Also, higher sales growth after acquisitions is also noted in this sample. This finding agrees with Ghosh's (2001) observations.

Second, for the potential consequences of concentrated ownership, this thesis produces results showing that after controlling for well-documented governance mechanisms and deal characteristics, there exists a non-linear relationship between concentrated 
ownership and the level and change in operating cash flow returns after acquisitions. Value creating deals are associated with higher levels of concentration consistent with decreasing agency costs as the controlling shareholder's wealth invested in the acquiring firm increases. The companies with large shareholders but with a lower holding of voting shares significantly underperform when compared to their peers. The curvilinear relationship expressed in this thesis is similar to that described by Morck, Shleifer and Vishny (1988b) and Anderson and Reeb (2003). Furthermore, this thesis confirms Ben-Amar and André (2006) who finds that the separation of ownership and voting rights leads to greater value destruction. Since these findings prove that ownership effects still exist even in acquiring firms with a so-called better legal system, this thesis concludes that legal origin itself is not enough to speak for a good corporate governance system which might mitigate agency costs.

Furthermore, before controlling institutional variables this thesis does not find any significant evidence to prove that family controlled firms use M\&As to obtain private benefits at the expense of minority shareholders. However, once institution mechanisms are controlled, it does find that family firms underperform when compared to non-family firms after M\&A transactions. This result contradicts the view that family firms tend to make value-persisting investment projects to maximize the firm value (Anderson and Reeb 2003). It is also clear that acquiring firms controlled by financial institutions have significantly poor acquisition performance. That financial institutional large shareholders do not act as effective monitors on M\&A decisions may be owing to their short-term vision and conservative natures. These results further support the findings in Weinstein and Yafeh (1998).

Third, for a broad set of corporate governance mechanisms, this thesis shows that acquiring firms with controlling CEO make significant improvements in post acquisition performance after controlling pre-performance. The presence of CEO-Chairman duality and board size are both significantly negatively associated with acquisition operating performance. When the cross effects between the type I agency problem (separation between ownership and voting rights) and the type II agency problem (separation between ownership and management) are compared, this thesis finds that controlling CEO has positive and dominant effects in the sample of this thesis. Once the type II agency cost is curbed, there exists no significant difference between companies with and without type I agency costs. The average performance in companies without type II but with type I agency costs is still 
significantly superior to that in companies without type I but with type II agency costs. These results are supported when compared with those discovered by Villalonga and Amit (2006).

Fourth, for the second generation governance mechanisms, this thesis concludes that the different level of legal mechanisms has a significant effect on acquisition operating performance among countries with the same legal origins. The greater investor protection, as measured by the initial anti-director right index in LLSV (1998) and revised anti-director rights index in DLLS (2006) has a positive impact on operating cash flow returns from acquisitions. However, this thesis does not document any differential performance with respect to the extra- legal systems of Dyck and Zingales (2004) and the anti-self-dealing index of DLLS (2006).

Thus, the empirical results of the broad set of corporate governance mechanisms again prove that individual governance mechanisms and characteristics of the legal system are important determinants of acquisition performance in English origin countries. Research focusing on the difference between legal families needs to exert some care when lumping all English origin firms together as having the same well-developed corporate governance and investor protections; firm and country-level protections can vary substantially even in the same legal system and thereby remain important for explaining differences in firm performance.

Finally, for deal characteristics, this thesis provides stable evidence concerning the significantly negative relationship between the acquiring performance and M\&A transactions with more than one bidder. The higher deviation in the size ratio of bidders and targets brings on a poorer post operating performance but not on the change performance. After controlling for institutional variables, a significant but negative relationship exists between the degree of the acquirer's leverage and the change performance. Except for the above deal variables, this thesis finds no significant relationship with other transaction characteristics such as target origin, transaction attitude, payment type, industry relatedness, toehold interests, and premium. 


\subsection{Limitations}

As with all empirical work, a number of limitations need to be considered regarding this thesis. First, the reason this thesis uses operating cash flow as the measure of long-term performance is to avoid most accounting ratios (such as ROA) which can be easily manipulated (Erickson and Wang 1999) or biased due to the accounting for mergers or the method of payment. However, it agrees with Powell and Stark (2005) that the HPR methodology using EBITDA as a denominator is still accrual based and that it is likely to be distorted by particular accounting policies. Data with respect to cash flow from operations varies from country to country as the cash flow statement is the least standardized of the statements in use. Powell and Stark (2005) suggest a 'pure' cash flow measure that is defined as pre-depreciation profit adjusted for changes in working capital. They compare both measures (EBITDA and pure cash flow) and conclude that results can be sensitive to particular methodological definitions but that inferences drawn are relatively robust to methodological concerns raised. While EBITDA may lead to some biased conclusions, this thesis still employs EBITDA as the operating cash flow measure in order to make results compatible with most papers that look at operational performance improvements following a significant corporate event (HPR 1992, Linn and Switzer 2001, Ghosh 2001).

Second, this thesis uses the market value of assets to deflate the measure of operating cash flow as based on the assumptions in HPR (1992) that the market is efficient to adjust price swiftly in relation to the news announcement, and that market values better represent the opportunity cost of the assets. However, this thesis also agrees with Powell and Stark (2005) that market values are a forward-looking measure and that investors tend to overestimate the expected gains arising from takeover. HPR (1992) also recognize that their market-based measure is potentially limited and thus test its sensitivity. They conclude that asset values based on either market or book do not affect the results; a conclusion reinforced by Powell and Stark (2005).

Third, the reason this thesis uses ROA as the proxy to develop performance-matching benchmark groups is simply because this measure is adopted by Barber and Lyon (1996) and is quite commonly used in prior studies. Also, this measure is available in Thomson Financial database that could easily be used as a filter. However, this thesis agrees with Ghosh (2001) and Powell and Stark (2005) that it might be helpful to do the matching on 
pre-deal operating cash flows. The exact pre-performance metric does vary from one study to the other and there exists no formal means of testing the impact of this choice on results. Ghosh (2001) and Powell and Stark, (2005) have no examination for their pre-performance matching criteria either. Given the fact that performance metrics are highly correlated and that matching on pre-performance is generally the last matching criteria, i.e., leaving a relatively small number of potential matches anyway, this thesis expects that the difference is likely minimal. Although this difference still remains an empirical question, the operation of a different matching scheme is a non-trivial extension that has not been performed for this investigation.

Fourth, this thesis does not include the acquisition of private targets. It agrees with Fuller, Netter and Stegemoller (2002) that looking at the impact of private acquisitions is of genuine interest. Market-based performance studies do point to a differential response. Nevertheless, the accounting-based performance literature, like this thesis, generally focuses on public acquisitions because private targets are usually much smaller than the acquirer, making it more difficult to pick up the operational impact. Also, the pre-performance metric is generally the combined performance of both the acquirer and the target; but data with respect to private targets is unavailable.

Finally, this thesis acknowledges that CEO ownership and compensation are important drivers behind M\&A decisions and performance. However, executive compensation has become increasingly complex as firms have formed various executive compensation packages. Moreover, the measures and reports of compensation data on executive bonuses and stock options are not consistent across firms, countries, and periods. Thus, this thesis is constrained by the CEO compensation information and fails to provide evidence in this field. Similarly, as evidenced in the sample, each county has different type of separation. This thesis is limited by a lack of more detailed measurements relative to the degree of separation between control rights and cash flow rights. 


\subsection{Avenues for Future Research}

This thesis provides the following insight for future research. First of all, English origin firms are beginning to see the effects of ownership concentration and governance mechanisms on M\&A performance in a single legal family. It concludes that firm-specific corporate governance and country-specific legal protections, rather than legal origins, have more influence on M\&A value creations. Future research might usefully extend this cross-country (one legal origin) research to cross-legal origins research by investigating the global village. There are many other dimensions to analyze due to the broad range of information. More interesting results might emerge concerning the relationship/mutual influence among ownership structures, governance characteristics, institutional mechanisms, and corporate performance.

Second, the results in this thesis show that most legal measures (except for the initial and revised anti-director right indexes) are sensitive to the particular methodology, operating performance measures and regression models used. One possible consideration that accounts for the sensitivity is the representativeness of these legal indexes. A better development of legal metrics for measuring cross-country differences is needed. For example, Bebchuk, Cohen and Ferrell (2005) constructed the entrenchment index based on "constitutional" and "takeover readiness". They provide evidence suggesting that entrenchment provisions appear to cause lower firm value. Developing this corporate governance index could be of great help in empirical research.

Beyond the representativeness concern, the other question is whether or not it is indeed counter-intuitive when legal measures are negative as related to the firm's performance? Could it be possible that overly strong legal enforcements are costly to the concentrated firm because they exacerbate the agency problem? Further investigation into the optimal legal system is strongly recommended.

Third, like the other empirical literature in the field of performance valuation, the choice of benchmark groups is always the core concern behind the research methodology in this thesis. This thesis basically selects matched firms by similar size, same industry, closest pre-performance and same origin (in the same way as in Barber and Lyon (1996)). However, how and why should certain individual multiples or certain comparable firms be selected? 
Bhojraj and Lee (2002) generate a particular valuation multiple called "warranted multiple" as based on profitability, growth, and risk characteristics. Matched firms whose warranted multiple is closest to that of matching firms are selected. Bhojraj, Lee and Oler (2003) further suggest that using GICS (The Global Industry Classification Standard system) instead of SIC codes as an industry classification scheme could provide a better explanation concerning stock return comovements, cross-sectional variations and various key financial ratios realization. More information on benchmark construction would be helpful in establishing a greater degree of accuracy on this matter.

Beyond benchmark construction, it also seems valuable to consider using a longer window of time for analysis. This thesis observes financial and accounting data for three years (36 months) before and after transactions. But some literature suggest that corporate events continue under- or over- performance beyond 36 months (Loughran and Ritter 2000). Changes over longer periods can be more informative because they might better specify the identity and relationships between observed variables and performance measures.

Fourth, this thesis shows that controlling shareholders who hold company shares at middle levels (around 20\%-60\%) are more likely to make value-enhancing deals because of the incentive effects. Acquiring firms with low level controlled (10-20 percent) and high level controlled (over 60 percent) large shareholders may have higher agency costs which will lead to M\&A performance decreases even in countries with so-called better legal origins. But what is the nature of these agency costs? Are they caused by bad investment choices, by poor management or by potential wealth transfers? This thesis does not attempt to measure this aspect and offers it as a challenge for further studies.

Finally, this thesis concludes by raising a question: why do minority shareholders remain for the ride if tunneling is possible and if investors are assumed to be rational? The concept of propping (negative tunneling) in recent work such as Friedman, Johnson and Mitton (2003) and Bae, Kang and Kim (2002) explains that underperformance might be compensated by the private funds of entrepreneurs, thus inducing small investors to stay on the investment. Propping is an interesting and innovative idea. More information and exploration into this idea might help to establish a greater degree of understanding in this matter. 


\section{References}

Admati, A. R. and Pfleiderer, P. (1994) Large Shareholder Activism, Risk Sharing, and Financial Market Equilibrium. Journal of Political Economy, 102, 1097-1130.

Agrawal, A., Jaffe, J. F. and Mandelker, G. N. (1992) The Post-Merger Performance of Acquiring Firms: A Re-examination of An Anomaly. Journal of Finance, 47, 1605-1621.

Agrawal, A. and Knoeber, C. R. (1996) Firm Performance and Mechanisms to Control Agency Problems between Managers and Shareholders. Journal of Financial and Quantitative Analysis, 31, 377-397.

Amihud, Y. and Lev, B. (1981) Risk Reduction as A Managerial Motive for Conglomerate Mergers. The Bell Journal of Economics, 12, 605-617.

Amihud, Y., Lev, B. and Travlos, N. G. (1990) Corporate Control and the Choice of Investment Financing: The Case of Corporate Acquisitions. Journal of Finance, 45, 603-616.

Anderson, R. C., Durub, A. and Reeb, D. (2006) Family Ownership and Corporate Opacity in the U.S. Working Paper.

Anderson, R. C., Mansi, S. A. and Reeb, D. M. (2003) Founding family ownership and the agency cost of debt. Journal of Financial Economics, vol. 68, p263-285.

Anderson, R. C. and Reeb, D. M. (2003) Founding-Family Ownership and Firm Performance: Evidence from the S\&P 500. Journal of Finance, 58, 1301-1329.

Anderson, R. C. and Reeb, D. M. (2004) Board Composition: Balancing Family Influence in S\&P 500 firms. Administrativ Science Quarterly, 49, 209-238.

André, P., Kooli, M. and L'Her, J.-F. (2004) The Long-run Performance of Mergers and Acquisitions: Evidence from the Canadian Stock Market. Financial Management, 33, 27-43.

Andrade, G., Mitchell, M. and Stafford, E. (2001) New evidence and perspectives on mergers. Journal of Economic Perspectives, 15, 103-120.

Ang, J. S. and Cole, R. A. (2000) Agency Costs and Ownership Structure. Journal of Finance, 55, 81-107.

Angrist, J. D. and Lavy, V. (2002) The Effect of High School Matriculation Awards: Evidence from Randomized Trials. Working Paper.

Asquith, P., Bruner, R. F. and Jr Mullins, D. W. (1983) The Gains To Bidding Firms From Merger. Journal of Financial Economics, 11, 121-139.

Asquith, P. and Kim, E. H. (1982) The Impact of Merger Bids on the Participating Firms' Security Holders. Journal of Finance 37, 1209-1228.

Ayers, B. C., Lefanowicz, C. E. and Robinson, J. R. (2003) Shareholder Taxes in Acquisition Premiums: The Effect of Capital Gains Taxation. The Journal of Finance, 58, 2783-2801.

Bae, K. H., Kang, J. K. and Kim, J. M. (2002) Tunneling or Value Added? Evidence from Mergers by Korean Business Groups. Journal of Finance, 57, 2695-2740.

Baker, J. B. and Bresnahan, T. F. (1985) The Gains from Merger or Collusion in Product-Differentiated Industries. The Journal of Industrial Economics, 33, 427-444.

Ball, R. and Brown, P. (1968) An Empirical Evaluation of Accounting Income Numbers. Journal of Accounting Research, 6, 159-178.

Banerjee, A. and Eckard, E. W. (1998) Are Mega-Mergers Anticompetitive? Evidence from the First Great Merger Wave. The RAND Journal of Economics, 29, 803-827.

Barber, B. M. and Lyon, J. D. (1996) Detecting Abnormal Operating Performance: The Empirical Power and Specification of Test Statistics. Journal of Financial Economics, 41, 359-399.

Barber, B. M. and Lyon, J. D. (1997) Detecting Long-Run Abnormal Stock Returns: The Empirical Power and Specification of Test Statistics. Journal of Financial Economics, 43, 341-372.

Barclay, M. and Holderness, C. (1989) Private Benefits from Control of Public Corporations. Journal of Financial Economics, 25, 371-395. 
Barnett, V. and Lewis, T. (1984) Outliers in Statistical Data, Chichester, Wiley

Barontini, R. and Caprio, L. (2005) The Effect of Ownership Structure and Family Control on Firm Value and Performance: Evidence from Continental Europe Working Paper, European Financial Management Symposium.

Barth, E., Gulbrandsen, T. and Schonea, P. (2005) Family Ownership and Productivity: The Role of Owner-management. Journal of Corporate Finance, 11, 107-127.

Basford, K. E. and McLachlan, G. J. (1985) Estimation of Allocation Rates in a Cluster Analysis Context. Journal of the American Statistical Association, 80, 286-293.

Bebchuk, L., Cohen, A. and Ferrell, A. (2005) What Matters in Corporate Governance? Working Paper.

Bebchuk, L. A., Kraakman, R. and Triantis, G. (2000) Stock Pyramids, Cross-ownership, and Dual Class Equity: The Creation and Agency Costs of Separating Control from Cash Flow Rights. IN Morck, R. K. (Ed.) Concentrated Corporate Ownership. Chicago and London, The University of Chicago Press.

Becher, D. A. and Campbell II, T. L. (2003a) Corporate Governance of Bank Mergers. Walking Paper.

Becher, D. A. and Campbell II, T. L. (2003b) Merger of Equals. Working Paper, Dekalb, IL, USA.

Becht, M. and Mayer, C. (2001) Corporate Control In Europe. IN Barca, F. and Becht, M. (Eds.) The Control of Corporate Europe. Oxford, Oxford Scholarship Online Monographs.

Bell, R. M. and McCaffrey, D. F. (2002) Bias Reduction in Standard Errors for Linear Regression with Multi-Stage Samples. Survey Methodology, 169-179.

Ben-Amar, W. and André, P. (2006) Separation of Ownership from Control and Acquiring Firm Performance: The Case of Family Ownership in Canada. Journal of Business Finance \& Accounting, 33, 517-543.

Bennedsen, M. and Nielsen, K. M. (2005) Separating the Impact of dual class shares, pyramids and cross-ownership on firm value across legal regimes in western Europe. Working Paper, European Financial Management, Symposium.

Beran, R. (1988) Prepivoting Test Statistics: A Bootstrap View of Asymptotic Refinements. Journal of the American Statistical Association, 83, 687-697.

Berkowitz, D., Pistor, K. and Richard, J.-F. (2003) Economic Development, Legality, and the Transplant Effect. European Economic Review, 47, 165-195.

Berle, A. and Means, G. (1932) The Modern Corporation and Private Property, New York, MacMillan.

Bertrand, M., Mehta, P. and Mullainathan, S. (2002) Ferreting Out Tunneling: An Application to Indian Business Groups. The Quarterly Journal of Economics, 2002, 1.

Bhojraj, S. and Lee, C. M. C. (2002) Who Is My Peer? A Valuation-Based Approach to the Selection of Comparable Firms. Journal of Accounting Research, 40, 407-439.

Bhojraj, S., Lee, C. M. C. and Oler, D. K. (2003) What's My Line? A Comparison of Industry Classification Schemes for Capital Market Research. Journal of Accounting Research, 41, 745-774.

Bigelli, M. and Mengoli, S. (2004) Sub-optimal Acquisition Decisions under A Majority Shareholder System Journal of Management and Governance, 8, 373-405.

Billett, M. T., King, T.-H. D. and Mauer, D. C. (2004) Bondholder Wealth Effects in Mergers and Acquisitions: New Evidence from the 1980s and 1990s. Journal of Finance, 59, 107-135.

Binder, J. J. (1985) On the Use of the Multivariate Regression Model in Event Studies. Journal of Accounting Research, 23, 370-383.

Binder, J. J. (1998) The Event Study Methodology Since 1969. Review of Quantitative Finance and Accounting, 11, 111-137.

Black, F. (1972) Capital Market Equilibrium with Restricted Borrowing. The Journal of Business, 45, 444-455. 
Blume, M. E. (1971) On the Assessment of Risk. Journal of Finance 26, 1-10.

Bolton, P. and Von Thadden, E.-L. (1998) Blocks, Liquidity, and Corporate Control. Journal of Finance, 53, 1-25.

Brickley, J. A., Coles, J. L. and Jarrell, G. (1997) Leadership Structure: Separating the CEO and Chairman of the Board. Journal of Corporate Finance, 3, 189-220.

Brickley, J. A., Lease, J. A. and Smith, C. W. (1988) Ownership Structure and Voting on Antitakeover Amendments. Journal of Financial Economics, 20, 267-291.

Bris, A. (2002) Toeholds, Takeover Premium, and the Probability of being Acquired. Journal of Corporate Finance, 8, 227-253.

Bris, A. and Cabolis, C. (2002) Corporate Governance Convergence by Contract: Evidence from Cross-border Mergers. Yale ICF Working Paper, No. 02-32, 40p.

Brown, P. and da Silva Rosa, R. (1998) Research Method and the Long-run Performance of Acquiring Firms. Australian Journal of Management, 23, 23-38.

Brown, S. J. and Warner, J. B. (1980) Measuring Security Price Performance. Journal of Financial Economics, 8, 205-258.

Brown, S. J. and Warner, J. B. (1985) Using Daily Stock Returns: The Case of Event Studies. Journal of Financial Economics, 14, 3-32.

Burkart, M., Panunzi, F. and Shleifer, A. (2003) Family Firms. Journal of Finance, 58, 2167-2201.

Cakici, N., Hessel, C. and Tandon, K. (1996) Foreign Acquisitions in the United States: Effect on Shareholder Wealth of Foreigh Acquiring Firms. Journal of Banking and Finance, 20, 307-329.

Campa, J. M. and Hernando, I. (2004) Shareholder Value Creation in European M\&As. European Financial Management, 10, 47-81.

Campbell, j. Y., Lo, A. W. and MacKinlay, A. C. (1997) The Econometric of Financial Markets, Princeton, New Jersey, Princeton University Press.

Capron, L. and Pistre, N. (2002) When do Acquirers Earn Abnormal Returns? Strategic Management Journal, 23, 781-794.

Carline, N. F., Linn, S. C. and Yadav, P. K. (2002) The Influence of Managerial Ownership on the Real Gains in Corporate Mergers and Market Revaluation of Merger Partners: Empirical Evidence. Working Paper.

Cernat, L. (2004) The Emerging European Corporate Governance Model: Anglo-Saxon, Continental, or Still the Century of Diversity? Journal of European Public Policy, 11, 147-166.

Chandra, R. and Rorhbach, K. (1990) A Methodological Note on Detecting a Location Shift in the Distribution of Abnormal Returns: A Nonparametric Approach. Contemporary Accounting Research, 7, 123-141.

Chatterjee, S. (1986) Types of Synergy and Economic Value: The Impact of Acquisitions on Merging and Rival Firms. Strategic Management Journal, 7, 119-139.

Chowdhry, B. and Jegadeesh, N. (1994) Pre-Tender Offer Share Acquisition Strategy in Takeovers. Journal of Financial and Quantitative Analysis, 29, 117-129.

Ciscel, D. H. and Carroll, T. M. (1980) The Determinants of Executive Salaries: An Econometric Survey. Review of Economics and Statistics, 62, 7-13.

Claessens, S., Djankov, S., Fan, J. P. H. and Lang, L. H. P. (2002) Disentangling the Incentive and Entrenchment Effects of Large Shareholdings. Journal of Finance, 57, 2741-2771.

Claessens, S., Djankov, S. and Lang, L. H. P. (2000) The Separation of Ownership and Control in East Asian Corporations. Journal of Financial Economics, 58, 81-112.

Coffee, J. C. (2001) Do Norms Matter?: A Cross-Country Examination of the Private Benefits of Control. Working Paper, Center for Law and Economic Studies, Columbia University.

Conyon, M. J. and Murphy, K. (Eds.) (2002) Stock Based Executive Compensation, Oxford University Press. 
Conyon, M. J. and Peck, S. I. (1998) Board Size and Corporate Performance: Evidence from European Countries. European Journal of Finance, 4, 291-304.

Core, J. E., Guay, W. R. and Verrecchia, R. E. (2003) Price versus Non-Price Performance Measures in Optimal CEO Compensation Contracts. The Accounting Review, 78, 957-981.

Cornett, M. M., Marcus, A. J., Saunders, A. and Tehranian, H. (2003) The Impact of Institutional Ownership on Corporate Operating Performance. Working Paper.

Cronqvist, H. and Nilsson, M. (2003) Agency Costs of Controlling Minority Shareholders. Journal of Financial and Quantitative Analysis, 38, 695-719.

Cyert, R. M., Sok-Hyon, K. and Kumar, P. (2002) Corporate Governance, Takeovers, and Top-Management Compensation: Theory and Evidence. Management Science, 48, p453-470.

Datta, D. K. and Pinches, G. E. (1992) Factors Influencing Wealth Creation From Mergers and Acquisitions : A Meta-Analysis. Strategic Management Journal, 13, 67-84.

David, P., Kochhar, R. and Levitas, E. (1998) The Effects of Institutional Investors on the Level and Mix of CEO Compensation. Academy of Management Journal, 41, 200-208.

Davies, J. R., Hillier, D. and McColgan, P. (2005) Ownership Structure, Managerial Behavior and Corporate Value. Journal of Corporate Finance, 11, 645-660.

DeAngelo, H. and DeAngelo, L. (1985) Managerial ownership of voting rights: A study of public corporations with dual classes of common stock. Journal of Financial Economics, vol. 14, p33-69.

Demsetz, H. and Lehn, K. (1985) The Structure of Corporate Ownership: Causes and Consequences. Journal of Political Economy, 93, 1155-1177.

Denis, D. J. and Denis, D. K. (1995) Performance changes following top management dismissals. Journal of Finance, 50, 1029-1057.

Denis, D. K. and McConnell, J. J. (2003) International Corporate Governance. Journal of Financial and Quantitative Analysis, 38, 1-37.

Dennis, D. K. and McConnell, J. J. (1986) Corporate Mergers and Security Returns. Journal of Financial Economics 16, 143-187.

Dimson, E. and Marsh, P. (1986) Event study methodologies and the size effect Journal of Financial Economics 17, p113-142.

Dittmar, A., Mahrt-Smith, J. and Servaes, H. (2003) International Corporate Governance and Corporate Cash Holdings. Journal of Financial and Quantitative Analysis, 38, 111-133.

Dixon, W. F. and Tukey, J. W. (1968) Approximate Behavior of the Distribution of Winsorized t (Trimming/Winsorization 2). Technometrics, 10, 83-98.

Djankov, S., La Porta, R., Lopez-de-Silanes, F. and Shleifer, A. (2006) The Law and Economics of Self-dealing. Working Paper.

Duggal, R. and Millar, J. A. (1999) Institutional Ownership and Firm Performance: The Case of Bidder Returns. Journal of Corporate Finance, 5, 103-117.

Dyck, A. and Zingales, L. (2004) Private Benefits of Control: An International Comparison. Journal of Finance, 59, 537-600.

Easton, V. J. and McColl, J. H. Statistics Glossary. Statistical Education through Problem Solving [online]. (Updated 19 Jan 2004 ), Available from: http:/www.stats.gla.ac.uk/steps/glossary/index.html [cited Mar. 25]

Eckbo, B. E. (1983) Horizontal Mergers, Collusion, and Stockholder Wealth. Journal of Financial Economics, 11, 241-273.

Eckbo, B. E. (1985) Mergers and the Market Concentration Doctrine: Evidence from the Capital Market. Journal of Business, 58, 325-349.

Eckbo, B. E. (1992) Mergers and the Value of Antitrust Deterrence. Journal of Finance, 47, 1005-1029. 
Edwards, C. D. (1955) Conglomerate bigness as a source of power. IN Research, I. N. B. o. E. (Ed.) Business Concentration and Price Policy. Princeton NJ, Princeton University Press.

Efron, B. (1979) Bootstrap methods: Another look at the jackknife. The Annals of Statistics, 7., 1-26.

Efron, B. (1992) Jackknife-After-Bootstrap Standard Errors and Influence Functions. Journal of the Royal Statistical Society, B. 54, 83-127.

Efron, B. and Gong, G. (1983) A Leisurely Look at the Bootstrap, the Jackknife, and Cross-Validation. The American Statistician, 37, 36-48.

Efron, B. and Tibshirani, R. (1986) Bootstrap Methods for Standard Errors, Confidence Intervals, and Other Measures of Statistical Accuracy. Statistical Science, 1, 54-75.

Eger, C. E. (1983) An Empirical Test of the Redistribution Effect in Pure Exchange Mergers. The Journal of Financial and Quantitative Analysis,, 18, 547-572.

Erickson, M. and Wang, S.-W. (1999) Earnings management by acquiring firms in stock for stock mergers. Journal of Accounting and Economics, 27, 149-176.

Esty, B. C. and Megginson, W. L. (2003) Creditor Rights, Enforcement, and Debt Ownership Structure: Evidence from the Global Syndicated Loan Market. Journal of Financial and Quantitative Analysis, 38, 37-59.

Faccio, M. and Lang, L. H. P. (2002) The Ultimate Ownership of Western European Corporations. Journal of Financial Economics, 65, 365-395.

Faccio, M., Lang, L. H. P. and Young, L. (2001) Dividends and Expropriation. American Economic Review, 91, 54-78.

Faccio, M. and Masulis, R. W. (2005) The Choice of Payment Method in European Mergers and Acquisitions. Journal of Finance, 60, 1345-1388.

Faccio, M. and Stolin, D. (2006) Expropriation vs. Proportional Sharing in Corporate Acquisitions. Journal of Business, 79 1413-1444.

Fama, E. F. (1998) Market Efficiency, Long-term Returns, and Behavioral Finance. Journal of Financial Economics, 49, 283-306.

Fama, E. F., Fisher, L., Jensen, M. and Roll, R. (1969) The Adjustment of Stock Prices to New Information. International Economic Review 10, 1-21.

Fama, E. F. and French, K. R. (1993) Common Risk Factors in Returns on Stocks and Bonds. Journal of Financial Economics, 33, 3-56.

Fama, E. F. and French, K. R. (1992) The Cross-Section of Expected Stock Returns. Journal of Finance, 47, 427-465.

Fama, E. F. and French, K. R. (1996) Multifactor Explanations of Asset Pricing Anomalies. Journal of Finance, 51, 55-84.

Fama, E. F. and Jensen, M. C. (1983a) Agency Problems and Residual Claims. Journal of Law \& Economics, 26, 327-350.

Fama, E. F. and Jensen, M. C. (1983b) Separation of Ownership and Control. Journal of Law \& Economics, 26, 301-326.

Fauver, L., Houston, J. and Naranjo, A. (2003) Capital Market Development, International Integration, Legal System, and the Value of Corporate Diversification: A Cross-country Analysis. Journal of Financial and Quantitative Analysis, 38, 135-157.

Firth, M. (1980) Takeovers, Shareholder Returns, and the Theory of the Firm. The Quarterly Journal of Economics, 94, 235-260.

Fluck, Z. and Lynch, A. W. (1999) Why Do Firms Merge and Then Divest? A Theory of Financial Synergy. Journal of Business, 72.

Franks, J. R. and Harris, R. S. (1989) Shareholder Wealth Effects of Corporate Takeovers: The U.K. Experience 1955-1985. Journal of Financial Economics, 23, 225-249. 
Franks, J. R., Harris, R. S. and Mayer, C. (1988) Means of Payment in Takeover: Results for the United Kingdom and the United States. IN Auerbach, A. J. (Ed.) Corporate Takeover: Causes and Consequences. Chicago, Chicago University Press.

Franks, J. R., Harris, R. S. and Titman, S. (1991) The Postmerger Share-price Performance of Acquiring Firms. Journal of Financial Economics, 29, 81-96.

Franks, J. R. and Mayer, C. (1996) Hostile Takeovers and Correction of Managerial Failure. Journal of Financial Economics, 40, 163-181.

Freedman, D. A. (2005) Statistical Models: Theory and Practice. Cambridge University Press.

Friedman, E., Johnson, S. and Mitton, T. (2003) Propping and Tunneling. Journal of Comparative Economics, 31, 732-750.

Fuller, K., Netter, J. and Stegemoller, M. (2002) What Do Returns to Acquiring Firms Tell Us? Evidence from Firms That Make Many Acquisitions. The Journal of Finance, 57, 1763-1793.

Galbraith, J. K. (1954) Fundamental Characteristics of the American Economy: Degrees of Competition, of Monopoly, and of Countervailing Power; Theoretical Significance Countervailing Power. The American Economic Review, 44, 1-6.

Garoupa, N. and Stephen, F. H. (2004) Optimal Law Enforcement with Legal Aid. Economica, 71, 493-500.

Ghosh, A. (2001) Does Operating Performance Really Improve following Corporate Acquisitions? Journal of Corporate Finance, 7, 151-178.

Ghosh, A. (2004) Increasing Market Share as a Rationale for Corporate Acquisitions. Journal of Business Finance \& Accounting, 31, 209-247.

Gilson, R. J., Scholes, M. S. and Wolfson, M. A. (1988) Taxation and the Dynamics of Corporate Control: the Uncertain Case for Tax-motivated Acquisitions. IN Coffee, J. C. (Ed.) Knights, Raiders and Targets: The Impact of Hostile Takeover. Oxford: Oxford University Press.

Goergen, M. and Renneboog, L. (2004) Shareholder Wealth Effects of European Domestic and Cross-border Takeover Bids. European Financial Management, 10, 9-45.

Goldberg, L. G. and Idson, T. L. (1995) Executive Compensations and Agency Effects. The Financial Review, 30, 313-335.

Goldstein, H. (1995) Multilevel Statistical Models, London, Arnold.

Gomes, A. and Novaes, W. (2001) Sharing of Control as A Corporate Governance Mechanism. PIER Working Paper, University of Pennsylvania Law School, 1-29.

Gonzalez, P. and Vasconcellos, G. M. (1998) Cross-Border Mergers and Acquisitions : The Undervaluation Hypothesis. The Quarterly Review of Economics and Finance, 38, 25-45.

Good, P. (1994) Permutation Tests, New York, Springer.

Gort, M. (1969) An Economic Disturbance Theory of Mergers. The Quarterly Journal of Economics, $83,624-642$.

Gorton, G. and Schmid, F. A. (2000) Universal Banking and the Performance of German Firms. Journal of Financial Economics, 58, 29-80.

Greene, W. (1998) Econometric Analysis, Prentice Hall.

Grossman, S. J. and Hart, O. D. (1981) The Allocational Role of Takeover Bids in Situations of Asymmetric Information. Journal of Finance, 36, 253-270.

Gugler, K. (Ed.) (2001) The Identy of Owners, New York, Oxford University Press.

Gugler, K. (2003) Corporate Governance, Dividend Payout Policy, and the Interrelation between Dividends, R\&D, and Capital Investment. Journal of Banking and Finance, 27, 1297-1321.

Gugler, K., Mueller, D. C. and Yurtoglu, B. B. (2004) Corporate Governance and the Returns on Investment Journal of Law \& Economics, 47, 589-633.

Gugler, K., Mueller, D. C., Yurtoglu, B. B. and Zulehner, C. (2003) The Effects of Mergers: An International Comparison. International Journal of Industrial Organization, 21, 625-654. 
Hample, F. R., Ronchetti, E. M., Rousseeuw, P. J. and Stahel, W. A. (1986) Robust Statistics: The Approach Based on Influence Functions, New York, Willey.

Harris, M. and Raviv, A. (1990) Capital Structure and the Informational Role of Debt. Journal of Finance, 45, 321-349.

Harris, M. and Raviv, A. (1991) The Theory of Capital Structure. Journal of Finance, 46, 297-355.

Haw, I.-M. and Hu, B. (2004) Ultimate Ownership, Income Management, and Legal and Extra-Legal Institutions. Journal of Accounting Research, 42, 423-462.

Hayward, M. L. A. and Hambrick, D. C. (1997) Explaining the Premium Paid for Large Acquisitions: Evidence of CEO Hubris. Administrative Science Quarterly, 42, 103-127.

Healy, P. M., Palepu, K. G. and Ruback, R. S. (1992) Does Corporate Performance Improve after Mergers? Journal of Financial Economics, 31, 135-175.

Healy, P. M., Palepu, K. G. and Ruback, R. S. (1997) Which Takeovers Are Profitable? Strategic or Financial? Sloan Management Review, 38, 45-58.

Heckman, J. J. (1979) Sample Selection Bias as A Specification Error. Econometrica, 47, 153-162.

Hermalin, B. E. and Weisbach, M. S. (1991) The Effects of Board Composition and Direct Incentives on Firm Performance. Financial Management, 20, 101-112.

Hermalin, B. E. and Weisbach, M. S. (2003) Boards of Directors as An Endogenously Determined Institution: A Survey of the Economic Literature. Economic Policy Review 9 7-26.

Higson, C. and Elliott, J. (1998) Post Takeover Returns: The UK Evidence. Journal of Empirical Finance, 5, 27-46.

Hillier, D. J. and McColgan, P. M. L. (2005) Firm Performance, Entrenchment and Managerial Succession in Family Firms. Working Paper, European Financial Management, Symposium.

Himmelberg, C. P., Hubbard, R. G. and Palia, D. (1999) Understanding the Determinants of Managerial Ownership and the Link between Ownership and Performance. Journal of Financial Economics, 53, 353-384.

Hirshleifer, D. and Thakor, A. V. (1994) Managerial Performance, Boards of Directors and Takeover Bidding. Journal of Corporate Finance, 1, 63-90.

Hitt, M., Harrison, J. R., Ireland, R. D. and Best, A. (1998) Attributes of Successful and Unsuccessful Acquisition of U.S. Firms. British Journal of Management, 9, 91-114.

Hoaglin, D. C., Iglewicz, B. and Tukey, J. W. (1986) Performance of Some Resistant Rules for Outlier Labeling. Journal of American Statistical Association, 18, 991-999.

Holderness, C. G. (2003) A Survey of Blockholders And Corporate Control. Economic Policy Review, $9,51-63$

Holderness, C. G. and Sheehan, D. P. (1988) The Role of Majority Shareholders in Public Held Corporations. Journal of Financial Economics, 20, 317-346.

Holmen, M. and Knopf, J. D. (2004) Minority Shareholder Protections and the Private Benefits of Control for Swedish Mergers. Journal of Financial and Quantitative Analysis, 39, 167-191.

Holmen, M. and Nivorozhkin, E. (2005) The Impact of Dual Class Shares on Takeover Risk and the Market for Corporate Control. Working Paper, European Financial Management, Symposium.

Holmstrom, B. and Kaplan, S. N. (2001) Corporate Governance and Merger Activity in the United States: Making Sense of the 1980s and 1990s. Journal of Economic Perspectives, 15, 121-144.

Hope, O.-K. (2003) Disclosure Practices, Enforcement of Accounting Standards, and Analysts' Forecast Accuracy: An International Study. Journal of Accounting Research, 41, 235-272.

Hubbard, R. G. and Palia, D. (1995) Benefits of Control, Managerial Ownership, and the Stock Returns of Acquiring Firms. RAND Journal of Economics, 26, 782-792.

Huber, P. J. (1964) Robust Estimation of A Location Parameter. The Annals of Mathematical Statistics, 35, $73-101$. 
Huber, P. J. (1967) The Behavior of Maximum Likelihood Estimates Under Non-Standard Conditions. Proceedings of the Fifth Berkeley Symposium on Mathematical Statistics and Probability 4, 221-233.

Huber, P. J. (1981) Robust Statistics, New York, Wiley.

Huddart, S. (1993) The Effect of a Large Shareholder on Corporate Value. Management Science, 39, 1407-1421.

Hunt, H. (1986) The Separation of Corporate Ownership and Control: Theory, Evidence and Implications. Journal of Accounting Literature, 20, 267-291.

Ikenberry, D., Lakonishok, J. and Vermaelen, T. (1995) Market Underreaction to Open Market Share Repurchases. Journal of Financial Economics, 39, 181-208.

Jaffe, J. F. (1974) Special Information and Insider Trading. Journal of Business, 47, 410-428.

James, H. S. (1999) Owner as Manager, Extended Horizons and the Family Firm International Journal of the Economics of Business, 6, 41-55.

Jensen, M. C. (1986) Agency Cost of Free Cash Flow, Corporate Finance and Takeovers. American Economic Review, 76, 323-329.

Jensen, M. C. (1988) Takeovers: Their Causes and Consequences. Journal of Political Economy, 2, 21-48.

Jensen, M. C. (1993) The Modern Industrial Revolution, Exit, and the Failure of Internal Control Systems. Journal of Finance, 48, 831-880.

Jensen, M. C. and Meckling, W. H. (1976) Theory of the Firm: Managerial Behavior, Agency Costs and Ownership Structure. Journal of Financial Economics, 3, 305-360.

Jensen, M. C. and Ruback, R. S. (1983) The Market for Corporate Control. Journal of Financial Economics, 11, 5-50.

John, K. and Senbet, L. W. (1998) Corporate Governance and Board Effectiveness. Journal of Banking and Finance 22,371-485.

Johnson, S., Boone, P., Breach, A. and Friedman, E. (2000a) Corporate Governance in the Asian Financial Crisis. Journal of Financial Economics, 58, 141-186.

Johnson, S., Lopez-de-Silanes, F., La Porta, R. and Shleifer, A. (2000b) Tunneling. American Economic Review, 90, 22-27.

Joskow, P., Rose, N., Shepard, A., Meyer, J. R. and Peltzman, S. (1993) Regulatory Constraints on CEO Compensation. Brookings Papers on Economic Activity Microeconomics, 1993, 1-72.

Kaplan, S. N. and Weisbach, M. S. (1992) The Success of Acquisitions: Evidence from Divestitures. Journal of Finance, 57, 107-138.

Karafiath, I. (1994) On the Efficiency of Least Squares Regression with Security Abnormal Returns as the Dependent Variable. Journal of Financial and Quantitative Analysis, 29, 279-300.

Karpoff, J. M., Malatesta, P. H. and Walkling, R. A. (1996) Corporate Governance and Shareholder Initiatives: Empirical Evidence. Journal of Financial Economics, 42, 365-395.

Kauermann, G. and Carroll, R. J. (2001) A Note on the Efficiency of Sandwich Covariance Matrix Estimation. Journal of the American Statistical Association, 96, 1387-1396.

Kaufmann, D., Kraay, A. and Zoido-Lobaton, P. (1999) Aggregating Governance Indicators. The World Bank, Washington, DC.

Kennedy, V. A. and Limmack, R. J. (1996) Takeover Activity, CEO Turnover, and the Market for Corporate Control. Journal of Business Finance \& Accounting, 23, 267-285.

Kim, E. H. and McConnell, J. J. (1977) Corporate Mergers and the Co-Insurance of Corporate Debt. Journal of Finance, 32, 349-365.

Kinnear, P. R. and Gray, C. D. (2004) SPSS 12 Made Simple, East Sussex, Psychology Press.

Kothari, S. P. and Warner, J. B. (1997) Measuring Long-Horizon Security Price Performance. Journal of Financial Economics, 43, 301-339. 
La Porta, R., Lopez-de-Silanes, F. and Shleifer, A. (1999) Corporate Ownership Around the World. Journal of Finance, 54, 471-517.

La Porta, R., Lopez-de-Silanes, F., Shleifer, A. and Vishny, R. W. (1997) Legal Determinants of External Finance. Journal of Finance, 52, 1131-1150.

La Porta, R., Lopez-de-Silanes, F., Shleifer, A. and Vishny, R. W. (1998) Law and Finance. Journal of Political Economy, 106, 1113-1155.

La Porta, R., Lopez-de-Silanes, F., Shleifer, A. and Vishny, R. W. (2000) Investor Protection and Corporate Governance. Journal of Financial Economics, 58, 3-27.

La Porta, R., Lopez-de-Silanes, F., Shleifer, A. and Vishny, R. W. (2002) Investor Protection and Corporate Valuation. Journal of Finance, 57, 1147-1170.

Lahey, K. E. and Conn, R. L. (1990) Sensitivity of Acquiring Firms' Returns to Alternative Model Specifications and Disaggregation. Journal of Business Finance \& Accounting 17, 421-439.

Lang, L. H. P. and Stulz, R. M. (1994) Tobin's q, Corporate Diversification, and Firm Performance. Journal of Political Economy, 102, 1248-1281.

Lange, H., Ramsay, I. and Woo, L.-A. (2000) Corporate Governance and Anti-Takeover Devices: evidence from Australia. Corporate Governance: An International Review, 8, 227-243.

Lasfer, M. and Faccio, M. (1999) Managerial Ownership, Board Structure and Firm Value: The UK Evidence. Working Paper.

Lee, J. (2004) The Effects of Family Ownership and Management on Firm Performance. SAM Advanced Management Journal vol. 58, p46-54.

Lee, T. S. and Yeh, T. H. (2004) Corporate Governance and Financial Distress: Evidence from Taiwan. Corporate Governance, 12, 378-388.

Leland, H. E. (2007) Financial Synergies and the Optimal Scope of the Firm: Implications for Mergers, Spinoffs, and Structured Finance. Journal of Finance, 62, 765-807.

Lerner, J. and Schoar, A. (2005) Does Legal Enforcement Affect Financial Transactions? The Contractual Channel in Private Equity. The Quarterly Journal of Economics, 120, 223-246.

Lev, B. and Mandelker, G. (1972) The Microeconomic Consequences of Corporate Mergers. The Journal of Business, 45, 85-104.

Levine, R., Loayza, N. and Beck, T. (2000) Financial Intermediation and Growth: Causality and Causes. Journal of Monetary Economics 46, 31-77.

Lewellen, W. G. (1971) A Pure Financial Rationale for the Conglomerate Merger. Journal of Finance, 26, 28-30.

Lewellen, W. G., Loderer, C. and Rosenfeld, A. (1985) Merger Decisions and Executive Stock Ownership in Acquiring Firms. Journal of Accounting \& Economics, 7, 209-232.

Lichtenberg, F. R. and Pushner, G. M. (1994) Ownership Structure and Corporate Performance in Japan. Japan and the World Economy, 6, 239-261.

Limmack, R. J. (1991) Corporate Mergers and Shareholder Wealth Effects: 1977-1986. Accounting and Business Research, 21, 239-251.

Limmack, R. J. and McGregor, N. (1995) Industrial Relatedness, Structural Factors and Bidder Returns. Applied Financial Economics, 5, 179-191.

Linn, S. C. and Switzer, J. A. (2001) Are Cash Acquisitions Associated with Better Post-combination Operating Performance than Stock Acquisitions? Journal of Banking and Finance, 25, 1113-1138.

Lintner, J. (1965) The Valuation of Risk Assets and the Selection of Risky Investments in Stock Portfolios and Capital Budgets. The Review of Economics and Statistics, 47, 13-37.

Lipton, M. and Lorsch, J. W. (1992) A Modest Proposal for Improved Corporate Governance. Business Lawyer, 48, 59-77.

Lombardo, D. and Pagano, M. (2000) Legal Determinants of the Return on Equity. Università di Salerno CSEF Working Paper, no. 24 and CEPR Discussion Paper no. 2276. 
Lorie, J. H. and Halpern, P. (1970) Conglomerates: The Rhetoric and the Evidence. Journal of Law and Economics, 13, 149-166.

Loughran, T. and Ritter, J. R. (1997) The Operating Performance of Firms Conducting Seasoned Equity Offerings. Journal of Finance, 52, 1823-1850.

Loughran, T. and Ritter, J. R. (2000) Uniformly Least Powerful Tests of Market Efficiency. Journal of Financial Economics 55, 361-389.

Loughran, T. and Vijh, A. M. (1997) Do Long-term Shareholders Benefit from Corporate Acquisitions? Journal of Finance, 52, 1765-1790.

Lubatkin, M. H. (1983) Mergers and the Performance of the Acquiring Firm. Academy of Management Review, 1983, 218-225.

Lyon, J. D., Barber, B. M. and Tsai, C.-L. (1999) Improved Methods for Tests of Long-Run Abnormal Stock Returns. Journal of Finance, 54, 165-201.

Mais, E. L., Moore, W. T. and Rogers, R. C. (1989) A Reexamination of Shareholder Wealth Effects of Calls of Convertible Preferred Stock. Journal of Finance 44, 1401-1410.

Maloney, M. T., McCormick, R. E. and Mitchell, M. L. (1993) Managerial Decision Making and Capital Structure. Journal of Business, 66, 189-217.

Mancl, L. A. and Leroux, B. G. (1996) Efficiency of Regression Estimates for Clustered Data. Biometrics, 52, 500-511.

Mandelker, G. (1974) Risk and Return: The Case of Merging Firms. Journal of Financial Economics, $1,303-335$.

Manne, H. G. (1965) Mergers and the Market for Corporate Control. Journal of Political Economy, 73, 110-120.

Maquieira, C. P., Megginson, W. L. and Nail, L. (1998) Wealth Creation versus Wealth Redistributions in Pure Stock-for-Stock Mergers. Journal of Financial Economics 48, 3-33.

Markides, C. C. and Ittner, C. D. (1994) Shareholder Benefits from Corporate International Diversification: Evidence from U.S. International Acquisition. Journal of International Business Studies, 25, 343-366.

Mason, R. H. and Goudzwaard, M. B. (1976) Performance of Conglomerate Firms: A Portfolio Approach. Journal of Finance, 31, 39-48.

Maury, B. (2005) Family Ownership and Firm Performance: Empirical Evidence from Western European Corporations. Journal of Corporate Finance, 12, 321-341.

Maury, B. and Pajuste, A. (2005) Multiple Large Shareholders and Firm Value. Journal of Banking and Finance, 29, 1813-1834.

McConaughy, D. L., Walker, M. C., Henderson, J. G. V. and Mishra, C. S. (1998) Founding Family Controlled Firms: Efficient and Value. Review of Financial Economics, 7, 1-19.

McConnell, J. J. and Servaes, H. (1990) Additional Evidence on Equity Ownership and Corporate Value. Journal of Financial Economics, 27, 595-612.

Meeks, G. and Meeks, J. G. (1981) Profitability Measures as Indicators of Post-Merger Efficiency. The Journal of Industrial Economics, 29, 335-344.

Megginson, W. L., Nash, R. C. and van Randenborgh, M. (1994) The Financial and Operating Performance of Newly Privatized Firms: An International Empirical Analysis. Journal of Finance, 49, 403-452.

Mehran, H. (1995) Executive Compensation Structure, Ownership, and Firm Performance. Journal of Financial Economics, 38, 163-185.

Melicher, R. W. and Neilson, J. F. (1978) Financial Factors That Affect Acquisition Prices. Review of of Business and Economic Research, 13, 95-108.

Mikkleson, W. H. and Partch, M. (1988) Withdrawn Security Offerings. Journal of Financial and Quantitative Analysis, 23, 119-134.

Miller, R. G. (1974) The Jackknife-A Review. Biometrika, 61, 1-15. 
Mitchell, M. L. and Stafford, E. (2000) Managerial Decisions and Long-term Stock Price Performance. Journal of Business, 73, 287-329.

Mitton, T. (2002) A Cross-Firm Analysis of the Impact of Corporate Governance on the East Asian Financial Crisis. Journal of Financial Economics, 64, 215-241.

Moeller, S. B. and Schlingemann, F. P. (2005) Global Diversification and Bidder Gains: A Comparison between Cross-border and Domestic Acquisitions. Journal of Banking and Finance, 29, 533-564.

Moeller, S. B., Schlingemann, F. P. and Stulz, R. M. (2004) Firm Size and the Gains from Acquisitions. Journal of Financial Economics, 73, 201-228.

Montgomery, C. A. (1994) Corporate Diversification. The Journal of Economic Perspectives, 8, 163-178.

Montgomery, C. A. and Singh, H. (1984) Diversification Strategy and Systematic Risk. Strategic Management Journal, 5, 181-191.

Morck, R., Shleifer, A. and Vishny, R. (1990) Do Managerial Objectives Drive Bad Acquisition? Journal of Finance, 45, 31-48.

Morck, R., Shleifer, A. and Vishny, R. W. (1988a) Characteristics of Targets of Hostile and Friendly Takeover. IN Auerbach, A. J. (Ed.) Corporate Takeovers : Cause and Consequences. Chicago, University of Chicago Press.

Morck, R., Shleifer, A. and Vishny, R. W. (1988b) Management Ownership and Market Valuation: An Empirical Analysis. Journal of Financial Economics, 20, 293-315.

Morck, R. and Yeung, B. (1991) Why Investors Value Multinationality. Journal of Business, 64, 165-187.

Morck, R. K. (2000) Introduction. IN Morck, R. K. (Ed.) Concentrated Corporate Ownership Chicago and London, The University of Chicago Press.

Mueller, D. C. (1969) A Theory of Conglomerate Mergers. The Quarterly Journal of Economics, 83, 643-659.

Mueller, D. C. and Yurtoglu, B. B. (2000) Country Legal Environments and Corporate Investment Performance. German Economic Review, 1, 187-220.

Murphy, K. J. (1999) Executive Compensation. IN Orley, A. and David, C. (Eds.) Handbook of Labor Economics. Amsterdam, North-Holland.

Myers, S. and Majluf, N. (1984) Corporate Financing and Investment Decisions When Firms Have Information That Investors Do Not Have. Journal of Financial Economics, 13, 187-221.

Nenova, T. (2003) The Value of Corporate Voting Rights and Control: A Cross-country Analysis. Journal of Financial Economics, 68, 325-351.

O'Sullivan, N. and Wong, P. (1998) The Impact of Board Composition and Ownership on the Nature and Outcome of UK Takeovers. Corporate Governance: An International Review, 6, 92-100.

O'Sullivan, N. and Wong, P. (1999) Board Composition, Ownership Structure and Hostile Takeovers: Some UK Evidence. Accounting and Business Research, 29, 139-155.

Pagano, M. and Roell, A. (1998) The Choice of Stock Ownership Structure: Agency Costs, Monitoring, and The Decision To Go Public. The Quarterly Journal of Economics, 113, $187-226$

Pettway, R. H. and Yamada, T. (1986) Mergers in Japan and Their Impact Upon Stockholders' Wealth. Financial Management, 15, 43-52.

Pfeffermann, D., Skinner, C. J., Holmes, D. and Goldstein, H. (1997) Weighting for Unequal Selection Probabilities in Multilevel Models. Journal of the Royal Statistical Society, B. 60, 23-40.

Pi, L. and Timme, S. G. (1993) Corporate Control and Bank Efficiency. Journal of Banking and Finance, 17, 515-530.

Pitselis, G. (2005) Application of M-Estimators to Cross-Section Effects Models. Communications in Statistics-Simulation and Computation, 34, 601-616. 
Polinsky, A. M. and Shavell, S. (2000) The Economic Theory of Public Enforcement of Law. Journal of Economic Literature, 38, 45-76.

Porter, M. E. (1987) From Competitive Advantage to Corporate Strategy. Harvard Business Review, 65, 43-59.

Posner, R. A. (1998) Creating a Legal Framework for Economic Development. The World Bank Research Observer, 13, 1-11.

Powell, R. G. and Stark, A. W. (2005) Does Operating Performance Increase Post-takeover for UK Takeovers? A Comparison of Performance Measures and Benchmarks. Journal of Corporate Finance, 11, 293-317.

Quenouille, M. (1949) Approximate Tests of Correlation in Times Series. Journal of the Royal Statistical Society, B 11, 68-84.

Raheja, C. G. (2005) Determinants of Board Size and Composition: A Theory of Corporate Boards. Journal of Financial and Quantitative Analysis, 40, 283-305.

Rahman, R. A. and Limmack, R. J. (2004) Corporate Acquisitions and the Operating Performance of Malaysian Companies. Journal of Business Finance \& Accounting, 31, 359-400.

Rajan, R. G. and Zingales, L. (1998) Financial Dependence and Growth. American Economic Review, $88,559-586$.

Rand, W. M. (1971) Objective Criteria for the Evaluation of Clustering Methods. Journal of the American Statistical Association, 66, 846-850.

Randøy, T. and Nielsen, J. (2002) Company Performance, Corporate Governance, and CEO Compensation in Norway and Sweden. Journal of Management and Governance, 6, 57-81.

Rasmussen, J. L. (1989) Computer-Intensive Correlational Analysis: Bootstrap and Approximate Randomization Techniques. British Journal of Mathematical and Statistical Psychology, 42, 103-111.

Rau, P. R. and Vermaelen, T. (1998) Glamour, Value and the Post-Acquisition Performance of Acquiring Firms. Journal of Financial Economics, 49, 223-253.

Ravenscraft, D. J. and Scherer, F. M. (1987) Life After Takeover. The Journal of Industrial Economics, $36,147-156$.

Rechner, P. L. and Dalton, D. R. (1991) Research Notes and Communications CEO Duality and Organizational Performance: A Longitudinal Analysis. Strategic Management Journal, 12, 155-160.

Rhoades, S. A. (1983) Power, Empire Building, and Mergers, Lexington, MA,, DC Heath \& Co.

Ritter, J. R. (1991) The Long-Run Performance of Initial Public Offerings. Journal of Finance, 46, 3-27.

Rivest, L. P. (1994) Statistical Properties of Winsorized Means for Skewed Distributions. Biometrika, 81, 373-383.

Riyanto, Y. E. and Toolsema, L. A. (2004) Tunneling and Propping: A Justification for Pyramidal Ownership. Working Paper.

Rodgers, J. L. (1999) The Bootstrap, the Jackknife, and the Randomization Test : A Sampling Taxonomy. Multivariate Behavioral Research, 34, 441-456.

Roll, R. (1986) The Hubris Hypothesis of Corporate Takeovers. Journal of Business, 59, 197-216.

Rose, N. L. and Shepard, A. (1997) Firm Diversification and CEO Compensation: Managerial Ability or Executive Entrenchment? RAND Joumai of Economics, 28, 489-514.

Rosenstein, S. and Wyatt, J. G. (1990) Outside Directors, Board Independence, and Shareholder Wealth. Journal of Financial Economics, 26, 175-191.

Rossi, S. and Volpin, P. F. (2004) Cross-country Determinants of Mergers and Acquisitions. Journal of Financial Economics, 74, 277-304.

Rousseeuw, P. J. and Leroy, A. M. (1987) Robust Regression and Outlier Detection, New York, John Wiley \& Sons, Inc. 
Ruback, R. S. (1983) Assessing Competition in the Market for Corporate Acquisitions. Journal of Financial Economics, 11, 141-153.

Scanlon, K. P., Trifts, J. W. and Pettway, R. H. (1989) Impacts of Relative Size and Industrial Relatedness on Returns to Shareholders of Acquiring Firms. Journal of Financial Research, $12,103-112$.

Scholes, M. S. and Williams, J. (1977) Estimating Betas from Nonsynchronous Data. Journal of Financial Economics, 5, 309-327.

Schulze, W. S., Lubatkin, M. H., Dino, R. N. and Buchholtz, A. K. (2001) Agency Relationships in Family Firms: Theory and Evidence. Journal of the Institute of Management Sciences, 12, 99-117.

Schwert, G. W. (1996) Markup Pricing in Mergers and Acquisitions. Journal of Financial Economics, 41, 153-192.

Scott, J. T. (1989) Purposive Diversification As A Motive for Merger. International Journal of Industrial Organization, 7, 35-47.

Seth, A., Song, L. P. and Pettit, R. R. (2002) Value Creation and Destruction Cross-Border Acquisitions: An Emperical Analysis of Foreign Acquisitions of U.S. Firms. Strategic Management Journal, 23, 921-940.

Shao, J. and Tu, D. (1995) The Jackknife and Bootstrap New York, Springer.

Sharma, D. S. and Ho, J. (2002) The Impact of Acquisitions on Operating Performance: Some Australian Evidence. Journal of Business Finance \& Accounting, 29, 155-200.

Sharpe, W. F. (1964) Capital Asset Prices: A Theory of Market Equilibrium under Conditions of Risk. The Journal of Finance, 19, 425-442

Shen, C.-H. and Chih, H.-L. (2005) Investor Protection, Prospect Theory, and Earnings Management: An International Comparison of the Banking Industry. Journal of Banking and Finance, 29, 2675-2697.

Shleifer, A. and Vishny, R. W. (1986) Large Shareholders and Corporate Control. Journal of Political Economy, 94, 461-489.

Shleifer, A. and Vishny, R. W. (1989) Managerial Entrenchment: the Case of Manager-specific Investments. Journal of Financial Economics, 25, 123-139.

Shleifer, A. and Vishny, R. W. (1997) A Survey of Corporate Governance. Journal of Finance, 52, 737-783.

Shleifer, A. and Wolfenzon, D. (2002) Investor Protection and Equity Markets. Journal of Financial Economics, 66, 3-27.

Singh, K. (1998) Breakdown Theory for Bootstrap Quantiles. The Annals of Statistics, 26, 1719-1732.

Smith, B. F. and Amoako-Adu, B. (1999) Management Succession and Financial Performance of Family Controlled Firms. Journal of Corporate Finance, 5, 341-368.

Staudte, R. G. and Sheather, S. J. (1990) Robust Estimation and Testing, New York, Wiley.

Stein, J. C. (1989) Efficient Capital Markets, Inefficient Firms: A Model of Myopic Corporate Behavior. The Quarterly Journal of Economics, 103, 655-669.

Stulz, R. M. (1988) Managerial Control of Voting Rights: Financing Policies and the Market for Corporate Control. Journal of Financial Economics, 20, 25-54.

Stulz, R. M. (1990) Managerial Discretion and Optimal Financing Policies. Journal of Financial Economics 26, 3-27.

Stulz, R. M., Walkling, R. A. and Song, M. H. (1990) The Distribution of Target Ownership and the Division of Gains in Successful Takeovers. Journal of Finance, 45, 817-833.

Stulz, R. M. and Williamson, R. (2003) Culture, Openness, and Finance. Journal of Financial Economics, 70, 313-349.

Subrahmanyam, V., Rangan, N. and Rosenstein, S. (1997) The Role of Outside Directors in Bank Acquisitions. Financial Management, 26, 23-36. 
Sudarsanam, P. S. and Gao, L. (2003) Value Creation in UK High Technology Acquisitions. Working Paper-EFMA 2004 Basel Meetings Paper

Sudarsanam, P. S. (2003) Creating Value From Mergers and Acquisition: The Challenges, London, FT Prentice Hall.

Sudarsanam, P. S., Holl, P. and Salami, A. (1996) Shareholder Wealth Gains in Mergers: Effect of Synergy and Ownership Structure. Journal of Business Finance \& Accounting, 23, 673-698.

Sudarsanam, P. S. and Huang, J. (2006) Managerial Incentives, Overconfidence, Risk-taking, and Acquirer Shareholder Value Creation in Mergers and Acquisitions. Working Paper.

Sudarsanam, P. S. and Mahate, A. A. (2006) Are Friendly Acquisitions Too Bad for Shareholders and Managers? Long-Term Value Creation and Top Management Turnover in Hostile and Friendly Acquirers. British Journal of Management, Supplement, 17, S7-S30.

Thomas, G. E. (2000) Use of the Bootstrap in Robust Estimation of Location. The Statistician, 49, 63-77.

Trautwein, F. (1990) Merger Motives and Merger Prescriptions. Strategic Management Journal, 11, 283-298.

Tukey, J. W. (1958) Bias and Confidence in Not-quite Large Samples (abstract). Annals of Mathematical Statistics, 29, 614-623.

Tukey, J. W. (1960) A Survey of Sampling from Contaminated Distribution IN Olkin (Ed.) In Contributions to Probability and Statistics. Stanford Univ. Press.

Tukey, J. W. (1970) Exploratory Data Analysis, Reading, MA, Addison-Wesley.

Vefeas, N. and Theodorou, E. (1998) The Relationship between Board Structure and Firm Performance in the UK. British Accounting Review, 30, 383-407.

Villalonga, B. and Amit, R. (2006) How Do Family Ownership, Control and Management Affect Firm Value? Journal of Financial Economics, 80, 385-417.

Walkling, R. A. and Edmister, R. O. (1985) Determinants of Tender Offer Premiums. Financial Analysts Journal, 41, 27-37.

Weinstein, D. E. and Yafeh, Y. (1998) On the costs of a bank-centered financial system: Evidence from the changing main bank relations in Japan. Journal of Finance, 53, 635-672.

Weir, C., Laing, D. and McKnight, P. J. (2002) Internal and External Governance Mechanisms: Their Impact on the Performance of Large UK Public Companies. Journal of Business Finance \& Accounting, 29, 579-611.

Weisbach, M. S. (1988) Outside Directors and CEO Turnover. Journal of Financial Economics, 20, 431-460.

Weston, J. F. and Mansinghka, S. K. (1971) Tests of the Efficiency Performance of Conglomerate Firms. Journal of Finance, 26, 919-936.

White, H. (1980) A Heteroskedasticity-Consistent Covariance Matrix Estimator and a Direct Test for Heteroskedasticity. Econometrica 48, 817-838.

Wilcox, R. R. (2001) Fundamentals of Modern Statistical Methods, New York, Springer-Verlag New York, Inc.

Wilcox, R. R. (2003) Multiple Comparisons Based on A Modified One-step M-estimator. Journal of Applied Statistics, 30, 1231-1241.

Wooldridge, J. M. (2003) Cluster-Sample Methods in Applied Econometrics. American Economic Review, 93, 133-138.

Wright, P., Kroll, M., Lado, A. and Van Ness, B. (2002) The Structure of Ownership and Corporate Acquisition Strategies. Strategic Management Journal, 23, 41-53.

Wu, C. F. J. (1986) Jackknife, Bootstrap and Other Resampling Methods in Regression Analysis. The Annals of Statistics, 14, 1261-1295.

Yermack, D. (1996) Higher Market Valuation of Companies with A Small Board of Directors. Journal of Financial Economics, 40, 185-211. 
Yuen, K. K. (1974) The Two-Sample Trimmed for Unequal Population Variances. Biometrika, 61, $165-170$

Yuen, K. K. (1975) Power Comparisons of Single-Sample Winsorized T, Trimmed T and Student's T. The Canadian Journal of Statistics, 3, 71-80.

Yurtoglu, B. B. (2003) Corporate Governance and Implications for Minority Shareholders in Turkey. Corporate Ownership \& Control, 1, 72-86.

Zeckhauser, R. and Pound, J. (1990) Are Large Shareholders Effective Monitors? An Investigation of Share Ownership and Corporate Performance. IN Hubbard, R. G. (Ed.) Asymmetric Information, Corporate Finance and Investment. Chicago, University of Chicago Press.

Zeger, S. L. and Liang, K.-Y. (1986) Longitudinal Data Analysis for Discrete and Continuous Outcomes. Econometrica, 42, 121-130.

Zhang, G. (1998) Ownership Concentration, Risk Aversion and the Effect of Financial Structure on Investment Decisions. European Economic Review, 42, 1751-1778.

Zingales, L. (2000) In Search of New Foundations. Journal of Finance, 55, 1623-1653. 


\section{Appendix}

\section{Appendix A: Company List}

\begin{tabular}{|c|c|c|c|c|c|c|}
\hline \multirow{2}{*}{ Seq } & \multicolumn{3}{|c|}{ Acquirers } & \multicolumn{3}{|l|}{ Targets } \\
\hline & Entity Name & Sedol & Country & Entity Name & Sedol & Country \\
\hline$\overline{\mathrm{a} 001}$ & Aristocrat Leisure Limited & 6253983 & AUS & Casino Data Systems & 2200466 & USA \\
\hline $\mathrm{a} 002$ & Australian Gas Light Company & 6064969 & AUS & NGC Holdings Limited & B00MSQ7 & NZL \\
\hline $\mathrm{a} 003$ & BHP Billiton Limited & 6144690 & AUS & Dia Met Minerals Ltd. & 2264053 & CAN \\
\hline $\mathrm{a} 004$ & BHP Billiton Limited & 6144690 & AUS & BHP Billiton PLC & 0056650 & GBR \\
\hline $\mathrm{a} 005$ & Baycorp Advantage Limited & 6128661 & AUS & Baycorp Holdings Ltd. & 6111100 & NZL \\
\hline $\mathrm{a} 006$ & Downer EDI & 6465573 & AUS & Evans Deakin Industries Ltd. & 6323552 & AUS \\
\hline $\mathrm{a} 007$ & Fosters Group Limited & 6349268 & AUS & Beringer Wine Estates Holdings, Inc. & 2120423 & USA \\
\hline a008 & Henry Walker Eltin Group & 6420884 & AUS & Eltin Limited & 6550639 & AUS \\
\hline $\mathrm{a} 009$ & Lion Nathan Limited & 6538215 & AUS & Petaluma Limited & 6080653 & AUS \\
\hline $\mathrm{a} 010$ & Lion Nathan Limited & 6538215 & AUS & Montana Group (NZ) Limited & 6225443 & NZL \\
\hline \begin{tabular}{|l|l}
$\mathrm{a} 011$ \\
\end{tabular} & Symbion Health Limited & 6574606 & AUS & F.H. Faulding \& Co Limited & 6332600 & AUS \\
\hline $\mathrm{a} 012$ & Symbion Health Limited & 6574606 & AUS & Australian Hospital Care Limited & 6054517 & AUS \\
\hline $\mathrm{a} 013$ & Paperlinx Limited & 6222206 & AUS & Spicers Paper Limited & 6834355 & AUS \\
\hline $\mathrm{a} 014$ & Publishing And Broadcasting Limited & 6637082 & AUS & Crown Limited & 6237932 & AUS \\
\hline $\mathrm{a} 015$ & Rio Tinto & 6220103 & AUS & Ashton Minign Limited & 6056999 & AUS \\
\hline $\mathrm{a} 016$ & Rio Tinto & 6220103 & AUS & North Limited & 6644037 & AUS \\
\hline $\mathrm{a} 017$ & Sons Of Gwalia Limited & 6821324 & AUS & Pacmin Mining Corporation Limited & 6120292 & AUS \\
\hline $\mathrm{a} 018$ & Sons Of Gwalia Limited & 6821324 & AUS & Gwalia Consolidated Limited & 6415567 & AUS \\
\hline $\mathrm{a} 019$ & Southern Cross Broadcasting & 6904344 & AUS & Telecasters Australia Limited & 6883766 & AUS \\
\hline $\mathrm{a} 020$ & Tabcorp Holdings Limited & 6873262 & AUS & Star City Holdings Limited & 6868718 & AUS \\
\hline $\mathrm{a} 021$ & Wesfarmers Limited & 6948836 & AUS & Howard Smith Limited & 6816308 & AUS \\
\hline $\mathrm{a} 022$ & Iluka Resources Limited & 6957575 & AUS & RGC Limited & 6732330 & AUS \\
\hline $\mathrm{a} 023$ & Alesco Corp. Limited & 6063557 & AUS & Parbury Limited & 6670504 & AUS \\
\hline $\mathrm{a} 024$ & Harvey Norman Holdings & 6173508 & AUS & Rebel Sport Limited & 6727013 & AUS \\
\hline $\mathrm{c} 001$ & Abitibi-Consolidated Inc. & 2056807 & CAN & Donohue Inc. & 2272379 & CAN \\
\hline $\mathrm{c} 002$ & Alcan (Aluminum) Ltd & 2013200 & CAN & Aluminium of Korea & 6021975 & KOR \\
\hline $\mathrm{c} 003$ & Alcan (Aluminum) Ltd & 2013200 & CAN & Alusuisse Group AG & 4780524 & $\mathrm{CHE}$ \\
\hline $\mathrm{c} 004$ & Alcan (Aluminum) Ltd & 2013200 & CAN & Indian Aluminium Company, Limited & 6142230 & IND \\
\hline $\mathrm{c} 005$ & Alimentation Couche Tard Inc. & 2528102 & CAN & Silcorp Limited & 2809272 & CAN \\
\hline $\mathrm{c} 006$ & Astral Media Inc. & 2060273 & CAN & Radiomutuel Inc. & 2214434 & CAN \\
\hline $\mathrm{c} 007$ & Barrick Gold Corp. & 2024644 & CAN & Homestake Minign Co. & 2435008 & USA \\
\hline $\mathrm{c} 008$ & Barrick Gold Corp. & 2024644 & CAN & Sutton Resources Ltd & 2861012 & CAN \\
\hline $\mathrm{c} 009$ & Baytex Energy Trust Limited & 2552736 & CAN & Bellator Exploration Inc. & 2091488 & CAN \\
\hline $\mathrm{c} 010$ & Baytex Energy Trust Limited & 2552736 & CAN & Dorset Exploration Ltd & 2277200 & CAN \\
\hline $\mathrm{c} 011$ & Baytex Energy Trust Limited & 2552736 & CAN & Triumph Energy Corporation & 2567837 & CAN \\
\hline $\mathrm{c} 012$ & BCE Inc. & 2089933 & CAN & CTV Inc. & 2084488 & CAN \\
\hline $\mathrm{c} 013$ & BCT.Telus Communications Inc. & 2381093 & CAN & Quebectel Group Inc.orporated (THE) & 2716800 & CAN \\
\hline $\mathrm{c} 014$ & Bell Canada International Inc. & 2969596 & CAN & Teleglobe Inc. & 2577825 & CAN \\
\hline $\mathrm{c} 015$ & Biovail Corp International & 2098199 & CAN & Fuisz Technologies Ltd. & 2357964 & USA \\
\hline $\mathrm{c} 016$ & Canadian National Railways Company & 2180632 & CAN & Illinois Central Corporation & 2457273 & USA \\
\hline $\mathrm{c} 017$ & Canadian National Railways Company & 2180632 & CAN & Wisconsin Central Transporation & 2973638 & USA \\
\hline $\mathrm{c} 018$ & Canadian Natural Resources Limited & 2171573 & CAN & Ranger Oil Limited & 2723004 & CAN \\
\hline $\mathrm{c} 019$ & Celestica Inc. & 2263362 & CAN & Omni Industries Limited & 6654865 & SGP \\
\hline $\mathrm{c} 020$ & Celestica Inc. & 2263362 & CAN & Primetech Electronics Inc. & 2272454 & CAN \\
\hline $\mathrm{c} 021$ & CGI Group Inc. & 2159740 & CAN & Imrglobal Corp. & 2448125 & USA \\
\hline $\mathrm{c} 022$ & CHC Helicopter Corp. & 2160281 & CAN & Helicopter Services Group ASA & 4419947 & NOR \\
\hline $\mathrm{c} 023$ & Co-Steel (Gerdau Ameristeel) Corp. & 2205018 & CAN & New Jersey Steel Corporation & 2630535 & USA \\
\hline $\mathrm{c} 024$ & Dorel Industries Inc. & 2262369 & CAN & Safety 1st, Inc. & 2766968 & USA \\
\hline $\mathrm{c} 025$ & Enbridge Inc. & 2466149 & CAN & Midcoast Energy Resources Inc.orporated & 2577342 & USA \\
\hline $\mathrm{c} 026$ & Finning International Inc. & 2339177 & CAN & Hewden Stuart PLC & 0424053 & GBR \\
\hline $\mathrm{c} 027$ & Glamis Gold Limited & 2371113 & CAN & Rayrock Rexources Inc. & 2726661 & CAN \\
\hline $\mathrm{c} 028$ & Hummingbird Limited & 2427812 & CAN & PC Docs Group International Inc. & 2717427 & CAN \\
\hline $\mathrm{c} 029$ & International Forest Products Limited & 2963963 & CAN & Primex Forest Products Ltd & 2703512 & CAN \\
\hline $\mathrm{c} 030$ & Kinross Gold Corp. & B03Z841 & CAN & AMAX Gold Inc. & 2023298 & USA \\
\hline $\mathrm{c} 031$ & Leitch Technology Corp. & 2511414 & CAN & Digital Processing Systems Inc. & 2269100 & CAN \\
\hline $\mathrm{c} 032$ & Loblaw Companies Limited & 2521800 & CAN & Provigo Inc. & 2706328 & CAN \\
\hline $\mathrm{c} 033$ & Magna International Inc. & 2554475 & CAN & Steyr-Daimler-Puch AG & 4846608 & AUT \\
\hline $\mathrm{c} 034$ & MDS Inc. & 2559696 & CAN & Phoenix International Life Sciences Inc. & 2711281 & CAN \\
\hline $\mathrm{c} 035$ & Catalyst Paper Corp. & 2342733 & CAN & Pacifica Papers Inc. & 2402530 & CAN \\
\hline $\mathrm{c} 036$ & Onex Corp. & 2659518 & CAN & American Buildings Company & 2034546 & USA \\
\hline $\mathrm{c} 037$ & PanCanadian Petroleum (Encana) Corp. & 2793193 & CAN & CS Resources Limited & 2160872 & CAN \\
\hline $\mathrm{c} 038$ & Petrobank Energy \& Resources Limited & 2683670 & CAN & Barrington Petroleum Ltd. & 2078083 & CAN \\
\hline $\mathrm{c} 039$ & Placer Dome Inc. & 2691714 & CAN & Getchell Gold Corporation & 2341934 & USA \\
\hline $\mathrm{c} 040$ & Precision Drilling & B0P0ZR6 & CAN & Computalog Ltd. & 2214791 & CAN \\
\hline $\mathrm{c} 041$ & Precision Drilling & B0P0ZR6 & CAN & Plains Energy Services Limited & 2692438 & CAN \\
\hline $\mathrm{c} 042$ & Primewest Energy Trust & 2977588 & CAN & Cypress Energy & 2206066 & CAN \\
\hline $\mathrm{c} 043$ & Primewest Energy Trust & 2977588 & CAN & Reserve Royalty Corporation & 2796363 & CAN \\
\hline $\mathrm{c} 044$ & Quebecor Printing (World) Inc. & 2716231 & CAN & World Color Press, Inc. & 2977522 & USA \\
\hline $\mathrm{c} 045$ & Shaw Communications Inc. & 2801836 & CAN & Moffat Communications Ltd. & 2598439 & $\mathrm{CAN}$ \\
\hline
\end{tabular}




\section{Appendix A (Continued)}

\begin{tabular}{|c|c|c|c|c|c|c|}
\hline $\mathrm{c} 046$ & Shaw Communications Inc. & 2801836 & CAN & WIC Western International Communications & 2964171 & CAN \\
\hline $\mathrm{c} 047$ & Talisman Energy Inc. & 2068299 & CAN & Lundin Oil AB & 4449159 & SWE \\
\hline $\mathrm{c} 048$ & Talisman Energy Inc. & 2068299 & CAN & Petromet Resources Limited & 2684598 & CAN \\
\hline $\mathrm{c} 049$ & Talisman Energy Inc. & 2068299 & CAN & Rigel Energy Corporation & 2898054 & CAN \\
\hline $\mathrm{c} 050$ & Teck Cominco Limited & 2879327 & CAN & Cominco Limited & 2213066 & CAN \\
\hline $\mathrm{c} 051$ & Tembec Inc. & 2883050 & CAN & Crestbrook Forest Industries Ltd. & 2233008 & CAN \\
\hline $\mathrm{c} 052$ & Thomson Corp. & $\mathrm{C} 000006385$ & CAN & Primark Corporation & 2702809 & USA \\
\hline $\mathrm{c} 053$ & Transcanada Corp. & 2665184 & CAN & Nova Corporation (OLD) & 2642110 & CAN \\
\hline $\mathrm{c} 054$ & Air Canada Inc. & 2011323 & CAN & Canadian Airlines Corporation & 2210454 & CAN \\
\hline $\mathrm{c} 055$ & Armbro Enterprises Inc. (AECON Group Corp) & 2699547 & CAN & BFC Construction Corp. & 2075170 & CAN \\
\hline $\mathrm{c} 056$ & Cangene Corp. & 2173397 & CAN & Chesapeake Biological Laboratories, Inc. & 2194785 & USA \\
\hline $\mathrm{c} 057$ & Cinar Corp & 2192994 & CAN & Edusoft Ltd. & 2305662 & ISR \\
\hline $\mathrm{c} 058$ & Coolbrands International Inc. & 2228844 & CAN & Eskimo Pie Corporation & 2321743 & USA \\
\hline $\mathrm{c} 059$ & Corus Entertainment Inc. & 2484516 & CAN & Nelvana Limited & 2629748 & CAN \\
\hline $\mathrm{c} 060$ & Crew Development (Gold) Corp & 2171636 & CAN & Mindex ASA & 5139868 & NOR \\
\hline $\mathrm{c} 061$ & Dorel Industries Inc. & 2262369 & CAN & Ameriwood Industries International Corp. & 2752246 & USA \\
\hline $\mathrm{c} 062$ & Exco Technologies Limited & 2325392 & CAN & Tecsyn International Inc. & 2148210 & CAN \\
\hline $\mathrm{c} 063$ & Heroux-Devtek Inc. & 2422947 & CAN & Devtek Corporation & 2267665 & CAN \\
\hline $\mathrm{c} 064$ & Laidlaw Inc. & 2039381 & CAN & Greyhound Canada Transporation Corp. & 2389600 & CAN \\
\hline $\mathrm{c} 065$ & Laidlaw Inc. & 2039381 & CAN & Greyhound Lines, Inc. & 2388522 & USA \\
\hline $\mathrm{c} 066$ & Laidlaw Inc. & 2039381 & CAN & Emcare Holdings Inc. & 2305543 & USA \\
\hline $\mathrm{c} 067$ & Lions Gate Entertainment Corp. & 2312684 & CAN & Trimark Holdings, Inc. & 2929385 & USA \\
\hline $\mathrm{c} 068$ & Nortel Networks Corp. & 2583877 & CAN & Architel Systems Corporation & 2049238 & CAN \\
\hline $\mathrm{c} 069$ & Nortel Networks Corp. & 2583877 & CAN & Clarify Inc. & 2194213 & USA \\
\hline $\mathrm{c} 070$ & Nortel Networks Corp. & 2583877 & CAN & Alteon Websytems, Inc. & 2492575 & USA \\
\hline $\mathrm{c} 071$ & Nortel Networks Corp. & 2583877 & CAN & Periphonics Corporation & 2686862 & USA \\
\hline $\mathrm{c} 072$ & Nortel Networks Corp. & 2583877 & CAN & Bay Networks, Inc. & 2947495 & USA \\
\hline $\mathrm{c} 073$ & NS Power Hldg (EMERA) Inc. & 2650050 & $\mathrm{CAN}$ & Bangor Hydro-Electric Company & 2470236 & USA \\
\hline $\mathrm{c} 074$ & Southernera Diamonds Inc. & 2831305 & CAN & Messina Limited & 6582706 & ZAF \\
\hline $\mathrm{c} 075$ & Thomson Corp. & $\mathrm{C} 000006385$ & CAN & Wave Technologies International, Inc. & 2943976 & USA \\
\hline in01 & Indian Rayon \& Industries Ltd & 6100421 & IND & PSI Data Systems Ltd & 6143073 & IND \\
\hline in02 & BPCL & 6099723 & IND & KRL & 6211839 & IND \\
\hline in03 & Pentamedia Graphics Ltd & 6124959 & IND & Film Roman Inc. & 2361307 & USA \\
\hline in04 & Hindalco Industries Ltd & B0GWF48 & IND & Indian Aluminum Co Ltd & C000008991 & IND \\
\hline in05 & Dr Reddys Laboratories Ltd & 6410959 & IND & Cheminor Drugs Ltd & 6099961 & IND \\
\hline in06 & Hindustan Lever Ltd & 6261674 & IND & Pond's India Ltd & 6693727 & IND \\
\hline ir01 & CRH PLC & 4182249 & IRL & Ibstock PLC & 0455406 & GBR \\
\hline ir02 & Elan Corporation PLC & 4305507 & IRL & Dura Pharmaceuticals, Inc. & 2288570 & USA \\
\hline ir03 & Elan Corporation PLC & 4305507 & IRL & Liposome Company, Inc. (THE) & 2518976 & USA \\
\hline ir04 & Elan Corporation PLC & 4305507 & IRL & Neurex Corporation & 2041869 & USA \\
\hline ir05 & Grafton Group PLC & B00NKF3 & IRL & British Dredging PLC & 0132505 & GBR \\
\hline ir06 & Greencore Group PLC & 5013832 & IRL & Paramount Foods PLC & 0170862 & GBR \\
\hline ir07 & Greencore Group PLC & 5013832 & IRL & Hazlewood Foods PLC & 0416685 & GBR \\
\hline ir08 & IWP International PLC & 5112609 & IRL & Jeyes Group PLC & 0474315 & GBR \\
\hline ir09 & Kerry Group PLC & 4519579 & IRL & Golden Vale PLC & 4376569 & IRL \\
\hline ir10 & Kingspan Group PLC & 4491235 & IRL & Hewetson PLC & 0422659 & GBR \\
\hline ir11 & Waterford Wedgwood PLC & 4942636 & IRL & Rosenthal AG & 4751401 & $\mathrm{DEU}$ \\
\hline is 01 & Gilat Satellite Networks Ltd & 7582170 & ISR & ZapMe! (RSTAR) Corp & C000066760 & USA \\
\hline $\mathrm{m} 001$ & IOI Corp Bhd & 6464514 & MYS & Palmco Holdings Bhd (Ioi Oleochemical) & 6668446 & MYS \\
\hline n001 & Fernz Corp (NUFARM) Ltd (AUS) & 6335331 & $\mathrm{NZL}$ & CIE Francaise Des Produits Indst'l-CFPI & 4160278 & FRA \\
\hline n002 & Nuplex Industries Limited & 6651372 & NZL & Australian Chemical Holdings Limited & 6064152 & AUS \\
\hline n003 & Telecom Corp. Of New Zealand Limited & 6881436 & $\mathrm{NZL}$ & AAPT Limited & 6086468 & AUS \\
\hline s001 & Flextronics International Limited & 2353058 & SGP & JIT Holdings Limited & 6085409 & SGP \\
\hline $\mathrm{s} 002$ & Fraser And Neave Limited & 6689458 & SGP & Times Publishing Limited & 6891855 & SGP \\
\hline s003 & GES International Limited & 6141903 & SGP & Eltech Electronics Limited & 6308214 & SGP \\
\hline s004 & Keppel Corp. Limited & 6490263 & SGP & Keppel Telecommunications Transportation & 6842444 & SGP \\
\hline $\mathrm{s} 005$ & Smrt Corp. Limited & 6274456 & SGP & TIBS Holdings Ltd. & 6900933 & SGP \\
\hline $\mathrm{sa} 01$ & Amalgamated Beverage Industry Ltd & 6023573 & ZAF & Suncrush Limited & 6806536 & ZAF \\
\hline $\mathrm{sa} 02$ & Anglogold Ashanti Limited & 6565655 & ZAF & Anglogold Australasia Limited & 6005582 & AUS \\
\hline $\mathrm{sa} 03$ & Aveng Limited & 6153339 & ZAF & LTA Limited & 6500805 & ZAF \\
\hline $\mathrm{sa} 04$ & Harmony Gold Mining Company Limited & 6410562 & $\mathrm{ZAF}$ & Evander Gold Mines Limited & 6301901 & $\mathrm{ZAF}$ \\
\hline $\mathrm{sa} 05$ & Harmony Gold Mining Company Limited & 6410562 & ZAF & Randfontein Estates Limited & 6723420 & ZAF \\
\hline $\mathrm{sa} 06$ & Impala Platinum Holdings Limited & 6457804 & ZAF & Platexco Inc. & 2692502 & CAN \\
\hline $\mathrm{sa} 07$ & Invicta Holdings Limited & 6650443 & $\mathrm{ZAF}$ & Bearing Man Limited & 6088657 & ZAF \\
\hline $\mathrm{sa} 08$ & Johnnic Holdings Limited & 6475141 & ZAF & Millenium Entertainment Group Africa Ltd. & 6160265 & ZAF \\
\hline $\mathrm{sa} 09$ & Johnnic Holdings Limited & 6475141 & ZAF & Times Media Ltd. & 6891866 & ZAF \\
\hline sa10 & Metrofile Holdings Limited & 6588016 & ZAF & Computer Configurations Holdings Limited & 6043708 & ZAF \\
\hline sa11 & Steinhoff International Holdings Limited & 6127936 & $\mathrm{ZAF}$ & Relyon Group P.L.C. & 0731708 & GBR \\
\hline sa12 & Tiger Brands Limited & B0J4PP2 & ZAF & ICS Holdings Limited & 6458506 & ZAF \\
\hline sa13 & Tiger Brands Limited & B0J4PP2 & ZAF & Adcock-Ingram Limited & 6016625 & ZAF \\
\hline sa14 & Trans Hex Group Limited & 6164267 & ZAF & Gem Diamond Mining Corporation Limited & 6127691 & ZAF \\
\hline
\end{tabular}




\section{Appendix A (Continued)}

\begin{tabular}{|c|c|c|c|c|c|c|}
\hline t001 & Thai Union Frozen Products PCL & 6422705 & THA & Songkla Canning & 6821487 & THA \\
\hline $\mathrm{u} 001$ & Acal PLC & 0005588 & GBR & Sedgemoor PLC & 0555373 & GBR \\
\hline $\mathrm{u} 002$ & Aegis Group PLC & 0965756 & GBR & Market Facts Inc. & 2566403 & USA \\
\hline $\mathrm{u} 003$ & Airtours PLC & B06BLB4 & GBR & Travel Services International & 2083140 & USA \\
\hline $\mathrm{u} 004$ & AMEC PLC & 0028262 & GBR & AGRA Inc. (AMEC Inc.) & 2058621 & CAN \\
\hline $\mathrm{u} 005$ & Ashtead Group PLC & 0053673 & GBR & Sheriff Holdings PLC & 0803908 & GBR \\
\hline $\mathrm{u} 006$ & BAA PLC & 0067340 & GBR & Duty Free International Inc. & 2289421 & USA \\
\hline $\mathrm{u} 007$ & Berisford PLC(ENODIS) & 0093152 & GBR & Scotsman Industries Inc. & 2779911 & USA \\
\hline $\mathrm{u} 008$ & Billiton PLC (BHP Billiton) & 0056650 & GBR & Rio Algom Ltd & 2740100 & CAN \\
\hline $\mathrm{u} 009$ & Bodycote International PLC & 0689562 & GBR & Lindberg Corp & 2516602 & USA \\
\hline $\mathrm{u} 010$ & British Airways PLC & 0129057 & GBR & British Regional Airlines Grp & 0289575 & GBR \\
\hline $\mathrm{u} 011$ & British American Tobacco PLC & 0287580 & GBR & Imasco Ltd & 2457767 & CAN \\
\hline $\mathrm{u} 012$ & British American Tobacco PLC & 0287580 & GBR & Rothmans Industries Ltd & 6752253 & SGP \\
\hline $\mathrm{u} 013$ & British Sky Broadcasting Group & 0141192 & GBR & Sports Internet Group PLC & 0540465 & GBR \\
\hline $\mathrm{u} 014$ & BSS Group PLC & B09BY45 & GBR & PTS Group PLC & 0666145 & GBR \\
\hline $\mathrm{u} 015$ & Cable \& Wireless PLC & 0162557 & GBR & Digital Island Inc. & 2432924 & USA \\
\hline $\mathrm{u} 016$ & Capital Radio PLC & 0174239 & GBR & Border Television PLC & 0112314 & GBR \\
\hline $\mathrm{u} 017$ & Daily Mail \& General Trust PLC & 0945736 & GBR & Bristol United Press PLC & 0125787 & GBR \\
\hline $\mathrm{u} 018$ & Dixons Group PLC & 0047245 & GBR & Elkjop ASA & 5682027 & NOR \\
\hline $\mathrm{u} 019$ & Ennstone PLC & 0178725 & GBR & Breedon PLC & 0121310 & GBR \\
\hline $\mathrm{u} 020$ & First Technology PLC & 0339135 & GBR & City Technology Holdings PLC & 0199221 & GBR \\
\hline $\mathrm{u} 021$ & First Technology PLC & 0339135 & GBR & Control Devices Inc. & $\mathrm{C} 000030846$ & USA \\
\hline $\mathrm{u} 022$ & Gallaher Group PLC & 0383369 & GBR & Austria Tabakwerke AG & 5355921 & AUT \\
\hline $\mathrm{u} 023$ & GKN PLC & 3064650 & GBR & Interlake Corp & 2463667 & USA \\
\hline $\mathrm{u} 024$ & Great Universal Stores (GUS) PLC & B0NH007 & GBR & Argos PLC & 0048679 & GBR \\
\hline $\mathrm{u} 025$ & Great Universal Stores (GUS) PLC & B0NH007 & GBR & Metromail Corp & 2601940 & USA \\
\hline $\mathrm{u} 026$ & Greene King PLC & 0387242 & GBR & Morland PLC & 0603313 & GBR \\
\hline $\mathrm{u} 027$ & Greene King PLC & 0387242 & GBR & Old English Inns PLC & 0659480 & GBR \\
\hline $\mathrm{u} 028$ & Gyrus Group PLC & 0170152 & GBR & Everest Medical Corp & 299806109 & USA \\
\hline $\mathrm{u} 029$ & Gyrus Group PLC & 0170152 & GBR & Somnus Medical Technologies & 2124072 & USA \\
\hline $\mathrm{u} 030$ & Hanson PLC & 3351608 & GBR & Pioneer International Ltd & 6688701 & AUS \\
\hline $\mathrm{u} 031$ & Headlam Group PLC & 0417008 & GBR & Eclipse Blinds PLC & 0303884 & GBR \\
\hline $\mathrm{u} 032$ & Hill \& Smith Holdings PLC & 0427030 & GBR & Ash \& Lacy PLC & 0052841 & GBR \\
\hline $\mathrm{u} 033$ & Homestyle Group PLC & 0750134 & GBR & Harveys Furnishing PLC & 0172501 & GBR \\
\hline $\mathrm{u} 034$ & Imperial Metal Industries(IMI) PLC & 0457963 & GBR & Polypipe PLC & 0693808 & GBR \\
\hline $\mathrm{u} 035$ & Invensys PLC & 0807041 & GBR & BAAN Co NV & 5380202 & NLD \\
\hline $\mathrm{u} 036$ & Invensys PLC & 0807041 & GBR & Marcam Solutions Inc. & 56614A107 & USA \\
\hline $\mathrm{u} 037$ & Jarvis PLC & B0DLKZ4 & GBR & Streamline Holdings PLC & 0842990 & GBR \\
\hline $\mathrm{u} 038$ & Johnson Matthey PLC & 0476407 & GBR & Meconic PLC & 0575166 & GBR \\
\hline $\mathrm{u} 039$ & Johnson Service Group PLC & 0476281 & GBR & Semara Holdings PLC & 0813004 & GBR \\
\hline $\mathrm{u} 040$ & Johnston Press PLC & 0476968 & GBR & Portsmouth \& Sunderland News & 0696205 & GBR \\
\hline $\mathrm{u} 041$ & Kingfisher PLC & 3319521 & GBR & But SA & 4233998 & FRA \\
\hline $\mathrm{u} 042$ & Kingfisher PLC & 3319521 & GBR & VCI PLC & 0930389 & GBR \\
\hline $\mathrm{u} 043$ & Mayflower Corp PLC & 0800222 & GBR & Dennis Group PLC & 0892489 & GBR \\
\hline $\mathrm{u} 044$ & Meggitt PLC & 0575809 & GBR & Whittaker Corp & 2963907 & USA \\
\hline $\mathrm{u} 045$ & Misys PLC & 0385785 & GBR & C-ATS Software Inc. & 2182683 & USA \\
\hline $\mathrm{u} 046$ & Misys PLC & 0385785 & GBR & Medic Computer Systems Inc. & 2575982 & USA \\
\hline $\mathrm{u} 047$ & Misys PLC & 0385785 & GBR & Sunquest Information Systems & 2809421 & USA \\
\hline $\mathrm{u} 048$ & National Express Group PLC & 0621520 & GBR & Prism Rail PLC & 0701240 & GBR \\
\hline u049 & National Grid Group PLC & B08SNH3 & GBR & New England Electric System & 2629726 & USA \\
\hline $\mathrm{u} 050$ & NSB Retail Systems PLC & 0157069 & GBR & Real Time Control PLC & 0727321 & GBR \\
\hline $\mathrm{u} 051$ & Pearson PLC & 0677608 & GBR & Dorling Kindersley Holdings & 0277570 & GBR \\
\hline $\mathrm{u} 052$ & Pearson PLC & 0677608 & GBR & National Computer Systems Inc. & 2625337 & USA \\
\hline $\mathrm{u} 053$ & Pendragon PLC & 0679529 & GBR & Evans Halshaw Holdings PLC & 0323785 & GBR \\
\hline $\mathrm{u} 054$ & Psion PLC & B0D5VH5 & GBR & Teklogix International Inc. & 2879145 & CAN \\
\hline $\mathrm{u} 055$ & QXL.com (Ricardo) PLC & 3270338 & GBR & Ricardo.de $\mathrm{AG}$ & 5731178 & $\mathrm{DEU}$ \\
\hline $\mathrm{u} 056$ & Reckitt \& Colman PLC (Reckitt Benckiser PLC) & 0727871 & GBR & Benckiser NV & $\mathrm{C} 000032852$ & NLD \\
\hline $\mathrm{u} 057$ & Retail Stores PLC (Liberty International ltd) & 0774208 & GBR & Liberty PLC & 0515979 & GBR \\
\hline $\mathrm{u} 058$ & Rexam PLC & 0425045 & GBR & American National Can Group & 2441942 & USA \\
\hline $\mathrm{u} 059$ & Rolls-Royce (Group) PLC & 3283648 & GBR & Vickers PLC & 0287052 & GBR \\
\hline $\mathrm{u} 060$ & Sage Group PLC & 0802165 & GBR & Best Software Inc. & 086579109 & USA \\
\hline $\mathrm{u} 061$ & Sage Group PLC & 0802165 & GBR & Interact Commerce Corp & 2423832 & USA \\
\hline $\mathrm{u} 062$ & Sage Group PLC & 0802165 & GBR & State of the Art Inc. & 2842318 & USA \\
\hline $\mathrm{u} 063$ & Sage Group PLC & 0802165 & GBR & Tetra PLC & 0184250 & GBR \\
\hline $\mathrm{u} 064$ & Scottish (\& Southern Energy) Hydro-Electric PLC & 0790873 & GBR & Southern Electric PLC & 0828677 & GBR \\
\hline $\mathrm{u} 065$ & Scottish Power PLC & 0690070 & GBR & PacifiCorp & 2715669 & USA \\
\hline $\mathrm{u} 066$ & Seton Healthcare Group PLC (SSL International) & 0798112 & GBR & Scholl PLC & 0323718 & GBR \\
\hline $\mathrm{u} 067$ & Seton Scholl Healthcare PLC (SSL International) & 0798112 & GBR & London International Group PLC & 0499802 & GBR \\
\hline $\mathrm{u} 068$ & Shanks (\& McEwan) Group PLC & 0799524 & GBR & Caird Group PLC & 0442293 & GBR \\
\hline $\mathrm{u} 069$ & Shield Diagnostics Group (Axis-Shield) PLC & 0803997 & GBR & Axis Biochemicals AS & 4055653 & $\mathrm{NOR}$ \\
\hline $\mathrm{u} 070$ & Shire Pharmaceuticals Grp PLC & B0KQX86 & GBR & BioChem Pharma Inc. & 2452171 & CAN \\
\hline
\end{tabular}




\section{Appendix A (Continued)}

\begin{tabular}{|c|c|c|c|c|c|c|}
\hline $\mathrm{u} 071$ & Shire Pharmaceuticals Grp PLC & B0KQX86 & GBR & Roberts Pharmaceutical Corp & 2743563 & USA \\
\hline $\mathrm{u} 072$ & SkyePharma PLC & 0812357 & GBR & DepoTech Corp & 2264826 & USA \\
\hline $\mathrm{u} 073$ & Smiths Group PLC & 0818270 & GBR & Barringer Technologies Inc. & 2081702 & USA \\
\hline $\mathrm{u} 074$ & Smiths Industries PLC (Smiths Group PLC) & 0818270 & GBR & TI Group PLC & 0868673 & GBR \\
\hline $\mathrm{u} 075$ & Somerfield PLC & 0821869 & GBR & Kwik Save Group PLC & 0499084 & GBR \\
\hline $\mathrm{u} 076$ & Stagecoach Holdings PLC & B01NL71 & GBR & Coach USA Inc. & 2210346 & USA \\
\hline u077 & Taylor Woodrow PLC & 0878230 & GBR & Bryant Group PLC & 0149408 & GBR \\
\hline $\mathrm{u} 078$ & Trinity Mirror PLC & 0903994 & GBR & Southnews PLC & 0831567 & GBR \\
\hline u079 & Unilever PLC & B10RZP7 & GBR & Bestfoods & 2230775 & USA \\
\hline $\mathrm{u} 080$ & United News \& Media (United Business Media) PLC & B0B2LQ7 & GBR & CMP Media LLC & 125891101 & USA \\
\hline $\mathrm{u} 081$ & Vodafone AirTouch PLC & 0719210 & GBR & Mannesmann AG & 5060322 & $\overline{\mathrm{DEU}}$ \\
\hline $\mathrm{u} 082$ & Vodafone Group PLC & 0719210 & GBR & AirTouch Communications Inc. & 2674588 & USA \\
\hline u083 & Vodafone Group PLC & 0719210 & GBR & Japan Telecom Co Ltd & 6475497 & JPN \\
\hline u084 & Westbury PLC & 0953687 & GBR & John Maunders Group PLC & 0572327 & GBR \\
\hline $\mathrm{u} 085$ & WH Smith (Group) PLC & B02Q4M5 & GBR & Hodder Headline PLC & 0417149 & GBR \\
\hline u086 & Whitbread PLC & B07FNF3 & GBR & Swallow Group PLC & 0927228 & GBR \\
\hline $\mathrm{u} 087$ & Wolseley PLC & 0976402 & GBR & British Fittings Group PLC & 0060242 & GBR \\
\hline u088 & Wolverhampton \& Dudley & 3122945 & GBR & Mansfield Brewery PLC & 0563332 & GBR \\
\hline u089 & Wolverhampton \& Dudley & 3122945 & GBR & Marston Thompson \& Evershed & 0568702 & GBR \\
\hline u090 & WPP Group PLC & B0J6N10 & GBR & Intelliquest Information Group & 2476966 & USA \\
\hline u091 & WPP Group PLC & B0J6N10 & GBR & Tempus Group PLC & 0160409 & GBR \\
\hline u092 & WPP Group PLC & B0J6N10 & GBR & Young \& Rubicam Inc. & 2238638 & USA \\
\hline u093 & WS Atkins PLC & 0060800 & GBR & Lambert Smith Hampton PLC & 0501763 & GBR \\
\hline u094 & WSP Group PLC & 0932374 & GBR & AB Jacobson \& Widmark & 4474731 & SWE \\
\hline u095 & Wyevale Garden Centres PLC & 0984568 & GBR & Country Gardens PLC & 0228813 & GBR \\
\hline u096 & Xenova Group PLC & 2780214 & GBR & Cantab Pharmaceuticals PLC & 0276889 & GBR \\
\hline u097 & ZENECA Group (Astrazeneca) PLC & 0989529 & GBR & Astra $\mathrm{AB}$ & 5241503 & SWE \\
\hline u098 & Alexon Group PLC & 0844402 & GBR & Style Holdings PLC & 0854519 & GBR \\
\hline u099 & Allied Domecq PLC & B012L67 & GBR & Montana Group (NZ) Limited & 6225443 & NZL \\
\hline $\mathrm{u} 100$ & Allied Domecq PLC & B012L67 & GBR & Bodegas Y Bebidas, S.A. & 5513440 & ESP \\
\hline u101 & Amdocs Limited & 2256908 & USA & International Telecommn Data Systems Inc. & $\mathrm{C} 000030910$ & USA \\
\hline $\mathrm{u} 102$ & Applied Optical Technologies PLC & 0046219 & GBR & Optical Security Group, Inc. & 683848204 & USA \\
\hline u103 & Austin Reed Group PLC & 0729684 & GBR & Country Casuals Holdings PLC & 0227393 & GBR \\
\hline u104 & Bloomsbury Publishing PLC & 3314775 & GBR & A. \& C. Black PLC & 0101709 & GBR \\
\hline u105 & BP PLC & 0798059 & GBR & Burmah Castrol PLC & 0566944 & GBR \\
\hline u106 & BP PLC & 0798059 & GBR & Atlantic Richfield Company & 2061618 & USA \\
\hline $\mathrm{u} 107$ & Bunzl PLC & B0744B3 & GBR & Provend Group PLC & 0698115 & GBR \\
\hline u108 & Cenes Pharmaceuticals PLC & 0207050 & GBR & Cambridge Neuroscience, Inc. & 2165736 & USA \\
\hline u109 & Compass Group PLC & 0533153 & GBR & Selecta Group & 5236253 & $\mathrm{CHE}$ \\
\hline $\mathrm{u} 110$ & Compass Group PLC & 0533153 & GBR & Morrison Management Specialists, Inc. & 2590747 & USA \\
\hline u111 & De La Rue PLC & B09JC23 & GBR & ATS Money Systems, Inc. & 2002264 & $\overline{\text { USA }}$ \\
\hline $\mathrm{u} 112$ & Delta PLC & 0261506 & GBR & Delta Electrical Industries Limited & 6260778 & ZAF \\
\hline u113 & Game Group PLC & 0736015 & GBR & Game PLC & 0285186 & GBR \\
\hline u114 & Ennstone PLC & 0178725 & GBR & Blockleys PLC & 0105411 & GBR \\
\hline $\mathrm{u} 115$ & Ennstone PLC & 0178725 & GBR & Natural Building Materials PLC & 0438872 & GBR \\
\hline u116 & Holidaybreak PLC & 0316495 & GBR & Baldwin PLC & 0072504 & GBR \\
\hline u117 & Spectris PLC & 0330860 & GBR & Servomex PLC & 0797885 & GBR \\
\hline $\mathrm{u} 118$ & Xansa PLC & 0330417 & GBR & Druid Group PLC & 0282079 & GBR \\
\hline u119 & Filtronic PLC & 0336299 & GBR & Sage Laboratories, Inc. & 786650101 & USA \\
\hline $\mathrm{u} 120$ & Findel PLC & 0337407 & GBR & Novara PLC & 0650041 & GBR \\
\hline $\mathrm{u} 121$ & Galliford TRY PLC & 0359906 & GBR & Try Group PLC & 0895240 & GBR \\
\hline $\mathrm{u} 122$ & Gaskell PLC & 0432045 & GBR & Tomkinsons PLC & 0896306 & GBR \\
\hline u123 & Canterbury Foods Group PLC & 3339820 & GBR & Sims Food Group PLC & 0809155 & GBR \\
\hline u124 & AGA Foodservice PLC & 0374288 & GBR & Friatec $\mathrm{AG}$ & 4423960 & DEU \\
\hline $\mathrm{u} 125$ & BIG Food Group PLC (THE) & 0455871 & GBR & Booker PLC & 0110523 & GBR \\
\hline u126 & Communisis PLC & 0668323 & GBR & John Waddington PLC & 0932006 & GBR \\
\hline u127 & Kier Group PLC & 0491563 & GBR & Bellwinch PLC & 0090595 & GBR \\
\hline u128 & Hilton Group PLC & 0500254 & GBR & Stakis PLC & 0838427 & GBR \\
\hline u129 & Luminar PLC & 0538244 & GBR & Northern Leisure PLC & 0654612 & GBR \\
\hline u130 & Mayflower Corp. PLC & 0800222 & GBR & Metrotrans Corporation & 2565143 & USA \\
\hline $\mathrm{u} 131$ & Mentmore PLC & 0576590 & GBR & Birkby PLC & 0098362 & GBR \\
\hline u132 & Acambis PLC & 0694179 & GBR & Oravax, Inc. & 2654933 & USA \\
\hline u133 & Peterhouse Group PLC & 0805410 & GBR & EVE Group PLC & 0324034 & GBR \\
\hline u134 & Photobition Group PLC & 0687351 & GBR & Katz Digital Technologies, Inc. & 2482167 & USA \\
\hline u135 & Protherics PLC & 0702920 & GBR & Therapeutic Antibodies Inc. & $88337 \mathrm{M} 100$ & USA \\
\hline u136 & Invensys PLC & 0807041 & GBR & Eurotherm PLC & 0323116 & GBR \\
\hline u137 & SIG PLC & 0802541 & GBR & Roskel PLC & 0751007 & GBR \\
\hline u138 & Telewest Communications PLC & 0654452 & GBR & Flextech PLC & 0343233 & GBR \\
\hline u139 & Interserve PLC & 0152815 & GBR & Band PLC & 0146807 & GBR \\
\hline $\mathrm{u} 140$ & Interserve PLC & 0152815 & GBR & How Group PLC & 0440383 & GBR \\
\hline u141 & Planestation Group PLC & B02TW20 & GBR & Tomorrows Leisure PLC & 0896577 & GBR \\
\hline
\end{tabular}




\section{Appendix A (Continued)}

Panel B Matched Acquirers and Matched Targets

\begin{tabular}{|c|c|c|c|c|c|c|}
\hline \multirow{2}{*}{ Seq } & \multicolumn{3}{|c|}{ Matched Acquirers } & \multicolumn{3}{|l|}{ Targets } \\
\hline & Entity Name & Sedol & Country & Entity Name & Sedol & Country \\
\hline 20 & Yankee Candles Company Inc. & 2433671 & USA & Official Information Company (THE) & C900021331 & USA \\
\hline $\mathrm{a} 002$ & Gaz Metro Limited Partnership & 2362418 & CAN & United Networks Limited & 6695916 & NZL \\
\hline a003 & Peabody Energy Corp. & 2753454 & USA & Mesa Air Group Inc. & 2582090 & USA \\
\hline \begin{tabular}{|l|l} 
a004 \\
\end{tabular} & Peabody Energy Corp. & 2753454 & USA & Corning Inc. & 2224701 & USA \\
\hline a005 & Forgent Networks Inc. & 2932037 & USA & Myob Limited & 6242862 & AUS \\
\hline a006 & Serco Group PLC & 0797379 & GBR & Featherlite Inc. & 2331504 & USA \\
\hline $\mathrm{a}$ a007 & Sysco Corp. & 2868165 & USA & Agribrands International, Inc. & $\mathrm{c} 000033225$ & USA \\
\hline a008 & Portman Limited & 6695154 & AUS & Anglogold Australasia Limited & 6005582 & AUS \\
\hline \begin{tabular}{|l} 
a009 \\
\end{tabular} & UNIFIED WESTERN GROCERS, Inc. & C900013941 & USA & Cranswick Premium Wines Limited & 6087621 & AUS \\
\hline $\mathrm{a} 010$ & UNIFIED WESTERN GROCERS, Inc. & C900013941 & USA & Gerber Childrenswear, Inc. & $\mathrm{c} 000044653$ & USA \\
\hline \begin{tabular}{|l|l|}
$\mathrm{a} 011$ \\
\end{tabular} & WR Grace \& Company & 2232685 & USA & Nufarm & 6335331 & AUS \\
\hline \begin{tabular}{|l}
$\mathrm{a} 012$ \\
\end{tabular} & WR Grace \& Company & 2232685 & USA & Interdent, Inc. & $\mathrm{c} 000031123$ & USA \\
\hline a013 & Intertape Polymer Group & 2459901 & CAN & Printpack, Inc. & $\mathrm{c} 000065952$ & USA \\
\hline $\mathrm{a} 014$ & Six Flags Inc. & 2891945 & USA & Alliance Gaming Corp. & 2380818 & USA \\
\hline $\mathrm{a} 015$ & Alumina Limited & 6954985 & AUS & Aber Diamond Corp. & 2033178 & CAN \\
\hline \begin{tabular}{|l} 
a016 \\
\end{tabular} & Alumina Limited & 6954985 & AUS & Minara Resources & 6031855 & AUS \\
\hline \begin{tabular}{|l}
$\mathrm{a} 017$ \\
\end{tabular} & Ticor Limited & 6890573 & AUS & Ranger Minerals Limited & 6723077 & AUS \\
\hline a018 & Agnico-Eagle Mines Limited & 2009823 & CAN & Rayrock Resources Inc. & 2726661 & CAN \\
\hline \begin{tabular}{|l|l}
$\mathrm{a} 019$ \\
\end{tabular} & Saga Communications Inc. & 2767013 & USA & CTN Media Group Inc. & 2952314 & USA \\
\hline $\mathrm{a} 020$ & Four Seasons Hotels Inc. & 2348935 & CAN & Vail Resorts Inc. & 2954194 & USA \\
\hline \begin{tabular}{|l|l}
$\mathrm{a} 021$ \\
\end{tabular} & United Stationers Inc. & 2923815 & USA & Email Limited & $\mathrm{c} 000005345$ & AUS \\
\hline \begin{tabular}{|l}
$\mathrm{a} 022$ \\
\end{tabular} & Henry Walker Eltin Group & 6420884 & AUS & Ashton Mining Limited & $\mathrm{c} 000005124$ & AUS \\
\hline \begin{tabular}{|l}
$\mathrm{a} 023$ \\
\end{tabular} & Patrick Industries & 2673154 & USA & DMI Furniture, Inc. & 2250933 & USA \\
\hline \begin{tabular}{|l|l}
$\mathrm{a} 024$ \\
\end{tabular} & Investa Property Group & 6954145 & AUS & Games Workshop Group PLC & 0371847 & GBR \\
\hline $\mathrm{c} 001$ & United Business Media PLC & B0B2LQ7 & GBR & Sonoco Products Company & 2821395 & USA \\
\hline $\mathrm{c} 002$ & Electronic Data Systems Corp. & 2312736 & USA & Nippon Kinzoku Company Limited & 6640444 & JPN \\
\hline $\mathrm{c} 003$ & Electronic Data Systems Corp. & 2312736 & USA & FPB Holding Aktiengesellschaft & 4333962 & DEU \\
\hline $\mathrm{c} 004$ & Electronic Data Systems Corp. & 2312736 & USA & Finolex Cables Limited & 6139856 & IND \\
\hline $\mathrm{c} 005$ & Arden Group Inc. & 2047425 & USA & Arden Group Inc. & 2047425 & USA \\
\hline $\mathrm{c} 006$ & Chum Limited & 2195766 & CAN & Canadian Satellite Communications Inc. & 2172071 & CAN \\
\hline $\mathrm{c} 007$ & Cameco Corp. & 2166160 & CAN & AUR Resources Inc. & 2002178 & CAN \\
\hline $\mathrm{c} 008$ & Phelps Dodge Corp. & 2685007 & USA & Glamis Gold Limited & 2371113 & CAN \\
\hline $\mathrm{c} 009$ & Penn Virginia & 2680228 & USA & Paladin Resources PLC & 0692032 & GBR \\
\hline $\mathrm{c} 010$ & Patterson UTI Energy Inc. & 2672537 & USA & Summit Resources Limited & 2859084 & $\mathrm{CAN}$ \\
\hline $\mathrm{c} 011$ & Paramount Resources Limited & B073FP1 & CAN & Gulfstream Resources Canada Limited & 2396729 & CAN \\
\hline $\mathrm{c} 012$ & BT Group PLC & 2816539 & USA & Keppel Telecommunications Transportation & 6842444 & SGP \\
\hline $\mathrm{c} 013$ & Cincinnati Bell Inc. & 2196877 & USA & Focal Communications Corp. & 2828824 & USA \\
\hline $\mathrm{c} 014$ & McLeodusa Inc. & 2876339 & USA & Cable \& Wireless Optus Limited & 6133160 & AUS \\
\hline $\mathrm{c} 015$ & Chattem Inc. & 2188982 & USA & Transkaryotic Therapies Inc. & $\mathrm{c} 000004578$ & USA \\
\hline $\mathrm{c} 016$ & Kansas City Southern & 2607647 & USA & Guangshen Railway Company Limited & 2394615 & USA \\
\hline $\mathrm{c} 017$ & Burlington Northern Santa Fe Corp & 2154927 & USA & Guangshen Railway Company Limited & 2394615 & USA \\
\hline $\mathrm{c} 018$ & Nexen Inc. & 2172219 & CAN & Weatherford International Limited & 2962421 & USA \\
\hline $\mathrm{c} 019$ & Whirlpool Corp. & 2960384 & USA & Devro PLC & 0267043 & GBR \\
\hline $\mathrm{c} 020$ & Whirlpool Corp. & 2960384 & USA & Universal Electronics Inc. & 2911683 & USA \\
\hline $\mathrm{c} 021$ & GEAC Computer Limited & 2362690 & CAN & Transaction Systems Architects & 2889155 & USA \\
\hline $\mathrm{c} 022$ & Skywest Inc. & 2814210 & USA & SAS Norge ASA & 5066472 & NOR \\
\hline $\mathrm{c} 023$ & Algoma Steel Inc. & 2850054 & CAN & EASCO, Inc. & $\mathrm{c} 000029927$ & USA \\
\hline $\mathrm{c} 024$ & La-Z-Boy Chair Inc. & 2508405 & USA & Federal Screw Works & 2338969 & USA \\
\hline $\mathrm{c} 025$ & Transalta Corp. & 2901628 & $\mathrm{CAN}$ & MGE Energy Inc. & 2554163 & USA \\
\hline $\mathrm{c} 026$ & Canfor Corp. & 2173416 & CAN & Korn Ferry International & 2386849 & USA \\
\hline $\mathrm{c} 027$ & Tenke Mining Corp. & 2430702 & CAN & Aberfoyle Limited & 6003100 & AUS \\
\hline $\mathrm{c} 028$ & Acxiom Corp. & 2159773 & USA & Medicalogic/Medscape Incorporated & $\mathrm{c} 000069418$ & USA \\
\hline $\mathrm{c} 029$ & Skyline Corp. & 2814005 & USA & Calloways Nursery Inc. & 2165231 & USA \\
\hline $\mathrm{c} 030$ & Inmet Mining Corp. & 2583026 & CAN & Coeur D'Alene Mines Corp. & 2208136 & USA \\
\hline $\mathrm{c} 031$ & Inter-Tel Inc. & 2466462 & USA & Minacs Worldwide Inc. & 2761963 & CAN \\
\hline $\mathrm{c} 032$ & Winn-Dixie Stores Inc. & 2972602 & USA & Foodland Associated Limited & 6347875 & AUS \\
\hline $\mathrm{c} 033$ & Jacuzzi Brands Inc. & 2937054 & USA & Riken Corporation & 6740203 & JPN \\
\hline $\mathrm{c} 034$ & Parkway Holdings Limited & 6811143 & SGP & NFO Worldwide, Inc. & 2619169 & USA \\
\hline $\mathrm{c} 035$ & Cascades Inc. & 2179254 & CAN & Glatfelter & 2372008 & USA \\
\hline $\mathrm{c} 036$ & Brunswick Corp. & 2149309 & USA & Hawk Corp. & 2154886 & USA \\
\hline $\mathrm{c} 037$ & Shell Canada Limited & 2802806 & CAN & Beau Canada Exploration Ltd.. & 2086622 & CAN \\
\hline $\mathrm{c} 038$ & Akita Drilling Limited & 2010728 & CAN & Tullow Oil PLC & 0150080 & GBR \\
\hline $\mathrm{c} 039$ & Cameco Corp. & 2166160 & CAN & AvgoldLimited & 2054102 & USA \\
\hline $\mathrm{c} 040$ & Rowan Companies Income & 2753197 & USA & Petromet Resources Limited & 2684598 & $\mathrm{CAN}$ \\
\hline $\mathrm{c} 041$ & XTO Energy Inc. & 2236911 & USA & Niko Resources Limited & 2639554 & CAN \\
\hline $\mathrm{c} 042$ & Ensign Energy Services Inc. & 2317623 & CAN & Denbury Resources Incorporated & 2167442 & CAN \\
\hline $\mathrm{c} 043$ & Horizon Offshore Inc. & 2231637 & USA & Warren Resources Inc. & 2981761 & USA \\
\hline $\mathrm{c} 044$ & Hollinger Inc. & 2253868 & CAN & Scripps EW Inc. & 2862532 & USA \\
\hline $\mathrm{c} 045$ & Publicis Group E SA & 2633482 & USA & AAPT Limited & 6086468 & AUS \\
\hline
\end{tabular}




\section{Appendix A (Continued)}

\begin{tabular}{|c|c|c|c|c|c|c|}
\hline $\mathrm{c} 046$ & United States Cellular Corp. & 2918996 & USA & CTV Inc. & 2084488 & CAN \\
\hline $\mathrm{c} 047$ & Shell Canada Limited & 2802806 & $\mathrm{CAN}$ & DNO ASA & B0BV818 & NOR \\
\hline $\mathrm{c} 048$ & Shell Canada Limited & 2802806 & CAN & Startech Energy Inc. & 2768782 & CAN \\
\hline $\mathrm{c} 049$ & Apache Corp. & 2043962 & USA & Plains Resources Inc. & 2691617 & USA \\
\hline $\mathrm{c} 050$ & Freeport-McMoran Copper \& Gold & 2352118 & USA & Antofagasta PLC & 2528395 & USA \\
\hline $\mathrm{c} 051$ & Cascades Inc. & 2179254 & $\mathrm{CAN}$ & Gaylord Container Corporation & 2362184 & USA \\
\hline $\mathrm{c} 052$ & Quebecor Inc. & 2716695 & $\mathrm{CAN}$ & Advanstar, Inc. & $\mathrm{c} 000065534$ & USA \\
\hline $\mathrm{c} 053$ & FPL Group Inc. & 2328915 & USA & Newell Rubbermaid Inc. & 2635701 & USA \\
\hline $\mathrm{c} 054$ & China Eastern Airlines Corporation Limited & 2191979 & USA & Dia Met Minerals Ltd. & $\mathrm{C} 000006061$ & CAN \\
\hline $\mathrm{c} 055$ & Atkins (WS) PLC & 0060800 & GBR & Gleeson (MJ) Group PLC & B01BNK2 & GBR \\
\hline $\mathrm{c} 056$ & Theratechnologies Inc. & 2889906 & CAN & Lannett Inc. & 2447694 & USA \\
\hline $\mathrm{c} 057$ & Laureate Education Inc. & 2867689 & USA & Intervoice Inc. & 2462244 & USA \\
\hline $\mathrm{c} 058$ & Global Natural Energy PLC & 3179189 & GBR & Professional Veterinary Products, Ltd. & C900043063 & USA \\
\hline $\mathrm{c} 059$ & Telemig Celular Participacoes SA & 2297996 & USA & Kushner-Locke Company & 2103684 & USA \\
\hline $\mathrm{c} 060$ & Continental Minerals Corp. & 2216775 & CAN & North Atlantic Natural Resources AB & 5261824 & SWE \\
\hline $\mathrm{c} 061$ & Virco Manufacturing Corp. & 2929705 & USA & HMG Worldwide Corp. & 2566425 & USA \\
\hline $\mathrm{c} 062$ & MET-Pro Corp. & 2582852 & USA & Osborne \& Little PLC & 0663050 & GBR \\
\hline $\mathrm{c} 063$ & Tinsley (Eliza) Group PLC & 0893040 & GBR & Intrenet Inc. & 2470076 & USA \\
\hline $\mathrm{c} 064$ & Arriva PLC & 0230346 & GBR & TIBS Holdings Ltd. & 6900933 & SGP \\
\hline $\mathrm{c} 065$ & Arriva PLC & 0230346 & GBR & TIBS Holdings Ltd. & 6900933 & SGP \\
\hline $\mathrm{c} 066$ & Arriva PLC & 0230346 & GBR & Response Oncology Inc. & 2098650 & USA \\
\hline $\mathrm{c} 067$ & Playboy Enterprises Inc. & 2691811 & USA & VTR PLC & 0929354 & GBR \\
\hline $\mathrm{c} 068$ & Matsushita Elect. Industrial Company LIM & 2572121 & USA & NMS Communications Corp. & 2622866 & USA \\
\hline $\mathrm{c} 069$ & Matsushita Elect. Industrial Company LIM & 2572121 & USA & Globe Business Resources, Inc. & $\mathrm{C} 000030360$ & USA \\
\hline $\mathrm{c} 070$ & Matsushita Elect. Industrial Company LIM & 2572121 & USA & SCO Group Inc. & 2855907 & USA \\
\hline $\mathrm{c} 071$ & Motorola Inc. & 2606600 & USA & Detection Systems, Inc. & 2266059 & USA \\
\hline $\mathrm{c} 072$ & Telefonaktiebolaget LM Ericsson & 2031730 & USA & Platinum Technology International, Inc. & 2691781 & USA \\
\hline $\mathrm{c} 073$ & Saskatchewan Power Corp. & c900014406 & CAN & SJW Corp. & 2811932 & USA \\
\hline $\mathrm{c} 074$ & Sterlite Gold Limited & 2352679 & CAN & Witwatersrand Gold Mining Co Ltd. & 6975317 & $\mathrm{ZAF}$ \\
\hline $\mathrm{c} 075$ & Quebecor Inc. & 2716695 & $\mathrm{CAN}$ & Printware, Inc. & $\mathrm{C} 000030756$ & USA \\
\hline in01 & Gainsco Inc. & $\mathrm{B} 0 \mathrm{QH} 402$ & USA & Technology One Limited & 6302410 & AUS \\
\hline in02 & Hindustan Petroleum Corp. Limited & 6100476 & IND & Helmerich Payne Inc. & 2420101 & USA \\
\hline in03 & HCL Technologies Limited & 6294896 & IND & Valcom Inc. & 2801784 & USA \\
\hline in04 & Bodycote International PLC & 0689562 & GBR & Finolex Cables Limited & 6139856 & IND \\
\hline in 05 & Ghcl Limited & 6397579 & IND & Goodlass Nerolac Paints Limited & 6291778 & IND \\
\hline in06 & Tata Chemicals Limited & 6101167 & IND & Sun Pharmaceuticals Industries Limited & 6582483 & IND \\
\hline ir01 & Hanson PLC & 2020125 & USA & Marshalls PLC & B012BV2 & GBR \\
\hline ir02 & Clorox Company & 2204026 & USA & Sinopec Beijing Yanhua Petroch.,Co.- ADR & 2022712 & USA \\
\hline ir03 & Clorox Company & 2204026 & USA & Bridgford Foods Corp. & 2123013 & USA \\
\hline ir04 & Watson Pharmaceuticals Inc. & 2943545 & USA & Geltex Pharmaceuticals, Inc. & $\mathrm{C} 000001980$ & USA \\
\hline ir05 & Travis Perkins PLC & 0773960 & GBR & Hampden Group PLC & 0407582 & GBR \\
\hline ir06 & Flowers Foods Inc. & 2744243 & USA & NFF PLC & 0648693 & GBR \\
\hline ir07 & Arla Foods PLC & 0257765 & GBR & Vlasic Foods International, Inc. & $\mathrm{C} 000033843$ & USA \\
\hline ir08 & Elizabeth Arden Inc. & 2856524 & USA & Innovata PLC & 0555470 & GBR \\
\hline ir09 & Glanbia PLC & 4058629 & IRL & Lance Inc. & 2503314 & USA \\
\hline ir10 & RTI International Metals Commerce & 2296993 & USA & Baltek Corporation & $\mathrm{C} 000000550$ & USA \\
\hline ir11 & Marshalls PLC & B012BV2 & GBR & Janis Limited & 6469081 & JPN \\
\hline is 01 & Spherion Corp. & 2473989 & USA & LQ Corporation Inc. & B020TV1 & USA \\
\hline $\mathrm{m} 001$ & Golden Hope Plantation Berhad & 6411929 & MYS & Carlsberg Brewery Malaysia Berhad & B09FGC9 & MYS \\
\hline n001 & OM Group Inc. & 2653684 & USA & Explosifs Et Products Chimiques N & 4326401 & FRA \\
\hline $\begin{array}{ll}\mathrm{n}(1001 \\
\mathrm{n} 002 \\
\end{array}$ & Stephan Company & 2844961 & USA & Orbus Pharma Inc. & 2965969 & CAN \\
\hline n003 & Telesp Celular Participacoes & 2297974 & USA & Tivo Inc. & 2492724 & USA \\
\hline $\mathrm{s} 001$ & IMI PLC & 0457963 & GBR & Lindeteves-Jacoberg Limited & 6537290 & SGP \\
\hline $\mathrm{s} 002$ & Asia Food \& Properties Limited & 6018450 & SGP & Vantage Corp. Limited & 6468668 & SGP \\
\hline $\mathrm{s} 003$ & MSC Software Corp. & 2553096 & USA & Jurong Technologies Industrial Corp. & 6231150 & SGP \\
\hline s004 & Delphi Corporation & 2385998 & USA & Impsat Fiber Networks & 2598967 & USA \\
\hline $\mathrm{s} 005$ & Arriva PLC & 0230346 & GBR & Prism Rail PLC & 0701240 & GBR \\
\hline $\mathrm{sa} 01$ & Cadbury Schweppes (S.A.) Limited & 6002602 & $\mathrm{ZAF}$ & Omega Protein Corp. & 2232652 & USA \\
\hline \begin{tabular}{l|l}
$\mathrm{sav01}$ \\
$\mathrm{sa} 02$
\end{tabular} & Palabora Mining Company Limited & 6667904 & $\mathrm{ZAF}$ & Western Metals & 6949721 & AUS \\
\hline $\mathrm{sa} 03$ & Beazer Homes USA Inc. & 2086172 & USA & Dorbyl Limited & 6277057 & ZAF \\
\hline $\mathrm{sa} 04$ & Breakwater Resources Limited & 2122021 & CAN & Auriongold Limited & 6370008 & AUS \\
\hline $\mathrm{sa} 05$ & JCI Limited & 6531515 & ZAF & Breakwater Resources Limited & 2122021 & CAN \\
\hline $\mathrm{sa} 06$ & Brascade Resources Inc. & B02YLJ5 & CAN & Eurasia Mining PLC & 0323042 & GBR \\
\hline $\mathrm{sa} 07$ & Ballantyne Omaha Inc. & 2070540 & USA & Boundless Corp. & 2224789 & USA \\
\hline $\mathrm{sa} 08$ & Tele Centro Oeste Celular Participacoes & 2298018 & USA & JJB Sports PLC & 0468523 & GBR \\
\hline sa09 & Tele Centro Oeste Celular Participacoes & 2298018 & USA & Wyndeham Press Group PLC & 0978505 & GBR \\
\hline sa10 & Harvey Nash Group PLC & 0657354 & GBR & Synplicity Inc. & 2652982 & USA \\
\hline sa11 & Miller (Herman) Inc. & 2594222 & USA & DMI Furniture, Inc. & 2250933 & USA \\
\hline $\mathrm{sa} 12$ & Alliance One International Inc. & 2269865 & USA & South African Druggists Limited & 6764775 & $\mathrm{ZAF}$ \\
\hline sa13 & Universal Corp. & 2923804 & USA & TL Administration Corp. & 2891451 & USA \\
\hline sa14 & Matodzi Resources Limited & 6975403 & ZAF & Matodzi Resources Limited & 6975403 & ZAF \\
\hline
\end{tabular}




\section{Appendix A (Continued)}

\begin{tabular}{|c|c|c|c|c|c|c|}
\hline t001 & Guinness Anchor Berhad & 6397803 & MYS & Tropical Canning & 6902188 & THA \\
\hline u001 & Northamber PLC & 0645638 & GBR & Sanderson Group PLC & 0774350 & GBR \\
\hline $\mathrm{u} 002$ & The Laird Group PLC & 0500522 & GBR & FTI Consulting Inc. & 2351449 & USA \\
\hline $\mathrm{u} 003$ & BBA Group PLC & 0067748 & GBR & Bidcorp PLC & $\mathrm{c} 000016345$ & GBR \\
\hline $\mathrm{u} 004$ & Interserve PLC & 0152815 & GBR & Guthrie GTS Limited & \begin{tabular}{|c|}
6399070 \\
\end{tabular} & SGP \\
\hline u005 & Keane Inc. & 2485371 & USA & Xansa PLC & 0330417 & GBR \\
\hline $\mathrm{u} 006$ & Singapore Airlines Limited & 6811734 & SGP & Cash American International & 2179425 & USA \\
\hline u007 & Idex Corp. & 2456612 & USA & Nordson Corp. & 2641838 & USA \\
\hline $\mathrm{u} 008$ & Companhia Siderurgica Nacional & 2220936 & USA & Truserv Corporation & $\mathrm{c} 000018871$ & USA \\
\hline u009 & Mueller Industries Inc. & 2609717 & USA & Insteel Industries Inc. & 2325875 & USA \\
\hline $\mathrm{u} 010$ & UAL Corp. & 2901178 & USA & Alpha Airports Group PLC & 0028132 & GBR \\
\hline $\mathrm{u} 011$ & Reynolds American Inc. & 2429090 & USA & CIT Group Inc. & 2965549 & USA \\
\hline u012 & Reynolds American Inc. & 2429090 & USA & British American Tobacco Holdings Ltd. & 6919207 & $\mathrm{ZAF}$ \\
\hline u013 & Nextel Partners Inc. & 2551874 & USA & Gearhouse Group PLC & 0363402 & GBR \\
\hline $\mathrm{u} 014$ & European Motor Holdings PLC & 0315113 & GBR & Adam \& Harvey Group PLC & 0007830 & GBR \\
\hline u015 & Time Warner Inc. & 2712165 & USA & Choice One Communications Inc. & $\mathrm{C} 000070176$ & USA \\
\hline u016 & Stratos Global Corp. & 2732754 & $\mathrm{CAN}$ & Vodavi Technology Inc. & 2537722 & USA \\
\hline u017 & Readers Digest Association Inc. & 2726951 & USA & Liberfabrica PLC & 0271680 & GBR \\
\hline $\mathrm{u} 018$ & Best Buy Company Inc. & 2094670 & USA & Schouw \& Co A/S & 5690859 & DNK \\
\hline $\mathrm{u} 019$ & Baggeridge Brick PLC & 0070360 & GBR & Calton Inc. & 2594040 & USA \\
\hline $\mathrm{u} 020$ & Renishaw PLC & 0732358 & GBR & Spire Corp. & 2834597 & USA \\
\hline u021 & Macrovision Corp. & 2546085 & USA & AZZ Inc. & 2067672 & USA \\
\hline $\mathrm{u} 022$ & Imperial Tobacco Group PLC & 0454492 & GBR & Kobayashi Pharmaceutical & 6149457 & JPN \\
\hline $\mathrm{u} 023$ & Tomkins PLC & 0896265 & GBR & Dorel Industries Inc. & 2262369 & CAN \\
\hline u024 & Rite Aid Corp. & 2740809 & USA & Brown (N) Group PLC & 0147297 & GBR \\
\hline $\mathrm{u} 025$ & Rite Aid Corp. & 2740809 & USA & Rollins Inc. & 2747305 & USA \\
\hline $\mathrm{u} 026$ & Starbucks Corp. & 2842255 & USA & Luby Inc. & 2162920 & USA \\
\hline u027 & Enterprise Inns PLC & 3387227 & GBR & Eldridge, Pope \& Co., PLC & 0257817 & GBR \\
\hline $\mathrm{u} 028$ & Orbit/FR Inc. & 2020017 & USA & APS Technologies Limited & 6152369 & $\mathrm{ZAF}$ \\
\hline u029 & Staar Surgical Company & 2836292 & USA & Trimedyne Inc. & 2904092 & USA \\
\hline $\mathrm{u} 030$ & CRH PLC & 2160816 & USA & The Morgan Crucible Company PLC & 0602729 & GBR \\
\hline $\mathrm{u} 031$ & Brammer PLC & 0119508 & GBR & European Telecom PLC & 0323495 & GBR \\
\hline u032 & Synalloy Corp. & 2867805 & USA & WYKO Group PLC & 0983952 & GBR \\
\hline u033 & Strategic Distribution Inc. & 2759139 & USA & Ultimate Electronics Inc. & 2907637 & USA \\
\hline $\mathrm{u} 034$ & Charter PLC & 0188263 & GBR & Devro PLC & 0267043 & GBR \\
\hline $\mathrm{u} 035$ & Olympus Corporation & 2658719 & USA & Trader Classified Media & 5934386 & NLD \\
\hline $\mathrm{u} 036$ & Danaher Corp. & 2250870 & USA & Modem Media, Incorporated & $\mathrm{c} 000062704$ & USA \\
\hline $\mathrm{u} 037$ & L \& M Group Investments Limited & 6388755 & SGP & Cerbco Inc. & \begin{tabular}{|l|}
2185176 \\
\end{tabular} & USA \\
\hline u038 & Worthington Industries Inc. & 2981932 & USA & Meridian Bioscience Commerce & 2580265 & USA \\
\hline u039 & Weightwatchers International Inc.o & 2813585 & USA & MAC-Gray Corp. & 2116950 & USA \\
\hline u040 & Saint Ives PLC & 0768900 & GBR & Bristol United Press PLC & 0125787 & GBR \\
\hline u041 & Costco Wholesale Corp. & 2701271 & USA & Macintosh Confectie NV & B13Y641 & NLD \\
\hline u042 & Costco Wholesale Corp. & 2701271 & USA & Ascent Media Group, Inc. & $\mathrm{c} 000020990$ & USA \\
\hline un 043 & Meggitt PLC & 0575809 & GBR & Adwest Automotive PLC & \begin{tabular}{|c|}
0008112 \\
\end{tabular} & GBR \\
\hline $\mathrm{u} 044$ & VT Group PLC & 3172973 & GBR & Summit Autonomous, Inc. & 2859103 & USA \\
\hline $\mathrm{u} 045$ & Logicacmg PLC & 0522708 & GBR & Effective Management Systems Inc. & \begin{tabular}{|l|} 
B02ZMY0 \\
\end{tabular} & USA \\
\hline $\mathrm{u} 046$ & Halma PLC & 0405207 & GBR & Dialogic Corporation & $\mathrm{c} 000001457$ & USA \\
\hline u047 & RH Donnelley Corp. & 2288752 & USA & Morrison Management Specialists, Inc. & 2590747 & USA \\
\hline u048 & Arriva PLC & 0230346 & GBR & Atlantic Express Transportation Corp. & $\mathrm{c} 000065784$ & USA \\
\hline $\mathrm{u} 049$ & Scottish \& Southern Energy PLC & 0790873 & GBR & Pinnacle West Capital Corp. & \begin{tabular}{|l|}
2048804 \\
\end{tabular} & USA \\
\hline u050 & Radstone Technology PLC & 0720483 & GBR & Linx Printing Technologies PLC & 0518558 & GBR \\
\hline uno51 & Quebecor World Inc. & 2716231 & CAN & Taylor \& Francis Group PLC & 0274258 & GBR \\
\hline $\mathrm{u} 052$ & Quebecor World Inc. & 2716231 & CAN & CDI Corp. & 2181129 & USA \\
\hline $\mathrm{u} 053$ & Lookers PLC & 0534446 & GBR & C.D. Bramall PLC & 0774349 & GBR \\
\hline $\mathrm{u} 054$ & Strongco Inc. & B08KZ62 & CAN & Harvey Nash Group PLC & 0657354 & GBR \\
\hline u055 & Hollywood Media Corp. & 2095941 & USA & Day Software Holding & 5932432 & CHE \\
\hline $\mathrm{u} 056$ & Boots Group PLC & 3231078 & GBR & UCB SA & 5596991 & BEL \\
\hline $\mathrm{u} 057$ & Gander Mountain Company & 2373216 & USA & Programmers Paradise Inc. & 2690476 & USA \\
\hline u058 & Domtar Inc. & 2276304 & $\mathrm{CAN}$ & SPX Corp. & 2787185 & USA \\
\hline u059 & Bombardier Inc. & 2109723 & CAN & IMI PLC & 0457963 & GBR \\
\hline$\frac{1}{u} 060$ & Amdocs Limited & 2256908 & USA & American Dental Partners & 2236546 & USA \\
\hline $\mathrm{u} 061$ & Logicacmg PLC & 0522708 & GBR & Extensity, Inc. & $\mathrm{c} 000069925$ & USA \\
\hline $\mathrm{u} 062$ & Mitcham Industries Inc. & 2597135 & USA & Warrantech Corp. & 2941044 & USA \\
\hline un063 & CSG Systems International & 2210885 & USA & K3 Business Technology Group PLC & B00P606 & GBR \\
\hline u064 & Canadian Utilities Limited & 2172639 & CAN & Wessex Water PLC & 0949277 & GBR \\
\hline u065 & International Power PLC & 0632016 & GBR & Niagara Mohawk Holdings Inc. & 2638722 & USA \\
\hline u066 & Moss Brothers Group PLC & 0605610 & GBR & Farmacias Benavides SA DE CV & 2328528 & USA \\
\hline u067 & Matalan PLC & 0259426 & GBR & British Polythene Industries PLC & 0779742 & GBR \\
\hline $\mathrm{u} 068$ & Bristol Water Group PLC & B0978K7 & GBR & York Waterworks PLC (THE) & 0988894 & GBR \\
\hline u069 & Regen Biologics Inc. & 2010762 & USA & Natural ASA & 5322011 & NOR \\
\hline $\mathrm{u} 070$ & Valspar Corp. & 2926739 & USA & Cell Genesys Inc. & 2209775 & USA \\
\hline
\end{tabular}




\section{Appendix A (Continued)}

\begin{tabular}{|c|c|c|c|c|c|c|}
\hline u071 & Nature Sunshine Products Inc. & 2627816 & USA & Stepan Company & 2845005 & USA \\
\hline $\mathrm{u} 072$ & Cephalon Inc. & 2185143 & USA & Viropharma Inc. & 2945660 & USA \\
\hline $\mathrm{u} 073$ & Harley-Davidson Inc. & 2411053 & USA & Meridian Medical Technologies, Inc. & $\mathrm{c} 000023114$ & USA \\
\hline $\mathrm{u} 074$ & American Axle \& Manufacturing Holdings & 2382416 & USA & NCR Corp. & 2632650 & USA \\
\hline $\mathrm{u} 075$ & Morrison (WM) Supermarkets PLC & 0604316 & GBR & Empire Company Limited & 2314000 & CAN \\
\hline $\mathrm{u} 076$ & Arriva PLC & 0230346 & GBR & CH Robinson Worldwide Inc. & 2116228 & USA \\
\hline u077 & Berkeley Group Holdings PLC & B02L3W3 & GBR & Bellway PLC & 0090498 & GBR \\
\hline $\mathrm{u} 078$ & New York Times Company & 2632003 & USA & Sanctuary Group PLC & B0Y6NC6 & GBR \\
\hline $\mathrm{u} 079$ & Astrazeneca PLC & 0989529 & GBR & Campbell Soup Company & 2162845 & USA \\
\hline $\mathrm{u} 080$ & VNU NV & 2650953 & USA & Dorling Kindersley Holdings PLC & 0277570 & GBR \\
\hline $\mathrm{u} 081$ & Time Warner Inc. & 2712165 & USA & Nagahori Corporation & 6619916 & JPN \\
\hline $\mathrm{u} 082$ & United States Cellular Corp. & 2918996 & USA & Sprint Nextel Corp. & 2922447 & USA \\
\hline $\mathrm{u} 083$ & Verizon Communications Inc. & 2090571 & USA & Tokyo Broadcasting Systems Inc. & 6894166 & JPN \\
\hline $\mathrm{u} 084$ & $\mathrm{M} / \mathrm{I}$ Homes Inc. & 2549385 & USA & CALA PLC & 0198518 & GBR \\
\hline $\mathrm{u} 085$ & Signet Group PLC & 0040374 & GBR & Bristol United Press PLC & 0125787 & GBR \\
\hline $\mathrm{u} 086$ & Darden Restaurants Inc. & 2289874 & USA & Legacy Hotels Real Estate Investment Tru & 2125633 & CAN \\
\hline $\mathrm{u} 087$ & Genuine Parts Company & 2367480 & USA & Saltire PLC & 0803102 & GBR \\
\hline $\mathrm{u} 088$ & Landrys Restaurants Inc. & 2504254 & USA & Bush Boake Allen Inc. & $\mathrm{c} 000000781$ & USA \\
\hline $\mathrm{u} 089$ & Triarc Companies Inc. & 2289744 & USA & Greene King PLC & 0387242 & GBR \\
\hline u090 & Computer Sciences Corp. & 2215200 & USA & Frontstep Incorporated & $\mathrm{c} 0000027490$ & USA \\
\hline u091 & Electronic Data Systems Corp. & 2312736 & USA & Guardian IT PLC & 0247807 & GBR \\
\hline u092 & Computer Sciences Corp. & 2215200 & USA & Equifax Inc. & 2319146 & USA \\
\hline u093 & Insituform Technologies & 2462039 & USA & Gremlin Group PLC & 0042477 & GBR \\
\hline u094 & Applied Optical Technologies PLC & 0046219 & GBR & Scandiaconsult $\mathrm{AB}$ & 5973947 & SWE \\
\hline $\mathrm{u} 095$ & Building Materials Holdings Corp. & 2069203 & USA & Wyevale Garden Centres PLC & 0984568 & GBR \\
\hline u096 & Macrochem Corp. & C901921319 & USA & Torch Offshore Inc. & 2763442 & USA \\
\hline $\mathrm{u} 097$ & Lyondell Chemical Company & 2540270 & USA & Novo Nordisk A/S & 7077524 & DNK \\
\hline $\mathrm{u} 098$ & Tarrant Apparel Group & 2876362 & USA & Wensum Company PLC & 0948531 & GBR \\
\hline u099 & Constellation Brands Inc. & 2170473 & $\begin{array}{l}\text { USA } \\
\text { USA }\end{array}$ & K-Swiss Inc. & 2479824 & USA \\
\hline $\mathrm{u} 100$ & Constellation Brands Inc. & 2170473 & USA & SOS Cuetara SA & B091DR1 & ESP \\
\hline $\mathrm{u} 101$ & Misys PLC & 0385785 & GBR & Macromedia Inc. & 2549512 & USA \\
\hline $\mathrm{u} 102$ & Christie Group PLC & 0195315 & GBR & Conductus, Inc. & $\mathrm{C} 000028851$ & USA \\
\hline $\mathrm{u} 103$ & DEB Shops Inc. & 2260493 & USA & QS Group PLC & 0714851 & GBR \\
\hline $\mathrm{u} 104$ & McGraw-Hill Ryerson Limited & 2551421 & CAN & Charterhouse Communications PLC & 0189200 & GBR \\
\hline u105 & Royal Dutch Shell PLC & B03MM40 & GBR & Murphy Oil Corp. & 2611206 & USA \\
\hline $\mathrm{u} 106$ & Royal Dutch Shell PLC & B03MM40 & GBR & Amerada Hess Corp. & 2023748 & USA \\
\hline $\mathrm{u} 107$ & Intertape Polymer Group & 2459901 & CAN & Ottakar's PLC & 0265188 & GBR \\
\hline $\mathrm{u} 108$ & Dyax Corp. & 2621487 & USA & Commonwealth Biotechnologies Inc. & 2593638 & USA \\
\hline $\mathrm{u} 109$ & Whitbread PLC & B07FNF3 & GBR & Fielmann AG & 4409205 & $\mathrm{DEU}$ \\
\hline $\mathrm{u} 110$ & Whitbread PLC & B07FNF3 & GBR & Odyssey Healthcare Inc. & 574 & USA \\
\hline $\mathrm{u} 111$ & Johnston Press PLC & 0476968 & GBR & Aqua Care System Inc. & 2148317 & USA \\
\hline $\mathrm{u} 112$ & Bucyrus International Inc. & B018TZ0 & USA & Mallett PLC & 0558350 & GBR \\
\hline $\mathrm{u} 113$ & Character Group PLC & 0897611 & GBR & Hamleys PLC & 0262640 & GBR \\
\hline $\mathrm{u} 114$ & Baggeridge Brick PLC & 0070360 & GBR & Darby Group PLC & 0264378 & GBR \\
\hline $\mathrm{u} 115$ & Baggeridge Brick PLC & 0070360 & GBR & Longmead Group PLC & 0224907 & GBR \\
\hline $\mathrm{u} 116$ & Monarch Casino \& Resort Inc. & 2599197 & USA & Providence \& Worcester Railroad Company & 2671084 & USA \\
\hline u117 & Cooper Companies Inc. & 2222631 & USA & Celsis International PLC & B0CD5F6 & GBR \\
\hline $\mathrm{u} 118$ & Kewill Systems PLC & 0738334 & GBR & Penna Consulting PLC & 0679466 & GBR \\
\hline $\mathrm{u} 119$ & Stadium Group PLC & 0837509 & GBR & Fiberstars Inc. & 2352390 & USA \\
\hline $\mathrm{u} 120$ & Sports Authority Inc. & 2483030 & USA & Mid-States PLC & 0268303 & GBR \\
\hline $\mathrm{u} 121$ & Orleans Homebuilders Inc. & 2331311 & USA & Montpellier Group PLC & 0535900 & GBR \\
\hline $\mathrm{u} 122$ & Hallwood Group Inc. & 2405744 & USA & PEX PLC & 0684738 & GBR \\
\hline $\mathrm{u} 123$ & Rea Holdings PLC & 0234906 & GBR & Zagro Asia Limited & 6991993 & SGP \\
\hline $\mathrm{u} 124$ & Amkor Technology Inc. & 2242929 & USA & Weru AG & 4948827 & $\mathrm{DEU}$ \\
\hline $\mathrm{u} 125$ & Maple Leaf Foods Inc. & 2555865 & CAN & US Office Products Company & 2253880 & USA \\
\hline $\mathrm{u} 126$ & Tadpole Technology PLC & 0870593 & GBR & Rural Press Limited & 6759470 & AUS \\
\hline $\mathrm{u} 127$ & Gleeson (MJ) Group PLC & B01BNK2 & GBR & Ben Bailey PLC & 0070605 & GBR \\
\hline $\mathrm{u} 128$ & Harrahs Entertainment Inc. & 2705648 & USA & Queens Moat Houses PLC & 0719890 & GBR \\
\hline u129 & Roadhouse Grill Inc. & 2735719 & USA & Clubhaus PLC & 0204512 & GBR \\
\hline $\mathrm{u} 130$ & Meggitt PLC & 0575809 & GBR & Pacific Aerospace \& Electronics Inc. & B00PS77 & USA \\
\hline $\mathrm{u} 131$ & Smithway Motor Xpress & 2856104 & USA & Compco Holdings PLC & 0214801 & GBR \\
\hline $\mathrm{u} 132$ & Datatrak International Inc. & 2181538 & USA & Proteome PLC & 0310419 & GBR \\
\hline $\mathrm{u} 133$ & 4Imprint Group PLC & 0664097 & GBR & Wescol Group PLC & 0949051 & GBR \\
\hline $\mathrm{u} 134$ & Dicom Group PLC & B0L2K15 & GBR & Baltimore Technologies PLC & 2504793 & USA \\
\hline $\mathrm{u} 135$ & Titan Pharmaceuticals Inc. & 2111557 & USA & Supergen Inc. & 2861313 & USA \\
\hline u136 & General Dynamics & 2365161 & USA & Oxford Instruments PLC & 0665045 & GBR \\
\hline $\mathrm{u} 137$ & Systemax Inc. & 2394712 & USA & Adam \& Harvey Group PLC & 0007830 & GBR \\
\hline $\mathrm{u} 138$ & CSC Holdings, Inc. & $\mathrm{c} 000065724$ & USA & Allied Technologies Limited & 6116406 & $\mathrm{ZAF}$ \\
\hline $\mathrm{u} 139$ & Serco Group PLC & 0797379 & GBR & Sharpe \& Fisher PLC & 0800329 & GBR \\
\hline $\mathrm{u} 140$ & Sembcorp Logistics Limited & B07W0X1 & SGP & Bracknell Corp. & 2728162 & CAN \\
\hline $\mathrm{u} 141$ & Air Methods Corp. & 2049777 & USA & Newmarket Investments PLC & 0128850 & GBR \\
\hline
\end{tabular}




\section{Appendix B: Results by using Enforcement measures with the average of three LLSV enforcement indexes}

Sample of 282 mergers and acquisitions by 222 acquiring firms in 11 English Origin countries (Australia, Canada, India, Ireland, Israel, Malaysia, New Zealand, Singapore, South Africa, Thailand and United Kingdom) between 1997 and 2001 for completed transactions over US\$ 10 million obtained from the Thomson Financial Securities Data's SDC PlatinumTM Worldwide Mergers \& Acquisitions Database. ACFRpre and ACFRpost is the pre and post industry, size, and pre performance adjusted cash flow return. $\triangle \mathrm{ACFR}$ is for the change in industry, size, and pre performance adjusted cash flow return. Outliers have been winsorized using Huber's M estimator approach. With OLS standard errors. Two tail tests $* * *$ denotes significant at the $1 \%$ level, ** significant at the $5 \%$ level, * significant at the $10 \%$ level. ENFOCE AVG is calculated by the average score of judicial efficiency, rule of law, and corruption in La Porta et al (1998). See table $5 . \overline{5}$ for the definitions of other variable.

\section{Panel A Univariate Analysis}

\begin{tabular}{l|c|ccc|cc}
\hline Full Sample $(\mathrm{N}=282)$ & Count & Mean & Median & SD & $\begin{array}{c}\text { ACFRpost } \\
\text { Pearson }\end{array}$ & $\begin{array}{c}\triangle A C F R \\
\text { Pearson }\end{array}$ \\
\hline \hline ENFORCE_AVG & 282 & 9.11 & 9.22 & 0.93 & $-0.127 * *$ & $-0.170 * * *$
\end{tabular}

Panel B Regressions Results (ENFORCE_AVG)

\begin{tabular}{|c|c|c|c|}
\hline \multirow{2}{*}{$(\mathrm{N}=\mathbf{2 8 2})$} & \multicolumn{3}{|c|}{ Model 8} \\
\hline & ACFRpost & \multicolumn{2}{|c|}{$\triangle A C F R$} \\
\hline Intercept & -0.158 & -0.182 & \\
\hline LSH1P & $-0.197^{* *}$ & -0.228 & $* *$ \\
\hline LSH1PSQ & $0.674 *$ & 0.762 & $*$ \\
\hline LSH1 PCUBE & $-0.554^{*}$ & -0.608 & * \\
\hline $\mathrm{SEP}$ & $-0.032 * *$ & -0.029 & $* *$ \\
\hline CEOLSH & $0.025 *$ & 0.018 & \\
\hline CEOdual & -0.011 & -0.021 & $*$ \\
\hline$\overline{\mathrm{BS}} \mathrm{SZE}$ & $-0.003^{* *}$ & -0.002 & \\
\hline INDDIR & -0.027 & -0.011 & \\
\hline OTHLSH & 0.005 & 0.016 & \\
\hline TGORI_English & -0.005 & 0.004 & \\
\hline ATTI_Hostile & 0.016 & 0.008 & \\
\hline PAY_stock & -0.011 & -0.006 & \\
\hline COMPETE & $-0.038 * *$ & -0.053 & $* * *$ \\
\hline IND_rel & 0.001 & 0.007 & \\
\hline TOEHOLD & 0.012 & 0.021 & $*$ \\
\hline PREM_1day & 0.000 & 0.000 & \\
\hline $\mathrm{SIZE}$ rel & $-0.005 *$ & -0.001 & \\
\hline LEV & -0.001 & -0.006 & \\
\hline ANTIDIR_high & $0.083 * *$ & 0.126 & *** \\
\hline ENFORCE_AVG & -0.001 & 0.012 & \\
\hline ACCTSTD & 0.003 & 0.000 & \\
\hline XLEG high & -0.028 & -0.013 & \\
\hline$U K$ & -0.064 & -0.125 & $* *$ \\
\hline$C A N$ & -0.061 & -0.141 & $* *$ \\
\hline$A U S$ & O. $055 * *$ & 0.027 & \\
\hline ACFRpre & $0.503 * * *$ & - & \\
\hline $\begin{array}{c}\text { Adjust } R^{2}(\%) \\
F\end{array}$ & $\begin{array}{c}33.9 \\
6.531 * * *\end{array}$ & 1.9 & $\begin{array}{l}7.8 \\
50 * * *\end{array}$ \\
\hline
\end{tabular}




\section{Appendix C: Non-Parametric Mann-Whitney Tests for Dummy Variables}

Sample of 282 mergers and acquisitions by 222 acquiring firms in 11 English Origin countries (Australia, Canada, India, Ireland, Israel, Malaysia, New Zealand, Singapore, South Africa, Thailand and United Kingdom) between 1997 and 2001 for completed transactions over US\$ 10 million obtained from the Thomson Financial Securities Data's SDC PlatinumTM Worldwide Mergers \& Acquisitions Database. ACFRpre and ACFRpost is the pre and post industry, size, and pre performance adjusted cash flow return. $\triangle \mathrm{ACFR}$ is for the change in industry, size, and pre performance adjusted cash flow return. Outliers have been winsorized using Huber's M estimator approach. Non-Parametric Mann-Whitney Tests are presented for dummy variables. *** denotes significant at the $1 \%$ level, ** significant at the $5 \%$ level, * significant at the $10 \%$ level. See table 5.5 for variable definitions.

\begin{tabular}{|c|c|c|c|c|c|c|c|}
\hline \multirow{2}{*}{\multicolumn{2}{|c|}{ Full Sample (N=282) }} & \multirow{2}{*}{\multicolumn{2}{|c|}{ Count }} & \multicolumn{2}{|c|}{ ACFRpost } & \multicolumn{2}{|c|}{$\triangle \mathrm{ACFR}$} \\
\hline & & & & Mean Rank & U test (Z-value) & \multirow[t]{2}{*}{ Mean Rank } & \multirow[t]{2}{*}{ U test (Z-value) } \\
\hline \multicolumn{6}{|c|}{ Ownership Variables } & & \\
\hline \multirow[t]{2}{*}{ CONCEN10 } & $\mathrm{Y}$ & 168 & $60 \%$ & 140.35 & \multirow{2}{*}{-0.286} & 138.68 & \multirow{2}{*}{-0.705} \\
\hline & $\mathrm{N}$ & 114 & $40 \%$ & 143.19 & & 145.66 & \\
\hline \multirow[t]{2}{*}{ CONCEN1020 } & $\mathrm{Y}$ & 81 & $29 \%$ & 136.84 & \multirow{2}{*}{-0.609} & 125.27 & \multirow{2}{*}{$-2.122^{* * *}$} \\
\hline & $\mathrm{N}$ & 201 & $71 \%$ & 143.38 & & 148.04 & \\
\hline \multirow[t]{2}{*}{ CONCEN20 } & $\mathrm{Y}$ & 87 & $31 \%$ & 143.63 & \multirow{2}{*}{-0.292} & 151.17 & \multirow{2}{*}{-1.330} \\
\hline & $\mathrm{N}$ & 195 & $69 \%$ & 140.55 & & 137.19 & \\
\hline \multirow[t]{2}{*}{ CONCEN2050 } & $\mathrm{Y}$ & 56 & $20 \%$ & 134.53 & \multirow[b]{2}{*}{-0.715} & 153.63 & \multirow{2}{*}{-1.243} \\
\hline & $\mathrm{N}$ & 226 & $80 \%$ & 143.23 & & 138.50 & \\
\hline \multirow[t]{2}{*}{ CONCEN50 } & $\mathrm{Y}$ & 31 & $11 \%$ & 160.06 & \multirow{2}{*}{-1.343} & 146.73 & \\
\hline & $\mathrm{N}$ & 251 & $89 \%$ & 139.21 & & 140.85 & $-0.3 / 8$ \\
\hline & & & Go & vernance $\mathrm{Va}$ & ables & & \\
\hline SEP & $\bar{Y}$ & 47 & $17 \%$ & 128.16 & -1229 & 131.16 & 0052 \\
\hline & $\mathrm{N}$ & 235 & $83 \%$ & 144.17 & -1.229 & 143.57 & -0.952 \\
\hline CEOLSH & $\mathrm{Y}$ & 39 & $14 \%$ & 168.53 & $-2230^{* *}$ & 142.65 & \\
\hline & $\mathrm{N}$ & 243 & $86 \%$ & 137.16 & -2.230 & 141.31 & -0.095 \\
\hline CEOdual & $\mathrm{Y}$ & 73 & $26 \%$ & 148.27 & & 131.28 & \\
\hline & $\mathrm{N}$ & 209 & $74 \%$ & 139.13 & $-0.8<4$ & 145.07 & -1.244 \\
\hline OTHLSH & $\mathrm{Y}$ & 54 & $19 \%$ & 145.94 & -0.445 & 152.24 & -1.076 \\
\hline & $\mathrm{N}$ & 228 & $81 \%$ & 140.45 & -0.445 & 138.96 & $-1.0 / 0$ \\
\hline & & & & Deal Variab & & & \\
\hline TGORI_English & $\mathrm{Y}$ & 260 & $92 \%$ & 141.61 & -0.075 & 141.64 & -0.101 \\
\hline & $\mathrm{N}$ & 22 & $8 \%$ & 140.25 & -0.013 & 139.82 & -0.101 \\
\hline ATTI_Hostile & $\mathrm{Y}$ & 9 & $3 \%$ & 155.44 & -0.521 & 160.61 & -0.715 \\
\hline & $\mathrm{N}$ & 273 & $97 \%$ & 141.04 & -0.521 & 140.87 & -0.115 \\
\hline PAY_Stock & $\mathrm{Y}$ & 48 & $17 \%$ & 125.06 & -1533 & 138.20 & -0308 \\
\hline & $\mathrm{N}$ & 234 & $83 \%$ & 144.87 & & 142.18 & \\
\hline COMPETE & $\mathrm{Y}$ & 19 & $7 \%$ & 125.68 & & 94.45 & $-2604^{* * * *}$ \\
\hline & $\mathrm{N}$ & 263 & $93 \%$ & 142.64 & -0.875 & 144.90 & -2.604 \\
\hline IND_rel & $\mathrm{Y}$ & 101 & $36 \%$ & 136.15 & -0822 & 142.28 & -0120 \\
\hline & $\mathrm{N}$ & 181 & $64 \%$ & 144.48 & -0.022 & 141.07 & -0.120 \\
\hline TOEHOLD & $\mathrm{Y}$ & 46 & $16 \%$ & 141.84 & -0.031 & 151.46 & -0.905 \\
\hline & $\mathrm{N}$ & 236 & $84 \%$ & 141.43 & & 139.56 & \\
\hline & & & Ins & titutional Va & iables & & \\
\hline ANTIDIR_high & $\bar{Y}$ & 236 & $84 \%$ & 143.60 & -0.979 & 142.01 & -0.239 \\
\hline & $\mathrm{N}$ & 46 & $16 \%$ & & & 138.87 & \\
\hline XLEG_high & $\mathrm{Y}$ & 174 & $62 \%$ & 135.93 & -1.456 & 140.10 & -0.365 \\
\hline & $\mathrm{N}$ & 108 & $38 \%$ & 150.48 & & 143.75 & \\
\hline PUBENFORCE_high & $\mathrm{Y}$ & 82 & $29 \%$ & 144.53 & -0.400 & 133.91 & -1.000 \\
\hline & $\mathrm{N}$ & 200 & $71 \%$ & 140.26 & & 144.61 & \\
\hline NANTIDIR_high & $\mathrm{Y}$ & 167 & $59 \%$ & 141.74 & -0.060 & 145.29 & -0.940 \\
\hline & $\mathrm{N}$ & 115 & $41 \%$ & 141.15 & & 136.00 & \\
\hline
\end{tabular}




\section{Appendix D: Regressions Results in Table 6.5 \& 6.6 with Beta Coefficients and R Square Changed}

Sample of 282 mergers and acquisitions by 222 acquiring firms in 11 English Origin countries (Australia, Canada, India, Ireland, Israel, Malaysia, New Zealand, Singapore, South Africa, Thailand and United Kingdom) between 1997 and 2001 for completed transactions over US\$ 10 million obtained from the Thomson Financial Securities Data’s SDC PlatinumTM Worldwide Mergers \& Acquisitions Database. ACFRpre and ACFRpost is the pre and post industry, size, and pre performance adjusted cash flow return. $\triangle$ ACFR is for the change in industry, size, and pre performance adjusted cash flow return. Outliers have been winsorized using Huber's M estimator approach. Two tail tests *** denotes significant at the $1 \%$ level, $* *$ significant at the $5 \%$ level, * significant at the $10 \%$ level. See table 5.5 for variable definitions. The following statistics in table are presented in Beta Coefficients.

\begin{tabular}{|c|c|c|c|c|c|}
\hline \multirow[b]{2}{*}{$(\mathrm{N}=282)$} & \multicolumn{5}{|c|}{ Panel A: ACFRpost } \\
\hline & $\begin{array}{c}\text { Model 7 } \\
\text { (Benchmark) }\end{array}$ & Model 8 & Model 8.1 & Model 9 & Model 9.1 \\
\hline$\overline{\overline{\text { LSH1P }}}$ & $-0.706^{* *}$ & $-0.593^{* *}$ & $-0.604^{* *}$ & $-0.670^{* *}$ & $-0.609^{* *}$ \\
\hline LSH1PSQ & $2.098^{* * *}$ & $1.397^{*}$ & $1.505^{* *}$ & $1.595^{* *}$ & $1.501 * *$ \\
\hline LSH1PCUBE & $-1.383 * * *$ & $-0.858^{*}$ & $-0.943^{*}$ & $-0.984^{* *}$ & $-0.943^{*}$ \\
\hline SEP & $-0.152^{* *}$ & $-0.165^{* *}$ & $-0.171^{* * * *}$ & $-0.172^{* * * *}$ & $-0.168^{-1 *}$ \\
\hline CEOLSH & 0.069 & $0.118^{*}$ & $0.105^{*}$ & 0.104 & 0.100 \\
\hline CEOdual & -0.077 & -0.064 & -0.072 & -0.066 & -0.087 \\
\hline$\overline{\mathrm{BSIZE}}$ & $-0.122^{* *}$ & $-0.143^{* *}$ & $-0.137^{* *}$ & $-0.128^{* *}$ & $-0.113^{*}$ \\
\hline INDDIR & -0.033 & -0.068 & -0.060 & -0.080 & -0.071 \\
\hline OTHLSH & 0.051 & 0.029 & _o.039 & 0.041 & 0.061 \\
\hline TGORI_English & 0.003 & -0.019 & -0.016 & -0.014 & -0.016 \\
\hline ATTI_Hostile & 0.018 & 0.039 & 0.030 & 0.012 & 0.027 \\
\hline PAY_stock & -0.059 & -0.056 & -0.065 & -0.063 & -0.070 \\
\hline COMPETE & $-0.119^{* *}$ & $-0.130^{* *}$ & $-0.128^{* *}$ & $-0.129^{* *}$ & $-0.125^{* *}$ \\
\hline IND_rel & 0.016 & 0.005 & 0.006 & 0.002 & 0.014 \\
\hline TOEHOLD & 0.029 & 0.059 & 0.060 & 0.052 & 0.046 \\
\hline PREM_1day & 0.033 & 0.065 & 0.061 & 0.064 & 0.060 \\
\hline SIZE rel & $-0.128 * *$ & $-0.108 *$ & $-0.117^{* *}$ & $-0.116^{* *}$ & $-0.127^{* *}$ \\
\hline LEV & -0.014 & -0.009 & - -0.027 & - & -0.043 \\
\hline ANTIDIR_high & & $0.422^{* * *}$ & 0.306 & & \\
\hline ENFORCE & & -0.023 & & & \\
\hline ACCTSTD & & 0.164 & & & \\
\hline XLEG_high & & -0.190 & -0.163 & & \\
\hline ANTISDI & & & & 0.080 & -0.131 \\
\hline PUBENFORCE_high & & & & $-0.435 *$ & \\
\hline NANTIDIR high & & & & $0.409^{* * *}$ & $0.305^{* *}$ \\
\hline$U K$ & & -0.439 & -0.226 & $-0.427 * *$ & -0.197 \\
\hline$C A N$ & & -0.374 & $-0.248^{* *}$ & $0.603^{* *}$ & 0.081 \\
\hline$A U S$ & & $0.212^{*}$ & $0.206^{* *}$ & $0.133^{*}$ & 0.129 \\
\hline ACFRpre & 0.496 *** & 0.483 & $0.493^{* * * *}$ & $0.492^{* * *}$ & $0.497^{* * *}$ \\
\hline Adjust $\mathrm{R}^{2}(\%)$ & 30.6 & 33.90 & 33.70 & 32.80 & 31.90 \\
\hline $\mathrm{R}^{2}$ Change (\%) & 35.3 & 4.7 & 4.1 & 3.5 & 2.5 \\
\hline F change & $7.512 * * *$ & $2.856 * * *$ & $3.510^{* * * *}$ & $2.465^{* * *}$ & $2.056 *$ \\
\hline
\end{tabular}

\begin{tabular}{|c|c|c|c|c|}
\hline \multicolumn{5}{|c|}{ Panel B: $\triangle$ ACFR } \\
\hline $\begin{array}{c}\text { Model 7 } \\
\text { (Benchmark) }\end{array}$ & Model 8 & Model 8.1 & Model 9 & Model 9.1 \\
\hline$-0.759^{* *}$ & $0.0 .713^{* *}$ & $-0.682^{*}$ & $-0.720^{* * *}$ & $-0.668 *$ \\
\hline $2.240 * * * *$ & $1.637^{*}$ & $1.584^{*}$ & $1.689^{*}$ & $1.609^{*}$ \\
\hline$-1.480^{* * *}$ & $-0.976^{*}$ & $-0.953^{*}$ & $-1.022^{*}$ & $-0.987^{*}$ \\
\hline$-0.139^{* *}$ & $-0.154^{* *}$ & $-0.146^{*}$ & $-0.1466^{*}$ & -0.144 \\
\hline 0.010 & 0.087 & 0.070 & 0.061 & 0.058 \\
\hline$-0.138^{* *}$ & $-0.129^{*}$ & $-0.131^{*}$ & $-0.129^{*}$ & $-0.147^{* *}$ \\
\hline-0.095 & -0.105 & -0.098 & -0.099 & -0.087 \\
\hline-0.010 & -0.030 & -0.017 & -0.026 & -0.020 \\
\hline 0.114 & 0.090 & 0.104 & 0.108 & $0.124^{*}$ \\
\hline 0.030 & 0.014 & 0.008 & 0.008 & 0.007 \\
\hline 0.038 & 0.020 & 0.034 & 0.031 & 0.043 \\
\hline-0.044 & -0.033 & -0.049 & -0.049 & -0.054 \\
\hline$-0.176^{* * *}$ & $-0.190^{* * *}$ & $-0.187^{* * *}$ & $-0.185^{* * *}$ & $-0.181^{* * *}$ \\
\hline 0.060 & 0.047 & 0.053 & 0.053 & 0.064 \\
\hline 0.078 & $0.111 *$ & $0.102 *$ & 0.094 & 0.089 \\
\hline 0.041 & 0.081 & 0.077 & 0.075 & 0.071 \\
\hline-0.055 & -0.034 & -0.041 & -0.042 & -0.052 \\
\hline$-0.106 *$ & $-0.107^{*}$ & $-0.125^{* *}$ & $-0.124^{*}$ & $-0.135^{* *}$ \\
\hline & 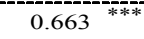 & $0.401^{* * *}$ & & \\
\hline & 0.313 & & & \\
\hline & -0.014 & & & \\
\hline & -0.092 & 0.037 & & \\
\hline & & & 0.033 & -0.144 \\
\hline & & & -0.366 & \\
\hline & & & $0.431^{* *}$ & $0.343^{* *}$ \\
\hline & $-0.893^{* *}$ & $-0.499^{*}$ & -0.436 & -0.242 \\
\hline & $-0.889^{* *}$ & $-0.363^{* * *}$ & 0.440 & 0.001 \\
\hline & 0.108 & 0.128 & 0.119 & 0.116 \\
\hline 4.6 & 7.80 & 7.90 & 6.60 & 6.10 \\
\hline 10.7 & 5.3 & 4.8 & 3.9 & 3.1 \\
\hline $1.749 * *$ & $2.308^{* *}$ & $2.919 * *$ & $1.942^{*}$ & $1.874 *$ \\
\hline
\end{tabular}




\section{Appendix E: Regressions Results in Table 6.5 \& 6.6 with VIF Value}

Sample of 282 mergers and acquisitions by 222 acquiring firms in 11 English Origin countries (Australia, Canada, India, Ireland, Israel, Malaysia, New Zealand, Singapore, South Africa, Thailand and United Kingdom) between 1997 and 2001 for completed transactions over US\$ 10 million obtained from the Thomson Financial Securities Data's SDC PlatinumTM Worldwide Mergers \& Acquisitions Database. ACFRpre and ACFRpost is the pre and post industry, size, and pre performance adjusted cash flow return. $\triangle \mathrm{ACFR}$ is for the change in industry, size, and pre performance adjusted cash flow return. Outliers have been winsorized using Huber's M estimator approach. Two tail tests *** denotes significant at the $1 \%$ level, ** significant at the $5 \%$ level, * significant at the $10 \%$ level. See table 5.5 for variable definitions.

\begin{tabular}{|c|c|c|c|c|c|c|c|c|}
\hline \multirow{3}{*}{$(\mathrm{N}=282)$} & \multicolumn{8}{|c|}{ Panel A: ACFRpost } \\
\hline & \multicolumn{2}{|c|}{ Model 8} & \multicolumn{2}{|c|}{ Model 8.1} & \multicolumn{2}{|c|}{ Model 9} & \multicolumn{2}{|c|}{$\begin{array}{l}\text { Model } 9.1 \\
\end{array}$} \\
\hline & $\mathrm{B}$ & $\mathrm{VIF}$ & $\mathrm{B}$ & $\mathrm{VIF}$ & $\mathrm{B}$ & $\mathrm{VIF}$ & $\mathrm{B}$ & $\mathrm{VIF}$ \\
\hline Intercept & -0.158 & & 0.055 & & 0.020 & & 0.108 & \\
\hline LSHIP & $-0.197^{* *}$ & 38.471 & -0.201 * * & 38.142 & -0.222 & 38.774 & -0.202 & 38.421 \\
\hline LSHIPSQ & $0.674^{*}$ & 232.709 & $0.726^{* *}$ & 228.426 & $0.769^{* *}=$ & 233.657 & $0.724^{* *}$ & 232.813 \\
\hline LSHIPCUBE & - $-0.554^{*}$ & 102.859 & $-0.6099^{*}$ & 100.849 & -0.635 ** & 103.041 & $-0.608^{*}$ & 102.874 \\
\hline SEP & -0.032 & 1.815 & -0.033 & 1.782 & -0.033 & 1.797 & $-0.033^{* *}$ & 1.795 \\
\hline CEOLSH & $0.025^{*}$ & 1.740 & 0.022 * & 1.682 & 0.022 & 1.684 & 0.021 & 1.682 \\
\hline CEOdual & -0.011 & 1.370 & -0.012 & 1.360 & -0.011 & 1.407 & -0.015 & 1.362 \\
\hline BSIZE & $-0.003^{* *}$ & 1.441 & $-0.003^{* *}$ & 1.430 & $-0.003 * *$ & 1.411 & $-0.002 *$ & 1.390 \\
\hline INDDIR & -0.027 & 1.789 & -0.023 & 1.761 & -0.031 & 1.786 & -0.028 & 1.779 \\
\hline OTHLSH & 0.005 & 1.526 & 0.007 & 1.487 & 0.008 & 1.506 & 0.011 & 1.472 \\
\hline TGORI_English & -0.005 & 1.185 & -0.004 & 1.169 & -0.004 & 1.171 & -0.004 & 1.170 \\
\hline ATTI_Hostile & 0.016 & 1.229 & 0.012 & 1.131 & 0.005 & 1.136 & 0.011 & 1.117 \\
\hline PAY_stock & -0.011 & 1.147 & -0.013 & 1.095 & -0.012 & 1.105 & -0.013 & 1.101 \\
\hline СОМРETE & $-0.038^{* *}$ & 1.125 & $-0.037^{* *}$ & 1.123 & -0.037 *" & 1.121 & $-0.036{ }^{* *}$ & 1.120 \\
\hline IND_rel & 0.001 & 1.101 & 0.001 & 1.094 & 0.000 & 1.107 & 0.002 & 1.091 \\
\hline TOEHOLD & 0.012 & 1.180 & 0.012 & 1.154 & 0.010 & 1.154 & 0.009 & 1.150 \\
\hline PREM_1day & 0.000 & 1.211 & 0.000 & 1.205 & 0.000 & 1.205 & 0.000 & 1.204 \\
\hline SIZE_rel & $-0.005^{*}$ & 1.306 & $-0.005^{* *}$ & 1.284 & -0.005 *" & 1.297 & $-0.005^{* *}$ & 1.286 \\
\hline LEV & -0.001 & 1.338 & -0.002 & 1.256 & -0.002 & 1.287 & -0.003 & 1.270 \\
\hline ANTIDIR_high & 0.083 & 19.452 & $0.060 *$ & 5.969 & & & & \\
\hline ENFORCE & -0.001 & 24.554 & & & & & & \\
\hline ACCTSTD & 0.003 & 6.187 & & & & & & \\
\hline XLEG_high & -0.028 & 18.124 & -0.024 & 14.894 & & & & \\
\hline ANTISDI & & & & & 0.046 & 11.929 & -0.075 & 7.665 \\
\hline PUBENFORCE_high & & & & & $-0.070^{*}$ & 18.054 & & \\
\hline NANTIDIR high & & & & & 0.060 ** & 9.712 & $0.045^{* *}$ & 8.668 \\
\hline$U K$ & -0.064 & 53.913 & -0.033 & 22.916 & -0.062 & 12.349 & -0.029 & 7.275 \\
\hline CAN & -0.061 & 61.308 & $-0.041^{* *}$ & 4.883 & 0.099 *. & 33.740 & 0.013 & 7.724 \\
\hline$A U S$ & $0.055^{*}$ & 4.095 & $0.054^{* * *}$ & 3.954 & $0.035^{*}$ & 2.888 & 0.034 & 2.886 \\
\hline ACFRpre & 0.503 * & 1.255 & 0.512 & 1.213 & 0.512 & 1.198 & $0.517^{* \ldots * *}$ & 1.196 \\
\hline Adjust $\mathrm{R}^{2}(\%)$ & 33 & & 33.7 & & & & 31.9 & \\
\hline $\mathrm{F}$ & 6.53 & & 6.963 & & & & $6.495^{\circ}$ & \\
\hline
\end{tabular}

\begin{tabular}{|c|c|c|c|c|c|c|c|}
\hline \multicolumn{8}{|c|}{ Panel B: $\triangle \mathrm{ACFR}$} \\
\hline \multicolumn{2}{|c|}{ Model 8} & \multicolumn{2}{|c|}{ Model 8.1} & \multicolumn{2}{|c|}{ Model 9} & \multicolumn{2}{|c|}{ Model 9.1} \\
\hline $\mathrm{B}$ & VIF & $\mathrm{B}$ & VIF & $\mathrm{B}$ & VIF & B & VIF \\
\hline-0.182 & & 0.015 & & 0.011 & & 0.083 & \\
\hline$-0.228^{* *}$ & 38.421 & $-0.219^{*}$ & 38.126 & $-0.231^{* *}$ & 38.771 & $-0.214 *$ & 38.413 \\
\hline 0.762 * & 232.523 & $0.737^{*}$ & 228.423 & 0.786 * & 233.650 & $0.749^{*}$ & 232.798 \\
\hline$-0.608^{*}$ & 102.820 & $-0.594^{*}$ & 100.846 & $-0.637^{*}$ & 103.041 & -0.615 * & 102.874 \\
\hline-0.029 ** & 1.814 & $-0.027^{*}$ & 1.776 & $-0.028{ }^{*}$ & 1.791 & $-0.027^{*}$ & 1.791 \\
\hline 0.018 & 1.734 & 0.014 & 1.674 & 0.012 & 1.673 & 0.012 & 1.672 \\
\hline$-0.021 *$ & 1.350 & $-0.021 *$ & 1.343 & -0.021 * & 1.389 & $-0.023 * *$ & 1.345 \\
\hline-0.002 & 1.431 & -0.002 & 1.421 & -0.002 & 1.405 & -0.002 & 1.385 \\
\hline-0.011 & 1.781 & -0.007 & 1.750 & -0.010 & 1.770 & -0.007 & 1.764 \\
\hline 0.016 & 1.507 & 0.019 & 1.467 & 0.019 & 1.485 & $0.022^{*}$ & 1.452 \\
\hline 0.004 & 1.179 & 0.002 & 1.166 & 0.002 & 1.168 & 0.002 & 1.168 \\
\hline 0.008 & 1.227 & 0.014 & 1.131 & 0.012 & 1.135 & 0.017 & 1.115 \\
\hline-0.006 & 1.144 & -0.009 & 1.093 & -0.009 & 1.103 & -0.010 & 1.099 \\
\hline$-0.053^{* * *}$ & 1.110 & $-0.052^{* * *}$ & 1.108 & $-0.052^{* * *}$ & 1.108 & $-0.051^{* * *}$ & 1.106 \\
\hline 0.007 & 1.092 & 0.008 & 1.083 & 0.008 & 1.093 & 0.009 & 1.078 \\
\hline $0.021 *$ & 1.167 & 0.019 * & 1.146 & 0.018 & 1.146 & 0.017 & 1.142 \\
\hline 0.000 & 1.210 & 0.000 & 1.204 & 0.000 & 1.204 & 0.000 & 1.203 \\
\hline-0.001 & 1.275 & -0.002 & 1.251 & -0.002 & 1.266 & -0.002 & 1.253 \\
\hline-0.006 * & 1.289 & $-0.007^{* *}$ & 1.208 & -0.007 * & 1.243 & $-0.008^{* *}$ & 1.228 \\
\hline 0.126 & 19.191 & 0.076 & 5.932 & & & & \\
\hline 0.012 & 23.974 & & & & & & \\
\hline 0.000 & 6.015 & & & & & & \\
\hline \multirow[t]{4}{*}{-0.013} & 18.068 & 0.005 & 14.677 & & & & \\
\hline & & & & 0.018 & 11.916 & -0.079 & 7.664 \\
\hline & & & & -0.056 & 18.018 & & \\
\hline & & & & $0.062^{* *}$ & 9.711 & $0.049^{* *}$ & 8.664 \\
\hline$-0.125^{* *}$ & 52.932 & $-0.070^{*}$ & 22.555 & -0.061 & 12.349 & -0.034 & $7.267^{\circ}$ \\
\hline$-0.141^{* *}$ & 60.022 & $-0.058^{* *}$ & 4.825 & 0.070 & 33.567 & 0.000 & 7.689 \\
\hline 0.027 & 4.031 & 0.032 & 3.917 & 0.030 & 2.886 & 0.029 & 2.885 \\
\hline \multicolumn{2}{|c|}{7.80} & \multicolumn{2}{|c|}{7.90} & \multicolumn{2}{|c|}{6.60} & \multicolumn{2}{|c|}{6.10} \\
\hline \multicolumn{2}{|c|}{$1.950^{* * *}$} & \multicolumn{2}{|c|}{$2.054^{* * * *}$} & \multicolumn{2}{|c|}{$1.826^{* * *}$} & \multicolumn{2}{|c|}{$1.799^{* *}$} \\
\hline
\end{tabular}




\section{Appendix F: Regressions Results on Robustness Test of Standard Error using Jackknife Approach}

Sample of 282 mergers and acquisitions by 222 acquiring firms in 11 English Origin countries (Australia, Canada, India, Ireland, Israel, Malaysia, New Zealand, Singapore, South Africa, Thailand and United Kingdom) between 1997 and 2001 for completed transactions over US\$ 10 million obtained from the Thomson Financial Securities Data's SDC PlatinumTM Worldwide Mergers \& Acquisitions Database. ACFRpre and ACFRpost is the pre and post industry, size, and pre performance adjusted cash flow return. $\triangle$ ACFR is for the change in industry, size, and pre performance adjusted cash flow return. Outliers have been winsorized using Huber's M estimator approach. With Jackknife standard errors below (Italics). Two tail tests *** denotes significant at the $1 \%$ level, $* *$ significant at the $5 \%$ level, * significant at the $10 \%$ level. See table 5.5 for variable definitions.

\begin{tabular}{|c|c|c|c|c|c|c|c|c|c|c|c|}
\hline \multirow{2}{*}{$(\mathrm{N}=\mathbf{2 8 2})$} & \multicolumn{11}{|c|}{ Clustered Jackknife Standard Errors } \\
\hline & Model 1 & Model 2 & Model 3 & $\begin{array}{ll}\text { Model } 4 \\
\end{array}$ & Model 5 & Model 6 & $\begin{array}{ll}\text { Model } 7 \\
\end{array}$ & Model 8 & Model 8.1 & Model 9 & Model 9.1 \\
\hline \multirow[t]{2}{*}{$\overline{\text { Intercept }}$} & $0.048^{* *}$ & $0.050^{* *}$ & $0.070^{* * * *}$ & $0.070^{* * *}$ & $0.041^{*}$ & $0.042^{*}$ & $0.056^{* *}$ & -0.158 & $0.055^{* *}$ & 0.020 & 0.108 \\
\hline & 0.0240 & 0.0222 & 0.0248 & 0.0247 & 0.0219 & 0.0223 & 0.0231 & 0.1860 & 0.0274 & 0.1375 & 0.0924 \\
\hline \multirow[t]{2}{*}{ CONCEN10 } & -0.012 & & & & & & & & & & \\
\hline & 0.0092 & & & & & & & & & & \\
\hline \multirow[t]{2}{*}{ CONCEN1020 } & & & $-0.025^{* * *}$ & $-0.025^{* * *}$ & & & & & & & \\
\hline & & & 0.0097 & 0.0097 & & & & & & & \\
\hline \multirow[t]{2}{*}{ CONCEN20 } & & $0.024^{* *}$ & 0.012 & & & & & & & & \\
\hline & & 0.0122 & 0.0129 & & & & & & & & \\
\hline CONCEN2050 & & & & 0.0135 & & & & & & & \\
\hline \multirow[t]{2}{*}{ CONCEN50 } & & & & 0.012 & & & & & & & \\
\hline & & & & 0.0177 & & & & & & & \\
\hline LSH1P & & & & & $\begin{array}{r}0.023 \\
0.0259\end{array}$ & $\begin{array}{r}0.006 \\
0.0662\end{array}$ & $\begin{array}{l}-0.2344^{* *} \\
0.1095\end{array}$ & $\begin{array}{l}-0.197 \text { * } \\
0.1123\end{array}$ & $\begin{array}{l}-0.200 \text { * } \\
0.1093\end{array}$ & $\begin{array}{l}-0.222 \text { ** } \\
0.1104\end{array}$ & $\begin{array}{l}-0.202 \text { * } \\
0.1105\end{array}$ \\
\hline \multirow[t]{2}{*}{ LSH1PSQ } & & & & & & 0.025 & $1.011^{* *}$ & 0.673 & $0.725^{*}$ & $0.768^{*}$ & 0.723 * \\
\hline & & & & & & 0.0965 & 0.4158 & 0.4445 & 0.4293 & 0.4379 & 0.4317 \\
\hline \multirow[t]{2}{*}{ LSH1PCUBE } & & & & & & & $-0.892^{* *}$ & -0.553 & -0.608 & -0.635 & -0.608 \\
\hline & & & & & & & 0.3851 & 0.4174 & 0.4015 & 0.4116 & 0.4036 \\
\hline SEP & -0.019 & $-0.028^{* *}$ & $-0.027^{* *}$ & $-0.027^{* *}$ & $-0.026 *$ & $-0.026^{*}$ & $-0.030^{* *}$ & $-0.032^{* *}$ & $-0.033^{* *}$ & $-0.033^{* *}$ & $-0.033^{* *}$ \\
\hline CEOLSH & 0.0152 & 0.0160 & 0.0158 & 0.0158 & 0.0158 & 0.0159 & 0.0159 & 0.0173 & 0.0166 & 0.0169 & 0.0168 \\
\hline \multirow[t]{2}{*}{$\underline{\text { CEOdual }}$} & -0.015 & -0.013 & -0.013 & -0.013 & -0.014 & -0.015 & -0.013 & -0.011 & -0.012 & -0.011 & -0.015 \\
\hline & 0.0102 & 0.0103 & 0.0103 & 0.0103 & 0.0104 & 0.0104 & 0.0103 & 0.0103 & 0.0102 & 0.0105 & 0.0107 \\
\hline \multirow[t]{2}{*}{ BSIZE } & -0.001 & $-0.002 *$ & $-0.003^{* *}$ & $-0.003^{* *}$ & -0.002 & -0.002 & $-0.003^{*}$ & $-0.003^{* *}$ & $-0.003^{* *}$ & $-0.003^{*}$ & -0.002 \\
\hline & 0.0013 & 0.0015 & 0.0015 & 0.0015 & 0.0014 & 0.0014 & 0.0015 & 0.0015 & 0.0015 & 0.0015 & 0.0015 \\
\hline \multirow[t]{2}{*}{ INDDIR } & -0.023 & -0.013 & -0.022 & -0.022 & -0.013 & -0.013 & -0.013 & -0.027 & -0.023 & -0.031 & -0.028 \\
\hline & 0.0256 & 0.0250 & 0.0251 & 0.0254 & 0.0254 & 0.0256 & 0.0254 & 0.0284 & 0.0286 & 0.0294 & 0.0298 \\
\hline \multirow[t]{2}{*}{ OTHLSH } & 0.012 & 0.001 & 0.005 & 0.005 & 0.006 & 0.007 & 0.009 & 0.005 & 0.007 & 0.008 & 0.011 \\
\hline & 0.0127 & 0.0120 & 0.0122 & 0.0123 & 0.0125 & 0.0125 & 0.0129 & 0.0131 & 0.0128 & 0.0131 & 0.0128 \\
\hline
\end{tabular}




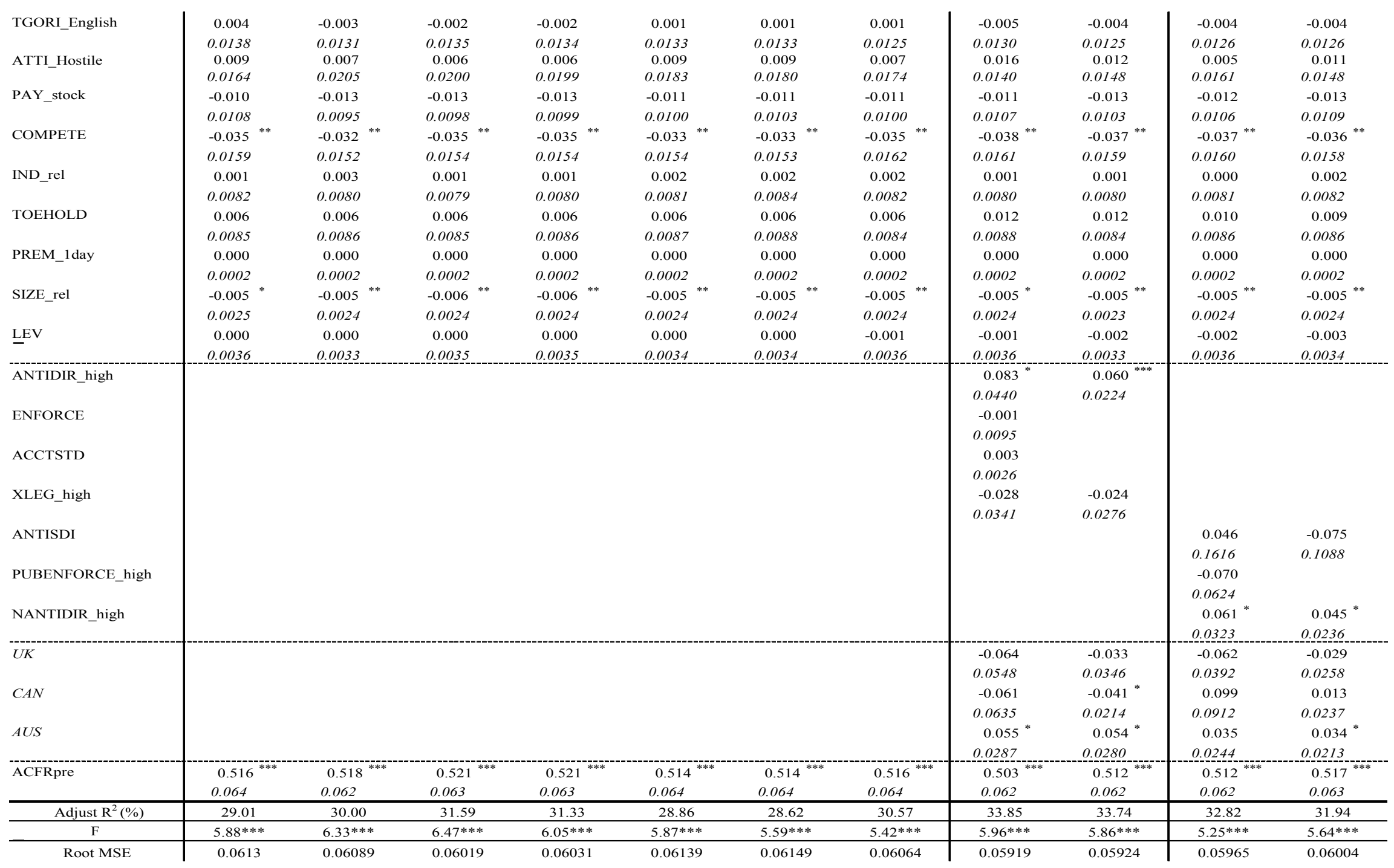


Appendix F (Continued)

Panel B Dependent Variable: $\triangle \mathrm{ACFR}$

\begin{tabular}{|c|c|c|c|c|c|c|c|c|c|c|c|}
\hline \multirow{2}{*}{$(\mathrm{N}=\mathbf{2 8 2})$} & \multicolumn{11}{|c|}{ Clustered Jackknife Standard Errors } \\
\hline & Model 1 & Model 2 & Model 3 & Model 4 & Model 5 & Model 6 & Model 7 & Model 8 & Model 8.1 & Model 9 & Model 9.1 \\
\hline \multirow[t]{2}{*}{ 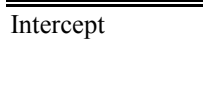 } & 0.021 & 0.023 & 0.045 & 0.048 & 0.013 & 0.014 & 0.028 & -0.182 & 0.015 & 0.011 & 0.083 \\
\hline & 0.0317 & 0.0296 & 0.0327 & 0.0325 & 0.0296 & 0.0302 & 0.0307 & 0.2072 & 0.0359 & 0.1651 & 0.0973 \\
\hline CONCEN10 & 0.0103 & & & & & & & & & & \\
\hline CONCEN1020 & & & $\begin{array}{r}-0.027 \\
0.110\end{array}$ & $\begin{array}{r}-0.027 \\
0.0110\end{array}$ & & & & & & & \\
\hline \multirow[t]{2}{*}{ CONCEN20 } & & $0.026^{*}$ & 0.013 & 0.0110 & & & & & & & \\
\hline & & 0.0135 & 0.0143 & & & & & & & & \\
\hline \multirow[t]{2}{*}{ CONCEN2050 } & & & & 0.017 & & & & & & & \\
\hline & & & & 0.0157 & & & & & & & \\
\hline \multirow[t]{2}{*}{ CONCEN50 } & & & & 0.007 & & & & & & & \\
\hline & & & & 0.0180 & & & & & & & \\
\hline \multirow[t]{2}{*}{ LSH1P } & & & & & 0.021 & 0.005 & $-0.243^{*}$ & $-0.228^{*}$ & $-0.218^{*}$ & $-0.230^{*}$ & $-0.214^{*}$ \\
\hline & & & & & 0.0270 & 0.0713 & 0.1241 & 0.1264 & 0.1251 & 0.1266 & 0.1271 \\
\hline \multirow[t]{2}{*}{ LSH1PSQ } & & & & & & 0.023 & $1.041^{* *}$ & 0.760 & 0.735 & $0.784^{*}$ & 0.747 \\
\hline & & & & & & 0.1000 & 0.4514 & 0.4721 & 0.4616 & 0.4740 & 0.4705 \\
\hline LSH1PCUBE & & & & & & & 0.4056 & 0.4257 & 0.4144 & 0.4273 & 0.4223 \\
\hline \multirow[t]{2}{*}{ SEP } & -0.016 & $-0.026^{*}$ & $-0.024 *$ & -0.023 & -0.023 & -0.023 & $-0.026^{*}$ & $-0.029^{*}$ & $-0.027^{*}$ & $-0.027^{*}$ & $-0.027^{*}$ \\
\hline & 0.0138 & 0.0139 & 0.0138 & 0.0136 & 0.0140 & 0.0139 & 0.0143 & 0.0160 & 0.0158 & 0.0161 & 0.0161 \\
\hline \multirow[t]{2}{*}{ CEOLSH } & 0.012 & -0.001 & 0.003 & 0.002 & 0.005 & 0.006 & 0.002 & 0.018 & 0.014 & 0.012 & 0.012 \\
\hline & 0.0155 & 0.0166 & 0.0164 & 0.0165 & 0.0161 & 0.0166 & 0.0166 & 0.0176 & 0.0169 & 0.0175 & 0.0173 \\
\hline \multirow[t]{2}{*}{ CEOdual } & $-0.024^{* *}$ & $-0.022^{* *}$ & $-0.023^{* *}$ & $-0.022^{* *}$ & $-0.024^{* *}$ & $-0.024^{* *}$ & $-0.022^{* *}$ & $-0.021^{*}$ & $-0.021^{*}$ & $-0.021 *$ & $-0.023^{* *}$ \\
\hline & 0.0110 & 0.0110 & 0.0110 & 0.0109 & 0.0111 & 0.0111 & 0.0112 & 0.0115 & 0.0114 & 0.0118 & 0.0119 \\
\hline \multirow[t]{2}{*}{ BSIZE } & -0.001 & -0.002 & -0.002 & -0.002 & -0.001 & -0.001 & -0.002 & -0.002 & -0.002 & -0.002 & -0.002 \\
\hline & 0.0015 & 0.0017 & 0.0017 & 0.0017 & 0.0016 & 0.0016 & 0.0017 & 0.0016 & 0.0016 & 0.0016 & 0.0016 \\
\hline \multirow[t]{2}{*}{ INDDIR } & -0.013 & -0.003 & -0.013 & -0.015 & -0.004 & -0.004 & -0.004 & -0.011 & -0.007 & -0.010 & -0.007 \\
\hline & 0.0283 & 0.0275 & 0.0279 & 0.0283 & 0.0283 & 0.0285 & 0.0283 & 0.0342 & 0.0337 & 0.0339 & 0.0344 \\
\hline \multirow[t]{2}{*}{ OTHLSH } & 0.023 & 0.011 & 0.016 & 0.014 & 0.017 & 0.018 & 0.020 & 0.016 & 0.019 & 0.019 & 0.022 \\
\hline & 0.0147 & 0.0142 & 0.0143 & 0.0145 & 0.0146 & 0.0144 & 0.0146 & 0.0146 & 0.0142 & 0.0147 & 0.0144 \\
\hline
\end{tabular}




\begin{tabular}{|c|c|c|c|c|c|c|c|c|c|c|c|}
\hline TGORI_English & 0.011 & 0.004 & 0.004 & 0.004 & 0.008 & 0.008 & 0.008 & 0.004 & 0.002 & 0.002 & 0.002 \\
\hline \multirow{3}{*}{ ATTI_Hostile } & 0.0170 & 0.0161 & 0.0166 & 0.0167 & 0.0165 & 0.0166 & 0.0161 & 0.0164 & 0.0163 & 0.0163 & 0.0165 \\
\hline & 0.017 & 0.014 & 0.013 & 0.011 & 0.017 & 0.017 & 0.015 & 0.008 & 0.014 & 0.012 & 0.017 \\
\hline & 0.0191 & 0.0215 & 0.0220 & 0.0221 & 0.0197 & 0.0197 & 0.0194 & 0.0218 & 0.0214 & 0.0207 & 0.0208 \\
\hline \multirow[t]{2}{*}{ PAY_stock } & -0.007 & -0.010 & -0.010 & -0.010 & -0.008 & -0.007 & -0.008 & -0.006 & -0.009 & -0.009 & -0.010 \\
\hline & 0.0125 & 0.0119 & 0.0120 & 0.0120 & 0.0121 & 0.0124 & 0.0123 & 0.0129 & 0.0125 & 0.0128 & 0.0130 \\
\hline \multirow[t]{2}{*}{ COMPETE } & $-0.050^{* * * *}$ & $-0.046^{* * *}$ & $-0.049^{* * *}$ & $-0.050^{* * *}$ & $-0.048^{* * * *}$ & $-0.048^{* * * *}$ & $-0.049^{* * *}$ & $-0.053^{* * *}$ & $-0.052^{* * *}$ & $-0.052^{* * * *}$ & $-0.051^{* * *}$ \\
\hline & 0.0187 & 0.0174 & 0.0173 & 0.0173 & 0.0181 & 0.0181 & 0.0187 & 0.0184 & 0.0185 & 0.0186 & 0.0187 \\
\hline \multirow[t]{2}{*}{ IND_rel } & 0.007 & 0.009 & 0.007 & 0.007 & 0.009 & 0.008 & 0.009 & 0.007 & 0.008 & 0.008 & 0.009 \\
\hline & 0.0092 & 0.0089 & 0.0089 & 0.0090 & 0.0090 & 0.0094 & 0.0092 & 0.0093 & 0.0092 & 0.0093 & 0.0093 \\
\hline TOEHOLD & 0.015 & 0.015 & 0.015 & 0.015 & 0.015 & 0.015 & 0.015 & $0.021^{*}$ & $0.019^{*}$ & 0.018 & 0.017 \\
\hline \multirow[t]{2}{*}{ PREM_1day } & 0.000 & 0.000 & 0.000 & 0.000 & 0.000 & 0.000 & 0.000 & 0.000 & 0.000 & 0.000 & 0.000 \\
\hline & 0.0002 & 0.0002 & 0.0002 & 0.0002 & 0.0002 & 0.0002 & 0.0002 & 0.0002 & 0.0002 & 0.0002 & 0.0002 \\
\hline \multirow[t]{2}{*}{ SIZE_rel } & -0.002 & -0.002 & -0.002 & -0.002 & -0.002 & -0.002 & -0.002 & -0.001 & -0.002 & -0.002 & -0.002 \\
\hline & 0.0026 & 0.0026 & 0.0025 & 0.0025 & 0.0027 & 0.0027 & 0.0026 & 0.0026 & 0.0025 & 0.0026 & 0.0026 \\
\hline \multirow[t]{2}{*}{$\underline{\text { LEV }}$} & -0.005 & -0.005 & -0.005 & -0.005 & -0.005 & -0.006 & -0.006 & -0.006 & $-0.007^{*}$ & -0.007 & $-0.008^{*}$ \\
\hline & 0.0044 & 0.0042 & 0.0044 & 0.0044 & 0.0043 & 0.0043 & 0.0044 & 0.0045 & 0.0041 & 0.0045 & 0.0043 \\
\hline \multirow[t]{2}{*}{ ANTIDIR_high } & & & & & & & & $0.126^{* * *}$ & 0.076 & & \\
\hline & & & & & & & & 0.0502 & 0.0259 & & \\
\hline \multirow[t]{2}{*}{ ENFORCE } & & & & & & & & 0.012 & & & \\
\hline & & & & & & & & 0.0107 & & & \\
\hline ACCTSTD & & & & & & & & 0.0030 & & & \\
\hline \multirow[t]{2}{*}{ XLEG_high } & & & & & & & & -0.013 & 0.005 & & \\
\hline & & & & & & & & 0.0423 & 0.0361 & & \\
\hline \multirow[t]{2}{*}{ ANTISDI } & & & & & & & & & & 0.018 & -0.079 \\
\hline & & & & & & & & & & 0.1882 & 0.1113 \\
\hline \multirow[t]{2}{*}{ PUBENFORCE_high } & & & & & & & & & & -0.056 & \\
\hline & & & & & & & & & & 0.0813 & \\
\hline \multirow[t]{2}{*}{ NANTIDIR_high } & & & & & & & & & & 0.062 & $0.049^{*}$ \\
\hline & & & & & & & & & & 0.0412 & 0.0278 \\
\hline \multirow[t]{2}{*}{$U K$} & & & & & & & & $-0.125^{* *}$ & -0.070 & -0.061 & -0.034 \\
\hline & & & & & & & & 0.0620 & 0.0434 & 0.0497 & 0.0309 \\
\hline \multirow{2}{*}{$C A N$} & & & & & & & & $-0.141^{* *}$ & $-0.058^{* *}$ & 0.070 & 0.000 \\
\hline & & & & & & & & 0.0695 & 0.0236 & 0.1168 & 0.0253 \\
\hline \multirow[t]{2}{*}{$A U S$} & & & & & & & & 0.027 & 0.032 & 0.030 & 0.029 \\
\hline & & & & & & & & 0.0350 & 0.0361 & 0.0292 & 0.0255 \\
\hline Adjust R ${ }^{2}(\%)$ & 3.06 & 4.30 & 6.23 & 6.01 & 2.76 & 2.41 & 4.58 & 7.79 & 7.90 & 6.58 & 6.10 \\
\hline $\mathrm{F}$ & $1.60^{*}$ & $1.54 *$ & $1.99 * *$ & $1.88 * *$ & 1.44 & 1.45 & $1.50^{*}$ & $2.00^{* *}$ & $2.10^{* * * *}$ & $1.84 * *$ & $1.81 * *$ \\
\hline Root MSE & 0.06916 & 0.06871 & 0.06802 & 0.0681 & 0.06926 & 0.06939 & 0.06861 & 0.06745 & 0.06739 & 0.06789 & 0.06805 \\
\hline
\end{tabular}




\section{Appendix G: Reprint of Published Papers}

Reprint of: Tze-Yu Yen and Paul André (2007). Ownership structure and operating performance of acquiring firms: The case of English-origin countries. Journal of Economics and Business. Article in Press

Permission to reprint the paper has been granted by the editor of Journal of Economics and Business and by co-author Dr. Paul André. 


\title{
Ownership structure and operating performance of acquiring firms: The case of English-origin countries
}

\author{
Tze-Yu Yen ${ }^{\mathrm{a}}$, Paul André ${ }^{\text {,* }}$ \\ a School of Management, University of Edinburgh, 16 Buccleuch Place, Edinburgh EH8 9LN, UK \\ b School of Management, University of Edinburgh and HEC Montréal, University of Edinburgh, \\ William Robertson Building - WRB 311, 50 George Square, Edinburgh EH8 9JY, UK
}

\begin{abstract}
This paper provides empirical evidence on the relation between concentrated ownership and the long term operating performance of acquiring firms. We investigate the performance around 287 takeovers in English-origin countries other than the US by following the classification of La Porta et al. [La Porta, R., Lopez-de-Silanes, F., Shleifer, A., \& Vishny, R. W. (1998). Law and finance. The Journal of Political Economy, 106(6), 1113-1155]. Our principal finding is that the relationship between concentrated ownership and the level and change in operating cash flow returns after takeovers is non-linear. Value creating deals are associated with higher levels of concentration consistent with decreasing agency costs as the dominant shareholder's wealth invested in the acquiring firm increases. We also find, although all acquiring firms are from English-origin countries, that greater investor protection, as measured by the updated anti-director rights index in Djankov et al. [Djankov, S., La Porta, R., Lopez-de-Silanes, F., \& Shleifer, A. (2006). The law and economics of self-dealing. Working Paper], has a positive impact on operating performance from acquisitions. We do not find a link between performance and their new anti-self-dealing index.
\end{abstract}

(C) 2007 Elsevier Inc. All rights reserved.

JEL classification: G12; G14; G34

Keywords: Mergers and acquisitions; Concentrated ownership; Operating performance; English-origin countries; Antiself-dealing index; Anti-director rights index

\section{Introduction}

Stemming mostly from the agency model of Jensen and Meckling (1976) but also from much earlier work such as Berle and Means (1932), corporate governance research has generally

\footnotetext{
* Corresponding author. Tel.: +44 131650 8351; fax: +44 1316508337.

E-mail address: paul.andre@ed.ac.uk (P. André).
} 
emphasized the role of control mechanisms in dispersed ownership structures as found in the US. However, La Porta, Lopez-de-Silanes, and Shleifer (1999), among others, show that dispersed ownership is only common in larger firms and in countries with good shareholder protection. Since concentrated ownership in a firm has its own specific costs and benefits, a growing body of empirically work investigates the unique characteristics of such firms (Bebchuk, Kraakman, \& Triantis, 2000; Claessens, Djankov, \& Lang, 2000; Faccio \& Lang, 2002). Following the investor protection classification scheme of La Porta, Lopez-de-Silanes, Shleifer, and Vishny (1998), subsequent cross-country research also focuses on comparing corporate performance among countries with different legal characteristics (Gugler, Mueller, \& Yurtoglu, 2004; Fauver, Houston, \& Naranjo, 2003; La Porta, Lopez-de-Silanes, Shleifer, \& Vishny, 2000; La Porta, Lopez-de-Silanes, Shleifer, \& Vishny, 2002). While English-origin countries ${ }^{1}$ are often lumped together and viewed as examples of dispersed ownership and greater investor protection, concentrated ownership is quite prevalent in many of these countries and the level of investor protection and the risks of self-dealing does vary among the group (Djankov, La Porta, Lopez-de-Silanes, \& Shleifer, 2006).

One of the most important drivers of corporate performance over the last decade is without a doubt the level of mergers and acquisitions (M\&A). The most recent merger wave which begins in the mid-1990 and reaches its peak in 2000 is not only confined to the US market but is truly global (Gugler, Mueller, Yurtoglu, \& Zulehner, 2003). One additional feature of the recent M\&A wave is that takeovers are larger than ever. Companies invest billions of dollars in making acquisitions but most empirical studies show that shareholders of acquiring firms experience wealth destruction on average or at best break even (Agrawal, Jaffe, \& Mandelker, 1992; Goergen \& Renneboog, 2004; Franks \& Harris, 1989; Jensen \& Ruback, 1983).

A recent stream of research focuses on ownership structure, governance and the value creation of specific corporate decisions such as M\&A. Concentrated ownership introduces new dimensions to the issue. In countries with low investor protection, some argue that M\&A are a tool used by controlling shareholders to facilitate tunneling that benefit them at the expense of minority shareholders (Bae, Kang, \& Kim, 2002; Bigelli \& Mengoli, 2004). In countries with better corporate governance, dominant shareholders may not be in a position to benefit from tunneling but they may choose to reduce risk by making sub-optimal investment decision (Ben-Amar \& André, 2006; Faccio \& Stolin, 2006; Holmen \& Knopf, 2004).

To date, most research examines the relationship between acquisition performance and ownership structures by adopting traditional market based event study methodology since it assumes that stock prices immediately reflect the benefits from the deal (Andrade, Mitchell, \& Stafford, 2001; Franks \& Harris, 1989; Goergen \& Renneboog, 2004; Limmack, 1991; Sudarsanam, 1996). However, Hitt, Harrison, Ireland, and Best (1998) argue that the nature of the short term market performance methodology may not fully capture anticipated benefits from an acquisition. Following the work of Healy, Palepu, and Ruback (1992), financial researchers take a longer term perspective and examine the change in operating cash flow returns to better understand value creation and its drivers.

Our study adds to the ongoing debate about the benefits and costs of concentrated ownership and further examines the effects of governance, legal investor protection and anti-self-dealing measures on value creation following M\&A. We extend the research of Ben-Amar and André

\footnotetext{
${ }^{1}$ La Porta et al. (1998) include the following countries in the English-origin category: Australia, Canada, Hong Kong, India, Ireland, Israel, Kenya, Malaysia, New Zealand, Nigeria, Pakistan, Singapore, South Africa, Sri Lanka, Thailand, United Kingdom, United States and Zimbabwe.
} 
(2006) by doing a cross-country analysis. Our study is based on a sample of 287 deals over 1997-2001 in 11 English-origin countries: Australia, Canada, India, Republic of Ireland, Israel, Malaysia, New Zealand, Singapore, South Africa, Thailand, and the United Kingdom.

We find, after controlling for well documented governance mechanisms and deal characteristics, that the relationship between concentrated ownership and the level and change in operating cash flow returns after acquisitions is non-linear. Value creating deals are associated with higher levels of concentration consistent with decreasing agency costs as the dominant shareholder's wealth invested in the acquiring firm increases. Further, separation of ownership and voting rights leads to greater value destruction. We also find, although all acquiring firms are from Englishorigin countries, that greater investor protection, as measured by the updated anti-director-rights index in Djankov et al. (2006) has a positive impact on abnormal cash flow returns from acquisitions. We do not document any differential performance with respect to their new anti-self-dealing index.

The rest of this paper is organized as follows. Section 2 summarizes the literature on the issues surrounding concentrated ownership structures. Section 3 describes the sample and methodology. Section 4 reports the major results. Section 5 concludes.

\section{Literature review}

A relatively large body of empirical research focuses on the agency problem between owners and managers in widely held companies. This work suggests that large shareholders, block holders, are a good internal mechanism to reduce agency costs since these shareholders have greater incentives and resources to efficiently monitor and ensure value maximization (Jensen \& Meckling, 1976, Schleifer \& Vishny, 1986).

However, an agency problem potentially exists between controlling shareholders and minority shareholders in concentrated ownership structures. Further, controlling shareholders often have greater control rights than their cash flow rights because of pyramidal structures, crossholdings, dual class shares and various other control devices (Claessens et al., 2000; La Porta et al., 1999). This separation provides an opportunity for controlling shareholders to expropriate minority shareholders. Tunneling is one of the common problems cited (Johnson, Lopez-deSilanes, La Porta, \& Shleifer, 2000). When dominant shareholders do not bear the full costs of their decisions, they may have incentives to act in their own interest at the expense of firm performance. There are many ways to achieve tunneling such as by special dividends, excessive perks, excess compensation, advantageous transfer prices, inter-company loans at nonmarket rates, guaranties of other entities borrowing or by enhancing the value of other firms in the group by sub-optimal investment decisions such as merger transactions. Further, Zhang (1998) provides empirical evidence that controlling shareholders may make sub-optimal decisions because they are more risk averse than other shareholders whose portfolios are better diversified.

Managerial entrenchment is another cost of concentrated ownership. Schulze, Lubatkin, Dino, \& Buchholtz (2001) argue that concentrated ownership structures, especially family structures, may limit top management positions to affiliated members instead of hiring more qualified outside professional managers. Further, high ownership stakes by those that are also top managers, such as in family firms, can reduce the effectiveness of outside monitoring since it lowers the probability of managerial turnover or of successful takeover bids when the firm is performing poorly (Davies, Hillier, \& McColgan, 2005; Morck, Shleifer, \& Vishny, 1988; Stulz, 1988). 
Based on the benefits and costs of concentrated ownership, our study investigates the following accentuating or mitigating factors:

\subsection{Separation}

Ownership and control rights can differ because corporations issue different classes of shares that provide different voting rights for given cash-flow rights (Faccio \& Lang, 2002). Separation of ownership and control rights means that controlling shareholders do not bear the full costs of their decisions. Separation has generally been shown to have a significantly negative effect on firm performance (Claessens et al., 2000; Cronqvist \& Nilsson, 2003; Faccio \& Lang, 2002; La Porta et al., 2002).

\subsection{CEO position}

Whether an individual related to or himself the dominant shareholder should occupy the seat of CEO is still debatable. Anderson and Reeb (2003) suggest that with effective outside monitors, family CEOs may provide essential firm-specific know-how and reduce agency problems. Many researchers, however, offer a different view: dominant CEOs may more easily entrench themselves and thus deviate from firm value maximization (Barth, Gulbrandsen, \& Schonea, 2005; Fama \& Jensen, 1983; Sharma \& Ho, 2002).

\subsection{Board structure}

Board structure is central to the corporate governance system. Directors are assumed to provide professional advice, to hire and compensate the CEO and to replace the CEO if necessary (Jensen, 1993). The board is generally composed of inside (related) and outside (unrelated) directors. Academics, regulators, as well as shareholder activists suggest that outside directors should enhance firm value through effective monitoring. They further suggest that the size of the board (not too large and not too small) and the separation of the CEO/COB position lead to better governance. Empirical studies on board characteristics have obtained mixed results. Several authors provide evidence that outside directors enhance board effectiveness (Rosenstein \& Wyatt, 1990; Weisbach, 1988) while others find either a weak relation (Weir, Laing, \& McKnight, 2002) or even a negative relationship (Agrawal \& Knoeber, 1996). Conyon and Peck (1998) investigate the effects of board size and find a negative association between measures of corporate performance and board size. André, Ben-Amar, and Saadi (2006) document a non-linear relationship. Similarly, the relationship between CEO-chairman duality and performance remains unclear (Brickley, Coles, \& Jarrell, 1997; Vefeas \& Theodorou, 1998).

\subsection{Other large shareholders}

Other large shareholders, or block holders, are recognized as an effective mitigating factor (André \& Schiehll, 2004). Large block holders such as institutional investors have the means of monitoring and influencing the controlling shareholder. Maury and Pajuste (2005) show that not only the presence but also the equal distribution of voting shares among block holders has positive effect on firm value. 


\subsection{Legal institutions}

Recent papers emphasize the importance of legal institutions in protecting investors and limiting self-dealing by controlling shareholders (Denis \& McConnell, 2003). La Porta et al. (1998) initially classify 49 countries around the world into four major families of law. Common-law has been adopted in the British colonies, including the United States, Canada, Australia, India, Malaysia, Thailand, and many other countries. They further show that these English-origin countries have the strongest investor protection rules. They measure the level of shareholder rights by an anti-director rights index. Recent papers provide evidence that companies in countries with an English-origin legal system have higher corporate performance due to the better corporate governance system and legal environment (Becht \& Roell, 1999; Gugler et al., 2004; Johnson, Boone, Breach, \& Friedman, 2000; Mueller \& Yurtoglu, 2000).

However, the anti-director rights index has been criticized for its ad-hoc nature and for coding errors. Djankov et al. (2006) revise their original anti-director rights index using more precise definitions of the proxies composing the index and correcting for coding errors. They further present a new measure of legal protection: the anti-self-dealing index. They design a questionnaire starting with a fixed self-dealing transaction and then attempt to measure the hurdles that controlling shareholders need to tackle in order to extract private benefit from this transaction. They then collect completed questionnaires from attorneys working in an international law firm. In summary, they show that common law countries have a higher average anti-self-dealing index since English-origin countries typically require extensive disclosure and approval of the transaction by interested shareholders. However, as in the case of the anti-director rights index, there remains a fair amount of variation across English-origin countries.

The impact of concentrated ownership on corporate performance is still an open question. Some studies show that firm value increases with the cash flow ownership of the largest shareholders (Anderson \& Reeb, 2003; Claessens, Djankov, Fan, \& Lang, 2002; La Porta et al., 2002; McConaughy, Walker, Henderson, \& Mishra, 1998). In contrast, other studies suggest that without effective monitoring, controlling shareholders are likely to exploit minority shareholders and make sub-optimal decisions and even more so when control rights exceed the cash flow rights (Cronqvist \& Nilsson, 2003; Faccio, Lang, \& Young, 2001). Also, many studies suggest that the relationship may not be linear (Anderson \& Reeb, 2003; McConnell \& Servaes, 1990; Morck et al., 1988).

Recent studies look at M\&A to examine whether controlling shareholder create or destroy value. Ben-Amar and André (2006) investigate Canadian deals and show that separation of ownership and control does not have the anticipated negative impact on value creation and that family ownership has a positive impact. European studies by Faccio and Stolin (2006) and Holmen and Knopf (2004) find no significant evidence to prove wealth transfer from minority shareholders to controlling shareholders through takeovers. They conclude that legal or extralegal institutions effectively mitigate the tunneling problem. However, Bigelli and Mengoli (2004) find a nonmonotonic relationship between the participation of the dominant shareholder and the abnormal returns for bidder shareholders in Italy.

Bae et al. (2002) investigate mergers by Korean business groups also called chaebols. They argue that the owner-managers of chaebols have substantial discretionary power and that legal protection against expropriation of minority shareholders is weak in Korea. They find that when chaebol affiliated firms make acquisitions, their share price drops so that the minority shareholders of these firms lose out while controlling shareholders gain because of the increase in value of 
other firms in the group. They further argue that the implicit guarantee of a bailout for chaebols members still make these investment interesting for minority shareholders. ${ }^{2}$

Our study proposes to re-examine the relationship between ownership structure and the performance of bidding firms in the context of ownership concentration and separation between cash-flow and control rights for a broad sample of English-origin countries while controlling for varying level of investor protection as measured by the updated anti-director rights index and new anti-self-dealing index of Djankov et al. (2006).

\section{Methodology}

\subsection{Sample selection}

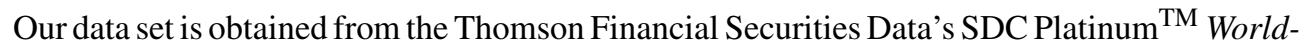
wide Mergers \& Acquisitions Database. Our sample meets the following criteria: (1) observations are for 1997-2001; (2) acquiring firms and targets are listed companies; (3) deals are completed and are mergers, exchange offers, or acquisitions of a majority interest; (4) companies with several M\&A during the period are included; (5) only transactions greater than US\$ 10 million are included; (6) adopting the La Porta et al. (1998) classification, acquiring nation is an Englishorigin country except for the $\mathrm{US}^{3}$; (7) companies have financial and accounting data for the 7-year window available in Datastream; and (8) ownership data is available from proxies or annual reports of each company from Mergent database, Canadian SEDAR filing system, EDGAR SEC fillings, or company websites. Note that government, financial, and investment companies are excluded because of their specific accounting and regulatory requirements. Our final sample comprises 287 deals (227 acquiring firms) in 11 countries.

Table 1, panel A, reports the annual numbers, aggregate values, and mean values of deals. Our sample comprises 287 acquisitions with a total market value of over US\$ 564 billion. Acquiring firms paid, on average (median), US\$ 1966.6 (239.3) million for the targets. Panel B presents acquisitions by primary SIC code. The largest proportion of deals is in the manufacturing sector. Panel C lists firms and deal values by country. Most deals are initiated in the UK (142 deals out of the 287 or $49.5 \%$ ) followed by Canada (77 deals or $26.8 \%$ ), and Australia (25 deals or $8.7 \%$ ). The other $43(15 \%)$ deals are spread across the following countries: South Africa (14), Ireland (11), India (6), Singapore (6), New Zealand (3), Israel (1), Malaysia (1), and Thailand (1).

\subsection{Variables}

\subsubsection{Dependent variable}

3.2.1.1. Performance measure. Based on Healy et al. (1992), this study uses pre-tax operating cash flow (OCF) to measure the acquisition performance. We define operating cash flow as operating income after depreciation plus depreciation and goodwill amortization (in other words, EBITDA). This definition ensures that the performance measure is unaffected by different merger

\footnotetext{
${ }^{2}$ La Porta et al. (2000), Friedman et al. (2003) and Shleifer and Wolfenzon (2002) discuss this notion of negative tunneling or propping.

3 The US market is excluded since it has been extensively studied and a greater proportion of large American firms are widely held. Nevertheless, Anderson and Reeb (2003) and other suggest that around a third of US large publicly listed firms can be characterized as family firms. Anderson, Duru, and Reeb (2006) find family ownership in $48 \%$ of the 2000 largest industrial firms.
} 
Table 1

Sample description

\begin{tabular}{|c|c|c|c|c|c|c|c|c|}
\hline Year & $\begin{array}{l}\text { Number of } \\
\text { transaction }\end{array}$ & \multicolumn{2}{|c|}{$\begin{array}{l}\text { Average value } \\
\text { (\$US million) }\end{array}$} & \multicolumn{3}{|c|}{$\begin{array}{l}\text { Median value } \\
\text { (\$US million) }\end{array}$} & \multicolumn{2}{|c|}{$\begin{array}{l}\text { Total value } \\
\text { (\$US million) }\end{array}$} \\
\hline \multicolumn{9}{|c|}{ Panel A: Number and value of transactions } \\
\hline 1997 & 11 & \multicolumn{2}{|c|}{373.9} & \multicolumn{2}{|r|}{198.0} & & \multicolumn{2}{|r|}{4112.8} \\
\hline 1998 & 45 & \multicolumn{2}{|c|}{684.0} & \multicolumn{2}{|r|}{173.5} & & \multicolumn{2}{|c|}{30779.7} \\
\hline 1999 & 74 & \multicolumn{2}{|c|}{1909.2} & \multicolumn{2}{|r|}{211.4} & & \multicolumn{2}{|c|}{141283.1} \\
\hline 2000 & 88 & \multicolumn{2}{|c|}{3852.7} & \multicolumn{2}{|r|}{297.5} & & \multicolumn{2}{|c|}{339039.5} \\
\hline 2001 & 69 & \multicolumn{2}{|c|}{713.1} & \multicolumn{2}{|r|}{205.5} & & \multicolumn{2}{|c|}{49201.2} \\
\hline Total & 287 & \multicolumn{2}{|c|}{1966.6} & \multicolumn{2}{|r|}{239.3} & & \multicolumn{2}{|c|}{564416.3} \\
\hline \multicolumn{2}{|l|}{ By SIC code } & & 1997 & 1998 & 1999 & 2000 & 2001 & 1997-2001 \\
\hline Panel B: Sample b & ndustry & & & & & & & \\
\hline Agriculture and & tural resource & 0000-1999 & 3 & 7 & 8 & 14 & 12 & 44 \\
\hline Manufacturing: & 100-3999 & & 2 & 24 & 35 & 45 & 29 & 135 \\
\hline Transportation: & 00-4999 & & 3 & 5 & 10 & 12 & 12 & 42 \\
\hline Consumer: 5000 & 5999 & & 1 & 6 & 7 & 6 & 5 & 25 \\
\hline Services: 7000 & & & 2 & 3 & 14 & 11 & 11 & 41 \\
\hline Total & & & 11 & 45 & 74 & 88 & 69 & 287 \\
\hline & $\begin{array}{l}\text { Number of } \\
\text { transaction }\end{array}$ & $\begin{array}{l}\text { Number } \\
\text { of firms }\end{array}$ & $\begin{array}{l}\text { Average value } \\
\text { (\$US million) }\end{array}$ & & $\begin{array}{l}\text { Median value } \\
\text { \$US million) }\end{array}$ & $\begin{array}{l}\text { Total v } \\
\text { (\$US n }\end{array}$ & $\begin{array}{l}\text { e } \\
\text { ion) }\end{array}$ & $\begin{array}{l}\text { Target: } \\
\text { English-origin }\end{array}$ \\
\hline Panel C: Sample b & acquirer natio & & & & & & & \\
\hline Australia & 25 & 20 & 177.6 & & 77.6 & 2293 & & 25 \\
\hline Canada & 77 & 57 & 895.6 & & 00.1 & 6896 & & 71 \\
\hline India & 6 & 6 & 155.1 & & 55.1 & 930 & & 6 \\
\hline Ireland-Rep & 11 & 8 & 207.8 & & 07.8 & 4629 & & 10 \\
\hline Israel & 1 & 1 & 53.4 & & 53.4 & & & 1 \\
\hline Malaysia & 1 & 1 & 49.5 & & 49.5 & 45 & & 1 \\
\hline New Zealand & 3 & 3 & 295.4 & & 6.2 & 88 & & 2 \\
\hline Singapore & 6 & 6 & 1601.8 & & 29.5 & 9610 & & 6 \\
\hline South Africa & 14 & 11 & 164.5 & & 64.5 & 294 & & 14 \\
\hline Thailand & 1 & 1 & 124.1 & & 24.1 & 12 & & 1 \\
\hline United Kingdon & 142 & 113 & 3192.2 & & 85.5 & 45328 & & 128 \\
\hline Total & 287 & 227 & 1966.6 & & 39.3 & 564410 & & 265 \\
\hline
\end{tabular}

Sample of 287 mergers and acquisitions by 227 acquiring firms in 11 English-origin countries (Australia, Canada, India, Ireland, Israel, Malaysia, New Zealand, Singapore, South Africa, Thailand and United Kingdom) between 1997 and 2001 for completed transactions over US\$10 million obtained from the Thomson Financial Securities Data's SDC Platinum ${ }^{\mathrm{TM}}$ Worldwide Mergers \& Acquisitions Database.

accounting methods, tax policy, or the type of financing used to fund the acquisition. Operating cash flow return (OCFR) is calculated as operating cash flow divided by market value of asset.

Operating cash flow returns are computed for each company up to 3 years before and after the acquisition event (MEG pre and post). Pre-acquisition performance is calculated as a weightedaverage of the operating cash flow rate for the bidder and the target. The weights are based on the market values of assets of both companies at the year before acquisition. This measurement is consistent with that of Healy et al. (1992), Healy, Palepu, and Ruback (1997) and Ghosh (2001). 
Following Ghosh's (2001) critic of Healy et al. (1992), we set criteria to select a list of matched firms based on size, industry, and pre-performance. After the list of matched firms is set, the steps for calculating operating cash flows are repeated and we get operating cash flow rates for the pair of matched firms (a match for the bidder and a match for the target). Since the pair of matched firms forms the benchmark, both post- and pre-acquisition performances is also measured as the weighted-average of the operating cash flow returns based on the market values of assets of the bidder and the target the year before acquisition (MAT pre and post).

The industry, size, and pre-performance adjusted operating cash flow return (ACFR) is the operating cash flow return of the merging firm minus that of the matched pair of firm. Similar to Healy et al. (1992), the median of ACFR 3 years before and after acquisition (ACFRpre and ACFRpost) is used. Furthermore, while most studies focus on post-acquisition performance only (Healy et al., 1992; Linn \& Switzer, 2001; Loughran \& Ritter, 1997; Powell \& Stark, 2005; Rahman \& Limmack, 2004), some papers also calculate the change in cash flow returns ( $\triangle \mathrm{ACFR})$ to examine the improvement in performance (Carline, Linn, \& Yadav, 2002; Rahman \& Limmack, 2004). $\triangle$ ACFR is defined as ACFRpost minus ACFRpre. We examine both performance metrics (ACFRpost and $\triangle \mathrm{ACFR}$ ).

3.2.1.2. Performance benchmark. Following Barber and Lyon (1996), most researchers adopt industry, size, and pre-performance based matching. For example, Loughran and Ritter (1997) choose their matched firms by using the following criteria: (1) 2-digit SIC, assets within 25-200\%, closest EBITDA/assets and (2) if there is no match, assets within 90-110\%, closest but higher EBITDA/assets. In Ghosh (2001), firms are matched by the same 2-digit SIC code, total assets between $25 \%$ and $200 \%$, and closest ratio of operating cash flow to market value of assets (sales). Powell and Stark (2005) select their matched firms with an initial size filter of between $25 \%$ and $200 \%$ within the bidders and targets industries. To make our results comparable with previous studies, our matching procedure is consistent with the recommendations of Barber and Lyon (1996) and similar to the approaches employed by Ghosh (2001) and Loughran and Ritter (1997). We construct our benchmarks with the following initial criteria:

1. Same 2-digit primary SIC code.

2. Similar size, measured as book value of assets within $70 \%$ and $130 \% 1$ year before takeover.

3. Similar pre-performance, measured as return on asset (ROA) within $90 \%$ and $110 \% 1$ year before takeover.

4. Same nation code as the bidder and the target.

From the list of potential matched firms, we select the firm with closest but highest ROA. If there is no match, the pre-performance restriction is extended by choosing a matching firm with ROA between $50 \%$ and $150 \%$. If still no firm meets the criteria, the same country rule is replaced by a same legal origin country rule and the pre-performance limit is reset to $90-110 \%$. If the first run criteria are too strict to give a matching firm, we do a second run with larger bands. That is, same 2-digit primary SIC code, book value of assets within $25 \%$ and $200 \%$, ROA between $90 \%$ and $110 \%$, and the same country. After the second run, we obtain $92 \%$ matching for acquiring firms and $94 \%$ for target firms. For the few cases without a match at this point, we select the firm with the closest ROA within size band and industry. 
Finally, statistical analysis shows that our original operating cash flow data of both merged and matched firms have heavy tailed distributions. We use Huber's $M$-estimator ${ }^{4}$ with $k=1.28$ to estimate the measure of location and detect the outliers and then winsorize the data. ${ }^{5}$

\subsubsection{Independent variables}

Independent variables are grouped into five categories: ownership variables; governance and legal variables as discussed above; typical deal variables found in event studies (see André, Kooli, \& L'Her, 2004; Ben-Amar \& André, 2006 for further discussions); and country control variables. All variables are defined in Table 2 . We discuss ownership variables below. Our coding approach is similar to Faccio and Lang (2002).

Ownership variables include five dummy variables reflecting different thresholds of voting shares held by the largest shareholder. We also have a continuous variable for the actual percentage of voting shares held. The information is obtained from the description of substantial/principal shareholders in each company's proxy circular or annual report the year prior to the deal.

3.2.2.1. Concentrated ownership at $10 \%$ threshold (CONCEN10). This dummy variable is for companies having a large shareholder holding more than $10 \%$ of the voting shares. The $10 \%$ level has been broadly used as a cut point to test the difference between dispersed and concentrated ownership structures because it provides a significant stake and most countries mandate disclosure at this level or lower (Faccio et al., 2001; La Porta et al., 1998). ${ }^{6}$

3.2.2.2. Concentrated ownership at $20 \%$ threshold (CONCEN20). Some researchers argue that $20 \%$ might be a better cut-off point to define ownership concentration (Claessens et al., 2000; Demsetz \& Lehn, 1985; Faccio et al., 2001; La Porta et al., 1999). Therefore, we set another dummy variable for when companies have a large shareholder with more than $20 \%$ of voting shares.

3.2.2.3. Concentrated ownership at 50\% threshold (CONCEN50). When a large shareholder holds more than $50 \%$ of the voting shares, it not only dominates but typically it legally controls the firm (Becht \& Roell, 1999; Faccio \& Lang, 2002). Therefore, we also set a dummy variable at the $50 \%$ threshold to examine this specific ownership structure.

\footnotetext{
${ }^{4} M$-estimators are highly recommended due to higher breakdown points than mean and more accurate variance than median from a normal distribution or trimmed means from a heavy tailed probability curve. Also, $M$-estimators play a more dominant role when dealing with regression analysis issues (Wilcox, 2001). For the $M$-estimators, the idea of flexibility of trimming ratio is introduced by Eq. (1) where any observed value $X$ is declared an outlier based on the sample median, $M$ and the median absolute deviation, MAD.

$$
\frac{|X-M|}{\operatorname{MAD} / 0.6745}>K
$$

This study uses a well-known $M$-estimator called one-step $M$-estimator which has been broadly applied by using $K=1.28$ (Huber, 1964).

5 The average level of winsorizing for right tails is $16.35 \%, 10.89 \%$ for left tails.

6 Australia, New Zealand, Singapore, and Thailand require the disclosure of top 20 large and substantial shareholders. Canada requires the disclosure of information with respect to the large shareholders who beneficially own $10 \%$ or more of outstanding common shares whereas the UK and South African thresholds are 3\% and 5\%, respectively.
} 
Table 2

Variable definitions

\begin{tabular}{|c|c|}
\hline Variables & Definition \\
\hline \multicolumn{2}{|c|}{ Independent variables: Ownership variables } \\
\hline CONCEN10 & One if a shareholder owns more than $10 \%$ of voting shares of the acquiring firm \\
\hline CONCEN20 & One if a shareholder owns more than $20 \%$ of voting shares of the acquiring firm \\
\hline CONCEN50 & One if a shareholder owns more than $50 \%$ of voting shares of the acquiring firm \\
\hline CONCEN1020 & One if a shareholder owns between $10 \%$ and $20 \%$ of voting shares in the acquiring firm \\
\hline CONCEN2050 & One if a shareholder owns between $20 \%$ and $50 \%$ of voting shares in the acquiring firm \\
\hline LSH1P & The percentage of voting shares held by the largest shareholder \\
\hline LSH1PSQ & The square of the percentage of voting shares held by the largest shareholder \\
\hline LSH1PCUBE & The cube of the percentage of voting shares held by the largest shareholder \\
\hline \multicolumn{2}{|c|}{ Other independent variables } \\
\hline \multicolumn{2}{|c|}{ Governance variables } \\
\hline SEP & One if there exists separation of ownership and cash flow rights in the acquiring firm \\
\hline CEOLSH & One if CEO is related to the largest shareholder \\
\hline CEOdual & One if CEO and COB positions are held by the same individual \\
\hline OTHLSH & $\begin{array}{l}\text { One if there is another shareholder with at least } 10 \% \text { of the voting shares of the acquiring } \\
\text { firms }\end{array}$ \\
\hline BSIZE & Numbers of directors on the board \\
\hline \multicolumn{2}{|l|}{ Deal variables } \\
\hline TGORI_English & One if the legal origin of target firm is English \\
\hline ATTI_Hostile & One if the management or board of target firm were initially opposed to the deal \\
\hline PAY_Stock & One if the payment method of transaction was stock only \\
\hline COMPETE & One if the acquiring firm had to compete with other possible acquirers \\
\hline IND_rel & One if the acquiring and target firms had equivalent 4-digit primary SIC code \\
\hline TOEHOLD & One if acquiring firm owns any target shares before transaction \\
\hline PREM_1day & Premium of offer price to target trading price 1 day prior to the announcement date \\
\hline SIZE_rel & $\begin{array}{l}\text { Natural logarithm of the acquiring firm's market value of assets divided by target firm's } \\
\text { market value of asset at the fiscal year end before the acquisition year }\end{array}$ \\
\hline LEV & $\begin{array}{l}\text { Natural logarithm of the acquiring firm's leverage (book value of debts divided by market } \\
\text { value of assets) at the fiscal year end before the acquisition year }\end{array}$ \\
\hline \multicolumn{2}{|l|}{ Legal variables } \\
\hline NANTIDIR_high & $\begin{array}{l}\text { One if the acquiring firm is in a country with highest score (5) of updated anti-director } \\
\text { rights index (Djankov et al., 2006) }\end{array}$ \\
\hline ANTISDI_level & Anti-self-dealing index (Djankov et al., 2006) \\
\hline \multicolumn{2}{|l|}{ Country variables } \\
\hline UK & One if acquiring firm nation is the United Kingdom \\
\hline CAN & One if acquiring firm nation is Canada \\
\hline AUS & One if acquiring firm nation is Australia \\
\hline
\end{tabular}

Ownership and governance variables are obtained from proxies or annual reports of each company. Proxies are obtained from Mergent database, Canadian SEDAR filing system, EDGAR SEC fillings, or company website. Deal variables are collected from Thomson Financial Securities Data's SDC Platinum ${ }^{\mathrm{TM}}$ Worldwide Mergers \& Acquisitions Database. Legal variables are scores from of Djankov et al. (2006).

3.2.2.4. Concentrated ownership between 10-20\% and 20-50\% (CONCEN1020 and CONCEN2050). These two dummy variables are created to allow three ownership categories: between $10 \%$ and $20 \%$, between $20 \%$ and $50 \%$, and more than $50 \%$ (CONCEN50).

3.2.2.5. Percentage of voting shares ( $L S H 1 P, L S H 1 P S Q, L S H 1 P C U B E)$. A continuous variable measures the actual percentage of voting shares held by the largest shareholder (from $10 \%$ or 
more). The variable is squared and cubed to capture the potential non-linear relationship between controlling ownership and acquiring performance. Authors having examined non-linear relationships include Morck et al. (1988), McConnell and Servaes (1990), and Anderson and Reeb (2003).

\section{Results}

\subsection{Operating cash flows returns}

Table 3 presents the operating cash flow returns (pre, post, and change) for the merging and matching firms and the adjusted operating cash flow return. The results in panel A report a median operating cash flow return for merged firms $\left(\mathrm{MEG}_{i}\right)$ in the 3 years before acquisition ranging from $11.32 \%$ to $12.20 \%$. The median pre-acquisition operating cash flow return for matched firms $\left(\mathrm{MAT}_{i}\right)$ is from $12.6 \%$ to $13.79 \%$. The median measure of industry, size, and pre-performance adjusted return $\left(\mathrm{MEG}_{i}-\mathrm{MAT}_{i}\right)$ for year $-3,-2$, and -1 is $-0.17 \%,-0.88 \%$, and $-1.42 \%$, respectively (all statistically different from zero). The median adjusted return over the 3-year pre-acquisition period is $-1.24 \%$ and statistically different from zero. Similar conclusions are drawn from the measure of mean operating performance.

In contrast, we see the mean and median measures of adjusted returns in each of the three postacquisition years are insignificant except for the mean adjusted return in year $+1(0.81 \%)$. The median adjusted return over post-acquisition years (ACFRpost) is $0.79 \%$ and the mean is $0.57 \%$. Although these results are generally not distinguishable from zero, mean measures are positive and concurrently decrease from $t+1$ to $t+3$. Furthermore, the mean and the median measure of the change of operating cash flow rate $(\triangle \mathrm{ACFR})$ are $2.43 \%$ and $2.20 \%$, respectively. Both are significantly different from zero at the $1 \%$ level.

Summarily, the results demonstrate that merged firms in our sample under-perform the benchmark firms before M\&A. This finding contrasts with some prior studies (Ghosh, 2001; Healy et al., 1992). We do find that operating performance of merged firms improves after M\&A events. This result is consistent with that reported by Healy et al. (1992). Powell and Stark (2005) find modest improvements for UK deals. Although the post-adjusted return is not statistically distinguishable from zero, the measures of change in adjusted returns are significant when combining the significantly poor pre-performance and positive postperformance.

In panel $\mathrm{B}$, we present the regression results of the 3-year post-acquisition median adjusted returns (ACFRpost) on the 3-year pre-acquisition median adjusted returns (ACFRpre). The intercept $\alpha(0.015)$ is positive and significant at the $1 \%$ level which indicates adjusted operating performance improvements of $1.5 \%$ in the post-acquisition period after controlling for the effects of pre-performance. The slope coefficient $(0.475)$ is also positive and different from zero. The slope coefficient captures the persistence over time. Healy et al. $(1992,1997)$ and Ghosh (2001) find similar results.In panels $\mathrm{C}$ and $\mathrm{D}$, we test the sensitivity of results to various windows (year -1 compared to year $+1,+2$, and +3 ) similar to Denis and Denis (1995). Results are qualitatively similar to the change in pre- and post-3-year median adjusted performance. Further analysis is based on these measures. ${ }^{7}$

\footnotetext{
${ }^{7}$ We also ran the regressions in Table 6 using these alternative measures, not reported, and results where again quantitatively similar.
} 
Table 3

Operating cash flows returns

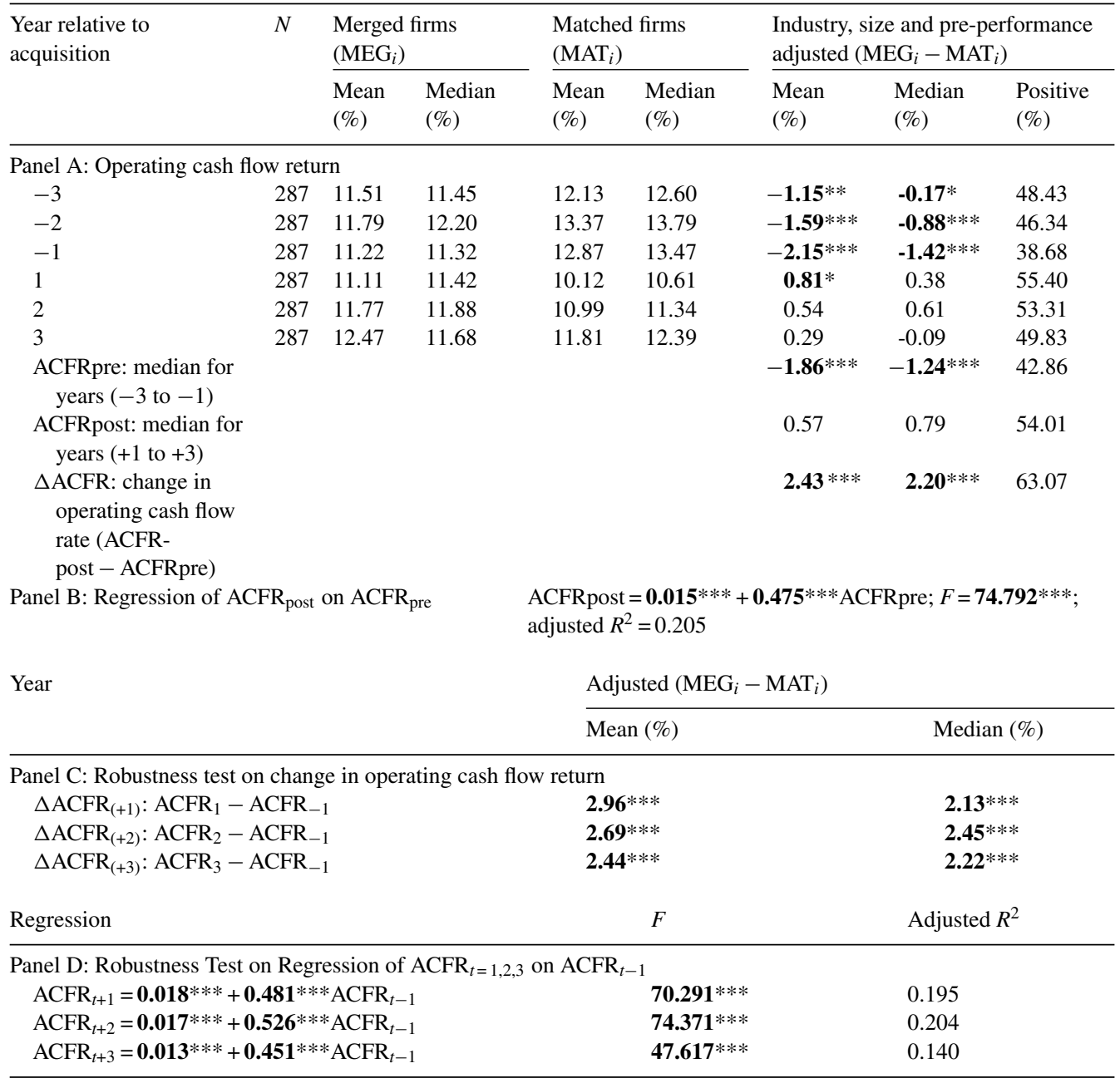

Sample of 287 mergers and acquisitions by 227 acquiring firms in 11 English-origin countries (Australia, Canada, India, Ireland, Israel, Malaysia, New Zealand, Singapore, South Africa, Thailand and United Kingdom) between 1997 and 2001 for completed transactions over US\$ 10 million obtained from the Thomson Financial Securities Data's SDC Platinum ${ }^{\mathrm{TM}}$ Worldwide Mergers \& Acquisitions Database. Operating cash flow return (OCFR) is calculated as operating cash flow divided by market value of asset. Operating cash flow is defined as operating income before depreciation. Post-acquisition performance for each deal is measured by the operating cash flow return of the surviving acquirer after transaction. Preacquisition performance is calculated as a weighted-average of the operating cash flow return for the bidder and the target included $\left(\mathrm{MEG}_{i}\right)$. The weights are based on the market values of assets of both companies in the year before acquisition. Post- and pre-acquisition performances of the matched firms are measured as weighted-average of the operating cash flow rates $\left(\mathrm{MAT}_{i}\right)$. Industry, size, and pre-performance adjusted operating cash flow rates (ACFR) is operating cash flow rates of merged firms minus those of matched firms. The change in industry, size, and pre-performance adjusted cash flow rate ( $\triangle \mathrm{ACFR}$ ) is defined as 3-year median ACFRpost minus 3-year-median ACFRpre. Outliers have been winsorized using Huber's $M$-estimator approach. ***Significance at the $1 \%$ level; **significance at the $5 \%$ level; *significance at the $10 \%$ level. 


\subsection{Descriptive statistics}

In Table 4, we display summary statistics of all variables for the full sample and a breakdown for the three major countries (Australia, Canada, and the UK). Comparing adjusted operating cash flows returns across countries, we see that Canadian firms have the best pre-performance and post-performance median measures (i.e., performance was not statistically different from matching firms) whereas our sample of firms from other English-origin countries experience poor pre-merger abnormal performance which improves in the post-merger period leading them to experience greater improvements in $\triangle \mathrm{ACFR}$ (all statistically significantly different from zero).

For ownership variables, we see that concentrated ownership at the $10 \%$ threshold is dominant in all countries (72\% in Australia, 64\% in Canada, 51\% in the UK, and 74\% for 'others'). The median voting shares of the largest shareholder is $12 \%$ in the UK (below the overall sample median of 21\%), 26\% in Australia, 47\% in Canada, and 38\% in other English-origin countries. While there are only 16 firms out $142(11 \%)$ with a $20 \%$ or more large shareholder in the UK, this is the case in $40 \%$ of the Australian sample and in 53\% of cases in Canada and 'others'. Canada has the largest number of controlling large shareholders (27\% of firms have a shareholder with over $50 \%$ of voting shares) followed by the other English-origin countries (23\%) but there is only one case in the UK and none in Australia. La Porta et al. (1999), using a 10\% cut off and looking at medium-sized firms, find concentrated ownership in $90 \%$ of cases in Australia, $90 \%$ in the UK, $60 \%$ in Canada, and $82.5 \%$ on average for 'others'. At a $20 \%$ cut off, they find $70 \%$ concentration in Australia, $40 \%$ in the UK and Canada, and 57\% for 'others'.

For governance variables, separation of voting and cash flow rights is present in $15 \%$ of the sample but mostly common in Australia and Canada but not in the UK or 'others'. CEOs are linked to the largest shareholder in $14 \%$ of cases but this is also most prevalent in Australia (20\%) and Canada (29\%). CEO is also COB in $26 \%$ of cases; Australia and the UK are below average whereas Canada and 'others' are above. There exists a second large shareholder in and around $20 \%$ of cases across all countries. Maury (2005), examining 1672 Western European non-financial firms, reports that $36 \%$ of the sample firms have multiple block holders. Median board size ranges between 7 and 10 members. Conyon and Peck (1998) show that UK board size is 8.56, on average.

Examining deal characteristics, we see that the quasi-totality of deals is with a target also from an English-origin country and that most deals are friendly. Cernat (2004) points out that there are relatively few hostile deals in Europe. Between $16 \%$ and $19 \%$ of deals are entirely paid with stock, compared to $11.3 \%$ pure stock European deals in Faccio and Masulis (2005). Overall, 36\% of deals are classified as being in the same industry (both target and acquirer having same 4-digit SIC code). Compared to the $13.29 \%$ level in Goergen and Renneboog (2004) for European takeovers, we have relatively fewer deals (7\%) involving a second bidder and only $16 \%$ of deals are initiated by acquirers with a toehold. The median 1-day premium is $30.43 \%$ overall, highest in the UK (37.14\%) and lowest in Canada (19.72\%). The average size of acquirers is about 5.7, exp (1.74) times larger than that of targets and the average level of leverage is $16 \%$ (compared to $21.5 \%$ in Maury, 2005 for Western European firms).

Looking at the updated anti-director rights index of Djankov et al. (2006), five sample countries (59\% of deals) including India, Malaysia, Singapore, South Africa, and the UK are classified as countries with top scores. As for their new anti-self-dealing index, the median score is 0.81 for all countries in our sample. We see that Canada and Australia have lower anti-director rights indexes and lower than median anti-self-dealing indexes ( 0.65 in Canada and 0.79 in Australia) whereas the UK has both a high anti-director rights index and a higher than median anti-self-dealing index (0.93). 
Table 4

Descriptive statistics (by country)

\begin{tabular}{|c|c|c|c|c|c|c|c|c|c|c|c|}
\hline & & Australia $(n=25)$ & & Canada $(n=77)$ & & $\begin{array}{l}\text { United Kingdom } \\
(n=142)\end{array}$ & & Others $(n=43)$ & & All $(n=287)$ & \\
\hline \multicolumn{12}{|c|}{ Performance variables } \\
\hline \multirow[t]{2}{*}{ ACFRpre } & Mean & $-2.24 *$ & & -0.40 & & $-2.16^{* * * *}$ & & $-3.29 * *$ & & $-1.86^{* * * *}$ & \\
\hline & Median & -2.68 & & 0.19 & & $-1.57 * * *$ & & $-2.04 * *$ & & $-1.24 * * *$ & \\
\hline \multirow[t]{2}{*}{ ACFRpost } & Mean & 0.55 & & 1.25 & & -0.03 & & 1.34 & & 0.57 & \\
\hline & Median & 1.24 & & 1.32 & & 0.55 & & 0.29 & & 0.79 & \\
\hline \multirow[t]{2}{*}{$\triangle \mathrm{ACFR}$} & Mean & $2.79 * *$ & & $1.64 *$ & & $2.13 * * *$ & & $4.63 * * *$ & & $2.43 * * *$ & \\
\hline & Median & $3.05^{*}$ & & $1.83^{* *}$ & & $2.00^{* * * *}$ & & $3.83^{* * * *}$ & & $2.20^{* * * *}$ & \\
\hline \multicolumn{12}{|l|}{ Ownership variables } \\
\hline CONCEN10 & $\#(1,0)$ & $18(72 \%)$ & $7(28 \%)$ & $49(64 \%)$ & $28(36 \%)$ & $72(51 \%)$ & $70(49 \%)$ & $32(74 \%)$ & $11(26 \%)$ & $171(60 \%)$ & $116(40 \%)$ \\
\hline CONCEN20 & $\#(1,0)$ & $10(40 \%)$ & $15(60 \%)$ & $41(53 \%)$ & $36(47 \%)$ & $16(11 \%)$ & $126(89 \%)$ & $23(53 \%)$ & $20(47 \%)$ & $90(31 \%)$ & $197(69 \%)$ \\
\hline CONCEN50 & $\#(1,0)$ & $0(0 \%)$ & $25(100 \%)$ & $21(27 \%)$ & $56(73 \%)$ & $1(1 \%)$ & $141(99 \%)$ & $10(23 \%)$ & $33(77 \%)$ & $32(11 \%)$ & $255(89 \%)$ \\
\hline CONCEN1020 & $\#(1,0)$ & $8(32 \%)$ & $17(68 \%)$ & $8(10 \%)$ & $69(90 \%)$ & $56(39 \%)$ & $86(61 \%)$ & $9(21 \%)$ & $34(79)$ & $81(28 \%)$ & $206(72 \%)$ \\
\hline CONCEN2050 & $\#(1,0)$ & $10(40 \%)$ & $15(30 \%)$ & $20(26 \%)$ & $57(74 \%)$ & $15(11 \%)$ & $127(89 \%)$ & $13(30)$ & $30(70 \%)$ & $98(0 \%)$ & $229(80 \%)$ \\
\hline \multirow{3}{*}{ LSH1P (\%) } & \# & $18(72 \%)$ & & $49(64 \%)$ & & $72(51 \%)$ & & $32(74 \%)$ & & $171(60 \%)$ & \\
\hline & Mean & 0.28 & & 0.47 & & 0.16 & & 0.37 & & 0.30 & \\
\hline & Median & 0.26 & & 0.47 & & 0.12 & & 0.38 & & 0.21 & \\
\hline \multicolumn{12}{|c|}{ Governance variables } \\
\hline SEP & $\#(1,0)$ & $16(64 \%)$ & $9(36 \%)$ & $24(31 \%)$ & $53(69 \%)$ & $3(2 \%)$ & $139(98 \%)$ & $1(2 \%)$ & $42(98 \%)$ & $44(15 \%)$ & $243(85 \%)$ \\
\hline CEOLSH & $\#(1,0)$ & $5(20 \%)$ & $20(80 \%)$ & $22(29 \%)$ & $55(71 \%)$ & $8(6 \%)$ & $134(94 \%)$ & $5(12 \%)$ & $38(88 \%)$ & $40(14 \%)$ & $247(86 \%)$ \\
\hline CEOdual & $\#(1,0)$ & $3(12 \%)$ & $22(88 \%)$ & $27(35 \%)$ & $50(65 \%)$ & $31(22 \%)$ & $111(78 \%)$ & $13(74 \%)$ & $30(70 \%)$ & $74(26 \%)$ & $213(74 \%)$ \\
\hline OTHLSH & $\#(1,0)$ & $5(20 \%)$ & $20(80 \%)$ & $16(21 \%)$ & $61(79 \%)$ & $24(17 \%)$ & $118(83 \%)$ & $9(21 \%)$ & $34(79 \%)$ & $54(19 \%)$ & $233(81 \%)$ \\
\hline \multirow[t]{2}{*}{ BSIZE } & Mean & 8.56 & & 10.27 & & 9.13 & & 10.63 & & 9.61 & \\
\hline & Median & 7.00 & & 10.00 & & 9.00 & & 10.00 & & 9.00 & \\
\hline \multicolumn{12}{|c|}{ Transaction variables } \\
\hline TGORI_English & $\#(1,0)$ & $25(100 \%)$ & $0(0 \%)$ & $71(92 \%)$ & $6(8 \%)$ & $128(90 \%)$ & $14(10 \%)$ & $41(95 \%)$ & $2(5 \%)$ & $265(92 \%)$ & $22 \%(8 \%)$ \\
\hline ATTI_Hostile & \# a,CO & $3(12 \%)$ & $22(88 \%)$ & $1(1 \%)$ & $76(99 \%)$ & $4(3 \%)$ & $138(97 \%)$ & $2(5 \%)$ & $41(95 \%)$ & $10(3 \%)$ & $277(97 \%)$ \\
\hline PAY_Stock & $\#(1,0)$ & $4(16 \%)$ & $21(84 \%)$ & $14(18 \%)$ & $63(82 \%)$ & $22(15 \%)$ & $120(85 \%)$ & $8(19 \%)$ & $35 \%(81 \%)$ & $48(17 \%)$ & $239(83 \%)$ \\
\hline COMPETE & $\#(1,0)$ & $3(12 \%)$ & $22(88 \%)$ & $6(8 \%)$ & $71(92 \%)$ & $9(6 \%)$ & $133(94 \%)$ & $1(2 \%)$ & $42(98 \%)$ & $19(7 \%)$ & $268(93 \%)$ \\
\hline IND_rel & $\#(1,0)$ & $8(32 \%)$ & $17(68 \%)$ & $33(43 \%)$ & $44(57 \%)$ & $51(36 \%)$ & $91(64 \%)$ & $10(23 \%)$ & $33(77 \%)$ & $102(36 \%)$ & $185(64 \%)$ \\
\hline TOEHOLD & $\#(1,0)$ & $6(24 \%)$ & $19(76 \%)$ & $10(13 \%)$ & $67(87 \%)$ & $23(16 \%)$ & $119(84 \%)$ & $8(19 \%)$ & $35(81 \%)$ & $47(16 \%)$ & $240(84 \%)$ \\
\hline \multirow[t]{2}{*}{ Prem_1day } & Mean & 22.91 & & 31.19 & & 37.05 & & 23.83 & & 32.66 & \\
\hline & Median & 21.55 & & 19.72 & & 37.14 & & 23.24 & & 30.43 & \\
\hline
\end{tabular}


Table 4 (Continued)

\begin{tabular}{|c|c|c|c|c|c|c|c|c|c|c|c|}
\hline & & Australia $(n=25)$ & & Canada $(n=77)$ & & $\begin{array}{l}\text { United Kingdom } \\
(n=142)\end{array}$ & & Others $(n=43)$ & & All $(n=287)$ & \\
\hline \multirow[t]{2}{*}{ LN(SIZE_rel) } & Mean (LN, non-LN) & 1.49 & 4.43 & 1.95 & 7.02 & 1.68 & 5.38 & 1.71 & 5.52 & 1.74 & 5.70 \\
\hline & Median (LN, non-LN) & 0.97 & 2.64 & 1.75 & 5.75 & 1.48 & 4.37 & 1.92 & 6.82 & 1.66 & 5.23 \\
\hline \multirow[t]{2}{*}{ LN(LEV) } & Mean (LN, non-LN) & -1.59 & 0.20 & -1.56 & 0.21 & -1.94 & 0.14 & -1.93 & 0.14 & -1.81 & 0.16 \\
\hline & Median (LN, non-LN) & -1.48 & 0.23 & -1.28 & 0.28 & -1.78 & 0.17 & -2.07 & 0.13 & -1.66 & 0.19 \\
\hline \multicolumn{12}{|l|}{ Legal variables } \\
\hline NANTIDIR_high & $\#(1,0)$ & $0(0 \%)$ & $25(100 \%)$ & $0(0 \%)$ & $77(100 \%)$ & $142(100 \%)$ & $0(0 \%)$ & $27(63 \%)$ & $16(37 \%)$ & $169(59 \%)$ & $118(41 *)$ \\
\hline \multirow[t]{2}{*}{ ANTISDI_level } & Mean & 0.79 & & 0.65 & & 0.93 & & 0.83 & & 0.82 & \\
\hline & Median & - & & - & & - & & 0.83 & & 0.81 & \\
\hline
\end{tabular}

Sample of 287 mergers and acquisitions by 227 acquiring firms in 11 English-origin countries (Australia, Canada, India, Ireland, Israel, Malaysia, New Zealand, Singapore, South Africa, Thailand and United Kingdom) between 1997 and 2001 for completed transactions over US\$ 10 million obtained from the Thomson Financial Securities Data's SDC Platinum ${ }^{\mathrm{TM}}$ Worldwide Mergers \& Acquisitions Database. ACFRpre and ACFRpost is the pre- and post-industry, size, and pre-performance adjusted cash flow return. $\triangle \mathrm{ACFR}$ is for the change in industry, size, and pre-performance adjusted cash flow return. Outliers have been winsorized using Huber's $M$-estimator approach. ${ }^{* * *, * * *}$ Indicate whether ACFR measures are statistically different from zero at $10 \%, 5 \%$ and $1 \%$ significance levels, respectively. See Table 2 for variable definitions. 


\subsection{Univariate analysis}

Table 5, panel A, examines the relationship between performance and the ownership, governance, and deal variables on a univariate basis. ${ }^{8}$ Looking at the ownership variables, we see that LSH1P, voting share percentage of the largest shareholder, is positively correlated with performance, but not significantly. Turning to CONCEN10, we find that the mean (median) postadjusted cash flow return, ACFRpost, for the 171 firms with a large shareholder (over 10\%) is $0.49 \%(0.79 \%)$ whereas it is $0.68 \%(0.84 \%)$ for the 116 widely held firms. The mean (median) change in ACFR, $\triangle \mathrm{ACFR}$, is $2.36 \%$ (1.72\%) for firms with a large shareholder and $2.53 \%(2.87 \%)$ for widely held firms, both differences not being significant. We also analyze the performance for various sub-groups and find that the CONCEN1020 group has the poorest post-performance whereas the CONCEN20 and CONCEN2050 groups do better than other groups. Table 5, panel B, further investigates and confirms the above results and suggest a potential non-linear relationship between performance and ownership. These univariate results suggest that firms with lower levels of concentration make poorer M\&A decisions.

Governance variables are weakly related to the change in adjusted cash flow returns ( $\triangle \mathrm{ACFR}$ ). Firms with controlling CEOs outperform their peers on post-adjusted performance (ACFRpost) at the $10 \%$ level of significance. This is consistent with Anderson and Reeb (2003) who suggest that family CEOs view themselves as the stewards of the firm. Further, board size has a significantly negative correlation with ACFRpost. Jensen (1993) argues that keeping boards small should improve firm performance. Yermack (1996) suggests that large boards are associated with problems such as communication and effective decision-making. Conyon and Peck (1998) also find empirical evidence of a negative relationship between board size and firm performance.

Among the deal variables, the COMPETE variable has a significantly negative relationship with $\triangle$ ACFR. This evidence is consistent with Duggal and Millar (1999) that show multiple bidders benefiting targets but not bidders. The correlation between premium and both performance measures (ACFRpost and $\triangle \mathrm{ACFR}$ ) is not significant. The correlation between the relative size and $\triangle$ ACFR or ACFRpost is -0.109 and -0.217 , both significant. Our results contrast with some studies which suggest that deal size is not related to post-merger returns (Agrawal et al., 1992; Healy et al., 1992; Franks \& Harris, 1989) but support the view that larger deviations in firm size leads to poorer acquisition performance (Loughran \& Vijh, 1997; Moeller, Schlingemann, \& Stulz, 2004). Our findings support the debt-monitoring hypothesis by documenting a significant relation between the leverage ratio, LEV, and post-adjusted performance at the 5\% level.

For legal variables, the companies with high anti-director rights indexes (NANTIDIR_high) have a lower mean measure (0.49) but a higher median measure $(0.95)$ of post-acquisition performance (ACFRpost). Companies with better investor protection have better mean and median measures (2.87 and 2.51) of the change in adjusted operating performance ( $\triangle \mathrm{ACFR}$ ). The correlation between the level of the anti-self-dealing index (ANTISDI_level) and ACFRpost is negative $(-0.08)$ while that with $\triangle \mathrm{ACFR}$ is positive $(0.024)$. None of the relationships are significant.

\subsection{Regression results}

Table 6 reports regression results for our two operating performance measures on ownership structure after controlling for governance mechanisms, transaction characteristics, and legal vari-

\footnotetext{
${ }^{8}$ We further perform non-parametric Mann-Whitney test for all dummy variables. Results are consistent with $t$-tests shown.
} 


\begin{tabular}{|c|c|c|c|c|c|c|c|c|c|}
\hline \multirow[t]{2}{*}{ Full sample $(N=287)$} & \multirow[t]{2}{*}{ Count } & \multicolumn{4}{|l|}{ ACFRpost } & \multicolumn{4}{|l|}{$\triangle \mathrm{ACFR}$} \\
\hline & & Mean $(\%)$ & Median (\%) & S.D. $(\%)$ & $t$-Test/Pearson & Mean $(\%)$ & Median (\%) & S.D. $(\%)$ & $t$-Test/Pearson \\
\hline \multicolumn{10}{|l|}{ Panel A: All variables } \\
\hline \multicolumn{10}{|l|}{ Ownership variables } \\
\hline $\mathrm{Y}$ & $171(60 \%)$ & 0.49 & 0.79 & 7.77 & \multirow[t]{2}{*}{-0.212} & 2.36 & 1.72 & 7.51 & \multirow[t]{2}{*}{-0.188} \\
\hline $\mathrm{N}$ & $116(40 \%)$ & 0.68 & 0.84 & 6.97 & & 2.53 & 2.87 & 7.80 & \\
\hline \multicolumn{10}{|l|}{ CONCEN1020 } \\
\hline $\mathrm{Y}$ & $81(28 \%)$ & -0.20 & 0.53 & 7.24 & \multirow[t]{2}{*}{-1.099} & 0.81 & -0.36 & 7.33 & \multirow[t]{2}{*}{$-2.273 * *$} \\
\hline $\mathrm{N}$ & $206(72 \%)$ & 0.87 & 1.08 & 7.52 & & 3.07 & 2.80 & 7.65 & \\
\hline \multicolumn{10}{|l|}{ CONCEN20 } \\
\hline $\mathrm{Y}$ & $90(31 \%)$ & 1.12 & 1.67 & 8.21 & \multirow[t]{2}{*}{0.840} & 3.76 & 2.77 & 7.45 & \multirow[t]{2}{*}{$2.019 * *$} \\
\hline $\mathrm{N}$ & $197(69 \%)$ & 0.32 & 0.56 & 7.08 & & 1.83 & 1.88 & 7.64 & \\
\hline \multicolumn{10}{|l|}{ CONCEN2050 } \\
\hline $\mathrm{Y}$ & $58(20 \%)$ & 0.80 & -0.60 & 8.18 & \multirow[t]{2}{*}{0.260} & 4.06 & 2.75 & 7.80 & \multirow[t]{2}{*}{$1.827 *$} \\
\hline $\mathrm{N}$ & $229(80 \%)$ & 0.51 & 1.16 & 7.27 & & 2.02 & 2.07 & 7.53 & \\
\hline \multicolumn{10}{|l|}{ CONCEN50 } \\
\hline $\mathrm{Y}$ & $32(11 \%)$ & 1.70 & 3.35 & 8.38 & \multirow[t]{2}{*}{0.907} & 3.21 & 2.77 & 6.85 & \multirow[t]{2}{*}{0.612} \\
\hline $\mathrm{N}$ & $255(89 \%)$ & 0.43 & 0.53 & 7.33 & & 2.33 & 2.06 & 7.72 & \\
\hline LSH1P $(\%)$ & $171(60 \%)$ & - & - & - & 0.055 & - & - & - & 0.110 \\
\hline \multicolumn{10}{|l|}{ Governance variables } \\
\hline \multicolumn{10}{|l|}{ SEP } \\
\hline $\mathrm{Y}$ & $44(15 \%)$ & -0.70 & -1.12 & 8.50 & \multirow[t]{2}{*}{-1.104} & 1.09 & 1.80 & 6.34 & \multirow[t]{2}{*}{-1.276} \\
\hline $\mathrm{N}$ & $243(85 \%)$ & 0.80 & 1.11 & 7.24 & & 2.68 & 2.36 & 7.81 & \\
\hline \multicolumn{10}{|l|}{ CEOLSH } \\
\hline $\mathrm{Y}$ & $40(14 \%)$ & 2.69 & 3.24 & 7.72 & \multirow[t]{2}{*}{$1.950 *$} & 1.74 & 2.41 & 6.50 & \multirow[t]{2}{*}{-0.619} \\
\hline $\mathrm{N}$ & $247(86 \%)$ & 0.23 & 0.34 & 7.36 & & 2.54 & 2.09 & 7.79 & \\
\hline \multicolumn{10}{|l|}{ CEOdual } \\
\hline $\mathrm{Y}$ & $74(26 \%)$ & 0.89 & 1.67 & 7.64 & \multirow[t]{2}{*}{0.430} & 1.53 & 1.76 & 8.18 & -1.187 \\
\hline $\mathrm{N}$ & $213(74 \%)$ & 0.46 & 0.68 & 7.40 & & 2.75 & 2.36 & 7.41 & \\
\hline
\end{tabular}




\begin{tabular}{|c|c|c|c|c|c|c|c|c|c|}
\hline \multicolumn{10}{|l|}{ OTHLSH } \\
\hline Y & $54(19 \%)$ & 1.08 & 0.85 & 8.55 & \multirow[t]{2}{*}{0.499} & 3.74 & 2.39 & 8.34 & \multirow[t]{2}{*}{1.401} \\
\hline $\mathrm{N}$ & $233(81 \%)$ & 0.45 & 0.79 & 7.18 & & 2.13 & 2.07 & 7.43 & \\
\hline BSIZE (\#) & $287(100 \%)$ & - & - & - & $-0.154 * * *$ & - & - & - & -0.097 \\
\hline \multicolumn{10}{|l|}{ Transaction variables } \\
\hline \multicolumn{10}{|l|}{ TGORI_English } \\
\hline $\mathrm{Y}$ & $265(92 \%)$ & 0.60 & 0.79 & 7.61 & \multirow[t]{2}{*}{0.287} & 2.44 & 2.20 & 7.67 & \multirow[t]{2}{*}{0.034} \\
\hline $\mathrm{N}$ & $22(8 \%)$ & 0.24 & 0.65 & 5.31 & & 2.38 & 2.45 & 7.15 & \\
\hline \multicolumn{10}{|l|}{ ATTI_Hostile } \\
\hline $\mathrm{Y}$ & $10(3 \%)$ & 2.64 & 2.77 & 7.93 & \multirow[t]{2}{*}{0.895} & 4.91 & 4.78 & 7.34 & \multirow[t]{2}{*}{1.046} \\
\hline $\mathrm{N}$ & $277(97 \%)$ & 0.50 & 0.68 & 7.43 & & 2.34 & 2.09 & 7.63 & \\
\hline \multicolumn{10}{|l|}{ PAY_Stock } \\
\hline $\mathrm{Y}$ & $48(17 \%)$ & -1.01 & 0.02 & 6.81 & \multirow[t]{2}{*}{-1.613} & 2.58 & 1.18 & 8.59 & \multirow[t]{2}{*}{0.146} \\
\hline $\mathrm{N}$ & $239(83 \%)$ & 0.89 & 1.16 & 7.54 & & 2.40 & 2.51 & 7.43 & \\
\hline \multicolumn{10}{|l|}{ COMPETE } \\
\hline $\mathrm{Y}$ & $19(7 \%)$ & -1.51 & -1.83 & 7.36 & \multirow[t]{2}{*}{-1.261} & -2.31 & -0.97 & 7.36 & \multirow{2}{*}{$-2.839 * * *$ ำ } \\
\hline $\mathrm{N}$ & $268(93 \%)$ & 0.72 & 1.00 & 7.45 & & 2.77 & 2.55 & 7.54 & \\
\hline \multicolumn{10}{|l|}{ IND_rel } \\
\hline $\mathrm{Y}$ & $102(36 \%)$ & 0.18 & 0.11 & 7.55 & \multirow[t]{2}{*}{-0.66} & 2.66 & 1.85 & 8.02 & \multirow[t]{2}{*}{0.375} \\
\hline $\mathrm{N}$ & $185(64 \%)$ & 0.79 & 1.23 & 7.40 & & 2.31 & 2.62 & 7.41 & \\
\hline \multicolumn{10}{|l|}{ TOEHOLD } \\
\hline $\mathrm{Y}$ & $47(16 \%)$ & 0.76 & 1.11 & 6.64 & \multirow[t]{2}{*}{0.192} & 3.07 & 3.12 & 5.43 & \multirow[t]{2}{*}{0.626} \\
\hline $\mathrm{N}$ & $240(84 \%)$ & 0.53 & 0.76 & 7.61 & & 2.31 & 1.91 & 7.98 & \\
\hline PREM_1day (\%) & $287(100 \%)$ & - & - & - & -0.028 & - & - & - & 0.033 \\
\hline SIZE rel (\#) & $287(100 \%)$ & - & - & - & $-0.217 * * *$ & - & - & - & $-0.109 *$ \\
\hline LEV (\#) & $287(100 \%)$ & - & - & - & $0.137 * *$ & - & - & - & -0.045 \\
\hline
\end{tabular}


Table 5 (Continued)

\begin{tabular}{|c|c|c|c|c|c|c|c|c|c|}
\hline \multirow[t]{2}{*}{ Full sample $(N=287)$} & \multirow[t]{2}{*}{ Count } & \multicolumn{4}{|l|}{ ACFRpost } & \multicolumn{4}{|l|}{$\triangle \mathrm{ACFR}$} \\
\hline & & Mean $(\%)$ & Median (\%) & S.D. $(\%)$ & $t$-Test/Pearson & Mean $(\%)$ & Median (\%) & S.D. $(\%)$ & $t$-Test/Pearson \\
\hline \multicolumn{10}{|l|}{ Legal variable } \\
\hline \multicolumn{10}{|l|}{ NANTIDIR_high } \\
\hline $\mathrm{Y}$ & $169(59 \%)$ & 0.95 & 0.95 & 7.08 & -0.209 & 2.51 & 2.51 & 8.03 & 1.158 \\
\hline $\mathrm{N}$ & $118(41 \%)$ & 0.61 & 0.61 & 1.81 & & 1.85 & 6.98 & 6.98 & \\
\hline ANTISDI_level (\#) & $287(100 \%)$ & - & - & - & -0.080 & - & - & - & 0.024 \\
\hline Full sample $(N=287)$ & \multicolumn{5}{|c|}{ ACFRpost (\% positive) } & \multicolumn{4}{|c|}{$\triangle \mathrm{ACFR}(\%$ positive $)$} \\
\hline \multicolumn{10}{|c|}{ Panel B: Further look at ownership } \\
\hline Widely held $(N=116)$ & \multicolumn{2}{|c|}{$0.68(52.6 \%)$} & $0.68(52.6 \%)$ & \multicolumn{2}{|c|}{$0.68(52.6 \%)$} & \multicolumn{3}{|c|}{$2.53(66.4 \%)$} & $2.53(66.4 \%)$ \\
\hline CONCEN1020 $(N=81)$ & \multicolumn{2}{|c|}{$0.49(55.0 \%)$} & $-0.20(54.3 \%)$ & \multicolumn{2}{|c|}{$-0.20(54.3 \%)$} & \multicolumn{3}{|c|}{$0.81(49.4 \%)$} & $0.81(49.4 \%)$ \\
\hline CONCEN2050 $(N=58)$ & & & $1.12(55.6 \%)$ & \multicolumn{2}{|c|}{$0.80(48.3 \%)$} & \multicolumn{3}{|c|}{$3.76(71.1 \%)$} & $4.06(72.4 \%)$ \\
\hline CONCEN50 $(N=32)$ & & & & \multicolumn{2}{|c|}{$1.70(68.8 \%)$} & & & & $3.21(68.8 \%)$ \\
\hline Test of difference & -0.2 & & 0.688 & & 557 & -0.188 & \multicolumn{2}{|c|}{$3.248 * *$} & $2.246^{*}$ \\
\hline
\end{tabular}

Sample of 287 mergers and acquisitions by 227 acquiring firms in 11 English-origin countries (Australia, Canada, India, Ireland, Israel, Malaysia, New Zealand, Singapore, South Africa, Thailand and United Kingdom) between 1997 and 2001 for completed transactions over US\$ 10 million obtained from the Thomson Financial Securities Data's SDC Platinum ${ }^{\mathrm{TM}}$ Worldwide Mergers \& Acquisitions Database. ACFRpre and ACFRpost is the pre- and post-industry, size, and pre-performance adjusted cash flow return. AACFR is for the change in industry, size, and pre-performance adjusted cash flow return. Outliers have been winsorized using Huber's $M$-estimator approach. $t$-Tests of differences are presented for dummy variables and Pearson correlations for continuous variables: ${ }^{* * *}$ significant at the $1 \%$ level, ${ }^{* *}$ significant at the $5 \%$ level, ${ }^{*}$ significant at the $10 \%$ level. See Table 2 for variable definitions. 
Table 6

Ownership structure and acquiring firm performance

\begin{tabular}{|c|c|c|c|c|c|c|c|}
\hline \multicolumn{8}{|l|}{ Panel A: ACFRpost } \\
\hline Variables $(N=287)$ & Model 1 & Model 2 & Model 3 & Model 4 & Model 5 & Model 6 & Model 7 \\
\hline Intercept & 0.059 & 0.086 & 0.096 & 0.098 & 0.065 & 0.064 & 0.072 \\
\hline CONCEN10 & -0.014 & & & & & & \\
\hline CONCEN1020 & & & $-0.026^{* * *}$ & $-0.026^{* * *}$ & & & \\
\hline CONCEN20 & & 0.208 & 0.009 & & & & \\
\hline CONCEN2050 & & & & 0.012 & & & \\
\hline CONCEN50 & & & & 0.005 & & & \\
\hline LSH1P & & & & & 0.007 & -0.020 & $-0.183^{*}$ \\
\hline LSH1PSQ & & & & & & 0.038 & $0.753^{*}$ \\
\hline LSH1PCUBE & & & & & & & $-0.026^{*}$ \\
\hline SEP & $-0.288^{* *}$ & $-0.036^{* *}$ & $-0.035^{* * *}$ & $-0.034^{* *}$ & $-0.032 * *$ & $-0.324 * *$ & $-0.035^{* *}$ \\
\hline CEOLSH & 0.228 & 0.011 & 0.015 & 0.014 & 0.017 & 0.019 & 0.014 \\
\hline CEOdual & -0.113 & -0.009 & -0.009 & -0.009 & -0.011 & -0.011 & -0.009 \\
\hline OTHLSH & 0.094 & -0.002 & 0.003 & 0.002 & 0.004 & 0.005 & 0.005 \\
\hline BSIZE & $-0.024 * *$ & $-0.003^{* *}$ & $-0.004 * * *$ & $-0.004 * * *$ & $-0.002 *$ & $-0.002 *$ & $-0.003^{* *}$ \\
\hline TGORI_English & -0.049 & -0.009 & -0.009 & -0.009 & -0.006 & -0.006 & -0.004 \\
\hline ATTI_Hostile & 0.027 & 0.026 & 0.024 & 0.023 & 0.028 & 0.028 & 0.026 \\
\hline PAY_stock & -0.134 & -0.150 & -0.015 & -0.015 & -0.014 & -0.013 & -0.014 \\
\hline COMPETE & $-0.037 * *$ & $-0.034 * *$ & $-0.037 * *$ & $-0.037 * *$ & $-0.035^{* *}$ & $-0.036^{* *}$ & $-0.036^{* *}$ \\
\hline IND_rel & -0.001 & 0.001 & -0.001 & 0.000 & 0.000 & 0.000 & 0.000 \\
\hline TOEHOLD & 0.009 & 0.008 & 0.008 & 0.008 & 0.009 & 0.009 & 0.008 \\
\hline PREM_1day & 0.000 & 0.000 & 0.000 & 0.000 & 0.000 & 0.000 & 0.000 \\
\hline SIZE_rel & $-0.007 * * *$ & $-0.007 * * *$ & $-0.007 * * *$ & $-0.007 * * *$ & $-0.007 * * *$ & $-0.007 * * *$ & $-0.007 * * *$ \\
\hline LEV & -0.002 & -0.001 & -0.001 & -0.001 & -0.002 & -0.002 & -0.002 \\
\hline NANTIDIR_high & $0.064 * * *$ & $0.049^{* *}$ & $0.050^{* *}$ & $0.052 * *$ & $0.057 * * *$ & $0.058 * * *$ & $0.048^{* *}$ \\
\hline ANTISDI_level & -0.032 & -0.061 & -0.052 & -0.054 & -0.046 & -0.043 & -0.041 \\
\hline UK & $-0.045^{* *}$ & -0.264 & -0.028 & -0.030 & $-0.037 *$ & $-0.038 *$ & -0.028 \\
\hline CAN & 0.029 & 0.019 & 0.018 & 0.018 & 0.025 & 0.025 & 0.022 \\
\hline AUS & $0.035^{*}$ & 0.031 & 0.032 & 0.031 & $0.033 *$ & $0.034 *$ & $0.033^{*}$ \\
\hline ACFRpre & $0.459 * * *$ & $0.466^{* * *}$ & $0.472 * * *$ & $0.473 * * *$ & $0.459 * * *$ & $0.460 * * *$ & $0.460 * * *$ \\
\hline$R^{2}$ & 32.1 & 32.3 & 34.0 & 34.1 & 31.5 & 31.6 & 32.6 \\
\hline$F$ & $5.75 * * *$ & $5.67 * * *$ & $5.94 * * *$ & $5.77 * * *$ & $5.56^{* * *}$ & $5.43 * * *$ & $4.92 * * *$ \\
\hline
\end{tabular}




\begin{tabular}{|c|c|c|c|c|c|c|c|}
\hline \multicolumn{8}{|l|}{ Panel B: $\triangle \mathrm{ACFR}$} \\
\hline Variables $(N=287)$ & Model 1 & Model 2 & Model 3 & Model 4 & Model 5 & Model 6 & Model 7 \\
\hline Intercept & 0.020 & 0.057 & 0.069 & 0.073 & 0.029 & 0.028 & 0.036 \\
\hline CONCEN10 & -0.015 & & & & & & \\
\hline CONCEN1020 & & & $-0.030 * * *$ & $-0.030 * * *$ & & & \\
\hline CONCEN20 & & $0.029 *$ & 0.015 & & & & \\
\hline CONCEN2050 & & & & 0.020 & & & \\
\hline CONCEN50 & & & & 0.006 & & & \\
\hline LSH1P & & & & & 0.014 & -0.030 & -0.196 \\
\hline LSH1PSQ & & & & & & 0.064 & $0.791 *$ \\
\hline LSH1PCUBE & & & & & & & $-0.665^{*}$ \\
\hline SEP & -0.020 & $-0.029 * *$ & $-0.028^{* *}$ & $-0.026^{*}$ & $-0.025^{*}$ & $-0.026^{*}$ & $-0.028 * *$ \\
\hline CEOLSH & 0.007 & -0.008 & -0.003 & -0.004 & 0.000 & 0.003 & -0.002 \\
\hline CEOdual & -0.017 & -0.014 & -0.014 & -0.014 & -0.017 & -0.017 & -0.015 \\
\hline OTHLSH & 0.019 & 0.005 & 0.010 & 0.009 & 0.012 & 0.015 & 0.015 \\
\hline BSIZE & -0.002 & $-0.003^{* *}$ & $-0.004 * *$ & $-0.004 * *$ & -0.002 & -0.002 & $-0.003^{*}$ \\
\hline TGORI_English & -0.003 & -0.009 & -0.009 & -0.010 & -0.005 & -0.005 & -0.004 \\
\hline ATTI_Hostile & 0.029 & 0.027 & 0.024 & 0.023 & 0.029 & 0.029 & 0.027 \\
\hline PAY_stock & -0.006 & -0.008 & -0.008 & -0.008 & -0.006 & -0.005 & -0.005 \\
\hline COMPETE & $-0.051 * * *$ & $-0.047 * * *$ & $-0.051 * * *$ & $-0.051 * * *$ & $-0.049 * * *$ & $-0.050 * * *$ & $-0.050 * * *$ \\
\hline IND_rel & 0.006 & 0.009 & 0.006 & 0.007 & 0.008 & 0.007 & 0.007 \\
\hline TOEHOLD & $0.016^{*}$ & 0.015 & 0.015 & 0.015 & 0.016 & 0.016 & 0.015 \\
\hline PREM_1day & 0.000 & 0.000 & 0.000 & 0.000 & 0.000 & 0.000 & 0.000 \\
\hline SIZE_rel & $-0.005^{*}$ & $-0.005^{*}$ & $-0.006^{* *}$ & $-0.006^{* *}$ & $-0.005^{*}$ & $-0.005^{*}$ & $-0.005^{* *}$ \\
\hline LEV & -0.007 & -0.005 & -0.005 & -0.005 & -0.006 & -0.006 & -0.006 \\
\hline NANTIDIR_high & $0.069 * * *$ & $0.049 * *$ & $0.051 * *$ & $0.054 * *$ & $0.060 * *$ & $0.061 * *$ & $0.050 * *$ \\
\hline ANTISDI_level & 0.008 & -0.029 & -0.019 & -0.023 & -0.008 & -0.005 & -0.002 \\
\hline UK & $-0.059 * *$ & -0.035 & -0.037 & -0.040 & $-0.049 *$ & $-0.051^{*}$ & -0.040 \\
\hline CAN & 0.024 & 0.011 & 0.009 & 0.011 & 0.018 & 0.018 & 0.015 \\
\hline AUS & 0.031 & 0.026 & 0.027 & 0.026 & 0.029 & 0.031 & 0.030 \\
\hline$R^{2}$ & 12.5 & 13.3 & 15.5 & 15.7 & 11.9 & 12.1 & 13.1 \\
\hline$F$ & $2.03^{* * *}$ & $1.92 * *$ & $2.42 * * *$ & $2.33 * * *$ & $1.80^{* *}$ & $1.86^{* *}$ & $1.78 * *$ \\
\hline
\end{tabular}

Sample of 287 mergers and acquisitions by 227 acquiring firms in 11 English-origin countries (Australia, Canada, India, Ireland, Israel, Malaysia, New Zealand, Singapore, South Africa, Thailand and United Kingdom) between 1997 and 2001 for completed transactions over US\$10 million obtained from the Thomson Financial Securities Data's SDC Platinum ${ }^{\mathrm{TM}}$ Worldwide Mergers \& Acquisitions Database. ACFRpre and ACFRpost is the pre- and post-industry, size, and pre-performance adjusted cash flow return. $\triangle$ ACFR is for the change in industry, size, and pre-performance adjusted cash flow return. Outliers have been winsorized using Huber's $M$-estimator approach. Clustered robust standard errors. Two tail tests: ${ }^{* * *}$ significant at the $1 \%$ level, ${ }^{* *}$ significant at the $5 \%$ level, ${ }^{*}$ significant at the $10 \%$ level. See Table 2 for variable definitions. 
ables. Panel A presents results for the post performance measure, ACFRpost. We can see that all models are significant and that $R^{2}$ are between $31.5 \%$ and $34.1 \%$. Panel B shows results for the change in performance, $\triangle \mathrm{ACFR}$. Again, all models are significant and have $R^{2}$ between $11.9 \%$ and $15.7 \%$. Looking at ownership, results further confirm the non-linear relationship between ownership of the largest shareholder and the two operating performance measures. The presence of a large shareholder (more than 10\%) does not suggest over or under-performance in either measures (Model 1 in panels A and B). However, the presence of a large shareholder (more than 20\%) improves the change in performance by $2.9 \%$ (panel B, Model 2). When we separate firms with large shareholders between $10 \%$ and $20 \%$ ownership (CONCEN1020) and more (CONCEN20), we clearly see that the CONCEN1020 group under-performs (-2.6\% for ACFRpost and $-3.0 \%$ for $\triangle \mathrm{ACFR}$, both significant) whereas the CONCEN20 group over-performs the widely held group (but not significantly).

We further investigate the actual level of concentration with our continuous variable LSH1P (Models 5-7). Given the indications of a non-linear relationship, we introduce a quadratic and cubic relationship. Model 5, the linear model, suggests that post performance (change in performance) increases by $0.7 \%(1.4 \%)$ for a one percent change in concentration. However, the cubic model (Model 7) better fits the data and captures the relationship exposed in prior models and in the univariate tests. For the post-performance (panel A, Model 7), we find a first inflection point at $15.13 \%$ where performance starts to increase with the level of concentration and a second inflection point at $61.62 \%$ where performance start to taper off. Further analysis shows that our curve remains below the level of widely held firms (the intercept, 0.072) up to the $34.85 \%$ level of ownership, but is always greater than zero (ACFRpost at the first inflexion point is around 0.059). Also, performance remains above the level of widely held firms up to the $80.3 \%$ level of ownership, dipping below zero at $97 \%$ (but the maximum level of ownership in our sample is $87 \%$ ). We find similar results for the change in performance with inflection points at $15.5 \%$ and $63.85 \% .{ }^{9}$ Hence, similar to Ben-Amar and André (2006) and others, firms with concentrated ownership structures make good M\&A decisions, on average. However, at lower levels of concentration there is some evidence that these firms perform more poorly than widely held firms or more concentrated ones. Anderson and Reeb (2003) show that US family firms outperform non-family firms over the entire spectrum of ownership levels, peaking at around $30 \%$.

When looking at governance variables, we confirm that the separation of cash flow rights and control rights is negatively related to performance similar to a number of studies (e.g., Bennedsen \& Nielsen, 2005; Claessens et al., 2000; Cronqvist \& Nilsson, 2003; Faccio \& Lang, 2002; La Porta et al., 2002). Perceived good governance or investor protection in these English-origin countries does not appear sufficient to mitigate the agency costs of separation. We also find that firms with smaller boards do better than those with larger boards, capturing the potential inefficiency of larger boards as suggested in the prior literature (e.g., Conyon \& Peck, 1998; Jensen, 1993; Yermack, 1996). Other variables such as related CEO, duality or other block holders are not significant in explaining long-term M\&A performance.

Among deal characteristics and consistent with our univariate results, the presence of multiple bidders and of larger relative acquirers has a significant negative impact on post-adjusted performance or the change in adjusted performance. Other variables such as hostility, payment

\footnotetext{
${ }^{9}$ For our change measure, the curve remains below the level of widely held firms (the intercept, 0.036 ) up to the $35.2 \%$ level of ownership, but is also always greater than zero (change in ACFR at the first inflection point is around 0.022). Performance remains above the level of widely held firms up to the $83.8 \%$ level of ownership, dipping below zero at $93.6 \%$ but again the maximum level of ownership in our sample is $87 \%$.
} 
method, relatedness, initial toehold, premium paid or leverage do not have a significant impact in explaining the change in performance.

For legal variables, we find that high anti-director rights based on the updated measures by Djankov et al. (2006) are positively associated with good M\&A decisions for all model specifications. Investor protection, even in English-origin countries, has an impact on performance. However, we do not find a link between long-term acquisition performance and the new Djankov et al. (2006) anti-self-dealing index.

\section{Conclusion}

This study investigates the relationship between concentrated ownership structure and long term operating performance of acquiring firms in English-origin countries other than the US, following the classification of La Porta et al. (1998). Our results confirm that after controlling for governance mechanisms, deal characteristics, and legal systems, a non-linear relationship exists between concentrated ownership and post-acquisition operating performance over 3 years after the transaction. The companies with large shareholders but with a lower holding (between $10 \%$ and $20 \%$ ) of voting shares significantly under perform their peers. Higher levels of ownership are associated with positive post-acquisition performance. Value creating deals are associated with higher level of concentration consistent with decreasing agency costs as large shareholder wealth invested in the acquiring firm increases. Further, separation of ownership and voting rights leads to greater value destruction.

We also find, although acquiring firms are all from English-origin countries, that investor protection has a varying influence on corporate performance. Our empirical results show that ownership structure, individual governance mechanisms and characteristics of the legal system are important determinants of performance in English-origin countries. Researchers need to exert some care when they lump all English-origin firms together as having high corporate governance and investor protection since firm and country differences remain important in explaining differences in performance.

\section{Acknowledgements}

Paul André gratefully acknowledges support from the Research Alliance in Governance and Forensic Accounting funded within the Initiative on the new economy program of the Social Sciences and Humanities Research Council of Canada (SSHRC). We appreciate the comments from seminar participants at the 2006 Multinational Finance Society Conference in Edinburgh, at the 2007 European Accounting Association Congress in Lisbon, at the EFM2007 Corporate Governance and Shareholder Activism Symposium, at HEC Paris, at the University of Ottawa, at Strathclyde University and at IRG Université de Paris XII.

\section{References}

Agrawal, A., Jaffe, J. F., \& Mandelker, G. N. (1992). The post-merger performance of acquiring firms: A re-examination of an anomaly. Journal of Finance, 47(4), 1605-1621.

Agrawal, A., \& Knoeber, C. R. (1996). Firm performance and mechanisms to control agency problems between managers and shareholders. Journal of Financial \& Quantitative Analysis, 31(3), 377-397.

Anderson, R., Duru, A., \& Reeb, D. (2006). Family ownership and corporate opacity in the U.S. Working Paper Kogod School of Business, 48 pp. 
Anderson, R. C., \& Reeb, D. M. (2003). Founding-family ownership and firm performance: Evidence from the S\&P 500. Journal of Finance, 58(3), 1301-1329.

Andrade, G., Mitchell, M., \& Stafford, E. (2001). New evidence and perspectives on mergers. Journal of Economic Perspectives, 15(2), 103-120.

André, P., Ben-Amar, W., \& Saadi, S. (2006). Corporate governance and acquiring firm shareholder wealth: Evidence from high-tech acquisitions in Canada. Working Paper, 38 pp.

André, P., Kooli, M., \& L'Her, J.-F. (2004). The long-run performance of mergers and acquisitions: Evidence from the Canadian stock market. Financial Management, 33(4), 27-43.

André, P., \& Schiehll, E. (2004). Système de gouvernance, actionnaires dominants et performance future des entreprises. Finance Contrôle et Stratégie, 7(Special issues on Governance), 165-194.

Bae, K. H., Kang, J. K., \& Kim, J. M. (2002). Tunneling or value added? Evidence from mergers by Korean business groups. The Journal of Finance, 57(6), 2695-2740.

Barber, B. M., \& Lyon, J. D. (1996). Detecting abnormal operating performance: The empirical power and specification of test statistics. Journal of Financial Economics, 41(3), 359-399.

Barth, E., Gulbrandsen, T., \& Schonea, P. (2005). Family ownership and productivity: The role of owner-management. Journal of Corporate Finance, 11(1/2), 107-127.

Bebchuk, L. A., Kraakman, R., \& Triantis, G. (2000). Stock pyramids, cross-ownership, and dual class equity: The creation and agency costs of separating control from cash flow rights. In R. K. Morck (Ed.), Concentrated corporate ownership (pp. 295-318). Chicago and London: The University of Chicago Press.

Becht, M., \& Roell, A. (1999). Blockholding in Europe: An international comparison. European Economic Review, 43(4-6), 1049-1056.

Ben-Amar, W., \& André, P. (2006). Separation of ownership from control and acquiring firm performance: The case of family ownership in Canada. Journal of Business Finance \& Accounting, 33(3/4), 517-543.

Bennedsen, M., \& Nielsen, K. M. (2005). Separating the Impact of dual class shares, pyramids and cross-ownership on firm value across legal regimes in Western Europe. Working Paper European Financial Management, Symposium.

Berle, A., \& Means, G. (1932). The modern corporation and private property. New York: MacMillan.

Bigelli, M., \& Mengoli, S. (2004). Sub-optimal acquisition decisions under a majority shareholder system. Journal of Management and Governance, 8(4), 373-405.

Brickley, J. A., Coles, J. L., \& Jarrell, G. (1997). Leadership structure: Separating the CEO and chairman of the board. Journal of Corporate Finance, 3(3), 189-220.

Carline, N. F., Linn, S. C., \& Yadav, P. K. (2002). The influence of managerial ownership on the real gains in corporate mergers and market revaluation of merger partners: Empirical evidence. Working Paper.

Cernat, L. (2004). The emerging European corporate governance model: Anglo-Saxon, continental, or still the century of diversity? Journal of European Public Policy, 11(1), 147-166.

Claessens, S., Djankov, S., Fan, J. P. H., \& Lang, L. H. P. (2002). Disentangling the incentive and entrenchment effects of large shareholdings. Journal of Finance, 57(6), 2741-2771.

Claessens, S., Djankov, S., \& Lang, L. H. P. (2000). The separation of ownership and control in East Asian corporations. Journal of Financial Economics, 58(1/2), 81-112.

Conyon, M. J., \& Peck, S. I. (1998). Board size and corporate performance: Evidence from European countries. European Journal of Finance, 4(3), 291-304.

Cronqvist, H., \& Nilsson, M. (2003). Agency costs of controlling minority shareholders. Journal of Financial \& Quantitative Analysis, 38(4), 695-719.

Davies, J. R., Hillier, D., \& McColgan, P. (2005). Ownership structure, managerial behavior and corporate value. Journal of Corporate Finance, 11(4), 645-660.

Demsetz, H., \& Lehn, K. (1985). The structure of corporate ownership: Causes and consequences. Journal of Political Economy, 93(6), 1155-1177.

Denis, D. J., \& Denis, D. K. (1995). Performance changes following top management dismissals. The Journal of Finance, 50(4), 1029-1057.

Denis, D. K., \& McConnell, J. J. (2003). International corporate governance. Journal of Financial and Quantitative Analysis, 38(1), 1-37.

Djankov, S., La Porta, R., Lopez-de-Silanes, F., \& Shleifer, A. (2006). The law and economics of self-dealing. Working Paper.

Duggal, R., \& Millar, J. A. (1999). Institutional ownership and firm performance: The case of bidder returns. Journal of Corporate Finance, 5(2), 103-117.

Faccio, M., \& Lang, L. H. P. (2002). The ultimate ownership of Western European corporations. Journal of Financial Economics, 65(3), 365-395. 
Faccio, M., Lang, L. H. P., \& Young, L. (2001). Dividends and Expropriation. American Economic Review, 91(1), 54-78.

Faccio, M., \& Masulis, R. W. (2005). The choice of payment method in European mergers and acquisitions. The Journal of Finance, 60(3), 1345-1388.

Faccio, M., \& Stolin, D. (2006). Expropriation vs. proportional sharing in corporate acquisitions. Journal of Business, 79(3), 1413-1444.

Fama, E. F., \& Jensen, M. C. (1983). Separation of ownership and control. Journal of Law \& Economics, 26(2), 301326.

Fauver, L., Houston, J., \& Naranjo, A. (2003). Capital market development, international integration, legal system, and the value of corporate diversification: A cross-country analysis. Journal of Financial \& Quantitative Analysis, 38(1), 135-157.

Franks, J. R., \& Harris, R. S. (1989). Shareholder wealth effects of corporate takeovers: The U.K. experience 1955-1985. Journal of Financial Economics, 23(2), 225-249.

Friedman, E., Johnson, S., \& Mitton, T. (2003). Propping and tunneling. Journal of Comparative Economics, 31(4), $732-750$.

Ghosh, A. (2001). Does operating performance really improve following corporate acquisitions? Journal of Corporate Finance, 7(2), 151-178.

Goergen, M., \& Renneboog, L. L. R. u. n. (2004). Shareholder wealth effects of European domestic and cross-border takeover bids. European Financial Management, 10(1), 9-45.

Gugler, K., Mueller, D. C., \& Yurtoglu, B. (2004). Corporate governance and the returns on investment. Journal of Law \& Economics, 47(2), 589-633.

Gugler, K., Mueller, D. C., Yurtoglu, B. B., \& Zulehner, C. (2003). The effects of mergers: An international comparison. International Journal of Industrial Organization, 21(5), 625-654.

Healy, P. M., Palepu, K. G., \& Ruback, R. S. (1992). Does corporate performance improve after mergers? Journal of Financial Economics, 31(2), 135-175.

Healy, P. M., Palepu, K. G., \& Ruback, R. S. (1997). Which takeovers are profitable? Strategic or financial? Sloan Management Review, 38(4), 45-58.

Hitt, M., Harrison, J. R., Ireland, R. D., \& Best, A. (1998). Attributes of successful and unsuccessful acquisition of U.S. firms. British Journal of Management, 9(2), 91-114.

Holmen, M., \& Knopf, J. D. (2004). Minority shareholder protections and the private benefits of control for Swedish mergers. Journal of Financial \& Quantitative Analysis, 39(1), 167-191.

Huber, P. J. (1964). Robust estimation of location. The Annals of Mathematical Statistics, 35(1), 73-101.

Jensen, M. C. (1993). The modern industrial revolution, exit, and the failure of internal control systems. The Journal of Finance, 48(3), 831-880.

Jensen, M. C., \& Meckling, W. H. (1976). Theory of the firm: Managerial behavior, agency costs and ownership structure. Journal of Financial Economics, 3(4), 305-360.

Jensen, M. C., \& Ruback, R. S. (1983). The market for corporate control. Journal of Financial Economics, 11(1-4), 5-50.

Johnson, S., Boone, P., Breach, A., \& Friedman, E. (2000). Corporate governance in the Asian financial crisis. Journal of Financial Economics, 58(1/2), 141-186.

Johnson, S., Lopez-de-Silanes, F., La Porta, R., \& Shleifer, A. (2000). Tunneling. The American Economic Review, $90(2)$, 22-27.

La Porta, R., Lopez-de-Silanes, F., \& Shleifer, A. (1999). Corporate ownership around the world. Journal of Finance, 54(2), 471-517.

La Porta, R., Lopez-de-Silanes, F., Shleifer, A., \& Vishny, R. W. (1998). Law and finance. The Journal of Political Economy, 106(6), 1113-1155.

La Porta, R., Lopez-de-Silanes, F., Shleifer, A., \& Vishny, R. W. (2000). Investor protection and corporate governance. Journal of Financial Economics, 58(1-2), 3-27.

La Porta, R., Lopez-de-Silanes, F., Shleifer, A., \& Vishny, R. W. (2002). Investor protection and corporate valuation. The Journal of Finance, 57(3), 1147-1170.

Limmack, R. J. (1991). Corporate mergers and shareholder wealth effects: 1977-1986. Accounting \& Business Research, 21(83), 239-251.

Linn, S. C., \& Switzer, J. A. (2001). Are cash acquisitions associated with better post-combination operating performance than stock acquisitions? Journal of Banking \& Finance, 25(6), 1113-1138.

Loughran, T., \& Ritter, J. R. (1997). The operating performance of firms conducting seasoned equity offerings. Journal of Finance, 52(5), 1823-1850.

Loughran, T., \& Vijh, A. M. (1997). Do long-term shareholders benefit from corporate acquisitions? Journal of Finance, 52(5), 1765-1790. 
Maury, B. (2005). Family ownership and firm performance: Empirical evidence from Western European corporations. Journal of Corporate Finance, 12(2), 321-341.

Maury, B., \& Pajuste, A. (2005). Multiple large shareholders and firm value. Journal of Banking and Finance, 29(7), 1813-1834.

McConaughy, D. L., Walker, M. C., Henderson, J. G. V., \& Mishra, C. S. (1998). Founding family controlled firms: Efficient and value. Review of Financial Economics, 7(1), 1-19.

McConnell, J. J., \& Servaes, H. (1990). Additional evidence on equity ownership and corporate value. Journal of Financial Economics, 27(2), 595-612.

Moeller, S. B., Schlingemann, F. P., \& Stulz, R. M. (2004). Firm size and the gains from acquisitions. Journal of Financial Economics, 73(2), 201-228.

Morck, R., Shleifer, A., \& Vishny, R. W. (1988). Management ownership and market valuation: An empirical analysis. Journal of Financial Economics, 20(1/2), 293-315.

Mueller, D. C., \& Yurtoglu, B. B. (2000). Country legal environments and corporate investment performance. German Economic Review, 1(2), 187-220.

Powell, R. G., \& Stark, A. W. (2005). Does operating performance increase post-takeover for UK takeovers? A comparison of performance measures and benchmarks. Journal of Corporate Finance, 11(1/2), 293-317.

Rahman, R. A., \& Limmack, R. J. (2004). Corporate acquisitions and the operating performance of Malaysian companies. Journal of Business Finance \& Accounting, 31(3/4), 359-400.

Rosenstein, S., \& Wyatt, J. G. (1990). Outside directors, board independence, and shareholder wealth. Journal of Financial Economics, 26(2), 175-191.

Schleifer, A., \& Vishny, R. W. (1986). Large shareholders and corporate control. Journal of Political Economy, 94(3), 461-489.

Schulze, W. S., Lubatkin, M. H., Dino, R. N., \& Buchholtz, A. K. (2001). Agency relationships in family firms: Theory and Evidence. Journal of the Institute of Management Sciences, 12(2), 99-117.

Sharma, D. S., \& Ho, J. (2002). The impact of acquisitions on operating performance: Some Australian evidence. Journal of Business Finance \& Accounting, 29(1/2), 155-200.

Shleifer, A., \& Wolfenzon, D. (2002). Investor protection and equity markets. Journal of Financial Economics, 66(1), $3-27$.

Stulz, R. M. (1988). Managerial control of voting rights: Financing policies and the market for corporate control. Journal of Financial Economics, 20(1/2), 25-54.

Sudarsanam, S. (1996). Large shareholders, takeovers and target valuation. Journal of Business Finance \& Accounting, 23(2), 295-314.

Vefeas, N., \& Theodorou, E. (1998). The relationship between board structure and firm performance in the UK. British Accounting Review, 30(4), 383-407.

Weir, C., Laing, D., \& McKnight, P. J. (2002). Internal and external governance mechanisms: Their impact on the performance of large UK public companies. Journal of Business Finance \& Accounting, 29(5/6), 579-611.

Weisbach, M. S. (1988). Outside directors and CEO turnover. Journal of Financial Economics, 20, 431-460.

Wilcox, R. R. (2001). Fundamentals of modern statistical methods. New York: Springer-Verlag New York, Inc..

Yermack, D. (1996). Higher market valuation of companies with a small board of directors. Journal of Financial Economics, 40(2), 185-211.

Zhang, G. (1998). Ownership concentration, risk aversion and the effect of financial structure on investment decisions. European Economic Review, 42(9), 1751-1778. 